\title{
NBSIR $84-3000$
}

\section{Reference}

\section{TECHNICAL REPORTS}

Al1104 529454 \section{MAGNETIC FUSION ENERGY APPLICATIONS AT LOW TEMPERATURES - VII}

MATERIALS STUDIES FOR
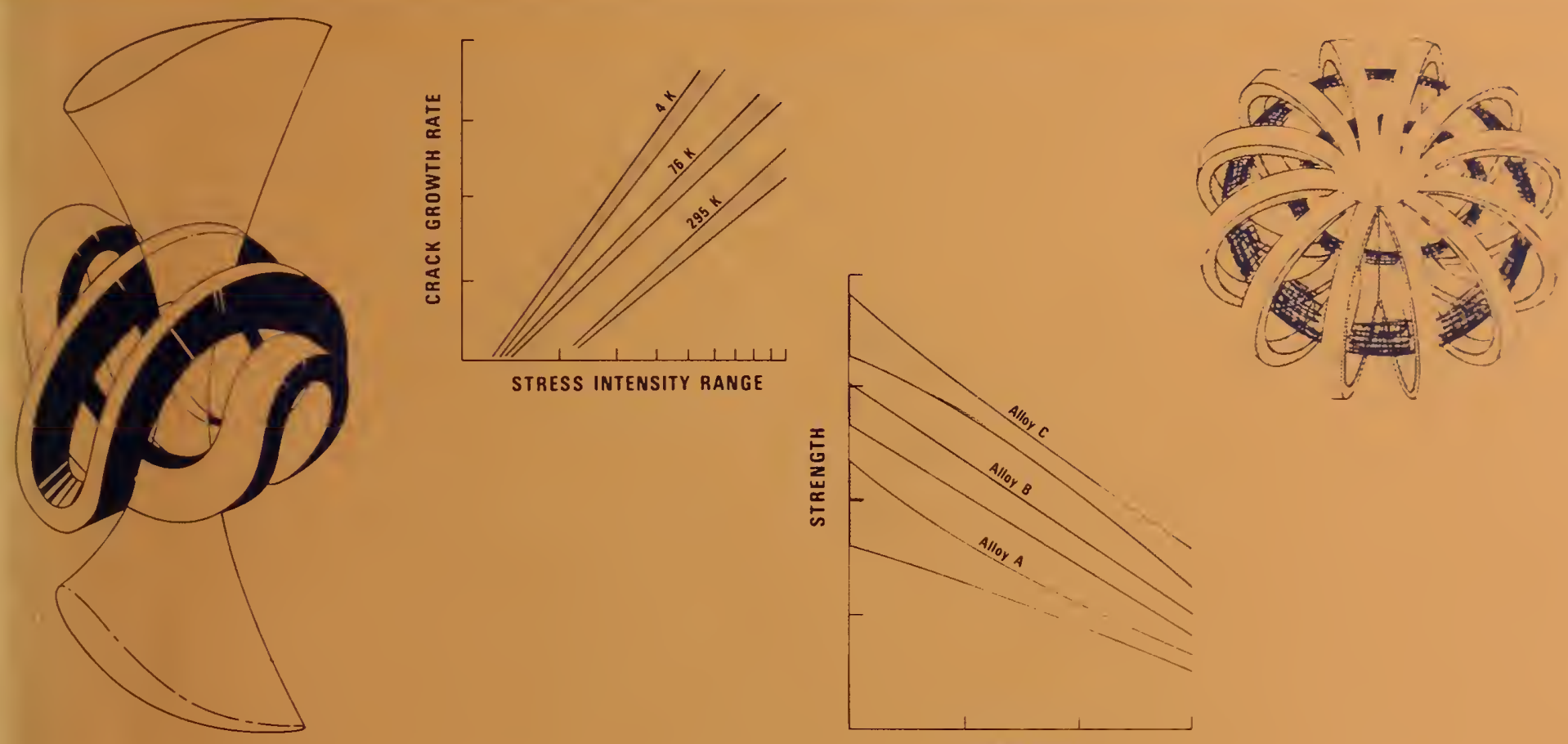

To

Department of Energy Office of Fusion Energy Washington, D.C. 20545

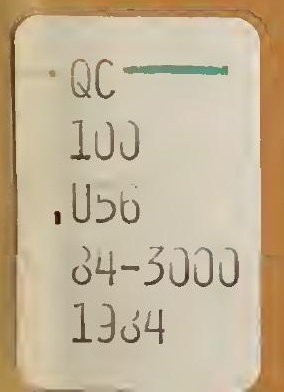

By

Fracture and Deformation Division National Bureau of Standards Boulder, CO 80303 


\section{MATERIALS STUDIES FOR MAGNETIC FUSION ENERGY APPLICATIONS AT LOW TEMPERATURES - VII}

Edited By

R.P. Reed and N.J. Simon

Fracture and Deformation Division

National Bureau of Standards

Boulder, Colorado 80303

May 1984

Sponsored By

Department of Energy

Office of Fusion Energy

Washington, D.C. 20545

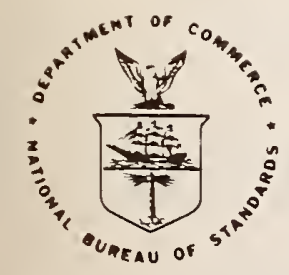

U.S. DEPARTMENT OF COMMERCE, Malcolm Baldrige, Secretary 

SUMMARY.

ORGANIZATIONAL CONTACTS. . . . . . . . . . . . . . . . . . . vi PROGRAM DESCRIPTION. . . . . . . . . . . . . . . . . . . . . . . . vii HIGHLIGHTS OF RESULTS. . . . . . . . . . . . . . . . . . . . . 1 STRUCTURAL ALLOYS

STRUCTURAL ALLOYS PROGRAM . . . . . . . . . . . . . . . . 11

SUMMARY OF MECHANICAL PROPERTY MEASUREMENTS OF STRUCTURAL ALLOYS. • . 12

LOW TEMPERATURE STRENGTHENING OF AUSTENITIC

STAINLESS STEELS WITH NITROGEN AND CARBON . . . . . . . . . . . . . 13

DILATION OF AN FCC Fe-Cr-Ni ALLOY BY INTERSTITIAL

CARBON AND NITROGEN . . . . . . . . . . . . . . . . . . 25

EFFECTS OF CARBON AND NITROGEN ON THE ELASTIC CONSTANTS OF 304 -TYPE STAINLESS STEEL . . . . . . . . . . . . . 47

THE TEMPERATURE DEPENDENCE OF THE TENSILE YIELD STRENGTH OF SELECTED AUSTENITIC STEELS. . . . . . . . . . . . . . 65

MAGNETIC SUSCEPTIBILITY AND STRAIN-INDUCED MARTENSITE FORMATION AT $4 \mathrm{~K}$ IN TYPE 304 STAINLESS STEEL. . . . . . . . . . . 75

FATIGUE CRACK GROWTH IN SENSITIZED Fe-18C $r-3 \mathrm{Ni}-13 \mathrm{Mn}-0.37 \mathrm{~N}$ AUSTENITIC STAINLESS STEEL: THE SIGNIFICANCE OF MICROMECHANISMS. • . 85

MIDRANGE FATIGUE CRACK GROWTH DATA CORRELATIONS FOR STRUCTURAL ALLOYS AT ROOM AND CRYOGENIC TEMPERATURES . . . . . . . . . . 103

AN AUTOMATED FATIGUE CRACK GROWTH RATE TEST SYSTEM. . . . . . . . . . . . . . . . . . . . . . 141

LOW TEMPERATURE MONOCRYSTAL ELASTIC CONSTANTS OF $\mathrm{Fe}-19 \mathrm{Cr}-10 \mathrm{Ni}$. . . . . . . . . . . . . . . . . . 157

A NUMERICAL AND EXPERIMENTAL VERFICATION OF COMPLIANCE FUNCTIONS FOR COMPACT SPECIMENS . . . . . . . . . . . . . . 181 DESIGN AND PERFORMANCE OF A RING-SHAPED CLIP GAGE FOR FRACTURE MECHANICS TESTING. . . . . . . . . . . . . . 209 EXPERIMENTAL DATA TO SUPPORT EXTENSION OF MECHANICAL PROPERTY TEST STANDARDS TO LIQUID HELIUM TEMPERATURE $(4 \mathrm{~K})$. . . . . . 227 
WELDMENTS AND CASTINGS

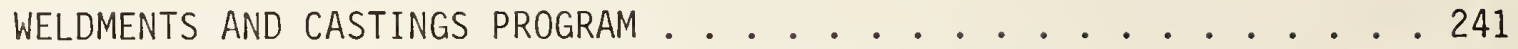

SUMMARY OF MECHANICAL PROPERTY MEASUREMENTS OF WELDS . . . . . 242

FRACTURE TOUGHNESS OF 25 Mn AUSTENITIC STEEL

WELDMENTS AT $4 \mathrm{~K} \ldots \ldots . \ldots . \ldots . \ldots . \ldots 243$

TENSILE PROPERTIES AND FRACTURE TOUGHNESS OF

320LR SMA WELD METAL AT $4 \mathrm{~K} \ldots \ldots 253$

FATIGUE CRACK GROWTH OF DUPLEX STAINLESS STEEL

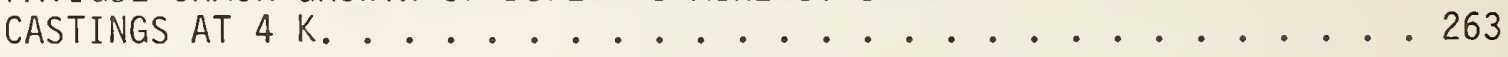

NONMETALLICS

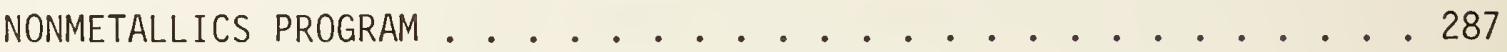

CONTINUOUS DAMAGE MECHANICS MODEL OF FRACTURE

IN LAMINATED COMPOSITES. . . . . . . . . . . . . . 289

INFLUENCE OF DAMAGE ON MECHANICAL PROPERTIES OF

WOVEN COMPOSITES AT LOW TEMPERATURES . . . . . . . . . . . . 329

NONMETALLIC MATERIAL STANDARDIZATION - MATERIALS

AND TEST METHODS . . . . . . . . . . . . . . 347

MECHANICAL PROPERTIES OF CONCRETE MORTAR AT LOW

TEMPERATURES . . . . . . . . . . . . . . 357

TENSILE, COMPRESSIVE, AND SHEAR PROPERTIES OF A

$64-\mathrm{kg} / \mathrm{m}^{3}$ POLYURETHANE FOAM AT LOW TEMPERATURES . . . . . . . 365

TENSILE, COMPRESSIVE, AND SHEAR PROPERTIES OF A

$96-\mathrm{kg} / \mathrm{m}^{3}$ POLYURETHANE FOAM AT LOW TEMPERATURES . . . . . . . . 397

EXPERIMENTAL DATA TO SUPPORT EXTENSION OF MECHANICAL

PROPERTY DATA FOR TENSILE TESTING OF COMPOSITE

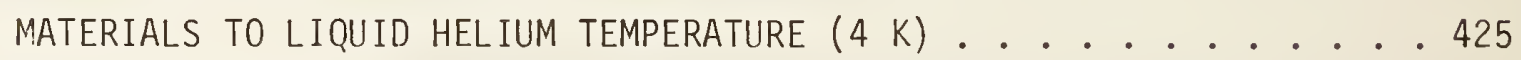

TECHNOLOGY TRANSFER

TECHNOLOGY TRANSFER PROGRAM. . . . . . . . . . . 435

NBS-DoE WORKSHOP: MATERIALS AT LOW TEMPERATURES . . . . . . . 437

ACKNOWLEDGMENT. . . . . . . . . . . . . . 4447 
SUMMARY

This report contains results of a research program to produce material property data that will facilitate design and development of cryogenic structures for the superconducting magnets of magnetic fusion energy power plants and prototypes. The program was developed jointly by the staffs of the National Bureau of Standards and the Office of Fusion Energy of the Department of Energy; it is managed by NBS and sponsored by DOE. Research is conducted at NBS and at various other laboratories through subcontracts with NBS.

Research results for 1983 are summarized in an initial "Highlights of Results" section and reported in detail in the 22 technical papers that form the ma in body of this report. The technical papers are presented under four headings reflecting the main program areas: structural alloys, weldments and castings, nonmetallics, and technology transfer. Objectives, approaches, and achievements are summarized in an introduction to each program area.

Work leading toward development of strong, tough structural alloys for use in superconducting magnets continued this year, with low temperature studies assessing the quantitative dependence of the yield strength, density, and elastic constants of AISI 304 stainless steels upon carbon and nitrogen concentration. Tensile property measurements of developmental austenitic steels from the U.S., Japan, and the U.S.S.R. confirmed a logarithmic dependence of yield strength upon temperature between $4 \mathrm{~K}$ and room temperature. Evidence is presented to show that the flow strength and austenite stability of stainless steels are not significantly affected by 8-T fields at $4 \mathrm{~K}$. New instrumentation developed for low-temperature testing included a computer-assisted apparatus that was used to measure threshold fatigue. Low-temperature welding research involved an investigation of the weld reinforcement effect on the weld joint strength and measurements of the 4-K fracture toughness of $25 \mathrm{MN}-5 \mathrm{Cr}$ steel weldments and 320LR electrodes. In the area of nonmetallics, a standardized test specimen was devised for a screening program to develop radiation-resistant composites for magnet insulation, and models to predict damage in woven glass/epoxy laminates were tested experimentally at low temperatures. Mechanical properties of concrete mortar and polyurethane foam at $4 \mathrm{~K}$ are reported.

Note: Certain commercial equipment, instruments, or materials are identified in this paper to specify the experimental procedure adequately. In no case does such identification imply recommendation or endorsement by the National Bureau of Standards, nor does it imply that the material or equipment identified is necessarily the best available for the purpose. Papers by non-NBS authors have not been reviewed or edited by the NBS editors. Therefore, the National Bureau of Standards accepts no responsibility for the comments or recommendations contained therein. 


\section{ORGANIZATIONAL CONTACTS}

The people responsible for the various major aspects of the program are listed below so that specific technical questions may be directed to them. Department of Energy, Office of Fusion Energy, Washington, D.C. 20545

Program Monitor D. Beard

(301) $353-4958$

(FTS) $233-4958$

National Bureau of Standards, Boulder, Colorado 80303

\begin{tabular}{|c|c|c|c|}
\hline Program Manager & R. P. Reed & $\begin{array}{l}(303) \\
\text { (FTS) }\end{array}$ & $\begin{array}{l}497-3870 \\
320-3870\end{array}$ \\
\hline Structural Alloys & $\begin{array}{l}\text { R. P. Reed } \\
\text { R. L. Tobler } \\
\text { J. M. Arvidson } \\
\text { R. P. Walsh }\end{array}$ & $\begin{array}{l}(303) \\
(303) \\
(303) \\
(303)\end{array}$ & $\begin{array}{l}497-3870 \\
497-3421 \\
497-3424 \\
497-3537\end{array}$ \\
\hline Elastic Properties & H. M. Ledbetter & $(303)$ & $497-3443$ \\
\hline Welding and Casting & $\begin{array}{l}\text { T. A. Siewert } \\
\text { H. I. McHenry } \\
\text { P. Purtscher }\end{array}$ & $\begin{array}{l}(303) \\
(303) \\
(303)\end{array}$ & $\begin{array}{l}497-3523 \\
497-3268 \\
497-5789\end{array}$ \\
\hline Nonmetallics & $\begin{array}{l}\text { M. B. Kasen } \\
\text { H. M. Ledbetter } \\
\text { R. D. Kriz }\end{array}$ & $\begin{array}{l}(303) \\
(303) \\
(303)\end{array}$ & $\begin{array}{l}497-3558 \\
497-3443 \\
497-3547\end{array}$ \\
\hline Technology Transfer & N. J. Simon & (303) & $497-3687$ \\
\hline
\end{tabular}

University of Colorado, Mechanical Engineering Department, Boulder, Colorado 80309

S. K. Datta

(303) $492-7750$ 


\section{PROGRAM DESCRIPTION}

The overall objective of the program is to assist in the design, construction, and safe operation of low-temperature magnetic fusion energy (MFE) systems, especially superconducting magnets, through effective materials research and materials technology transfer. The specific steps taken to achieve this objective are: (1) evaluation of low-temperature materials research needs specific to MFE devices; (2) development and monitoring of a research program to acquire the necessary data; and (3) rapid dissemination of the data to potential users through personal contacts, publications, and workshops.

Efforts directed at the first specific objective began with the publication of the "Survey of Low Temperature Materials for Magnetic Fusion Energy" in March 1977. A recent publication updating part of this survey, "Structural Alloys for Superconducting Magnets in Fusion Energy System," was included in volume IV (1981) of this series. In volume VI (1983), reviews of the properties of austenitic stainless steels and of austenitic-steel elastic constants also contributed to this objective. Through interactions with low-temperature design, construction, and measurement programs, such as the Large Coil Project and MFTF-B, we are aware of new problems as they arise. This year's contribution to the second objective is described in Table 1 in the form of an outline of the research projects. The results appear later in this report. Again this year, increased emphasis has been placed upon research oriented toward the establishment of test standards. The third objective is satisfied, in part, by these annual reports and by the series of NBS-DoE Workshops on Materials at Low Temperatures, which are held in Vail, Colorado. Since 1982 , handbook pages presenting the available data for specific materials have been distributed to interested members of the low-temperature materials community. 
Table 1. Outline of the NBS/DoE Program on Material Studies for Magnetic Fusion Energy Applications at Low Temperatures.

\section{A. Structural Alloys}

1. Strong, tough alloys NBS

2. Strong, fatigue-resistant NBS alloys

3. Low-temperature codes and standards

4. Physical properties

NBS

NBS
Assessment of low-temperature properties of selected austenitic alloys containing varying concentrations of $C$, $\mathrm{N}$, and $\mathrm{Mn}$ with an $\mathrm{Fe}-\mathrm{Cr}$ base. Assessment of Japanese austenitic alloys with an Fe-Mn base.

Assessment of fatigue and fatigue crack-growth rates of candidate structural a 11 oys, including 300 series steels, Fe-Mn base alloys, and age-hardened alloys.

Research to establish lowtemperature mechanical test standards, now emphasizing tensile, fracture toughness, and fatigue.

Measurement and theory of properties, such as elastic constants and volume; especially, alloying effects.

\section{B. Weldments and Castings}

1. Austenitic-steel welds

NBS

Evaluation of the strength and toughness properties of weldments at $4 \mathrm{~K}$. Continuation of studies to understand the mechanisms by which residual delta ferrite affects the deformation and fracture of stainless-steel welds. 
2. Testing program NBS

Continuation of mechanical property testing at $4 \mathrm{~K}$ of welds and plate material in support of superconducting magnet design and construction.

\section{Nonmetallics for Magnet Structures}

1. Standardization

2. Characterization

3. Research materials

4. International cooperation NBS,

Rutherford Laboratory, Osaka University

NBS

NBS
Continued cooperation with industry to refine cryogenic-grade specifications for commercial nonmetallic bulk insulating laminates.

Determination of the variability in cryogenic mechanical properties of G-10CR cryogenic-grade industrial laminates produced by five U.S. manufacturers.

Development of methods for rapidiy and inexpensively producing highly characterized, small specimens for use in screening the significant parameters influencing cryogenic radiation resistance of nonmetallic composite insulators.

Agreement to actively cooperate in development of specimens, materials selection, and test procedures in developing radiationresistant insulating materials. 


\begin{tabular}{|c|c|c|c|}
\hline & Program Area & Organization & Program Description \\
\hline \multirow[t]{2}{*}{5.} & $\begin{array}{l}\text { Property determination } \\
\text { and modeling }\end{array}$ & NBS & $\begin{array}{l}\text { For laminated composites, } \\
\text { experimental and theoretical } \\
\text { study of the physical- } \\
\text { mechanical properties, } \\
\text { especially at low } \\
\text { temperatures. Study of } \\
\text { the local-stress distribution } \\
\text { in a glass-fiber/epoxy } \\
\text { composite "unit cell" using } \\
\text { finite-element methods. }\end{array}$ \\
\hline & & \multicolumn{2}{|c|}{ D. Technology Transfer } \\
\hline 1. & NBS/DoE Workshop & NBS & $\begin{array}{l}\text { Presentation of research } \\
\text { results to the fusion com- } \\
\text { munity, discussion of new } \\
\text { problems, and interaction } \\
\text { between interested parties } \\
\text { during a workshop. }\end{array}$ \\
\hline & Handbook & NBS & $\begin{array}{l}\text { Distribution (1983) of } \\
\text { preliminary handbook data } \\
\text { pages on mechanical and } \\
\text { physical properties of } 21 \mathrm{Cr} \text { - } \\
6 \mathrm{Ni-9Mn} \text { stainless steel. } \\
\text { Distribution (1984) of } \\
\text { AISI } 304 \mathrm{~N} \text { and } 304 \mathrm{LN} \\
\text { stainless steels data pages } \\
\text { and prel iminary work on } \\
\text { handbook pages for AISI } 316 \mathrm{~L} \\
\text { and } 304 \text { weldments. }\end{array}$ \\
\hline
\end{tabular}


HIGHLIGHTS OF RESULTS

1 



\section{HIGHLIGHTS OF RESULTS}

STRUCTURAL ALLOYS:

Strong, Tough Alloys

The studies leading toward development of strong, tough structural alloys for superconducting magnet use continued, resulting in the following major accomp 1 ishments:

1. The functional dependence of the yield strength on carbon and nitrogen concentration in austenitic stainless steel 304 was assessed using regression analyses of all available data at 4,77 , and $295 \mathrm{~K}$. This study indicated that carbon and nitrogen contribute about equally at room temperature, but at $4 \mathrm{~K}$ nitrogen contributes about 3 times more than carbon to yield strength. Both elements contribute substantially to strength at low temperatures. No clear power dependence of strength upon carbon and nitrogen content could be found.

2. Tensile measurements on two Japanese austenitic steels, one steel from the USSR, and two U.S. austenitic stainless steels confirmed that the $\log$ of the yield strength is linearly related to the test temperature.

3. Further measurements of the effects of magnetic field on austenitic stainless steels provided additional evidence that the flow strength and austenite stability are not significantly affected by fields up to $8 \mathrm{~T}$ at $4 \mathrm{~K}$.

\section{Strong, Fatigue-Resistant Alloys}

An program to measure fatigue crack growth rates at low stress-intensity factors was initiated. Highlights are: 
1. A computer-assisted program to measure threshold fatigue at low temperatures has been developed and is now being used for measurements.

2. Fatigue crack initiation measurements were begun.

\section{Codes and Standards}

A proposal to provide the information needed to extend tensile test standards to very low temperatures has been prepared for the Metal Properties Council (MPC). The program considers the effects of strain rate on specimen heating (and, therefore, flow strength) and grain size (to establish minimum specimen sizes). Cooperation is continuing between NBS, industry, and other government laboratories in an established MPC Low Temperature Task Group to develop this program.

\section{Physical Properties}

Programs to understand the alloying effects in austenitic steels were continued. Such understanding is essential to the design and processing of these steels to insure optimum strength and toughness.

1. Using ultrasonic methods (near $5 \mathrm{MHz}$ ), the monocrystal elastic constants $\left(\mathrm{C}_{11}, \mathrm{C}_{12}, \mathrm{C}_{44}\right)$ of a $\mathrm{Fe}-19 \mathrm{Cr}-10 \mathrm{Ni}$ alloy were determined. This information is essential to understanding the property changes that occur in these alloys because of a magnetic phase transition near $50 \mathrm{~K}$.

2. By ultrasonic methods, the effect of interstitial atoms on the polycrystalline elastic constants (B, E, G, $v$ ) of a typical austenitic stainless steel (AISI 304) was examined.

3. By x-ray diffraction from bulk specimens, the effect of interstitial atoms in expanding the f.c.c. austenitic-iron unit cell of AISI 304 was studied. Such information is essential to models of solid-solution strengthening. 


\section{Weldments}

An investigation of the weld reinforcement effect on the weld joint strength of the 304L base/E316L filler weldment system in the temperature range of 4 to $295 \mathrm{~K}$ shows that there is no adverse effect of the reinforcement on strength. The results also indicate that the tensile strengths obtained from the large specimens (cross-sectional area of $258 \mathrm{~mm}^{2}$ ) agree well with those obtained from the smaller specimens (cross-sectional area of $9.62 \mathrm{~mm}^{2}$ ).

The fracture toughness, J Ic of $25 \mathrm{Mn}-5 \mathrm{Cr}$ steel weldments was measured at $4 \mathrm{~K}$. The highest $\mathrm{J}_{\text {Ic }}$ value obtained was from a GTA weld, followed by an SMA weld; an SA weld had the lowest $J_{I c}$ value. Degradation of fracture toughness of the HAZ was observed because of the excessive carbide precipitation along the grain boundary. The present results compare favorably with those of stainless steel weldments produced with the same welding processes.

The tensile properties and fracture toughness of the 320LR electrode were measured at $4 \mathrm{~K}$. The results show that the $320 \mathrm{LR}$ electrode has slightiy lower yield and ultimate tensile strengths than the $316 \mathrm{~L}$ electrode does. The fracture toughnesses of the $320 \mathrm{LR}$ and $316 \mathrm{~L}$ electrodes are comparable.

\section{Castings}

The fatigue crack growth rates of a series of CF8M stainless steel castings with varying delta-ferrite content were measured at $4 \mathrm{~K}$. The results show that the range of fatigue crack growth rates in CF8M castings fal1 within the scatter band of AISI 316 results and are not significantly affected by the delta-ferrite content, which ranged from 0 to 29 percent. Tensile properties and fracture toughness measurements of this series of CF8M castings are reported in volume VI of these reports. 
NONMETALLICS:

\section{Standardization}

We continue to work with representatives of the United States laminating industry to provide magnet builders with commercial sources of standardized, reliable, nonmetallic insulating materials. The original specifications for the CR-grade products were found to be unnecessarily restrictive in component selection and did not contain minimum performance criteria. The specification for G-10CR was therefore modified with industry consultation and guidance. Further development of the G-11CR specification will take place when the extent of its future use by industry is clarified.

\section{Characterization}

By mechanical testing at $77 \mathrm{~K}$, we have shown that the differences in room temperature or cryogenic mechanical performance of G-10CR products produced by five U.S. laminating firms are not statistically significant. The existing specification for this material, therefore, appears capable of ensuring the desired uniformity in material performance.

\section{Controlled Test-Specimen Development}

Recognizing the unique demands put on specimens to be used in radiation research, we have begun development of methods to produce specimens combining the attributes of low cost, a high degree of characterization, small size, and flexibility in component selection and treatment. These specimens will be used in a screening program to define the significant parameters influencing cryogenic radiation degradation. This information will then be used to design optimum types of insulating laminates for use in magnet systems.

\section{International Cooperation}

Agreement has been reached between representatives of NBS, the Rutherford Laboratory (England) and the ISIR (Osaka, Japan) to work toward development of a common type of test specimen to be used in evaluating the influence of 
various parameters on cryogenic composite radiation property degradation. A common approach to a method of specimen production has been agreed upon, and procedures have been worked out for cooperative assessment of this method.

\section{Property Determination and Modeling}

1. Prediction of cumulative damage in graphite/epoxy laminates at low temperatures. By Kachanov's cumulative damage model, the influence of residual thermal stresses at $76 \mathrm{~K}$ on the growth of ply cracks in load-bearing plies of graphite/epoxy laminates were predicted. The model assumes a localization of fiber fractures ahead of a dominant ply crack. The model predicts a latent phase of damage development followed by a rapid and severe damage localization occurring just prior to final fracture. The results verify the experimental results of previous investigators. A decrease in ply crack growth caused by residual stresses at $76 \mathrm{~K}$ is predicted. Absorbed moisture was observed to increase the growth of the dominant ply crack.

2. Prediction of stress redistribution caused by damage development in woven composites at $76 \mathrm{~K}$. By finite-element analysis, the redistribution of localized stresses in the woven glass/epoxy unit cell was studied. Stress concentrations in the warp-fiber bundles are predicted near damaged fill-fiber bundles. Increases in curvature and residual stresses at low temperatures decreased the stress concentration near damaged fill-fiber bundles. Previous experiments verify this increase in strength at low temperature.

\section{TECHNOLOGY TRANSFER}

An NBS/DoE Workshop on Materials at Low Temperatures was held in Vail, Colorado on October 17-19, 1983. The workshop brought together representatives of the fusion energy materials and magnet design community and served as a focal point to identify and discuss structural materials problems in superconducting magnet design and construction. The workshop is informal and its proceedings are not published. A copy of the program and highlights of the discussions may be found in the Technology Transfer section of this report. 
Handbook and supporting documentation pages have been prepared for $21 \mathrm{Cr}$ $6 \mathrm{Ni}-9 \mathrm{Mn}$ stainless steels and distributed in preliminary draft format. Properties covered include: tensile strength, yield strength, elongation, reduction of area, stress-strain curves, elastic constants, impact energy, fracture toughness, stress- and strain-controlled fatigue life, fatigue crack growth rate, and electromagnetic and thermal properties. These pages were also submitted to the advisory committee of the "Materials Handbook for Fusion Energy Systems" and are currently in the review process. Preliminary work on handbook pages covering AISI $304 \mathrm{~N}$ and $304 \mathrm{LN}$ is in progress. 
STRUCTURAL ALLOYS 

LEADER: R. P. Reed, NBS

STAFF: J.M. Arvidson, H. M. Ledbetter, R. L. Tobler, R. P. Walsh, NBS

OBJECTIVES:

(1) Development of strong, tough structural alloys for use at $4 \mathrm{~K}$ in superconducting magnets.

(2) Development of strong, fatigue-resistant structural alloys for use at $4 \mathrm{~K}$ in pulsed superconducting magnets.

(3) Development of effective codes and standards related to 10 wtemperature property measurements and structural design.

RESEARCH PAST YEAR (1983):

(1) Analysis of $\mathrm{C}$ and $\mathrm{N}$ effects on low temperature tensile properties of 304 austenitic stainless steel.

(2) Characterization of the tensile behavior of Japanese, Soviet and U.S. austenitic steels.

(3) Examination of effects of magnetic fields on low-temperature strength and phase stability of 304 and 310 austenitic stainless steels.

(4) Determination of monocrystal elastic constants of an austenitic stainless steel ( $\mathrm{Fe}-19 \mathrm{Cr}-10 \mathrm{Ni})$ at low temperatures.

Measurements of the effects of $\mathrm{C}$ and $\mathrm{N}$ on the elastic constants and dilatation of an austenitic steel.

RESEARCH THIS YEAR (1984):

(1) Characterization of Japanese high-manganese and austenitic stainless steels.

(2) Assessment of the use of the notch-tensile test to replace the J-integral fracture toughness test for routine testing at $4 \mathrm{~K}$.

(3) Measurement of temperature-dependence of flow strength of OFHC copper and 1100 aluminum.

(4) Initiation of a cooperative program with industry to develop a lower cost alloy than 304 LN, with equivalent strength and toughness at $4 \mathrm{~K}$.

(5) Threshold fatigue testing of 304,316 , and 310 steels at 4, 76 , and $295 \mathrm{~K}$.

(6) Continued studies on low temperature elastic properties of austenitic steels.

(7) Initiation of a program to measure the stacking-fault energy of high-manganese austenitic steels.

(8) Continuation of efforts to establish a program to develop low-temperature mechanical-property test standards. 


\begin{tabular}{|c|c|c|c|c|c|c|c|c|}
\hline $\begin{array}{l}\text { Alloy } \\
\text { (Designation) }\end{array}$ & $\begin{array}{l}\text { Country } \\
\text { of } \\
\text { Supplier }\end{array}$ & $\begin{array}{l}\text { Tensile } \\
295,4 \mathrm{~K}\end{array}$ & $\begin{array}{l}\text { Elastic } \\
295-4 \mathrm{~K}\end{array}$ & $\begin{array}{l}\text { Fracture } \\
\text { Toughness } \\
295,76,4 \mathrm{~K}\end{array}$ & $\begin{array}{l}\text { Fatigue Cra } \\
\text { Growth Rate } \\
295,76,4 \text { K }\end{array}$ & & $\begin{array}{l}\text { Fatigue } \\
\mathrm{S}-\mathrm{N} \\
4 \mathrm{~K}\end{array}$ & $\begin{array}{l}\text { Report Volume* } \\
\text { (page) }\end{array}$ \\
\hline 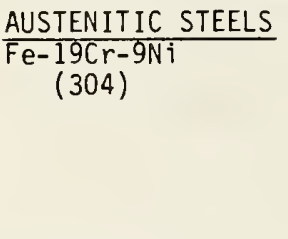 & U.S. & $\begin{array}{l}\text { I , I I , I I I } \\
\text { IV }, \text { I I }\end{array}$ & $\begin{array}{l}\text { I , I I , I I I } \\
\text { IV, VI }\end{array}$ & I IV II III & II, III, IV & & I & $\begin{array}{l}\text { I }(15,71,213), \\
\text { II }(79,149,175), \\
\text { II }(15,91,105, \\
\text { I17), IV }(37,101, \\
203,215,227), V(71) \\
\text { VI }(73)\end{array}$ \\
\hline $\begin{array}{c}\mathrm{Fe}-19 \mathrm{Cr}-9 \mathrm{Ni} \\
(304 \mathrm{~L})\end{array}$ & U.S. & II, III & $\mathrm{IV}_{\mathrm{IV}}$ & III, IV & II I, IV & & & $\begin{array}{l}\text { I (213), II }(79,123, \\
175), \text { III }(15), \operatorname{IV}(37, \\
101,131,302,215)\end{array}$ \\
\hline $\begin{array}{c}\text { Fe- } 19 C r-9 N i-N \\
(304 N)\end{array}$ & U.S. & $\operatorname{IV}_{\text {IV II }}$ & IV & I , I I I , IV & I , I I I , IV & & & $\begin{array}{l}\text { I }(93), \operatorname{III}(15), \text { IV } \\
(37,101,203,215)\end{array}$ \\
\hline $\begin{array}{l}\text { Fe-19Cr-9Ni-N } \\
\qquad(304 L N)\end{array}$ & U.S. & $\begin{array}{l}\text { I I , I I I , } \\
\text { IV,V,VI }\end{array}$ & IV & II I I I , & I I , I I I , IV & & I I & $\begin{array}{l}\text { II }(35,79), \operatorname{III}(15) \\
\text { IV }(37,101,203), V(29) \\
\text { VI }(113)\end{array}$ \\
\hline $\begin{array}{c}\mathrm{Fe}-19 \mathrm{Cr}-9 \mathrm{Ni}- \\
1 \text { to } 8 \mathrm{Nin} \\
(304 \mathrm{LN})\end{array}$ & U.S. & IV,V & v & IV, V & & & & $\operatorname{IV}(77), V(15,59,189)$ \\
\hline $\mathrm{Fe}-17 \mathrm{Cr}-9 \mathrm{Ni}-8 \mathrm{Mn}$ & U.S. & & I I I & & & & & $\operatorname{III}(91)$ \\
\hline $\begin{array}{l}\mathrm{Fe}-17 \mathrm{Cr}-13 \mathrm{Ni}-2 \mathrm{Mo} \\
\quad(316)\end{array}$ & U.S. & $\begin{array}{l}\text { I , I I I I I I } \\
\text { IV }, \text { VI }\end{array}$ & VI & I, I I & II & & I & $\begin{array}{l}\text { I }(15,71), \operatorname{II}(79) \\
\text { II I }(49,105,117) \\
\text { IV }(147), V(185), \operatorname{VI}(87), \\
\text { VI }(157)\end{array}$ \\
\hline $\begin{array}{l}\mathrm{Fe}-17 \mathrm{Cr}-13 \mathrm{Ni}-2 \mathrm{Mo}_{0} \\
(316 \mathrm{LN})\end{array}$ & U.S. & II & & II & II & & & II $(79)$ \\
\hline $\begin{array}{l}\mathrm{Fe}-25 \mathrm{Cr}-21 \mathrm{Ni} \\
\quad(310)\end{array}$ & U.S. & $V, V I$ & I I I , V I & V & & & & $\begin{array}{l}\text { II I }(105,117), V(71, \\
145), V I(73)\end{array}$ \\
\hline $\mathrm{Fe}-18 \mathrm{Cr}-3 \mathrm{Ni}-13 \mathrm{Mn}$ & U.S. & $I, V I$ & I I I & I & $I, V I$ & & & $\mathrm{I}(93), \operatorname{III}(91), \mathrm{VI}(53)$ \\
\hline $\begin{array}{l}\text { Fe-21Cr-6Ni-9Mn } \\
\quad(21 / 6 / 9)\end{array}$ & U.S. & I & II I , V I & I & & & I & $\mathrm{I}(15,71), \mathrm{III}(91), \mathrm{VI}(157)$ \\
\hline $\mathrm{Fe}-21 \mathrm{Cr}-12 \mathrm{Ni}-5 \mathrm{Mn}$ & U.S. & $\mathrm{I}, \mathrm{II}$ & II I & I, I I & I , I I & & & $\begin{array}{l}\operatorname{I}(93), \operatorname{II}(79) \\
\operatorname{III}(91)\end{array}$ \\
\hline $\mathrm{Fe}-13 \mathrm{Cr}-19 \mathrm{Mn}$ & USSR & & III & & VI & & & $\operatorname{III}(79), \operatorname{VI}(41)$ \\
\hline $\mathrm{Fe}-20 \mathrm{Cr}-16 \mathrm{Ni}-6 \mathrm{Mn}$ & USSR & $V, V I$ & v & & & & & $V(29,213), V I(113)$ \\
\hline $\begin{array}{l}\text { Fe-19Ni-9Co } \\
(200-300 \text { grades })\end{array}$ & U.S. & & IV & & & & & $\operatorname{IV}(237)$ \\
\hline $\mathrm{Fe}-5 \mathrm{Cr}-26 \mathrm{Mn}$ & Japan & & VI & & & & & VI (181) \\
\hline Many alloys & & $\begin{array}{l}\text { Review } \\
\text { IV,V,VI }\end{array}$ & $\begin{array}{l}\text { Review } \\
\text { IV,V,VI }\end{array}$ & $\begin{array}{l}\text { Review } \\
\text { IV,V,VI }\end{array}$ & $\begin{array}{l}\text { Review } \\
\text { IV,V,VI }\end{array}$ & Rev & $\begin{array}{l}\text { iew } \\
\text {, VI }\end{array}$ & $\begin{array}{l}\operatorname{IV}(17,257), V(171) \\
\operatorname{VI}(11), \operatorname{VI}(127), V I(157)\end{array}$ \\
\hline $\begin{array}{l}\frac{\text { ALUMINUM ALLOYS }}{\mathrm{A} T-4 \mathrm{Mg}} \\
\quad(5083-0)\end{array}$ & U.S. & IV & & & & & II & $\operatorname{II}(35), \operatorname{IV}(185)$ \\
\hline $\begin{array}{l}\text { A } 1-6 C u-0.2 \mathrm{Mn}-0.1 \mathrm{Fe} \\
(2219-\mathrm{T} 87) \\
\text { SUPERCONDUCTORS } \\
\text { Nb-45Ti }\end{array}$ & U.S. & U.S. & II & I I & II & & II & I I I (133) \\
\hline
\end{tabular}

*Materials Studies for Magnetic Fusion Energy Applications at Low Temperatures: NBSIR 78-884 (I); NBSIR 79-1609 (II); NBSIR 80-1627 (III); NBSIR 81-1645 (IV); NBSIR 82-1667 (V); NBSIR 83-1690(VI) 
LOW TEMPERATURE STRENGTHENING OF AUSTENITIC

STAINLESS STEELS WITH NITROGEN AND CARBON*

\author{
R. P. Reed and N. J. Simon \\ Fracture and Deformation Division \\ National Bureau of Standards \\ Boulder, Colorado 80303
}

\title{
ABSTRACT
}

The quantitative effects of $\mathrm{N}$ and $\mathrm{C}$ concentration upon the yield strength of $18 \mathrm{Cr}-9 \mathrm{Ni}$ austenitic stainless steels (AISI 304 series) was determined at room temperature, $77 \mathrm{~K}$, and $4 \mathrm{~K}$, based upon data available in the 1iterature. Strengthening by $\mathrm{N}$ and $\mathrm{C}$ was found to be strongly dependent upon temperature, with effects of $\mathrm{N}$ generally dominating those of $\mathrm{C}$, except at room temperature. Results are discussed with regard to solid-solution strengthening theories.

*Published in Advances in Cryogenic Engineering - Materials, vol. 30, Plenum Press, New York (1984), pp. 127-136. 



\section{INTRODUCTION}

Austenitic steels have been used extensively in the construction of superconducting magnets. To restrain high field forces in the support structures, stronger alloys than the conventional AISI 300 series stainless steels must be developed and characterized for use at liqujd helium temperatures. These stronger alloys must also retain adequate low temperature toughness. In the past few years there have been several studies of high-N $18 \mathrm{Cr}-9 \mathrm{Ni}$ austenitic stainless steels (AISI 304LN, 304N, and higher $N$ alloys). They demonstrate that $\mathrm{N}$ and $\mathrm{C}$ additions significantly raise the strength of the steels at low temperatures.

This paper examines quantitative effects of $\mathrm{N}$ and $\mathrm{C}$ on the strength of $18 \mathrm{Cr}-9 \mathrm{Ni}$ austenitic stainless steels (304 base) at room temperature, $77 \mathrm{~K}$, and $4 \mathrm{~K}$. The dependence of tensile yield strength $(\sigma)$ on the at.\% of $N$ and $C$ (designated as [N] and [C]) is analyzed. The results are discussed with respect to current solid-solution strengthening theories.

\section{PROCEDURE}

Data sets of most of the tensile yield-strength measurements $(0.2 \%$ offset) between 4 and $300 \mathrm{~K}$ on $18 \mathrm{Cr}-9 \mathrm{Ni}$ alloys for which both [N] and [C] are specified were assembled.1-23 The range of [N] was from 0.12 to $1.0(0.03$ to $0.26 \mathrm{wt} . \%)$. An adequate number of data points for model testing was available for only three temperatures: $4 \mathrm{~K}, 77 \mathrm{~K}$, and room temperature $(57,36$, and 166 points, respectively). Data from laboratory and production heats of annealed bar 
and plate stock greater than 6.4-mm thick were used. Grain sizes, when specified, ranged from 55 to $180 \mu \mathrm{m}$; reported hardness varied from 79 to $94 R_{3}$.

Preliminary analyses of these data at all temperatures indicated a high degree of correlation between $\sigma$ and $[\mathrm{N}],[\mathrm{C}]$, and ([N] $+[\mathrm{C}]$ ). (Correlation coefficients ranged fróm 0.42 to 0.91 .). However, low temperature plots of $\sigma$ vs $([N]+[C])$ showed an apparent change of slope at approximately $([\mathrm{N}]+[\mathrm{C}])=0.6$, as illustrated by Figs. 1 and 2. The room temperature plot (Fig. 3) does not show this break in slope, though it may be obscured by the scatter of the data. A recent set of measurements showed similar trends. ${ }^{3}$ In the range $([\mathrm{N}]+[\mathrm{C}])<0.6$, austenite metastability may affect $\sigma$; in the high $([\mathrm{N}]+[\mathrm{C}])$ range, the alloys were considered stable with respect to martensite transformation at $0.2 \%$ offset strain. Consequently, limited composition data sets were used to test the models given in Table 1 as well as the complete data sets described above. These limited data sets were restricted to $([N]+[C]) \geq 0.60$ (approximately $0.15 \mathrm{wt} . \%)$.

A linear least squares computer program was used to fit sums of the powers of $[\mathrm{N}]$ and [C] according to Eqs. 1, 2, 3, and 4 given in Table 1. These powers were suggested by previous characterization of $\mathrm{N}$ and $\mathrm{C}$ dependence in austenitic stainless steels of power 1 and by various solid solution strengthening theories predicting powers of $1 / 2$ and $2 / 3$. To obtain an independent assessment of the optimum exponent per temperature, Eq. 5 was used in an iterative, nonlinear least squares program. Because the fitting of Eqs. 1 through 5 to the data indicated that the [C] terms were smaller than the [N] terms (at least at 4 and $77 \mathrm{~K}$ ), Eq. 6, which omits any [C] dependence, was also tested. Plotting the data from the only set of yield-strength measurements in which [N] was held constant while [C] was varied ${ }^{3}$ suggested Eq. 7. For completeness, Eq. 8 was included to test the possibility that [N] and [C] acted additively to some power.

A set of about 210 measurements of yield strength at $4 \mathrm{~K}$ and room temperature on $304 \mathrm{LN}$ production heats from one supplier was made available to the authors, 24 but was not used in the present analysis. A separate, preliminary analysis of these data indicated that the observed coefficient of variation (S.D./mean yield strength) of 7 to $14 \%$ in the measured yield strengths was not due to the relatively narrow differences of about 0.1 in [N] and 0.3 for [C], but was probably caused by metallurgical factors, such as grain size variations or crystalline anisotropy in large grain size specimens. The variances observed in these measurements are important to designers and will be treated in separate reports.25,26 The agreement of these measurements with an equation fitted to the limited data set is discussed below. 


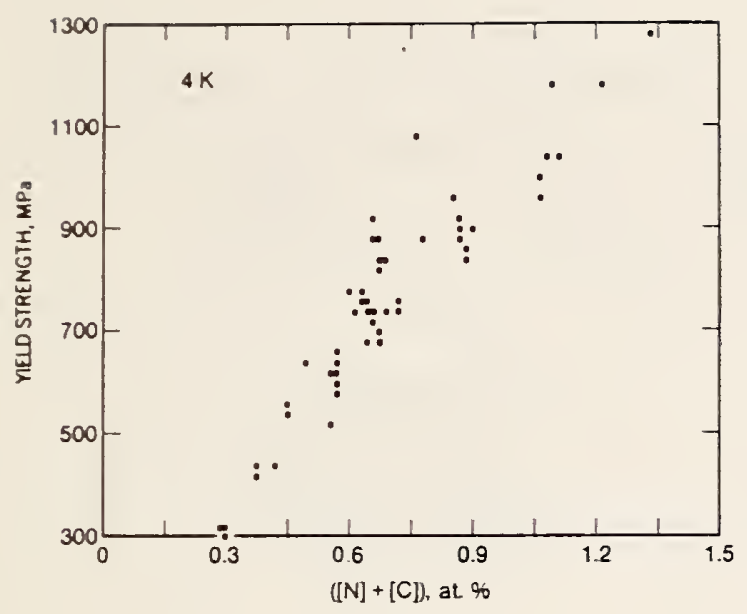

Fig. 1. Yield strength measurements at $4 \mathrm{~K}$ plotted against $[\mathrm{N}]+[\mathrm{C}]$.

Fig. 2. Yield strength measurements at $77 \mathrm{~K}$ plotted against $[\mathrm{N}]+[\mathrm{C}]$.
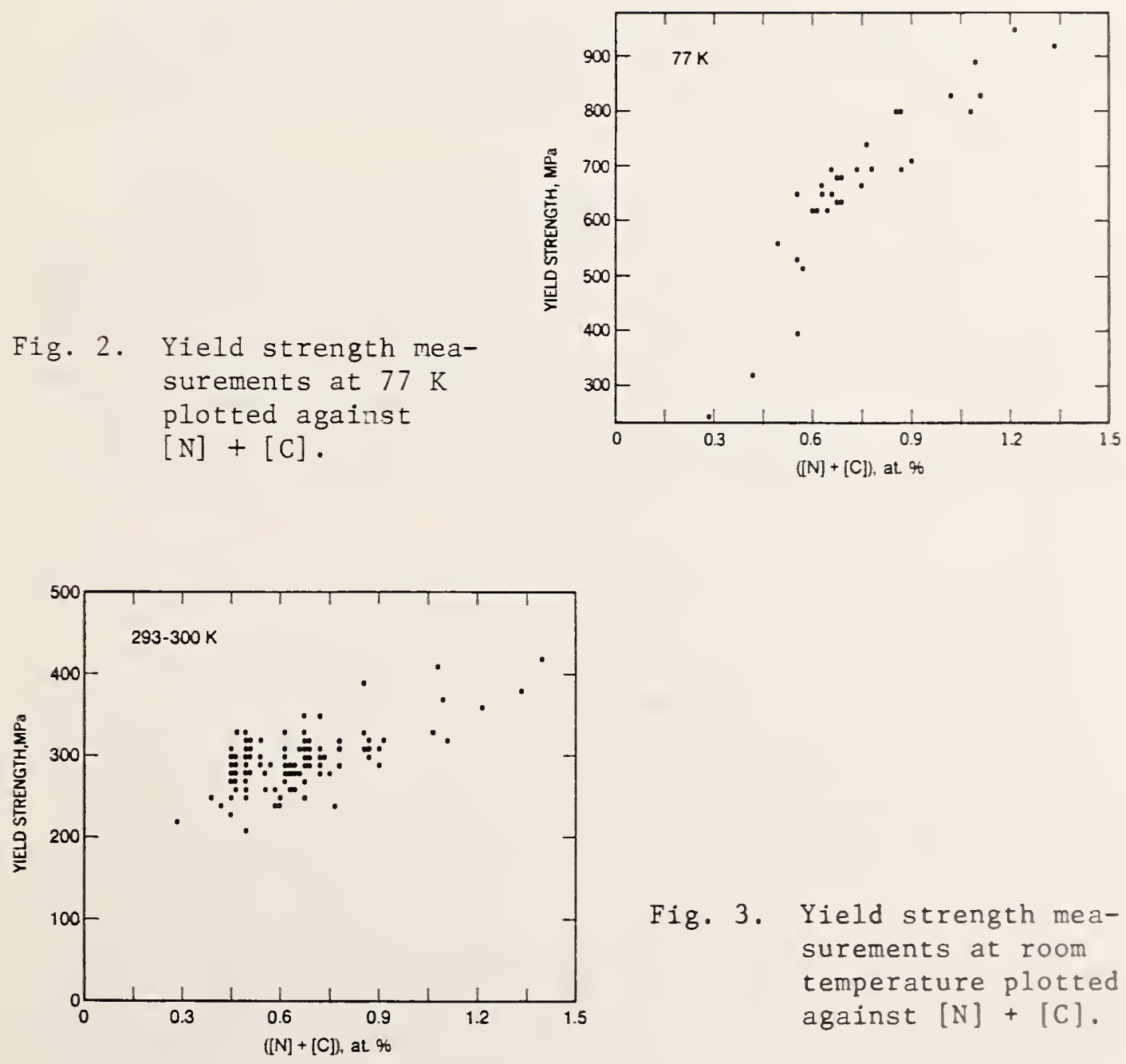

Fig. 3. Yield strength measurements at room temperature plotted against $[\mathrm{N}]+[\mathrm{C}]$. 
Table 1. Equations Fitted to Yield Strength Data

\begin{tabular}{ll}
\hline (1) $\sigma_{y}=\sigma_{0}+A_{N}[N]+A_{C}[C]$ & (5) $\sigma_{y}=\sigma_{0}+A_{N}[N]{ }^{B}+A_{C}[C]{ }^{B} C$ \\
(2) $\sigma_{y}=\sigma_{0}+A_{N}[N]^{2 / 3}+A_{C}[C]^{2 / 3}$ & (6) $\sigma_{y}=\sigma_{0}+A_{N}[N]{ }^{B}$ \\
(3) $\sigma_{y}=\sigma_{0}+A_{N}[N]^{1 / 2}+A_{C}[C]^{1 / 2}$ & (7) $\sigma_{y}=\sigma_{0}+A_{N C}[N]^{B}{ }^{B}[C]{ }^{B} C$ \\
(4) $\left.\sigma_{y}=\sigma_{0}+A_{N}[N]\right]^{1 / 3}+A_{C}[C]^{1 / 3}$ & (8) $\sigma_{y}=\sigma_{0}+A_{N C}\left([N]+[C]{ }^{B}{ }^{B C}\right.$ \\
\hline
\end{tabular}

RESULTS

At each temperature, only slight variation was found in the standard deviation (S.D.) for the fit of the complete data set to Eqs. 1 through 5, 7, and 8. However, the S.D. for the fit of Eq. 6 was always larger, by about 6 to 30\%, indicating that inclusion of the [C] term is preferable.

Results for the fit of the limited composition data sets to Eqs. 1 through 4 are shown in Tables 2 through 4 . Restricting the data to the range $([\mathrm{C}]+[\mathrm{N}]) \geq 0.6$ did not significantly reduce the S.D.'s. No significant differences were observed in the S.D.'s as the power of $[\mathrm{N}]$ and [C] varied from one to 1/3. Factors that make the determination of the power difficult are (1) the relatively narrow range of [N] and [C] for which yield strength data are available, (2) possible systematic differences in the yield strength measurements, which were made by a number of different laboratories, and (3) variation of metallurgical factors, such as grain size.

Although it is not possible to show that any of Fas. 1 through 8 is clearly preferable, it is important to observe that all the calculated S.D.'s are a small fraction of the mean $\sigma(\bar{\sigma})$ at each temperature. The values of S.D. $/ \bar{\sigma}$ vary from 3 to $\mathrm{y}_{8 \%}$ : $\mathrm{y}$ these values are smaller than the coefficient of variation found for the 210 production heat measurements ${ }^{24}$ discussed earlier. Metallurgical variability is thought to be the cause of the variation. Figures 4 , 5 , and 6 show the deviation of the observed yield strengths from those calculated using Eq. 1, and the range of the data from these production heat measurements is also shown on Figs. 4 and 6 .

Figure 7 shows the relative contributions from the [N] and [C] terms of Eq. 1 as a function of temperature for the hypothetical case of $[\mathrm{N}]=[\mathrm{C}]=0.1 \mathrm{wt} . \%$. It appears that $[\mathrm{N}]$ and [C] play a larger role at $4 \mathrm{~K}$ than they do at room temperature, and that [N] is 
Table 2. Yield Strength Equations ( $4 \mathrm{~K}, 36$ Data Points)

\begin{tabular}{|c|c|c|c|c|c|c|c|c|}
\hline \multirow{2}{*}{\multicolumn{3}{|c|}{$\begin{array}{c}\text { Equation } \\
\sigma_{y}(\mathrm{MPa}) ; \\
{[\mathrm{N}],[\mathrm{C}] \quad(\mathrm{Bt} . \mathrm{z})}\end{array}$}} & & \multirow{2}{*}{$\begin{array}{c}\text { S.D. of } \\
\text { F1t to } \\
\text { Data (MPa) }\end{array}$} & \multicolumn{4}{|c|}{ Contribution of term for $[\mathrm{N}]=[\mathrm{C}]=0.10 \mathrm{we \%}$} \\
\hline & & & & & $\begin{array}{c}\sigma_{0} \\
(\mathrm{MPa})\end{array}$ & $\begin{array}{c}\text { [N] term } \\
(\mathrm{MPa} a)\end{array}$ & $\begin{array}{l}{[\mathrm{C}] \text { term }} \\
(\mathrm{MPa})\end{array}$ & $\begin{array}{c}\sigma_{y} \\
(M P a)\end{array}$ \\
\hline (1) & $\sigma_{y}=$ & $275+851[N]$ & $+379[\mathrm{C}]$ & 54 & 275 & 340 & 170 & 785 \\
\hline (2) & $\sigma_{y}=$ & $-35+1105[\mathrm{~N}]^{2 / 3}$ & $+348[\mathrm{C}]^{2 / 3}$ & 56 & -35 & 599 & 204 & 768 \\
\hline (3) & $\sigma_{y}=$ & $-344+1366[N]^{1 / 2}$ & $+360[\mathrm{c}]^{1 / 2}$ & 57 & -344 & 863 & 242 & 761 \\
\hline (4) & $\sigma_{y}=$ & $-962+1895[\mathrm{~N}]^{1 / 3}$ & $+416[C]^{1 / 3}$ & 58 & -962 & 1397 & 319 & 754 \\
\hline
\end{tabular}

Table 3. Yield Strength Equations ( $77 \mathrm{~K}, 27$ Data Points)

\begin{tabular}{|c|c|c|c|c|c|c|c|c|c|c|}
\hline \multirow{2}{*}{\multicolumn{4}{|c|}{$\begin{array}{c}\text { Equation } \\
\sigma_{y}(M P a) ; \\
{[\mathbb{N}],[C] \quad(a t . \%)}\end{array}$}} & & \multirow{2}{*}{\multicolumn{2}{|c|}{$\begin{array}{c}\text { S.D. of } \\
\text { Fit to } \\
\text { Data (MPa) }\end{array}$}} & \multicolumn{4}{|c|}{ Contribution of term for $[\mathrm{N}]=[\mathrm{C}]=0.10 \mathrm{wt} \%$} \\
\hline & & & & & & & $\begin{array}{c}\sigma \\
0 \\
(M P a)\end{array}$ & $\begin{array}{c}\text { [N] term } \\
\text { (MPa) }\end{array}$ & $\begin{array}{l}\text { [C] cerm } \\
\text { (MPa) }\end{array}$ & $\begin{array}{c}\sigma_{\mathrm{y}} \\
(\mathrm{MPa})\end{array}$ \\
\hline (1) & $\sigma_{y}=$ & $364+$ & $520[\mathrm{~N}]$ & $+186[\mathrm{C}]$ & & 24 & 364 & 208 & 84 & 656 \\
\hline (2) & $\sigma_{y}=$ & $171+$ & $685[\mathrm{~N}]^{2 / 3}$ & $+173\left[c l^{2 / 3}\right.$ & & 25 & 171 & 371 & 102 & 644 \\
\hline (3) & $\sigma_{y}=$ & $-23+$ & $855[\mathrm{~N}]^{1 / 2}$ & $+180[\mathrm{C}]^{1 / 2}$ & & 26 & -23 & 540 & 121 & 638 \\
\hline (4) & $\sigma_{y}=$ & $-412+$ & $1200[\mathrm{~N}]^{1 / 3}$ & $+209[\mathrm{C}]^{1 / 3}$ & & 26 & -412 & 884 & 160 & 632 \\
\hline
\end{tabular}

Table 4. Yield Strength Equations (293-300 K, 76 Data Points)

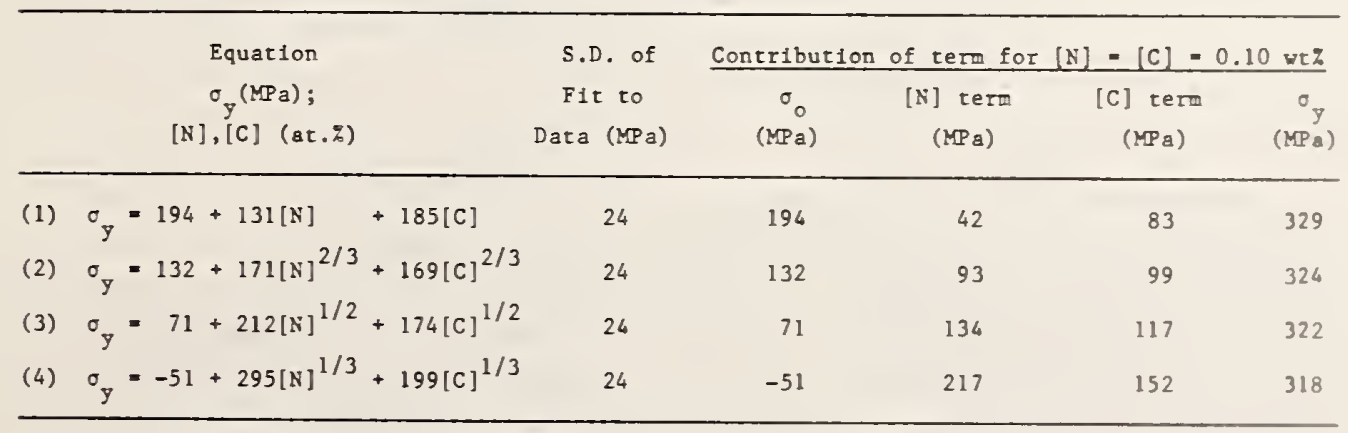




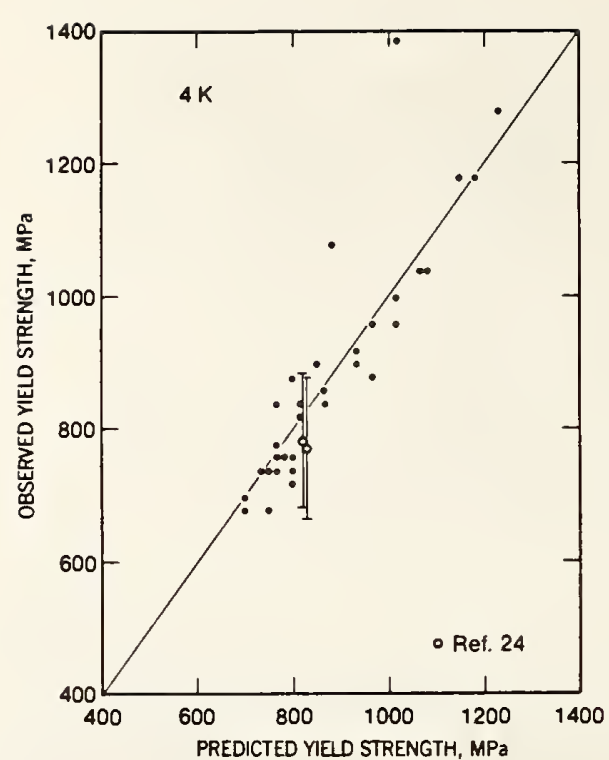

Fig. 4. Experimentally determined yield strengths at $4 \mathrm{~K}$ plotted against yield strengths predicted from Eq. 1 .

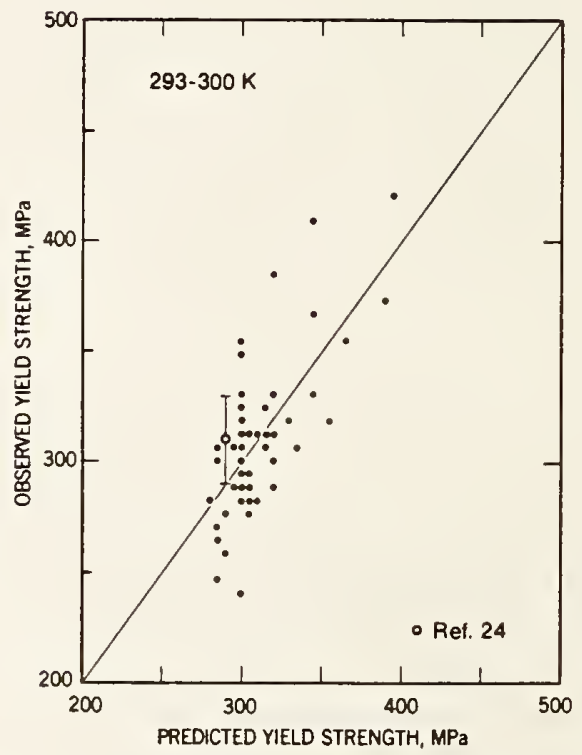

Fig. 6. Experimentally determined yield strengths at room temperatures plotted against yield strengths predicted from Eq. 1 .

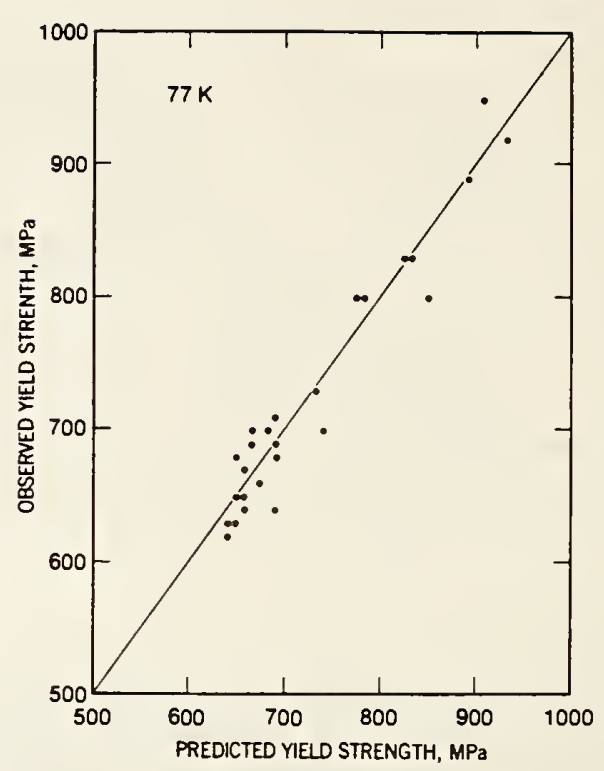

Fig. 5. Experimentally determined yield strengths at $77 \mathrm{~K}$ plotted against yield strengths predicted from Eq. 1 .

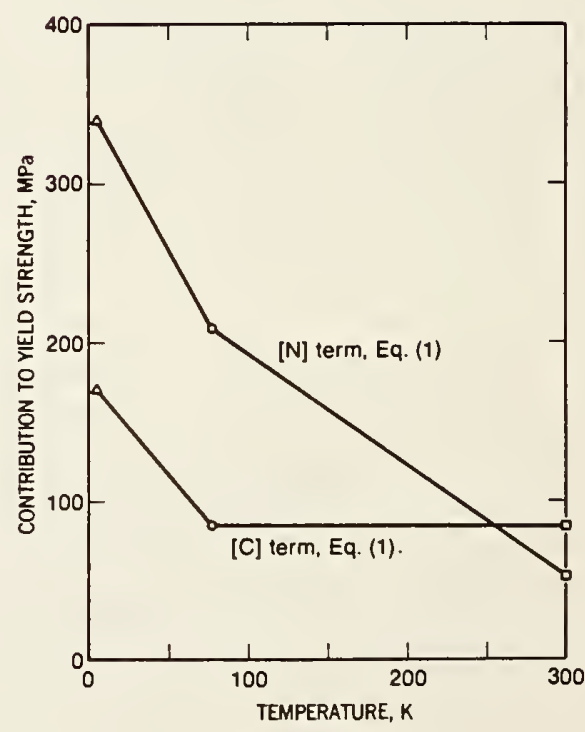

Fig. 7. Contribution of [N] and [C] terms in Eq. 1 as a function of temperature for a hypothetical 304 alloy with $[\mathrm{N}]=[\mathrm{C}]=$ 0.1 wt. $\%$. 
considerably more important than [C] at $4 \mathrm{~K}$, but at room temperature the contributions become approximately equal. Similar trends are found with Eqs. 2, 3, and 4 (Tables 2 through 4) but the magnitude of the ratio of the [N] term to the [C] term is different, owing to the change in sign and magnitude of the $\sigma_{0}$ term.

\section{DISCUSSION}

From Tables 2 through 4 and Fig. 7 it is clear that $N$ and $C$ strengthening is strongly temperature dependent. Both [N] and [C] contributions increase considerably from room temperature to $4 \mathrm{~K}$. At low temperatures, the effect of [N]. becomes more dominant, as shown in Fig. 7. Nitrogen contributes about 6 times more at $4 \mathrm{~K}$ than at $295 \mathrm{~K}$, while the carbon contribution is about twice as large at $4 \mathrm{~K}$.

Generally, three contributions to solid-solution interstitial strengthening are considered: (1) the misfit in atom size ( $\delta$ ) usually assessed by measuring the lattice parameter $\left(a_{0}\right)$ with alloy concentration (c):

$$
\delta=\frac{1}{a_{0}} \frac{\Delta a_{0}}{\Delta c}
$$

(2) the shear modulus (G) effect:

$$
\eta=\frac{1}{G} \frac{\Delta G}{\Delta c}
$$

and (3) a core interaction, usually considered in terms of electronic or dislocation-solute atom interactions. The first and second contributions are considered to be long range and therefore athermal; the third contribution involves short-range force interactions that thermal fluctuations can overcome. Preliminary analysis of available data indjcates that $\delta$ and $\eta$ for $N$ and $C$ additions to $\mathrm{Fe}-\mathrm{Cr}-\mathrm{Ni}$ alloys are adequate to account for the strength increase observed at room temperatures in these alloys. However, at low temperatures the shear modulus decreases slightly as $\mathrm{N}$ and $\mathrm{C}$ are added.27 The lattice parameters as a function of [N] and [C] have not been measured at $4 \mathrm{~K}$; however, it is very unlikely that the increase is sufficient to account for the 6- and 2-fold strength increases from $\mathrm{N}$ and $\mathrm{C}$, respectively.

Several theories predict a concentration dependence to the $2 / 3$ power at $0 \mathrm{~K}$. Asimov 28 considered the interaction of double-kinked dislocations with solute atoms that are present in sufficient concentration to promote larger elastic distortions. Nabarro, ${ }^{29}$ clarifying earlier treatments, also considers the breaking away and interaction of segments from numerous obstacles. Although these models 
produce a $2 / 3$ power dependence of concentration at $0 \mathrm{~K}$, their temperature dependence has not been clarified. The uniform temperature dependence of the flow strength ${ }^{30}$ of austenitic steels implies the predominance of one rate-limiting deformation mechanism. The present study found that the power of concentration dependence of [N] and [C] could not be rigorously determined. As listed in Tables 2 through 4 , the variation of standard deviation is negligible between power 1 and order $1 / 3$ (Eqs.1 through 4 ). The variation of $\sigma$ also can not be used to assess the power dependence of [N] and [C] . The low magnitude of $\sigma$ at 4 and $77 \mathrm{~K}$ reflects the instability of the austenite with respect to martensitic transformation ${ }^{31}$ of $18 \mathrm{Cr}-8 \mathrm{Ni}$ steels; at low $[\mathrm{N}]+[\mathrm{C}]$ contents the steel is very metastable, tends to transform during straining, and the flow strength is lower. 31

The S.D.'s of all fits obtained at each temperature (Tables 2 through 4) are about 5 to $10 \%$ of the yield strengths. This uncertainty is comparable to the metallurgical and measurement variabilities. For example, the coefficient of variation of 210 measurements on $304 \mathrm{LN}$ production heats ${ }^{24}$ with [N] and [C] held rather constant is 7 to $14 \%$. This suggests that the $N$ and $C$ alloying elements are primarily responsible for the low-temperature strength of the Fe-18Cr-9Ni alloys.

To develop stronger austenitic stainless steels at low temperatures, $N$ additions are essential. Carbon should be kept reasonably low, to enhance weldability and to reduce carbide formation. Nitrogen is also expected to contribute greater strengthening in high-Mn austenitic alloys and in higher $\mathrm{Cr}$ or $\mathrm{Ni}$ austenitic stainless steels.

\section{CONCLUSIONS}

In austenitic stainless steels, $N^{*}$ and $C$ concentrations strongly influence the low-temperature flow strength. Nitrogen contributes significantly more to strengthening than $\mathrm{C}$ in austenitic Fe-Cr-Ni alloys at low temperature; at room temperature the contributions are essentially equal. The power dependence of [C] and [N] terms cannot be determined from the data available.

\section{ACKNOWLEDGMENT}

This research was supported by the Department of Energy, Office of Fusion Energy; Donald Beard, coordinator. 


\section{REFERENCES}

1. E. Tada, K. Yoshida, K. Koizumi, T. Ando, S. Shimamoto, N. Tada, T. Mori, and K. Yasukochi, Memo 9224, Japan Atomic Energy Research Institute, Tokai Research Establishment, Japan (1980).

2. K. Nohara, T. Kato, T. Sasaki, S. Suzuki, and Y. Ono, in: "Austenitic Steels at Low Temperatures," R. P. Reed and T. Horiuchi, eds., Plenum Press, New York, (1983), p. 117.

3. R. L. Tobler and R. P. Reed, in: NBSIR 80-1627, National Bureau of Standards, Boulder, Colorado (1980), p. 17.

4. C. E. Witherel1, Weld. J. Res. Suppl. 59:326s (1980).

5. E. A. Erez and H. D. Becker, "Evaluation of Materials for Internally Cooled, Cabled Superconductor Jackets," presented at 1981 Cryogenic Engineering Conference, International Cryogenic Materials Conference, San Diego, California (1981).

6. K. Mukai, K. Hoshino, and T. Fujioka, Tetsu to Hagane 65:1756 (1979).

7. D. T. Read and R. P. Reed, in: NBSIR 78-884, National Bureau of Standards, Boulder, Colorado (1978), p. 91.

8. D. T. Read and R. P. Reed, in: NBSIR 79-1609, National Bureau of Standards, Boulder, Colorado (1979), p. 81.

9. R. P. Reed, R. L. Tobler, and J. W. Elmer, in: NBSIR 82-1667, National Bureau of Standards, Boulder, Colorado (1982), p. 29 .

10. R. L. Tobler and R. P. Reed, in: NBSIR 81-1645, National Bureau of Standards, Boulder, Colorado (1981), p. 77.

11. S. Tone, M. Ogawa, M. Yamaga, H. Kaji, T. Horiuchi, Y. Kasamatsu, H. Nakajima, K. Yoshida, Y. Takahashi, and M. Shimada, in: "Austenitic Steels at Low Temperatures," R. P. Reed and T. Horiuchi, eds., Plenum Press, New York (1983), p. 263.

12. Y. Takahaski, K. Yoshida, M. Shimada, and E. Tada, in:

"Advances in Cryogenic Engineering - Materials," Vol. 28, R. P. Reed and A. F. Clark, eds., Plenum Press, New York (1982), p. 73 .

13. T. Horiuchi, R. Ogawa, M. Shimada, S.Tone, M. Yamaga, and Y. Kasamatsu, in: "Advances in Cryogenic Engineering Materials," Vol. 28, R. P. Reed and A. F. Clark, eds., Plenum Press, New York (1982), p. 93.

14. C. E. Spaeder, Jr. and W. F. Domis, Report (44.012-062)(2), United States Steel Applied Research Laboratory, Pittsburgh, Pennsylvania (1969), $30 \mathrm{pp}$.

15. R. Voyer and L. Weil, in: "Advances in Cryogenic Engineering," Vol. 11, K. D. Timmerhaus, ed., Plenum Press, New York (1966), p. 447.

16. Y. Takahashi, Japan Atomic Energy Research Institute, Ibaraki-ken, Japan, private communication. 
17. "Austenitic Stainless Steels for Use at Cryogenic Temperatures," Nippon Steel Corporation, Kawasaki, Japan (1983), 10 pp.

18. A. Randak, W. Wessling, H. E. Bock, H. Steinmaurer, and L. Faust, Stah1 Eisen 91:1255 (1971).

19. P. G. Stone, in: "High Temperature Properties of Steels," Publication 97, The Iron and Steel Institute, London, England (1967), p. 505.

20. K. J. Irvine, D. T. Llewellyn, and F. B. Pickering, J. Iron Steel Inst., London 199:153 (1961).

21. R. B. Gunia and G. R. Woodrow, J. Mater. Sci. 5:413 (1970).

22. C. A. Schwanbeck, Report NASA CR-54881, Lockheed Nuclear Products, Sunnyvale, CA (1965).

23. F. Mathers and J. E. M. Jubb, in: "Welding Low Temperature Containment Plant," The Welding Institute, Abington Hall, Cambridge, England (1973), p. 130.

24. E. N. C. Dalder, Mirror Fusion Test Facility - B Project, Lawrence Livermore National Laboratory, Livermore, California, private communication (1982).

25. Hanford Engineering Development Lab., Richland, Washington, "Materials Handbook for Fusion Energy Systems," U.S. Dept. of Energy, DOE/TIC-10122.

26. R. P. Reed and N. J. Simon, National Bureau of Standards, Boulder, Colorado, unpublished data (1983).

27. H. M. Ledbetter, National Bureau of Standards, Boulder, Colorado, unpublished data (1983).

28. R. M. Asimov, in: "Quantitative Relation Between Properties and Microstructure," D. C. Brandon and A. Rosen, eds., Israel University Press, Haifa (1969), p. 69.

29. F. R. N. Nabarro, Philos. Mag. 35:613 (1977).

30. R. P. Reed and J. M. Arvidson, in: "Advances in Cryogenic Engineering - Materials," Vol. 30, A. F. Clark and R. P. Reed, eds., Plenum Press, New York (1984).

31. R. P. Reed, in: "Materials at Low Temperatures," American Society for Metals, Metals Park, Ohio (1983), pp. 295-342. 
DILATION OF AN FCC Fe-Cr-Ni ALLOY BY INTERSTITIAL CARBON AND NITROGEN*

H. M. Ledbetter and M. W. Austin

Fracture and Deformation Division

Center for Materials Science

National Bureau of Standards

Boulder, Colorado 80303

\section{Abstract}

We studied the volume change arising from introducing interstitial carbon and nitrogen into an $\mathrm{fCC} \mathrm{Fe-Cr-Ni}$ alloy, an alloy corresponding to AISI-304 stainless steel, $\mathrm{Fe}-18 \mathrm{Cr}-10 \mathrm{Ni}-2 \mathrm{Mn}$. Carbon-plus-nitrogen content varied from 0.3 to 1.3 atomic percent. To complement these studies, we also examined Fe-18Cr-14Ni-4Mn alloys with low, constant carbon content and with nitrogen content varying from 0.04 to 0.91 atomic percent. We determined volume using electropolished bulk polycrystalline specimens and x-ray diffraction, which yielded the fcc unit-cell dimension. We find that an atom of carbon or nitrogen increases volume by approximately three times its own interstitialatom volume and approximately 70 percent of iron's atomic volume. Contrary to some studies, we find that nitrogen exceeds carbon in dilating the fcc-iron lattice. This occurs despite carbon's atomic volume exceeding nitrogen's. He ascribe this to electronic effects, to carbon-iron bonds stronger than nitrogeniron bonds. For the dilation, we give a model calculation. Concerning interstitial-iron interatomic bonds, we give some elementary discussion based on quantum-mechanical wave functions.

Key Words: alloying effects; austenite; face-centered-cubic alloy; interstitial; iron alloy; lattice parameter; stainless steel; volume.

*Intended for publication in Acta Metallurgica. 



\section{INTRODUCTION}

This study sought to determine how carbon and nitrogen interstitial alloying additions affect the volume of 304-type stainless-steel alloys. Especially, we wondered whether carbon or nitrogen causes larger effects. Such questions arise during various researches: for example, solid-solution strengthening, nature of interatomic bonding, and interstitial-dislocation interactions.

Both carbon and nitrogen increase the strength of austenitic $\mathrm{Fe}-\mathrm{Cr}-\mathrm{Ni}$ alloys. Nitrogen stabilizes the austenite, reducing the tendency at low temperatures toward martensitic transformations. Carbon functions similarly, but higher concentrations cause welding sensitization (chromium-carbide precipitation)

Being a physical property, volume (or mass density) is insensitive to details of internal structure related to thermomechanical treatment. However, when determined with sufficient sensitivity, it provides an important parameter for indicating interatomic-force changes, which may occur during alloying. Indeed, small changes in volume may indicate large changes in the nature of the interatomic bonding.

Commercial austenitic stainless steels always contain some carbon and nitrogen, in amounts up to a few atomic percent. These small foreign atoms enter the octahedral hole of the face-centered-cubic (fcc) lattice. This largest $\mathrm{fcc}$ interstice provides a space up to $(\sqrt{ } 2-1) r_{a}=0.41 r_{a}$, where $r_{a}$ denotes the radius of the host atom on the fcc sites. Based on a rigid-sphere model, atoms larger than the interstice must expand the fcc lattice. As shown in Fig. 1, carbon and nitrogen atoms exceed the octahedral-hole size: $r_{C} / r_{F e}=0.890 / 1.271=0.700 ; r_{N} / r_{F e}=0.855 / 1.271=0.672$. (The nitrogenatom radius poses some uncertainty. Here, as for carbon, we use the Pauling 
tetrahedral-covalent radius, corrected for co-ordination number, as described below.) The lattice expansion caused by carbon and nitrogen does not remove the usual metallic properties of ductility and conductivity. They are reduced. Consistent with a trend toward covalent-material properties, strength increases.

\section{EXPERIMENT}

Materials

Nine stainless-steel plates were purchased from the research laboratory of a U.S. steel manufacturer. A11 plates had nearly the same base composition, which fell within the 1 imits of ASTM specification A240 for AISI-304 stainless steel, nominally $\mathrm{Fe}-18 \mathrm{Cr}-10 \mathrm{Ni}-1.5 \mathrm{Mn}-0.01 \mathrm{P}-0.02 \mathrm{~S}-0.55 \mathrm{Si}-0.2 \mathrm{Mo}-0.2 \mathrm{Cu}$ weight percent. The carbon and nitrogen contents varied as shown in the mill chemical analyses in Table 1. The nine plates were produced from three $136-\mathrm{kg}$ vacuuminduction-melted heats, split with respect to carbon level, and teemed into $7.6-\mathrm{cm} \times 20-\mathrm{cm} \times 36-\mathrm{cm}$ hot-topped cast-iron ingot molds. The ingots were reheated and soaked at $1561 \mathrm{~K}\left(2350^{\circ} \mathrm{F}\right)$, hot-rolled into $2.54-\mathrm{cm}$ plates, and air cooled. The plates were finally annealed at $1332 \pm 7 \mathrm{~K}\left(1937 \pm 13^{\circ} \mathrm{F}\right)$ for $1 \mathrm{~h}$ and water quenched. Hardness and grain size are also listed in Table 1.

Eight stainless-steel plates were obtained from the Soviet Union. Considering their carbon and nitrogen contents, we selected five of these for study. Chemical analyses appear in Table 1. A 11 these plates were hot-rolled to 2.4-cm thickness, annealed at $1450 \mathrm{~K}\left(2150^{\circ} \mathrm{F}\right)$ for $1 \mathrm{~h}$, and fast waterquenched.

Methods

Samples were ground flat within $\pm 0.005 \mathrm{~mm}$ and were electropolished in a solution of $\mathrm{H}_{3} \mathrm{PO}_{4}$ to remove the surface damage. Specimens were measured in a commercial manual diffractometer whose movement and electronics were modified 
for computer control. A copper target at $34 \mathrm{kV}$ and $20 \mathrm{~mA}$ irradiated the steels through 3 -degree Soller slits. The diffracted beam then passed a 0.2-degree slit and graphite monochromator. Profiles of (111), (200), (220), (311), (222), (400), (331), and (420) lines were automatically recorded at 0.05 - degree 2 -theta intervals with 60 -s exposures. Peak positions determined by a parabolic fit were plotted against $\cos ^{2} \theta / \sin \theta$. Repeatability of the lower-index lines was such that we considered it more accurate to determine the lattice parameter by averaging the four (331) and (420) $K_{\alpha 1}$ and $K_{\alpha 2}$ values, which were well defined.

\section{RESULTS}

Figure 2 shows the variation of $f c c$ unit-cell dimension with carbonplus-nitrogen content. Figure 3 shows the mass density determined two ways: from x-ray diffraction using average atomic weights and by Archimedes's method. We attribute the approximately 0.7 -percent-higher $x$-ray density to the occurrence of defects not detected by $x$-rays. These defects include grain boundaries, voids, cracks, and lower-density inclusions.

Linear least-squares analysis of the results gives, when carbon and nitrogen are not distinguished

$$
a(\AA)=3.586+0.00854 x_{C+N}
$$

When carbon and nitrogen effects are separated, one obtains

$$
a(\AA)=3.5866+0.00783 x_{C}+0.00861 x_{N}
$$

where $a$ is in angstroms and $x$ denotes atomic percent. For the Soviet steels with nearly constant, low-carbon content, one obtains

$$
a(\AA)=3.5869+0.00761 x_{C+N}
$$


Table 2 contains the above results expressed as the percentage latticeparameter change per atomic percent solute. This table also contains results from twelve other sources.

\section{MODEL PREDICTIONS}

Here we consider the predicted unit-cell dimension change due to interstitial atoms in the fcc octahedral hole. We use two models: a rigid-sphere lattice model and an elastic-continuum model. The first assumes incompressible atoms; the second allows for elastic defarmation by introducing the elastic constants. Essential input to these calculations are the atomic sizes. For iron, we use an atomic radius of $r_{\mathrm{Fe}}=1.271 \AA$. We obtained this by correcting Pearson's [13] fcc-Fe lattice parameter, $a_{\gamma}=3.6468 \AA$ at $916^{\circ} \mathrm{C}$, for therma expansion and using the nearest-neighbor $(n n)$ relationship

$$
r_{F e}=r_{n n}=\sqrt{ } 2 a_{\gamma} / 4
$$

For carbon and nitrogen, we start with Pauling's [14] tetrahedral-covalent radii: $r_{C}=0.771 \AA$ and $r_{N}=0.740 \AA$. But these must be corrected from $c n=4$ to $c n=6$ ( $c n=$ co-ordination number $=$ number of nearest-neighbor atoms). Pauling gave equations for this correction. Here, we take another approach and consider the atomic radius from Eq. (4) compared with the nearest-neighbor-atom spacing. The ratio of these varies with crystal structure (co-ordination number). For the diamond-cubic lattice $(c n=4)$, we find

$$
\frac{r^{(4)}}{r_{n n}}=\frac{(3 / 32 \pi)^{1 / 3} a}{\sqrt{3(a) 18}}=1.433
$$

and for a simple-cubic lattice $(c n=6)$

$$
\frac{r^{(6)}}{r_{n n}}=\frac{(3 / 4 \pi)^{1 / 3} a}{a / 2}=1.241
$$


Thus,

$$
r^{(6)} / r^{(4)}=2 / \sqrt{ } 3=1.155
$$

which leads to $r_{c}=0.890 \AA$ and $r_{N}=0.854 \AA$. Higher $c n$ means that fewer valence electrons contribute to binding, thus less-tight binding between adjacent atom pairs. Pauling argued that higher cn means less-tight binding reflected in a larger atomic radius. Zachariasen [15] pointed out that $r(\mathrm{cn})$ varies with crystal structure simply because of energy requirements; energy alone requires $r^{(\mathrm{cn})}$ to decrease with decreasing $\mathrm{cn}$. Simple lattice model

Here we assume incompressible spherical atoms and consider what happens locally to the $\mathrm{fcc}$ unit-cell dimension, $a$, when we insert an interstitial atom into the octahedral hole. This hole-site possesses full cubic symmetry, even though the overall unit-cell symmetry reduces from Fm3m to P43m. Thus, the interstitial behaves as a pressure center and produces isotropic effects. From Fig. 1, we can write

$$
\frac{\Delta a}{a}=\frac{r_{a}+r_{x}-\sqrt{ } 2 r_{a}}{\sqrt{2} r}=\frac{1-\sqrt{ } 2+r_{x} / r_{a}}{\sqrt{2}}
$$

where subscript a denotes host atom (in this case, iron) and subscript $x$ denotes interstitial atom (in this case, carbon or nitrogen). Table 2 gives the results of the calculation. For comparisons made below, we also compute that the total volume change associated with a single interstitial:

$$
\frac{\Delta V}{V}=\left(1+\frac{\Delta a^{3}}{a}\right)^{3}-1
$$

which yields 0.74 for carbon in fcc iron. Thus, $\Delta V=(\Delta V / V)\left(a^{3} / 4\right)=8.58 \AA^{3}$. Continuum model

Here we approach the problem differently, from the viewpoint of a homogeneous, isotropic elastic continuum. For point defects, one sometimes 
calls this a sphere-in-hole model. Several authors, notably Eshelby [16], considered this model. Considering image forces and the elastic constants, in this model the total volume change caused by an interstitial is:

$$
\Delta V=4 \pi c \gamma=4 \pi r_{0 h}^{3} \varepsilon \gamma
$$

where $c$ denotes the singularity "strength," $r_{\text {oh }}$ the octahedral-hole radius, $\varepsilon$ the strain at $r_{o h}$, and $\gamma$ an elastic-constant function

$$
\gamma=\frac{3 B+4 G}{3 B}=3 \frac{1-v}{1+v}
$$

where $B$ denotes bulk modulus, $G$ shear modulus, and $v$ Poisson's ratio. For typical metals, $\nu \cong 1 / 3$ and $\gamma \cong 3 / 2$. (For 304-type stainless steel, $v=0.290$ and $\gamma=1.653$.) In Eq. (10) it is difficult to estimate either $c$ or $\varepsilon\left(r_{\text {oh }}\right)$. We can use the above $\Delta V$ estimate to infer these. To do this, we invoke an idea from Eshelby: the volume change contains two parts

$$
\Delta V=\Delta V^{\infty}+\Delta V^{I}=\gamma \Delta V^{\infty}
$$

where $\Delta V^{\infty}$ arises from the classical elastic-displacement solution for a center of dilation in an infinite medium (Love [17]) and $\Delta V^{I}$ arises from image forces necessary to ensure vanishing stress at the surface of a finite-size specimen. Thus, for most cases $\Delta V^{\infty}$ and $\Delta V^{I}$ are approximately the same size. Leibfried and Breuer [18] described how to obtain a crude estimate of local displacements from $\Delta V^{\infty}$. That is, $\Delta V^{\infty}$ gives information concerning local changes near the defect. Following them, we confine the volume change to the first-neighbor displacements, $U_{1 n n}$. Then

$$
\Delta V^{\infty}=\Delta V / \gamma=4 \pi r_{1 n n}^{2} u_{1 n n}^{\infty}
$$

The strain at the $1 n n$ distance is:

$$
\varepsilon_{1 n n}=2 u_{1 n n}^{\infty} / a=\Delta V / \gamma 8 \sqrt{ } 2 \pi r_{a}^{3}
$$


For carbon in gamma iron $(c n=6)$ this predicts $\varepsilon_{1 \mathrm{nn}}=0.018$, or approximately two percent strain at the 1 nn distance.

\section{DISCUSSION}

This study contains two principal results. First, both carbon and nitrogen interstitial atoms in fcc iron increase volume approximately $0.7 \mathrm{~V}_{\mathrm{Fe}}$ or approximately three times the volume of the interstitial atom. Second, despite carbon's larger atomic size, carbon dilates less than nitrogen.

The first result was explained above by a simple lattice-model calculation. The interstitial occupies the center of an octahedron of iron atoms. It acts effectively as a point pressure and pushes away all six Inn iron atoms. It remains to see whether a complete continuum model would also predict the large volume increase.

We now consider the second result: the smaller effect of carbon. In this we can profit from recognizing the equivalence of $\mathrm{Fe}_{4} \mathrm{X}$ to a local fCciron unit cell containing one octahedral-site interstitial atom, denoted $X$. This permits us to infer properties of the alloy from those of the interstitial compound. Viewed another way, $\mathrm{Fe}_{4} \mathrm{X}$ corresponds to $\mathrm{fcc}$ iron with one-fourth of the octahedral sites occupied in an ordered way by carbon. If all octahedral interstices (see Fig. 4) are occupied, then the interstitial compound FeX arises. This compound possesses a symmetry: Fm3m.

Nitrogen's extra electron probably produces a weaker metal-nonmetal bonding. To complete its octet, carbon can share four electrons with its six nearest-neighbor metal atoms, but nitrogen only three. Lower melting points of nitrides relative to carbides supports the idea of weaker bonding. Hume-Rothery [19] pointed out that "unless charges are to be built up...bonding in nitrides will be weaker than in carbides." 
We believe that stronger bonding in $\mathrm{Fe}-\mathrm{C}$ than in $\mathrm{Fe}-\mathrm{N}$ accounts for nitrogen expanding $\gamma-\mathrm{Fe}$ more than carbon does, even though carbon is a larger atom than nitrogen. Carbon produces stronger bonding, higher melting point, higher elastic stiffness, and lower volume. The inverse relationship between stiffness (and bonding strength) and volume is well known.

For models of solid-solution strengthening, and realizing that nitrogen strengthens $\gamma$-iron more than carbon does [20], the present results produce an interesting conclusion. Strengthening may not arise from simple carbondislocation and nitrogen-dislocation interactions. Perhaps it arises from a complex-defect/dislocation interaction. This complex defect could be an interstitial pair, an interstitial host-atom pair, or an interstitial/selfinterstitial pair, but, in any case, one involving nitrogen interstitials. Indeed, Igata et al. [21] suggested that a complex defect pins dislocations more effectively than either carbon or nitrogen atoms alone. Igata and coworkers' internal-friction studies on mechanically deformed 304-type stainless steel showed three peaks versus temperature. They ascribed the lowest peak to unpinning from carbon, the middle peak to unpinning from nitrogen, and the highest peak to unpinning from a carbon-nitrogen/self-interstitial complex. We can understand the stronger bonding in $\mathrm{Fe}-\mathrm{C}$ compared with that in $\mathrm{Fe}-\mathrm{N}$ by considering the simplest quantum theory of atomic bonding, especially electron-pair bonds. Carbon's normal electron configuration, $1 s^{2} 2 s^{2} 2 p^{2}$, implies a valence of 2 corresponding to two unpaired electrons. But organicchemistry facts show that carbon's actual configuration is $1 s^{2} 2 s^{1} 2 p^{3}$, a low-lying excited state with four unpaired electrons and a valence of 4 . Indeed, carbon's four tetrahedral orthogonal, normalized s-p hybrid wave functions are well known [22]: 


$$
\begin{aligned}
& T_{e 1}=\left(s+p_{x}+p_{y}+p_{z}\right) / 2 \\
& T_{e 2}=\left(s+p_{x}-p_{y}-p_{z}\right) / 2 \\
& T_{e 3}=\left(s-p_{x}+p_{y}-p_{z}\right) / 2 \\
& T_{e 4}=\left(s-p_{x}-p_{y}+p_{z}\right) / 2
\end{aligned}
$$

The strengths of an $s$ bond and a $p$ bond are 1 and $\sqrt{3}$, respectively [23]. On this scale, these tetrahedral orbitals have bond energies of 2 , the highest possible for $2 s-2 p$ hybrids, corresponding to the maximum possible number of unpaired s-p electrons (four). Nitrogen's extra electron suggests a normal electron configuration of $1 s^{2} 2 s^{2} 2 p^{3}$ or, more probably, the excited configuration $1 s^{2} 2 s^{1} 2 p^{4}$. In either case, nitrogen has only three unpaired electrons. Thus, compared with carbon, it offers one-fourth fewer electrons for covalentionic bonding with iron. We note also that carbon's four wave functions fit well into the octahedral symmetry of the interstitial sites in fcc iron. There are three bonds at right angles formed by dumbbell-shaped p orbitals, and a fourth bond, the s orbital, having spherical symmetry and, therefore, no special direction. Following Hund, Dehlinger [24] emphasized the importance of wave-function direction for bonding: "binding energy is a maximum if the number of valence electrons per atom equals the number of degenerate functions... and if the neighboring atoms $l i e$ in the direction of the preferred wave-function directions, and in these directions only."

We can carry these elementary quantum-mechanical considerations one step farther and consider the detailed wave functions that may occur between carbon and its six octahedral-symmetry neighboring iron atoms. One can construct equivalent octahedral orbitals by suitable hybridization of two d orbitals, one s orbital, and three p orbitals, and thus obtain a $s p^{3} d^{2}$ hybridization [25]. The maximum $s-p-d$ bond strength is 3 . This hybrid possesses nearly a maximum strength, 2.923. From symmetry, only two $d$ orbitals, $d_{x}{ }^{2}$ and $d_{x}{ }^{2}+y^{2}$, combine 
with $s$ and $p$ :

$$
\begin{aligned}
& d_{x x}=f_{d}(r)\left(2 x^{2}-y^{2}-z^{2}\right) \\
& d_{y y}=f_{d}(r)\left(-x^{2}+2 y^{2}-z^{2}\right) \\
& d_{z z}=f_{d}(r)\left(-x^{2}-y^{2}+2 z^{2}\right)
\end{aligned}
$$

with the constraint

$$
d_{x x}+d_{y y}+d_{z z}=0
$$

This $\mathrm{sp}^{3} \mathrm{~d}^{2}$ hybrid bond requires six bonding electrons; carbon possesses only four. Thus, carbon may capture two electrons from iron's metallic electron gas and acquire a negative charge. Band-structure calculations [26] predict a

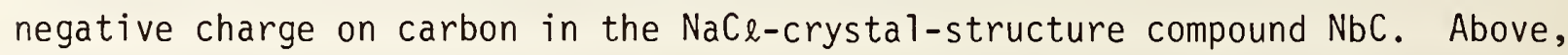
we described the similarity between the compounds $\mathrm{FeX}$ and $\mathrm{Fe}_{4} \mathrm{X}$ and the $\gamma$-Fe solid solution containing interstitial $X$.

\section{CONCLUSIONS}

Both carbon and nitrogen interstitial atoms increase the volume of an Fe-Cr-Ni-alloy with composition near 304-type stainless steel. Even though nitrogen is a smaller atom than carbon, it dilates more. $\mathrm{Fe}-\mathrm{C}$ bonds stronger than $\mathrm{Fe}-\mathrm{N}$ bonds may explain this. Compared with their own atomic volumes, the interstitials produce a surprisingly large dilation. A simple local lattice model explains this.

\section{ACKNOWLEDGMENT}

Some support for this study came from the US DoE Office of Fusion Energy. R. P. Reed of NBS provided encouragement. R. E. Schramm contributed to the early $x$-ray-diffraction studies. 


\section{REFERENCES}

1. V. G. Paranjpe, M. Cohen, M. B. Bever, and C. F. Floe, J. Met. 2, 261 (1950).

2. C. S. Roberts, Trans. AIME 197, 203 (1953).

3. W. B. Pearson, Lattice Spacings and Structures of Metals and Alloys, Volume 1, p. 921. Pergamon, New York (1958).

4. K. J. Irvine, D. T. Llewellyn, and F. B. Pickering, J. Iron Steel Inst. $199,153-175$ (1961).

5. L. Zwe11, E. J. Fasiska, Y. Nakada, and A. S. Keh, Trans. Met. Soc. AIME $242,765-766$ (1968).

6. N. Ridley, H. Stuart, and L. Zwell, Trans. Met. Soc. AIME 245, 1834-1836 (1969).

7. N. Ridley and H. Stuart, Met. Sci. J. 4, 219-222 (1970).

8. D. J. Dyson and B. Holmes, J. Iron Steel Inst. 208, 469-414 (1970).

9. D. E. Diesburg, Ph.D. Thesis, Iowa State University, Ames, Iowa (1971).

10. M. Kikuchi, T. Tanaka, K. Hamagami, Y. Ogura, and R. Tanaka, Met. Trans. A 7, 906-908 (1976).

11. J. Charles, Ph.D. Thesis, Universite Catholique de Louvain, Malonne, Belgium (1982).

12. T. Sakamoto, Y. Nakagawa, I. Yamauchi, T. Zaizen, H. Nakajima, and S. Shimamoto, in Advances in Cryogenic Engineering, Volume 30, p. 137. Plenum, New York (1984).

13. W. B. Pearson, Lattice Spacings and Structures of Metals and Alloys, Volume 2, p. 82. Pergamon, New York (1967).

14. L. Pauling, The Nature of the Chemical Bond, p. 246. Cornell University Press, I thaca, New York (1960).

15. W. H. Zachariasen, Z. Kristallogr. 80, 137 (1931).

16. J. D. Eshelby, J. Appl. Phys. 25, 255-261 (1954).

17. A. E. H. Love, Mathematical Theory of Elasticity, p. 142. Cambridge University Press, New York (1927).

18. G. Leibfried and N. Breuer, Point Defects in Metals I, p. 150. SpringerVerlag, Berlin (1978).

19. W. Hume-Rothery, Philos. Mag. 44, 1154-1160 (1953). 
20. R. P. Reed and N. J. Simon, in Advances in Cryogenic Engineering, Volume 30, p. 127. Plenum, New York (1984).

21. N. Igata, H. B. Chen, K. Miyahara, and T. Uba, J. Phys. 42, C5193-C5198 (1981).

22. R. Dande1, R. Lefebvre, and C. Moser, Quantum Chemistry, p. 158. Interscience, New York (1959).

23. Ref. 14, p. $119 f$.

24. U. Dehlinger, Theoretische Metal1kunde, p. 66. Springer-Verlag, Berlin (1955).

25. Ref. 14, p. 149 .

26. W. Weber, Phys. Rev. B 8, 5082-5092 (1973). 


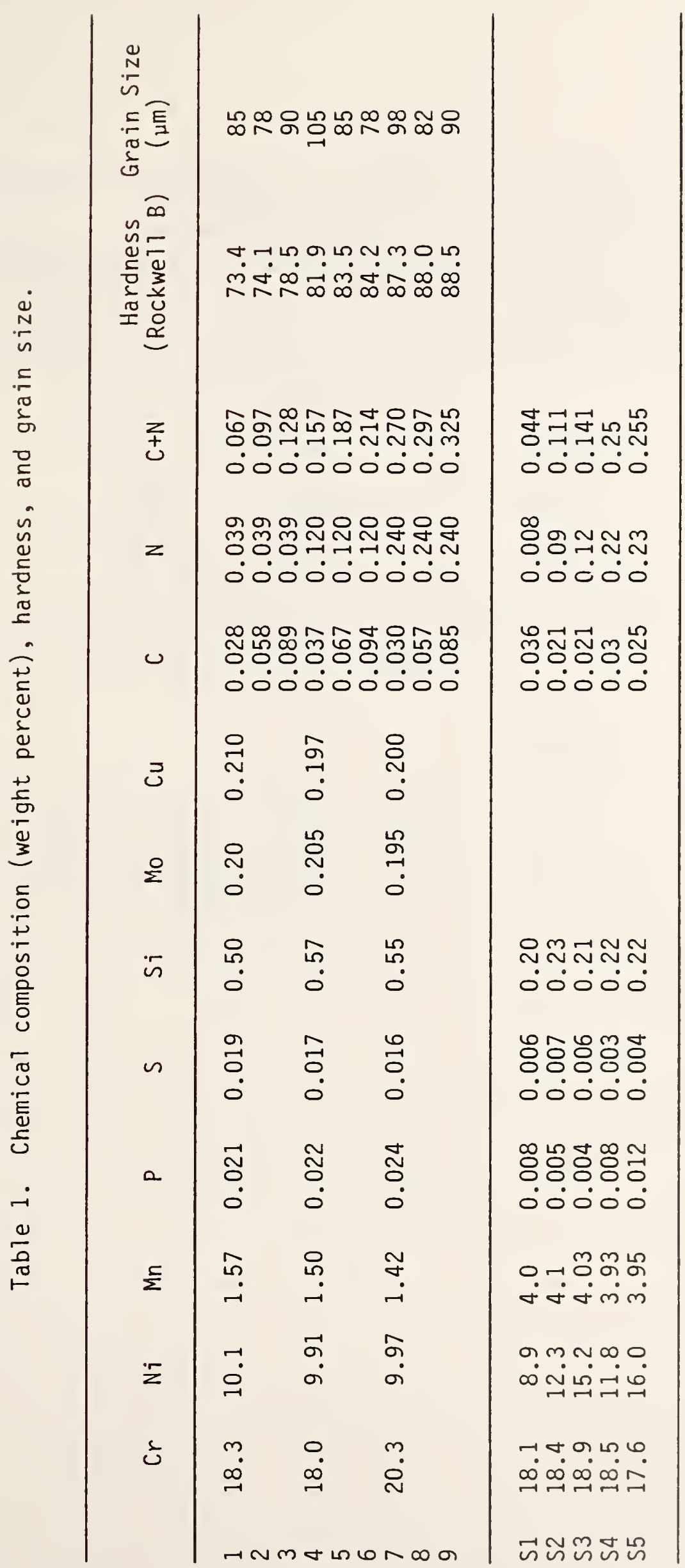


Table 2. Effects of interstitial carbon and nitrogen on the lattice parameter of $\mathrm{fCC} \mathrm{Fe}-\mathrm{Cr}-\mathrm{Ni}$ alloys; expressed as $100(1 / x)\left(\Delta a / a_{0}\right)$ where $x$ denotes atomic percent.

\begin{tabular}{|c|c|c|c|}
\hline Al 1 oy & $C$ & $\mathrm{~N}$ & Source \\
\hline $\begin{array}{l}\text { Fe } \\
\text { Fe } \\
\text { Fe } \\
\text { Fe-18Cr-10Ni } \\
\text { Ni } \\
\text { Fe } \\
\text { Fe } \\
\text { Fe-18Cr-16Ni } \\
\text { Fe-14-29Ni } \\
\text { Fe-25Cr-28Ni } \\
\text { Fe-25Cr-28Ni-2Mo } \\
\text { Fe-10Cr-5Al } \\
\text { Fe-23Mn-5Al } \\
\text { Fe-30Mn-5Al } \\
\text { Fe-30Mn-8Al } \\
\text { Fe-17-25Cr-8-13Ni } \\
\text { Fe-18Cr-10Ni }-2 \mathrm{Mn} \\
\text { Fe- } 18 \mathrm{Cr}-14 \mathrm{Ni}-4 \mathrm{Mn}\end{array}$ & $\begin{array}{l}0.267 \\
0.275 \\
0.167 \\
0.210 \\
0.199 \\
0.190 \\
0.182 \\
0.210\end{array}$ & $\begin{array}{l}0.157 \\
0.201 \\
0.200 \\
0.221\end{array}$ & $\begin{array}{l}\text { Paranjpe et al. [1] } \\
\text { Roberts [2] } \\
\text { Pearson [3] } \\
\text { Irvine et al. [4] } \\
\text { Zwell et al. [5] } \\
\text { Ridley et al. [6] } \\
\text { Ridley, Stuart [7] } \\
\text { Dyson, Holmes [8] } \\
\text { Diesburg [9] } \\
\text { Kikuchi et al. [10] } \\
\text { Charles [11] }\end{array}$ \\
\hline
\end{tabular}




\section{List of Figures}

Fig. 1. Schematic representation of a face-centered-cubic unit cell. Partly-covered circles represent corner atoms. Full circles represent face-centered atoms. Shaded circle represents maximum diameter of octahedral hole. Dashed circle represents relative size of carbon atom in iron. Cube axes lie along [100]-type directions and closepacking occurs along [110]-type directions.

Fig. 2. Unit-cell dimension versus combined carbon-plus-nitrogen interstitialatom content.

Fig. 3. Mass density versus combined carbon-plus-nitrogen interstitial-atom contents.

Fig. 4. Face-centered-cubic unit cell. Open circles denote fcc atoms.

Filled circles denote equivalent octahedral-hole interstitial atoms. Lines define octahedron with interstitial atom at center with six near-neighbor host-lattice atoms. 


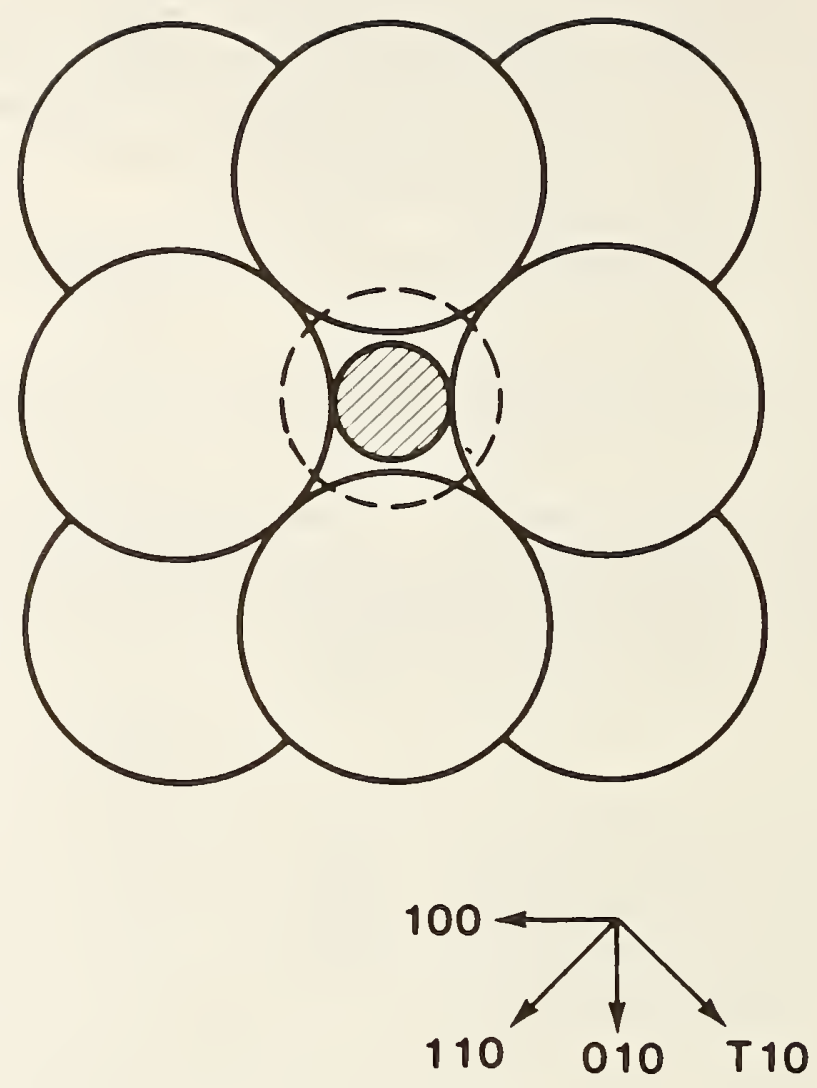

Fig. 1. Schematic representation of a face-centered-cubic unit cell. Partly-covered circles represent corner atoms. Full circles represent face-centered atoms. Shaded circle represents maximum diameter of octahedral hole. Dashed circle represents relative size of carbon atom in iron. Cube axes lie along [100]-type directions and closepacking occurs along [110]-type directions. 


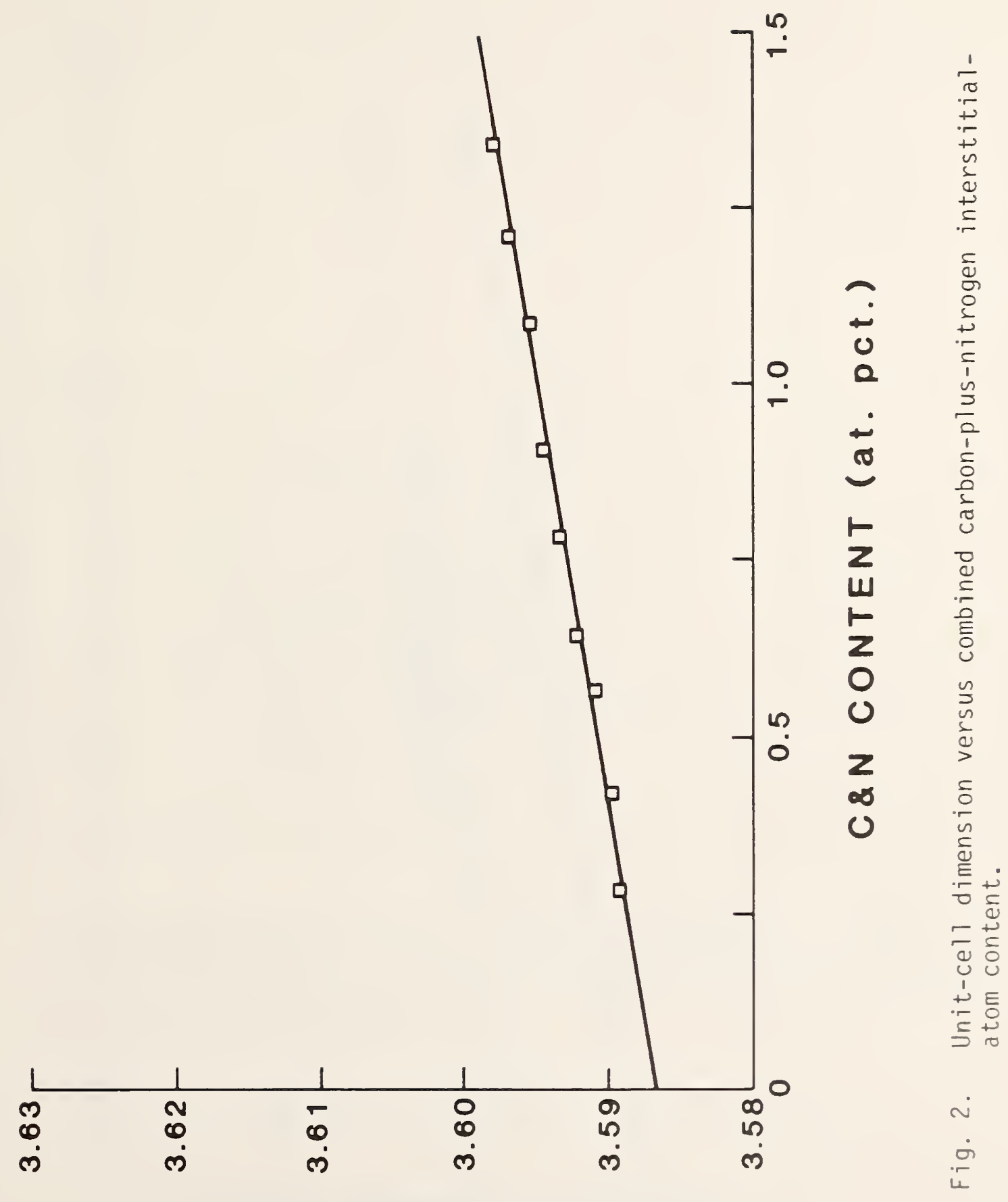

(sModtsGue) ${ }^{O^{8}}$ 


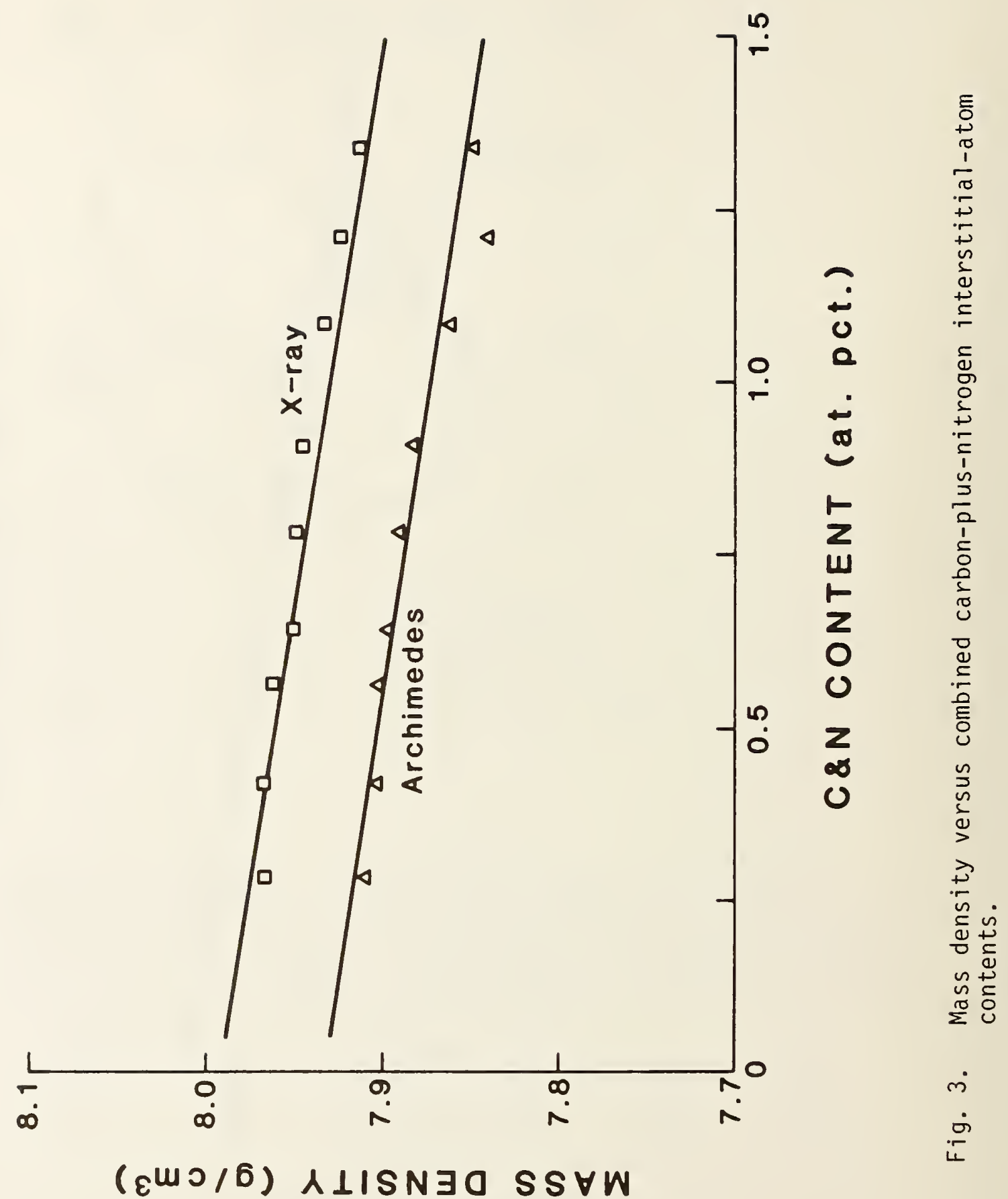




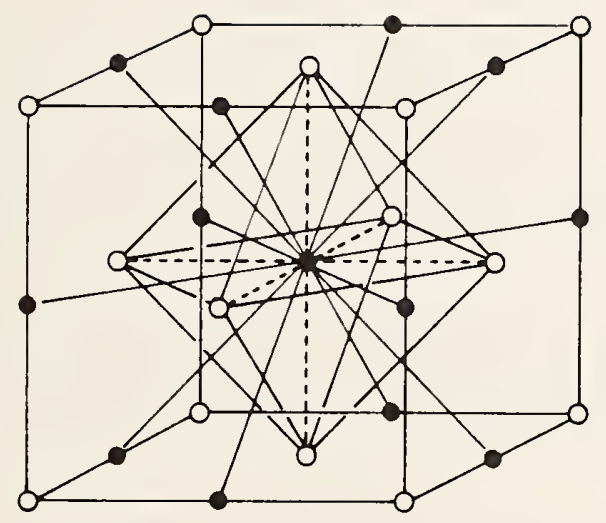

Fig. 4. Face-centered-cubic unit cel1. Open circles denote fcc atoms. Filled circles denote equivalent octahedral-hole interstitial atoms. Lines define octahedron with interstitial atom at center with six near-neighbor host-lattice atoms. 



\title{
EFFECTS OF CARBON AND NITROGEN ON THE ELASTIC CONSTANTS OF 304-TYPE STAINLESS STEEL*

\author{
H. M. Ledbetter and M. W. Austin \\ Fracture and Deformation Division \\ Center for Materials Science \\ National Bureau of Standards \\ Boulder, Colorado 80303
}

\begin{abstract}
Nine 304-type stainless-steel alloys were studied at room temperature. Carbon-plus-nitrogen contents of these alloys ranged from 0.067 to 0.325 weight percent ( 0.3 to 1.3 atomic percent). Five elastic constants-longitudinal modulus, Young's modulus, shear modulus, bulk modulus, and Poisson's ratio--were determined by a pulse-echo ultrasonic method. All the elastic stiffnesses decrease 0.5 to 0.9 percent per atomic percent solute. Poisson's ratio remains unaffected by carbon-nitrogen alloying. Existing theory predicts decreases in elastic stiffness. A model by Eshelby relates the elastic-stiffness decrease to the volume increase.

Note: A previous report in this series contained a manuscript on this subject. Subsequent study showed that those specimen numbers were scrambled. The present manuscript contains corrected results and conclusions.
\end{abstract}

Key words: bulk modulus; elastic constants; physical property; Poisson's ratio; pulse-echo method; shear modulus; stainless steels; Young's modulus; ultrasonics.

*Intended for publication in Materials Science and Engineering. 



\section{IMTRODUCTION}

This study sought to determine how carbon and nitrogen alloying additions affect the elastic constants of 304-type stainiess-steel alloys.

Both carbon and nitrogen increase strength of austenitic $\mathrm{Fe}-\mathrm{Cr}-\mathrm{lli}$ alloys. Nitrogen stabilizes the austenite, reducing the tendency at low temperatures toward martensitic transformations. Carbon functions similarly, but higher concentrations cause sensitization during welding. The increasing uses of these alloys, together with a dearth of reliable physical-property measurements, prompted the present study.

Being physical properties, elastic constants are relatively insensitive to details of internal structure related to thermomechanical ireatment. However, when determined with sufficient sensitivity, they provide important parameters for indicating interatomic-force changes, which may occur during alloying. Indeed, small changes in elastic constants may indicate large changes in the nature of the interatomic bonding.

Commercial austenitic stainless steels always contain some carbon and nitrogen, in amounts up to a few atomic percent. These small foreign atoms occupy the octahedral hole of the face-centered-cubic (fcc) lattice. This largest $\mathrm{fcc}$ interstice provides a space up to $(1 / 2-1) r_{a}=0.41 r_{a}$, where $r_{a}$ denotes the radius of the host atom on the fcc sites. Larger interstitial atoms must expand the fCc lattice. Both carbon and nitrogen atoms exceed the octahedral-hole size: $\quad r_{C} / r_{F e}=0.890 / 1.271=0.70 ; r_{N} / r_{F e}=0.855 / 1.271=0.67$. (The nitrogen-atom radius poses some uncertainty. Here, as for carbon, we use the Pauling tetrahedral-covalent radius corrected for co-ordination number.) The lattice expansion caused by carbon and nitrogen does not remove the usual metallic properties of ductility and conductivity. They are reduced. Consistent with a trend toward covalent-material properties, strength increases. 


\section{EXPERIMENT}

Materials

Nine stainless-steel plates were purchased from the research laboratory of a U.S. steel manufacturer. All plates had nearly the same base composition, which fell within the 1 imits of ASTM specification A240 for AISI-304 stainless steel, nominally $\mathrm{Fe}-18 \mathrm{Cr}-10 \mathrm{Ni}-1.5 \mathrm{Mn}-0.20 \mathrm{P}-0.20 \mathrm{~S}-0.55 \mathrm{Si}-0.2 \mathrm{Mo}-0.2 \mathrm{Cu}$ weight percent. The carbon and nitrogen contents varied as shown in the mill chemical analyses in Table I. The nine plates were produced from three $136-\mathrm{kg}$ vacuuminduction-melted heats, split with respect to carbon level, and teemed into $7.6-\mathrm{cm} \times 20-\mathrm{cm} \times 36-\mathrm{cm}$ hot-topped cast-iron ingot molds. The ingots were reheated and soaked at $1561 \mathrm{~K}\left(2350^{\circ} \mathrm{F}\right)$, hot-rolled into $2.54-\mathrm{cm}$ plates, and air cooled. The plates were finally annealed at $1332 \pm 7 \mathrm{~K}\left(1937 \pm 13^{\circ} \mathrm{F}\right)$ for $1 \mathrm{~h}$ and water quenched. Hardness and grain size are also listed in Table I, and mass densities are given in Table II.

Methods

Room-temperature sound velocities were determined by a pulse-echo-overlap technique [1]. Quartz piezoelectric crystals with fundamental resonances between 4 and $7 \mathrm{MHz}$ were cemented with phenyl salicylate to one end of a specimen with flat and parallel surfaces. An $x$-cut transducer was used for longitudinal waves and an ac-cut for transverse waves. The specimen in this case was a $1.59-\mathrm{cm} \times 1.59-\mathrm{cm} \times 1.27-\mathrm{cm}$ parallelepiped with opposite faces ground flat and parallel within $2.5 \mu \mathrm{m}$. Ultrasonic pulses 1 to 2 cycles long were launched into the specimen by electrically exciting the transducer. The pulses propagated through the specimen, reflected from the opposite face, and propagated back and forth. The pulse echoes were detected by the transducer and displayed on an oscilloscope equipped with a time delay and a microprocessor for time-interval measurements. The sound velocity was computed by 


$$
v=2 l / t
$$

where $\ell$ denotes specimen length, and $t$, the round-trip transit time. On the oscilloscope, $t$ was the time between adjacent echoes, the first and second echoes usually being measured, and within these the time between leading cycles. Elastic constants were computed from the general relationship

$$
c=\rho v^{2}
$$

where $\rho$ denotes mass density. The usual engineering elastic constants are related to the longitudinal and transverse sound velocities, $v_{l}$ and $v_{t}$, by

$$
\begin{aligned}
& \text { longitudinal modulus }=C_{\ell}=\rho v_{\ell}^{2} \\
& \text { shear modulus }=G=\rho v_{t}^{2} \\
& \text { bulk modulus }=B=C_{\ell}-(4 / 3) G \\
& \text { Young's modulus }=E=3 G B /\left(C_{\ell}-G\right) \\
& \text { Poisson's ratio }=v=(E / 2 G)-1 \\
& =(1 / 2)\left(C_{\ell}-2 G\right) /\left(C_{\ell}-G\right)
\end{aligned}
$$

We measured mass density both by an Archimedes method and by $x$-ray diffraction. We used the latter values because they scattered less from a linear fit.

\section{RESULTS}

Table II gives the principal results of the study: sound velocities and elastic constants for nine type-304 stainless-steel alloys with different carbon and nitrogen contents. Table III shows for one case, alloy 1 , the directional variation of the ultrasonic wave velocities. Table III implies also that ultrasonic velocities can be measured in these alloys with an uncertainty of 0.05 percent or less. Figure 1 shows these results graphi- 
cally. Table IV contains the linear-least-squares parameters for the various elastic constants. The last column in Table IV gives the percent elasticconstant change per atomic percent interstitial.

\section{DISCUSSION}

Results in Table II and Fig. 1 lead to the following conclusion: although the effects are smal1, carbon and nitrogen additions reduce the elastic stiffnesses--C $, G, B, E$--of 304-type stainless steel. By small, we mean less than one percent stiffness reduction per atomic percent solute. Poisson's ratio remains unaffected.

Present results contrast sharply with observations reported for ferritic iron. Speich, Schwoeble, and Leslie [2] reported that carbon added to alpha iron reduces elastic stiffnesses, such as $E$ and $G$, by about five percent per atomic percent carbon. Indeed, carbon is the most effective known alloying element in altering alpha iron's elastic constants. Quantitative results for nitrogen remain unreported, but one would expect nitrogen to behave like carbon because their atomic diameters are similar. The essential distinction between the ferritic and austenitic cases is the crystal structure. Bodycentered-cubic crystals are less accommodating to interstitials than are face-centered-cubic crystals. Carbon alloyed into bcc iron occupies a distortedoctahedral interstice that has tetragonal symmetry, which produces a strong tetragonal distortion; no similar distortion occurs in fcc iron, where carbon occupies larger octahedral interstices and the lattice distortion is isotropic. This distortion reflects also in the much higher solubility of carbon and nitrogen in $f c c$ iron compared with bcc iron.

Present results dispute those of a previous study. Laddach and Schüler [3] studied the influence of nitrogen on the elastic properties of an Fe-21Cr-20Ni alloy containing 0.02 and 0.29 weight percent nitrogen. They 
concluded that "nitrogen raises the modulus of elasticity as well as the modulus of rigidity, regardless of the nitrogen being either in interstitial solution or precipitated in the form of nitrides." No reconciliation of this conclusion and that of the present study seems apparent.

A related study by Diesburg [4] tends to support our findings. Diesburg measured the single-crystal elastic constants of several fcc Fe-Ni-C alloys containing 11.3 to 33.3 atomic percent $\mathrm{Ni}$ and 0.0 to 4.5 atomic percent carbon. All the elastic constants softened with increasing carbon content. Of course, Diesburg's alloys differ distinctly from ours: they contained no chromium; they contained no trace elements; they were studied below the Curie temperature (in the ferromagnetic state); and they contained no grain boundaries. Thus, any comparison must be cautious.

Because the effects are small and difficult to measure, one can usefully consider the view of theory. Most existing theory applies to self-interstitials, thus to atoms larger than most foreign interstials and with the same electronic structure as the host-lattice atoms.

Simple theory fails to predict the effect of interstitials on elastic constants. This failure arises from three factors: (1) the geometricalmechanical misfit, which causes changes in volume and sometimes shape; (2) the electric-field misfit, which causes charge redistribution, atomic-bond change, and changes in interatomic potential and force constants; (3) the coupling of these two types of misfit. The usual interstitial effects are to increase volume (which reduces the elastic stiffness) and to increase the elastic spring constants (which increases elastic stiffness).

A simple model by Dienes [5] predicted for copper that $S \equiv(1 / x)(\Delta C / C)=$ 10 percent; here $x$ denotes interstitial concentration and $C$ denotes elastic stiffness. The Dienes model considers only the elastic-spring-constant 
changes; neglecting volume, it represents an upper limit. Nabarro [6] criticized this model and gave an alternative elastic-continuum calculation that predicted $S=4$ percent. Eshelby [7] pointed out two features of Dienes's calculations. First, Dienes neglected image forces that are large and might even reverse the sign of S. Second, Dienes's calculations should apply in the immediate vicinity of the interstitial, predicting an elastic stiffening near the interstitial, but an overall macroscopic elastic softening.

Experiment on unalloyed fcc metals shows that $S$ is larger than these estimates, and is negative! Thus, one requires a more detailed model that considers the above-mentioned coupling.

Apparently, Ludwig [8] first gave a detailed model based on energy methods, but he considered only a vacancy defect in an fcc lattice. Pistorius [9] extended Ludwig's method to interstitials and predicted $S= \pm 5$ percent.

Perhaps Melngailis [10] provided the first successful calculation for interstitial-atom effects on S. From elastic-energy methods, he predicted that $S=-18$ percent. By assuming that the interstitial-atom elastic field extended out to two unit-cell dimensions, he accounted for the low-temperature radiation-induced elastic-constant change in copper.

Subsequent calculations predict similar effects. Dederichs et al. [11], using Ludwig's energy method and the t-matrix method of Elliot et al. [12], gave predictions for the individual $C_{i j}: S=-10$ percent for $C_{11}+2 C_{12},-19$ percent for $C_{11}-C_{12},-37$ percent for $C_{44}$. These predictions depend sensitively on both the interatomic repulsive potential and the defect geometry. The principal prediction is that $S$ is large and negative. Leibfried and Breuer [13] review the theory of point defects in metals, but give no detailed calculations for S for interstitials. They emphasize that smaller interatomic distances 
induce negative transverse-spring constants. For certain atomic motions, this causes small restoring forces. Regions near interstitials become soft (almost unstable). Local static and dynamic response to stress deviates considerably from the average-medium response.

Thus, theory, both lattice-dynamic and elastic-continuum, predicts that interstitials reduce elastic stiffness. This agrees with our present experimental findings for 304-type stainless steels alloyed with interstitial carbon and nitrogen.

Using ideas by Eshelby [7], we can invoke theory more quantitatively and examine the effects of volume change on changes in bulk and shear moduli. (Recall that these two elastic moduli correspond to the two extreme forms of mechanical deformation: volume change without shape change and shape change without volume change.)

Eshelby pointed out that in a correct elastic-continuum calculation for defects two forces arise:

$$
p_{i j}=p_{i j}^{\infty}+p_{i j}^{I}
$$

The first arises from the classical elastic solution for a dilatation center in an infinite medium. The second, image stress, arises to ensure zero stress at the body's surface. Although many models neglect image forces, they are large, they sometimes dominate, and they sometimes reverse the effect of $\mathrm{p}_{i j}^{\infty}$. Eshelby described essential differences in these two forces in terms of the displacement field:

$$
u=u^{\infty}+u^{I}
$$

The displacement $u^{\infty}$ fluctuates rapidly with position and is associated with pure shear. But $u^{I}$ varies smoothly, except near the surface, and is 
associated mainly with hydrostatic stress. Thus, in alloying, $y^{\infty}$ produces changes in the shear modulus while $u^{I}$ changes the bulk modulus.

Eshelby suggested, a bulk-modulus and volume relationship:

$$
\frac{\Delta B}{B}=\frac{d \ln B}{d \ln V} \frac{\Delta V}{V}=\frac{d \ln B}{d \ln V} \quad \frac{d V}{V} \quad \frac{\gamma-1}{\gamma}
$$

where $B$ denotes bulk modulus; $V$, volume; $V^{I}$, the volume change arising from image forces; and $\gamma$, an elastic-constant function.

$$
\gamma=\frac{3 B+4 G}{3 B}=3 \frac{1-v}{1+v}
$$

where $G$ denotes shear modulus and $v$, Poisson's ratio. Because denB/denV is always negative, this relationship predicts that $\Delta B / B$ has an sign opposite to that of the volume change $d V / V$. Slater [14] showed that

$$
-d \ln B / d \ln V=2 \Gamma+4 / 3
$$

where the Grüneisen constant, $\Gamma$, is approximately two for most materials. Taking $v \cong 1 / 3$, Eq. (10) becomes

$$
(\Delta B / B) \cong-(16 / 9)(d V / V)
$$

Ledbetter and Austin [15] found for these alloys that $(1 / x)(d V / V)=0.0072$, which predicts $(1 / x)(\Delta B / B)=-0.0128$ compared with the observed value, -0.0085 .

Considering now the shear modulus, G, by analogy with Eq. (10), we write

$$
\frac{\Delta G}{G}=\frac{d \ln G}{d \ln V} \quad \frac{\Delta V^{\infty}}{V}=\frac{d \ln G}{d \ln V} \quad \frac{d V}{V} \quad \frac{1}{\gamma}
$$

where $V^{\infty}$ denotes the volume change arising from a point defect in an infinite medium. For denG/denV, no relationship exists analogous to Eq. (12). Thus, we use the thermodynamic relationship

$$
\frac{d \ln G}{d \ln V}=-\frac{d G}{d P} \quad \frac{B}{G}
$$


where $P$ denotes pressure. We intend to obtain $d G / d P$ from measurement. Since this measurement does not yet exist for either an austenitic steel or fcc iron, we use the values reported for fcc-copper monocrystals: $d^{\prime} / d P=0.375$ and $\mathrm{dC}_{44} / \mathrm{dP}=2.63[16]$. (Of the $3 \mathrm{~d}$-electron transition metals, copper is the fcc nonmagnetic element closest to iron.) We convert these to the isotropic (polycrystal) value by computing the Voigt and Reuss bounds and taking the Hill arithmetic average. We obtain $(d G / d P)_{\text {Voigt }}=1.73,(d G / d P)_{\text {Reuss }}=0.92$, and $(d G / d P)_{H i 11}=1.32$. From Eqs. (11), (14), and (15), we obtain $\Delta G / G=-0.0118$. Compared with observation, -0.0052 , this is too high by a factor of approximately 2 .

Thus, Eshelby's model, based on continuum elasticity and including the image force accounts quite well for the present results. Model-measurement disagreement for the shear modulus suggests that factors other than elastic misfit enter the problem. Carbon-iron and nitrogen-iron electronic interactions are a possibility [17].

\section{CONCLUSION}

In the studied composition range, elastic constants are determined mainly by interactions among atoms occupying lattice sites; carbon and nitrogen interstitial atoms lower elastic stiffness by approximately 0.5 percent per atomic percent solute. Since elastic constants are determined by the interatomic force constants, these also must be nearly independent of carbon and nitrogen content. Thus, the present results relate also to other force-constant-determined physical properties, such as thermal expansivity and specific heat. Eshelby's model accounts rather well for our observations, relating the elastic-stiffness decrease to volume increase. Whether electronic interactions affect the shear modulus requires further study. 


\section{ACKNOWLEDGMENTS}

The U.S. DoE Office of Fusion Energy supported part of this study. R. L. Tobler of NBS contributed the materials and grain-size measurements. J. Dahnke of NBS assisted in measurements. 


\section{REFERENCES}

1. H. M. Ledbetter, N. V. Frederick, and M. W. Austin, J. Appl. Phys. 51, 305-309 (1980).

2. G. R. Speich, A. J. Schwoeble, and W. C. Leslie, Metall. Trans. $\underline{3}$, 2031-2037 (1972).

3. H. Laddach and P. Schüler, DEW-Tech. Ber. 13, 85-88 (1973).

4. D. E. Diesburg, The Elastic Constants of Fe-Ni-C Alloys. Ph.D. Thes is, Iowa State University, Ames, Iowa (1971).

5. G. J. Dienes, Phys. Rev. 86, 228-234 (1952).

6. F. R. N. Nabarro, Phys. Rev. 87, 665-666 (1952).

7. J. D. Eshelby, J. Appl. Phys. 25, 255-261 (1954).

8. W. Ludwig, in Calculations of the Properties of Vacancies and Interstitials, pp. 151-159. Misc. Publ. 207, National Bureau of Standards, Boulder, Colorado (1967).

9. M. Pistorius, Z. Angew. Phys. 29, 145 (1970).

10. J. Melngailis, Phys. Status Solidi 16, 247-252 (1966).

11. P. H. Dederichs, C. Lehmann, and A. Scholz, Z. Phys. B 20, 155-163 (1975).

12. R. J. Elliot, J. A. Krumhansl, and T. H. Merrett, in Localized Excitations in Solids. Plenum, New York (1968).

13. G. Leibfried and N. Breuer, Point Defects in Metals I, Introduction to the Theory. Springer-Verlag, Berlin (1978).

14. J. C. Slater, Introduction to Chemical Physics, p. 239. McGraw-Hill, New York (1939).

15. H. M. Ledbetter and M. W. Austin, to be submitted to Acta Metall.

16. Y. Hiki and A. V. Granato, Phys. Rev. 144, 411-419 (1966).

17. W. Hume-Rothery, Philos. Mag. 44, 1154-1160 (1953). 


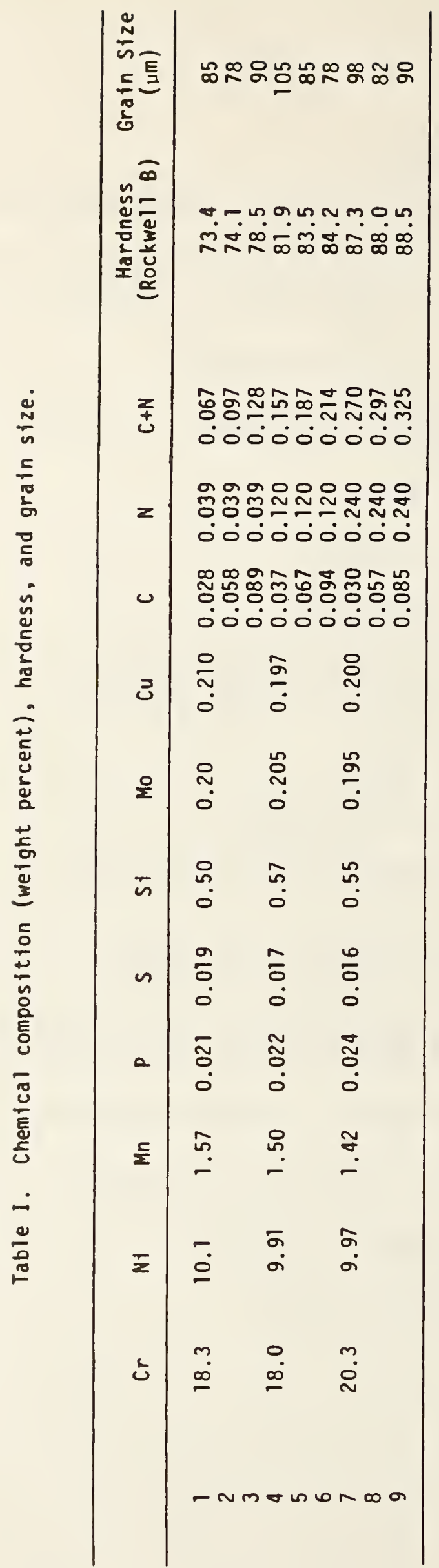


Table II. Mass density, sound velocities, and elastic constants of nine carbon-plus-nitrogen-alloyed 304-type stainless-steel alloys.

\begin{tabular}{|c|c|c|c|c|c|c|c|c|}
\hline & $\begin{array}{l}\text { Density } \\
\left(\mathrm{g} / \mathrm{cm}^{3}\right)\end{array}$ & $\begin{array}{c}v_{\ell} \\
(\mathrm{cm} / \mu \mathrm{s})\end{array}$ & $\begin{array}{c}v_{t} \\
(\mathrm{~cm} / \mu \mathrm{s})\end{array}$ & $\begin{array}{c}C_{\ell} \\
(\mathrm{GPa})\end{array}$ & $\begin{array}{c}E \\
(\mathrm{GPa})\end{array}$ & $\begin{array}{c}\mathrm{G} \\
(\mathrm{GPa})\end{array}$ & $\begin{array}{c}\mathrm{B} \\
(\mathrm{GPa})\end{array}$ & $v$ \\
\hline 1 & 7.967 & 0.5751 & 0.3140 & 263.5 & 202.3 & 78.5 & 158.8 & 0.288 \\
\hline 2 & 7.966 & 0.5766 & 0.3146 & 264.9 & 203.1 & 78.8 & 159.7 & 0.288 \\
\hline 3 & 7.962 & 0.5751 & 0.3142 & 263.3 & 202.4 & 78.6 & 158.5 & 0.287 \\
\hline 4 & 7.950 & 0.5769 & 0.3141 & 264.6 & 202.2 & 78.4 & 160.0 & 0.289 \\
\hline 5 & 7.948 & 0.5747 & 0.3150 & 262.5 & 202.7 & 78.9 & 157.4 & 0.285 \\
\hline 6 & 7.945 & 0.5748 & 0.3144 & 262.5 & 201.1 & 78.5 & 157.8 & 0.287 \\
\hline 7 & 7.933 & 0.5757 & 0.3139 & 262.9 & 201.4 & 78.2 & 158.7 & 0.288 \\
\hline 8 & 7.923 & 0.5743 & 0.3155 & 261.3 & 202.5 & 78.9 & 156.2 & 0.284 \\
\hline 9 & 7.914 & 0.5764 & 0.3135 & 262.9 & 200.7 & 77.8 & 159.2 & 0.290 \\
\hline Mean & 7.945 & 0.5755 & 0.3144 & 262.2 & 202.2 & 78.5 & 158.5 & 0.287 \\
\hline $\begin{array}{l}\text { Std. } \\
\text { dev. }\end{array}$ & 0.019 & 0.0009 & 0.0006 & 1.1 & 0.7 & 0.4 & 1.2 & 0.002 \\
\hline $\begin{array}{l}\text { Pct. } \\
\text { std. } \\
\text { error }\end{array}$ & 0.2 & 0.2 & 0.2 & 0.4 & 0.4 & 0.5 & 0.8 & 0.7 \\
\hline
\end{tabular}


TABLE III. Directional variation of uttrasonic wave velocities in specimen 1 , where the $z$ direction is perpendicular to the rolling plane.

\begin{tabular}{cccc}
$\begin{array}{c}\text { Propagation } \\
\text { Direction }\end{array}$ & $\begin{array}{c}\text { Polarization } \\
\text { Direction }\end{array}$ & $\begin{array}{c}v_{\ell} \\
(\mathrm{cm} / \mu \mathrm{s})\end{array}$ & $\begin{array}{c}v_{t} \\
(\mathrm{~cm} / \mu \mathrm{s})\end{array}$ \\
\hline$x$ & $x$ & 0.5746 & 0.3140 \\
$x$ & $y$ & 0.3143 \\
$y$ & $z$ & & \\
$y$ & $y$ & 0.5753 & 0.3139 \\
$y$ & $x$ & & 0.3138 \\
$z$ & $z$ & 0.5753 & 0.3143 \\
$z$ & $z$ & & 0.3140 \\
$z$ & $x$ & & 0.3141 \\
Mean & & & 0.0002 \\
Std. Dev. & & 0.0751 & 0.07 \\
Pct. std. error & & & \\
\hline
\end{tabular}


Table IV. Least-square parameters for various elastic constants; $C=C_{0}+a x c+N$

\begin{tabular}{lccc}
\hline$C$ & $\begin{array}{c}C_{0} \\
(G P a)\end{array}$ & $\begin{array}{c}a \\
(G P a)\end{array}$ & $100 a / C_{0} \times{ }_{C+N}$ \\
\hline$B$ & 159.6 & -1.349 & -0.85 \\
$G$ & 78.8 & -0.410 & -0.52 \\
$E$ & 203.2 & -1.314 & -0.65 \\
$C_{\ell}$ & 264.8 & -2.040 & -0.77 \\
$v$ (dimensionless) & 0.288 & -0.00049 & -0.15 \\
\hline
\end{tabular}



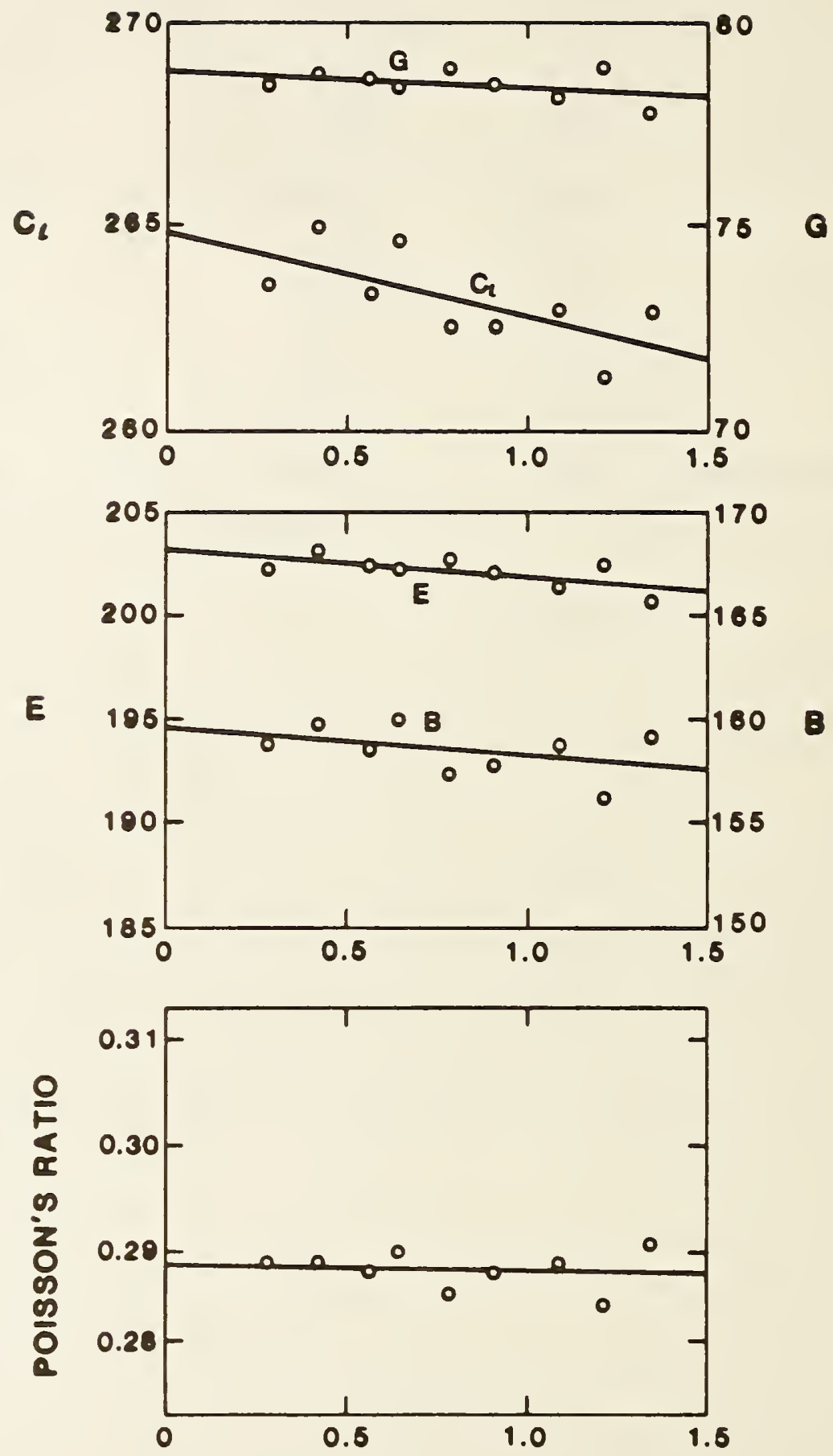

C\&N CONTENT (at. pet.)

Fig. 1. For 304-type stainless steel, variation of elastic constants with interstitial carbon-plus-nitrogen content. $B=$ bulk modulus, $C_{l}=$ longitudinal modulus, $E=$ Young's modulus, $G=$ shear modulus, $v^{l}=$ Poisson's ratio. Except for the dimensionless Poisson's ratio, all units are GPa. 
THE TEMPERATURE DEPENDENCE OF THE TENSILE YIELD STRENGTH OF SELECTED AUSTENITIC STEELS*

R. P. Reed and J. M. Arvidson

National Bureau of Standards

Fracture and Deformation Division

Boulder, Colorado 80303

\section{ABSTRACT}

The temperature dependence of tensile yield strength has been measured for five austenitic steels from 4 to $295 \mathrm{~K}$. Two alloys (25Mn-5Cr-0.2C, $22 \mathrm{Mn}-13 \mathrm{Cr}-0.2 \mathrm{~N}$ ) have been supplied by Japanese companies, one alloy (19Mn-13Cr) was supplied by a USSR institute, and two alloys were supplied by U.S. suppliers (18Mn-17Cr-0.5N, AISI 310). All exhibit logarithmic dependence of yield strength versus temperature.

*Published in Advances in Cryogenic Engineering - Materials, vo1. 30 , Plenum Press, New York (1984), po. 263-270. 



\section{INTRODUCTION}

The trend toward the use of higher field superconducting magnets is creating the need for strong, tough structural materials to restrain the high magnetic forces. Austenitic and high-N-austenitic stainless steels are considered for such uses because of their high strength and good toughness, combined with high Young's modulus and low thermal conductivity. Study of the temperature dependence of tensile flow strength leads to better understanding of deformation mechanisms in these face-centered cubic, polycrystalline alloys.

The tensile properties of five austenitic $\mathrm{Fe}-\mathrm{Cr}-\mathrm{Ni}$ and $\mathrm{Fe}-\mathrm{Cr}-\mathrm{Mn}$ steels were measured. In these steels the $\mathrm{Cr}$ contents varied from 4.67 to $24.8 \mathrm{wt} . \%$, the $\mathrm{Ni}$ from 0.8 to $20.8 \mathrm{wt} \%$, and the $\mathrm{Mn}$ from 1.7 to 21.79 wt.\%. Yet it has been demonstrated that steels obtain their low temperature yield strength primarily from $\mathrm{C}$ and $\mathrm{N}$.

Previously, we have identified that, in general, there is a linear dependence of the log of the tensile yield strength $\left(\sigma_{y}\right)$ on temperature ( $\mathrm{T}$ ) for $\mathrm{Fe}-\mathrm{Cr}-\mathrm{Ni}$ base austenitic steels at low temperatures.1,2 In these austenitic stainless steels changes (3\%) of Young's modulus (E) as a function of temperature are observed through the low-temperature magnetic transformation (beginning at the Neel temperature). However, in the $\mathrm{Fe}-\mathrm{Cr}-\mathrm{Mn}$ austenitic steels changes of elastic properties are greater ( $4-5 \%)$ at the Neel temperature; also, the magnetic transitions occur at higher temperatures $(200-330 \mathrm{~K})$. In this paper, sensitive flow strength measurements indicate that a better linear fit is obtained when the flow strength is "normalized" and $\ln \left(\sigma_{y} / G\right)$ is plotted versus $T$ ( $G$ is the shear modulus). 
The logarithmic dependence of flow strength on temperature suggests a common and singular deformation process. This paper presents the suggestion that the limiting deformation process of polycrystalline austenitic steels at low temperatures may be overcoming obstacles or cross-slip.

\section{TEST PROCEDURES}

Tensile measurements were performed using a commercial 89-kN (20,000-1bf) tensile/compression machine equipped with a calibrated load cell accurate to $\pm 0.5 \%$. All specimens were $0.5 \mathrm{~cm}$ in diameter in the reduced sections, subsize according to ASTM standard E-8/81. ${ }^{3}$ The strain rate was $5 \times 10^{-3} \mathrm{~min}^{-1}$. Tensile measurements were conducted to failure at $295 \mathrm{~K}$ (air), $76 \mathrm{~K}$ (1iquid nitrogen), and $4 \mathrm{~K}$ (1iquid helium). The cryostat ${ }^{1,2}$ incorporates a universal joint for the upper pull-rod and a spherical nut seating arrangement at the lower end to ensure good axial alignment. Strain was measured using Ni-Chrome low-temperature strain gages that have a sensitivity of about $10^{-5}$ at $4 \mathrm{~K}$. The strain-gage-to-specimen bonded joint usually broke at a specimen strain of about $10^{-2}$ at $4 \mathrm{~K}$. Intermediate temperatures were achieved by means of controlled thermal conduction from the fluid reservoir below the specimen and resistive heaters on both specimen grips. The specimen temperature, measured using a type "E" thermocouple bonded to the center of the specimen, was automatically regulated to within $\pm 0.2 \mathrm{~K}$ with estimated uncertainty of $\pm 1 \mathrm{~K} .{ }^{1}$ The procedure for conducting variable temperature tests on single specimens has been previously discussed. I

\section{MATERIALS}

The chemical composition, hardness, and grain size for each of these five austenitic steels are listed in Table 1 . The $17 \mathrm{Cr}-18 \mathrm{Mn}$ alloy was received as annealed flat plate $(2.86 \times 8.28 \mathrm{~cm})$ rolled from electroslag remelted ingots. The $14 \mathrm{Cr}-17 \mathrm{Mn}$ alloy was obtained as annealed, forged plate $(2.5-\mathrm{cm}$ thick). The $5 \mathrm{Cr}-26 \mathrm{Mn}$ alloy, solution treated at $1323 \mathrm{~K}$ for one hour and water quenched, was received as plates $(2.7 \mathrm{~cm} \times 50 \mathrm{~cm} \times 50 \mathrm{~cm}$ ). The $25 \mathrm{Cr}-21 \mathrm{Ni}$ alloy (AISI 310) was received as $1.9-\mathrm{cm}$-diameter annealed bar. Tensile specimens of the $13 \mathrm{Cr}-5 \mathrm{Ni}-22 \mathrm{Mn}$ alloy were supplied in the hot-rolled condition. After machining to specimen form, all alloys were annealed at $1350 \mathrm{~K}$ for $15 \mathrm{~min}$.

\section{EXPERIMENTAL RESULTS}

The tensile properties of the five austenitic steels are 1isted in Table 2. Notice that all alloys have good strength and that the elongation tends to vary inversely as the yield strength. The 
Table 1. Alloy Characterization

\begin{tabular}{|c|c|c|c|c|c|c|c|c|c|}
\hline $\begin{array}{c}\text { Alloy } \\
\text { Designation }\end{array}$ & $\begin{array}{l}\text { Source } \\
\text { Country }\end{array}$ & $c^{\prime} r$ & $\begin{array}{l}\text { Compo } \\
\text { N1 }\end{array}$ & $\begin{array}{c}\text { sition } \\
\text { Mn }\end{array}$ & $\begin{array}{l}\text { (wt. } \\
\text { C }\end{array}$ & $\begin{array}{c}\text { percent) } \\
N\end{array}$ & others & $\begin{array}{l}\text { Hardness } \\
\qquad\left(\mathrm{R}_{B}\right)\end{array}$ & $\begin{array}{l}\text { Grain } \\
\text { Size } \\
(\mu \mathrm{m})\end{array}$ \\
\hline $18 \mathrm{Cr}-18 \mathrm{Mn}$ & U.s. & 17.44 & 0.40 & 17.70 & 0.11 & 0.48 & $\begin{array}{l}0.48 \mathrm{Si}, 0.013 \mathrm{P}, \\
0.002 \mathrm{~S}, 0.99 \mathrm{Mo}, \\
1.01 \mathrm{Cu}, 0.01 \mathrm{Co}\end{array}$ & 101 & 105 \\
\hline $14 \mathrm{Cr}-17 \mathrm{Mn}$ & USSR & 13.9 & 0.8 & 17.0 & .008 & 0.16 & $\begin{array}{l}0.4 \mathrm{Si}, 0.1 \mathrm{Cu}, \\
0.02 \mathrm{P}, 0.01 \mathrm{~S}, \\
0.1 \mathrm{~V}\end{array}$ & 86 & 320 \\
\hline $5 \mathrm{Cr}-26 \mathrm{Mn}$ & Japan & 4.67 & 0.97 & 25.56 & 0.22 & 0.04 & $\begin{array}{l}0.86 \mathrm{~S} 1,0.024 \mathrm{P} \\
0.001 \mathrm{~s}, 0.009 \mathrm{~A} 1 \\
0.04 \mathrm{Cu}, 0.04 \mathrm{Nb}\end{array}$ & 86 & 59 \\
\hline $25 \mathrm{Cr}-21 \mathrm{~N} 1$ & U.s. & 24.8 & 20.8 & 1.7 & 0.08 & 0.03 & $\begin{array}{l}0.02 \mathrm{P}, 0.02 \mathrm{~S} \\
0.1 \mathrm{Mo}, 0.7 \mathrm{Si} \\
0.1 \mathrm{Cu}\end{array}$ & 69 & 105 \\
\hline $13 \mathrm{Cr}-5 \mathrm{Ni}-22 \mathrm{Mn}$ & Japan & 12.82 & 4.94 & 21.79 & 0.05 & 0.21 & $\begin{array}{l}0.36 \mathrm{~S} 1,0.013 \mathrm{P}, \\
0.005 \mathrm{~S}\end{array}$ & 93 & 51 \\
\hline
\end{tabular}

Table 2. Tensile Properties at $4 \mathrm{~K}$

\begin{tabular}{lccccc}
\hline \multicolumn{1}{c}{ Alloy } & $\begin{array}{c}\text { Yield } \\
\text { Strength } \\
\text { (MPa) }\end{array}$ & $\begin{array}{c}\text { Tensile } \\
\text { Strength } \\
\text { (MPa) }\end{array}$ & $\begin{array}{l}\text { Elongation } \\
\text { (percent) }\end{array}$ & $\begin{array}{c}\text { Reduction } \\
\text { of Area } \\
\text { (percent) }\end{array}$ & $\begin{array}{c}\text { Young's } \\
\text { Modulus } \\
\text { (GPa) }\end{array}$ \\
\hline $18 \mathrm{Cr}-18 \mathrm{Mn}$ & 1780 & 2050 & 11 & 32 & $199^{\mathrm{a}}$ \\
$14 \mathrm{Cr}-17 \mathrm{Mn}$ & 829 & - & - & - & 198 \\
$5 \mathrm{Cr}-26 \mathrm{Mn}$ & 855 & 1500 & 39 & 62 & 191 \\
$25 \mathrm{Cr}-21 \mathrm{N1}$ & 765 & 1240 & 43 & 20 & 206 \\
$13 \mathrm{Cr}-5 \mathrm{Ni}-22 \mathrm{Mn}$ & 1160 & 1580 & 22 & 44 & $196^{\mathrm{a}}$ \\
\hline
\end{tabular}

astimated by H. M. Ledbetter ${ }^{8}$

fracture toughness of most austenitic steels was also found to vary inversely as the yield strength. ${ }^{4}$ Young's modulus data are from Ledbetter, ${ }^{5-8}$ who used a pulse-echo measurement technique. Bodycentered cubic $\left(\alpha^{\prime}\right)$ martensite was not detected in the tensile specimens of any of the alloys after failure at $4 \mathrm{~K}$ (a bar-magnet torsion balance with $0.04 \%$ sensitivity was used).

The log of the tensile yield strength is plotted versus temperature in Figure 1. The data of Figure 1 and Table 2 represent the results from only one or two specimens per temperature per alloy. A better fit is obtained if the flow strength is "normalized" by dividing by the shear modulus $(G)$. This normalization accounts for the effects of the elastic modulus decreases ( $3 \%$ for $\mathrm{Fe}-\mathrm{Cr}-\mathrm{Ni}$ alloys, $4-5 \%$ for $\mathrm{Fe}-\mathrm{Cr}-\mathrm{Mn}$ alloys) at the Nél temperatures ${ }^{5-7}$ and for the effects of the reduced moduli on flow strength. Thus, one obtains 


$$
\frac{\sigma_{\mathrm{y}}}{\mathrm{G}}=\frac{\sigma_{0}}{\mathrm{G}_{\mathrm{o}}} \mathrm{e}^{-\mathrm{AT}}
$$

where $\sigma / G$ is the normalized yield strength at $0 \mathrm{~K}$ and $\mathrm{A}$ is a constant. ${ }^{O}$ Values of $\sigma$ and $A$ from Equation 1 are listed in Table 3 . The shear moduli at $0 \mathrm{~K}^{0}\left(\mathrm{G}_{0}\right)$ from Ledbetter ${ }^{5-9}$ are included in Table 3 . Table 3 also includes data of three other alloys (17Cr-12Ni-2Mo:AISI 316 ; 18Cr-10Ni:AISI 304LN; 20Cr-16Ni-6Mn) for which both temperaturedependent yield strength and shear moduli data are available.1,2,10

\section{DISCUSSION}

Schwartz and co-workers (see, e.g., reference 11), studying the observance of a maximum in the temperature dependence of dilute alloys, have proposed that the flow strength varies as $\mathrm{T}^{2 / 3}$ at low temperatures in the absence of dislocation inertial effects. There is a linear dependence of $\sigma / G$ as a function of $T^{2 / 3}$ for austenitic

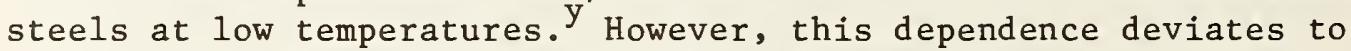
lower than predicted values at very low temperatures $(\sim<20 \mathrm{~K})$ for the high-Mn austenitic steels. The linear dependence of $\ln \left(\sigma_{\mathrm{y}} / \mathrm{G}\right)$ versus $\mathrm{T}$ is maintained at these low temperatures for all austenitic steels included in Table 3. Although no decreases of flow strength at low temperatures are observed in these austenitic steels, it may be argued that the "softening" from a $\mathrm{T}^{2 / 3}$ dependence at low temperatures is caused by reduced damping and dislocation overshoot. However, in lieu of more experimental clarification of the distinctions

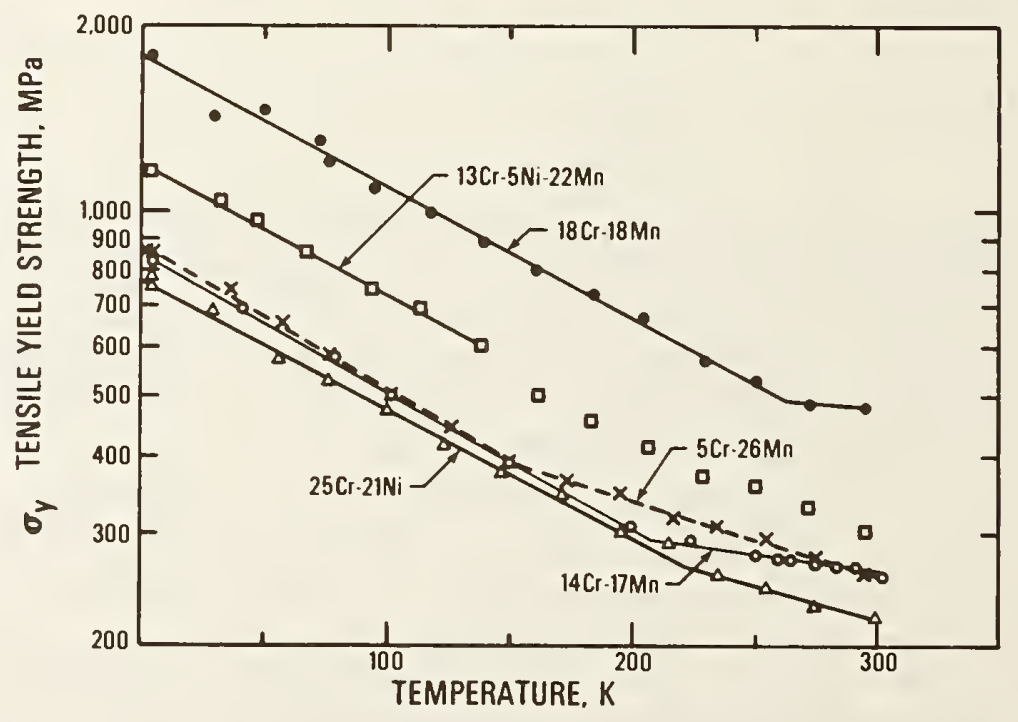

Fig. 1. Tensile yield strength of austenitic alloys versus temperature. 
Table 3. Tensile Flow Characteristics

\begin{tabular}{lcccc}
\hline Alloy & $\begin{array}{c}\text { Equat1on }(1) \\
\sigma_{0}\left(10^{-3}\right)\end{array}$ & $\begin{array}{c}\text { Parameters } \\
\text { A }\left(10^{-3} / \mathrm{K}\right)\end{array}$ & $\begin{array}{c}\text { Néel } \\
\text { Temperature } \\
(\mathrm{K})\end{array}$ & $\begin{array}{c}\text { Shear Modulus } \\
\text { at } \mathrm{K}\left(\mathrm{G}_{\mathrm{o}}\right) \\
(\mathrm{GPa})\end{array}$ \\
\hline 18Cr-18Mn & 23.0 & $4.3^{\mathrm{a}}$ & 207 & $78.0^{\mathrm{b}}$ \\
$14 \mathrm{Cr}-17 \mathrm{Mn}$ & 10.7 & 4.8 & 274 & 78.5 \\
$5 \mathrm{Cr}-26 \mathrm{Mn}$ & 11.7 & 5.3 & 330 & 74.5 \\
$25 \mathrm{Cr}-21 \mathrm{N1}(310)$ & 9.7 & 4.6 & 10 & 79.9 \\
$13 \mathrm{Cr}-5 \mathrm{~N} 1-22 \mathrm{Mn}$ & 15.0 & $4.4^{\mathrm{a}}$ & 231 & $77.0^{\mathrm{b}}$ \\
$17 \mathrm{Cr}-12 \mathrm{NI}-2 \mathrm{Mn}(316)$ & 7.3 & 3.4 & 30 & 81.0 \\
$18 \mathrm{Cr}-10 \mathrm{NI}(304 \mathrm{LN})$ & 8.9 & 3.2 & 50 & 82.1 \\
$20 \mathrm{Cr}-16 \mathrm{NI}-6 \mathrm{Mn}$ & 14.2 & 4.3 & 54 & 83.4 \\
\hline
\end{tabular}

astimated; temperature-dependent shear modulus data not avallable.

bstimated by H. M. Ledbetter ${ }^{8}$

between these possible flow strength dependences, we assume that equation 1 fits the experimental data best.

Characterization by plotting the log of the flow strength versus temperature produces two regions of linear dependence. The transition temperature between the two regions varies from about $160 \mathrm{~K}$ $(5 \mathrm{Cr}-26 \mathrm{Mn}$ alloy) to $260 \mathrm{~K}(18 \mathrm{Cr}-18 \mathrm{Mn}$ a11oy). However, there is no apparent correlation of the transition temperature with magnetic behavior (Néel temperature) ${ }^{6-9}$ listed in Table 3 or with deformation characteristics such as the stacking-fault energy. While the Néel temperature has been measured for most of the alloys included in Table 3 and is considered accurate, estimation of stacking-fault energies for these austenitic steels is considered inaccurate. Schramm and Reed 12 reported stacking-fault energies as a function of $\mathrm{Cr}, \mathrm{Ni}$, $\mathrm{Mn}$, and Mo concentration, obtained using regression analysis of $\mathrm{x}$-ray peak shift data of deformed $\mathrm{Fe}-\mathrm{Cr}-\mathrm{Ni}$ alloys and normalized to existing electron microscopy node data at the time of the study. Later, Rhodes and Thompson 13 argued, on the basis of newer weak-beam electron microscopy data on $\mathrm{Fe}-\mathrm{Cr}-\mathrm{Ni}$ alloys, that the calculated values of Schramm and Reed were too high and should be reduced some $30 \%$. They presented a modified equation, but the form of their equation places too great a dependence of Mn on stacking-fault energy to permit its use for high- Mn austenitic steels. Furthermore, Stolz and VanderSande ${ }^{14}$ caution about the use of regression analyses for high-N alloys.

The constant $\sigma / G$ of Equation 1 represents the extrapolated normalized yield strength at $0 \mathrm{~K}$. This strength depends primarily on $\mathrm{C}$ and $\mathrm{N}$ concentration. This is illustrated in Figure 2 which illustrates that $\sigma / G$ is approximately linearly dependent on $\mathrm{C}+2 \mathrm{~N}$ for the alloys ${ }^{\mathrm{O}} 1$ isted in Table 3 . More precise functional 
relations between $\sigma$ and $C$ and $N$ content is discussed in another paper. 15 The constant A of Equation 1 may be related to the stacking-fault energy. Schoeck and Seeger ${ }^{16}$ associated the onset of stage 3 of face-centered-cubic (f.c.c.) single-crystal stressstrain curves with cross-slip. From their theory the log of the associated stress ( $\tau_{\text {III }}$ ) should vary linearly with temperature.

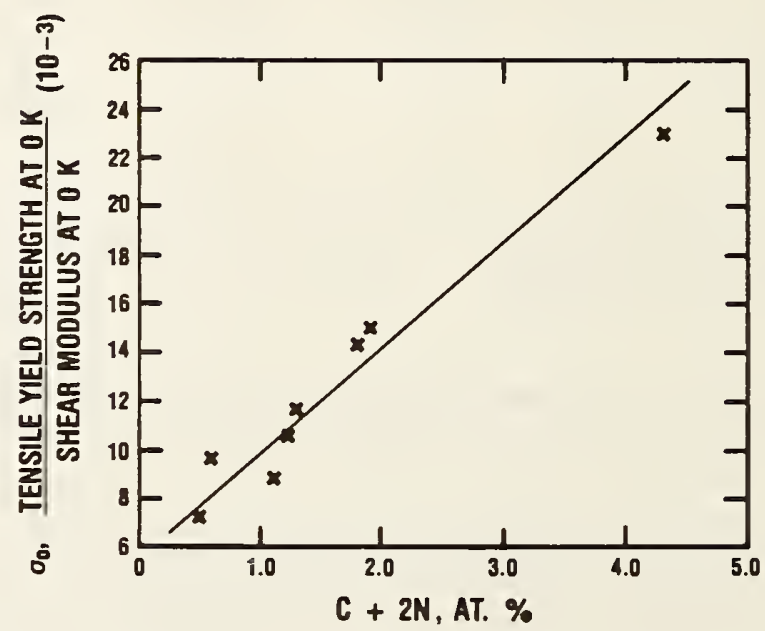

Fig. 2. Normalized tensile yield strength, $\sigma_{0} / G$, as a function of $\mathrm{C}$ and $\mathrm{N}$ content of the austenitic stê ${ }^{\circ} \mathrm{s}^{\circ}$ listed in Table 3 .

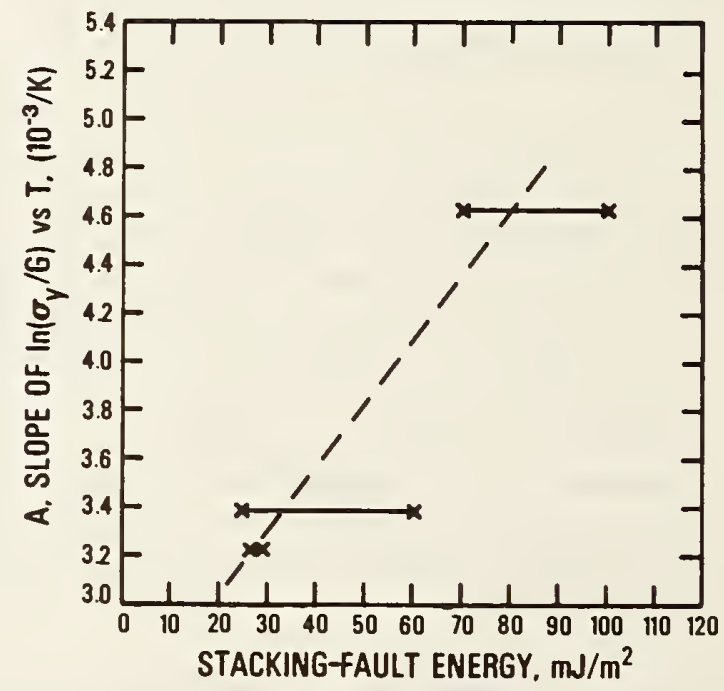

Fig. 3. Temperature dependence of normalized tensile yield strength of $25 \mathrm{Cr}-21 \mathrm{Ni}, 17 \mathrm{Cr}-12 \mathrm{Ni}-2 \mathrm{Mn}$, and $18 \mathrm{Cr}-10 \mathrm{Ni}$ alloys (Table 3 ) versus estimated stacking-fault energy. 
This has been confirmed experimentally in single crystals. 17 If the early $\sigma-\varepsilon$ region of $\mathrm{f} . \mathrm{c} . \mathrm{c}$. polycrystalline metals is primarily controlled by cross-slip, this same temperature dependence should be expected. Unfortunately, as pointed out earlier, the stacking-fault energies $(\gamma)$ of high-Mn austenitic steels are not accurately predictable yet. One can correlate $d(\sigma / G) / d T$ with the $\gamma^{\prime}$ s of the $\mathrm{Fe}-\mathrm{Cr}-\mathrm{Ni}$ steels; this correlation is $\mathrm{y}$ shown in Figure 3 . Here the range of $\gamma$ is from the predictions of Schramm and Reed ${ }^{2}$ (higher values) and Rhodes and Thompson ${ }^{13}$ (lower values). The slope of the $\sigma_{y}-T$ relation decreases with increasing $\gamma$. However, the slope is expected to be zero, when $\gamma$ is zero; since this is not the case, the fit in Figure 3 of three data points may be fortuitous.

More recently, Escaig ${ }^{18}$ has developed an alternative cross-slip theory, and his model has been used to predict the stacking-fault energy of polycrystalline $\mathrm{Ag}$ and $\mathrm{Cu}$ alloys by Beneteau and Coulomb.19 The Escaig model, however, predicts a linear dependence of stress on temperature. It does appear that one rate process may control low temperature polycrystalline deformation at low plastic strains; however, work remains to identify this process.

\section{SUMMARY}

The temperature dependence of the flow strength of five austenitic steels, with varying $\mathrm{Cr}, \mathrm{Mn}, \mathrm{Ni}, \mathrm{C}$, and $\mathrm{N}$ contents, has been measured at low temperatures $(4-295 \mathrm{~K})$. A relation of the form

$$
\frac{\sigma_{y}}{G}=\frac{\sigma_{0}}{G_{0}} e^{-A T}
$$

fits the experimental data best. The normalized strength at $0 \mathrm{~K}$, $\sigma / G$, has been correlated with a function of $C$ and $N$ content. The constant, A, has been correlated with the stacking-fault energy for three $\mathrm{Fe}-\mathrm{Cr}-\mathrm{Ni}$ alloys.

\section{ACKNOWLEDGMENTS}

We thank Robert Walsh who carefully conducted many of the tensile tests. We are indebted to the suppliers of most of the steels included in this study: $\mathrm{K}$. Yushchenko, Paton Institute (14Cr-17Mn); L. Meyers, Carpenter Technology Corporation (18Cr-18Mn); R. Ogawa, Kobe Steel (13Cr-5Ni-22Mn), and T. Inoue, Nippon Steel (5Cr-26Mn). This project was partially supported by the Office of Fusion Energy (DoE), Donald Beard project monitor. 
1. R. P. Reed, R. L. Tobler, and J. W. Elmer, Proceedings of the International Cryogenic Materials Conference, Kobe, Japan; May 11-14, 1982, Butterworths, Guildford, Great Britain, pp. 98-103.

2. R. L. Tobler, R. P. Reed, and D. S. Burkhalter, Advances in Cryogenic Engineering - Materials, Vol. 26, Plenum Press, New York (1980), Pp. 107-119.

3. 1981 Annual Book of ASTM Standards, Part 10, Metals-Physical, Mechanical, Corrosion Testing, American Society for Testing Materials, Philadelphia, Pennsylvania (1981), pp. 197-217.

4. R. L. Tobler and R. P. Reed, Advances in Cryogenic Engineering Materials, Vol. 28., Plenum Press, New York (1982), PP. 83-92.

5. H. M. Ledbetter, Metal1. Trans. 11A:543-544 (1980).

6. H. M. Ledbetter, J.Appl. Phys. 52:1587-1589 (1981).

7. H. M. Ledbetter, accepted for publication in Physica (1983).

8. H. M. Ledbetter, private communication, National Bureau of Standards, Boulder, Colorado (1983).

9. H. M. Ledbetter and M. W. Austin, Materials Studies for Magnetic Fusion Energy - V, NBSIR 82-1667, report to Office of Fusion Energy (DoE), R. P. Reed and N. S. Simon, eds., National Bureau of Standards, Boulder, Colorado (1982), pp. 213-228.

10. R. L. Tobler, D. H. Beekman, and R. P. Reed, Austenitic Steels at Low Temperatures, Plenum Press, New York (1983), pp. 135-160.

11. R. B. Schwartz, R. D. Isaac, A. V. Granato, Phys. Rev. Lett. $38: 554-557$ (1977).

12. R. E. Schramm and R. P. Reed, Metall. Trans. 6A:1345-1351 (1975).

13. C. G. Rhodes and A. W. Thompson, Metal1. Trans. 8A:1901-1906 (1977).

14. R. E. Stolz and J. B. VanderSande, SAND 79-8735, Sandia Laboratories, Albuquerque, New Mexico (1979).

15. R. P. Reed and N. S. Simon, Advances in Cryogenic Engineering - Materials, Vol. 30, Plenum Press, New York (1983).

16. G. Schoeck and Seeger, Defects in Crystalline Solids, The Physical Society, London (1955), pp. 340-346.

17. S. Mader, Electron Microscopy and Strength of Crystals, Interscience, New York (1963), pp. 183-230.

18. B. Escaig, J. Phys. 29:225-234 (1968).

19. A. Beneteau and P. Coulomb, Scr. Metall. 12:741-743 (1978). 


\title{
MAGNETIC SUSCEPTIBILITY AND STRAIN-INDUCED MARTENSITE FORMATION

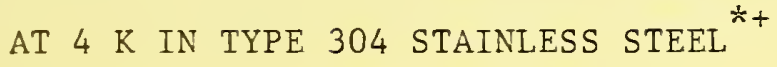 \\ R. B. Goldfarb, R. P. Reed, J. W. Ekin, and J. M. Arvidson \\ National Bureau of Standards \\ Boulder, Colorado
}

\begin{abstract}
Changes in magnetic susceptibility, $x$, as a function of strain-induced structural transformations in AISI type 304-stainless steel at $4 \mathrm{~K}$ have been observed using a mutual inductance technique with simultaneous measurement of stress and strain. There is a small increase in $\chi$ coincident with plastic strain and a large increase in $\chi$ with the load drops that occur during serrated yielding. These are attributed to the formation of bcc martensite. The increases in $x$ are irreversible upon unloading. The application of a moderate $3-\mathrm{MA} / \mathrm{m}(37-\mathrm{kOe}) \mathrm{dc}$ field had no effect on the martensite formation.
\end{abstract}

* Sponsored, in part, by the Office of Fusion Energy, U.S. Department of Energy.

+ Published in Advances in Cryogenic Engineering - Materials, vo1. 30, Plenum Press, New York (1984), pp. 475-482. 



\section{INTRODUCTION}

Plastic deformation of some metastable austenitic stainless steels, such as AISI type 304, at cryogenic temperatures causes localized transformations to martensite. This phase is ferromagnetic, with a large coercivity at $4 \mathrm{~K}$. These alloys are also known to exhibit serrated yielding at liquid helium temperatures. 1 The first measurement of magnetic susceptibility during plastic deformation was by Kelha and Niinikoski. ${ }^{2}$ Bolshutkin et al. investigated susceptibility correlated with martensite transformations at cryogenic temperatures. ${ }^{3}$ In the present work, quantitative measurements of susceptibility changes at $4 \mathrm{~K}$ during martensite formation, with and without a background field, are reported. The results show that most of the martensite formation occurs during the serrated yielding, and that the amount formed increases with the magnitude of the load drops. 


\section{EXPERIMENT}

Tensile specimens with about 6-mm gauge diameter and 4-cm reduced-section length (cf: Ref 4) were machined from type 304 stainless steel rod stock. Composition (by weight) was nominally $73 \% \mathrm{Fe}, 18 \% \mathrm{Cr}$, and $9 \% \mathrm{Ni}$. The specimens were annealed in helium gas at $1066^{\circ} \mathrm{C}$ for $15 \mathrm{~min}$, quenched in water, and electropolished to remove $0.1 \mathrm{~mm}$ from the diameter. Tension was applied with the specimen immersed in liquid helium within the bore of a $3-\mathrm{MA} / \mathrm{m}$ (37-k0e) superconducting magnet. Magnetic ac susceptibility, $X$, could be measured with the dc field off. When the dc field was on, it saturated the specimens and precluded measurement of $\chi$.

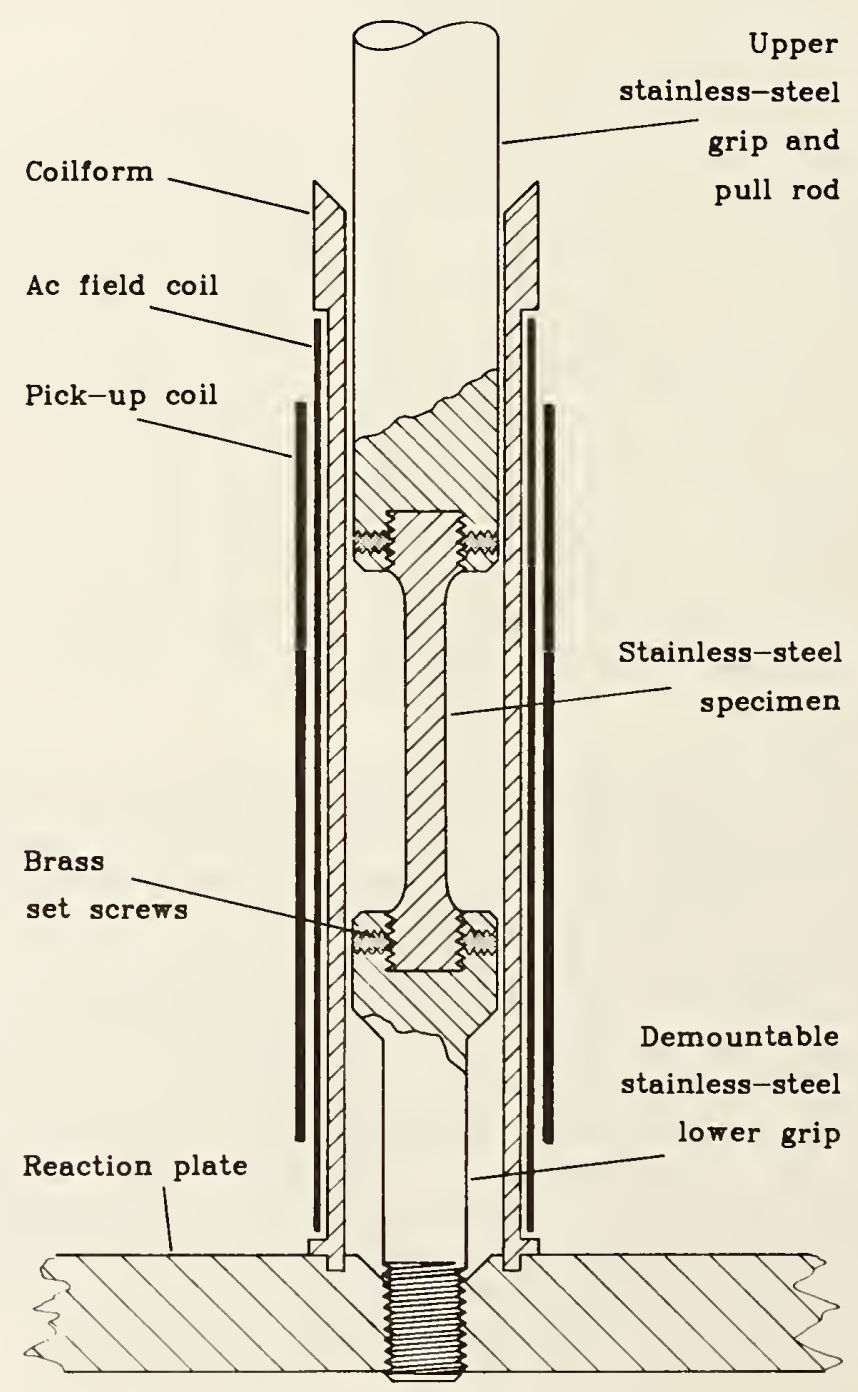

Fig. 1. Construction of susceptometer and demountable grips. Reaction tube not shown. 
The unfractured specimens could be unscrewed from the reaction plate and, while still attached to the pull rod, withdrawn from the Dewar. This allowed the samples to be changed without warming the magnet and reaction-tube assembly. The construction of the susceptometer is shown in Fig. 1. It was calibrated with a standard of dimensions similar to those of the specimens. The calibration was verified by numerical methods. Note that the entire specimen is well within the pick-up coil and remains so even after straining.

A mutual inductance technique was used to measure $x$. A schematic of the electronics is shown in Fig. 2. An ac oscillator, in constant current mode, drives the field coil and provides a reference for the lock-in amplifier, the phase-lock phase-shifter, and the oscilloscope. When a magnetic transformation in the specimen occurs, the mutual inductance between the field coil and the pick-up coil increases. The constant ac current, I, ensures a constant field even when the self-inductance of the field coil increases. The emf induced in the pick-up coil is input to a differential amplifier. The high input impedance of the amplifier

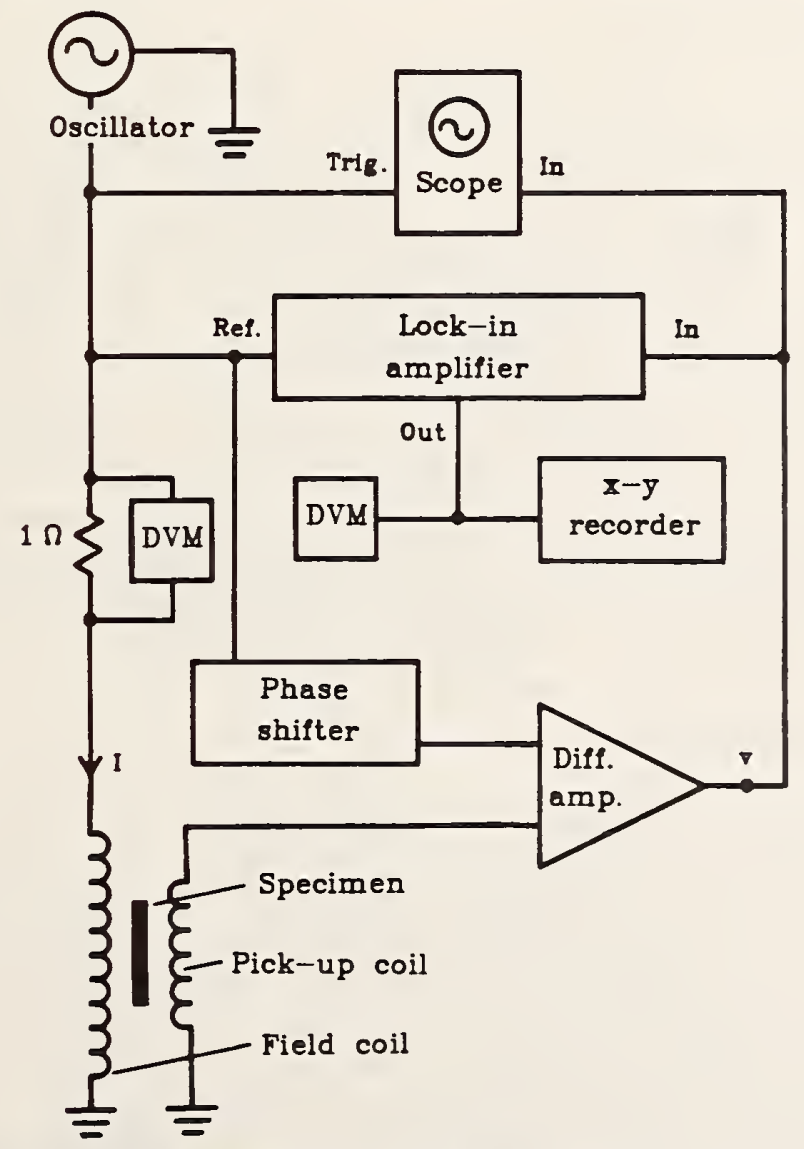

Fig. 2. Electronics schematic for susceptibility measurements. 
ensures that substantially no current flows in the pick-up coil so that the emf is about equal to its open-circuit value. Also connected to the differential amplifier is a phase shifter. This specially designed circuit locks onto the frequency of the driving signal. Its output, variable in amplitude and phase, is set to null the output of the differential amplifier, $v$, after the specimen is inserted but before it is strained. The usual method of compensation with an identical coaxial compensating (or "bucking") coil was not chosen because of the limited space in the Dewar. The output of the differential amplifier is connected to a lock-in amplifier. The dc output of the lock-in was recorded vs. stroke (strain). Load (stress) was also recorded vs. stroke.

The irequency selected for the ac $X$ measurement was $100 \mathrm{~Hz}$. For the specimen geometry, permeability, and resistivity, this frequency was not high enough to cause eddy-current problems.5 The field coil was operated at $4 \mathrm{kA} / \mathrm{m}(50 \mathrm{Oe}) \mathrm{rms}$. This relatively large ac field was needed because of the large coercivity of martensite at $4 \mathrm{~K}$.

\section{RESUITS AND DISCUSSION}

Figure 3 is a plot of $x$ and load (stress) vs. stroke (strain). Stroke was controlled at $0.1 \mathrm{~mm} / \mathrm{min}$. The specimen was unloaded at various points on the curve to see whether the increased magnetic signal was reversible. In the initial elastic and plastic regions ( $a, b$, and $c$ in Fig. 3), there was a small, reversible increase in $x$ (d). In the plastic region prior to each serrated yield (e), there was a small irreversible increase in $X(f)$. Colncident with each of the serrated yields (i), there was a large, irreversible increase in $X(j)$ caused by the formation of strain-induced bcc martensite, which is ferromagnetic. Immediately following the load drops, as reloading occurred ( 0 ), the increase in $x$ was once again reversible ( $p)$. The slope of this increase became larger as the number of load drops increased. The reversible increases in $x$ may be attributed to the inverse positive magnetostrictive effect: an increase in $x$ due to stress, ${ }^{6}$ predominantly of the already transforwed martensite.

The martensite formation at low temperature in metastable austenitic stainless steels is strain induced. 7 The magnitude of the increase in $x$, and therefore the amount of martensite formed, correlates with the magnitude of the strain (load drops). This relationship is plotted in Fig. 4 for two specimens strained at the usual rate of 0.1 min. A third specimen was strained at the rates of $0.2 \mathrm{~mm} / \mathrm{min}$ and $1.2 \mathrm{~mm} / \mathrm{min}$. The increase in $x$ depended on the magnitude of the load drop but not on the strain rate. Because of the adiabatic conditions at $4 \mathrm{~K}$ during the sudden load drops, large localized rises in temperature occurred. It is likely that the nonlinear relation between the magnitudes of the load 


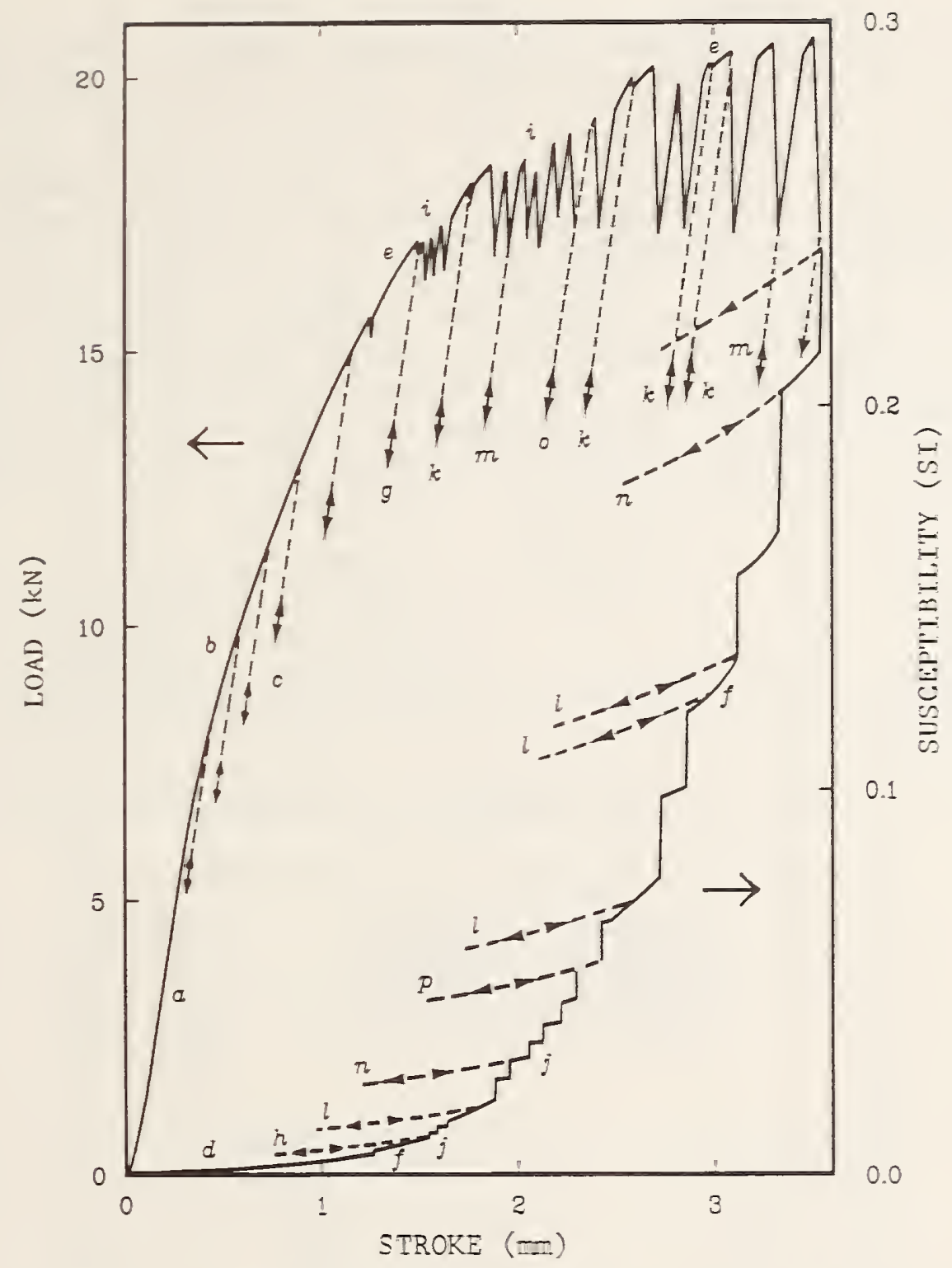

Fig. 3. Load and increase in volume susceptibility vs. stroke: (a) initial elastic region, (b) initial plastic region, (c) unloading to zero and reloading, (d) reversible increase in $x$ during $a, b$ \& $c$, (e) plastic region prior to load drop, (f) irreversible increase in $x$ during $e,(g)$ unloading and reloading prior to second load drop, (h) reversible decrease and increase in $x$ during $g$ at higher level than $d$, (i) serrated yielding, ( $j$ ) irreversible increases in $x$ during $i,(k)$ unloading and reloading prior to load drop, (I) reversible decrease and increase in $x$ during $k$, (m) unloading and reloading immediately following load drop, ( $n$ ) reversible decrease and increase in $x$ during $m,(0)$ elastic loading, unloading, and reloading following load drop, ( $p$ ) reversible increase, decrease, and then increase in $x$ during 0 . 
drop and the increase in $x$ reflects the isothermal nature of the transformation of martensite in austenitic steels: larger temperature increases are associated with larger load drops, and larger amounts of martensite form at higher cryogenic temperatures. 1

A 3-MA/m (37-k0e) dc field had no effect on the amount of martensite formed. A comparison was made of four specimens, two strained with the background dc field off and two with it on. The ratio of $X$ after straining divided by percent strain (about $6 \%$ ) was virtually the same for all four specimens. Another specimen was strained until it was in the serrated yielding region. After each load drop, the specimen was unloaded, the field alternately applied or removed, and the specimen reloaded until the next load drop. The increase in $x$ was recorded for 10 cycles and did not depend on the presence or absence of the field.

Although it does not apply to the above results, one possible source of error in measuring the effects of magnetic fields on mechanical properties is that the application and removal of a dc field may exert a force on the reaction tube or on the pull rod, which results in changes in load. This could lead to spurious

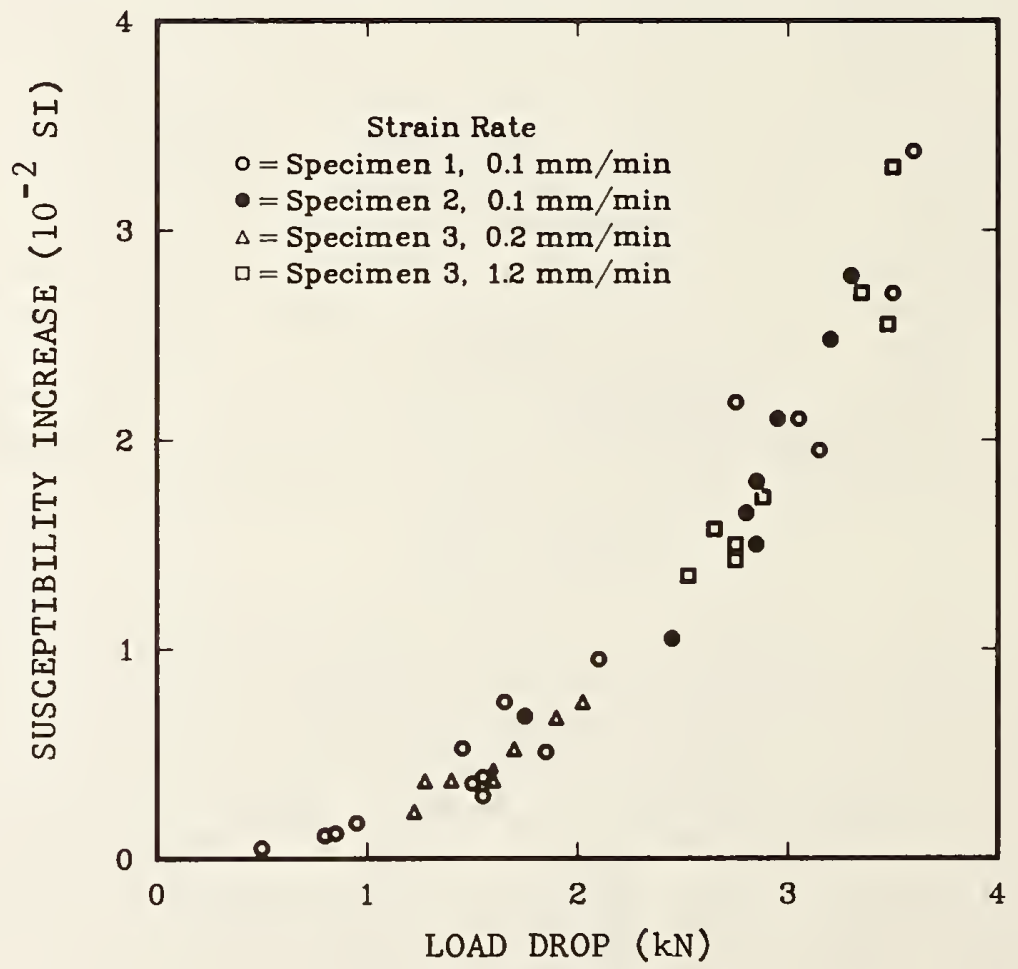

Fig. 4. Increase in volume susceptibility as a function of magnitude of load drop. 
conclusions regarding transient magnetic field effects in the specimens. Figure 5 shows load and magnetic field vs. stroke (controlled as a function of time) in the elastic region of a specimen (in this case austenitic type 310 stainless steel, nominal composition: $54 \% \mathrm{Fe}, 25 \% \mathrm{Cr}, 21 \% \mathrm{Ni}$ ). No changes in the stressstrain curve due to transient field conditions nor significant magnetostriction would be expected in the elastic region of this low-magnetization, stable alloy. However, as the field increased, the load increased above its trendline. A reduction in field caused the load to return to its trendline. The magnet was quenched after its final charge, causing a precipitous drop in load. These apparently transient effects in the specimen were actually due to the interaction of the magnetic field with the weakly magnetic reaction tube and pull rod and local magnetic fields caused by eddy currents. Such effects should be considered in transient-field experiments (cf: Ref. 8).

\section{CONCLUSIONS}

AISI type 304 stainless steel, when plastically strained at $4 \mathrm{~K}$, is known to undergo serrated yielding. This results in a pronounced increase in $\chi$, as measured at room temperature, which has been attributed to the transformation of $\mathrm{fcc}$ austenite ( $\gamma$ phase)

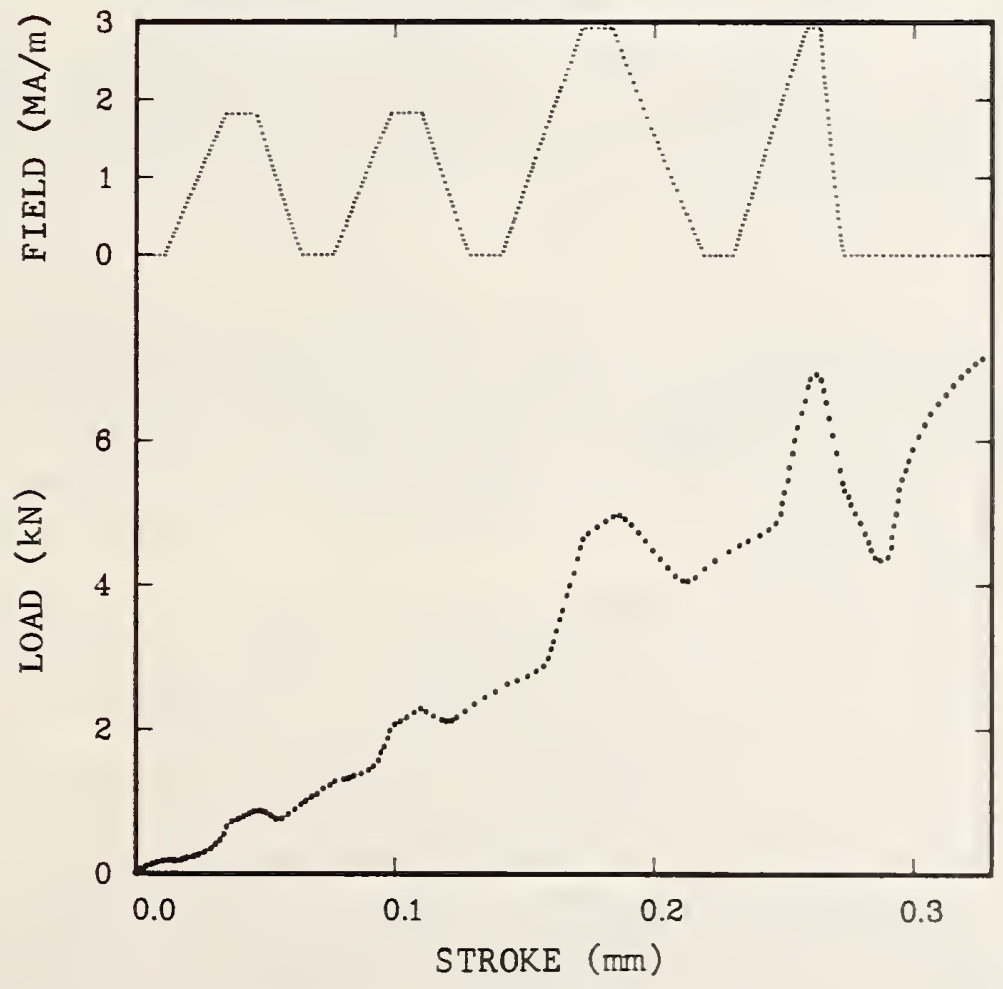

Fig. 5. Artifacts in load-stroke curve caused by application and removal of magnetic field. 
to ferromagnetic bcc martensite ( $\alpha^{\prime}$ phase). In this work, the ac $\chi$ was measured at $4 \mathrm{~K}$ using a mutual inductance technique while simultaneously measuring stress and strain. The following results were obtained.

1. There was a small increase in $\chi$ in the initial elastic and plastic regions, which was reversible upon unloading.

2. There was a small, irreversible increase in $X$ with plastic deformation prior to serrated yielding. This is attributed to the formation of strain-induced martensite.

3. There were large, irreversible increases in $x$ coincident with the load drops associated with serrated yielding. These are also attributed to the irreversible formation of strain-induced martensite. The magnitude of the increases in susceptibility correlated with the magnitude of the load drops.

4. Immediately following a load drop in the serrated yielding region, there was a reversible increase in $\chi$ as elastic reloading occurred. The slope of this increase became larger as the number of load drops increased. This may be attributed to the inverse magnetostrictive effect. After reloading, further plastic strain prior to the next load drop caused a small, irreversible increase in $x$.

5. The application of a moderate, 3-MA/m (37-k0e) dc field at $4 \mathrm{~K} \mathrm{had} \mathrm{no} \mathrm{effect} \mathrm{on} \mathrm{the} \mathrm{formation} \mathrm{of} \mathrm{martensite.}$

6. The application and removal of a dc magnetic field caused changes in the stress-strain curve when measured as load vs. stroke. These changes were likely due to the magnetic force on the reaction tube and pull rod rather than transient magnetic effects in the specimen.

\section{REFERENCES}

1. C. J. Guntner and R. P. Reed, ASM Trans. Q. 55:399 (1962).

2. V. Kelha and T. Nilnikoski, Acta Polytech. Scand. (Helsinki), Phys. Incl. Nucleon. Ph 76:1 (1971).

3. D. N. Bolshutkin, V.A. Desnenko, and V. Ya. Ilichev, Phys. Met. Metallogr. 50:131 (1980) [Fiz. Met. Metalloved. $\overline{50: 826(1980)]}$.

4. 1983 Annual Book of ASTM Standards, Vo1. 03.01, A370-77, Standard E6, ASTM, Philadelphia, 1983, pp. 41-42.

5. H. Zijlstra, "Experimental Methods in Magnetism," Vol. 2 North-Holland, Amsterdam (1976), pp. 72-79.

6. B. D. Cullity, "Introduction to Magnetic Materials," AddisonWesley, Reading, Massachusetts (1972), pp. 266-275.

7. R. P. Reed, Martensitic phase transformations, in: "Materials at Low Temperatures," R. P. Reed and A. F. Clark, eds., American Society for Metals, Metals Park, Ohio (1983), pp. 295-341.

8. D. N. Bolshutkin, V. A. Desnenko, and V. Ya. Ilichev, Cryogenics 19:231 (1979). 


\title{
FATIGUE CRACK GROWTH IN SENSITIZED Fe-18Cr-3Ni-13Mn-0.37N AUSTENITIC STAINLESS STEEL: THE SIGNIFICANCE OF MICROMECHANISMS ${ }^{+}$
}

\author{
R. L. Tobler \\ Fracture and Deformation Division \\ National Bureau of Standards \\ Boulder, Colorado
}

\begin{abstract}
A nitrogen-bearing austenitic stainless steel (Fe-18Cr-3Ni-13Mn-0.37N) was fatigue tested in both the annealed and isothermally sensitized conditions at 295 and $4 \mathrm{~K}$. This temperature reduction caused fatigue and fracture failure mode transitions in conjunction with a significant increase of strength. Comparison of the sensitized versus annealed material at $295 \mathrm{~K}$ indicated no difference in the fatigue crack growth behavior at intermediate $\Delta K$. At $4 \mathrm{~K}$, however, the fatigue resistance was degraded, with sensitized material showing greater degradation than annealed material. These differences were interpreted in terms of the operative failure micromechanisms.
\end{abstract}

Key Words: Austenitic stainless steels; chromium carbo-nitride precipitation; cryogenic properties of materials; fatigue; fatigue crack growth; failure micromechanisms; sensitization.

+Work supported by DoE, Office of Fusion Energy; not subject to copyright. 


\section{INTROOUCTION}

The austenitic stainless steels are highly regarded as reliable cryogenic alloys, but property degradations due to sensitization may limit their performance in some applications. Sensitization is a microstructural phenomenon encountered when these steels are heated at temperatures from 700 to $1100 \mathrm{~K}$. After sufficient time at these temperatures, chromium carbo-nitrides begin to precipitate at the grain boundaries.

Sensitization can be detrimental to corrosion resistance, as well as cryogenic ductility and toughness, ${ }^{1,2}$ but very little is known about the effects of sensitization on fatigue properties. In a study of AISI 310 S stainless steel, Logsdon, Wells, and Kossowsky ${ }^{3}$ report that sensitization produced no change at all in the $4 \mathrm{~K}$ fatigue crack growth rates $(\mathrm{da} / \mathrm{dN})$ at intermediate stress-intensity factors $(\Delta K)$, whereas the $4 \mathrm{~K}$ fracture toughness $\left(\mathrm{K}_{\mathrm{IC}}\right)$ was reduced $36 \%$. The present paper describes new data for a nitrogenstrengthened $\mathrm{Fe}-18 \mathrm{Cr}-3 \mathrm{Ni}-13 \mathrm{Mn}-0.37 \mathrm{~N}$ steel, documents its failure mechanisms, and contrasts its performance with that of AISI 310 S.

\section{EXPERIMENTAL MATERIAL AND PROCEDURE}

The studied material is a commercial plate of Fe-18Cr-3Ni-13Mn-0.37N austenitic stainless steel, 25-mm thick and previously characterized by Read and Reed. ${ }^{4}$ The composition in weight percent is: Fe-18.09Cr-3.26Ni-13.22Mn$0.37 \mathrm{~N}-0.038 \mathrm{C}-0.12 \mathrm{Mo}-0.52 \mathrm{Si}-0.005 \mathrm{~S}-0.028 \mathrm{P}$. In the as-received condition the material was annealed $1 \mathrm{~h}$ at $1353 \mathrm{~K}$ and water quenched. The nominal value of grain size is ASTM No. 6, the Rockwell hardness is B93, and the tensile properties are shown in Table 1.

The fatigue tests were performed on material in both the as-received (i.e., annealed) and sensitized conditions. Representative microstructures 
are shown in Fig. 1. The isothermal sensitization was induced by either of two treatments designated as follows:

$\mathrm{S}_{1}$ condition: $977 \mathrm{~K}, 0.75 \mathrm{~h}$, water quench

$\mathrm{S}_{2}$ condition: $977 \mathrm{~K}, 1.5 \mathrm{~h}$, water quench

A11 tests used compact specimens $25-\mathrm{mm}$ thick and 50.8-mm wide. The notch was machined in the longitudinal plate direction and the load was applied transversely (TL orientation). The specimen and cryogenic test apparatus are described el sewhere. 5

The properties measured were the fatigue crack growth rates at 295 and $4 \mathrm{~K}$ and the $4-\mathrm{K}$ fatigue fracture toughness $\left(K_{f C}\right){ }^{6}$ All tests used sinusoida load control at a stress ratio of 0.1 . The cycling rate was $20 \mathrm{~Hz}$, except near $K_{f c}$ when the frequency was reduced to values as $10 \mathrm{w}$ as $2 \mathrm{~Hz}$. Cheng's ${ }^{7}$ computer-aided compliance method was used to record curves of crack length (a) versus cycles $(N)$, to plot $d a / d N-v e r s u s-\Delta K$, and to calculate the Paris equation parameters $C$ and $n$ (i.e., $d a / d N=C(\Delta K)^{n}$ ) on the basis of least-squares fits. Calculations of $\mathrm{K}_{\mathrm{fc}}$ were based on the maximum fatigue load and the crack length at instability as the crack grew to critical size at progressively increasing $\Delta K$ values.

\section{RESULTS}

\section{Fatigue Crack Growth}

The fatigue crack growth rate data are shown in Figs. 2 and 3 . At $295 \mathrm{~K}$, the rates for both the $S_{1}$ and $S_{2}$ conditions were equivalent to rates for the annealed condition ${ }^{4}$ (not shown). Figure 4 illustrates the micromechanism of failure at room temperature. The distinguishing feature here is transgranular striation formation owing to reversed plastic flow at the crack tip, and there 
is no intergranular fracture. The same failure mode persisted for this steel at $295 \mathrm{~K}$ in all three metallurgical conditions: annealed, $\mathrm{S}_{1}$, and $\mathrm{S}_{2}$. Thus, the effect of grain-boundary precipitation on the fatigue crack growth rates and failure mode at room temperature was negligible for the $\Delta K$ range studied.

The temperature reduction from 295 to $4 \mathrm{~K}$ greatly accelerated the crack growth rates for $\mathrm{Fe}-18 \mathrm{Cr}-3 \mathrm{Ni}-13 \mathrm{Mn}-0.37 \mathrm{~N}$ steel, both for the sensitized conditions (Fig.2) and for the annealed condition. 4 The change from 295 to $4 \mathrm{~K}$ also had remarkable effects on the Paris parameters: $c$ decreased while $n$ increased strongly, as shown in Table 2. This behavior relates to some striking transitions in the fatigue failure mechanisms, as shown in Fig. 4. The ductile striation formations observed at $295 \mathrm{~K}$ were replaced at $4 \mathrm{~K}$ by relatively brittle mechanisms promoting higher crack growth rates. The brittle mechanisms at $4 \mathrm{~K}$ involved transgranular facet formation in the annealed condition and intergranular failure in the sensitized conditions.

The fatigue crack growth rates at $4 \mathrm{~K}$ are compared in Fig. 3 . At this test temperature an effect of sensitization emerged: da/dN increased at $4 \mathrm{~K}$ relative to the annealed condition, but the difference varied with $\Delta K$ as well as the degree of sensitization. In particular, the rates for the $\mathrm{S}_{2}$ condition accelerated well above the rates for both the $\mathrm{S}_{1}$ and annealed conditions when $\Delta \mathrm{K}$ exceeded $30 \mathrm{MPa} \cdot \mathrm{m}^{\frac{1}{2}}$.

\section{Fatigue Fracture Toughness}

The $K_{f c}$ measurements showed that sensitization decreased the toughness relative to the annealed condition if sufficient time was allowed at the sensitizing temperature. Single specimen tests at $4 \mathrm{~K}$ yielded a value of $K_{f c}=61 \mathrm{MPa} \cdot \mathrm{m}^{\frac{1}{2}}$ for the annealed condition and values of 61 and $41 \mathrm{MPa} \cdot \mathrm{m}^{\frac{1}{2}}$ for the $S_{1}$ and $S_{2}$ conditions, respectively. As shown in Fig. 5 , the lower toughness of the $\mathrm{S}_{2}$ condition was associated with $100 \%$ intergranular failure, whereas 
the annealed steel showed a mixed-mode mechanism consisting of transgranular facets amidst dimpled failure zones. Intergranular failure was evidently a consequence of the fact that carbide-matrix interfaces possess relatively low cohesive strength. Carbide precipitation along the grain boundaries therefore caused an overall reduction of the boundary cohesive strength owing to the relative weakness of the carbide-matrix interface, and failure at the boundaries became energetically favorable compared with the transgranular alternative. The altered austenite stability and strength of the accompanying near-boundary chromium-depleted zones may also have contributed to intergranular failure. In any case, the consequences of such effects were obviously more severe in the $S_{2}$ condition, which has more advanced carbide precipitation than $S_{1}$.

\section{DISCUSSION}

The limited data available indicate that sensitization may significantly reduce the fatigue crack growth resistance of stainless steels under certain conditions, and in other cases there may be little or no effect. It is suggested that the effect of sensitization on the alloy fatigue crack growth behavior in the Paris range is a function of test temperature and alloy composition, and can be qualitatively predicted from the effect of sensitization on $\mathrm{K}_{\mathrm{IC}}$. The suggested prediction scheme hinges on the relationship between $n$ and $\mathrm{K}_{\mathrm{IC}}$, as shown in Fig. 6. The data in this figure represent austenitic steels with fracture toughness values covering a broad range, from 40 to 500 $\mathrm{MPa} \cdot \mathrm{m}^{\frac{1}{2}}$. On this plot, two distinct regions are identified as follows:

In region $I$, the low toughness region, $n$ depends on $K_{I c}$, increasing with decreasing toughness and reaching values much greater than 4 . Here, both the fatigue and fracture mechanisms are essentially brittle, involving significant portions of either transgranular faceting or intergranular failure. 
In region II, the high toughness region, $n$ is nearly constant at values near 4, independent of $K_{I c}$. Here the failure mechanisms are predominantly ductile: striations form during fatigue, and dimples form during monotonic loading to fracture.

Thus, it appears that the two-stage behavior of Fig. 6 is determined by the operative failure mechanisms and that the transition between the toughnessdependent and toughness-independent fatigue regions can be gaged approximately by the value of $\mathrm{K}_{\mathrm{IC}}$. For the austenitic stainless steels of Fig. 6 , this transition occurs at $\mathrm{K}_{\mathrm{IC}}=150$ to $200 \mathrm{MPa} \cdot \mathrm{m}^{\frac{1}{2}}$.

The contrasting behaviors of Fe-18Cr-3Ni-13Mn-0.37N and AISI $310 \mathrm{~S}$ at $4 \mathrm{~K}$ can now be explained as follows: The low toughness Fe-18Cr-3Ni-13Mn-0.37N steel at $4 \mathrm{~K}\left(\mathrm{~K}_{\mathrm{IC}}=71 \mathrm{MPa} \cdot \mathrm{m}^{\frac{1}{2}}\right)$ corresponds to region $\mathrm{I}$. In this region $n$ is dependent on $K_{I C}$, and because sensitization decreases the toughness at $4 \mathrm{~K}$, there is a corresponding increase of $n$, which alters da/dN. In contrast, the high toughness AISI $310 \mathrm{~S}$ steel at $4 \mathrm{~K}\left(\mathrm{~K}_{\mathrm{IC}}=282 \mathrm{MPa} \cdot \mathrm{m}^{\frac{1}{2}}\right)$ corresponds to region II. In this case sensitization decreases the toughness to $181 \mathrm{MPa} \cdot \mathrm{m}^{\frac{1}{2}}$, but $\mathrm{n}$ remains unaffected in region II, and there is no effect of sensitization on $\mathrm{da} / \mathrm{dN} .^{3}$ Similarly, the fact that there exists an effect of sensitization on the fatigue crack growth resistance of $\mathrm{Fe}-18 \mathrm{Cr}-3 \mathrm{Ni}-13 \mathrm{Mn}-0.37 \mathrm{~N}$ steel at $4 \mathrm{~K}$ but not at $295 \mathrm{~K}$ is explained because at room temperature the toughness is quite high and corresponds to region-II.

\section{SUMMARY AND CONCLUSIONS}

At $295 \mathrm{~K}$, the $\mathrm{Fe}-18 \mathrm{Cr}-3 \mathrm{Ni}-13 \mathrm{Mn}-0.37 \mathrm{~N}$ steel is characterized by high toughness, and its fatigue and failure mechanisms are ductile. Precipitates located at grain boundary sites owing to sensitization ( $1.5 \mathrm{~h}$ at $977 \mathrm{~K}$ ) are unable to alter $d a / d N$ since the fatigue mechanism at $295 \mathrm{~K}$ invariably is 
transgranular striation formation.

At $4 \mathrm{~K}$, the yield strength of this steel is more than triple its room temperature value; consequently, the $4-K$ fracture toughness is relatively low and the fatigue crack growth properties are degraded. At this low temperature, extensive sensitization $(1.5 \mathrm{~h}$ at $977 \mathrm{~K}$ ) induces a transition in micromechanisms from transgranular failure (annealed material) to intergranular failure (sensitized material). Thereby, the 4-K fatigue crack growth resistance and fracture toughness properties are measurably reduced.

It is concluded, in general, that the effects of sensitization on $\mathrm{da} / \mathrm{dN}$ at intermediate $\Delta K$ values appear to depend on the type of failure mechanisms that operate at different material and temperature combinations, and on this basis a predictive scheme is suggested.

\section{ACKNOWLEDGMENT}

The Department of Energy, Office of Magnetic Fusion Energy supported this work. I am grateful to Mr. P. T. Purtscher of NBS who assisted in fractographic examinations. 


\section{REFERENCES}

1. D. A. Wigley, "Heat Treatments to Desensitize and Remove Delta Ferrite from a 21Cr-6Ni-9Mn Stainless Steel Intended for the Fabrication of Aerofoil Models for Cryogenic Wind Tunnels," in: Austenitic Steels at Low Temperatures, R. P. Reed and T. Horiuchi, eds., PTenum Press, New York (1983), pp. 249-261.

2. S. Danyluk and J. Y. Park, "Low Temperature Intergranular Fracture and Grain Boundary Chemistry of Sensitized Type 304 Stainless Steel," Scripta Metallurgica, 16, (1982), pp. 769-774.

3. W. A. Logsdon, J. M. Wells, and R. Kossowsky, "Fracture Mechanics Properties of Austenitic Stainless Steels for Advanced Cryogenic Applications," in: Proceedings of the Second International Conference on Mechanical Behavior of Materials, American Society for Metals, Metals Park, Ohio (1976), pp. 1283-1289.

4. D. T. Read and R. P. Reed, "Toughness, Fatigue Crack Growth, and Tensile Properties of Three Nitrogen-Strengthened Stainless Steels at Cryogenic Temperatures," in: The Metal Science of Stainless Steel, E. W. Collings and H. W. King, eds., Metallurgical Society of AIME, New York (1979), pp. 92-121.

5. D. T. Read and R. L. Tobler, "Mechanical Property Measurements at Low Temperatures," in: Advances in Cryogenic Engineering, vol. 28, Plenum Press, New York (1982), pp. 17-28.

6. T. Yokobori and T. Aizawa, "Reports of the Research Institute for Strength and Fracture of Materials," vol. 6, Tohoku University, Tohoku, Japan (1970), p. 19.

7. Yi-W. Cheng, "A Computer-Interactive Fatigue Crack Growth Rate Test Procedure," in: Materials Studies for Magnetic Fusion Energy Applications At Low Temperatures-VI, NBSIR 83-1690, R. P. Reed and N. J. Simon, eds. National Bureau of Standards, Boulder, Colorado (1983), pp. 41-52. 
Table 1. Mechanical Properties for Annealed Fe-18Cr-3Ni-13Mn-0.37N Stainless Steel. 4

\begin{tabular}{ccccc}
\hline Temperature & $\begin{array}{l}\text { Yield } \\
\text { Strength, } \\
\sigma_{y}(\mathrm{MPa})\end{array}$ & $\begin{array}{l}\text { Ultimate } \\
\text { Strength, } \\
\sigma_{\mathrm{u}}(\mathrm{MPa})\end{array}$ & $\begin{array}{c}\text { Elongation } \\
\text { in } 25 \mathrm{~mm} \\
(\%)\end{array}$ & $\begin{array}{c}\text { Reduction } \\
\text { of Area } \\
(\%)\end{array}$ \\
\hline 295 & 440 & 796 & 56 & 53 \\
4 & 1540 & 1811 & 4 & 26 \\
\hline
\end{tabular}

Table 2. Fatigue crack growth rate data for Fe-18Cr-3Ni-13Mn-0.37N and AISI 310 S stainless steels.

Material, and Condition
Temperature (K)
No. of data pts.
Paris equation parameters, ${ }^{a}$ C $n$

$\mathrm{Fe}-18 \mathrm{Cr}-3 \mathrm{Ni}-13 \mathrm{Mn}-0.37 \mathrm{~N}$

Annealed
Sensitized, $S_{1}$
Sensitized, $S_{2}$
Annealed
Sensitized, $S_{1}$
Sensitized, $S_{2}^{1}$

295

295

295

$4 \quad 41$

$4 \quad 28$

$4 \quad 20$

AISI $310 S^{3}$

Annealed, STQ
Sensitized, STFC

$\begin{array}{ll}77,4 & -- \\ 77,4 & --\end{array}$

$0.97 \times 10^{-10}$

$2.10 \times 10^{-10}$

$1.35 \times 10^{-10}$

$1.09 \times 10^{-12}$

$1.29 \times 10^{-11}$

$2.80 \times 10^{-15}$

3.82

3.63

3.70

5.73

5.18

7.78

a For metric units, with $\mathrm{da} / \mathrm{dN}$ in $\mathrm{mm} / \mathrm{cycle}$ and $\Delta \mathrm{K}$ in $\mathrm{MPa} \cdot \mathrm{m}^{\frac{1}{2}}$.

b Solution treated and water quenched.

c Solution treated and furnace cooled. 


\section{LIST OF FIGURES}

Fig. 1. Fe-18Cr-3Ni-13Mn-0.37N steel microstructures.

Fig. 2. Fatigue crack growth rate data for sensitized Fe-18Cr-3Ni-13Mn-0.37N steel at 295 and $4 \mathrm{~K}$.

Fig. 3. Fatigue crack growth rate data for Fe-18Cr-3Ni-13Mn-0.37N steel in the annealed and sensitized conditions at $4 \mathrm{~K}$.

Fig. 4. Fatigue failure mechanisms Fe-18Cr-3Ni-13Mn-0.37N steel: a) S condition at $295 \mathrm{~K}, \mathrm{~b})$ annealed condition at $4 \mathrm{~K}, \mathrm{c}) \mathrm{S}_{1}$ condition at $4 \mathrm{~K}$, d) $\mathrm{S}_{2}$ condition at $4 \mathrm{~K}$.

Fig. 5. Fracture modes $\mathrm{Fe}-18 \mathrm{Cr}-3 \mathrm{Ni}-13 \mathrm{Mn}-0.37 \mathrm{~N}$ steel corresponding to overload at $4 \mathrm{~K}$.

Fig. 6. The n-yersus-K correlation for selected austenitic stainless steels. (The arrows show the change in properties before and after sensitization.) 

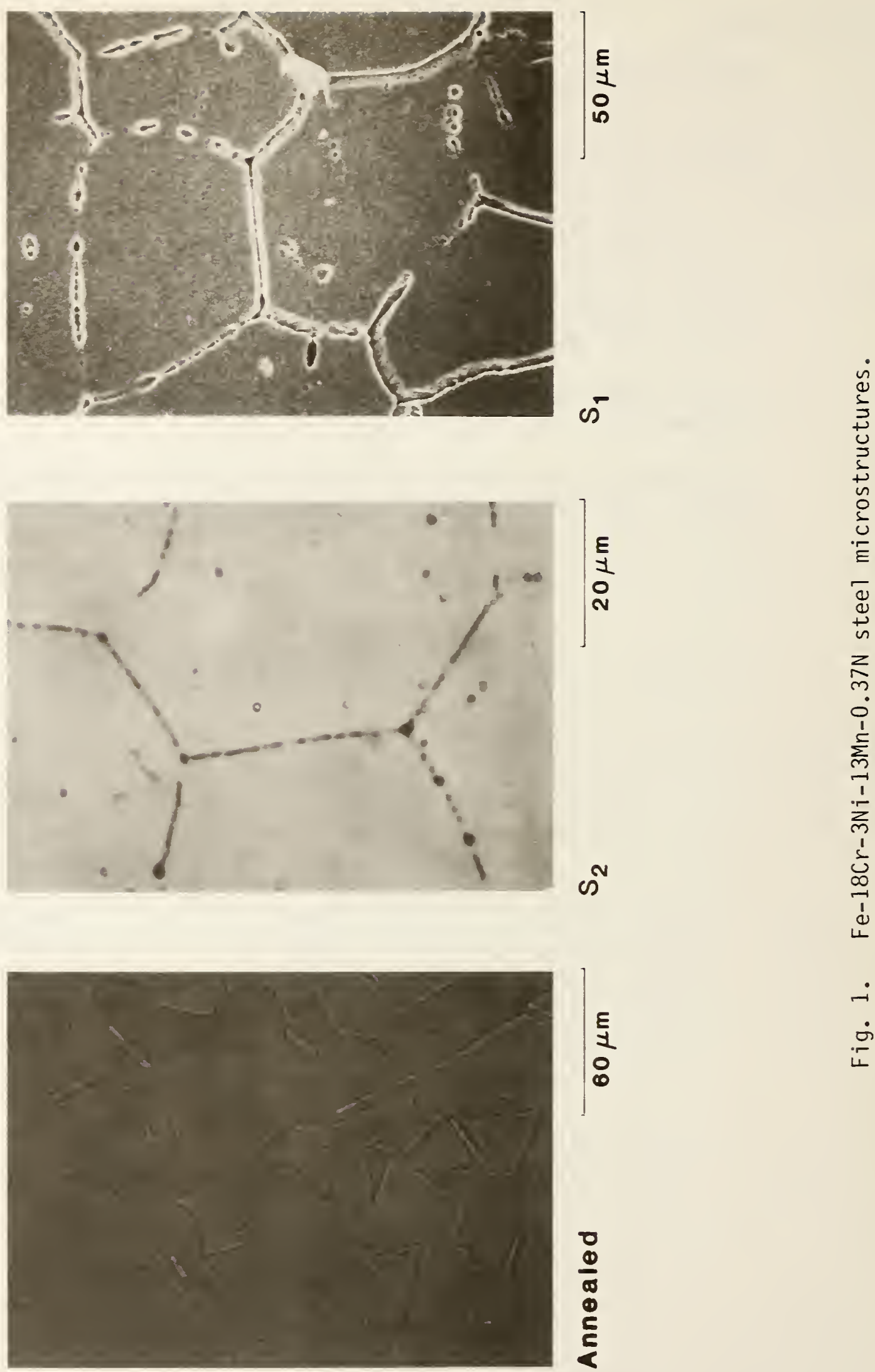

0
0
$\frac{0}{6}$
0
$\frac{0}{2}$ 
STRESS INTENSITY FACTOR RANGE, $\Delta \mathrm{K}, \mathrm{MPa} \cdot \mathrm{m}^{1 / 2}$

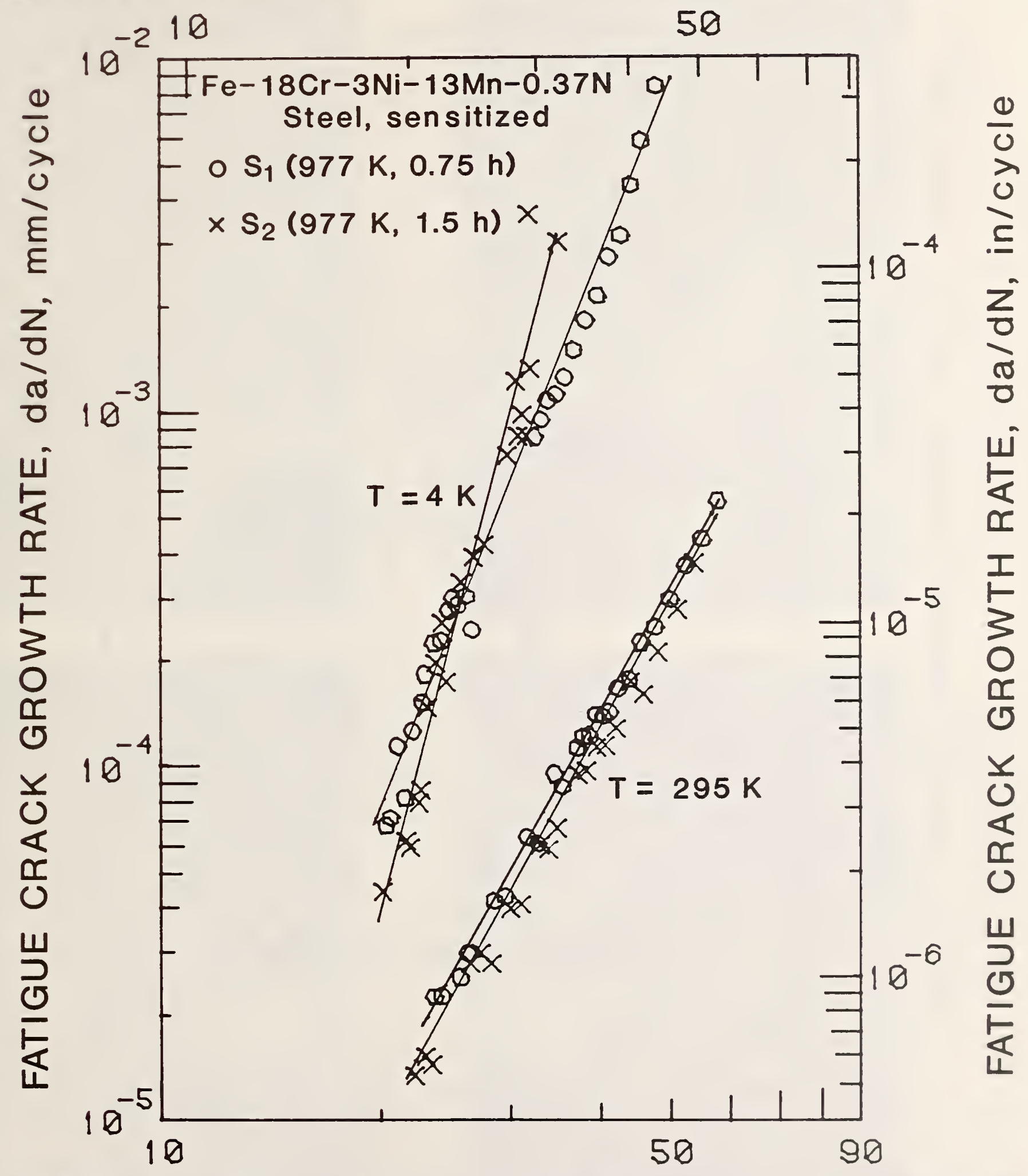

STRESS INTENSITY FACTOR RANGE, $\triangle \mathrm{K}, \mathrm{MPa} \cdot \mathrm{m}^{1 / 2}$

Fig. 2. Fatigue crack growth rate data for sensitized Fe-18Cr-3Ni-13Mn-0.37N steel at 295 and $4 \mathrm{~K}$. 
STRESS INTENSITY FACTOR RANGE, $\Delta K, \mathrm{ksi} \cdot \mathrm{in}^{1 / 2}$

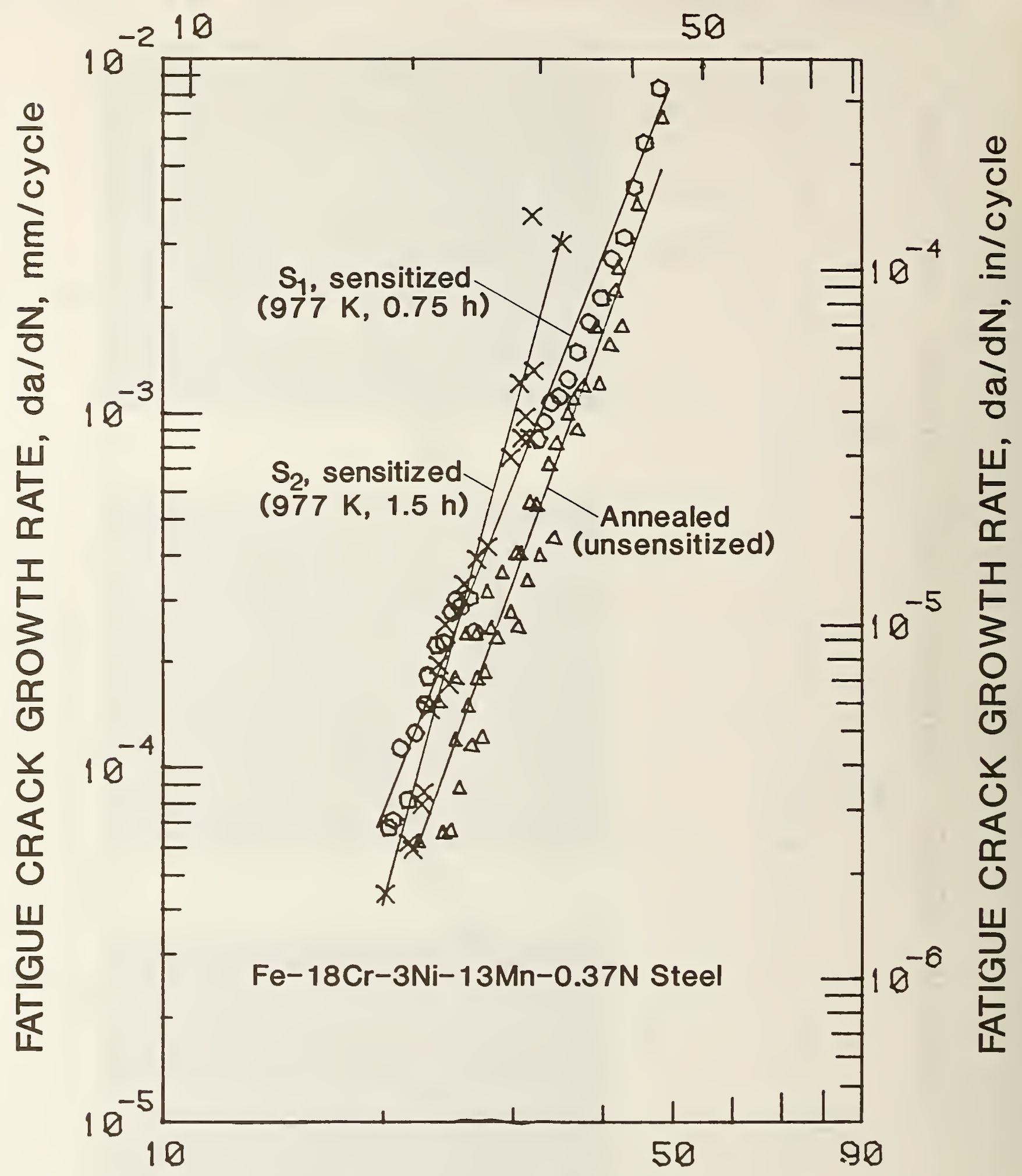

STRESS INTENSITY FACTOR RANGE, $\Delta \mathrm{K}, \mathrm{MPa} \cdot \mathrm{m}^{1 / 2}$

Fig. 3. Fatigue crack growth rate data for $\mathrm{Fe}-18 \mathrm{C} r-3 \mathrm{Ni}-13 \mathrm{Mn}-0.37 \mathrm{~N}$ steel in the annealed and sensitized conditions at $4 \mathrm{~K}$. 

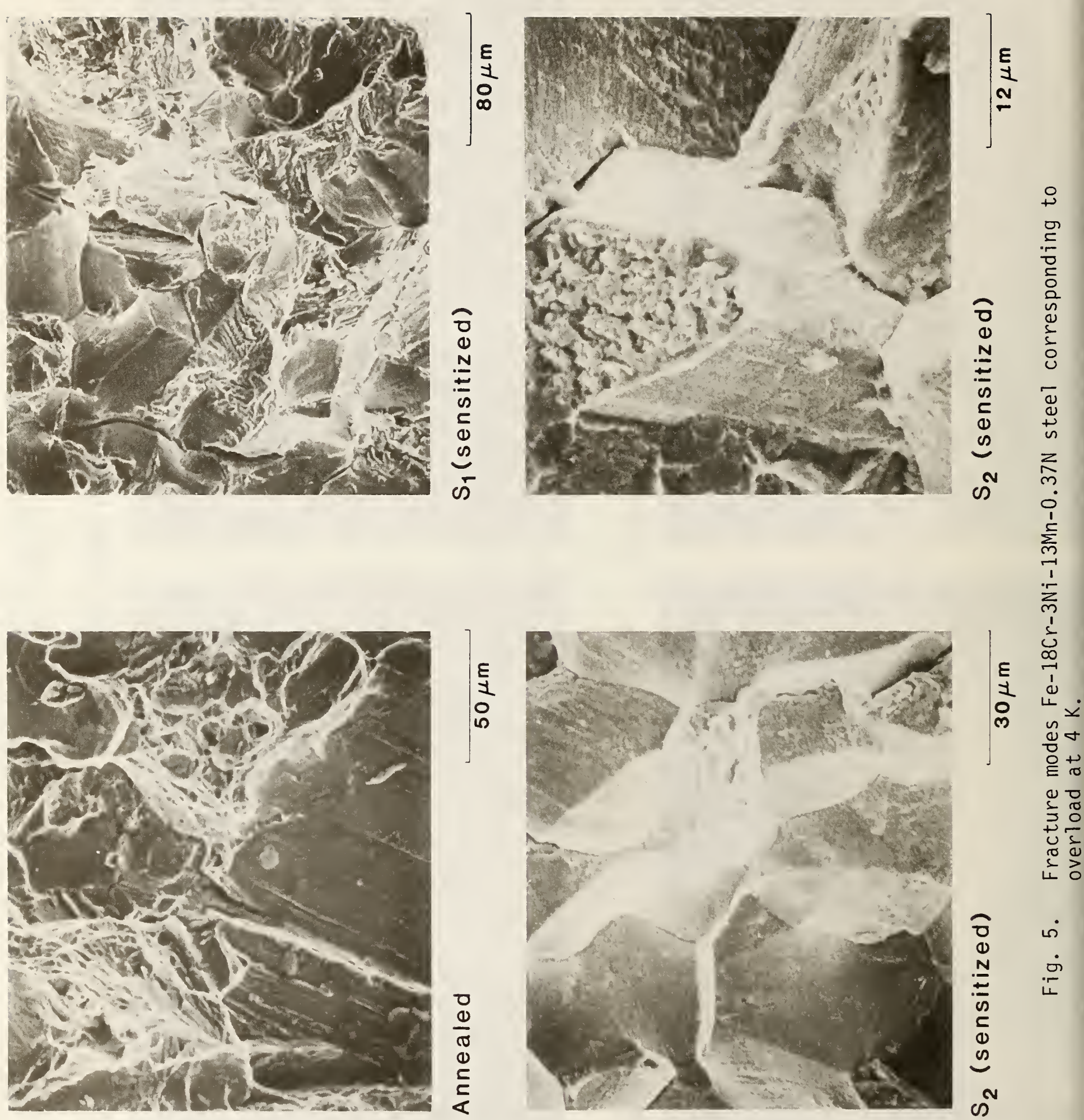


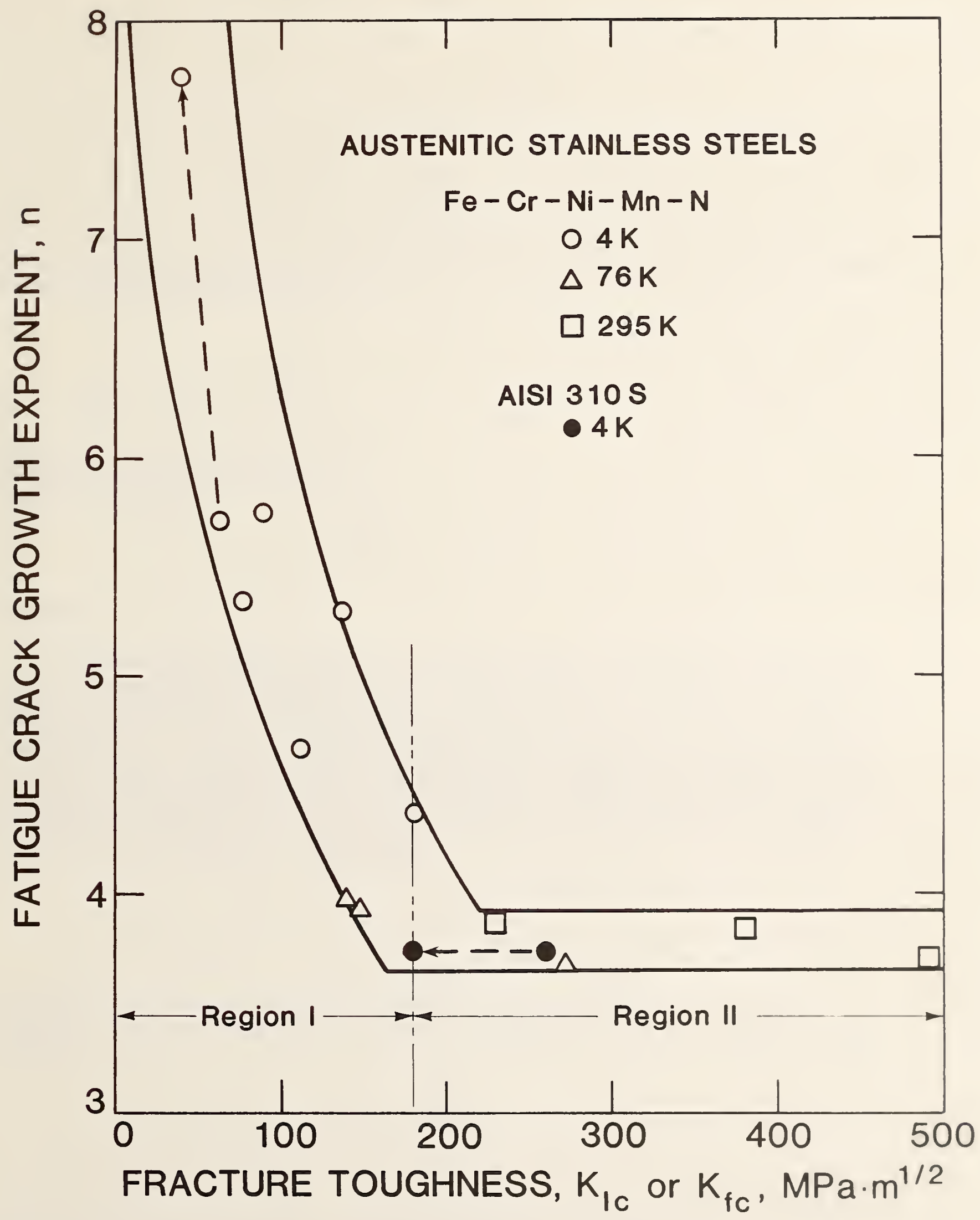

Fig. 6. The n-yersus-K correlation for selected austenitic stainless steels. (The arrows show the change in properties before and after sensitization.) 

Midrange Fatigue Crack Growth Data Correlations for Structural Alloys at Room and Cryogenic Temperatures* +

R. L. Tobler and Y. W. Cheng

Fracture and Deformation Division

National Bureau of Standards

Boulder, Colorado

\section{ABSTRACT}

Fatigue crack growth rate data for pure metals, structural alloys, and welds at temperatures from 295 to $4 \mathrm{~K}$ are selectively reviewed. The data for more than 200 material and temperature combinations are discussed in terms of the parameters $C$ and $n$ for the midrange of the da/dN-vs. $-\Delta K$ curve. Fatigue resistance varies greatly among the different alloy classes and crystal structure types, especially at extreme cryogenic temperatures where alternative failure mechanisms emerge. Good general correlations were achieved on the basis of Young's modulus, fracture toughness, and empirical equations relating $C$ and $n$ for each alloy class.

Key words: austenitic stainless steels; cryogenic properties of metals; fatigue; fatigue crack growth; fracture toughness; structural alloys; Young's modulus.

*Work supported by DoE, Office of Fusion Energy; not subject to copyright. +To be published by the American Society for Testing and Materials. 



\section{INTRODUCTION}

To the surprise of many at the time, Paris and his colleagues $[1,2]$ correlated fatigue crack growth rates, da/dN, with the linear-elastic stressintensity factor range, $\Delta K$. For the midrange of the da/dN-vs. $-\Delta K$ curve they proposed the power-1aw equation:

$$
\mathrm{da} / \mathrm{dN}=\mathrm{C}(\Delta \mathrm{K})^{\mathrm{n}}
$$

where the parameters $\mathrm{C}$ and $\mathrm{n}$ were interpreted as material constants. Subsequent studies have shown that the material behavior in this range is governed by continuum mechanics and marked by a strong dependence on Young's modulus, E. Often there is a relative insensitivity to metallurgical and microstructural variables $[3,4]$. In theory, the conventional mechanical properties, such as yield strength, $\sigma_{y}$, and fracture toughness, $K_{I c}$, play significant roles, but in practice their influence is difficult to predict.

For a number of alloy families at room temperature, it has been shown that the coefficients and exponents of Eq (1) are related by the expression:

$$
C=A\left(1 / \Delta K_{0}\right)^{n}
$$

or, equivalently,

$$
\log C=\log A+n \log \left(1 / \Delta K_{0}\right)
$$

Kitagawa and Misumi [5] first demonstrated these relationships for ferritic steels. Subsequent correlations for austenitic steels, titanium alloys, and aluminum alloys (a11 at room temperature) indicate that for each alloy system 
$A$ and $\Delta K_{0}$ depend on the fatigue stress ratio, $R$, but are independent of metallurgical and microstructural variations and environment to a considerable extent $[6-14]$. The $A(\mathrm{~mm} / \mathrm{cycle})$ and $\Delta \mathrm{K}_{0}\left(\mathrm{MPa} \cdot \mathrm{m}^{\frac{1}{2}}\right)$ parameters correspond to the coordinates of a pivot point where the da/dN-vs. $-\Delta K$ curves for a given alloy system intersect one another [14].

The present paper surveys the available data for cryogenic structural alloys, noting some simple correlations between fatigue crack growth rates and conventional mechanical properties. In continuation of a previous study [15], Eqs (2) and (3) are used to describe data at cryogenic temperatures where the $C$ and $n$ parameters for materials show great variations. Pivot points for various alloy families are calculated and compared, and the concepts of structure-sensitive and structure-insensitive da/dN behavior are discussed.

\section{MATERIALS AND PROCEDURES}

The $C$ and $n$ parameters for a variety of materials [16-44] were collected and reviewed for this paper. The alloys of interest are grouped as follows:

1. ferritic nickel steels (high-modulus bcc alloys)

2. austenitic stainless steels (high-modulus fcc alloys, stable or metastable with respect to martensitic phase transformations at cryogenic temperatures)

3. nickel-base superalloys (high-modulus fcc alloys)

4. titanium-base alloys (intermediate-modulus hcp or hcp + bcc alloys)

5. aluminum-base alloys (low-modulus fcc alloys)

Data for pure metals and for austenitic steel or nickel-base alloy welds produced using various processes and filler metals are also briefly considered.

The majority of the data were measured at NBS, using compliance methods and compact or bend specimens with constant amplitude loading, typically at a 
stress ratio of $R=0.1$ and at frequencies of $20 \pm 10 \mathrm{~Hz}$. Additional relevant data from other sources are included for comparison and confirmation, but an exhaustive search was not attempted. Three temperatures and media are emphasized: $296 \pm 2 \mathrm{~K}$ (room-temperature air), 76 or $77 \mathrm{~K}$ (1 iquid nitrogen), and 4 or $4.2 \mathrm{~K}$ (liquid helium). At these temperatures, substantial tensile, fracture, and elastic property data are available for correlations. The $K_{I C}$ values referred to in the text are direct measurements or estimates from $J$-integral tests. The $E$ moduli are taken from original publications, handbooks, or review papers [45-47]. For further details of metallurgical characterization and test procedures, it is necessary to refer to the original publications [16-44].

\section{RESULTS}

General data trends for alloy systems of major engineering significance are represented in Fig. 1. Each alloy system shows greater property variations at cryogenic than at room temperature. Three alloy systems were considered: 1) ferritic steels containing up to $18 \% \mathrm{Ni}$ (bcc structures), 2) austenitic stainless steels ( $f c c$, both stable and metastable alloys), and 3) austenitic nickel-base alloys (stable fcc structure). The pivot points for these data are discussed later in the text. The general behavior is summarized here as follows:

At $295 \mathrm{~K}$, the materials are ductile and tough, and fatigue crack growth is produced by reversed plastic flow in the crack tip zones. The fatigue exponents, $n$, typically range from 2 to 4 . Striation formations, resolvable by scanning electron microscopy at higher $\Delta K$, are the principal failure mechanisms .

At 76 or $4 \mathrm{~K}$, behavior is more diverse. Systematic compositional effects emerge, such as the effect of nickel content in the ferritic steels at low 
temperature. In many cases, the ductile striation mechanisms at $295 \mathrm{~K}$ are replaced by brittle mechanisms at 76 or $4 \mathrm{~K}$, and the fatigue exponents are inflated to values greater than 4. Transgranular or intergranular fatigue facets may be observed, even in some austenitic stainless steels. Extensive martensitic phase transformations also occur in the metastable austenitic stainless steels and may affect behavior at cryogenic temperatures. Correlation of $\mathrm{n}$ with Yield Strength or Fracture Toughness

Figure 2 illustrates relationships between the fatigue exponents and the conventional material properties for alloys having nearly equivalent values of E. As shown, $n$ tends to increase at high $\sigma_{y}$ or at low $K_{I c}$. (In general, $\sigma_{y}$ is inversely related to $\left.K_{I c}.\right)$ The sizable scatter here is due to the fact that data for different steels and nickel-base alloys have been combined with data for welds. The n-vs.-K Ic plots for individual alloy families, Figs. 3 and 4 , show more uniform trends. In these figures, two regions of behavior can be clearly identified as follows:

1. Region I (the low-toughness region): The fatigue behavior depends on K Ic, $n$ increasing as K Ic decreases.

2. Region II (the high-toughness region): The fatigue behavior is independent of $K_{I C}$, and $n$ remains constant in the range 2 to 4.

This two-stage behavior appears to be a basic feature for all metals. The point of transition from toughness-dependent to toughness-independent behavior is material dependent and not yet predictable. We suggest that the transition point hinges on the type of failure mechanisms operating, and that these can be gaged approximately by the magnitude of $K_{I c}$. In region $I$, brittle fatigue and fracture mechanisms are observed, whereas in region II, ductile mechanisms are observed. The significance of the failure mechanisms in affecting this two-stage behavior is taken up later in the discussion. 
A correlation between $n$ and $K_{I C}$ (region I) has significant implications. Like $\sigma_{y}, K_{I c}$ is dependent on metallurgical and microstructural variables and temperature. Since regions of $\mathrm{K}_{\mathrm{IC}}$-dependent and $\mathrm{K}_{\mathrm{Ic}}$-independent behavior exist, a more general conclusion follows, namely that the fatigue crack growth data of materials in general must exhibit two regimes of behavior: one is sensitive to metallurgical variables and temperature, the other is not. The following sections demonstrate some ramifications of this idea for lowtemperature fatigue.

Correlation of $\mathrm{n}$ and Temperature

In region $I$ where $n$ is inversely related to $K_{I C}$, a dependence of $n$ on test temperature is expected since temperature influences $K_{I c}$. This is shown in Figs. 5 and 6 where $n$ and $K_{I c}$ are plotted vs. temperature for $9 \% \mathrm{Ni}$ ferritic steel and a high-strength Fe-18Cr-3Ni-13Mn-0.37N austenitic steel. In both cases, $n$ eventually becomes inversely related to $K_{I c}$ and increases to values greater than 4 at extreme cryogenic temperatures, where $K_{I c}$ is reduced sufficiently to reach region $I$.

As noted previously, there is no similar effect for the conventional AISI 300 series austenitic stainless steels [15]. The explanation for this relates to the link between $n$ and $K_{I c}$, as described above. High-strength alloys such as ferritic steels, are subject to ductile-brittle transitions (DBT). AISI 300 series stainless steels, owing to their fcc structure and relatively low strength, do not exhibit DBT transitions, even at extreme cryogenic temperatures. Thus, ferritic steels at cryogenic temperatures shift from region II to region I behavior, whereas AISI 300 series steels always maintain region II behavior.

Correlation of $n$ and Composition

Nickel additions to ferritic steels will lower the DBT temperature while increasing the $K_{I c}$ at sub-transition temperatures. Therefore, composition 
becomes a crucial influence on the behavior of ferritic steels at low temperatures. In Fig. $7, n$ for ferritic steels is plotted as a function of nickel content at two temperatures, one ambient and one cryogenic. At $76 \mathrm{~K}, \mathrm{n}$ decreases as nickel increases from 0 to $5 \%$, but at higher nickel contents $n$ remains at relatively low values, independent of composition. Again, this relates to the interaction of $n$ with $K_{I c}$; this time the behavior depends on whether the composition establishes conditions corresponding to region I or region II behavior. The Fe-Ni binary alloys behave similarly [48]. Correlation of $\log C$ and $n$

The purpose of this section is to apply Eqs. (2) and (3) to cryogenic data. Accordingly, log C-vs.-n plots for various structural alloys are shown in Figs. 8 and 9. The data demonstrate the $C$ and $n$ dependence expected from Eq. (3), and this makes it possible to seek correlations with one parameter (n) only.

Data for pure iron [16], titanium [39], and aluminum $[40,41]$ are also plotted on the appropriate graphs in Figs. 8 and 9. In comparison, data for pure metals often do not fit the trends developed for their respective alloys. For unalloyed iron and aluminum, the temperature reduction from 295 to $76 \mathrm{~K}$ produces contrary effects: in the case of iron, $\log C$ decreases while $n$ decreases, whereas for aluminum, $\log C$ decreases while $n$ is constant. In contrast, however, Eq. (3) indicates that $\log C$ should decrease as $n$ increases.

Least-squares regression analyses for the $\log C-v s .-n$ plots, excluding the nonconforming data for pure metals, are summarized in Table 1. Fairly good fits are obtained, some of which may be improved by distinguishing temperature effects or differences in failure mechanisms. As listed in Table 1 , the correlation coefficients range from 0.92 to 0.99 ( 1.0 implies a perfect 
correlation). Characteristics of the alloys' distinctive fatigue behavior are:

Ferritic Steels: The spread of $n$ increases at $4 \mathrm{~K}$, reaching values up to 8. A single $\log$ C-vs.-n regression apparently fits the majority of data from 295 to 4 K. The scatter increases, however, when cryogenic data are admitted to the correlation, and it is appropriate to exclude data for extraordinarily brittle steels from the correlation [14].

AISI 300 Austenitic Stainless Series: The log C-vs.-n plot appears to be temperature independent from 295 to $4 \mathrm{~K}$, and $\mathrm{n}$ does not increase significant?y at $4 \mathrm{~K}$, in contrast to the behavior of ferritic steels.

Other Austenitic Stainless Steels: In this group are the $\mathrm{Fe}-\mathrm{Cr}-\mathrm{Mn}$, $\mathrm{Fe}-\mathrm{Ni}-\mathrm{Cr}$, and $\mathrm{Fe}-\mathrm{Cr}-\mathrm{Ni}-\mathrm{Mn}-\mathrm{N}$ steels that were not included in the AISI 300 series. Owing to exceptional strength in some grades, a behavior similar to ferritic steels is observed at $4 \mathrm{~K}$ : high $\mathrm{n}$ values (up to 8 ) are obtained and the scatter in $\log \mathrm{C}-\mathrm{vs} .-\mathrm{n}$ plot increases.

Nickel Alloys: The available data are for superalloys having $E$ moduli only slightly higher than steels. For these alloys the correlations slightly improve if temperature effects are separated; the $\log C$-vs. $-n$ plots then give a slightly lower pivot point value at 76 and $4 \mathrm{~K}$ than at $295 \mathrm{~K}$.

Titanium Alloys: The data are limited to measurements for the $T i-5 A, 7-2.5 S n$ and $T i-6 A T-4 V$ alloys for which the log $C-v s .-n$ plot shows a high correlation with absolutely no temperature dependence.

Aluminum Alloys: Again, cryogenic data are limited, but the correlation coefficients for $\log C$ vs. $n$ improve significantly if temperature effects are distinguished. The pivot point and $\log \mathrm{C}-\mathrm{vs} .-\mathrm{n}$ trend at 76 and $4 \mathrm{~K}$ is clearly lower than at $295 \mathrm{~K}$. This is similar to the effect observed in the nickel alloys, but stronger. The $295-\mathrm{K}$ data derive largely from tests of a 3003-0 
alloy in various environments, but there is no discernable environmental effect on $\log C$ vs. $n$.

Pivot Points

The pivot points corresponding to each of the alloy families discussed above are 1 isted in Table 2. Approximate agreement among different alloy systems is found after normalization. Two normalizing parameters were considered: $\Delta K_{0} / E$ and $\Delta K_{0} /(E / b)$ [13], where $b$ is the equivalent of the Burgers vector and is taken from Cullity's 1ist [49] of the distances of closest atomic approach for unalloyed metals. The correlations based on $\Delta K_{0} / E$ and on $\Delta K_{0} /(E / b)$ are equally effective.

\section{DISCUSSION}

\section{$\underline{\log C-v s .-n \text { Correlations }}$}

In principle, Eq. (2) predicts that a $11 \mathrm{da} / \mathrm{dN}$ curves must intersect at a single point $\left(A, \Delta K_{0}\right)$ and fan out as a function of $n$ [14]. In fact, there are numerous materials with $d a / d N-v s .-\Delta K$ trends that fail to intersect at the calculated "pivot points." In practice, therefore, Eq. (2) serves to approximate the entire data base, which includes nonconforming material behaviors. Under these circumstances, the calculated pivot points for various material classes are a measure of the center of gravity for the data in a statistical sense.

One limitation of representing fatigue crack growth results in terms of $\log$ C-vs. $-n$ plots and pivot points is that the $\Delta K$ ranges for the associated $\mathrm{da} / \mathrm{dN}$ are not conveyed. Therefore, interpretations concerning individual alloy behavior must be guarded in view of the unspecified information and the approximate nature of such data representations.

Although the $\log$ C-vs.-n correlations are approximate, their usefulness for certain purposes cannot be denied. In this paper, the format suggested by 
Eq. (3) provided a concise basis for data presentation, summary, and comparison. The trends of Figs. 8 and 9 help to distinguish the exceptional behavior of pure metals. Similarly, some errors in the published $C$ and $n$ data for structural alloys were identified, since they disagreed with the general data trends. Finally, the pivot point normalizations conclusively demonstrate the strong effect of Young's modulus on $d a / d N$.

Significance of Young's Modulus

Fatigue is the result of plastic deformation processes, but under the assumption of small-scale yielding, the plastic deformation is limited and localized at the crack tip so it is possible to correlate da/dN with elastic parameters: for midrange behavior, da/dN is directly proportional to $\Delta K$ (an elastic stress-intensity factor) and $1 / E$ (reciprocal of the elastic modulus). As a fundamental physical property relating to atomic binding forces, Young's modulus figures prominently in dislocation theory as well as continuum mechanics. A dependence of $d a / d N$ on $1 / E$ is explicit in some analytical models of fatigue crack growth [3]. The significance of the modulus in fatigue crack growth is likewise evident from experimental correlations. The normalizing parameter, $\Delta K / E$, was first proposed by Anderson [2] and later used to correlate striation spacings [50], pivot points [13], and macroscopic fatigue crack growth rates [4]. The data demonstrate that a strong influence of Young's modulus persists in both region I and region II.

From a materials viewpoint, $E$ is fixed mainly by the primary alloy elements and is only weakly dependent on secondary alloy elements, microstructure, and related variables, including cold work, heat treatment, or phase transformations [45]. Therefore, alloys of a given base metal system are closely grouped with respect to elastic properties. It follows that if $\mathrm{da} / \mathrm{dN}$ is strongly influenced by $E$ and weakly dependent on the conventional 
mechanical properties as postulated for region II, then a structureinsensitive behavior is expected since $E$ itself is structure insensitive.

Typically, Young's moduli for metals at low temperature show "regular" behavior [45]: a nearly linear increase below $295 \mathrm{~K}$, a plateau near $76 \mathrm{~K}$, and little or no change between $76 \mathrm{~K}$ and absolute zero. For the alloys of this survey, the overall increase of $\mathrm{E}$ between 295 and $4 \mathrm{~K}$ never exceeds 11 percent. Such small changes are consistent with a temperature-insensitive behavior in region II.

Maraging steels seem to provide an excellent example of the structure and temperature-insensitive behavior just described. Data for $18 \% \mathrm{Ni}$ maraging steel at $295 \mathrm{~K}$ show no change in $\mathrm{da} / \mathrm{dN}$ for the aged and unaged conditions [51], while for the unaged condition there is no difference in da/dN at 295 and 76 $K[22]$. In contrast, strong effects on $\sigma_{y}$ and $K_{I c}$ are induced by aging or test-temperature reduction. The observations are plausible, assuming that we are dealing with region II behavior, and realizing that the aging step and test-temperature reduction to $76 \mathrm{~K}$ will increase $\mathrm{E}$ by only 9 and $5 \%$, respectively.

Additional evidence for the role of Young's modulus derives from Fig. 1. If the 295-K data presented there are superimposed, the bands for the three material classes nearly overlap, despite significant differences in composition (iron-vs.-nickel base) and crystal structure (bcc vs. fcc, stable or metastable). This explanation is offered: these alloys have nearly equivalent moduli, and at $295 \mathrm{~K}$ all undergo fatigue by relatively ductile mechanisms involving reversed plastic flow in region II where rather wide variations of $\sigma_{y}$ and $K_{I c}$ are of minor consequence to fatigue crack growth. Temperature Dependence

Some alloys show improved fatigue resistance at cryogenic temperatures, whereas others are degraded. 
An improved performance cannot be attributed to favorable temperature effects on $E$, since any increase between 300 and $4 K$ is too small to account for measurable improvements in fatigue crack growth rates. Instead, we assume that significant temperature effects on the fatigue resistance at cryogenic temperatures are induced when the plastic work for fatigue crack propagation is altered. This may occur in conjunction with failure mode transitions, the effects combining competitively or synergistically to account for the diversity of behaviors observed at 76 or $4 K$ compared with those at $295 \mathrm{~K}$. Plastic Work

Fine and Davidson [52] reviewed the measurements of plastic work. Although few data are available at present, it is clear that temperature reductions can improve the fatigue crack growth resistance of some metals at cryogenic temperatures by increasing the plastic work for fatigue failure. For example, pure aluminum exhibits a 100-fold decrease of rates as temperature drops from 295 to $77 \mathrm{~K}$, and the associated increase of energy required for unit fatigue crack extension at $77 \mathrm{~K}$ has been measured [41]. For an identical temperature reduction, the rates for the solid-solution alloy 5083-0 decrease 3 or 4 times [42]. Thus, a similar but less powerful effect may operate in alloys. This may explain the improved fatigue crack growth resistance of the aluminum-base, nickel-base, and stable iron-base alloy families at cryogenic temperatures [25], but confirmation is needed. Failure Micromechanisms

Temperature-induced transitions in microfailure mechanisms may introduce either beneficial or detrimental effects, since the amount of plastic work required for fatigue crack extension may then be increased or decreased. Transitions from ductile to brittle mechanisms cause the shift from region II 
to region I behavior as described in the text. In Fe-18Cr-3Ni-13Mn-0.37N steel, for example, the incidence of brittle mechanisms at $4 \mathrm{~K}$ drastically increased $n$ (Fig. 5), eclipsing any favorable trend that may have been expected from a temperature effect on plastic work without a transition in failure mode.

The explanation offered for high $n$ in low-toughness alloys is that brittle-failure mechanisms associated with monotonic loading begin to operate concurrently with the cyclic mechanisms of crack growth [53-55]. This was proposed in a study of ferritic steels at room temperature where the brittle mechanism was intergranular fracture [54]. Another brittle mechanism common in ferritic steels at low temperature is transgranular cleavage. Both mechanisms generate brittle facets and both are sensitive to the maximum applied $K$ level because they are subject to a critical tensile-stress failure criterion.

Inflated fatigue exponents and degraded fracture toughness are common at cryogenic temperatures owing to the increased probability of brittle-failure mechanisms relative to room temperature. In fact, this phenomenon is virtually universal at extreme cryogenic temperatures, having now been observed in some austenitic steels, as well as ferritic steels, and nickel-base, magnesium-base, and titanium-base alloys [56-58]. Our $4 \mathrm{~K}$ data for austenitic stainless steels indicate that the high-strength $\mathrm{Fe}-\mathrm{Cr}-\mathrm{Ni}-\mathrm{Mn}-\mathrm{N}$ steels are susceptible, whereas the relatively low strength $\mathrm{Fe}-\mathrm{Cr}-\mathrm{Ni}$ (AISI 300 series) steels are not.

The occurrence of high exponents associated with toughness degradation in austenitic stainless steels at $4 \mathrm{~K}$ may seem surprising since these materials are generally reputed to be ductile and tough at all temperatures. The newly developed $\mathrm{Fe}-\mathrm{Cr}-\mathrm{Ni}-\mathrm{Mn}-\mathrm{N}$ steels, however, contain up to 0.4 percent 
nitrogen, high enough to elevate $\sigma_{y}$ and reduce $K_{I c}$ sufficiently to attain region I behavior.

The brittle mechanisms associated with high exponents in cryogenic structural alloys may include transgranular crystallographic faceting, slip-band decohesion, twin-boundary parting, and intergranular fracture. Some representative fractographs are shown in Figs. 10 and 11 . The brittle mechanisms at $4 \mathrm{~K}$ are quite distinct from the striation mechanisms operating at $295 \mathrm{~K}$ (Fig. 10). For example, a pronounced transgranular faceting occurs in annealed $\mathrm{Fe}-18 \mathrm{Cr}-3 \mathrm{Ni}-13 \mathrm{Mn}-0.37 \mathrm{~N}$ austenitic stainless steel at $4 \mathrm{~K}$ (Fig. 11A). Intergranular failure in this steel at $4 \mathrm{~K}$ is also induced after sensitization treatments, owing to the embrittling effects of chromium carbonitride precipitation along the grain boundaries (Figs. 11B, 11C).

In contrast to the adverse effects of transitions to brittle-failure mechanisms described above, favorable transitions in fatigue failure mechanisms are also possible, although less commonly encountered. An outstanding example of a favorable transition occurs in metastable AISI 304L stainless steel. In this steel, the usual transgranular crystallographic mechanism at $295 \mathrm{~K}$ (Fig. 12) is replaced at $76 \mathrm{~K}$ by a unique transgranular mechanism involving very fine, nondistinct features producing a very smooth macroscopic failure surface (Fig. 13). This transition is associated with extensive martensitic phase transformations, and a significant reduction of $\mathrm{da} / \mathrm{dN}$ occur between 295 and $76 \mathrm{~K}$ [28]. The austenitic instability may be directly responsible for the improved fatigue resistance, for a variety of reasons, as discussed by Schuster and Altstetter [59]. 


\section{SUMMARY AND CONCLUSIONS}

The midrange fatigue crack growth rate data for a variety of structural alloys at room and cryogenic temperatures are selectively reviewed. The data presentation follows a format suggested by the Kitagawa-Misumi equation, where $\log C$ is plotted versus $n$. Pivot points are calculated for cryogenic alloys, regions of structure-sensitive and structure-insensitive behavior are identified, and the significance of some factors influencing the temperature dependence of fatigue crack growth are briefly discussed.

The variability in $d a / d N$ is greater at 76 and $4 \mathrm{~K}$ than at $295 \mathrm{~K}$. On the basis of pivot point calculations, Young's modulus exerts a dominant effect in that $\Delta K_{0} / E$ approximately normalizes the data for different alloy families. Within each family the behavior is strongly influenced by failure mechanisms. Plastic work and cyclic stress-strain properties are highly relevant to the determination of fatigue property correlations, but such data are not generally available for cryogenic alloys. In the absence of such data, correlations were sought using conventional mechanical properties. Those correlations indicate that two regions of behavior can be identified for structural alloys:

1. In region $\mathrm{I}, \mathrm{da} / \mathrm{dN}$ is temperature and microstructure sensitive: $\mathrm{E}$, $\sigma_{y}$, and $K_{I c}$ influence the results.

2. In region $I I, d a / d N$ is temperature and microstructure insensitive: $E$ influences the results, whereas $\sigma_{y}$ and $k_{I c}$ are irrelevant. 


\section{REFERENCES}

1. Paris, P. C. and Erdogan, F., J. Basic Eng., Trans. ASME, Vol. 85 D, 1963 , pp. 528-534.

2. Paris, P. C., in: Fatigue Thresholds - Fundamentals and Engineering Applications, J. Backlund, A. F. Blom, and C. J. Beevers, Eds., Engineering Materials Advisory Services, U.K., 1982, pp. 3-10.

3. Irving, P. E. and McCartney, L. N., Met. Sci., Vol. 11, 1977 , pp. $351-361$.

4. Lindley, T. C. and McCartney, L. N., Mechanics and Mechanisms of Fatigue Cracks Growth, in: Developments in Fracture Mechanics, G. G. Chell, Ed., Applied Science Publishers, London, 1981, pp. 247-322.

5. Kitagawa, H. and Misumi, M., Jap. Soc. Mech. Eng. No. 7, 1971, pp. 710-717; and, Proceedings, International Conference On Mechanical Behavior of Materials, Vol. 2, 1972, pp. 218.

6. Koshiga, F. and Kawahara, M., J. Jap. Soc. Naval Arch., Vol. 133, 1983, p. 249 .

7. Yokobori, T., Kawada, I., and Hata, H., Reports of the Research Institute for Strength and Fracture of Materials, Tohoku University, Vol. 9, 1973, p. 35 .

8. Niccolls, E. H., Scripta Metal1., Vol. 10, 1976, pp. 295-298.

9. McCartney, L. N. and Irving, P. E., Scripta Metal1., Vol. 11, 1977, pp. $181-183$.

10. Bailon, J. P., Masounave, J., and Bathias, L., Scripta Meta11., Vol. 11, 1977, pp. 1101-1106.

11. Tanaka, K. and Matsuoka, S., Int. J. Fract., Vol. 13, No. 5, 1978, pp. 563-583.

12. Benson, J. P. and Edmonds, D. V., Scripta Metall., Vol. 12, 1978, pp. 645-647.

13. Tanaka, K., Masuda, C., and Nishijima, S., Scripta Metal1., Vol. 15, 1981 , pp. 259-264.

14. Tanaka, K., Int. J. Fract., Vol. 15, No. 1, 1979, pp. 57-68.

15. Cheng, Y.W. and Tobler, R. L., in: Proceedings of ICF International Symposium on Fracture Mechanics, Tan Deyan and Chen Daning, Eds., Science Press, Beijing, China, 1983, pp. 635-640..

16. Burck, L. H., and Weertman, J., Metal1. Trans., Vol. 7A, 1976, pp. 257-264. 
17. Prokopenko, A. V., Strength Mater., Vo1. 10, No. 6, 1979, pp. 673-678.

18. Pokrovskii, V. V., Strength Mater., Vo1. 10, 5, 1979, pp. 534-539.

19. Stonesifer, F. R., Eng. Fract. Mech., Vo1. 10, 1978, pp. 305-314.

20. Tobler, R. L., Mikesel1, R. P., and Reed, R. P., in: Fracture Mechanics ASTM STP 677, C. W. Smith, Ed., American Society for Testing and Materials, Philadelphia, 1979, pp. 85-105.

21. Tobler, R. L., Mikese11, R. P., Durcholz, R. L., and Reed, R. P., in: Properties of Materials For LNG Tankage, ASTM STP 579, American Society forTesting and Materials, Philadelphia, 1975, pp. 261-287.

22. Tobler, R. L., Reed, R. P., Schramm, R. E., J. Eng. Mater. Technol. Vol. 100, 1978, pp. 189-194.

23. Tobler, R. L. and Reed R. P., Adv. Cryog. Eng., Vol. 24, 1978, pp. 82-90.

24. Schwartzberg F. R., in: Materials Research for Superconducting

Machinery-I, Semi-Annual Technical Report, ADA004586, National Bureau of Standards, 1974. Available from NTIS, Springfield Virginia.

25. Tobler, R. L. and Reed, R. P., Adv. Cryog. Eng., Vo1. 22, 1977, pp. $35-46$.

26. Read, D. T. and Reed, R. P., in: Metal Science of Stainless Steels, Metallurgical Society of AIME, New York, 1979, pp. 92-121.

27. Read, D. T. and Reed R. P., Cryogenics, Vol. 21, 7, 1981, pp. 415-417.

28. Tobler, R. L. and Reed, R. P., "Interstitial Carbon And Nitrogen Effects On The Cryogenic Fatigue Crack Growth Of AISI 304 Type Stainless Steels", submitted for publication.

29. Wells, J. M., Kossowsky, R., Logsdon, W. A., and Daniel, M. R., in: Materials Research for Superconducting Machinery-IX, Semi-Annual Technical Report, ADA036919, National Bureau of Standards, 1976. Available from NTIS, Springfield, Virginia.

30. Mahoney, M. W. and Paton, N. E., Nuc1. Technol., Vol. 6, 23, 1974, pp. 53-62.

31. We11s, J. M., Kossowsky, R., Logsdon, W. A., and Daniel M. R., in: Materials Research for Superconducting Machinery-VI, Semi-Annual

Technical Report, ADA036919, National Bureau of Standards, 1976. Available from NTIS, Springfield, Virginia.

32. Tobler, R. L., McHenry, H. I., and Reed, R. P., Adv. Cryog. Eng, Vol. 24, 1978, pp. 560-572.

33. Tobler, R. L., "Fatigue Crack Growth In Sensitized Fe-18Cr-3Ni-13Mn-0.37N Austenitic Stainless Steel", to be published. 
34. Whipple, T. A., McHenry, H. I., and Read, D. T., Weld. J., Weld. Res. Suppl. Vol. 60, 1981, pp. 72s-78s.

35. McHenry, H. I. and Whipple, T. A., in: Materials Studies For Magnetic Fusion Energy Applications at Low Temperatures-IV, NBSIR 80-1627, National Bureau of Standards, Boulder, Colorado, 1980, pp. 155-165.

36. Whipple, T. A. and McHenry, H. I. in: Materials Studies For Magnetic Fusion Energy Applications at Low Temperatures-IV, NBSIR 81-1645, National Bureau of Standards, Boulder, Colorado, 1981, pp. 273-288.

37. Tobler, R. L., Cryogenics, Vol. 16, 1976, pp. 669-674.

38. McHenry, H. I. and Schramm, R. E., Adv. Cryog. Eng., Vol. 24, 1978, pp. 161-165.

39. Thompson, A. W., Frandsen, J. D., and Williams, J. C., Met. Sci., Vol. 9, 1975 , pp. 46-48.

40. Ogura, T., Karashima, S., and Tsurukame, K., Trans. Jap. Inst. Met., Vol. 16,1975, pp. 43-48.

41. Liaw, P. K., Fine, M. E., Kiritani, M., and Ono, S., Scripta Metall., Vol. 11, 1977, pp. 1151-1155.

42. Tobler, R. L. and Reed, R. P., J. Eng. Mater. Technol., Vol. 100, 1977, pp. 306-312.

43. McHenry, H. I., Naranjo, S. E., Read, D. T., and Reed, R. P., Adv. Cryog. Eng., Vol. 24, 1978, pp. 519-527.

44. Roberts, R., Wnek, K., and Tafuri, J. C., Adv. Cryog. Eng. Vol. 24, 1978, pp. 187-196.

45. Ledbetter, H. M., Elastic Properties, in: Materials at Low Temperatures, R. P. Reed and A. F. Clark, Eds., American Society for Metals, Metals Park, Ohio, 1983, pp. 1-45.

46. Ledbetter, H. M., Cryogenics., Vo1. 22, 12, 1982, pp. 653-656.

47. Naimon, E. R., Weston, W. F., and Ledbetter, H. M., Cryogenics, Vol. 14, 1974 , pp. 246-249.

48. Gerberich, W. W. and Moody, N. R., in: Fatigue Mechanisms, ASTM STP 675 , American Society for Testing and Materials, Philadelphia, 1979 , pp. 292-341.

49. Cullity, B. D., Elements of X-Ray Diffraction, Addison-Wesley Inc., Reading, Massachusetts, 1956, pp. 482-484.

50. Bates, R. C. and Clark, W. G., Jr., Trans. Am. Soc. Met., Vol. 62, 1969, p. 380 . 
51. Bathias, C. and Pelloux, R. M., Metall. Trans., Vo1. 4, 1973, pp. $1265-1273$.

52. Fine, M. E. and Davidson, D. L., in: Fatigue Mechanisms: Advances in Quantitative Measurement of Physical Damage, ASTM STP 811, J. Lankford, D. L. Davidson, W. L. Morris, and R. P. Wei, Eds., American Society for Testing and Materials, Philadelphia, 1983, pp. 350-370.

53. Ritchie, R. 0. and Knott, J. F., Mater. Sci. Eng., Vol. 14, 1974, p. 7.

54. Ritchie, R. 0. and Knott, J. F., Acta Metal1., Vol. 21, 1973, pp. 639-648.

55. Richards, C. E. and Lindley, T. C., Eng. Fract. Mech., Vol. 4, 1972, pp. 951-978.

56. Katz, Y., Bussiba, A., and Matthias, H., "The Reflection of Warm Pre-Stressing on the Low-Temperature Fatigue Crack Growth Curve," submitted for publication.

57. Ryder, J. T. and Witzel1, W. E., Effect of Low Temperature on Fatigue and Fracture Properties of Ti-5A7-2.5Sn (ELI) For Use in Engine Components, submitted for publication.

58. Verkin, B. I., Grinberg, N. I., and Serdyuk, V. A., Correlation of the Parameters of Fatigue Crack Growth With the Depth of Plastic Zone and Fracture Micromechanisms In Vacuum and at Low Temperatures, submitted for publication.

59. Schuster, G., and Altstetter, C., in: Fatigue Mechanisms: Advances in Quantitative Measurement of Physical Damage, ASTM STP 811, J. Lankford, D. L. Davidson, W. L. Morris, and R. P. Wei, Eds., American Society for Testing and Materials, Philadelphia, 1983, pp. 445-463. 
LIST OF TABLES

Table 1. Pivot point calculations for structural alloy families.

Table 2. Pivot point normalizations for structural alloy families. 


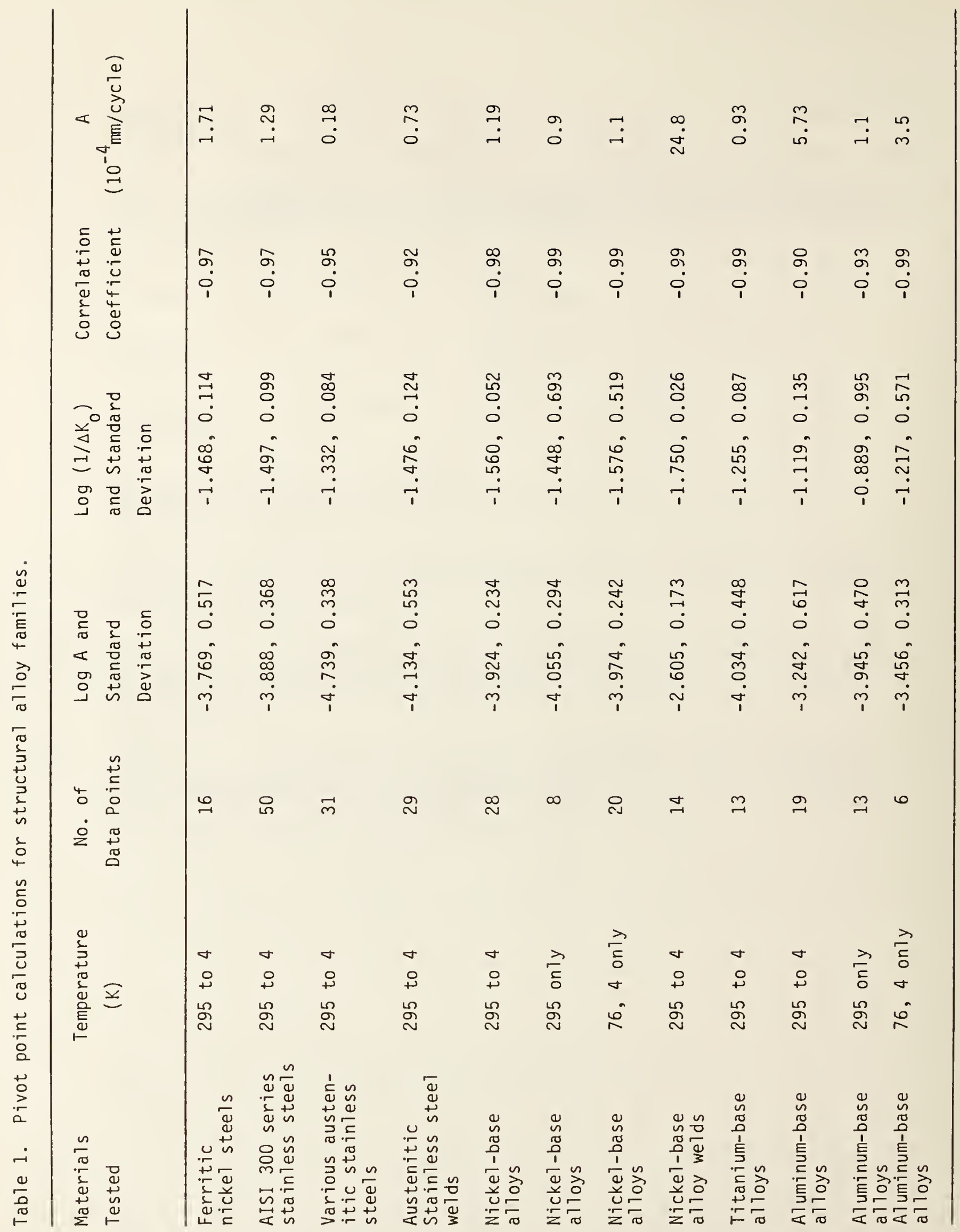




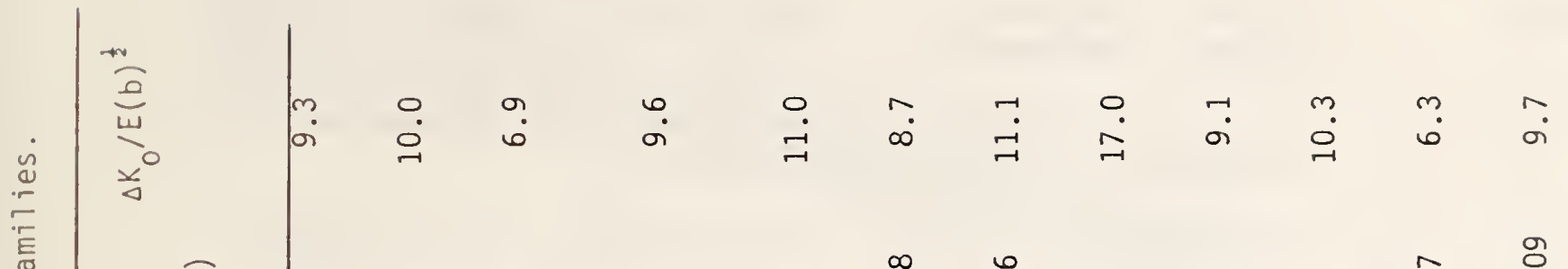

$$
\begin{aligned}
& \text { 崖震焉 }
\end{aligned}
$$

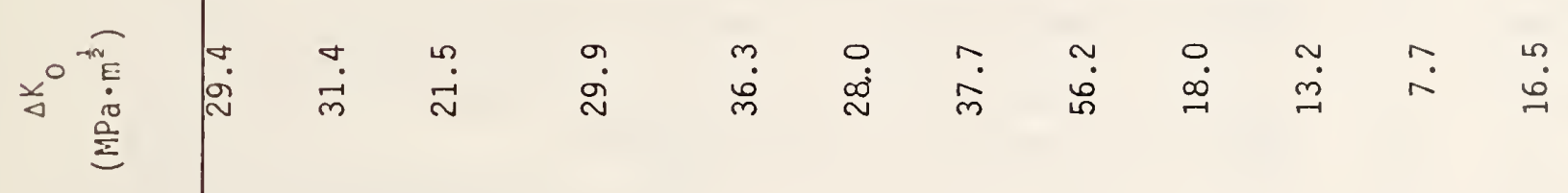

$$
\begin{aligned}
& \text { < }
\end{aligned}
$$

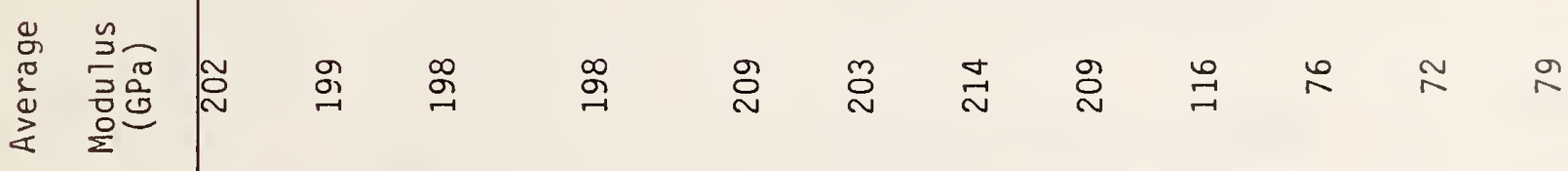

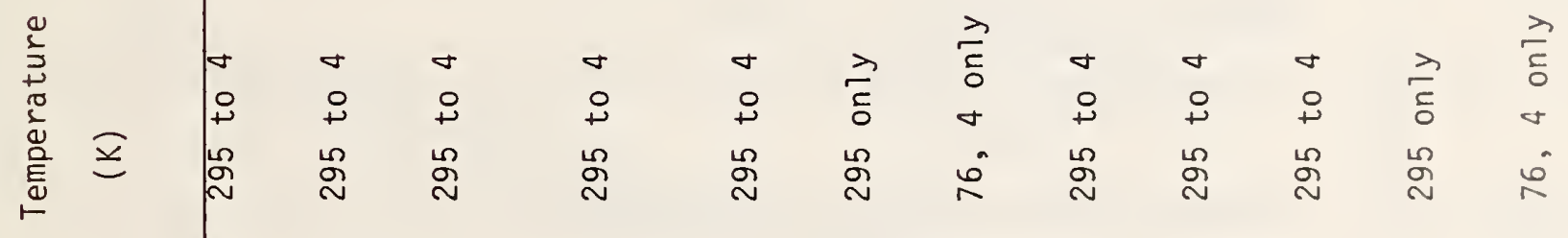

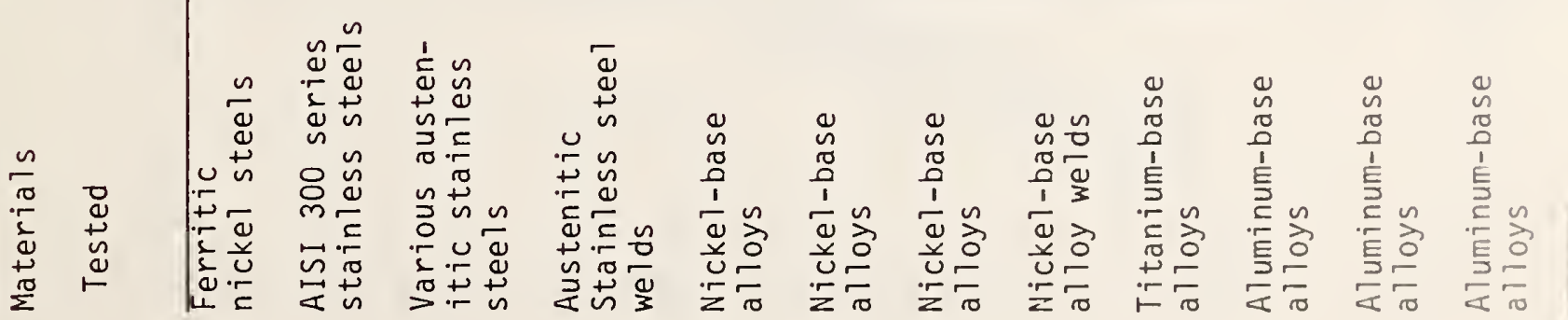


LIST OF FIGURES

Figure 1. Fatigue crack growth rate data trends for alloys at room and cryogenic temperatures.

Figure 2. Correlation of fatigue exponent $n$ with the conventional yield strength and fracture toughness.

Figure 3. Correlation of $n$ and $K_{I c}$ : various ferritic nickel steels.

Figure 4. Correlation of $n$ and $K_{I I}$ : various nitrogen-strengthened $\mathrm{Fe}-\mathrm{Cr}-\mathrm{Ni}-\mathrm{Mn}$ austenitic $\mathrm{Stainless}$ steels.

Figure 5. Effect of temperature on $\mathrm{n}$ and $\mathrm{K}_{\mathrm{Ic}}$ : $9 \% \mathrm{Ni}$ ferritic steel.

Figure 6. Effect of temperature on $n$ and $K_{I}$ : nitrogen-strengthened $\mathrm{Fe}-\mathrm{Cr}-\mathrm{Ni}-\mathrm{Mn}$ austenitic stainless $\mathrm{s}$ tee?

Figure 7. Effect of nickel content on fatigue exponent of ferritic steels at 295 and $76 \mathrm{~K}$.

Figure 8. Log C-vs.-n relationship for various steels (o $295 \mathrm{~K}, \Delta 76 \mathrm{~K}$, $\square 4 \mathrm{~K})$.

Figure 9. $\quad$ Log C-vs.-n relationship for three alloy systems having different elastic modul $i$ and comparison of several systems (o $295 \mathrm{~K}, \Delta 76 \mathrm{~K}, \mathrm{\square} 4 \mathrm{~K}$ ).

Figure 10. Fatigue failure mechanism in Fe-18Cr-3Ni-13Mn-0.37N austenitic stainless steel at $295 \mathrm{~K}$.

Figure 11. Fatigue failure mechanisms in Fe-18Cr-3Ni-13Mn-0.37N austenitic stainless steel at $4 \mathrm{~K}$.

Figure 12. Fatigue failure mechanism in AISI $304 \mathrm{~L}$ stainless steel at $295 \mathrm{~K}$.

Figure 13. Fatigue failure mechanism in AISI $304 \mathrm{~L}$ stainless steel at $4 \mathrm{~K}$. 


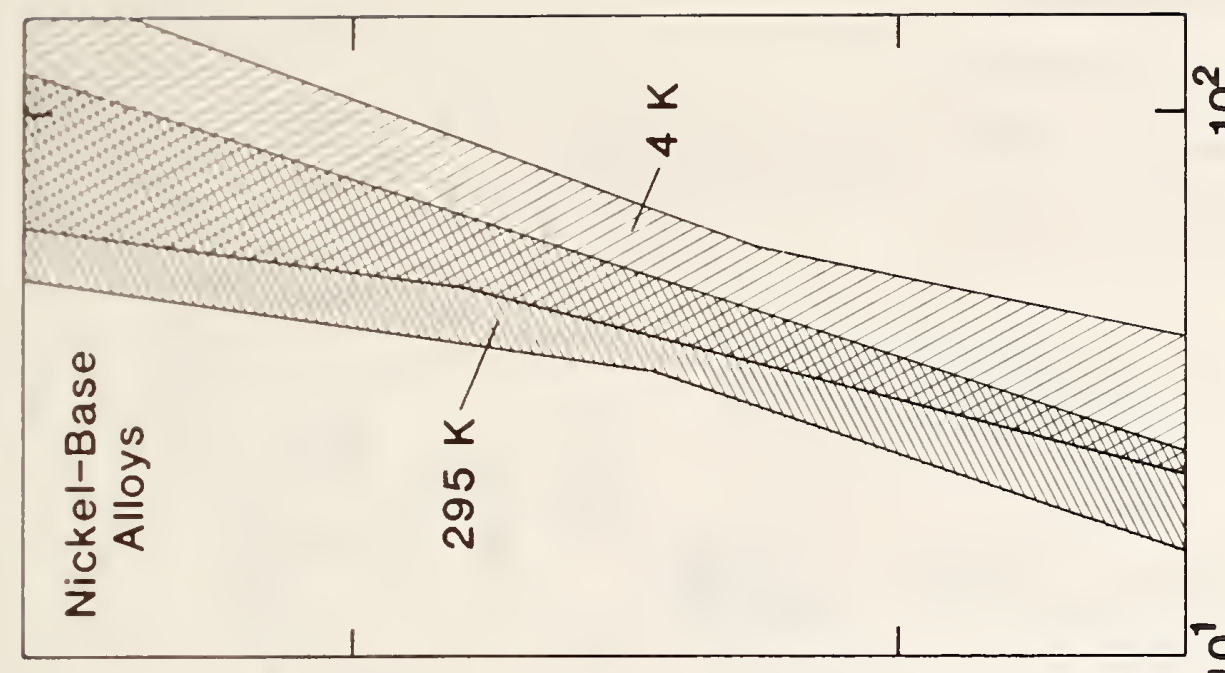

$-?$

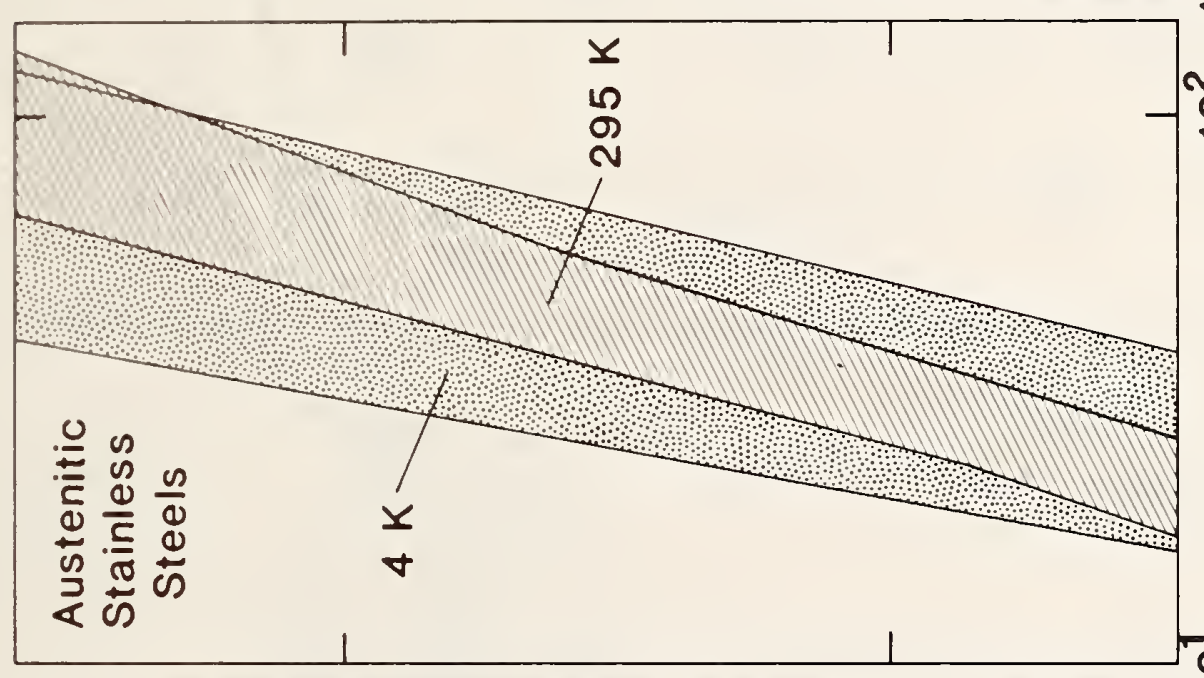

인

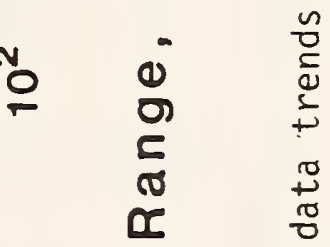

$\frac{1}{4}$

$0 \quad 2$ i

U ᄃ

(1)

L

\ $\quad$ 芩怘

$\infty$

을

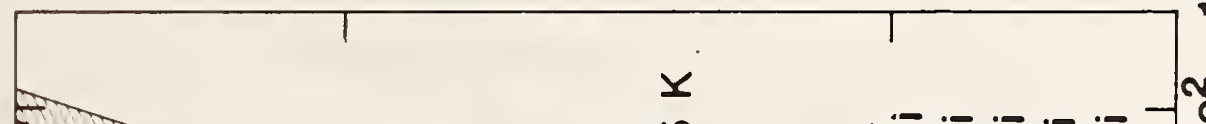

(1)

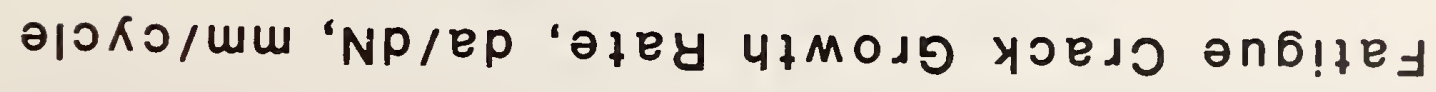




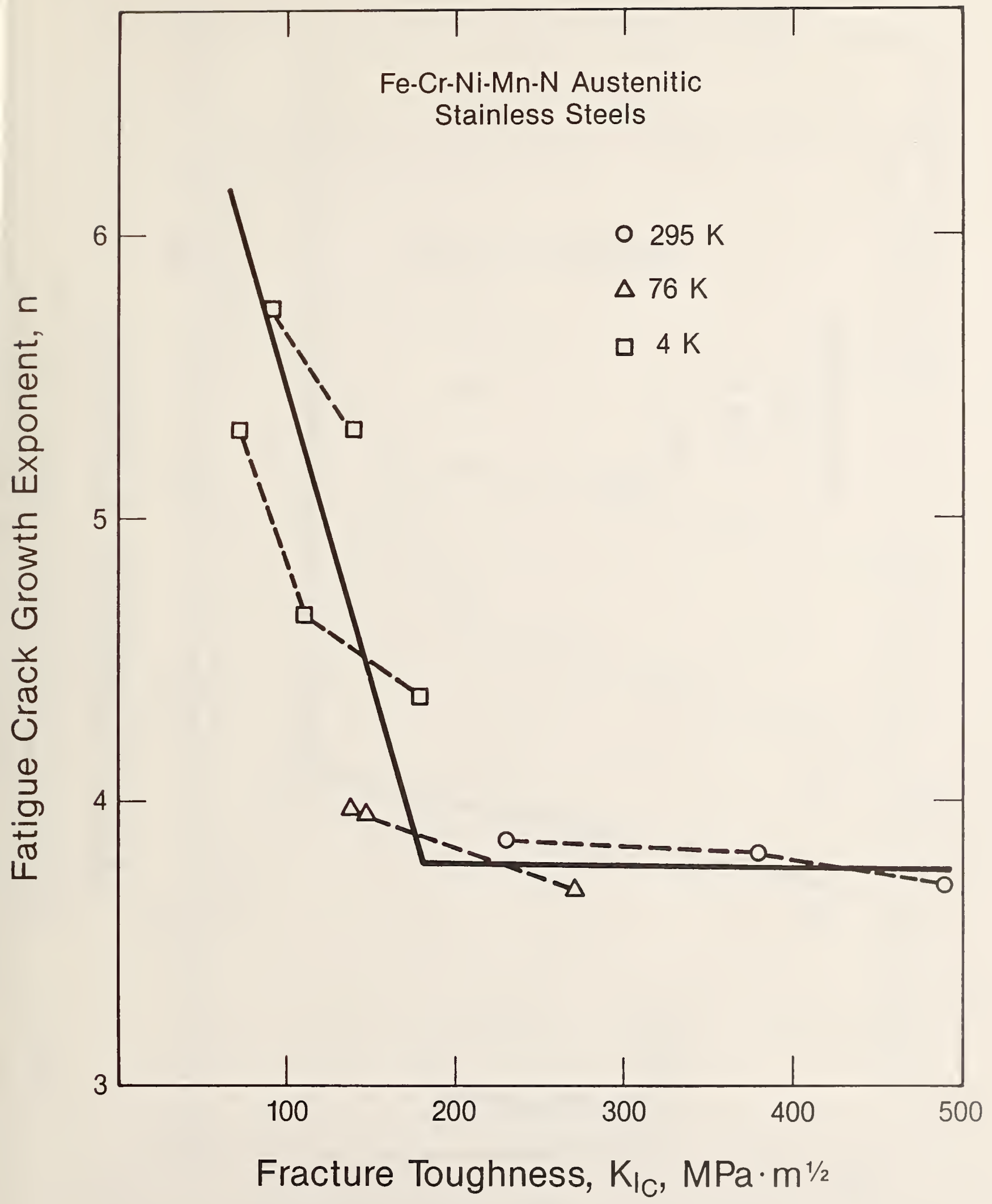

Figure 3. Correlation of $n$ and $K_{I c}$ : various ferritic nickel steels. 


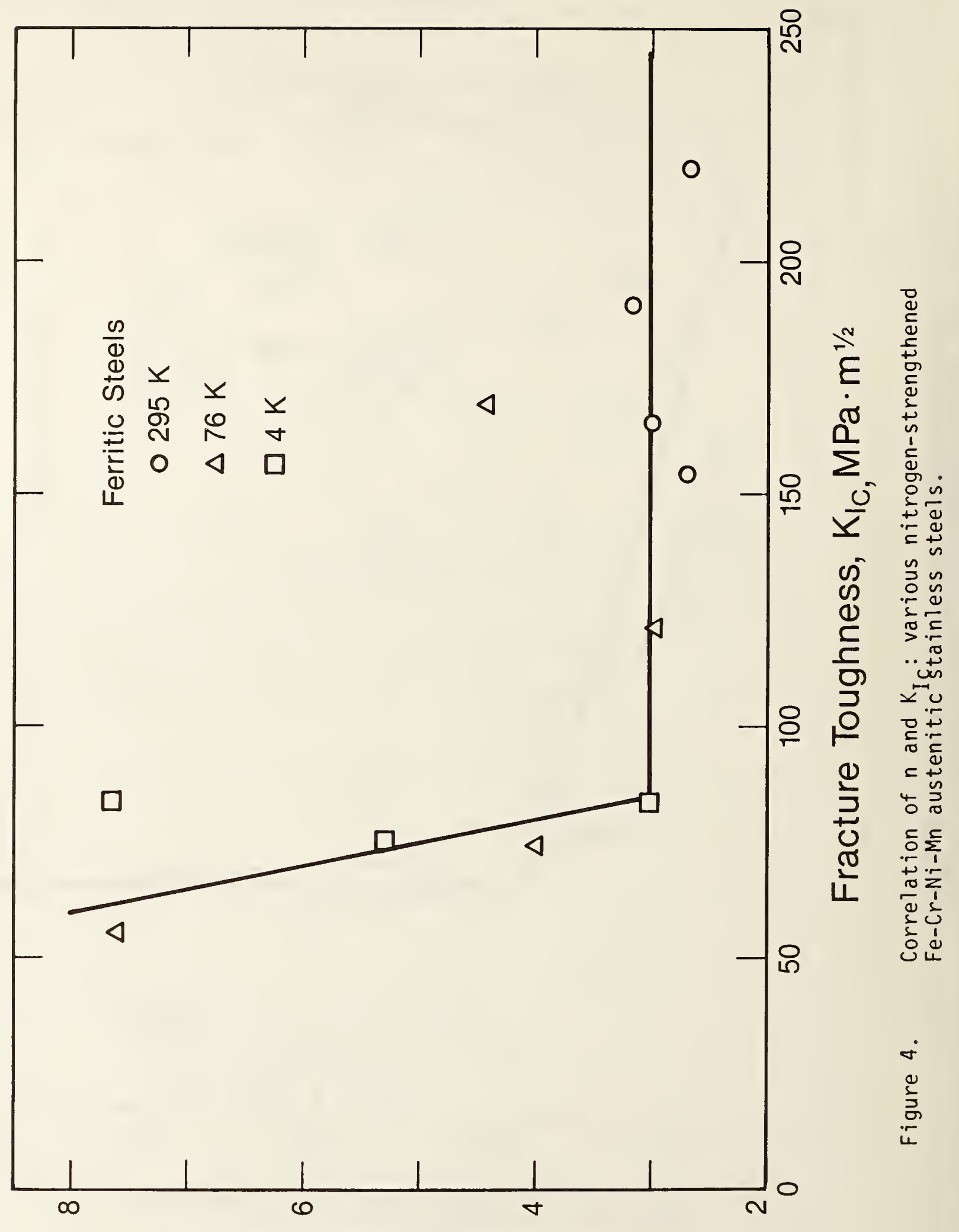

u 'fuəuodx 


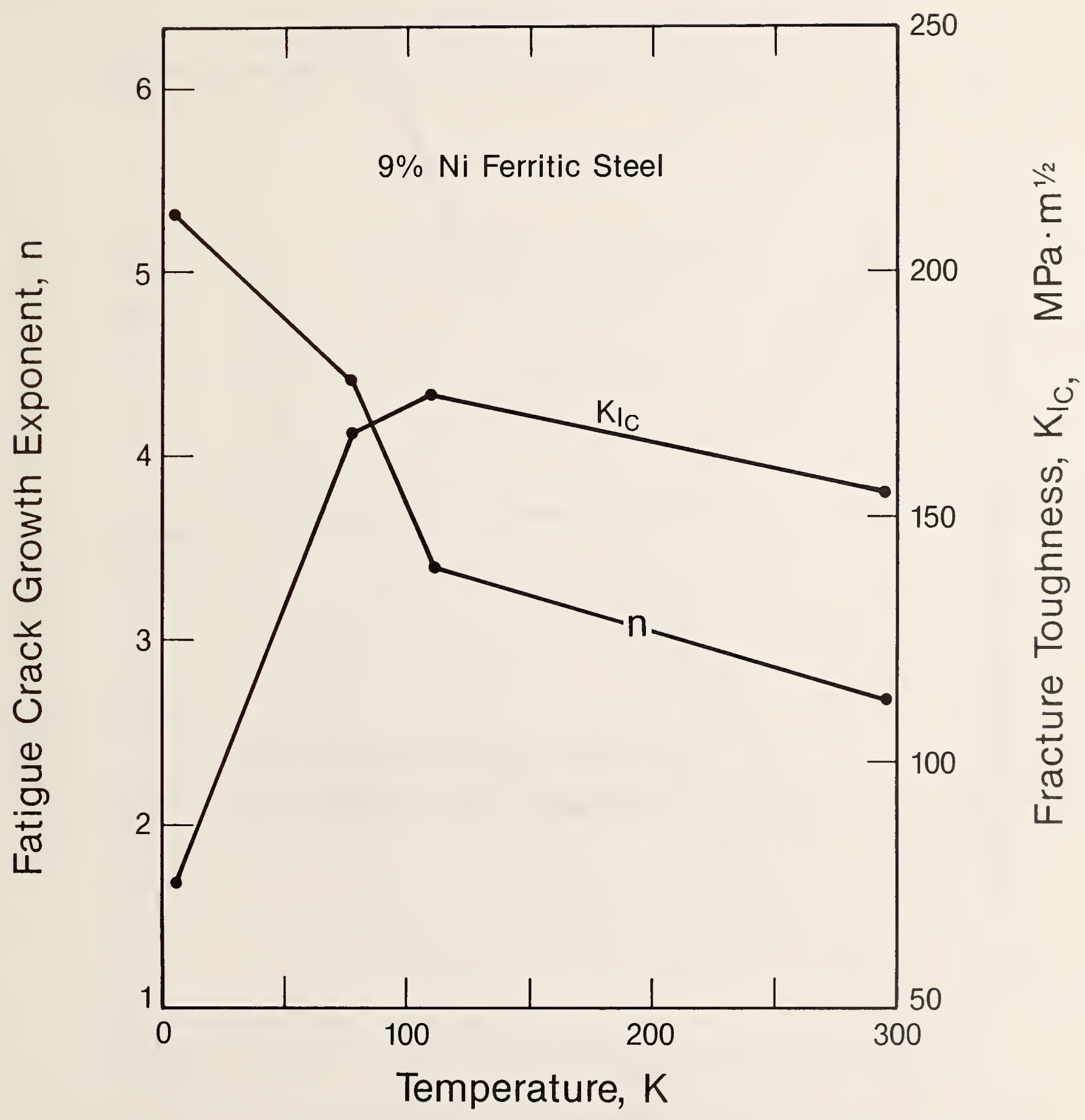

Figure 5. Effect of temperature on $n$ and $K_{I C}: 9 \% N i$ ferritic steel. 


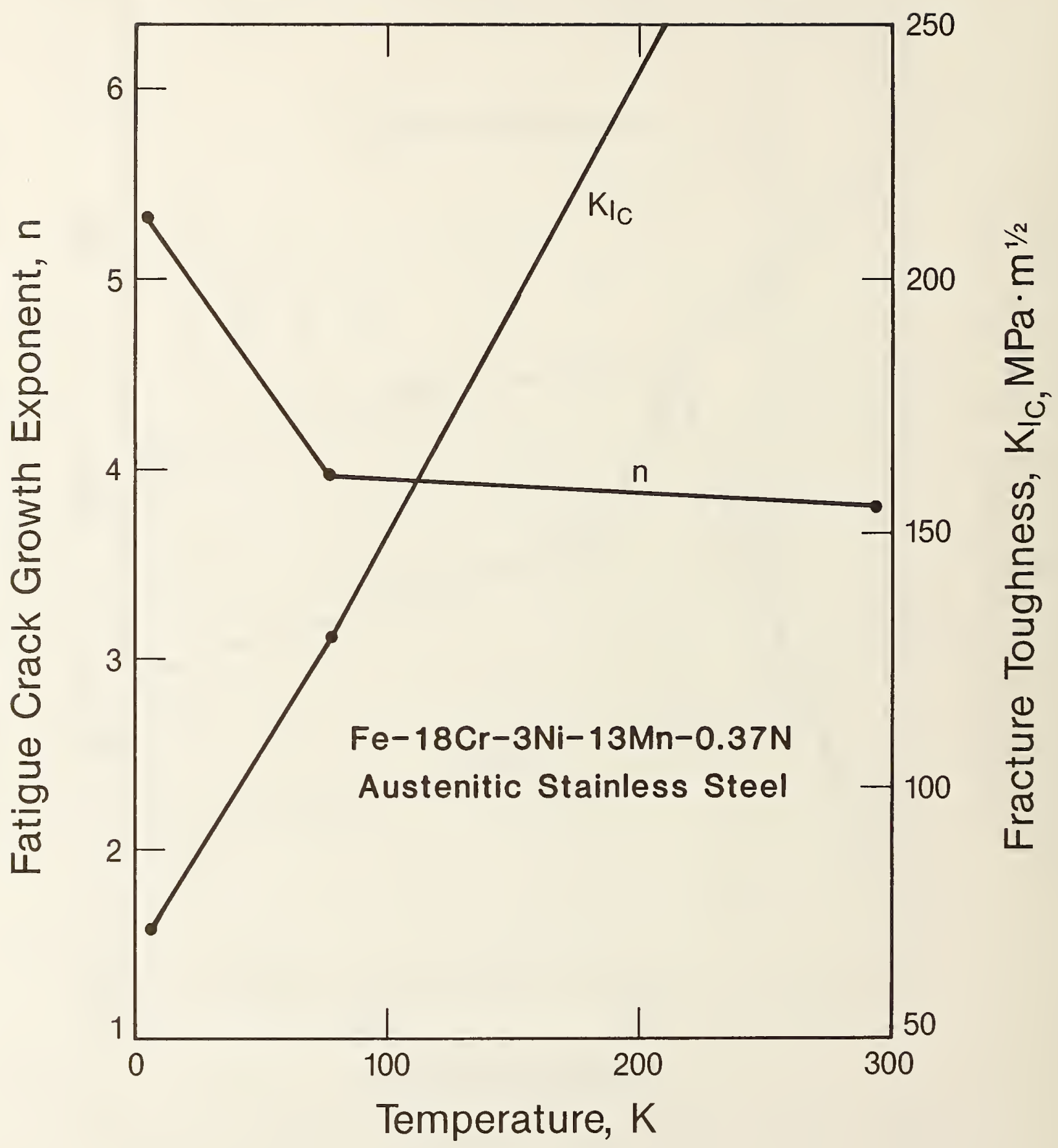

Figure 6. Effect of temperature on $n$ and $K_{1}$ : nitrogen-strengthened $\mathrm{Fe}-\mathrm{Cr}-\mathrm{Ni}-\mathrm{Mn}$ austenitic stainless $\mathrm{\xi teel}$. 


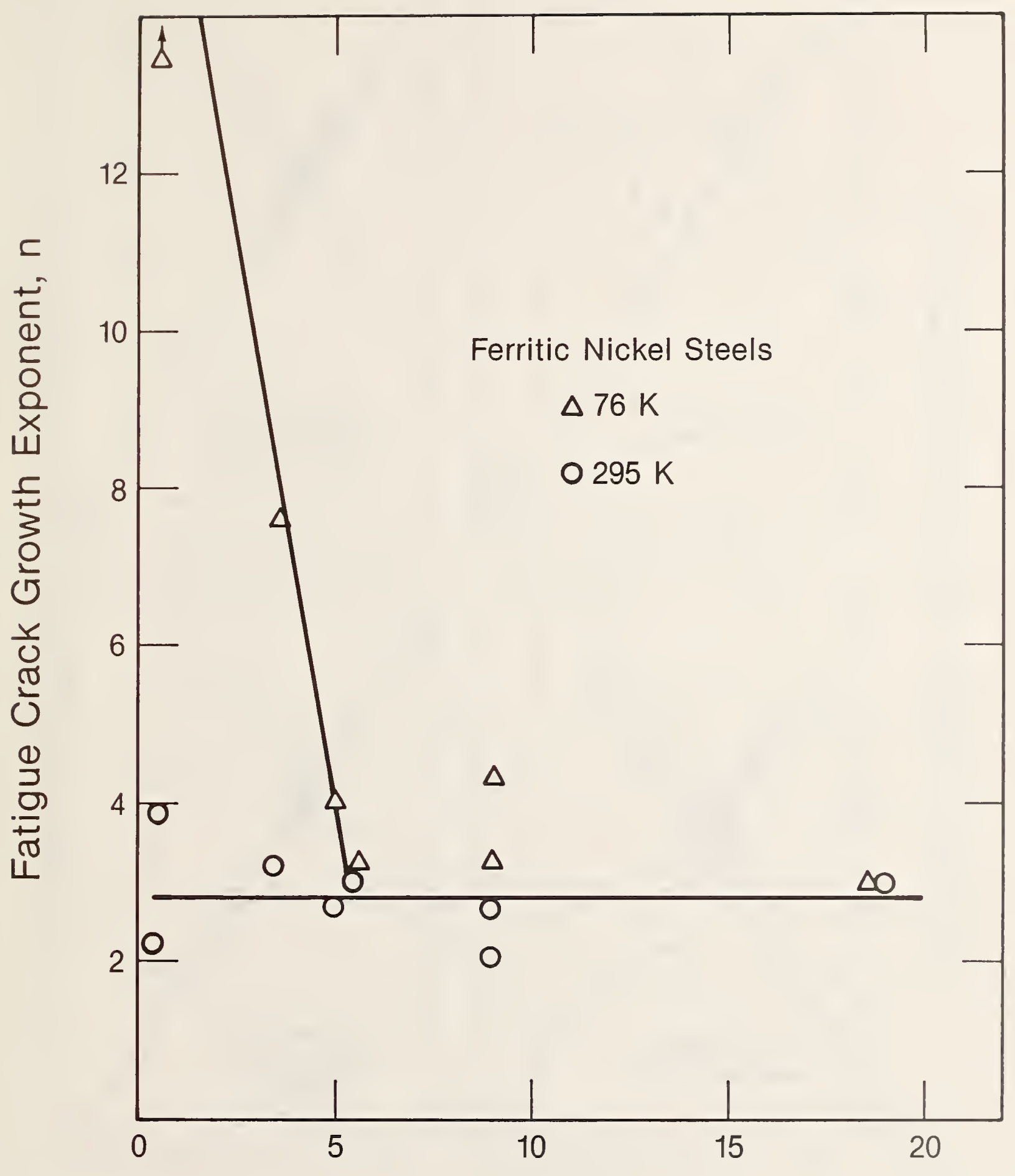

Nickel Content, wt. \%

Figure 7. Effect of nickel content on fatigue exponent of ferritic steels at 295 and $76 \mathrm{~K}$. 


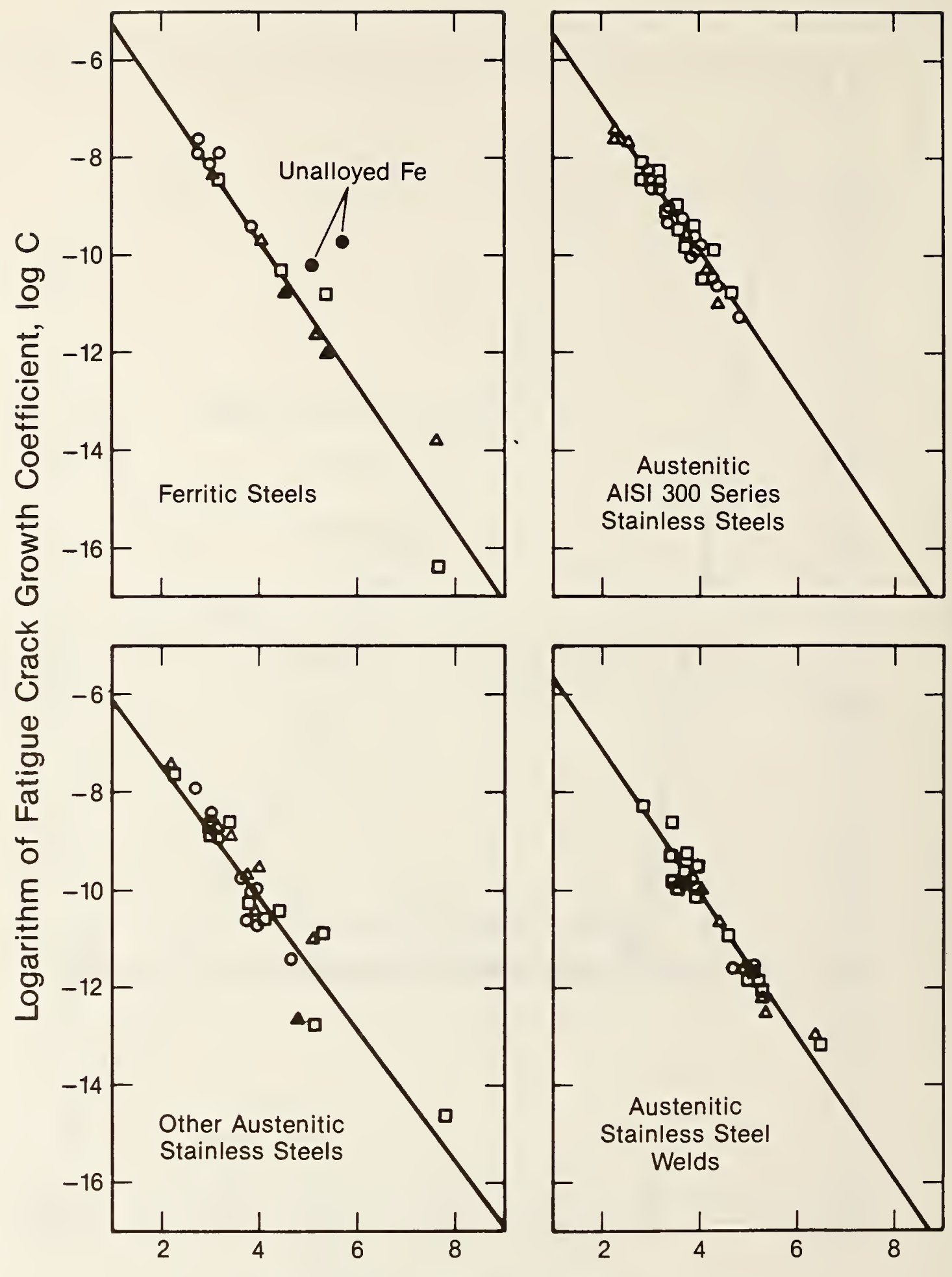

Fatigue Crack Growth Exponent, $\mathrm{n}$

Figure 8. $\quad$ Log C-vs. $-n$ relationship for various steels (o $295 \mathrm{~K}, \Delta 76 \mathrm{~K}$, 口 $4 \mathrm{~K})$. 

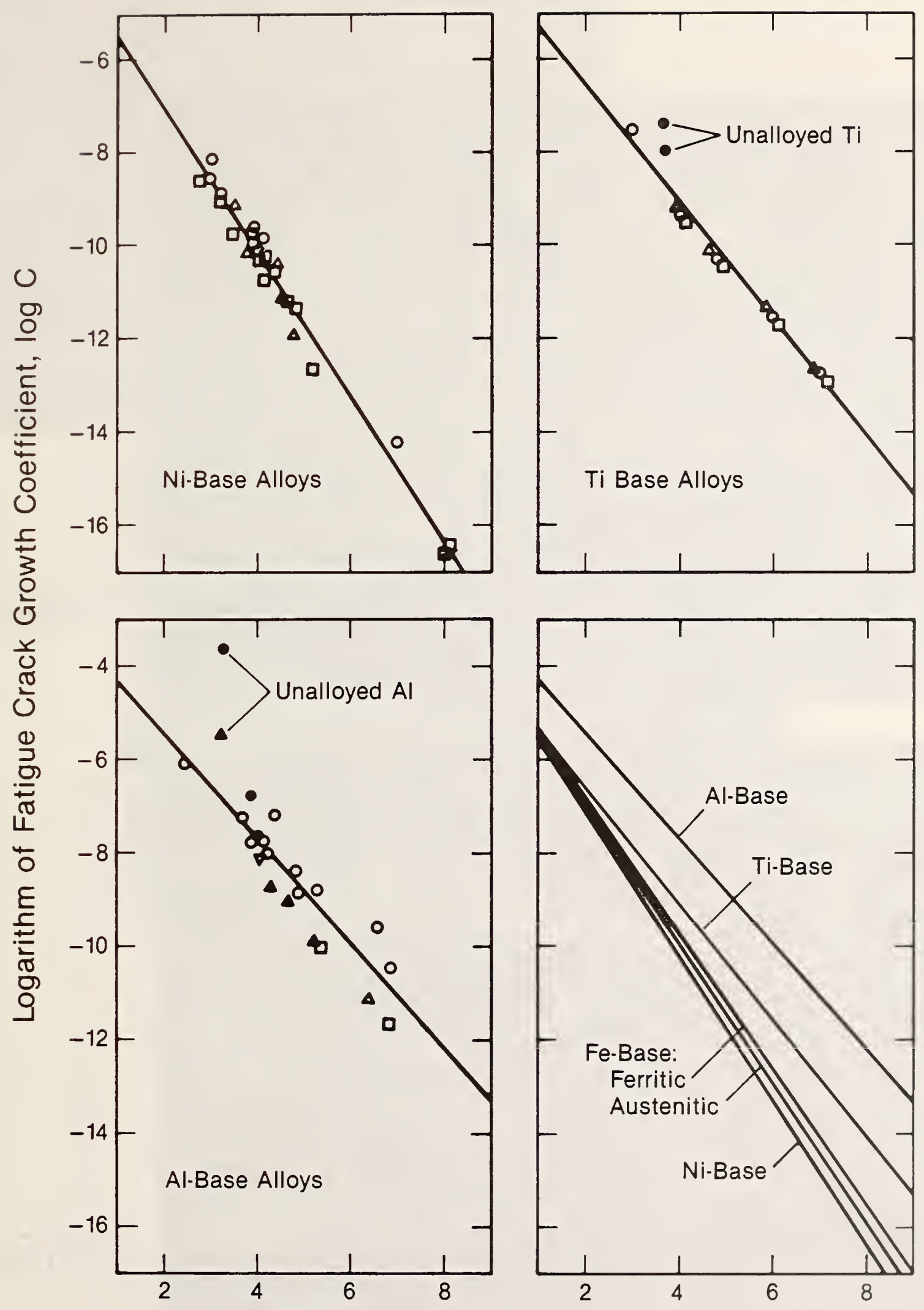

Fatigue Crack Growth Exponent, $n$

Figure 9. Log C-vs. - n relationship for three alloy systems having different elastic modul $i$ and comparison of several systems (० $295 \mathrm{~K}, \Delta 76 \mathrm{~K}$, 口 $4 \mathrm{~K}$ ). 


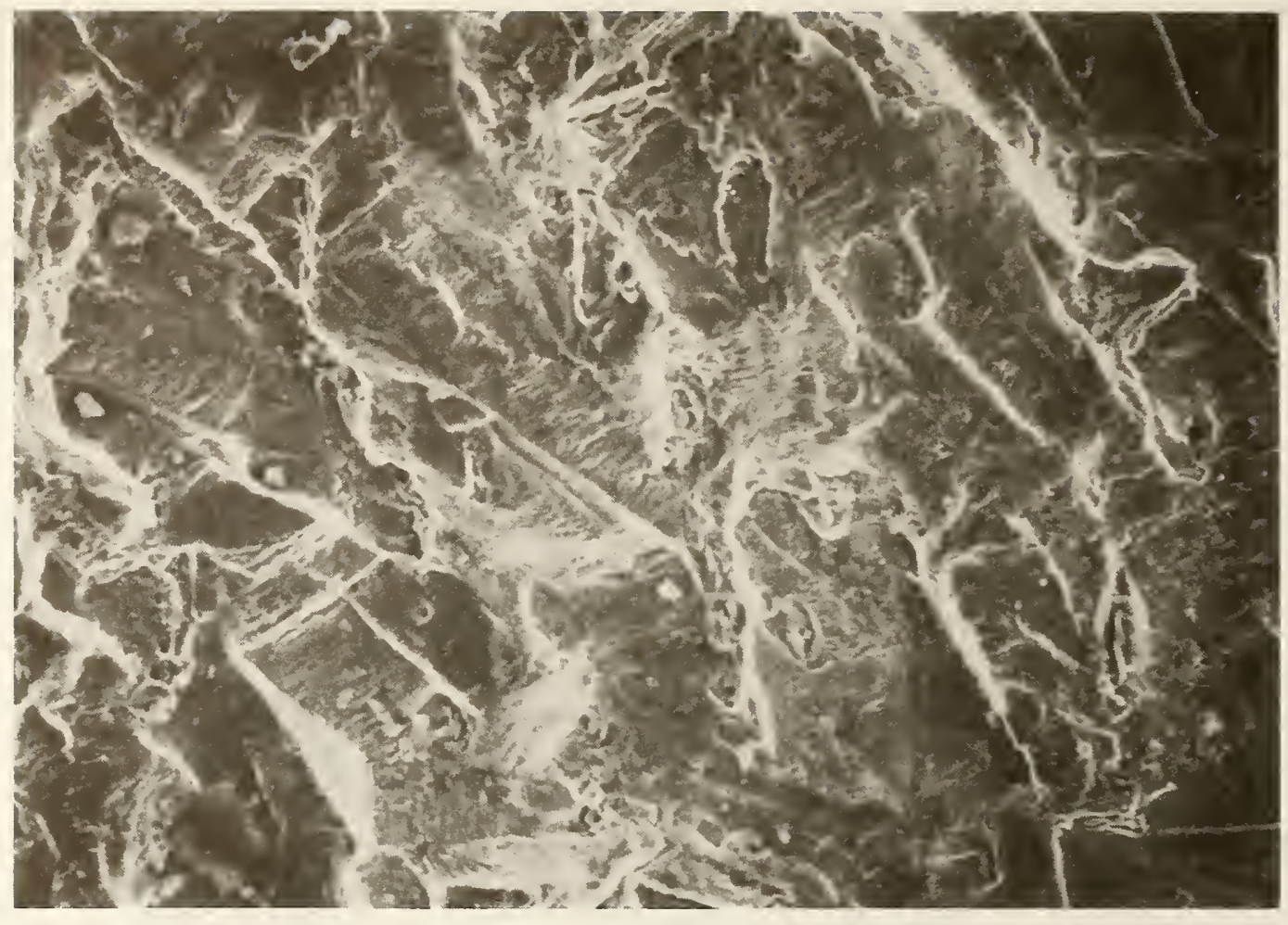

\section{A}

\section{$100 \mu \mathrm{m}$}

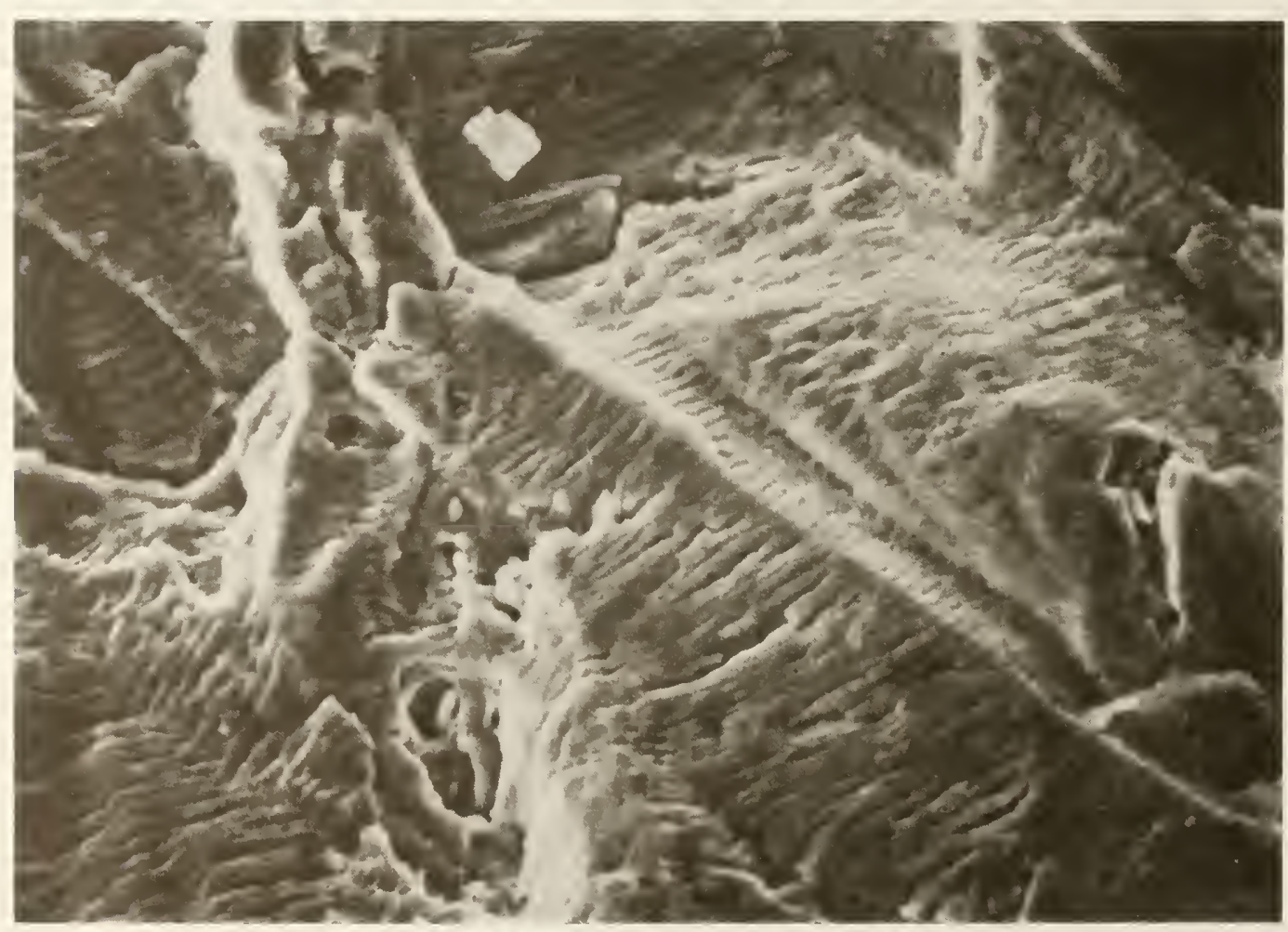

\section{B}

$30 \mu \mathrm{m}$

Figure 10. Fatigue failure mechanism in Fe-18Cr-3Ni-13Mn-0.37N austenitic stainless steel at $295 \mathrm{~K}$. 


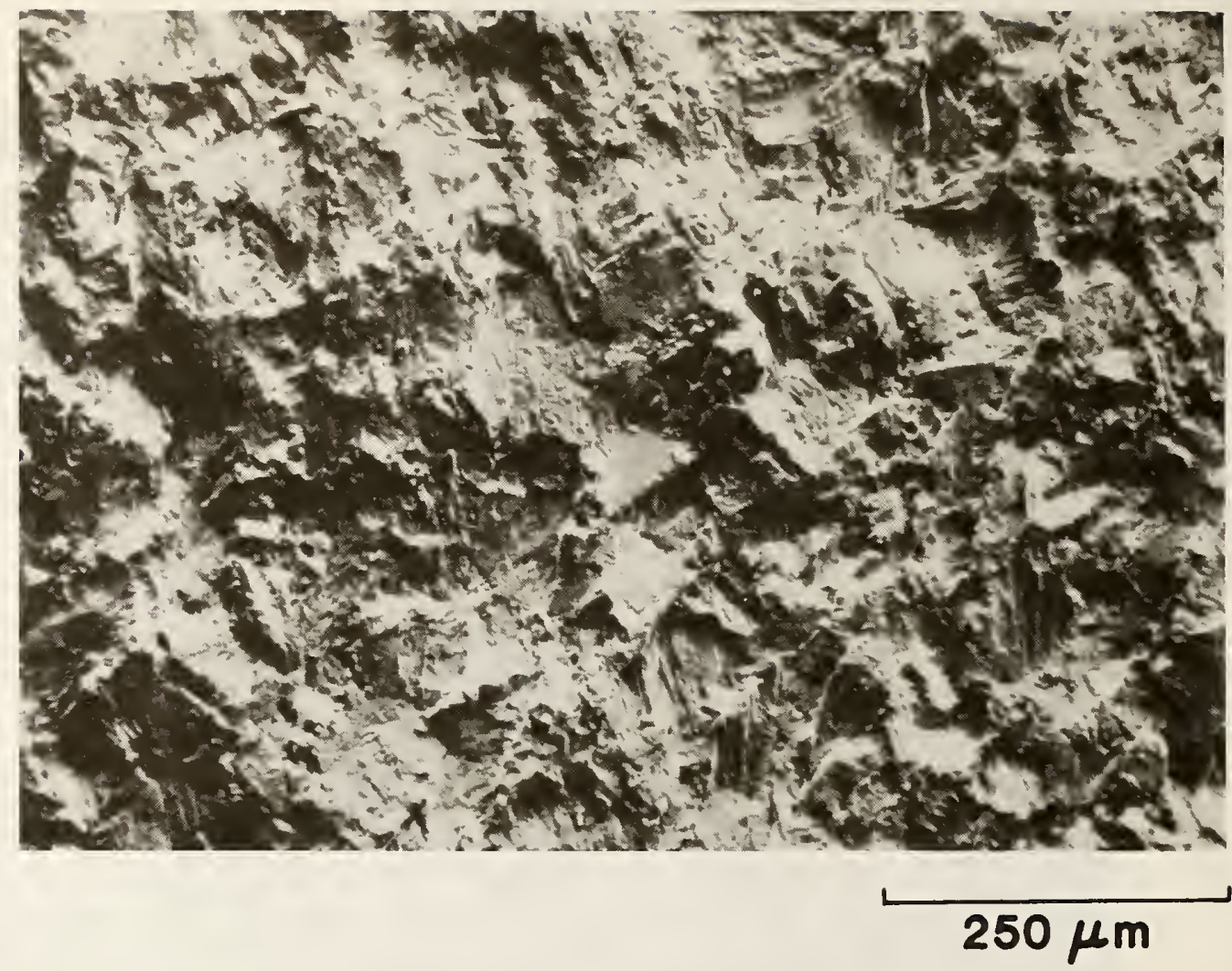




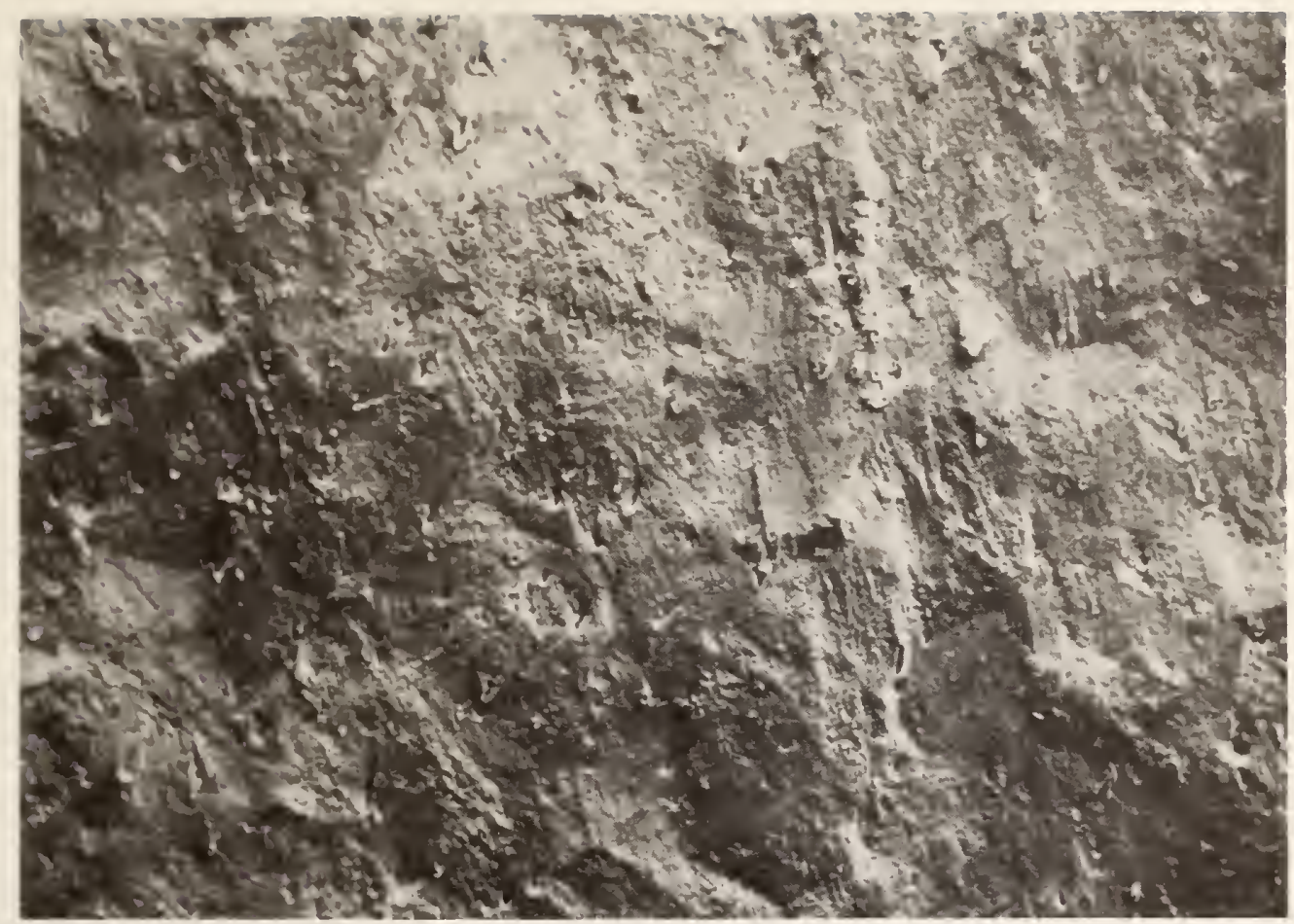

\section{$250 \mu \mathrm{m}$}

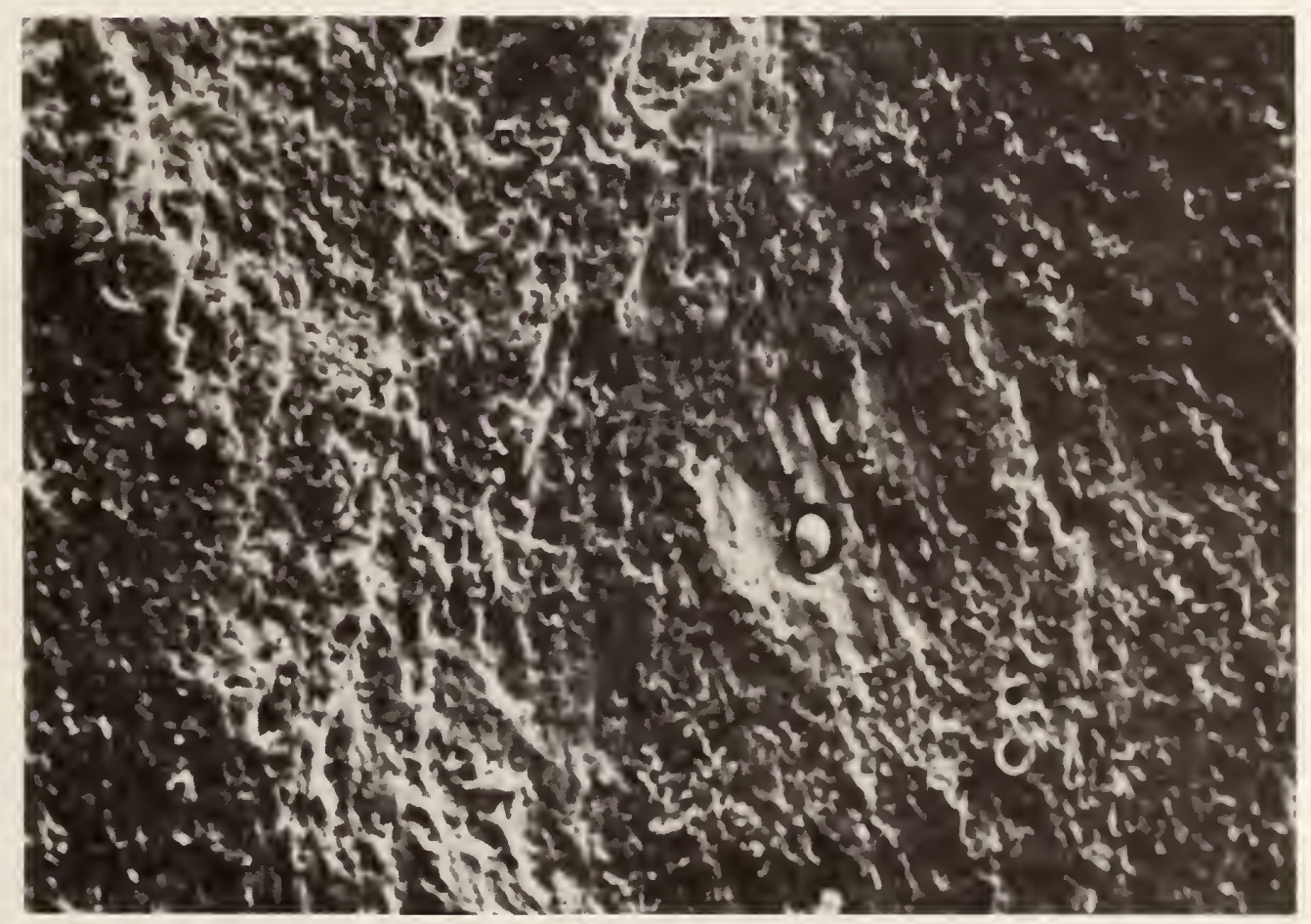

$50 \mu \mathrm{m}$

Figure 13. Fatigue failure mechanism in AISI $304 \mathrm{~L}$ stainless steel at $4 \mathrm{~K}$. 



\title{
AN AUTOMATED FATIGUE CRACK GROWTH RATE TEST SYSTEM*+
}

\author{
Yi-Wen Cheng \\ David T. Read \\ Fracture and Deformation Division \\ National Bureau of Standards \\ Boulder, Colorado
}

\begin{abstract}
An automated fatigue crack growth rate (FCGR) test system has been developed that can be used for tests of constant-load-amplitude FCGR above $10^{-8} \mathrm{~m} / \mathrm{cycle}$ (ASTM E647-83) at normal $(\sim 10 \mathrm{~Hz})$ or low $(\sim 0.1 \mathrm{~Hz})$ cyclic frequencies and for tests of near-threshold and variable-load-amplitude FCGR. The test system consists of a minicomputer, a programmable arbitrary waveform generator, a servohydraulic test frame, and a programmable digital osci110scope. The crack length is measured using the compliance technique; the FCGR and the stress intensity range are calculated and plotted automatically during the test.
\end{abstract}

Key Words: automated test system; compliance technique; fatigue crack growth rate; fatigue of materials; near-threshold fatigue test; variable-load-amplitude fatigue test.

*Contribution of NBS; not subject to copyright.

+ Submitted for inclusion in the Proceedings of Symposium on Automated Test Methods for Fracture and Fatigue Crack Growth, November 7-8, 1983, Pittsburgh, Pennsylvania. 



\section{INTRODUCTION}

Fatigue crack growth rate (FCGR) data can be used for material characterization and for fracture mechanics reliability analysis of structures subjected to cyclic loading. A standard test method for measuring FCGR above $10^{-8}$ $\mathrm{m} /$ cycle under constant amplitude loading has been developed and published in the 1983 Annual Book of ASTM Standards under the designation ASTM E647-83. ${ }^{1}$

With the increased interest in the near-threshold FCGR ${ }^{2,3}$ and FCGR under environmental influence at low cyclic frequencies, 4 more FCGR measurements are being made, and they can be tedious and time-consuming. An automated FCGR test system, such as that described in this paper, allows testing to proceed, data to be taken, and load range to be altered in the absence of an operator.

There are four advantages of using an automated test system to measure FCGR. ${ }^{5}$ First, it minimizes the testing time and operator attention. Second, it reduces the data scatter. Third, because the testing is interactive and automatic in nature, its procedure is relatively easy to follow and it requires minimal operator training. Fourth, it eliminates subjective interpretation and influence of the experimenter.

\section{THE FCGR TEST METHOD}

The sequence of the FCGR test is: first, obtain the raw data, namely, fatigue crack length, a, versus elapsed fatigue cycles, $N$; then, reduce a and $N$ data to a plot of $d a / d N$ versus $\Delta K$, where da/dN is the FCGR in mm/cycle and $\Delta K$ is the crack-tip stress-intensity range in $\mathrm{MPa} \cdot \mathrm{m}^{1 / 2}$. Typical outputs are presented in Figure 1 .

The number of elapsed fatigue cycles can be obtained from counters (electronic or mechanical) or conversion from time elapsed at the given frequency. The methods of crack length measurement are complicated and have been a subject of extensive study. 6,7 Although several methods of crack 
length measurement have been developed, some require specialized equipment not commonly available in mechanical testing laboratories. The compliance technique, however, requires only monitoring of the load cell and the clip gage outputs, which is routinely achieved in mechanical testing. Compliance is defined as the specimen deflection per unit load, which is a function of crack length. The load and deflection signals (voltages) can be interfaced to a computer. Because of the simple instrumentation and the need in our laboratory for environmental chambers for cryogenic temperature and saltwater corrosion-fatigue tests, the compliance technique was chosen to measure the crack length.

\section{EQUIPMENT OF THE AUTOMATED FCGR TEST SYSTEM}

A schematic of the automated FCGR test system is shown in Figure 2. Figure 2 also shows the sequence of operation and interaction between various components. The test system consists of a closed-loop servo-controlled hydraulic mechanical testing machine, a programmable digital oscilloscope, a programmable arbitrary waveform generator, and a minicomputer.

The machine control unit, which is included in the hydraulic mechanical test machine, includes a servo-control system, a feedback system, two dc conditioners, and a valve drive. A nonprogrammable function generator with an electronic pulse counter is usually built into the machine control unit of a commercially available mechanical testing machine. Signal amplifiers and a load cell are also included in the mechanical testing machine.

The programmable digital oscilloscope contains two 15-bit 100-kHz digitizers and it serves as an analog-to-digital (A/D) converter. In addition to its high speed $A / D$ conversion rate, this oscilloscope features the ability to instantaneously freeze and hold data in memory. The problems encountered with slower $A / D$ converters, such as interruptions during the test ${ }^{5}$ and low test frequencies ${ }^{8}$ are eliminated because of the high $A / D$ conversion rate and the 
freeze-and-hold ability of this oscilloscope. For the near-threshold and the variable-load-amplitude FCGR tests, load levels vary with time and a programmable function generator is needed. For these tests, the programmable arbitrary waveform generator is used. The present programmable waveform generator is not connected to any cycle-counting device and the fatigue cycle counts are inferred from the cyclic frequency and the time elapsed, as given by the computer. For the constant-load-amplitude FCGR test, the built-in function generator is used.

Included in the minicomputer are a cathode-ray-tube (CRT) terminal, a line printer, a dual floppy disk storage unit, and a digital plotter. The minicomputer uses the 16-bit word and has $128 \mathrm{~K}$ words of memory. The minicomputer al so contains an internal clock that reads to $1 / 60 \mathrm{~s}$. The IEEE-488/GPIB is used for the interface between the computer and the programmable digital oscilloscope and between the computer and the programmable arbitrary waveform generator.

\section{APPLICATIONS}

In the following discussion, attention is focused on how the test system described above is used to conduct the FCGR tests. Requirements on grips, fixtures, specimen design, and specimen preparation are detailed in various standards ${ }^{1,4,9}$ and are not discussed in this paper. Constant-Load-Amplitude FCGR Test

The test system described in the previous section can be programmed to run the constant-load-amplitude FCGR test. The operational details, implementing the procedures set forth by ASTM E647-83, ${ }^{1}$ are described in this section.

As shown in Figure 3 , the input parameters are fed into the computer through the CRT terminal using an interactive operation between the operator and the computer. The input parameters include specimen identification, 
specimen dimensions, Young's modulus, selected time interval for measuring crack length, minimum load level for compliance measurement, load levels, and test frequency. The time interval for measuring crack length must be kept to a value small enough that every increment of crack growth will not exceed the recommended value as prescribed in the standards. ${ }^{1}$ The minimum load level for compliance measurement is used to eliminate the possible crack closure effects, ${ }^{10}$ which have a significant effect on the accuracy of crack length measurement.

The precracked specimen is fatigue cycled under the prescribed loading conditions and cyclic frequency. The typical frequency is $10 \mathrm{~Hz}$. When the preselected time interval for crack length measurement is reached, the computer requests the load-versus-deflection data from the programmable digital.oscilloscope, which freezes the load-deflection data in the memory instantaneously, and correlates the data to a straight line using a linear least-squares fit. The portion of the load-versus-deflection curve used for compliance calculation is from the specified minimum load level to a value corresponding to 95 percent of the maximum load. The reason for excluding the upper 5 percent of the load for calculation is that the clip gage tends to vibrate, and noise in the clip-gage signal increases at the maximum load during the high-frequency test. A linear correlation coefficient of 0.999 or better is usually obtained. From the resulting compliance, the instantaneous crack length is computed using the appropriate expression for the compliance calibration of the specimen. ${ }^{11}$ The precision of the crack length measurement is typically within $0.04 \mathrm{~mm}$.

The increment of crack growth (the difference between the current measured crack length and the last recorded crack length) is checked against the recommended values. ${ }^{1}$ If the increment of crack growth is larger than the minimum recommended values, the computer calculates $N, \frac{1}{4} K$, and $d a / d N$; the 
digital plotter plots the data points $(a, N)$ and $(d a / d N, \Delta K)$ on the a-versus-N and on the $d a / d N$-versus- $\Delta K$ graphs, such as shown in Figure 1; the 1ine printer prints the value of calculated compliance, the linear least-squares correlation coefficient, a, $N$, da/dN, and $\Delta K$ results. All the resulting data are stored on the floppy disk for the post-test analyses.

During the test, the point-to-point data reduction technique is used to calculate $\Delta K$ and $d a / d N$ from a and $N$. Usually the results are consistent with minimum scatter, as those shown in Figure 1. If the results of $\Delta K$ versus $\mathrm{da} / \mathrm{dN}$ scatter, the seven-point incremental polynomial method is used to smooth the results after the test is completed.

The computer programs for post-test analyses include the following capabilities:

1. Reducing a-versus $-N$ data to $\Delta K-$ versus-da/dN by the seven-point incremental polynomial method;

2. Converting units;

3. Plotting data in desired units;

4. Plotting data in desired coordinate ranges;

5. Plotting data of several different specimens on one graph (for comparison);

6. Calculating the materials constants $C$ and $n$ in the Paris equation, 12 $\mathrm{da} / \mathrm{dN}=\mathrm{C}(\Delta K)^{n}$, and drawing the regression line through the data.

The computer programs, including the data acquisition routines, were written in the PDP-11 Fortran language.

Near-Threshold FCGR Test

The computer programs used in the constant-load-amplitude FCGR test, with some modifications, can be used for near-threshold FCGR tests. The major difference in procedures between the two tests is that the load levels in the near-threshold FCGR test decrease according to the initial $\triangle K$ value (in the 
K-decreasing test technique). The load levels are calculated from the following equations: ${ }^{9}$

$$
\begin{aligned}
& \Delta K=\Delta K_{0} \exp \left[C^{\prime}\left(a-a_{0}\right)\right] \\
& \Delta P \quad=B W^{1 / 2} \Delta K / f(a / W) \text { for compact-type specimen } \\
& \Delta P \quad=B \Delta K / f(a / W) \quad \text { for center-cracked-tension specimen } \\
& P_{\max }=\Delta p /(1-R) ; P_{\min }=P_{\max } R
\end{aligned}
$$

where $P_{\max }=$ maximum load

$$
P_{\text {min }}=\text { minimum load }
$$$$
R=P_{\min } / P_{\max }
$$

$B=$ specimen thickness

$W \quad=$ specimen width

$\mathrm{a}=$ the current crack length

$a_{0}=$ the crack length at the beginning of the test

$f(a / W)=$ function of $(a / W)$ dependent upon specimen geometry

$\Delta K=$ current crack-tip stress-intensity range

$\Delta K_{0}=$ crack-tip stress-intensity range at the beginning of the test

$C^{\prime}=$ negative constant

The flow chart of the automated near-threshold FCGR test is summarized in Figure 4. After each crack length measurement, the crack length is compared with the last measured crack length to ensure that the minimum increment of crack growth has occurred. If this is not done, then some unnecessary load level adjustments will take place because of scatter in the crack length measurement. After the crack length has increased a certain amount (for example, $0.13 \mathrm{~mm}$ ), the new $\Delta K$ is calculated according to equation (1). The load levels are then adjusted using equations (2), (3), and (4).

In high-frequency fatigue testing, which is desirable in the near-threshold FCGR test, hydraulic lag is a problem. This results in the specimen not being 
actually subjected to the load range commanded by the computer (or waveform generator). This problem is overcome by overprogramming the load range command using the trial-and-error method. During the overprogramming process, the computer monitors the values of $P_{\max }$ and $P_{\min }$ through the programmable digital oscilloscope and makes necessary changes to achieve the desired values of $P_{\max }$ and $P_{\min }$. The overprogramming is done whenever there is a change in load range.

If the measured crack-growth increment, which is the difference between the current measured crack length and the last recorded crack length, is larger than the minimum recommended values, ${ }^{8}$ the values of $N, \frac{1}{4} \mathrm{~K}$, and $\mathrm{da} / \mathrm{dN}$ are calculated and the results are printed, plotted, and stored. The previously mentioned computer programs for post-test analyses are also applicable for analyzing the data obtained in the near-threshold FCGR test. Variable-Load-Amplitude FCGR Test

The automated FCGR test system is also used in the variable-load-amplitude FCGR test. The procedures used in this application are similar to those described in the previous two sections.

The computer reads the prerecorded load-time history from the floppy disks and controls the hydraulic machine through the programmable waveform generator. At a preselected time interval, the crack length is measured. The desired output in the variable-load-amplitude FCGR test is time versus crack length. The results are printed, plotted, and stored for post-test analyses.

The present system has several limitations in the application of variableload-amplitude FCGR testing. The major one is that the waveform generator needs about $0.1 \mathrm{~s}$ for changing one command to another, and this limits the average frequency to about $1 \mathrm{~Hz}$. 


\section{SUMMARY}

An automated FCGR test system has been developed that can be used for tests of constant-1oad-amplitude FCGR above $10^{-8} \mathrm{~m} /$ cycle (ASTM E647-83), near-threshold FCGR, and variable-load-amplitude FCGR. The test system offers considerable time savings in data acquisition and in data reduction. The test procedure is relatively easy to follow and enables technicians to produce data with less scatter (with respect to the non-computer-aided technique), because no manual data interpretation or data fitting is done.

\section{ACKNOWLEDGMENTS}

Mr. J. C. Moulder of NBS is acknowledged for helpful discussions on the interface between the computer and the instruments. The work is supported by the Department of Interior, Minerals Management Service, and the Department of Energy, Office of Fusion Energy.

\section{REFERENCES}

1. "Standard Test Method for Constant-Load-Amplitude Fatigue Crack Growth Rates above $10^{-8} \mathrm{~m} / \mathrm{cycle}$ " (Designation E647-83), in:1983 Annual Book of ASTM Standards, section 3, Vol. 03.01, American Society for Testing and Materials, Philadelphia, Pennsylvania (1983), pp. 710-730.

2. Fatigue Thresholds: Fundamentals and Engineering Applications, J. Backlund, A. F. Blour, and C. J. Beevers, eds., Engineering Materials Advisory Services, Chameleon Press, London, United Kingdom (1982).

3. R. J. Bucci, "Development of a Proposed ASTM Standard Test Method for Near-Threshold Fatigue Crack Growth Rate Measurement," in: Fatigue Crack Growth Measurement and Data Analysis, ASTM STP 738, S. J. Hudak, Jr. and R. J. Bucci, eds., American Society for Testing and Materials, Philadelphia, Pennsylvania (1981), pp. 5-28.

4. T. W. Crooker, F. D. Bogar, and G. R. Yoder, "Standard Method of Test for Constant-Load-Amplitude Fatigue Crack Growth Rates in Marine Environments," NRL Memorandum Report 4594 (August 6, 1981).

5. Y.-W. Cheng, "A Computer-Interactive Fatigue Crack Growth Rate Test Procedure," in: Materials Studies for Magnetic Fusion Energy Applications at Low Temperatures-VI, R. P. Reed and N. J. Simon, eds., NBSIR 83-1690, National Bureau of Standards, Boulder, Colorado (1983), pp. 41-51. 
6. The Measurement of Crack Length and Shape During Fracture and Fatigue, $C$. J. Beevers, ed., Engineering Materials Advisory Services, Chameleon Press, London, United Kingdom (1980).

7. Advances in Crack Length Measurement, C. J. Beevers, ed., Engineering Materials Advisory Services, Chameleon Press, London, United Kingdom (1981).

8. J. J. Ruschau, "Fatigue Crack Growth Rate Data Acquisition System for Linear and Nonlinear Fracture Mechanics Applications, "Journal of Testing and Evaluation, Vol. 9, No. 6 (Nov. 1981), pp. 317-323.

9. "Proposed ASTM Test Method for Measurement of Fatigue Crack Growth Rates," in: Fatigue Crack Growth Measurement and Data Analysis, ASTM STP 738, S. J. Hudak, Jr. and R. J. Bucci, eds., American Society for Testing and Materials, Philadelphia, Pennsylvania (1981), pp. 340-356.

10. W. Elber, "The Significance of Fatigue Crack Closure," in: Damage Tolerance in Aircraft Structures, ASTM STP 486, M. S. Rosenfeld, ed., American Society for Testing and Materials, Philadelphia, Pennsylvania (1971), pp. 230-242.

11. S. J. Hudak, Jr., A. Saxena, R. J. Bucci, and R. C. Malcolm, "Development of Standards of Testing and Analyzing Fatigue Crack Growth Rate Data," AFML-TR-78-40, Air Force Materials Laboratory, Wright-Patterson Air Force Base, Ohio (May 1978).

12. P. C. Paris and F. Erdogan, "A Critical Analysis of Crack Propagation Laws," Transactions of ASME, Journal of Basic Engineering, series D, vol. 85, No. 3 (1963), pp. 528-534.

\section{LIST OF FIGURES}

1. Data outputs from the automated FCGR test.

2. Schematic of the automated FCGR test system.

3. Summary flow chart of the automated constant-load-amplitude FCGR test.

4. Summary flow chart of the automated near-threshold FCGR test. 


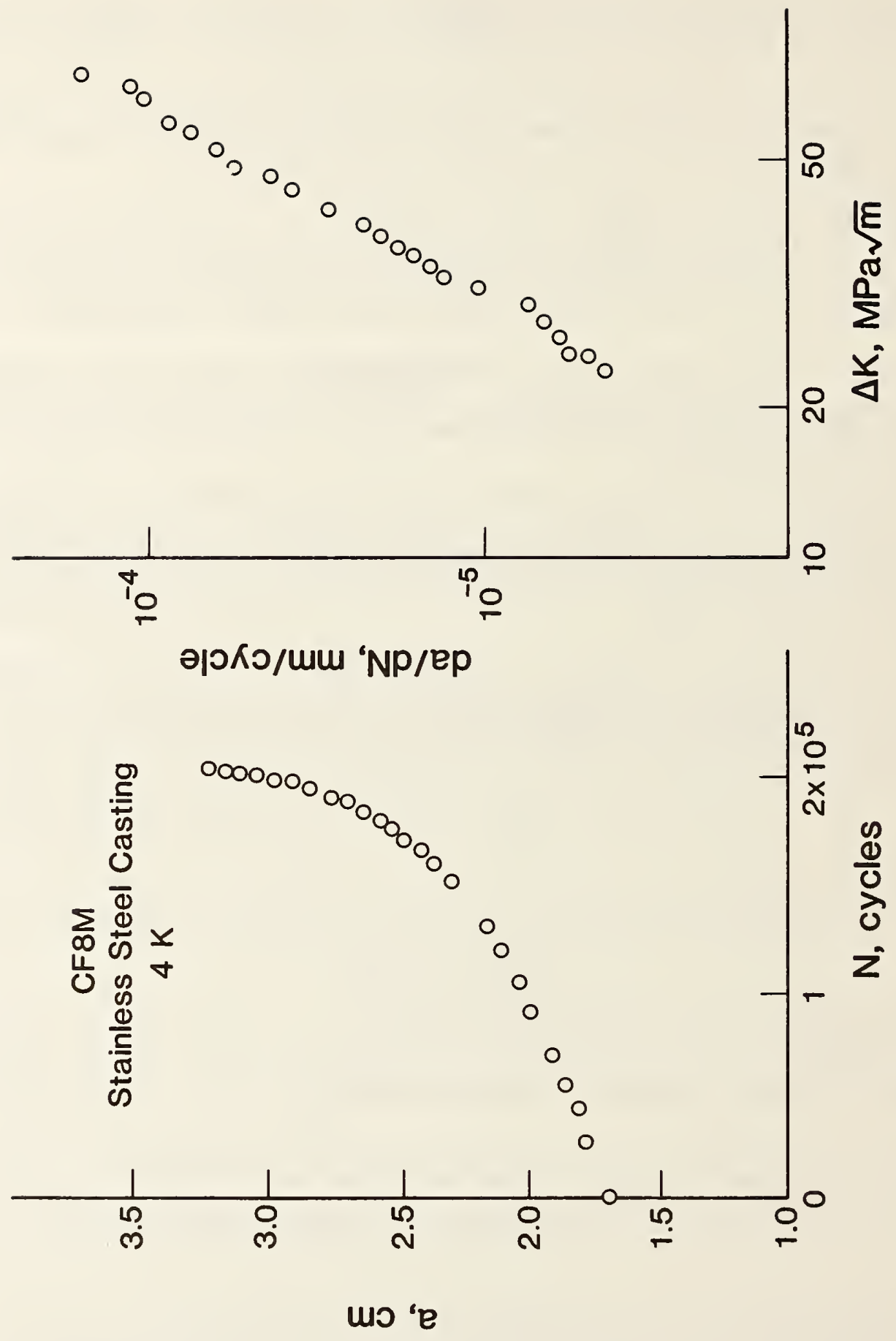




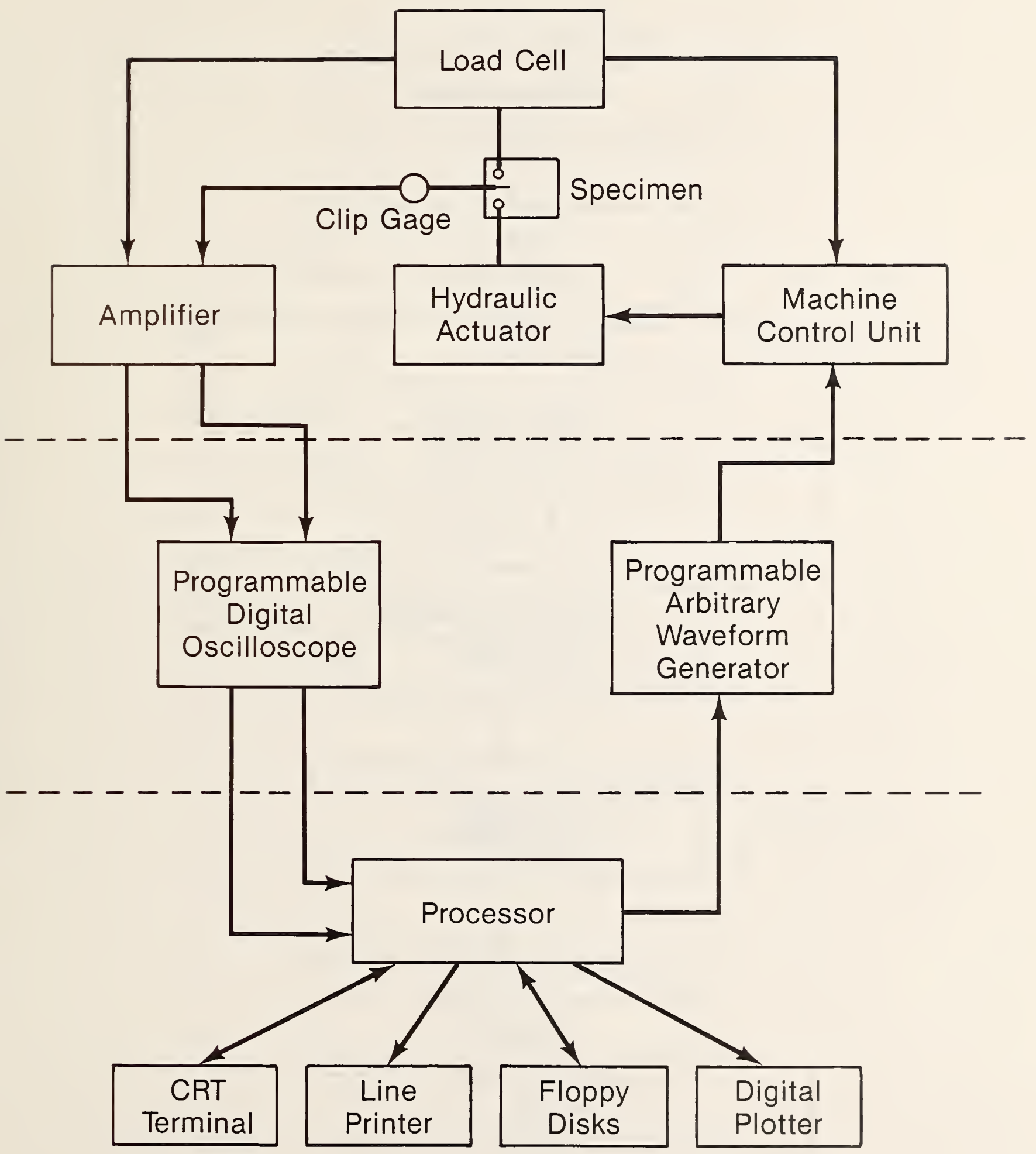

Figure 2. Schematic of the automated FCGR test system. 


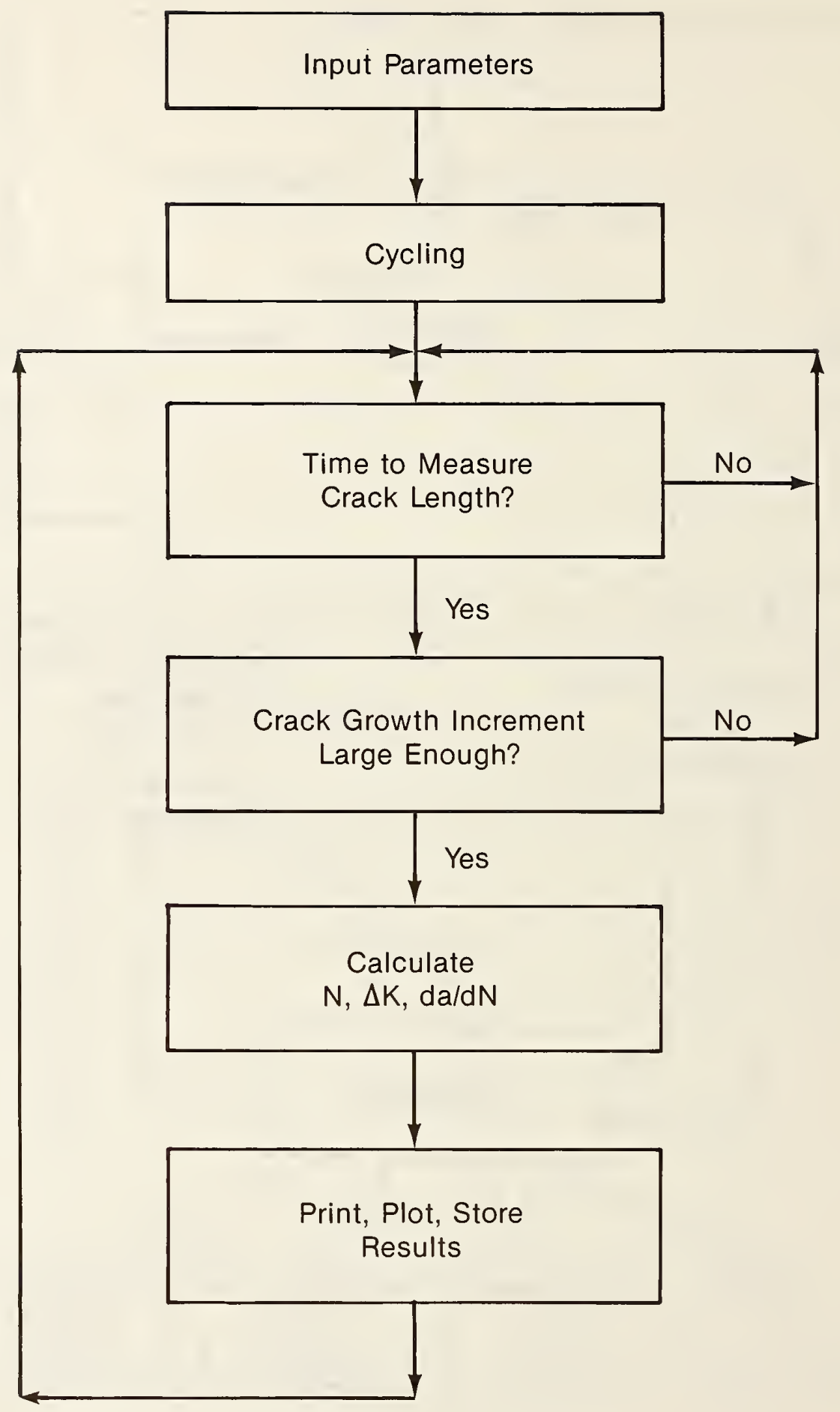

Figure 3. Summary flow chart of the automated constant-load-amplitude FCGR test. 


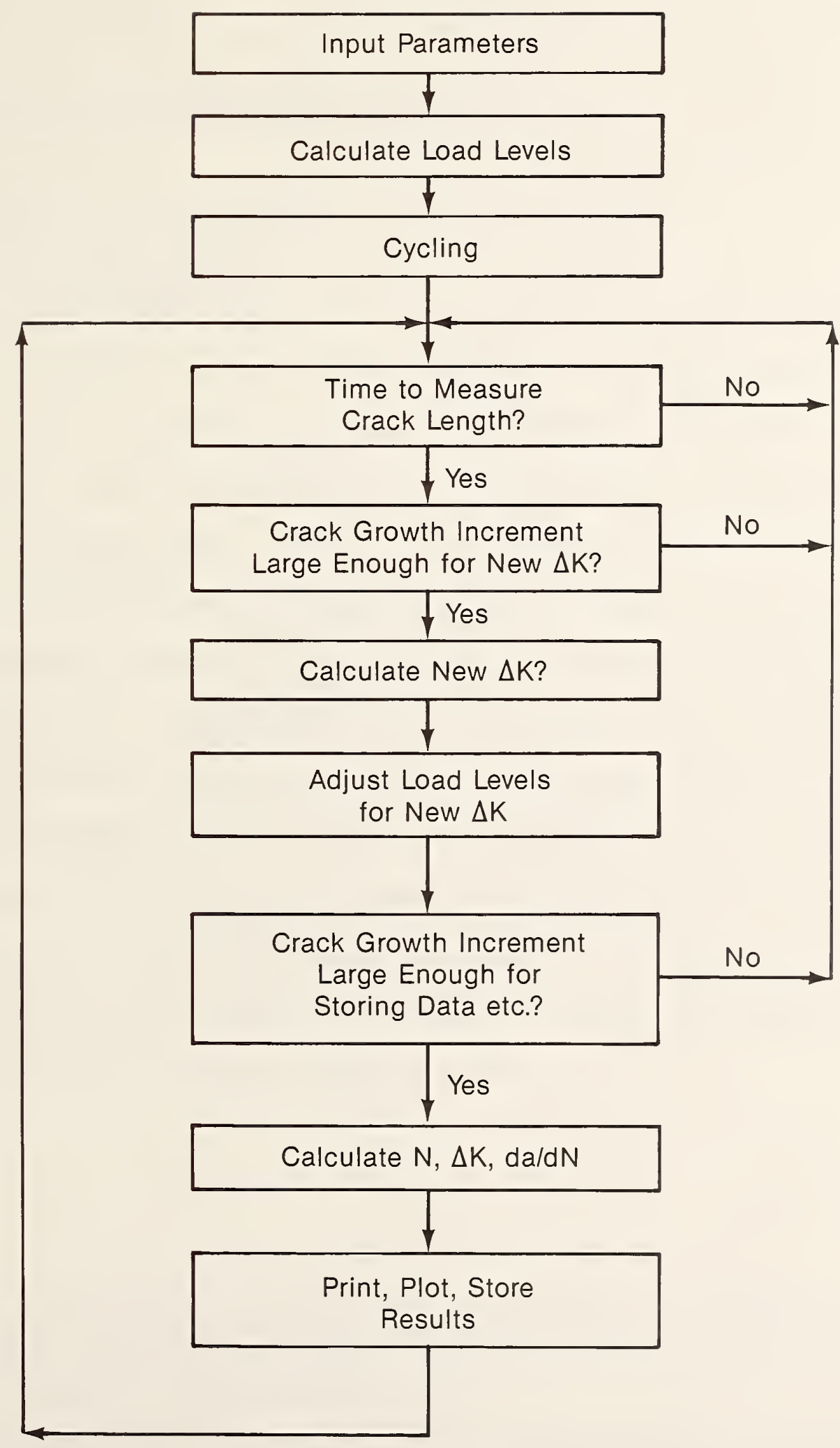

Figure 4. Summary flow chart of the automated near-threshold FCGR test. 

Low-temperature monocrystal elastic constants

of $\mathrm{Fe}-19 \mathrm{Cr}-10 \mathrm{Ni}$

H. M. Ledbetter

Fracture and Deformation Division

Center for Materials Science

National Bureau of Standards

Boulder, Colorado 80303 USA

By a pulse-echo-overlap ultrasonic method, we determined the monocrystal elastic constants $\left(C_{11}, C_{12}, C_{44}\right)$ of an Fe-19Cr-10Ni alloy between 295 and 4 K. In composition this laboratory alloy approximates a technological austenitic stainless steel: AISI 304. Many previous studies on polycrystalline steels found a low-temperature magnetic phase transition that affects physical properties, including elastic constants. At the transition, anomalies occur in all polycrystal elastic constants: Young's modulus, shear modulus, bulk modulus, and Poisson's ratio. The present study found that the transition, near $50 \mathrm{~K}$, does not affect one monocrystal elastic constant: $C_{44}$, the resistance to shear on a (100) plane in a [100]-type direction. We interpret this new observation from the viewpoint of a Born-type lattice model. Also, we comment about the relationship between the elastic-constant changes and the low-temperature magnetic state.

Key Words: austenite; bulk modulus; elastic constants; low temperatures; magnetic phase transition; monocrystal; phase transition; physical properties; Poisson's ratio; shear modulus; sound velocities; stainless steels; Voigt elastic stiffnesses; Young's modulus.

Intended for publication in Journal of Physics and Chemistry of Solids. 
Austenitic stainless steels rank high among existing technological materials. They enter many varied applications, often in large quantities.

Probably best known among these steels is AISI 304, nominally Fe-18Cr10Ni-2Mn. Currently, much research effort focuses on improving the properties of these steels. Much remains not understood. A principal obstacle to understanding is the nature of the ingredient elements: $\mathrm{Fe}, \mathrm{Cr}, \mathrm{Ni}, \mathrm{Mn}, \mathrm{C}, \mathrm{N}$. A11 four metals exhibit either ferromagnetism or antiferromagnetism; the magnetic state affects physical properties. Among all common elements, the antiferromagnetic ones present the most formidable resistance to theoretical understanding. Mainly this resistance arises from the d-shell electrons that determine bonding and magnetic state. Present theory of metals deals cautiously with d-shell electrons. The two interstitial elements, $\mathrm{C}$ and $\mathrm{N}$, present another set of problems. What are their in-alloy atomic volumes and electron states? Are they dispersed or clustered? Do they bond preferentially with one element?

Because these steels retain their ductility and toughness, they find widespread low-temperature applications. Changing temperature alters their properties, especially their magnetic state, which relates fundamentally to many other properties.

For the 304-type steel, Ledbetter [1] recently reported the polycrystal elastic constants between 293 and $4 \mathrm{~K}$. Those results comprise the following features: (1) From 293 to approximately $100 \mathrm{~K}$, a11 elastic constants behave regularly. (2) Below this, centered near $50 \mathrm{~K}$, the alloy undergoes a phase transition that magnetic-susceptibility measurements reveal to be magnetic: high-temperature paramagnetic to low-temperature antiferromagnetic or to low-temperature spin glass [2]. (3) Cooling through the transition softens 
all the elastic stiffnesses: bulk modulus, shear modulus, Young's modulus. (4) At the same time, Poisson's ratio increases. (5) Below the transition, further cooling restores the regular temperature behavior of all the elastic constants, except Poisson's ratio, which either remains constant or increases, contrary to the regular behavior of decreasing continuously during cooling. (6) Above the transition temperature, the bulk modulus shows "premonitory" softening. Studies on many other similar alloys show qualitatively the same behavior $[3,4]$. The main difference in these alloys is that their transition temperature depends on chemical composition, especially $\mathrm{Mn}$, which raises the transition temperature. Some high-Mn-content alloys exhibit a transition above ambient temperature $[5,6]$.

Magnetic-susceptibility-versus-temperature measurements $[3,7]$ on the polycrystal alloys reveal that a magnetic phase transition always accompanies the elastic-constant discontinuities. Susceptibility, $x$, shows a sharp upward-pointing cusp. The curve shape corresponds to that of a classical paramagnetic-antiferromagnetic transition [8], but also to that of a spin glass condensation [9]. Thus, simple $x(T)$ measurements fail to distinguish between the two possibilities: antiferromagnetic and spin glass. Above the transition temperature, $x$ fits a modified Curie-Weiss law:

$$
x(T)=x_{0}+C /(T-\theta)
$$

where $x_{0}, C$, and $\theta$ are adjustable parameters. Various alloys yielded a nearly alloy-independent background paramagnetic susceptibility, $x_{0}$, of $13.5 \mathrm{emu} / \mathrm{g}$. In these alloys, $\theta$ tends to be small, either positive or negative, and a fraction of the transition temperature, $T_{t}$. Kittel [10] lists properties of many antiferromagnets; in all cases, $\theta$ is negative and the absolute value 
almost always exceeds $T_{t}$ by a factor up to 5 .

The present research sought a better understanding of these lowtemperature elastic-constant phenomena by studying them in a monocrystal laboratory alloy, which eliminates many extraneous variables, such as interstitial $C$ and $N$ atoms, substitutional Mn atoms, and possible grain-boundary and grain-size effects. At the same time, one obtains more information because an $f c c$ crystal has three independent elastic constants $\left(C_{11}, C_{12}, C_{44}\right.$ in Voigt notation), whereas a quasi-isotropic polycrystalline aggregate has only two independent elastic constants. The $c_{i j}$ relate directly to interatomic forces and to well-defined deformation modes. From reported lowtemperature anomalies [1] in the polycrystal shear modulus, $G$, we do not know which of the two principal cubic-symmetry shear moduli, $C_{44}$ or $\left(C_{11}-C_{12}\right) / 2$, or both, shows anomalies. As described below, knowing this helps elucidate the magnetic transition.

\section{EXPERIMENT}

Material

An alloy of nominal weight-percent composition $\mathrm{Fe}-19 \mathrm{Cr}-10 \mathrm{Ni}$ was vacuum melted and vacuum cast from high-purity metals. Single crystals were grown by a Bridgman technique, homogenized at $1350^{\circ} \mathrm{C}$ for $20 \mathrm{~h}$, cut to shape and size with a spark cutter, and annealed at $1100^{\circ} \mathrm{C}$ for $20 \mathrm{~h}$. Back-reflection Laue $x$-ray diffraction was used to establish the crystal orientation, which was $2.5^{\circ}$ from a [110] axis. Specimen dimensions were $1.5 \mathrm{~cm} \times 1.5 \mathrm{~cm} \times 0.7 \mathrm{~cm}$. Mass density measured by Archimedes's method was $7.937 \mathrm{~g} / \mathrm{cm}^{3}$. Method

For brevity we omit the measurement-method description, which we gave elsewhere [11], including low-temperature procedures [12]. Particular details 
that differ here include: 5 to $10 \mathrm{MHz}$ measurement frequency, commercial adhesive transducer-specimen bond.

\section{RESULTS}

Figure 1 gives relative measured values between 293 and $4 \mathrm{~K}$ for three elastic constants: $\quad C_{L}=\left(C_{11}+C_{12}+2 C_{44}\right) / 2, C_{44}$, and $C^{\prime}=\left(C_{11}-C_{12}\right) / 2$, from which one calculates, for $T=293 \mathrm{~K}, C_{11}=205, C_{44}=126, C^{\prime}=33.4$, and $C_{12}=138 \mathrm{GPa}$. Figure 2 shows, versus temperature, some derived monocrystal elastic constants: $C_{12}, B=\left(C_{11}+2 C_{12}\right) \% 3$, and the Zener elastic anisotropy [see Eq. (2)]. In Fig. 3, we give the quasi-isotropic (polycrystal) elastic constants derived from the $C_{i j}$ by Kroner's method [13]. At $293 \mathrm{~K}$, these are: bulk modulus, $B,=160$; shear modulus, $G,=75.6$; Young's modulus, $E,=196$ GPa; and Poisson's ratio, $v,=0.296$.

\section{DISCUSSION}

\section{The low-temperature anomaly}

The study's most remarkable result is that near $50 \mathrm{~K}$ all $\mathrm{C}_{i j}$ behave anomalously, except $C_{44}$. Although upon cooling through the transition the lattice softens its resistance to $(110)[1 \overline{10}], C^{\prime}$-type, shear, it retains its resistance to $(100)[\overline{100}], C_{44}$-type, shear. Thus, the Zener anisotropy factor

$$
A=2 C_{44} /\left(C_{11}-C_{12}\right)
$$

increases abruptly during cooling through the transition.

Because we know from magnetic-susceptibility-versus-temperature measurements that the transition involves a change from paramagnetic to antiferromagnetic or spin glass, and because antiferromagnetic phases involve spin 
ordering on lattices or sublattices, we consider the contributions to the elastic constants from first-nearest and second-nearest neighboring atoms. We assume a central-force pair interaction. (This is not exact. One requirement of a central potential is the Cauchy condition, $C_{12}=C_{44}$. As shown above, this condition holds within 10 percent for this alloy.) It makes sense to neglect volume-dependent, structure-independent energy terms because they affect all the $C_{i j}$. Also, this approach agrees with a conclusion of Alers, Neighbours, and Sato [14]. They considered the magnetic-exchange interaction in an experimental study of $\mathrm{Fe}-30 \mathrm{Ni}$ elastic constants and concluded that "the effects of a noncentral interaction were ... too small to be observed."

If the interatomic potential is denoted $\Phi(r)$, then, following Born's classical studies, the Brugger elastic constants, which are fourth-rank tensors, are given at $T=0 \mathrm{~K}$ by:

$$
c_{i j k 1}=\frac{\partial^{2} U}{\partial n_{i j} \partial n_{k l}}=\frac{1}{2 v^{0}}\left[\sum D^{2} \Phi(x) r_{i}^{0} r_{j}^{0} r_{k}^{0} r_{1}^{0}\right]_{r=r_{0}}
$$

where $D \Phi(x)$ denotes $(1 / x)[\partial \Phi(x) / \partial r]$. The energy density, $U$, of the crystal is obtained by a sum over two-body atom-atom interaction energies:

$$
U=\left(1 / 2 V^{0}\right) \Sigma \Phi(x)
$$

where $V^{0}$ is the undeformed atomic volume. The $n_{i j}$ are components of the Lagrangean elastic strain matrix

$$
n=(1 / 2)\left(l^{t} \downarrow-\downarrow\right)
$$

where $I$ is the $3 \times 3$ identity matrix, $t$ denotes transposition, and the deformation matrix, $l$, is defined by 


$$
x=3 x^{\circ}
$$

where $x^{0}$ and $x$ are the interatomic spacings in the initial state and in the deformed state, respectively.

Face-centered cubic crystals have twelve nearest neighbors at $< \pm 1, \pm 1,0>a / 2$ and six next-nearest neighbors at $\langle \pm 1,0,0>a$, where $a$ is the unit-cell dimension. In this case one obtains from Eq. (3):

$$
C_{44}\left(=C_{2323}\right)=\frac{1}{2 v^{0}}\left[4\left(\frac{a}{2}\right)^{4} D^{2} \Phi\left(\frac{a}{\sqrt{2}}\right)+0+\ldots\right]
$$

where ... indicates contributions from pairs beyond second-nearest neighbors. Similarly, one obtains

$$
\begin{aligned}
C^{\prime} & =\left(C_{11}-C_{12}\right) / 2=\left(C_{1111}-C_{1122}\right) / 2 \\
& =\frac{1}{2 V^{0}}\left[2\left(\frac{a}{2}\right)^{4} D^{2} \Phi\left(\frac{a}{\sqrt{2}}\right)+a^{4} D^{2} \Phi(a)+\ldots\right]
\end{aligned}
$$

We find an important difference. First and second neighbors contribute to $C^{\prime}$; only first neighbors contribute to $\mathrm{C}_{44}$. (In bcc crystal structures, the situation reverses: second neighbors contribute to $C_{44}$ but not to $C^{\prime}$ [15].) Thus, the second-neighbor interaction can change dramatically without affecting $\mathrm{C}_{44}$.

Now we consider--how can second-neighbor interactions affect the elastic constants while first-neighbor interactions do not? The answer lies in two factors: the electron-spin structure and the Bethe-Slater curve Figs. 4 and 5). This electron-spin structure is based on 4-K neutron-diffraction studies of $\gamma$-Fe by Abrahams et al. [16] and of $\mathrm{Fe}-15 \mathrm{Cr}-15 \mathrm{Ni}$ by Ishikawa et al. [17]. These studies found Neel temperatures of $8 \mathrm{~K}$ and $21 \mathrm{~K}$, respectively. The 
structure consists of (200)-plane sheets of parallel spin with alternate sheets being antiparallel. The magnetic moments align nearly parallel and antiparallel with a cube axis, a [100]-type direction. (We neglect the angle between the spin vectors and the cube axes, which tends to make the crystal structure monoclinic. We consider the spins either up or down.) Examination of Fig. 4 reveals that all six second-neighbor spins are parallel to the reference spin. However, for the twelve first-neighbors, eight are antiparallel (antiferromagnetic array) but four are parallel (ferromagnetic array). Thus, if we write an expression for the exchange energy [18]:

$$
U_{e}=-2 \sum_{i>j} J(r) S_{i} \cdot S_{j}
$$

where $J(r)$ is the exchange integral shown in Fig. 5 and $\mathbb{S}_{j}$ is the spin on atom $i$; through second neighbors this becomes (taking $S=1$ )

$$
U_{e}=8 J\left(r_{1}\right)-12 J\left(r_{2}\right)
$$

Thus, second neighbors dominate the exchange energy because approximately

$$
J\left(r_{2}\right)=-7 J\left(r_{1}\right)
$$

Thus, in this case, second neighbors (at $r_{2}$ ) contribute approximately twelve times as much to exchange energy as do first neighbors (at $r_{1}$ ).

For elastic-stiffness constants, which relate to $J(r)$ 's second spatial derivative, the second-neighbors also dominate. Consider, for example, the bulk modulus: 


$$
\begin{aligned}
B & =\left(C_{11}+2 C_{12}\right) / 3=\left(C_{1111}+2 C_{1122}\right) / 3 \\
& =\left(1 / 2 V^{\circ}\right)\left[(16 / 3)(a / 2)^{4} D^{2} \Phi(a / \sqrt{ } 2)+(2 / 3) a^{4} D^{2} \Phi(a)+\ldots\right]
\end{aligned}
$$

Written out in terms of first and second derivatives of $J(r)$, this becomes

$$
B_{e}=\left(1 / 3 V^{\circ}\right)\left[2 r_{1} J^{\prime \prime}\left(r_{1}\right)-4 r_{1} J^{\prime}\left(r_{1}\right)+r_{2}^{2} J^{\prime \prime}\left(r_{2}\right)-2 r_{2} J^{\prime}\left(r_{2}\right) \ldots\right]
$$

where primes denote derivatives with respect to $r$. For the present case, Fig. 5 shows that $J^{\prime}\left(r_{2}\right)$ and $J^{\prime \prime}\left(r_{1}\right)$ practically vanish. Thus,

$$
\begin{aligned}
B_{e} & \cong\left(1 / 3 V^{\circ}\right) \quad\left[-4 r_{1} J^{\prime}\left(r_{1}\right)+r_{2}^{2} J^{\prime \prime}\left(r_{2}\right)\right] \\
& \cong\left(1 / 3 V^{\circ}\right) B_{e}\left(r_{1}\right)+B_{e}\left(r_{2}\right)
\end{aligned}
$$

Because $J^{\prime}\left(r_{1}\right)$ is positive and $J^{\prime \prime}\left(r_{2}\right)$ is negative (indeed near its maximum negative value), both first-neighbor and second-neighbor exchange-energy interactions reduce the bulk modulus. But to see their relative contributions, $\mathrm{B}_{\mathrm{e}}\left(\mathrm{r}_{2}\right) / \mathrm{B}_{\mathrm{e}}\left(\mathrm{r}_{1}\right)$, we need a relationship between $\mathrm{J}^{\prime}\left(r_{1}\right)$ and $\mathrm{J}^{\prime \prime}\left(r_{2}\right)$. To do this we approximate $J(r)$ with the function

$$
J(r)=a r^{-1}-b r^{-n}
$$

After some algebra, recognizing that $r_{2} \cong r\left(J_{\max }\right)$ and taking $n=10$ (higher $n$ raises the ratio), we find the ratio

$$
B_{e}\left(r_{2}\right) / B_{e}\left(r_{1}\right) \cong 4
$$

Thus, this confirms that second neighbors dominate the exchange contributions 
to the elastic constants. Taking $n=10$ corresponds to a high positive slope at low $r / d$, as suggested in Fig. 5. The exact shape of the $J(r)$ curve remains unknown. With some success, several studies [20,21] attempted to relate elastic constants to the $J(r)$ curve. Unlike the present study, they focused mainly on first-neighbor interactions.

The above considerations are consistent with an antiferromagnetic lowtemperature phase where the main exchange-energy contributions to the elastic constants originate in the first-neighbor and second-neighbor interactions. Indeed, Fig. 5 shows that Heisenberg exchange forces are short-range.

These same considerations are not consistent with the ideal spin glass. This magnetic state envisages "negligible effect of directly coupled pairs" and "results from a random distribution ... of the interactions between neighboring moments" [22]. That is, forces are long-range as provided, for example, by an RKKY coupling [23]. Spin glasses provide no distinction in magnetic moment at first-neighbor and second-neighbor positions. Both sets of atoms exhibit randomly oriented moments frozen in time. Concerning concentration, Hurd [22] points out that "the spin glass ... exists only within a limited range of concentration of magnetic solute. The concentration must be high enough to give interactions via RKKY coupling yet low enough to avoid clusters or linkages of directly coupled moments ... the 'dilute' and 'percolation' limits, respectively ... occur in an fcc alloy at about 0.01 and 20 atomic percent ... direct exchange dominates above the percolation limit, leading to ferromagnetism or antiferromagnetism." Thus, in the present case, by this reasoning, concentration also excludes the spin glass possibility. It remains unclear whether mictomagnetism or cluster magnetism [24] provide possible low-temperature magnetic states in these $\mathrm{Fe}-\mathrm{Cr}-\mathrm{Ni}$ alloys. 
Another factor favors a low-temperature antiferromagnetic phase over spin glass: the shear-modulus softening. Eshelby's elastic-continuum studies [25] show that a shear-modulus change arises from local short-range changes in the immediate neighborhood of the imperfection, usually within the second-neighbor distance. (Here we take imperfection to mean a departure from the nonmagnetic paramagnetic state, a spin arrangement that exerts an internal pressure, analogous to a point defect. This pressure alters volume and elastic stiffness [26].) Antiferromagnetism can alter $G$ because it involves short-range forces that arise from wave-function overlap. As Fig. 5 shows, antiferromagnetism vanishes for large interatomic spacings. On the other hand, the spin glass state depends on indirect exchange, such as RKKY, and, therefore, on long-range forces. Thus, we can exclude spin glass forces from thoṣe affecting the shear modulus.

\section{Monocrystal-polycrystal relationship}

Now we consider how the present measured monocrystal elastic constants measured here compare with those for a similar-composition polycrystal reported previously [11]. This may represent the first such comparison for a concentrated ternary alloy. This comparison requires "averaging" the monocrystal constants to obtain the effective polycrystal constants. Landau and Lifshitz [27] remind us that "there is ... no general relation between the moduli of elasticity of a polycrystal and those of a single crystal of the same substance." Ledbetter $[28,29]$ showed recently for $\mathrm{Cu}$ that the best averaging method, among eight considered, is Kröner's [13]. Table I gives the comparison. The one-to-two percent disagreement probably arises from the monocrystalpolycrystal chemical-composition difference.

\section{Elastic anisotropy}

During cooling from ambient temperature to the antiferromagnetic transi- 
tion, the Zener elastic anisotropy, A, Eq. (2) behaves regularly. It decreases slightly as for other fcc metals such as $\mathrm{Al}, \mathrm{Cu}$, and $\mathrm{Ni}$ and for bcc Fe. At the transition, A rises abruptly and exceeds its ambient-temperature value. This occurs because $C^{\prime}$ softens whereas $C_{44}$ does not. Many authors (e.g., Ref. 30) associate high A with incipient lattice instability. This suggests that the low-temperature magnetic phase offers less resistance than the high-temperature nonmagnetic phase to crystal-structure change to a bcc or cph crystal structure. However, magnetic energy may offset this.

\section{Other matters}

It should not escape attention that $C_{12}$ behaves anomalously in the paramagnetic region. Whereas $\mathrm{dC} / \mathrm{dT}$ is negative for all the other monocrystal elastic constants, $\mathrm{dC}_{12} / \mathrm{dT}$ is practically zero and very slightly positive, as shown in Fig. 2. Negative $d C / d T$ is the usual, normal behavior for all the $c_{i j}$. For this particular anomaly we offer no explanation. $C_{12}$ is difficult to consider theoretically because, unlike most other $C_{i j}$, it is nonphysical. In a crystal, no elastic wave exists corresponding to $C_{12}$. The anomaly suggests some material-state change that offsets the expected temperature change of $C_{12}$. Perhaps a magnetic change occurs. One useful view of $C_{12}$ is in terms of Poisson's ratio:

$$
v_{100}=-\frac{s_{12}}{s_{11}}=\frac{c_{12}}{c_{11}+c_{12}}
$$

where $S_{i j}$ denote the elastic compliances. With $\mathrm{dC}_{12} / \mathrm{dT} \cong 0$, then

$$
d v_{100} / v_{100} \cong-d c_{11} /\left(c_{11}+c_{12}\right)
$$

and Poisson's ratio decreases more rapidly with decreasing temperature. Figure 3 shows that $\Delta v / \nu=-4.0$ percent between $T=293$ and $0 \mathrm{~K}$. For $\mathrm{Cu}$, an 
elastically softer material where one expects larger changes with temperature, one finds $\Delta v / \nu=-2.0$ percent. This small difference is important because, as Köster and Franz [31] pointed out, "Poisson's ratio depends to a much greater extent on the conditions of bonding than do the other elastic coefficients." Small anomalous Poisson's-ratio changes signal a significant change in the nature of the interatomic bonding. In usual materials, a reduction in $C_{12} / C_{11}$ indicates a move from metallic bonding toward covalent or ionic bonding [32]. But, in magnetic materials, reduced $C_{12} / C_{11}$ perhaps signifies something quite different, related to electron-spin rearrangements. The drastically different temperature behavior of $\mathrm{C}_{12}$ and $\mathrm{C}_{44}$ suggests strong noncentral force interactions. Such forces arise, for example, in many-body interactions, which may enter the description of magnetic clusters.

Neither can one neglect the softening of all elastic stiffnesses except $C^{\prime}$ and $C_{44}$ (the shear moduli) at temperatures above the magnetic transition. This softening of all dilation-related elastic stiffnesses occurs upon cooling below approximately $100 \mathrm{~K}$. We will call this premonitory dilation softening. Probably it arises from some magnetic interaction that expands the lattice and reduces the bulk modulus. As Eshelby [25] pointed out, pure bulk-modulus changes tend to be associated not with rapidly fluctuating forces (such as arise from the exchange interaction), but with long-range, smoothly varying forces. Upon cooling, one would expect long-range, indirect interactions to emerge before the direct-exchange interactions that depend on $d$-shell overlap.

\section{CONCLUSION}

The first measurements of austenitic-steel-like monocrystal elastic constants at low temperatures show an interesting result: $C_{44}$ behaves regularly 
while all other $C_{i j}$ behave anomalously at the magnetic transition. We interpret this to mean that only second-neighbor interatomic interactions change during the transition. A possible model puts both antiparallel and parallel electrons on first-neighbor sites and parallel-spin electrons on secondneighbor sites. Because of the $\mathrm{C}_{44}$ behavior, because a softened shear modulus implies short-range interatomic-force changes, and because of high concentrations of magnetic species, we conclude that the low-temperature phase is antiferromagnetic rather than spin glass. Other peculiarities include a nearly temperature-independent $C_{12}$ and premonitory softening of bulk-modulusrelated elastic constants.

\section{ACKNOWLEDGEMENTS}

The U. S. DoE Office of Fusion Energy supported this study. Dr. N. F. Fiori of Cabot Corporation loaned the monocrystals. Mr. J. Ward assisted with measurements, and Mr. M. W. Austin with many miscellaneous contributions. 


\section{REFERENCES}

1. H. M. Ledbetter, J. App1. Phys. 52, 1587-1589 (1981).

2. E. W. Collings and H. M. Ledbetter, Phys. Lett. 72A, 53-56 (1979).

3. H. M. Ledbetter and E. W. Collings, in The Metal Science of Stainless Steels (Metallurgical Society of the AIME, 1979), pp. 22-40.

4. H. M. Ledbetter, Meta11. Trans. 11A, 1067-1069 (1980).

5. H. M. Ledbetter, Meta11. Trans. 11A, 543-544 (1980).

6. H. M. Ledbetter and M. W. Austin, to be published; available in National Bureau of Standards Report NBSIR 83-1690, pp. 181-194.

7. E. W. Collings and H. M. Ledbetter, Phys. Lett. 72A, 53-56 (1979).

8. S. Chikazumi, Physics of Magnetism (Wiley, New York, 1964), p. 82.

9. V. Cannella, J. A. Mydosh, and J. I. Budnick, J. Appl. Phys. 42, 1689 (1971).

10. C. Kittel, Solid State Physics (Wiley, New York, 1966), p. 483.

11. H. M. Ledbetter, N. F. Frederick, and M. W. Austin, J. Appl. Phys. 51, 305-309 (1980).

12. E. R. Naimon, W. F. Weston, and H. M. Ledbetter, Cryogenics 14, 246-249 (1974).

13. E. Kröner, Z. Phys. 151, 504-518 (19.58).

14. G. A. Alers, J. R. Neighbours, and H. Sato, J. Appl. Phys. 4, 231S-232S (1959).

15. H. M. Ledbetter, Z. Naturforsch. 31a, 1539-1542 (1976).

16. S. C. Abrahams, L. Guttman, and J. S. Kasper, Phys. Rev. 127, 2052-2055 (1962).

17. Y. Ishikawa, Y. Endoh, and T. Takimoto, J. Phys. Chem. Solids 31, 1225$1234(1970)$.

18. Ref. 10, p. 456 .

19. E. Kneller, Ferromagnetismus (Springer-Verlag, Berlin, 1962).

20. G. Alers, J. R. Neighbours, and H. Sato, J. Phys. Chem. Solids 13, 40-55 (1960).

21. G. Hausch, Phys. Status Solidi (a) 15, 501-510 (1973). 
22. C. M. Hurd, Contemp. Phys. 23, 469-493 (1982).

23. D. C. Mattis, The Theory of Magnetism I (Springer-Verlag, Berlin, 1981), p. $229 \mathrm{ff}$.

24. P. A. Beck, in Progress in Materials Science, Volume 23 (Pergamon, Elmsford, New York, 1978), pp. 1-49.

25. 1. D. Eshe1by, J. App1. Phys. 25, 255-261 (1954).

26. J. F. Janak and A. R. Williams, Phys. Rev. B 14, 4199-4204 (1976).

27. L. D. Landau and E. M. Lifshitz, Theory of Elasticity (Pergamon, Elmsford, New York, 1959), p. 40.

28. H. M. Ledbetter, J. Phys. D: Appl. Phys. 13, 1879-1884 (1980).

29. H. M. Ledbetter, Phys. Status Solidi (a) 66, 477-484 (1981).

30. C. Zener, Elasticity and Anelasticity of Metals (U. of Chicago Pr., Chicago, 1948), p. $32 \mathrm{ff}$.

31. W. Köster and H. Franz, Meta11. Rev. $\underline{6}, 1-55$ (1961).

32. H. M. Ledbetter, to be published. 
TABLE I. Calculated and measured polycrystal elastic constants. Units are $\mathrm{GPa}$, except $v$, which is dimensionless.

\begin{tabular}{lcccc}
\hline & B & $E$ & $G$ & $v$ \\
\hline Calculated & 160 & 196 & 75.6 & 0.296 \\
Measured $^{\mathrm{a}}$ & 158 & 200 & 77.4 & 0.290 \\
\hline
\end{tabular}

a Ref. 11. 


\section{List of Figures}

Fig. 1a. From 4 to $293 \mathrm{~K}$, relative measured elastic constants $C_{L}=$ $\left(C_{11}+C_{12}+2 C_{44}\right) / 2, C^{\prime}=\left(C_{11}-C_{12}\right) / 2$, and $C_{44}$.

Fig. 2 From 4 to $293 \mathrm{~K}$, derived monocrystal elastic constants $\mathrm{C}_{12}$ and $\mathrm{B}$, and Zener elastic anisotropy, A.

Fig. 3. From 4 to $293 \mathrm{~K}$, quasi-isotropic (polycrystal) elastic constants computed from $C_{j j}$ by Kroner's method. B denotes bulk modulus, $E$, Young's modulus; $; G$, shear modulus; and $v$, Poisson's ratio.

Fig. 4. Suggested electron-spin structure of $\gamma$-Fe and Fe-15Cr-15Ni. Adapted from references 16 and 17 .

Fig. 5. Bethe-Slater curve of magnetic exchange energy versus $r / d$, where $r$ denotes interatomic spacing and d, diameter of $3 d$-electron shell. Adapted from reference 19. For fcc Fe, the second-neighbor distance, $r_{2}=\sqrt{ } 2 r_{1}$, lies only slightly to the left of the Co point. 


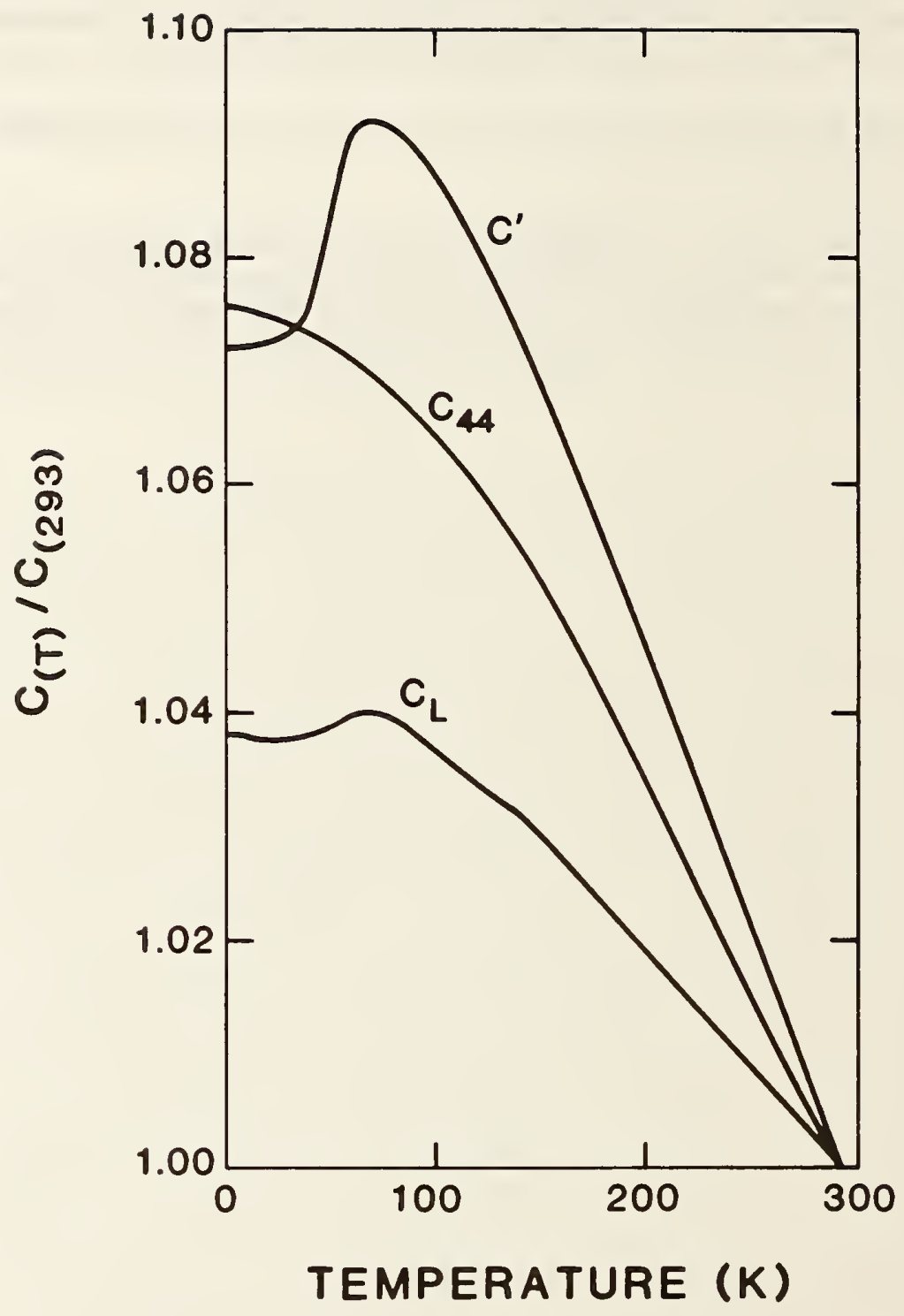

Fig. 1a. From 4 to $293 \mathrm{~K}$, relative measured elastic constants $C_{L}=$ $\left(C_{11}+C_{12}+2 C_{44}\right) / 2, C^{\prime}=\left(C_{11}-C_{12}\right) / 2$, and $C_{44}$. 


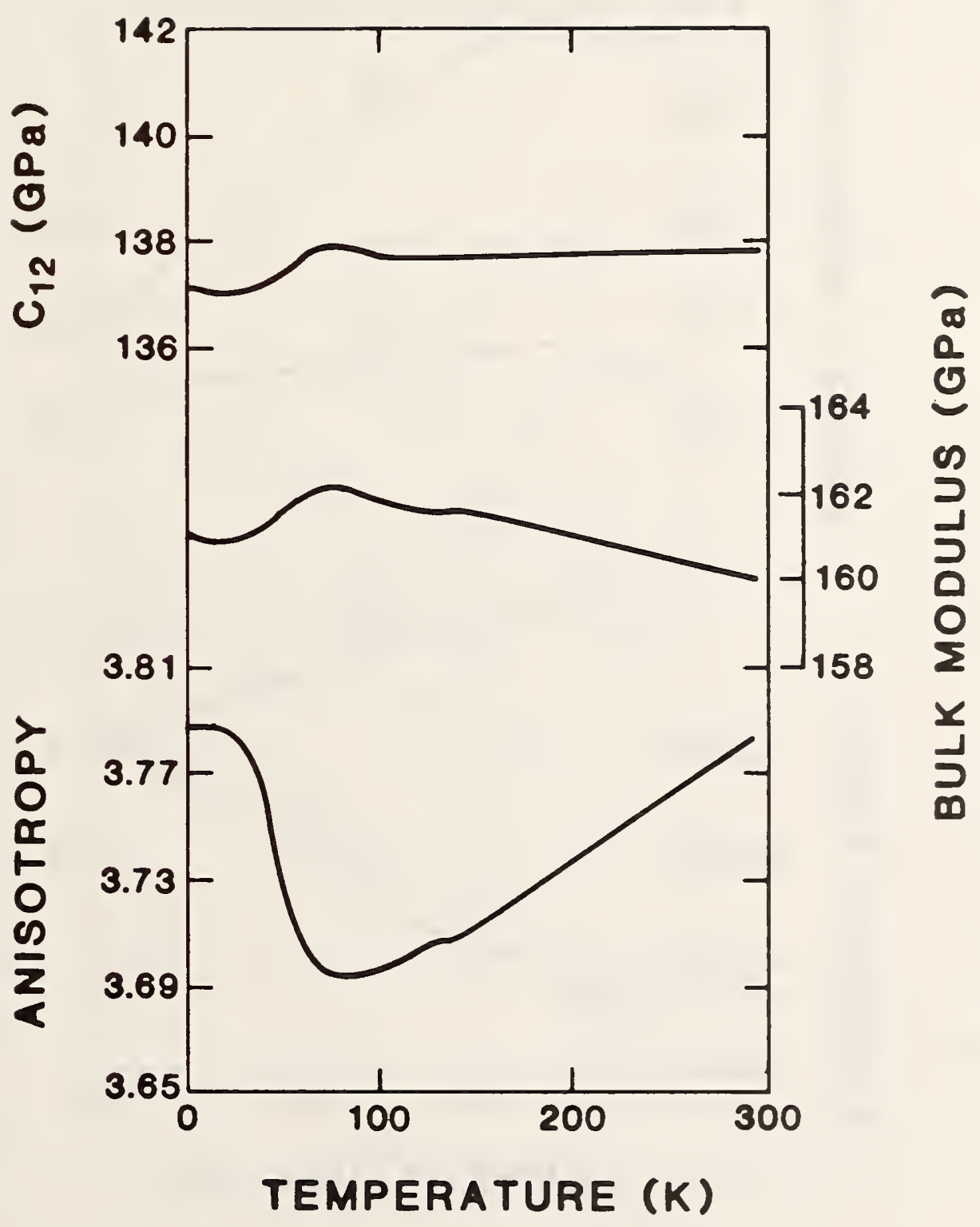
Fig. 2 From 4 to $293 \mathrm{~K}$, derived monocrystal elastic constants $C_{12}$ and $B$,
and Zener elastic anisotropy, $A$. 


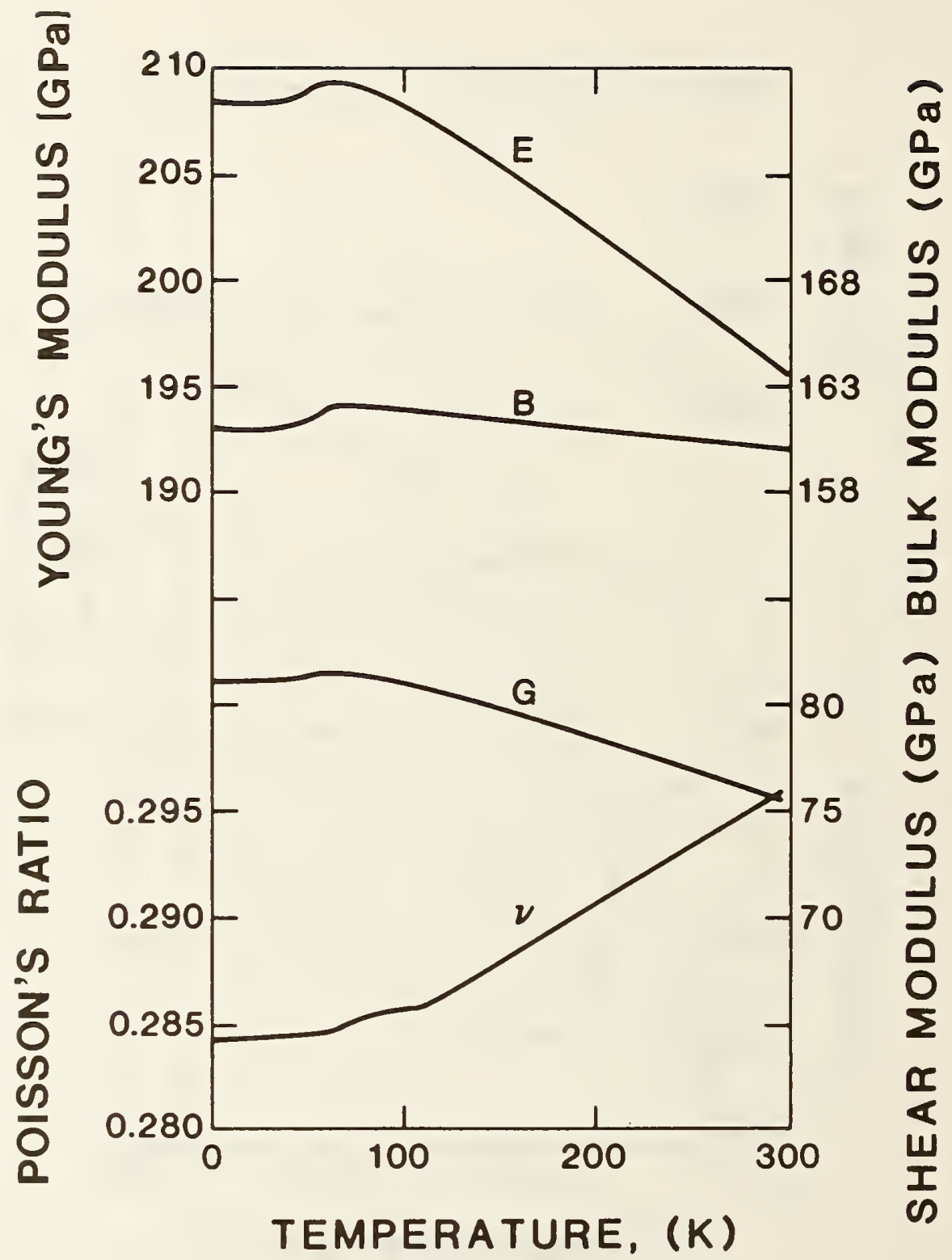

Fig. 3. From 4 to $293 \mathrm{~K}$, quasi-isotropic (polycrystal) elastic constants computed from $C_{j j}$ by Kroner's method. B denotes bulk modulus, $E$, Young's modulus ${ }^{j} G$, shear modulus; and $v$, Poisson's ratio. 


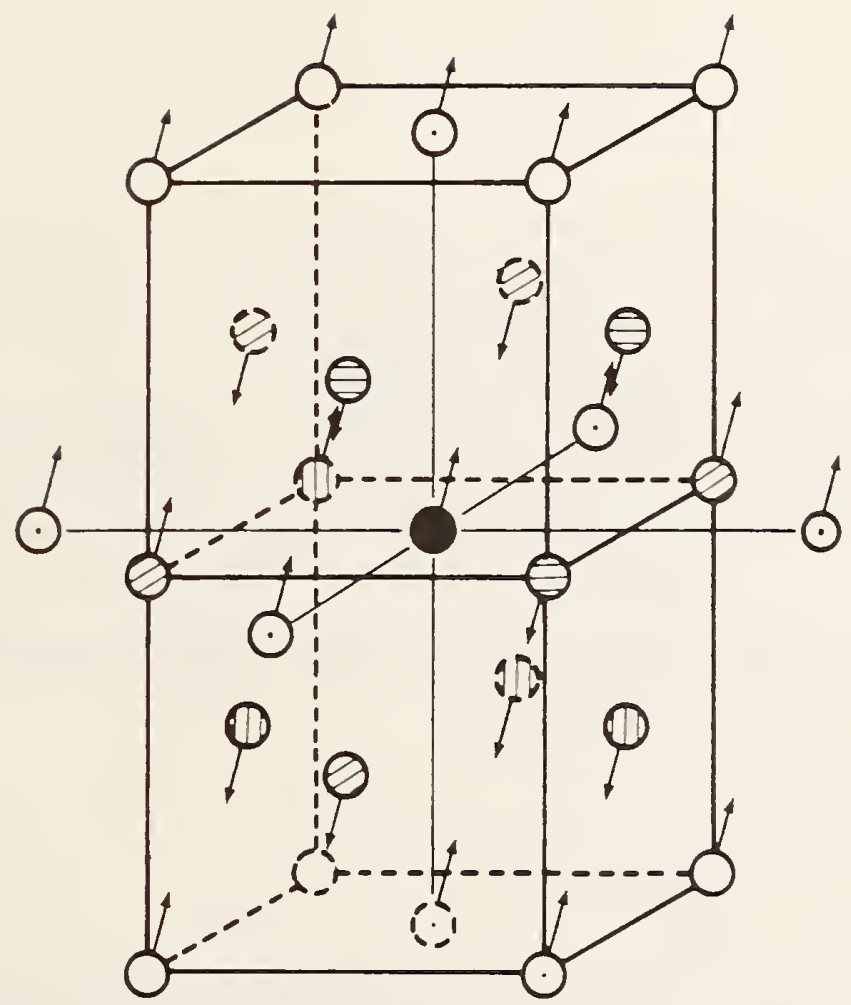

ref. atom in (111) plane

O $6 \mathrm{nn}$ in (111) plane

O 3 nn above (111) plane

(1) 3 nn below (111) plane

$\odot 6 n n$

Fig. 4. Suggested electron-spin structure of $\gamma-\mathrm{Fe}$ and $\mathrm{Fe}-15 \mathrm{C} r-15 \mathrm{Ni}$. Adapted from references 16 and 17 . 


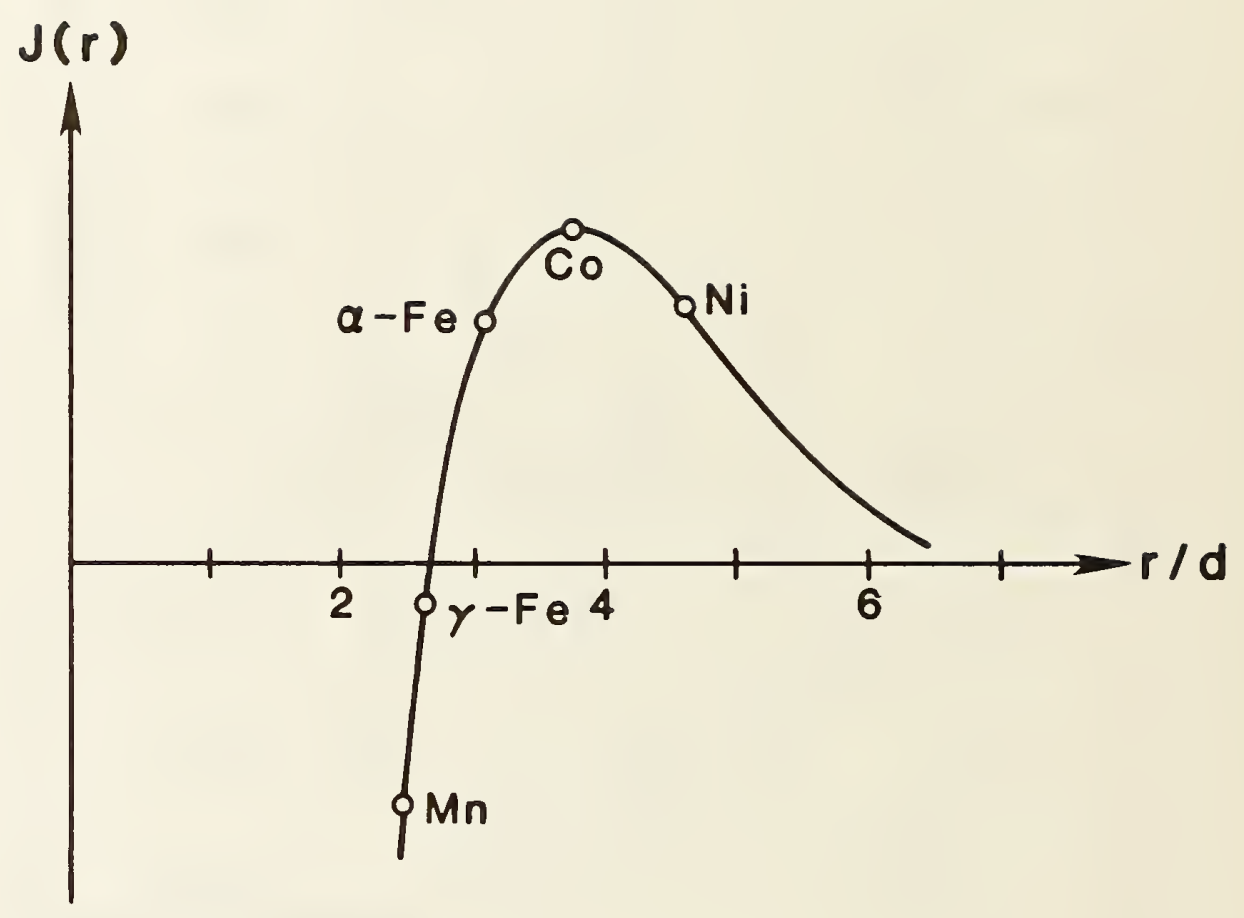

Fig. 5. Bethe-Slater curve of magnetic exchange energy versus $r / d$, where $r$ denotes interatomic spacing and d, diameter of 3d-electron shell. Adapted from reference 19. For fcc Fe, the second-neighbor distance, $r_{2}=\sqrt{2} r_{1}$, lies only slightly to the left of the Co point. 
A Numerical and Experimental Verification of Compliance Functions for Compact Specimens

R. L. Tobler and W. C. Carpenter**

Fracture and Deformation Division

National Bureau of Standards

Boulder, Colorado

\section{ABSTRACT}

A two-dimensional finite-element study of the compact specimen was performed in verification of its elastic compliance calibration functions. The finite-element results confirm Newman's boundary collocation solutions within $2 \%$. Empirical calibrations were also obtained using alloys with well-known elastic moduli. The numerical and empirical agreement depends on the state of stress assumed in the model, with better agreement for plane stress than for plane strain. Assuming plane stress and a Poisson's ratio of 0.3 , numerical solutions predict the true crack lengths within $4 \%$ or better for relative crack lengths, a/W, greater than 0.35 .

Key Words: Compact tension specimen; compliance; crack-mouth-opening displacement; elastic modulus; finite elements; numerical analysis.

*Work supported by Office of Fusion Energy, U.S. Department of Energy; not subject to copyright.

to be published in Engineering Fracture Mechanics.

**National Bureau of Standards Guest Worker, on leave from Department of Civil

Engineering and Mechanics, University of South Florida, Tampa, Florida. 



\section{INTRODUCTION}

Crack-opening-displacement measurements have been used in a wide variety of experimental fracture mechanics studies [1-5]. Such measurements provide a method of detecting crack initiation and growth, based on the fact that the specimen compliance, $V$, increases with increasing crack length, a. In this paper, compliance is defined simply as the ratio between the elastic-crackopening displacement, $\delta$, measured between two reference points spanning the crack surfaces, and the load, P.

The advantages and limitations of compliance techniques are reviewed elsewhere [6-12]. The accuracy of crack length predictions clearly depends on the validity of both the expression used to correlate $\delta / P$ and $a$, and the experimental uncertainties of the relevant physical measurements and material elastic properties [13-17]. To obtain accurate correlations, experimentalists sometimes develop their own empirical calibration curves. This tedious procedure is necessary for some less-common specimen configurations [6], but in general, it is far more efficient to employ the published analytical expressions that are available for standard specimens. In the latter case, slight adjustments may be desirable for reasons described in the text.

A number of analytical calibrations have been published for compact specimens [18-30]. The elastic compliance calibration functions are usualiy given in normalized form by polynomial expressions as follows:

$$
E B V=f(a / W)
$$

where $E$ is Young's modulus, $B$ is specimen thickness, $W$ is specimen width, and $V_{i}=\delta_{j} / P$. In this notation, $i=0$ designates measurements at the specimen edge, and $i=L$, the load line. Earlier solutions to obtain the calibration 
functions employed boundary collocation techniques because of the difficulty at the time of characterizing the crack-tip singularity with finite elements [24]. These functions so derived have been incorporated into standard fracture mechanics test procedures. This paper examines the reliability of the existing collocation solutions based on a combination of some new finiteelement calculations and physical measurements. Calibration functions for standard and modified compact specimens are considered.

\section{EXPERIMENTAL PROCEDURE}

Numerical Calculations by Finite Elements

Two compact tension specimen configurations were analyzed using the POLO-FINITE program [31]. These two specimens are recommended in the ASTM standards for $K_{I c}$ and $J_{I c}$ testing $[32,33]$. Typical finite-element idealizations of these configurations, shown in Figs. 1 and 2 , consisted of 8-node quadrilateral isoparametric finite elements [34]. The crack-tip idealization shown in Fig. 3 illustrates how the quadrilateral elements adjacent to the crack were collapsed to zero length with the midside nodes of adjacent faces at quarterpoints to exactly model the elastic $1 / \sqrt{ } r$ strain singularity $[31,35,36]$. Figure 4 illustrates the three types of pinhole loadings investigated.

The numerical results depend on assumptions about the stress state and elastic properties. Plane strain was assumed, and because of symmetry, only one-half of each specimen was idealized. The plane stress displacements and compliance functions were obtained by conversion from the plane strain results [24].

Specimen Designs

Compact specimens having either the standard $K_{I c}$ configuration or that shown in Fig. 5 were machined from the AISI 316 stainless steel and 2024-T351 
aluminum alloys described in Table 1 . These served as calibration specimens to confirm the analytical results. The configuration of Fig. 5 is the J-integral specimen often used at NBS; it specifies cutouts for knife-edge positioning at the load line, and to facilitate this modification the pinhole centers are shifted slightly to $0.3 \mathrm{~W}$ from the notch plane centerline. The standard $K_{I C}$ specimen is diagramed in ASTM E 399-83 and it specifies pinhole centers at $0.275 \mathrm{~W}[32]$. All specimens were of the TL orientation with $B=$ $25 \mathrm{~mm}$ and $W / B=2$. Razor-blade knife edges were spot-welded to the edge or load line positions and ASTM E399-83 clevises were used.

\section{Elastic Properties}

Young's modulus, E, and Poisson's ratio, $\nu$, of the calibration materials were measured ultrasonically at $295 \mathrm{~K}$ using cubic specimens $\left(1.95 \mathrm{~cm}^{3}\right)$. Results are listed in Table 1. The ultrasonic technique [37-39] gives dynamic moduli $\left(E_{d}\right)$ with uncertainties of $\pm 1 \%$, whereas conventional tensile tests give static moduli $\left(E_{s}\right)$ with uncertainties of $\pm 5-10 \%$. For this reason, ultrasonic data are preferable.

The elastic moduli at $76 \mathrm{~K}$ were not measured directly but were estimated as follows:

$$
E_{76} \cong E_{295}\left(E_{76}^{1} / E_{295}^{1}\right)
$$

Here $E_{295}$ is the measured value at $295 \mathrm{~K}$ for the present alloys; $E_{76}^{1}$ and $E_{295}^{1}$ are ultrasonic data for other heats [38-39]. Physical Crack-Length-Compliance Measurements

Displacements were measured with a clip-gage meeting the requirements of section 6.3 of ASTM E 399-83. Using an extensometer micrometer, calibrations with a repeatability $\pm 0.5 \%$ were performed at each temperature, 295 and $76 \mathrm{~K}$. 
To obtain EBV, specimens were fatigue tested at $20 \mathrm{~Hz}$ with periodic interruptions for single-cycle loading at $0.02 \mathrm{~Hz}$. At this lower rate, the load cell and clip-gage outputs were put into a minicomputer after analog-digital conversion, and $V_{0}$ or $V_{L}$ for each crack length was calculated by the method of least squares. Typically, 180 readings were input from the upper half of the $\delta$ vs $P$ records but data from the lower half were excluded to avoid crack-closure effects.

To correlate EBV with a/W, crack-front markings were created on the failure surface by altering the stress ratio, $R=P_{\min } / P_{\max }$, between 0.1 and 0.5 with $P_{\max }$ held constant. The physical crack lengths were then measured from the failure surfaces after testing, taking the average of five readings ( 2 at the specimen edges, 2 at the quarter points of thickness, and 1 at the midthickness). This method of crack-front marking simulates actual fatigue tests and is preferable to saw-cutting or machining successively deeper notches, since those procedures would reduce the specimen stiffness by removing material.

The precision of both the 1 oad cell and gage output was $\pm 0.01 \mathrm{mV}$ as read from a digital voltmeter. The linear correlation coefficients for $V$ were 0.999 or better, and the repeatability of individual crack length determinations was $\pm 0.025 \mathrm{~mm}$. The specimen dimensions were measured to the nearest $0.025 \mathrm{~mm}$, and the physical crack length was measured to the nearest $0.5 \%$. RESULTS

Numerical Calculations

For the standard $K_{\text {IC }}$ specimen of ASTM E 399-83 [32], Fig. 6 compares the present finite-element results with the results of Newman [23-25], who used boundary collocation to obtain his solutions. Shown are results for plane 
strain with $v=0,0.3$, and 0.5 . The finite-element solution blows up at $v=0.5$, so only results at $v=0$ and $v=0.3$ are given. The finite-element idealization modeled the machined notch tip, whereas the collocation procedure did not. This is a minor distinction, however, and the two compliances for $V_{0}$ agree within 1\%. The present results, therefore, confirm Newman's solutions.

For the recommended $J_{\text {IC }}$ specimen of ASTM E 813-81 [33], it was of interest to determine whether the modifications made to allow load-line displacement measurements would significantly affect $V_{L}$. In Fig. 7 finiteelement calculations for this specimen are compared with the $V_{L}$ collocation results [24] for the standard $K_{I C}$ specimen without modifications. In this case, the agreement is typically better than $1 \%$ and never exceeds $2 \%$, indicating that the effect of notch modifications on load-line displacements for the J $J_{\text {Ic }}$ specimen can, indeed, be ignored.

Three different assumptions about loading conditions were modeled for both the standard $K_{I C}$ and $J_{I C}$ specimen configurations, as illustrated in Fig. 4, but the effects of these variations on $V_{0}$ and $V_{L}$ were found to be negligible (less than $0.5 \%$ ), once again confirming Newman [24].

Empirical Observations

The experimentally measured compliances are 1 isted in Tables 2 and 3 , while comparisons between the numerical results of Newman [24,27] and experimental data are shown in Figs. 8 and 9 for edge and load-line displacements.

As shown in Tables 4 and 5 , the experimental calibrations agree best with the numerical solutions assuming plane stress, while the agreement assuming plane strain is relatively poor. An apparent agreement is achieved assuming plane strain with $v=0$, but this is fortuitous, since $v$ is nearly 0.3 for the materials tested. As shown in Fig. 7, $v$ has a strong effect in plane strain; 
the percent difference between EBV $\mathrm{L}_{\mathrm{L}}$ for $v=0$ and $v=0.5$ is on the order of $20 \%$, depending on $a / W$. Therefore, when plane strain is assumed with $v=$ 0.3 instead of $v=0.0$, the calibration function is altered so that experimental agreement is poor.

However, reasonable agreement is achieved with models assuming plane stress, in which case Poisson's ratio has negligible effect on the numerical results. Assuming plane stress with $v=0.3$, the disparity between the measured and calculated $V_{0}$ and $V_{L}$ is not more than $4 \%$ at $a / W=0.35$, and it decreases to 1 ess than $2 \%$ for longer cracks, $a / W \geq 0.5$. Since an error of $2 \%$ or less borders on experimental uncertainty, the calibrations are in virtual agreement at $a / W \cong 0.5$. At the 1 ower a/W ratios where the errors are measurable, the numerical results slightly underestimate $V_{0}$ and slightly overestimate $V_{L}$.

The experimental data were fitted with curves similar to those used for the numerical solutions so that quantitative comparisons in Tables 4 and 5 could be made at convenient a/W ratios.

\section{DISCUSSION}

The main contributions of the present study are: First, the two-dimensional finite-element analysis undertaken shows that it is possible to apply the finite-element method to the compact specimen with results equivalent to a boundary collocation method. Second, the question of the uncertainty of Young's modulus on the normalization parameter, EBV, is addressed experimentally by using calibration materials with ultrasonically measured elastic constants. Hence, the numerical and empirical calibration functions can be more accurately compared. Finally, the experimental results also confirm that $E$ is truly a linear scaling factor and normalizing 
parameter. In this study $E$ was varied experimentally by altering the alloy composition or the test temperature. Temperature has no inherent effect on the calibration curves if the appropriate values of $E$ and displacement gage calibrations are used.

In general, the calculated and experimental displacement calibration functions must inevitably show some disagreement. Fundamental errors may arise from failure of the model to replicate the specimen in full detajl or from assumptions about the stress state and elastic properties, as discussed below. Uncertainty also attends physical measurements, with possible errors arising from instrumentation, mismachining, or friction in the clevis grips. These errors would tend to alter the calibration functions by introducing nonlinear effects; such effects are thought to be minor for the compact specimens and modifications. studied here, but perhaps they contribute to the results in Fig. 9 .

Overall, the finite-element results of this study confirmed the results of Newman in several respects, including his finding that the empirical data agree better with numerical solutions for plane stress than for plane strain. We think this is fortuitous to some extent, since the analytic models assume a two-dimensional problem with conditions of either plane strain or plane stress, whereas the specimens actually have three dimensions, and the stress state varies with thickness, approaching plane stress only at the surfaces. In any case, the relative success of the plane stress solution justifies its practical use and incorporation into standard procedures (e.g., Table Al.1 of ASTM E 813-81 [33]).

Using the analytical solution of Saxena and Hudak [2?] for plane stress to predict the specimen behavior, several authors cite Young's modulus as the major source of systematic error in determining the normalizing parameter, 
EBV $[2,12]$. Usually $E$ is not precisely known for the alloy being tested, so it must be estimated. Some recent publications are helpful in these estimations. For example, Young's moduli for forty engineering alloys between 590 and $0 \mathrm{~K}$ are now available from a single source [37]. Yet, sizable error remains since heat-to-heat uncertainties can amount to 5\% [37] or, in extreme cases, 15\% [12]. For this reason, the use of handbook values or other estimates of $E$ limits accuracy, and most experimentalists employ correction factors to the published numerical solutions to obtain more accurate calibration curves for physical crack length predictions.

Since $E$ is considered to be the major source of uncertainty, an "effective modulus" correction is often adopted. According to this method, an effective modulus, $E_{\text {eff }}$, is deduced from the calculated and measured EBV data. First, $E$ is estimated for the test material, and then a comparison in terms of the ratio of the measured-to-predicted EBV reveals a mismatch. This ratio multiplied times $E$ is taken as $E_{\text {eff }}$ and is substituted back into the calculations to correct for the mismatch.

Then:

$$
E_{e f f} B V=f(a / W)
$$

Usually, $E_{\text {eff }}$ is deduced from one well-defined crack front (perhaps the final fatigue crack length) that is visible on the post-test failure surface. This factor to linearly shifts the analytical curve, which then predicts the physical crack lengths over the entire range of $\mathrm{a} / \mathrm{W}$.

Actually, the effective modulus is a simplified correction factor that compensates for all errors regardless of source. It approximately accounts for the linear errors in E, as well as any nonlinear errors from other sources, 
including any error in the analytical approach that uses a two-dimensional model for a three-dimensional specimen. In the present paper, the uncertainty normally associated with $E$ was minimized by employing ultrasonic measurements at $295 \mathrm{~K}$. Consequent7y, $\mathrm{E}$ was known with good accuracy (1\%), and the remaining disparity between numerical and empirical calibrations (Fig. 9) was attributable to other sources.

The findings suggest that when using a correction factor, it may be desirable to determine the effective modulus correction for relatively deep cracks first, and then use a second correction factor determined from Fig. 9 to obtain better accuracy in predicting shorter crack lengths. SUMMARY AND CONCLUSIONS

A finite-element modeling of the edge $\left(V_{0}\right)$ and load-line $\left(V_{L}\right)$ elastic compliances for compact specimens is described. The finite-element solutions are compared with existing boundary collocation solutions and with empirical data for alloys of well-known elastic properties and a/W ratios from 0.3 to 0.7. Plane strain was assumed and the results were also converted to obtain solutions in plane stress. The physical crack curvature was accounted for using a five-point average experimental crack length measurement. Conclusions are:

1) The present finite-element and published collocation solutions agree within $2 \%$ or less.

2) Assuming plane stress with $v=0.3$, the numerical solutions are in near agreement with experiment: $V_{0}$ is slightly overpredicted, while $V_{L}$ is slightly underpredicted, but the differences do not exceed $4 \%$ at $a / W=0.35$, and at higher $a / W$ the differences are negligible.

3) Various assumptions about pin loading, a slight shift of the pinhole location, and moderate notch modifications to locate knife edges at 
the load-line in J-integral test specimens do not have significant effects on the calibrations.

\section{ACKNOWLEDGMENTS}

The elastic constants were measured by $\mathrm{Dr}$. H. M. Ledbetter with assistance from M. W. Austin. Helpful discussions with them and with Drs. Y. W. Cheng, D. T. Read, and R. H. Dodds are gratefully acknowledged.

\section{REFERENCES}

1. H. I. McHenry, Journal of Materials 6 (1971) 862-873.

2. R. J. Bucci, B. N. Greene, and P. C. Paris, in: Progress in Flaw Growth and Fracture Toughness Testing, ASTM STP 536, American Society for Testing and Materials, Philadelphia (1973) 206-228.

3. C. W. Fowlkes and R. L. Tobler, Engineering Fracture Mechanics 8 (1976) 487-500.

4. A. M. Sullivan and T. W. Crooker, Engineering Fracture Mechanics 9 (1977) $159-166$.

5. R. C. Donath, T. Nicholas, and L. S. Fu, in Fracture Mechanics:

Thirteenth Conference, ASTM STP 743, American Society for Testing and Materials, Philadelphia (1981) 186-206.

6. A. E. Carden, Welding Research Council Bulletin 283 (1983) 1-11.

7. R. T. Bubsey, M. H. Jones, and W. F. Brown, Jr., Materials Research and Standards 9 (1969) 32-37.

8. R. T. Bubsey, D. M. Fisher, M. H. Jones, and J. E. Srawley, in: Experimental Techniques in Fracture Mechanics, A. S. Kobayashi, Ed., Iowa State University Press and Society for Experimental Stress Analysis, Ames, Iowa (1973) 76-95.

9. W. F. Brown, Jr. and J. E. Srawley, Plane Strain Crack Toughness Testing of High Strength Metallic Materials, ASTM STP 410, American Society for Testing and Materials, Philadelphia (1966) 81-85.

10. T. V. Duggan and M. W. Proctor in: The Measurement of Crack Length and Shape during Fracture and Fatigue, C. J. Beevers, Ed., Chameleon Press, London (1980) 1-27.

11. D. A. Curry and J. Milne, in The Measurement of Crack Length and Shape During Fracture and Fatigue, C. J. Beevers, Ed., Chameleon Press, London (1980) 401-433. 
12. G. R. Yoder, L. A. Cooley, and T. W. Crooker, in Fatigue Crack Growth Measurement and Data Analysis, ASTM STP 738, S. J. Hudak, Jr. and R. J. Bucci, Eds., American Society for Testing and Materials, Philadelphia (1981) 85-102.

13. D. L. Dul1, J. D. Buch, and L. Raymond, Engineering Fracture Mechanics 4 (1972) 523-531.

14. A. M. Sullivan, NRL Report 7888, Naval Research Laboratory, Washington, D.C. (1975) 1-31.

15. J. T. Ryder, G. E. Bowie, and D. E. Pettit, Engineering Fracture Mechanics 9 (1977) 901-923.

16. T. Nicholas, N. E. Ashbaugh, and T. Weerasooriya, On the use of compliance for determining crack length in the inelastic range, to be published.

17. R. L. Hewitt, Journal of Testing and Evaluation 11 (1983) 150-155.

18. B. Gross, E. Roberts, Jr., and J. E. Srawley, International Journal of Fracture Mechanics 4 (1968) 267-276.

19. E. Roberts, Jr., Materials Research and Standards 9 (1969) 27.

20. W. K. Wilson, Engineering Fracture Mechanics 2 (1970) 169-171.

21. M. J. Orloski, Journal of Research 74C (1970) 21-27.

22. J. E. Srawley and B. Gross, Engineering Fracture Mechanics 4 (1972) 587-589.

23. J. C. Newman, Jr., NASA Tech Note, NASA TN D 6736 (1971) 1-45.

24. J. C. Newman, Jr., in Fracture Analysis, ASTM STP 560, American Society for Testing and Materials, Philadelphia (1974) 105-121.

25. J. C. Newman, Jr., NASA Tech Note, NASA TN D 8268 (1976) 1-31.

26. J. E. Srawley, International Journal of Fracture 12 (1976) 475-476.

27. A. Saxena and S. J. Hudak, Jr., International Journal of Fracture 14 (1978) 453-468.

28. T. J. Rudolphi, AFML-TR-78-113 (1978).

29. E. T. Wessel, Engineering Fracture Mechanics 1 (1968) 77-103.

30. T. V. Duggan, M. W. Proctor, and L. J. Spence, International Journal of Fatigue 1 (1979) 37-47.

31. L. A. Lopez, R. H. Dodds, Jr., D. R. Rehak, and J. Urzua, POLO-FINITE, A Structural Mechanics System For Linear and Nonlinear Analys is, Department of Civil Engineering and the Academic Computer Center, University of Kansas, Lawrence, Kansas (1983). 
32. Standard Test Method for Plane Strain Fracture Toughness of Metallic. Materials, ASTM Designation E 399-83, 1983 Annual Book of ASTM Standards, American Society for Testing and Materials, Philadelphia (1983) 518-553.

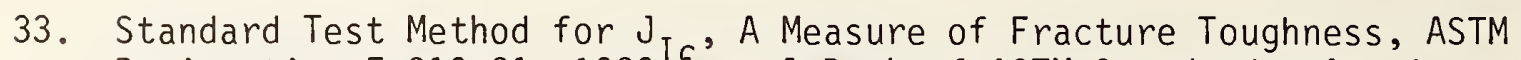
Designation E 813-81, 1983 Annual Book of ASTM Standards, American Society for Testing and Materials, Philadelphia (1983) 762-780.

34. 0. C. Zienkiewiez, The Finite Element Method in Engineering Science, McGraw-Hi11, New York (1971).

35. S. L. Pu and M. A. Hussain, International Journal for Numerical Methods in Engineering 12 (1978) 1727-1742.

36. R. S. Barsoum, International Journal for Numerical Methods in Engineering 11 (1977) 85-98.

37. H. M. Ledbetter, Cryogenics 22 (1982) 653-656.

38. E. R. Naimon, H. M. Ledbetter, and W. F. Weston, Journal of Materials (1975) $1309-1316$.

39. H. M. Ledbetter, W. F. Weston, and E. R. Naimon, Journal of Applied Physics 46 (1975) 185-194.

\section{LIST OF TABLES}

1. Calibration specimen materials and their elastic properties at $295 \mathrm{~K}$.

2. Crack length and edge compliance $\left(V_{0}\right)$ data tabulation.

3. Crack length and load-line compliance $\left(V_{L}\right)$ data tabulations.

4. Normalized compliance, EBV ${ }_{0}$, for displacements at the specimen edge.

5. Normalized compliance, EBV $V_{L}$, for displacements at the specimen load line.

\section{LIST OF FIGURES}

1. A finite-element idealization for the $K_{\text {IC }}$ compact specimen of Fig. 1 .

2. A finite-element idealization for the $J_{\text {Ic }}$ compact specimen of Fig. 2.

3. Finite-element crack-tip substructure.

4. Three possible assumptions about pinhole loading.

5. An alternative $J_{I C}$ compact specimen used at NBS.

6. Finite-element results for the $K_{I c}$ compact specimen of Figure 1. 

7. Finite-element results for the recommended J Ic specimen with load-line
modification.

8. Comparison of numerical and experimental elastic displacement calibrations.

9. Relative agreement of numerical and experimental results. 
Table 1. Calibration specimen materials and their elastic properties at $295 \mathrm{~K}$.

\begin{tabular}{llcc}
\hline $\begin{array}{c}\text { Alloy } \\
\text { Designation }\end{array}$ & $\begin{array}{c}\text { Condition } \\
\text { and Form }\end{array}$ & $\begin{array}{c}\text { Young's Modulus, } \\
\text { E (GPa) }\end{array}$ & $\begin{array}{c}\text { Poisson's Ratio, } \\
\text { v }\end{array}$ \\
\hline 2024-T351 aluminum & $\begin{array}{l}\text { cold-worked 25.4-mm } \\
\text { bar }\end{array}$ & 73.45 & 0.343 \\
$\begin{array}{l}\text { AISI 316 stainless } \\
\text { steel }\end{array}$ & $\begin{array}{l}\text { annealed 50.8-mm } \\
\text { plate }\end{array}$ & 198.0 & 0.294 \\
\hline
\end{tabular}


Table 2. Crack length and edge compliance $\left(V_{0}\right)$ data tabulation.

\begin{tabular}{|c|c|c|c|c|c|c|}
\hline Alloy & $\begin{array}{l}\text { Crack L } \\
\text { (m } \\
\text { Measured, } \\
a_{m}\end{array}$ & $\begin{array}{l}\text { ength, a } \\
\text { m) } \\
\text { Predicted, } \\
a_{p}\end{array}$ & $\begin{array}{l}\text { Absolute } \\
\text { Difference, } \\
a_{m}-a_{p}(m m)\end{array}$ & $\begin{array}{l}\text { Percent } \\
\text { Difference, } \\
\left(a_{m}-a_{p}\right) / a_{m} \times 100\end{array}$ & $\begin{array}{l}\text { Relative } \\
\text { Crack } \\
\text { Length, } \\
\text { a/w }\end{array}$ & $E B V_{0}$ \\
\hline 2024-T351 & $\begin{array}{l}15.350 \\
16.000 \\
18.250 \\
19.175 \\
22.900 \\
24.600 \\
30.075 \\
30.375\end{array}$ & $\begin{array}{l}16.100 \\
16.775 \\
18.875 \\
19.825 \\
23.250 \\
25.050 \\
30.100 \\
30.350\end{array}$ & $\begin{array}{l}-0.750 \\
-0.775 \\
-0.625 \\
-0.650 \\
-0.350 \\
-0.450 \\
-0.025 \\
+0.025\end{array}$ & $\begin{array}{l}-4.88 \\
-4.84 \\
-3.42 \\
-3.39 \\
-1.53 \\
-1.83 \\
-0.083 \\
+0.082\end{array}$ & $\begin{array}{l}0.302 \\
0.315 \\
0.360 \\
0.378 \\
0.451 \\
0.485 \\
0.592 \\
0.600\end{array}$ & $\begin{array}{l}26.44 \\
27.75 \\
32.38 \\
34.87 \\
45.60 \\
53.10 \\
85.78 \\
88.41\end{array}$ \\
\hline
\end{tabular}


Table 3. Crack length and load-line compliance $\left(V_{L}\right)$ data tabulation.

\begin{tabular}{|c|c|c|c|c|c|c|}
\hline Alloy & $\begin{array}{l}\text { Crack } L \\
\text { Measured, } \\
a_{m}\end{array}$ & $\begin{array}{l}\text {-ength, a } \\
\text { nm) } \\
\text { Predicted, } \\
a_{p}\end{array}$ & $\begin{array}{c}\text { Absolute } \\
\text { Difference } \\
a_{m}-a_{p} \text { (mm) }\end{array}$ & $\begin{array}{l}\text { Percent } \\
\text { Difference } \\
\left(a_{m}-a_{p}\right) / a_{m} \times 100\end{array}$ & $\begin{array}{l}\text { Relative } \\
\text { Crack } \\
\text { Length, } \\
\text { a/W }\end{array}$ & $E_{0}$ \\
\hline 2024-T351 & $\begin{array}{l}15.525 \\
16.200 \\
18.325 \\
18.900 \\
21.525 \\
22.075 \\
25.050 \\
26.675 \\
28.025 \\
28.775 \\
30.325\end{array}$ & $\begin{array}{l}14.475 \\
15.125 \\
17.725 \\
18.250 \\
20.900 \\
21.550 \\
24.675 \\
26.100 \\
27.925 \\
28.450 \\
30.300\end{array}$ & $\begin{array}{l}1.050 \\
1.075 \\
0.600 \\
0.650 \\
0.625 \\
0.525 \\
0.375 \\
0.575 \\
0.100 \\
0.325 \\
0.025\end{array}$ & $\begin{array}{l}6.73 \\
6.64 \\
3.27 \\
3.44 \\
2.90 \\
2.38 \\
1.50 \\
2.15 \\
0.35 \\
1.13 \\
0.08\end{array}$ & $\begin{array}{l}0.306 \\
0.319 \\
0.361 \\
0.372 \\
0.424 \\
0.435 \\
0.493 \\
0.525 \\
0.552 \\
0.567 \\
0.597\end{array}$ & $\begin{array}{l}13.21 \\
14.10 \\
17.93 \\
18.83 \\
24.02 \\
25.47 \\
36.15 \\
39.45 \\
47.44 \\
50.26 \\
61.67\end{array}$ \\
\hline AISI 316 & $\begin{array}{l}19.800 \\
22.050 \\
23.225 \\
24.600 \\
26.350 \\
28.000 \\
33.775\end{array}$ & $\begin{array}{l}19.075 \\
21.675 \\
22.400 \\
24.000 \\
25.950 \\
27.675 \\
33.650\end{array}$ & $\begin{array}{l}0.725 \\
0.375 \\
0.825 \\
0.600 \\
0.400 \\
0.325 \\
0.125\end{array}$ & $\begin{array}{l}3.66 \\
1.70 \\
3.55 \\
2.44 \\
1.52 \\
1.16 \\
0.37\end{array}$ & $\begin{array}{l}0.391 \\
0.435 \\
0.458 \\
0.485 \\
0.520 \\
0.552 \\
0.666\end{array}$ & $\begin{array}{l}20.46 \\
26.02 \\
27.91 \\
32.45 \\
39.33 \\
47.01 \\
95.08\end{array}$ \\
\hline
\end{tabular}


Table 4. Normalized compliance, EBV ${ }_{0}$, for displacements at the specimen edge.

Boundary Collocation $(v=0.3)$
Finite-Element Solution

$(v=0.3)$
Experiment Results

\section{a/W Plane Strain Plane Stress Plane Strain Plane Stress $(v=0.294$ or 0.343$)$}

0.322 .54

0.4

0.45

32.80

40.24

0.5

49.72

0.6

80.90

0.7

152.46

0.75

223.3
24.90

36.18

44.23

54.76

89.02

165.48

245.4
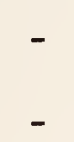

35.1

49.6

80.6

149.3

221.1
26

37

38.5

45

56

89

Table 5. Normalized compliance, EBV $V_{L}$, for displacements at the specimen load line.

Boundary Collocation $(v=0.3)$
Finite-Element Solution $(v=0.3)$
Experiment Results

\section{a/W Plane Strain Plane Stress Plane Strain Plane Stress $(\nu=0.294$ or 0.343$)$}

$\begin{array}{lccccc}0.3 & 12.98 & 14.26 & - & - & 13 \\ 0.4 & 20.78 & 22.84 & - & - & 21.5 \\ 0.45 & 26.35 & 28.96 & 25.7 & 28.24 & 27.5 \\ 0.5 & 33.65 & 36.99 & 33.0 & 36.27 & 36 \\ 0.6 & 57.02 & 63.32 & 56.1 & 61.65 & 62 \\ 0.7 & 114.24 & 125.55 & 110.1 & 121.0 & 123 \\ 0.75 & 168.7 & 185.4 & 166.2 & 182.65 & -\end{array}$




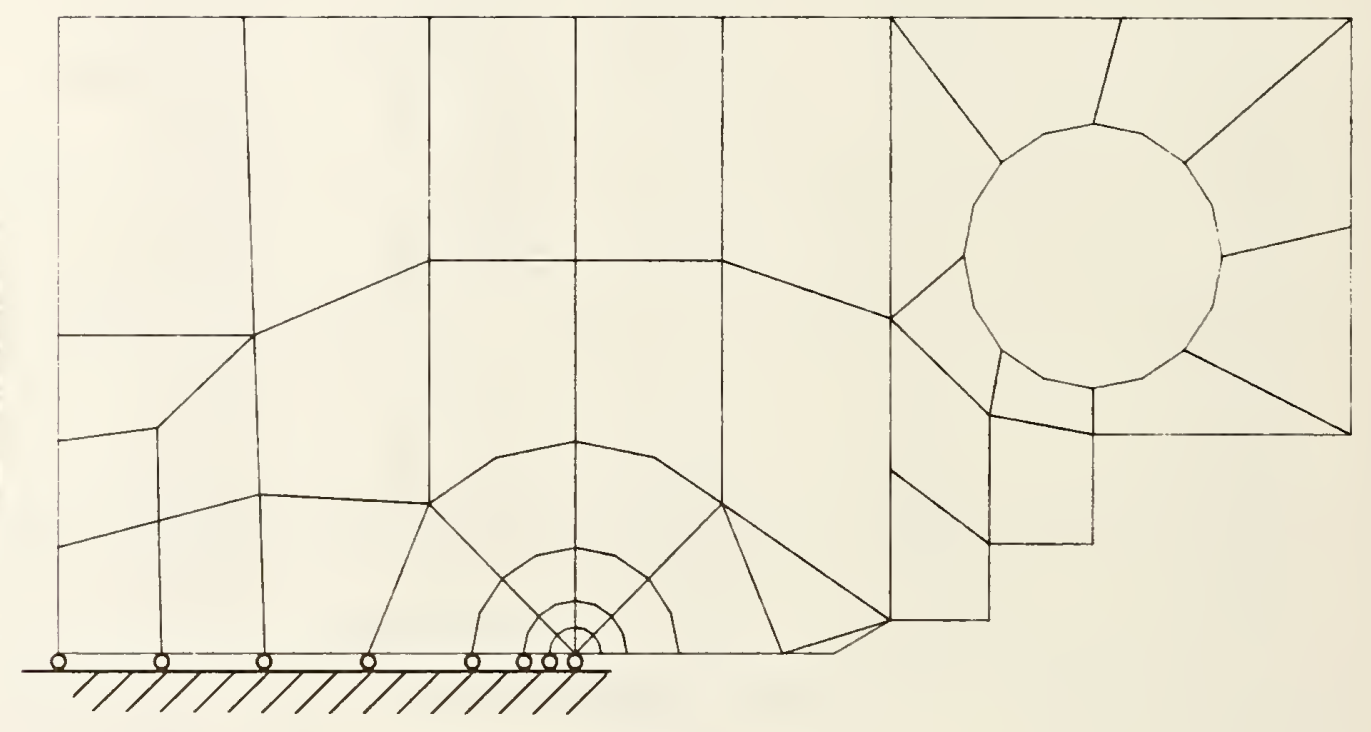

Fig. 1. A finite-element idealization for the $K_{I c}$ compact specimen of Fig. 1 .

200 


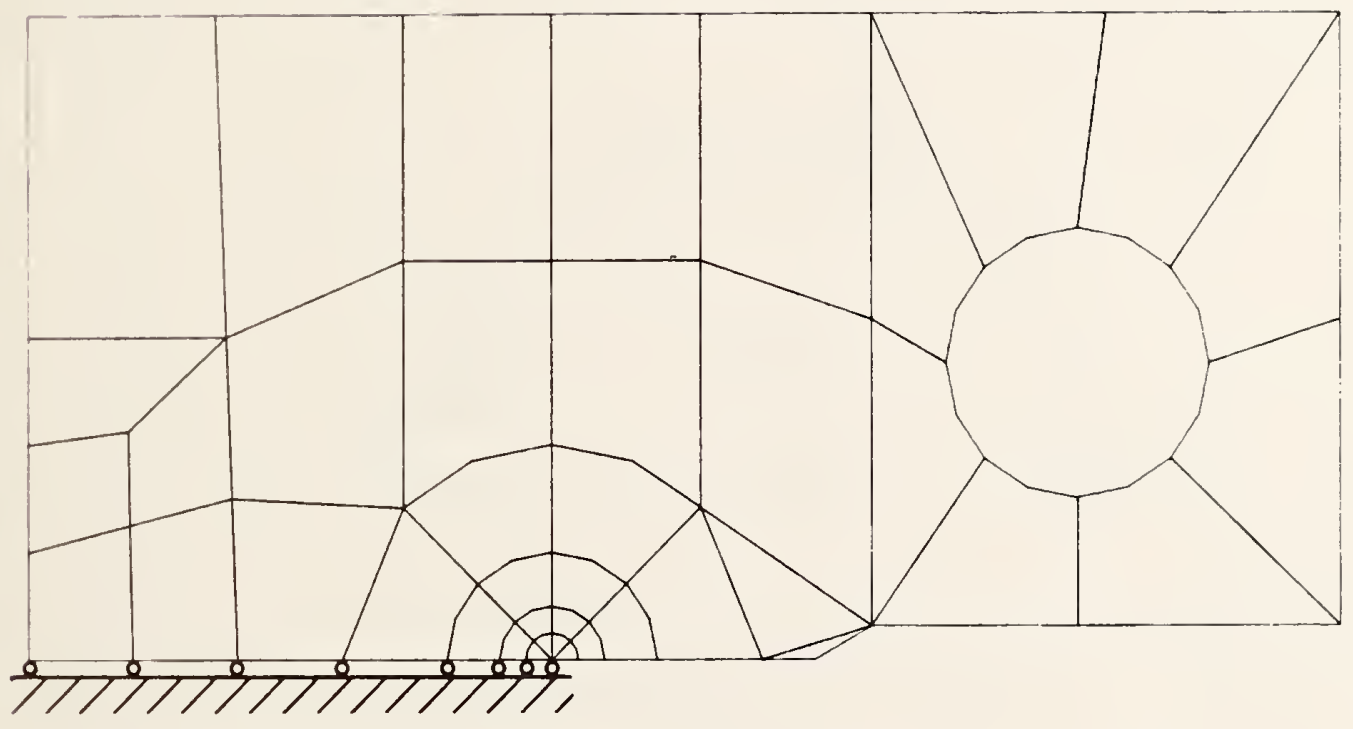

Fig. 2. A finite-element idealization for the $\mathrm{J}_{\text {Ic }}$ compact specimen of Fig. 2. 


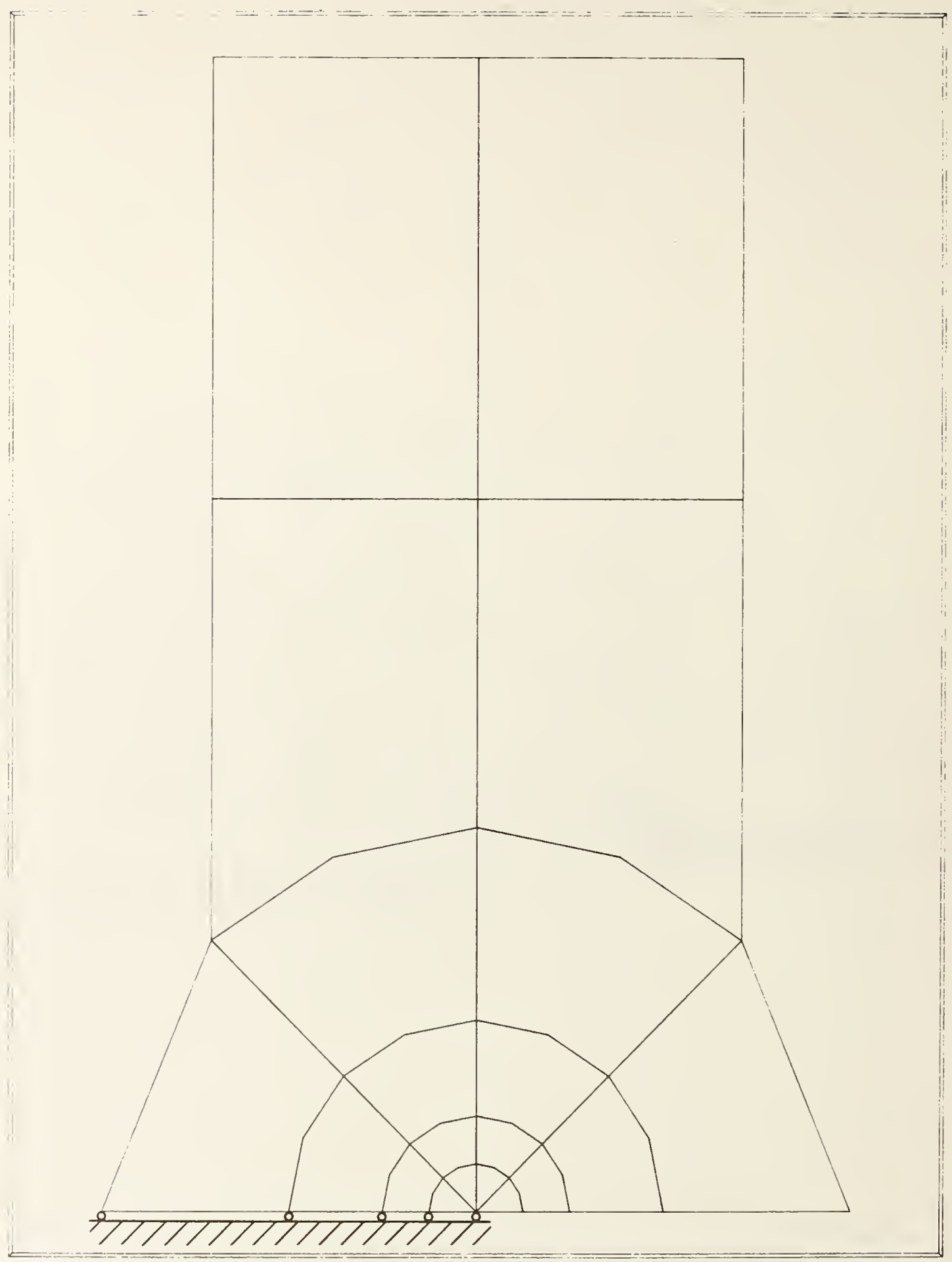

Fig. 3. Finite-element crack-tip substructure. 

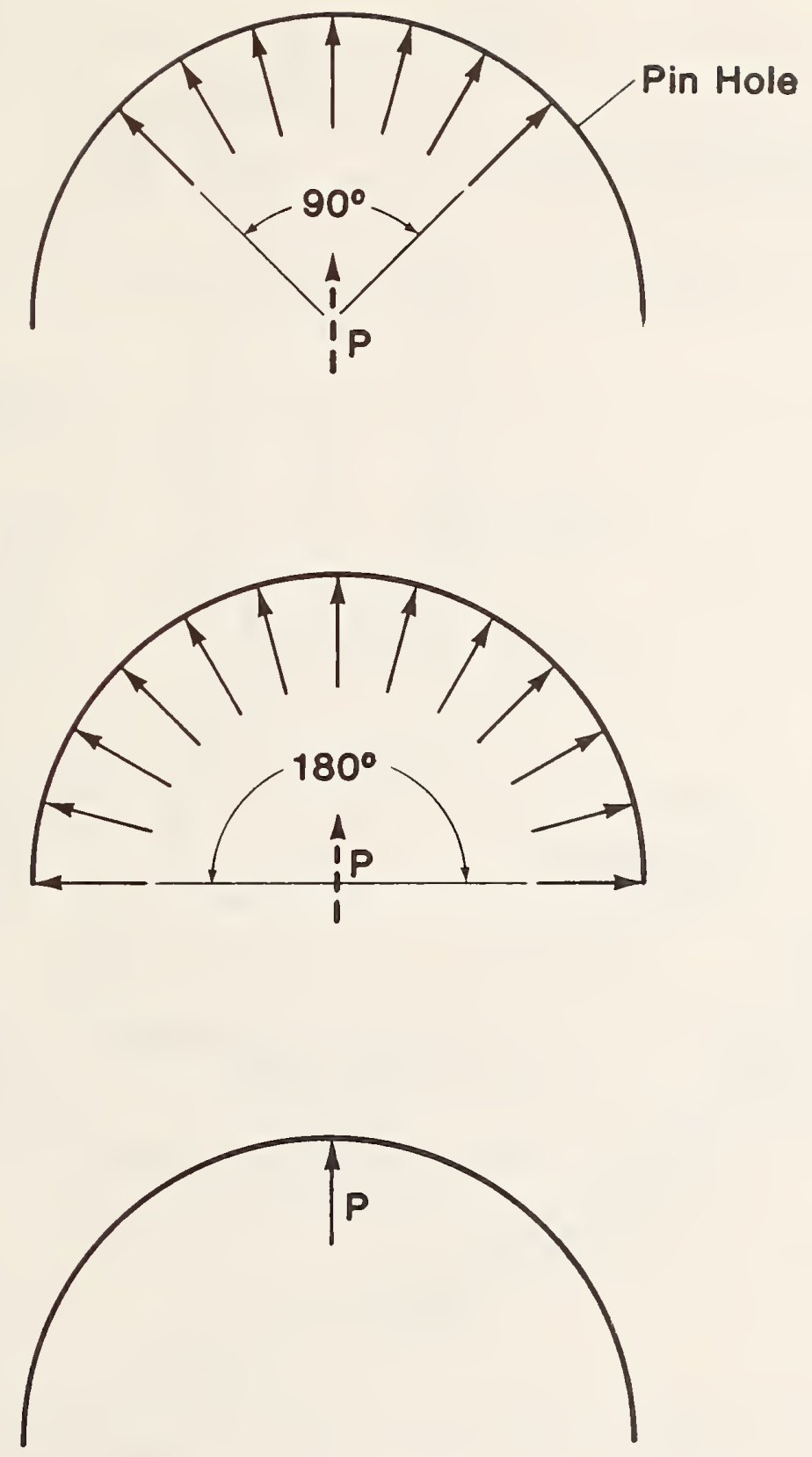

Fig. 4. Three possible assumptions about pinhole loading. 


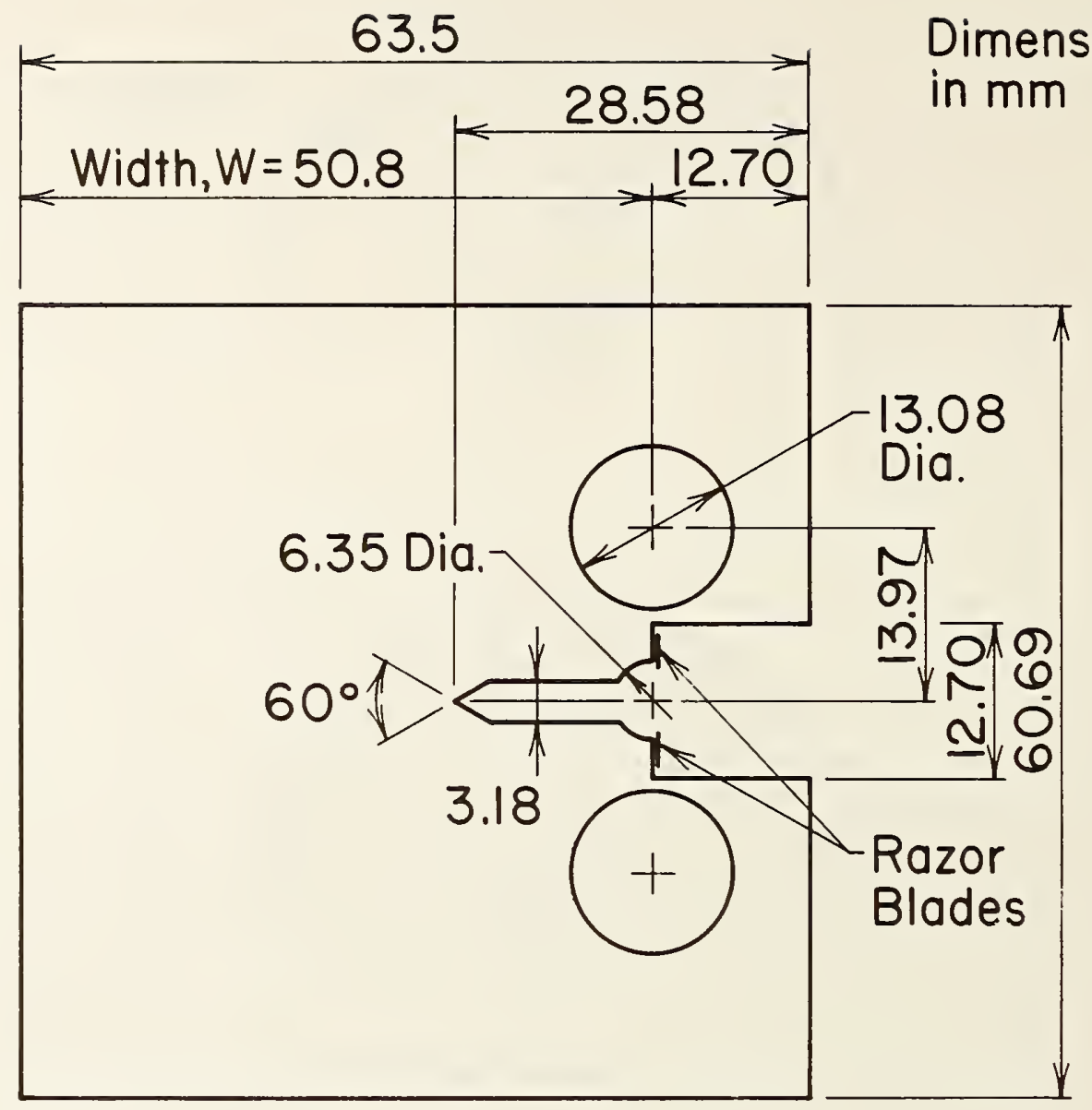

Fig. 5. An alternative $\mathrm{J}_{\mathrm{Ic}}$ compact specimen used at NBS. 


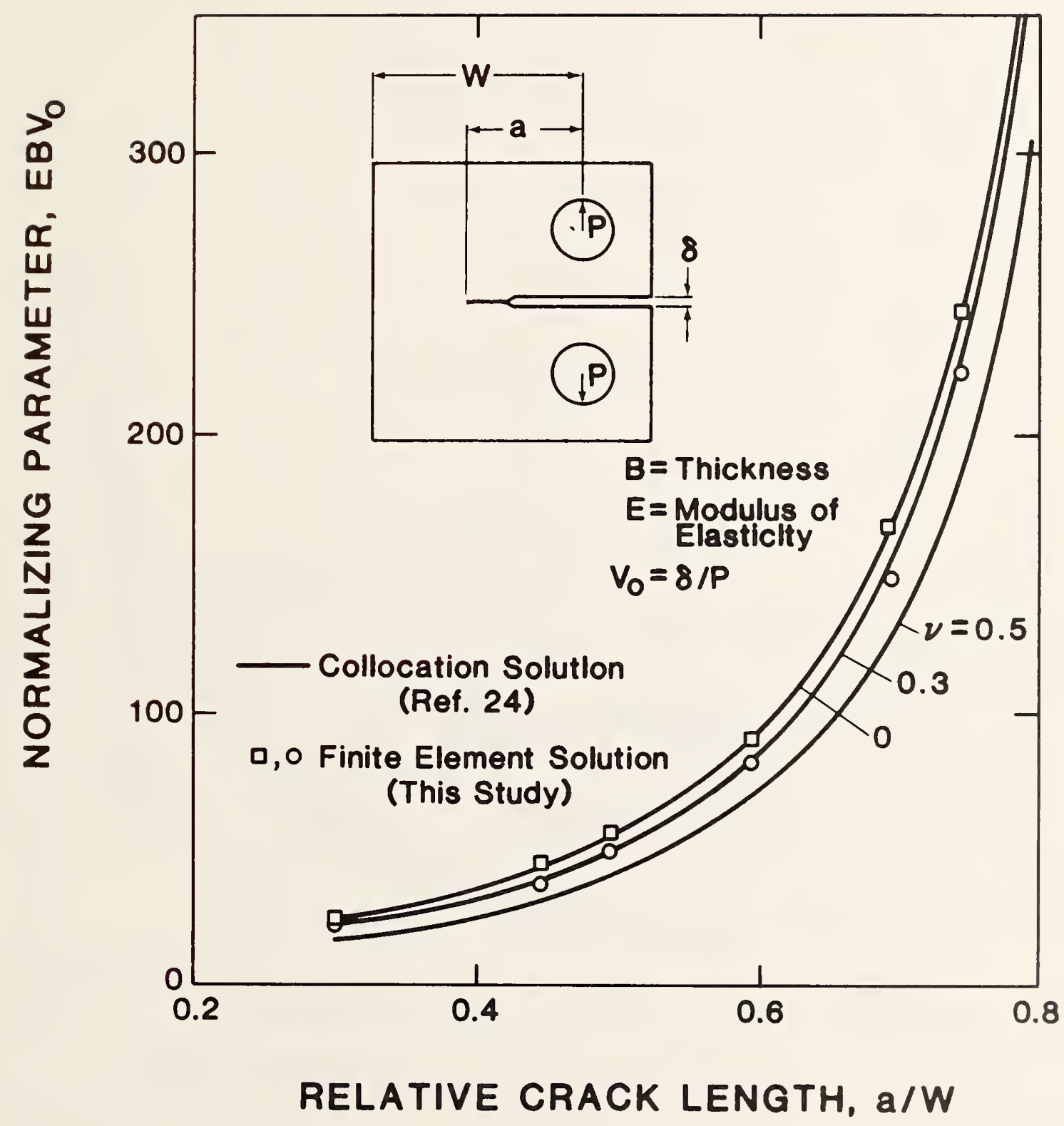

Fig. 6. Finite-element results for the $K_{\text {Ic }}$ compact specimen of Figure 1. 


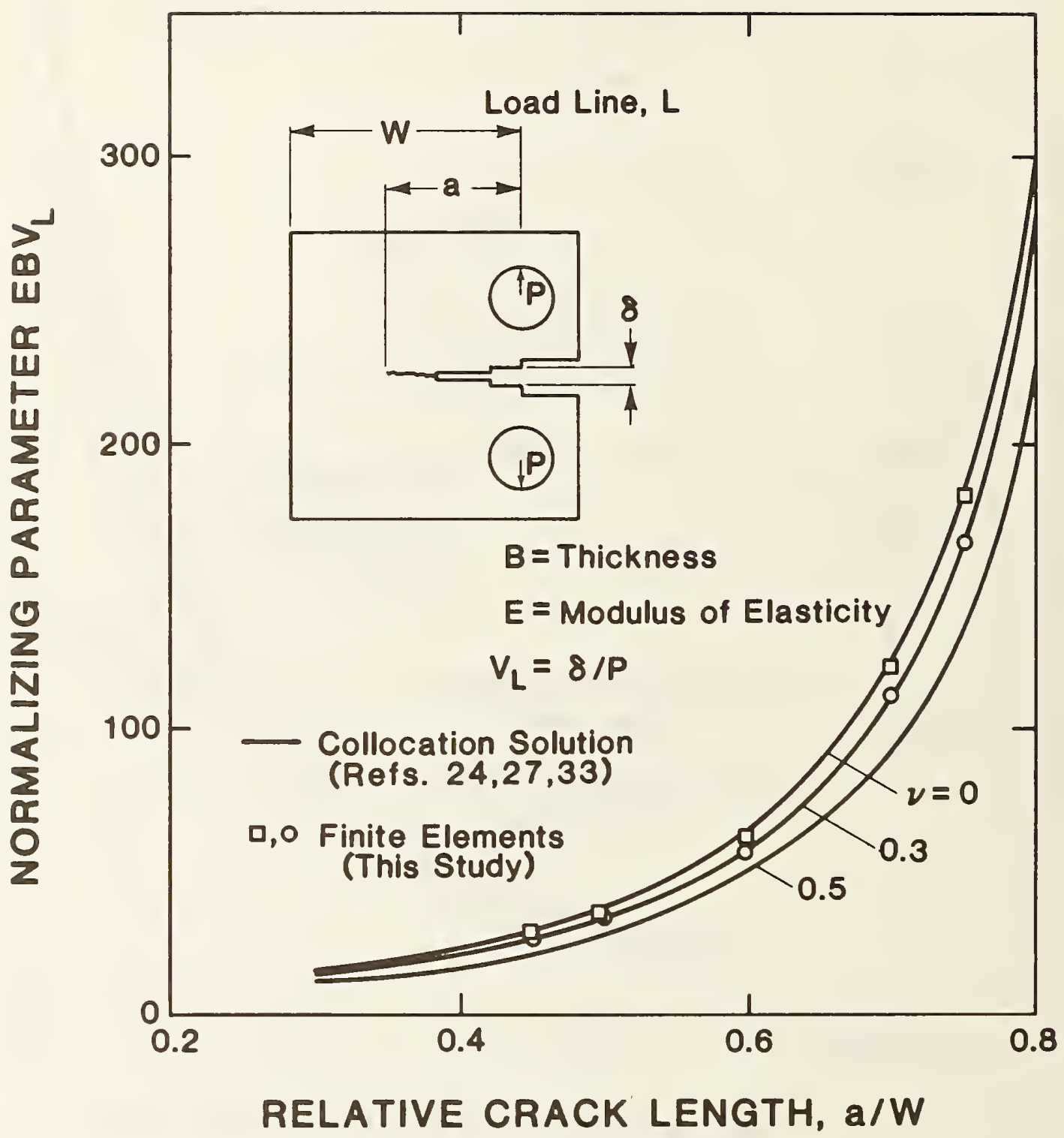

Fig. 7. Finite-element results for the recommended $J_{I c}$ specimen with load-line
modification. 


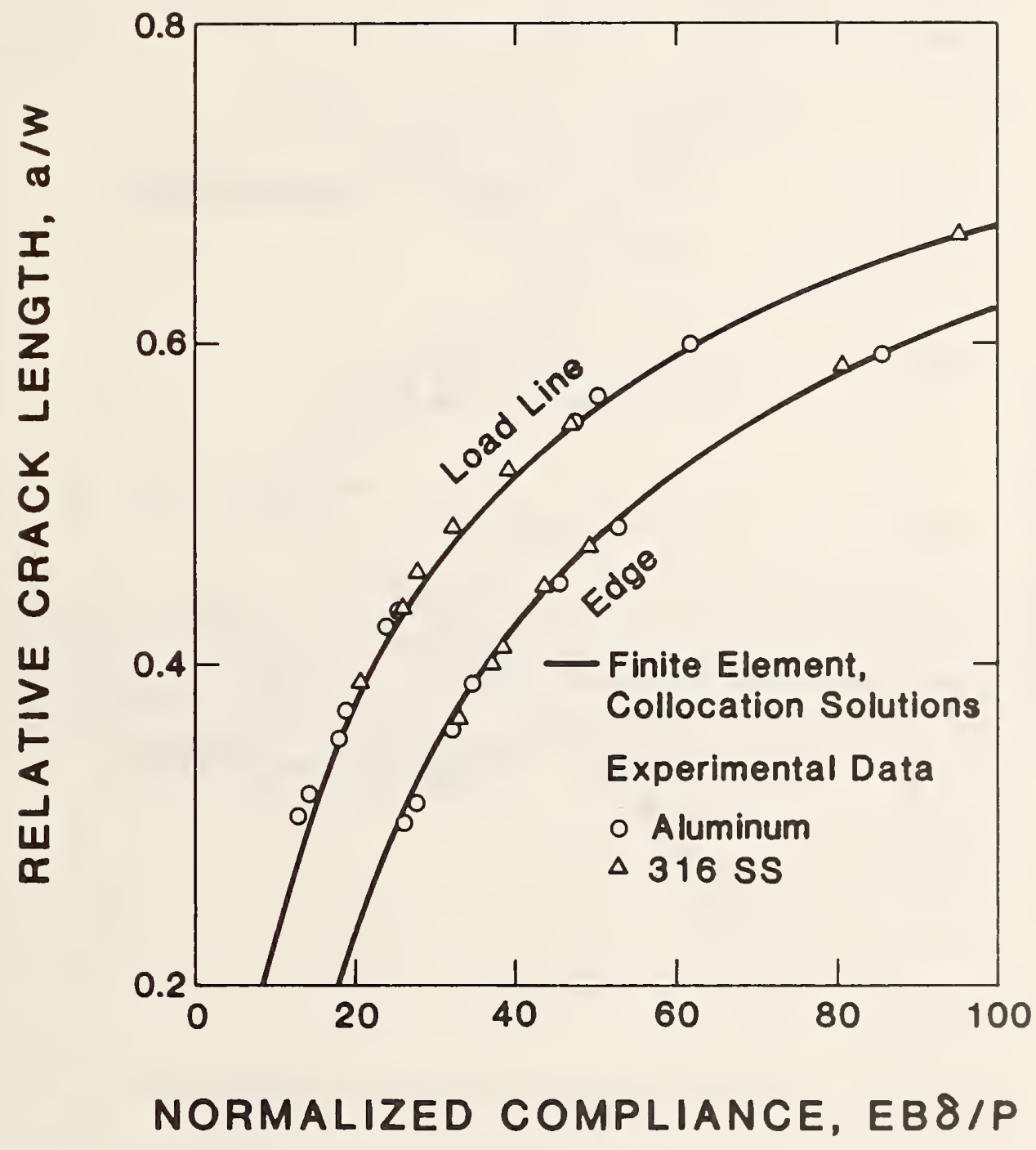

Fig. 8. Comparison of numerical and experimental elastic displacement calibrations. 


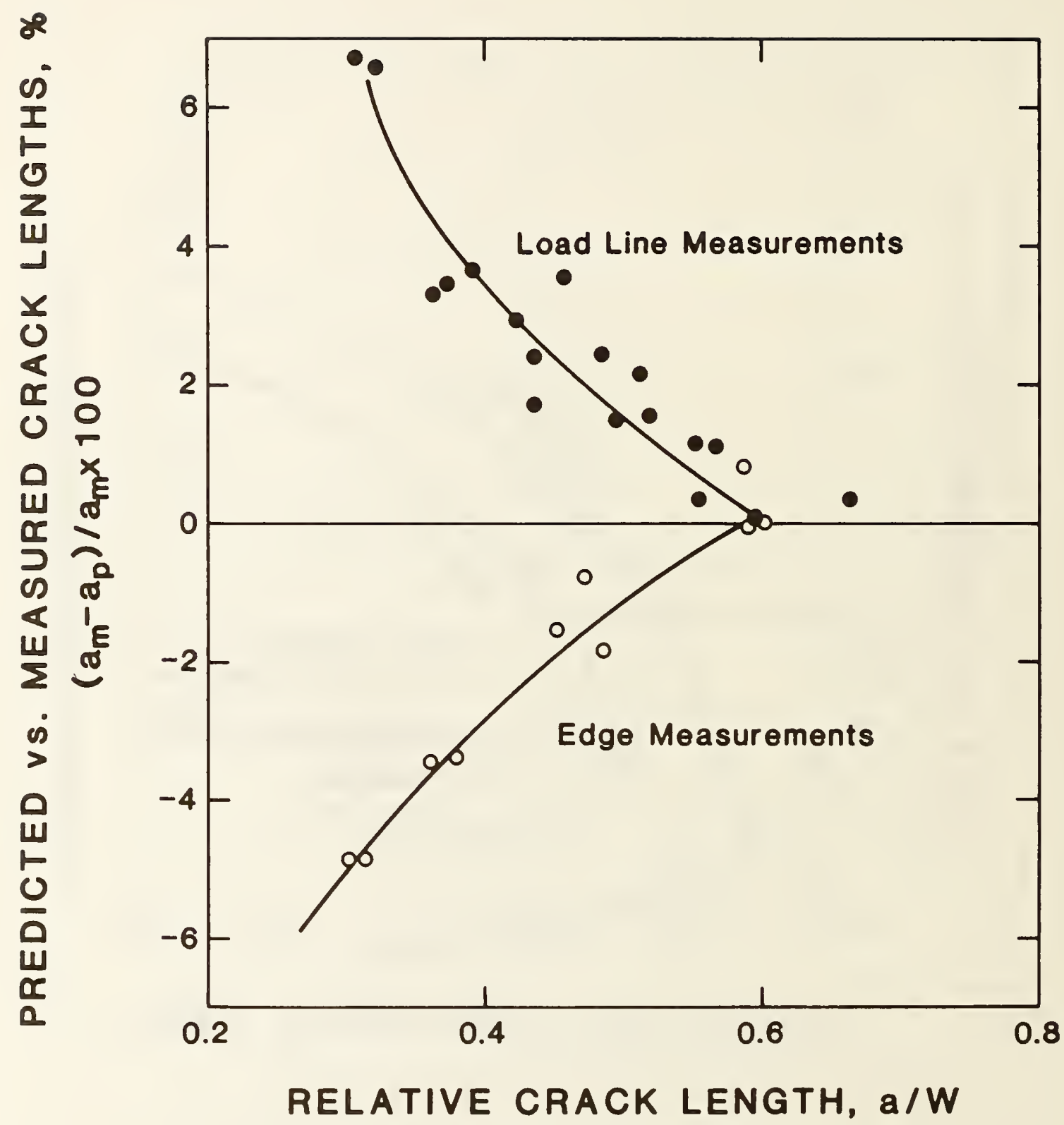

Fig. 9. Relative agreement of numerical and experimental results. 


\title{
Design and Performance of a Ring-Shaped Clip Gage for Fracture Mechanics Testing ${ }^{*}$
}

\author{
R. L. Tobler \\ Fracture and Deformation Division \\ National Bureau of Standards \\ Boulder, Colorado \\ and \\ J. Shepic \\ Martin Marietta Aerospace \\ Denver, Colorado
}

\begin{abstract}
A ring-shaped clip-on displacement gage for fracture mechanics testing is described. The novel design of this gage offers superior sensitivity and operating conveniences compared with the conventional double-cantilever beam type gage referenced in ASTM fracture test standards. The construction of ring gages for room temperature and cryogenic applications is discussed.
\end{abstract}

Key Words: cryogenic instruments; displacement gages; fracture mechanics testing; materials testing; strain gages.

*Sponsored in part by the Office of Fusion Energy, U.S. Department of Energy.

${ }^{\dagger}$ To be published by ASTM Journal of Testing and Evaluation. 



\section{INTRODUCTION}

Clip-on displacement gages are utilized in all types of fracture mechanics tests to obtain records of load versus displacement, which provide the basic data from which resistance to crack extension is evaluated. In standard tests of bend or compact specimens, for example, displacement is measured between knife edges at reference points spanning the mouth of the crack. ${ }^{l}$ The clip gage is placed in position and held there by the spring action of its beams. As the specimen deforms under load, the crack-opening displacement increases, the gage flexes, the electrical signal is altered, and the gage is released without damage if the maximum opening range is exceeded or if the specimen fractures.

The widespread use of clip gages is due to their simplicity, convenience, and reusability. Clip gages may be purchased or custom built to suit all kinds of specimens, and they provide a linear output that is adaptable with analog-digital conversion to computerized testing.

In 1966, Krafft² employed a dual-lobed clip-on gage for low-temperature high-strain-rate tests. At about the same time, NASA researchers ${ }^{-6}$ developed the double-cantilever beam type (DCB) gage. Today the DCB gage is recommended in ASTM standards ${ }^{1}$ for ambient temperature tests. Fowlkes ${ }^{7}$ also succeeded in constructing a DCB type gage for extreme cryogenic environments. The purpose of this paper is to document the development of a new ring-shaped gage that represents a departure from the conventional DCB design, with some improvements. GAGE DESIGN

A 20-mm-diameter ring-shaped clip gage with $5.7-m m$ travel is shown in Fig. 1. This new design calls for an aluminum alloy ring-shaped body that is 
slotted to accept short beams of 17-7 PH stainless steel. The rear of the aluminum ring is reduced in thickness and provides the bending element onto which four 350- $\Omega$ commercial electrical resistance strain gage films are bonded. Two films are located on the inner diameter and two on the outer diameter of the ring. The outer films are protected by a stainless steel guard fixed to the ring with set screws.

In contrast, the conventional DCB gage design consists of a solid block body that serves as a spacer between two titanium alloy cantilever beams. In this case, the strain gage films are bonded to the upper and lower beam surfaces. Thus, the principal differences in the two gage designs lie in the geometry of the body and the location of the films.

The different designs account for some significant differences in performance. The DCB gage has two bending elements, whereas the ring gage has only one. In principle, this should result in superior linearity for the ring gage, especially for large gages with wide travel. For most applications this advantage may be academic, however, since moderately sized gages of both designs are able to meet the linearity requirements of section 6.3 .2 of the ASTM E 399-83 standard. I A more obvious practical benefit derives from the different handling characteristics of these gages, as described in the next section.

\section{GAGE INSTALLATION}

For a conventional $K_{I c}$ test, the gage is mounted at the specimen edge, since this is convenient and since any reference point for displacement measurement is adequate. In a $J_{\text {Ic }}$ test, however, it is necessary to measure load-line displacements so that the work done on the specimen can be calculated from the area under the load-versus-displacement record. 
Therefore, it is common to recess the knife edges to a position on the load line. A notch modification for this purpose is shown in Fig. 2.

Unfortunately, modifications such as those shown in Fig. 2 tend to hinder the installation of conventional DCB gages. It is difficult to depress the gage beams manually while attempting to attach the beam tips at the knife edges. Therefore, forceps must be used to position the gages properly. Also, the strain gage films on the top of DCB beam surfaces are exposed and can be damaged by the forceps or the specimen.

By virtue of its relatively low spring constant, the ring gage can be easily installed by squeezing the body of the ring between the thumb and index finger of one hand. Unlike conventional DCB gages, the beams themselves are not handled, fingers do not interfere as the beams contact the knife edges, and there is no risk of damage to the strain gage films during mounting.

In cryogenic tests, operations are more complicated, and the ability to rapidly mount or demount the clip gage greatly facilitates the transfer and testing of specimens. Immediately after a J-integral test, the specimen is still intact and access to the gage from either side is blocked by the clevis grips (see Fig. 2). Typically the gage and specimen are too frigid to handle, so the use of forceps is necessary. With ring gages, however, protective gloves can be worn without compromising dexterity because only light pressure needs to be applied to the gage body, which is freely accessible.

\section{INSTRUMENTATION}

Like the $D C B$ gage, the ring gage employs four strain-gage films wired in a conventional wheatstone bridge arrangement. The excitation is provided by a commerical power supply or by the modular circuitry built into the servo- 
hydraulic test machine. The gage output is also conditioned using conventional circuitry.

For room temperature service, the selection of strain gage films and wiring techniques are the same as for conventional DCB gages. Cryogenic applications require additional screening of strain gages and related materials, as well as proper construction techniques and low-voltage signal processing.

With ring gages operating in liquid helium at $4 \mathrm{~K}$, a low excitation voltage of $2.5 \mathrm{Vdc}$ is preferred, because at higher excitation voltages the noise at $4 \mathrm{~K}$ increases disproportionately to the signal output. In Fig. 3, the degradation of the signal quality is reflected in terms of the correlation coefficients for the compliance measurements of a cracked compact test specimen. Compliance is defined as the slope of the elastic displacement versus load plot. To obtain the data of Fig. 3, five loadings were taken for a specimen with fixed crack length, and the data were averaged. A correlation coefficient of 1.0 represents a perfectly linear fit. The data show that as the excitation voltage exceeds $5 \mathrm{Vdc}$, the noise becomes especially marked and unacceptable. This may be due to localized boiling of the helium at the gage surfaces due to Joule heating.

\section{CRYOGENIC APPLICATIONS}

Tests in our laboratory are frequently performed with specimens submerged in liquid nitrogen or helium. These media are chemically inert, but they entail problems of thermal cycling, moisture condensation, and freeze-up. Gage failures may take the form of excessive electrical noise, film debonding, deterioration of solder joints, or electrical shorting. Excessive electrical noise may arise from inadequate solder connections, conductive debris on gage 
surfaces, or other sources, such as electromagnetic radiation. These problems have been surmounted by proper techniques, so that the ring gages now in operation have remained in service for more than two years, surviving mil1ions of fatigue cycles and hundreds of fracture toughness tests at $4 \mathrm{~K}$.

\section{MATERIALS AND CONSTRUCTION TECHNIQUES}

Foil resistance strain gages are produced in a wide variety of sizes and forms, with various active alloy elements. Options include protective encapsulation, solder dots, integrated terminals, preattached leads, high endurance leads, stripable backings, and self-temperature compensation. One vendor boasts forty thousand variations, but not every kind is stocked and not every kind of wire element and backing combination works we11 at al1 temperatures.

Since strain-gage primers and reference books do not discuss cryogenic applications, our selection of strain gages for cryogenic applications was guided by the available literature $8^{-15}$ and manufacturers' recommendations. For test temperatures ranging from 300 to $4 \mathrm{~K}$, we selected a nickel-chromium alloy having a self-temperature-compensated active element and a glass-fiberreinforced epoxy-phenolic resin with a fully encapsulated matrix.

Self-temperature-compensating gages were chosen to minimize the apparent strain that is created when the gage films are bonded to substrates and cooled. The residual apparent strain that remains after cooling is then cancelled electrically.

Bondable terminals were used to create a stress-relief point between the foils and the lead wires to prevent accidental damage when the lead wires are yanked. 
Commercially available polytetrafluoroethylene (PTFE) insulated lead wires were used. A11 common insulating materials retain good insulating properties at cryogenic temperatures. However, such materials are typically brittle at cryogenic temperatures, and they eventually crack in response to thermal cycling. Therefore, the greatest problem is mechanical failure leading to electrical shorts. But PTFE is an exceptional polymer, retaining several percent ductility at $4 \mathrm{~K}$ and offering superior cryogenic flexibility compared with the polyethylene and polyvinyl chloride insulations, which are commonly used at room temperature. ${ }^{16}$ Noise from electromagnetic radiation was reduced further by shielding the PTFE-insulated lead wires with additional commercial insulation containing a thin wrapping of conductive material.

The choice of solder for cryogenic service was based on composition. All $\mathrm{Pb}-\mathrm{Sn}$ solders are ductile at room temperature, but not all retain ductility at cryogenic temperatures. ${ }^{17}$ A small amount of tin is needed to promote wetting and compatibility with rosin fluxes, but greater amounts cause brittleness at cryogenic temperatures. The ductile solders for extreme cryogenic service are the Pb-rich face-centered-cubic alloys. ${ }^{17}$ Therefore, we used a $97.5 \% \mathrm{~Pb}-1 \%$ Sn $-1.5 \%$ Ag solder composition to connect leads, strain gages, and bondable terminals. This solder shows improved strength and high ductility at temperatures down to $77 \mathrm{~K} .{ }^{18}$

Appropriate adhesives for bonding the strain gages and terminals to the gage body for cryogenic service are available from the gage manufacturers, as are cleaners, solders, applicators, and hardware kits.

\section{GAGE CALIBRATION}

Calibrations at room and cryogenic temperatures are performed using a vertical dial micrometer with the clip gage attached to knife edges at the 
bottom of a rod-in-tube apparatus, as shown in Fig. 4. Calibrations at cryogenic temperatures are performed after enclosing the gage in a Dewar covered at the mouth with styrofoam.

Fixed-point calibrations are performed in room-temperature air or in baths of liquid nitrogen or liquid helium. The corresponding cryogenic temperatures are 76 and $4 \mathrm{~K}$, respectively, at the atmospheric pressure and elevation in Boulder, Colorado. Variable temperature calibrations are also performed in nitrogen or helium vapor. In this case, a thermocouple is attached to the gage, and calibrations are performed as the Dewar is gradualiy warmed or cooled by periodic injections of gas.

Calibration data for a ring gage are shown in Fig. 5. The performance is desirable in that the gage output is only weakly temperature dependent. Between 295 and $4 \mathrm{~K}$ the calibration may vary by several percent, while the reproducibility of calibrations at fixed points is typically within $\pm 0.5 \%$. The calibrations are repeated regularly to check for small changes due to extended periods of service.

SUMMARY AND CONCLUSION

A clip gage design incorporating a ring-shaped geometry is proposed. The design is simple and functional and offers sensitivity and linearity matching or exceeding the conventional double-cantilever-beam gage. Moreover, the ring gage offers practical advantages for some tests owing to superior handiing characteristics as described in the text. Ring-gages have demonstrated excellent service life for tests at ambient and cryogenic temperatures. Cryogenic applications are facilitated by the fact that the gage calibrations at 295 and $4 \mathrm{~K}$ are nearly equivalent. 


\section{REFERENCES}

1. Standard Test Method for Plane-Strain Fracture Toughness of Metallic Materials, ASTM Designation E 399-83, in: 1983 Annual Book of ASTM Standards, Section 3, American Society for Testing and Materials, Philadelphia, 1983, pp. 518-553.

2. Krafft, J. M., A Rate Spectrum of Strain Hardenability and Fracture Toughness, in: Report of NRL Progress, Naval Research Laboratory, Washington, D.C., 1966, p. 6.

3. Fisher, D. M., Bubsey, R. T., and Srawley, J. E., NASA Tech Note D-3724, 1966.

4. Brown, W. F., Jr. and Srawley, J. E., Fracture Toughness Testing and Its Applications, ASTM STP 381, American Society for Testing and Materials, Philadelphia, 1965, pp. 133-196.

5. Brown, W. F., Jr. and Srawley, J. E., Plane Strain Crack Toughness Testing of High Strength Metal1ic Materials, ASTM STP 410, American Society for Testing and Materials, Philadelphia, 1966, pp. 1-129.

6. Bubsey, R. T., Fisher, D. M., Jones, M. H., and Srawley, J. E., Compliance Measurements, in: Experimental Techniques in Fracture Mechanics, A. S. Kobayashi, Ed., Iowa State University Press, Ames, Iowa, and Society For Experimental Stress Analysis, Westport, Connecticut, 1973, pp. 76-93.

7. Fowlkes, C.W. and Tobler, R. L., Fracture Testing and Results for a Ti-6Al-4V Alloy at Liquid Helium Temperature, Eng. Fract. Mech., 8, 1976, pp. 487-500.

8. Gillette, 0. L., Strain Gages at Cryogenic Temperatures, ISA Journal, 1964, pp. 51-54.

9. Wnuk, S. P., Jr., Strain Gages for Cryogenics, ISA J., 1964, pp. 67-71.

10. Kaufman, A, Investigation of strain Gages for Use at Cryogenic

Temperature, Exp. Mech., 3, No. 8, 1963, pp. 177-183.

11. Silbert, L., Meyer, H. E., and Van Beek, W. M., Strain Gage Development Program, Test Report 826-2003 May 1976, Martin Marietta, Denver, Colorado, pp. 131.

12. Telinde, J. C., Strain Gages in Cryogenic Environment, Exp. Mech., 10, 1970 , p. 394.

13. Walstrom, P. L., Strain Gages for Superconducting Magnet Testing, Cryogenics, 9, 1980, p. 509 .

14. Freynik, H. S., Jr., Roach, D. R., Deis, D. W., and Hirzel, D. G., Evaluation of Metal-Foil Strain Gages for Cryogenic Application in Magnetic Fields, Adv. Cryog. Eng., 24, 1978, p. 473. 
15. Sparks, L. L., Temperature, Strain, and Magnetic Field Measurements, Chapter 14, in: Materials at Low Temperatures, R. P. Reed and A. F. Clark, Eds., American Society for Metals, Metals Park, Ohio, 1983, pp. 515-571.

16. Mathes, K. N., Electrical and Mechanical Behavior of Polymers at Cryogenic Temperatures, SPE Journa1, 20, No. 7, 1964, pp. 643-637.

17. Kalish, H. S., and Dunkerley, K. J., The Low Temperature Properties of Tin and Tin-Lead Alloys, Trans. AIME, 180, 1949, pp. 637-656.

18. Kaufman, A. B., Selecting Solders for Low Temperature Service, Mater. Des. Eng., 48, No. 6, 1958, pp. 114-115. 


\section{List of Figures}

Figure 1. Design of a ring-shaped clip gage.

Figure 2. A ring-shaped clip gage and compact specimen with recessed notch used in J-integral fracture toughness testing.

Figure 3. Effect of excitation voltage on noise level at $4 \mathrm{~K}$. (The noise decreases the correlation coefficient of the displacement-versusload plot for a compact specimen with a stationary crack.)

Figure 4. Cryogenic gage calibration apparatus.

Figure 5. Temperature dependence of the calibration factor for a ring-shaped clip gage. 


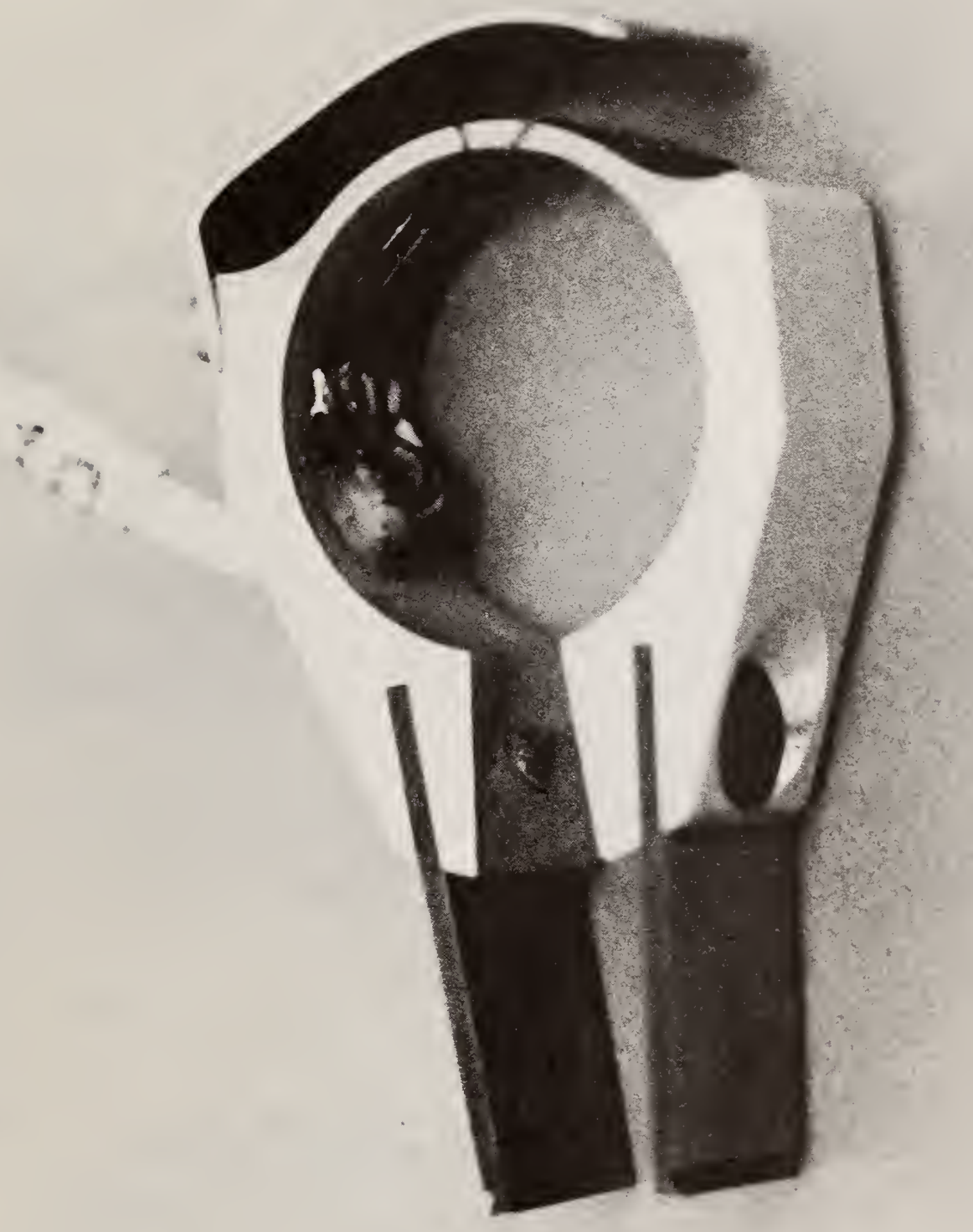

Figure 1. Design of a ring-shaped clip gage. 


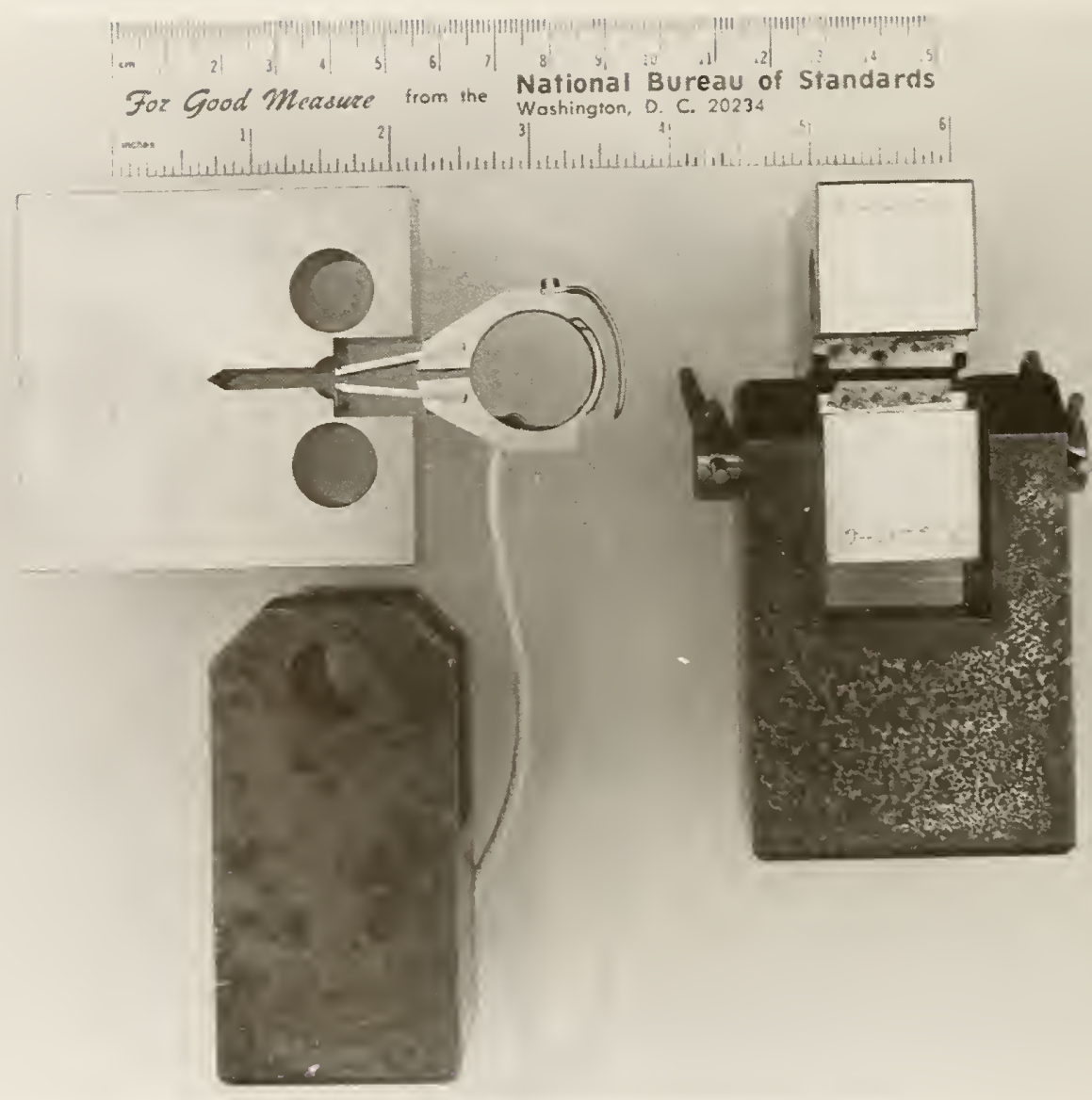

Figure 2. A ring-shaped $\mathrm{clip}$ gage and compact specimen with recessed notch used in J-integral fracture toughness testing. 


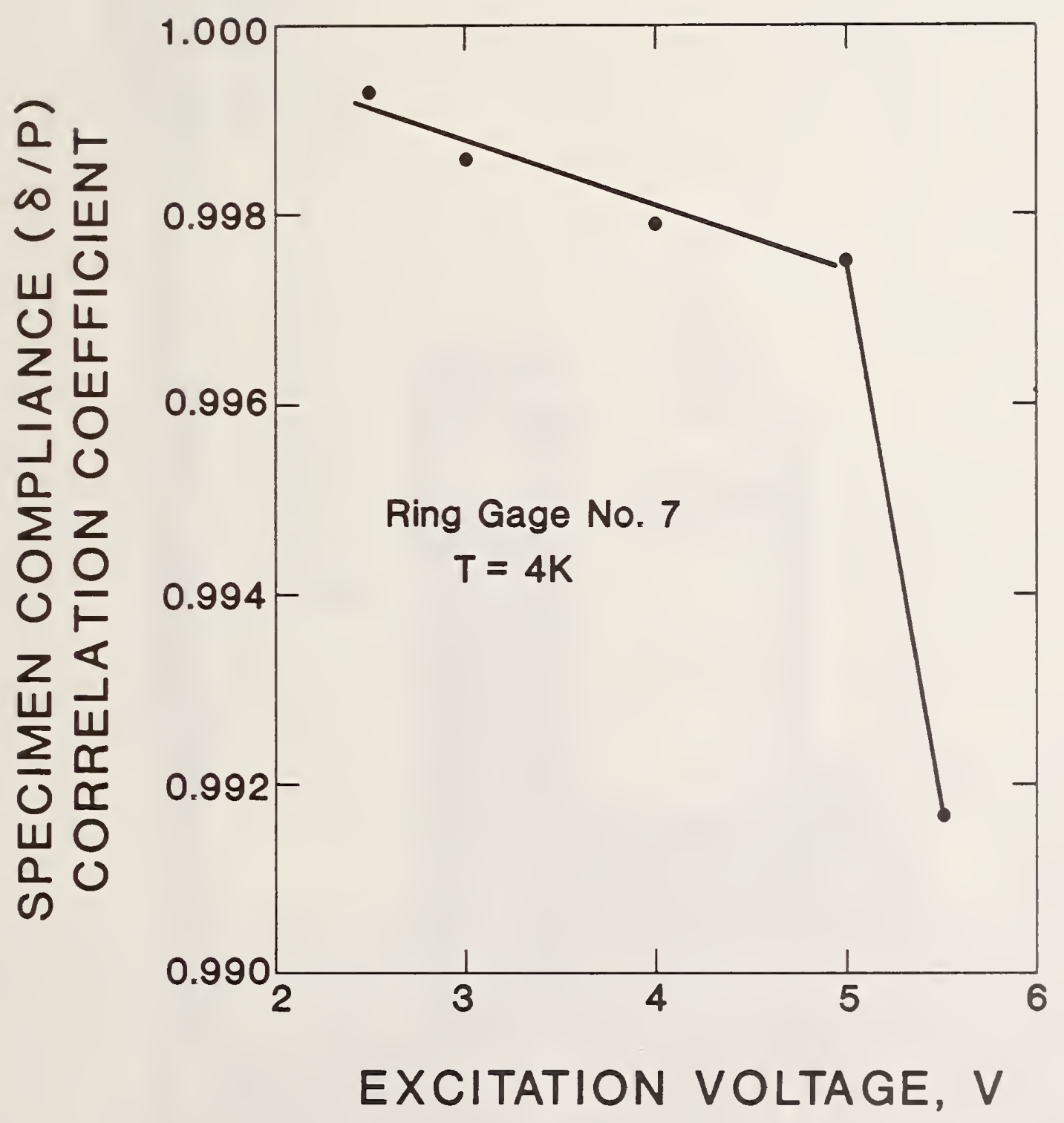

Figure 3. Effect of excitation voltage on noise level at $4 \mathrm{~K}$. (The noise decreases the correlation coefficient of the displacement-versusload plot for a compact specimen with a stationary crack.) 


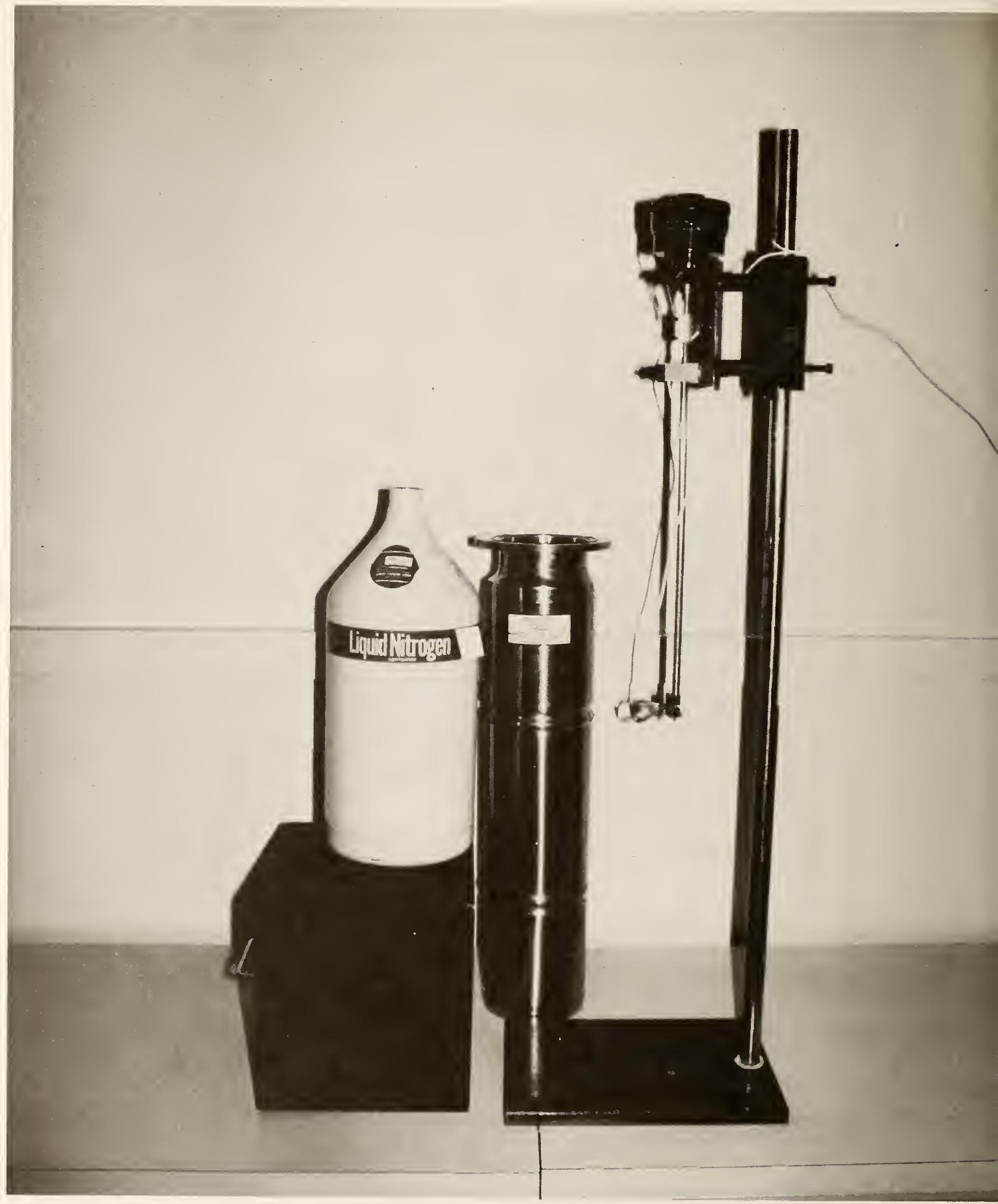

Figure 4. Cryogenic gage calibration apparatus. 


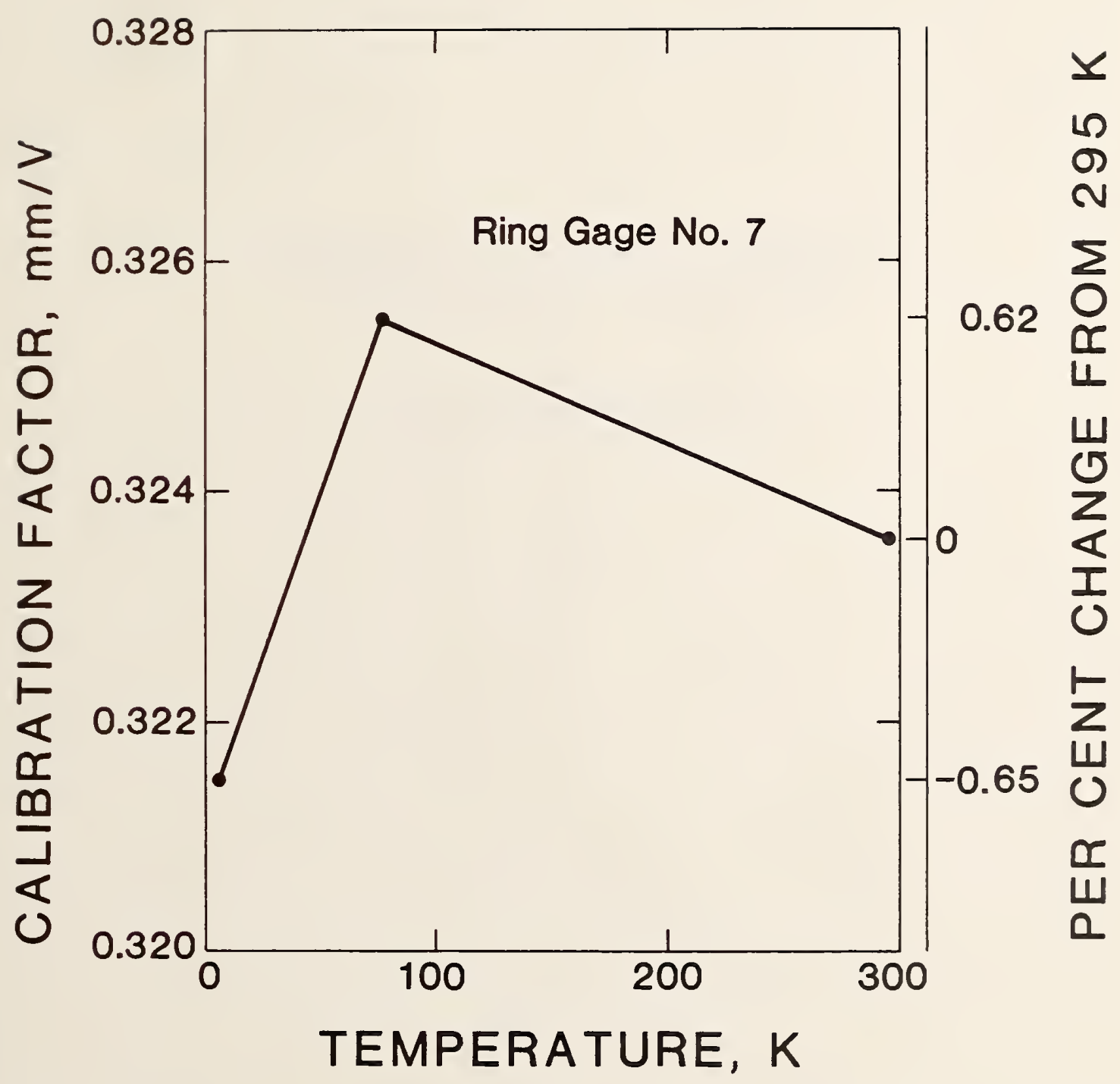

Figure 5. Temperature dependence of the calibration factor for a ring-shaped cl ip gage. 



\section{EXPERIMENTAL DATA TO SUPPORT EXTENSION OF MECHANICAL PROPERTY TEST STANDARDS \\ TO LIQUID HELIUM TEMPERATURE ( $4 \mathrm{~K})$ * \\ Metal Properties Council Low Temperature Task Group \\ Proposal Statement of Work}

\section{$1 / 8 / 84$}

*This proposal was written and approved by the Low Temperature Task Group of the Metal Properties Council. NBS guidelines for the use of SI units were not followed. 

EXPERIMENTAL DATA TO SUPPORT EXTENSION OF

MECHANICAL PROPERTY TEST STANDARDS

TO LIQUID HELIUM TEMPERATURE (4 K)

\section{Introduction}

There has been recent emphasis on the use of superconducting magnets to constrain and direct plasma flow in fusion and magneto hydrodynamic (MHD) energy experiments. The high magnetic fields necessary for plasma confinement create large forces that must be restrained by the magnet support structure. This places emphasis on sound structural design and dependable material properties at liquid helium temperature. Prototype magnet structures, ever increasing in size, continue to be designed and built. Although most magnets have operated successfully over their brief experimental lifetime, there has recently been a structural failure reported at the Tullahoma, Tennessee MHD magnet.

Currently, there are no standardized mechanical property test procedures for use at 7 iquid nitrogen $\left(77 \mathrm{~K},-320^{\circ} \mathrm{F}\right.$ ) temperatures or below. Mechanical testing at liquid helium $\left(4 \mathrm{~K},-452^{\circ} \mathrm{F}\right.$ ) temperatures involves unique conditions, compared to room temperature. At $4 \mathrm{~K}$, the thermal conductivity of metals and alloys is considerably reduced (usually several orders of magnitude) and the specific heat is tending toward zero. Consequently, when work is done on the specimen during testing, the resuitant internal heat is not easily removed from the specimens. Heating within the specimen tends to be localized and heat transfer is difficult. This is commonly referred to as adiabatic heating. Serrated yielding is produced during tensile tests. Each serration results from localized specimen yielding and temperature increases greater than $50 \mathrm{~K}$ have been recorded. Typical stress-strain curves for an austenitic stainless steel at room temperature, 195, 76, and $4 \mathrm{~K}$ are shown in Figure 1. Special attention must be paid to strain rates and the cooling media, to ensure maintenance of test temperature in the specimen.

It is expensive to use liquid helium. The capital costs of an efficient cryostat, the liquid costs, and the special handling, storage, and transfer costs associated with liquid helium add complexity and expense. Additionally, the strength of most metals and alloys increases at lower temperatures, requiring the use of larger loading trains if the room temperature specimen size is maintained. For strong alloys, load capacities of pull rods, grips, 
and cryostat would have to exceed 100,000 1bs. It is not efficient and is much too costly to design such large-capacity test systems and, to date, none in the world exist. Instead, typically 20,000 - 50,000 pound capacity tensile cryostats are used in testing at $4 \mathrm{~K}$. Therefore, assessment is needed of the consequences of using reduced specimen sizes when testing at 1 ow temperatures.

The research described in the following sections is necessary to produce the information required to extend existing room temperature mechanical property testing standards to low temperature $(77 \mathrm{~K})$. Proposals are hereby solicited, to perform the work described. Proposals which do not address all the tasks will be given equal consideration and the work described here may be divided among more than one contractor.

\section{Task I. Internal Specimen Heating}

\section{A. Experimenta 1: Strain Rate Effects}

At ambient temperature, specimen heating induced during straining in a tensile test is relatively small, on the order of a few degrees at strain rates normally used. As the test temperature decreases, in most materials, the specific heat decreases, and the temperature rise will be greater than at room temperature for the same amount of work. Similarly, thermal conductivity decreases in most materials and, therefore, any additional heating is slower to dissipate. These effects become increasingly pronounced as the test temperature is decreased until at $4 \mathrm{~K}\left(-452^{\circ} \mathrm{F}\right)$, if tensile tests are performed at strain rates commonly used at room temperature, substantial temperature increases are observed, possibly on the order of $50 \mathrm{~K}\left(100^{\circ} \mathrm{F}\right)$. The magnitude of this effect varies from one type of material to another and may even vary within materials of nominally the same composition. Temperature increases during testing are believed to lower the measured yield and ultimate strength and probably increase elongation and reduction in the area.

Notice, for example, the effect of strain rate on two austenitic stainless steels ${ }^{1}$ at $4 \mathrm{~K}\left(-452^{\circ} \mathrm{F}\right)$, shown in Figures 2 and 3 . The $304 \mathrm{~L}$ a 11 oy is metastable and martensite forms during plastic deformation; the 3105 alloy

IFrom the research of Dr. K. Ishikawa, National Research Institute for Metals, Isukuba, Japan (1983). 
is stable and no martensite forms during straining. Increasing the strain rate from $3.3 \times 10^{-5} \mathrm{~s}^{-1}$ to $3.3 \times 10^{-2} \mathrm{~s}^{-1}$ reduces the amplitude of the discontinuous yields and increases the amount of internal specimen heating from periodic jumps of $55 \mathrm{~K}$ to continuous increases of $150 \mathrm{~K}$. The ultimate strength is reduced almost 40 percent and the elongation increased about 20 percent as the strain rate is increased. Clearly, the effect of strain rate is very significant.

It is necessary to assess the magnitude of strain rate effects at very low temperatures in order to:

1. Determine a maximum strain rate for tensile tests which will produce mechanical property data that accurately reflect reliable material properties at the test temperature.

2. Assure that data generated in different laboratories is directly comparabie.

The materials of interest in this study are: 1) austenitic stainless steels, 2) aluminum alloys, and 3) copper. Testing is to be performed at $4.2 \mathrm{~K}\left(-452^{\circ} \mathrm{F}\right), 77 \mathrm{~K}\left(-320^{\circ} \mathrm{F}\right)$ and $295 \mathrm{~K}$ (room temperature). The test environments are liquid helium, liquid nitrogen, and air, respectively.

The magnitude of strain-induced heating in the candidate materials at the temperatures of interest is to be assessed. Several materials including one stable and one metastable austenitic stainless steel, one austenitic stainless steel weld, one aluminum and one copper alloy should be tested. A minimum of three and preferably four strain rates, not exceeding those given in appropriate ASTM standards, are needed to clarify dynamic heating conditions. Each specimen shall be instrumented to record internal specimen temperature continuously during testing. Only two repiicate specimens are required of each test condition. See Table 1 for a list of test conditions. Although the proposer is free to suggest modification to this schedule. Stress-strain curves should be recorded and tensile properties should be measured as a function of strain rate. Standard low temperature cylindrical specimens should be used. 
The proposal should clearly state the intended strain rates, the method of temperature measurement, the method of strain measurement, and the method of obtaining and maintaining the proper test environment. The specimens to be used in the investigation should be described in the proposal.

Materials used in this program should be adequately characterized prior to the start of testing. This includes measurement of grain size, hardness and chemistry. The proposer should indicate where and how the material for testing will be obtained.

Post-test examinations should be used to correlate experimental results with physical changes which may take place during testing. As a minimum, some metallography and fracture surface examinations should be conducted for this purpose. The proposer should suggest the extent of post-test examinations to be conducted.

\section{B. Model Development: Effects of Strain Rate and Cooling Media}

Cryogenic tensile tests carried out in a liquid media have the advantage of relatively good heat transfer characteristics between the specimen and 1iquid. Tests, which are conducted at temperatures other than those for which a common cryogenic liquid is available, require a cold gas as the cooling medium. Because of the relatively poor heat transfer of gases as opposed to liquids, the internal heating effects in gaseous environments are magnified. The heat transfer characteristics of the gases, thermal conductance of the specimen, and heat capacity of both the specimen and gas change with temperature.

An experimental program to assess all of the variables could be very large. Because the specimen geometry is simple and the physical properties of the materials relatively well known, this task lends itself to analytical modeling. A model should be developed or adopted to predict the internal specimen heating in terms of gas, liquid, and alloy thermal conductivity; alloy and cooling media heat capacity; specimen load and strain rate; and temperature. 
This model should be correlated with the strain rate experiments of Test Program IA and predict the increase of internal specimen heating as a function of cooling media. A few measurements should be conducted in other media (gaseous helium and nitrogen) to verify the model. The proposer should suggest a verification test matrix. This model should then be used to suggest a standard tensile test procedure for testing in gaseous environments.

\section{Task II. Subsize Specimen Use: Effects of Grain Size}

When testing polycrystalline metals and alloys at low temperatures, it is advantageous to use reduced specimen sizes. Reduced specimen sizes are necessary to minimize coolant usage and to conserve loading capacity (since material strengths are typically 2-3 times greater than at room temperature). The major deterrent to the use of smaller specimens is the effect of grain size, in relation to specimen size, on strength, ductility and other property variability. Specimens must contain a representative number of grains per cross-section to ensure the absence of anisotropic crystallographic influence on material strength and ductility. Therefore, research must be conducted to assess the influence of grain size on properties of common structural alloys used in cryogenic service.

The research should characterize the effects of grain size on tensile yield strength, ultimate strength, elongation, and reduction of area. The standard ASTM E-8 tensile bar specimen and two reduced bar specimens (suggested $1 / 8$ and 1/4 inch diameter) should be compared. Grain size should vary over at least 1.5 orders of magnitude. Strain rate should be held constant $(0.02$ $\mathrm{in} / \mathrm{in} / \mathrm{min}$ is suggested). Test temperatures should include 4, 77, and $295 \mathrm{~K}$. Alloys must include one austenitic stainless steel, one austenitic stainless steel weld, one aluminum alloy and one copper alloy. Special attention must be given to the method for obtaining grain size variation to ensure the same degree of prepared orientation for each grainsize. The proposal should state how grain size and orientation will be achieved in each specimen.

As in IA of this request for proposal, the proposer should describe the specimen to be used and the pre- and post-test material characterizations required. 
This model should be correlated with the strain rate experiments of Test Program IA and predict the increase of internal specimen heating as a function of cooling media. A few measurements should be conducted in other media (gaseous helium and nitrogen) to verify the model. The proposer should suggest a verification test matrix. This model should then be used to suggest a standard tensile test procedure for testing in gaseous environments.

\section{Task II. Subsize Specimen Use: Effects of Grain Size}

When testing polycrystalline metals and alloys at low temperatures, it is advantageous to use reduced specimen sizes. Reduced specimen sizes are necessary to minimize coolant usage and to conserve loading capacity (since material strengths are typically 2-3 times greater than at room temperature). The major deterrent to the use of smaller specimens is the effect of grain size, in relation to specimen size, on strength, ductility and other property variability. Specimens must contain a representative number of grains per cross-section to ensure the absence of anisotropic crystallographic influence on material strength and ductility. Therefore, research must be conducted to assess the influence of grain size on properties of common structural alloys used in cryogenic service.

The research should characterize the effects of grain size on tensile yield strength, ultimate strength, elongation, and reduction of area. The standard ASTM E- 8 tensile bar specimen and two reduced bar specimens (suggested $1 / 8$ and $1 / 4$ inch diameter) should be compared. Grain size should vary over at least 1.5 orders of magnitude. Strain rate should be held constant $(0.02$ in/in/min is suggested). Test temperatures should include 4, 77, and $295 \mathrm{~K}$. Alloys must include one austenitic stainless steel, one austenitic stainless steel weld, one aluminum alloy and one copper alloy. Special attention must be given to the method for obtaining grain size variation to ensure the same degree of prepared orientation for each grainsize. The proposal should state how grain size and orientation will be achieved in each specimen.

As in IA of this request for proposal, the proposer should describe the specimen to be used and the pre- and post-test material characterizations required. 
Table 1

Suggested Test Matrix for

Part IA

Materials

Stainless Steels

a) Stable Austenitic

b) Metastable Austenitic Copper

Aluminum
Strain Rates

Replications Temperatures
2 $4 \mathrm{~K}$
$77 \mathrm{~K}$
$295 \mathrm{~K}$

Total Number of Tests: $4 \times 4 \times 2 \times 3=96$ 


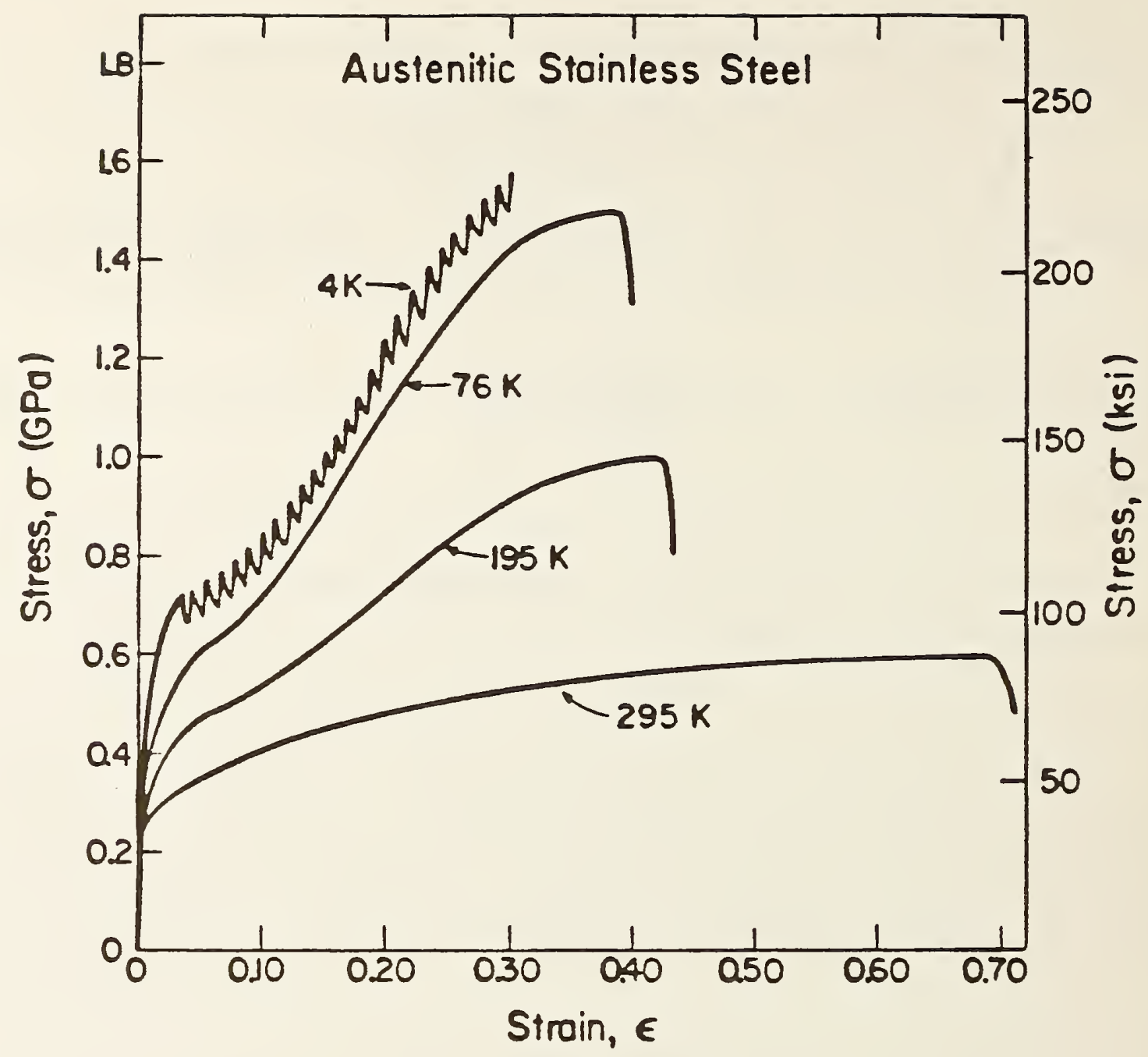

Figure 1. Typical stress-strain curves at low temperatures of AISI 300 series austenitic stainless steels. 

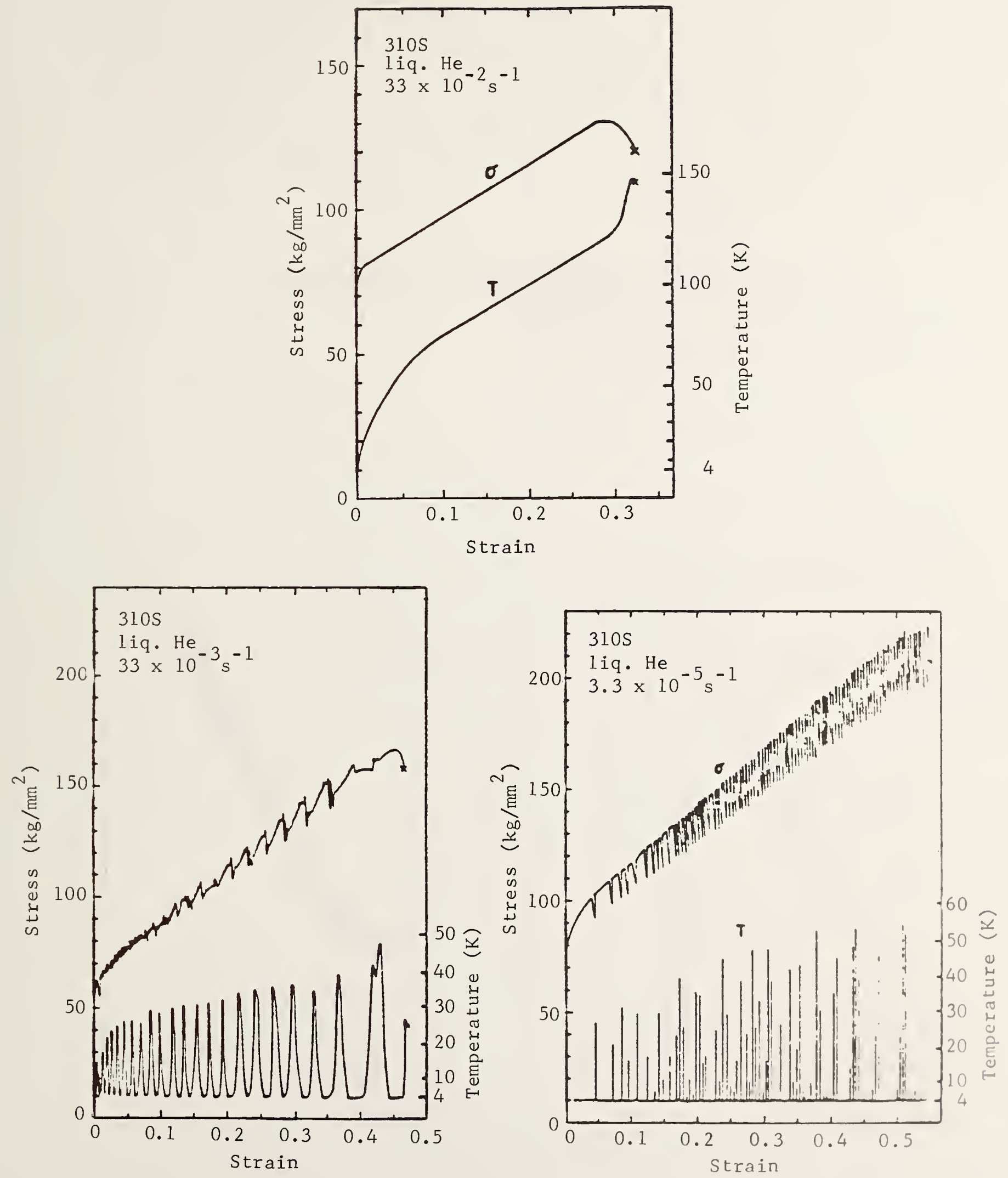

Figure 2. Stress-strain curves at liquid helium temperatures of AISI 310 at three strain rates. Lower data, indicated by $\mathrm{T}$ in lower figures, represents temperature rises associated with the total drops. 

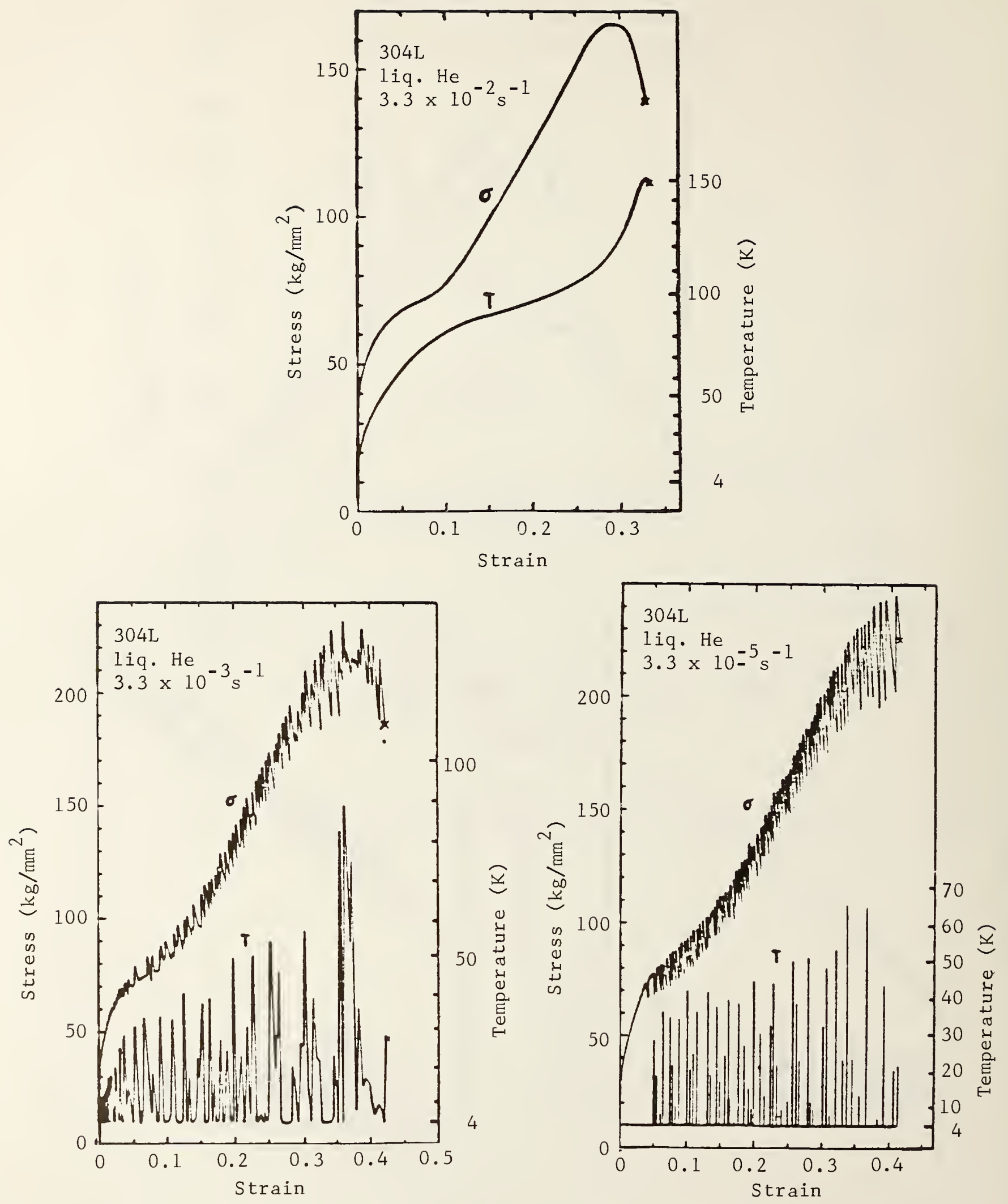

Figure 3. Stress-strain curves at liquid helium temperatures of AISI $304 \mathrm{~L}$ at three strain rates. Lower data, indicated by $\mathrm{T}$ in lower figures, represents temperature rises associated with the total drops. 


\section{WELDMENTS AND CASTINGS}



LEADER: T. A. Siewert (After Apri1 1, 1984)

STAFF: H. I. McHenry, P. T. Purtscher, NBS

\section{OBJECTIVES:}

(1) To investigate the metallurgical factors that affect the mechanical properties of stainless-steel weldments and castings at cryogenic temperatures.

(2) To contribute to the development of improved filler metals for welding stainless steels for liquid-helium service.

(3) To evaluate the mechanical properties of weldments and castings at $4 \mathrm{k}$.

(4) To develop methods of detecting defects and evaluating their significance in stainless-steel weldments.

\section{RESEARCH PAST YEAR (1983)}

(1) The fracture toughness of $25 \mathrm{Mn}-5 \mathrm{Cr}$ weldments produced by three different welding processes was measured at $4 \mathrm{~K}$.

(2) The tensile properties and fracture toughness of E320LR filler metal were measured at $4 \mathrm{~K}$.

(3) Tensile tests were conducted on large-scale stainless steel weldments with the weld reinforcement in place.

(4) Fatigue crack growth rates were measured at $4 \mathrm{~K}$ on CF8M castings with varying ferrite content.

(5) Mechanical properties testing at $4 \mathrm{~K}$ in support of superconducting magnet design and construction continued.

RESEARCH THIS YEAR (1984)

(1) The tensile properties and fracture toughness of weldments produced by selected welding processes will be measured at $4 \mathrm{~K}$.

(2) An evaluation of fully austenitic weld metals with low sulfur and phosphorus contents will be initiated.

(3) A series of stainless steel welds with varying oxygen contents will be produced.

(4) Mechanical property testing at $4 K$ in support of superconducting magnet design and construction will continue. 


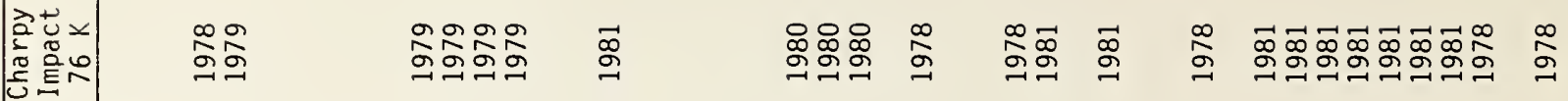

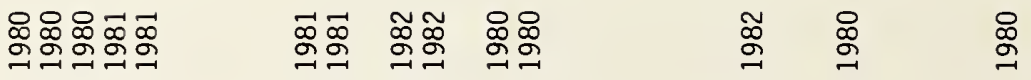

$\vec{\infty} \ddot{\infty}$

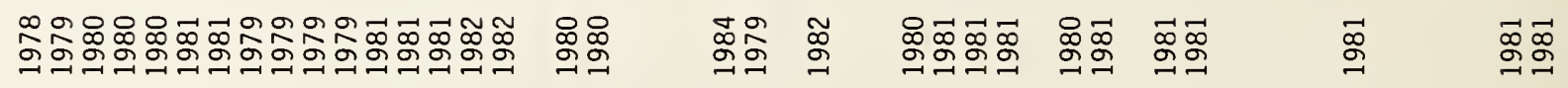

$\stackrel{\infty}{\mathscr{\infty}}$

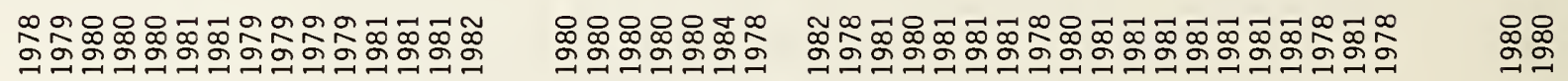

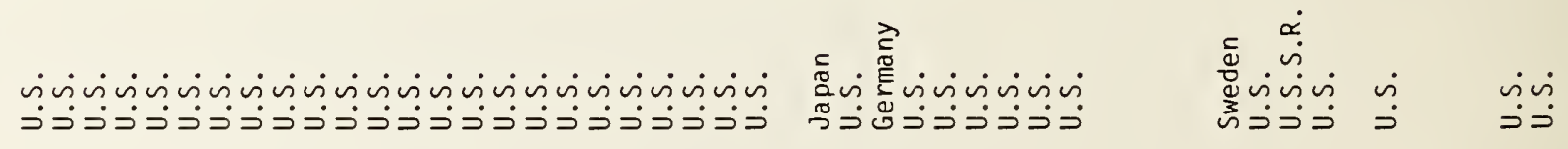

लำ

$z \quad$ 通恋 它 
FRACTURE TOUGHNESS OF 25MN AUSTENITIC STEEL WELDMENTS AT $4 \mathrm{~K} *$

\author{
Y. W. Cheng, H. I. McHenry, and P.N. Li ${ }^{\dagger}$ \\ National Bureau of Standards \\ Boulder, Colorado 80303 \\ T. Inoue and T. Ogawa \\ Nippon Steel Corporation, Kawasaki, Japan
}

\title{
ABSTRACT
}

The fracture toughness of $25 \mathrm{Mn}$ steel weldments was measured at $4 \mathrm{~K}$ using the single-specimen J-integral procedure. The highest $\mathrm{J}_{\mathrm{Ic}}$ value obtained was from the gas-tungsten-arc weld, followed by the shielded-metal-arc weld; the submerged arc weld had the lowest $\mathrm{J}_{I_{c}}$ value. Degradation of fracture toughness of the heat-affected zone was observed because of carbide precipitation along the grain boundary.

*Published in Advances in Cryogenic Engineering - Materials, vol. 30, Plenum Press, New York (1984), pp. 303-310.

${ }^{\dagger}$ Guest Worker; on leave from East China Institute of Chemical Technology, Shanghai, China. 



\section{INTRODUCTION}

In recent years, there has been an increased interest in the study of replacing nickel with manganese in steels for cryogenic applications. $1^{-2}$ The driving force behind this interest stems from the relative price of manganese and nickel. Nickel is an important element in steels for cryogenic applications, such as $5 \%$ nickel steel, $9 \%$ nickel steel, and the AISI 300-series austenitic stainless steels.

One of the high-manganese steels developed for cryogenic applications is the $25 \mathrm{Mn}-5 \mathrm{Cr}-1 \mathrm{Ni}$ steel. Previous studies indicate that this steel has desirable cryogenic properties, i.e., high strength and high toughness, ${ }^{-4}$ low thermal expansion coefficient, 5 and stable austenitic microstructure. ${ }^{-4}$ Filler metal with nearly matching composition has also been developed. ${ }^{2}$ This paper presents the results of a weldability study in which fracture toughness measurements of the $25 \mathrm{Mn}-5 \mathrm{Cr}-1 \mathrm{Ni}$ steel weldments were performed in liquid helium at $4 \mathrm{~K}$.

\section{MATERIALS}

The test weldments were $27-m m-t h i c k$ plates welded by three different welding processes in the flat position: shielded-metal $\operatorname{arc}(\mathrm{SMA})$, submerged arc (SA), and gas-tungsten arc (GTA) welding 
processes. The welding parameters and joint preparation are given in Figure 1. For GTA and SA weldments, the joints were deep U-grooves with a $30^{\circ}$ included angle. The grooves were filled with weld metals. The welds were then back-gouged right underneath the previous welds to a depth of $15 \mathrm{~mm}$ and filled with weld metals. So the weld contours outlined with solid and dashed lines (Figure 1) were on top of each other and overlapped at mid-thickness of the plates. The welds were $x$-ray inspected and no detectable flaws were found. The chemical compositions and tensile properties at $4 \mathrm{~K}^{4}$ of the weld metals are presented in Tables 1 and 2 .

\section{EXPERIMENTAL PROCEDURES}

Fracture toughness of the 25.4-mm-thick compact tension (CT) specimens was measured with the J-integral method. ${ }^{6}$ Tests were conducted in liquid helium at $4 \mathrm{~K}$ using a cryostat described by Fowlkes and Tobler. ${ }^{7}$ The single-specimen unloading-compliance technique $^{8}$ was used to measure J- $\Delta$ a (crack extension) resistance curves. The J- $\Delta \mathrm{a}$ curves were then used to determine J Ic. The plane strain fracture toughness estimate, $\mathrm{K}_{\mathrm{Ic}}(\mathrm{J})$, was calculated from $\mathrm{J}_{\mathrm{Ic}}$ using the following relation: ${ }^{6}$

$$
\mathrm{K}_{I c}(J)=\left[\frac{\mathrm{J}_{I c} \cdot E}{1-v^{2}}\right]^{\frac{1}{2}}
$$

At $4 \mathrm{~K}$, Young's modulus, $\mathrm{E}$, was taken to be $190 \mathrm{GPa}$, and Poisson's ratio, $v$, was taken as $0.274 .{ }^{9}$

For GTA and SA welds, the notches were at the center of the weld metal. For SMA welds, the notches were at the fusion line, in the heat-affected-zone (HAZ--2 $\mathrm{mm}$ from the fusion line), and in

process

groove

current, voltage \& rate
SMA

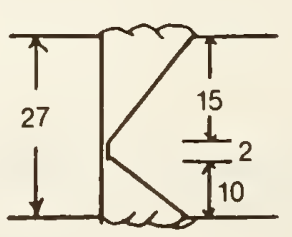

$150 \mathrm{~A} \cdot 25 \mathrm{~V} \cdot 8 / 10 \mathrm{~cm} / \mathrm{min}$. $4.0 \varnothing$ DCRP
SA

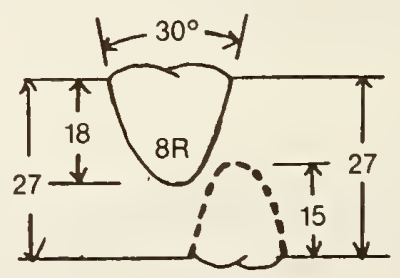

$500 \mathrm{~A}-34 \mathrm{~V}-35 \mathrm{~cm} / \mathrm{min}$. $4.0 \varnothing$, coil flux: $\mathrm{MgO}-\mathrm{SiO}_{2}-\mathrm{CaF}_{2}$
GTA

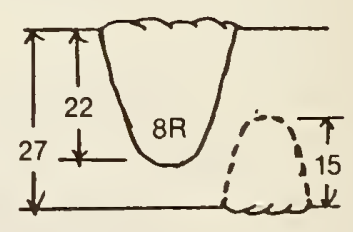

$250 \mathrm{~A}-15 \mathrm{~V}-10 \mathrm{~cm} / \mathrm{min}$. $2.4 \varnothing$ Ar shielding

Fig. 1. Welding parameters; dimensions are in millimeters. 
Table 1. Chemical Composition of Weld Metals (wt.\%)

\begin{tabular}{|c|c|c|c|c|c|c|c|c|c|}
\hline & C & Si & $\mathrm{Mn}$ & P & $\mathrm{S}$ & $\mathrm{Ni}$ & $\mathrm{Cr}$ & Mo & $\mathrm{Fe}$ \\
\hline GTA & 0.156 & 0.13 & 26.55 & 0.003 & 0.006 & 3.15 & 6.44 & 1.18 & bal. \\
\hline SMA & 0.224 & 0.54 & 26.68 & 0.006 & 0.002 & 3.02 & 7.24 & 1.11 & bal. \\
\hline SA & 0.19 & 0.46 & 25.86 & 0.008 & 0.004 & 2.94 & 7.19 & 1.05 & bal. \\
\hline
\end{tabular}

Table 2. Tensile Properties of $25 \mathrm{Mn}$ Steel at $4 \mathrm{~K}^{4}$

\begin{tabular}{lccc}
\hline & $\begin{array}{c}0.2 \% \text { YS } \\
\text { MPa }\end{array}$ & $\begin{array}{c}\text { UTS } \\
\text { MPa }\end{array}$ & \%EL \\
\hline & & & \\
Base Metal & 894 & 1525 & 49 \\
Weld Metal(SMA) & 962 & 1338 & 35 \\
& & & \\
\hline
\end{tabular}

the weld metal ( $3 \mathrm{~mm}$ from the fusion line). The specimen locations and orientations are shown in Figure 2 .

\section{RESULTS AND DISCUSSION}

The results of the fracture toughness tests at $4 \mathrm{~K}$ are summarized in Table 2. The materials tested were ranked in descending order in terms of fracture toughness: GTA weld metal, SMA fusion line, SMA weld metal, SMA HAZ, and SA weld metal. The $J$ value of the SMA weld metal in the present study was $86 \%$ higher than that of a previous report $\left(119 \mathrm{~kJ} / \mathrm{m}^{2} \mathrm{vs} .221 \mathrm{~kJ} / \mathrm{m}^{2}\right) .^{4}$

Fig. 2. Specimen locations and orientations: left: GTA and SA; right: SMA.

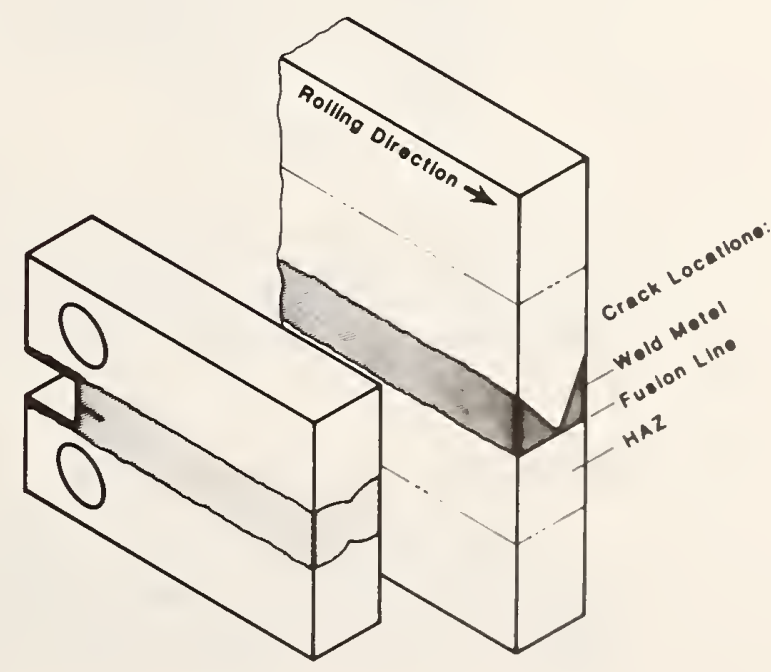




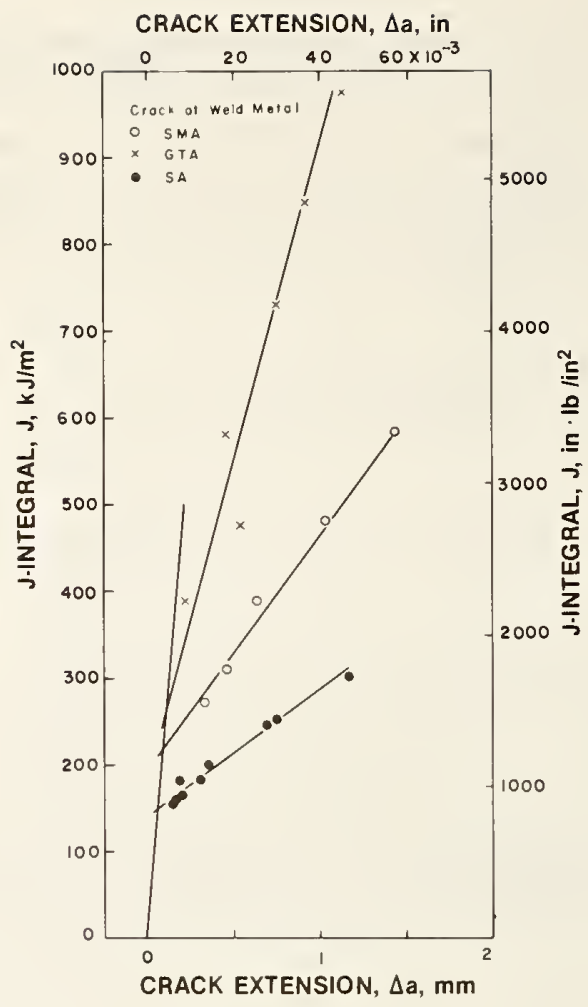

Fig. 3. J- $\Delta$ a curves of weld metals.

Table 3. Fracture Toughness of $25 \mathrm{Mn}$ Steel Weldments at $4 \mathrm{~K}$.

\begin{tabular}{llll}
\hline Type & Crack Position & $\begin{array}{c}\mathrm{J}_{\mathrm{Ic}} \\
\mathrm{kJ} / \mathrm{m}^{2}\end{array}$ & $\begin{array}{c}\mathrm{K}_{\mathrm{Ic}} \\
\mathrm{MPa} / \mathrm{m}\end{array}$ \\
\hline GTA & Weld Metal & 258 & 230 \\
SA & Weld Metal & 139 & 169 \\
SMA & Weld Metal & 221 & 213 \\
SMA & Fusion Line & 232 & 218 \\
SMA & HAZ & 140 & 169 \\
Base Metal T-L & 280 & 242 \\
\hline
\end{tabular}

The reason for the discrepancy is not clear. The fracture toughness of the $25 \mathrm{Mn}$ steel weldments compared favorably with austenitic stainless steel weld metals of the AISI 300 series ( $\mathrm{Fe}-\mathrm{Cr}-\mathrm{Ni}$ steels).10-12

\section{Effects of Welding Process}

As shown in Table 3 and Figure 3, the GTA weld metal not only has the highest $\mathrm{J}$ value, but its $\mathrm{J}-\Delta \mathrm{a}$ curve has the steepest slope. This is indicative of high resistance to both crack initiation and ductile tearing. The SA weld metal has the poorest 


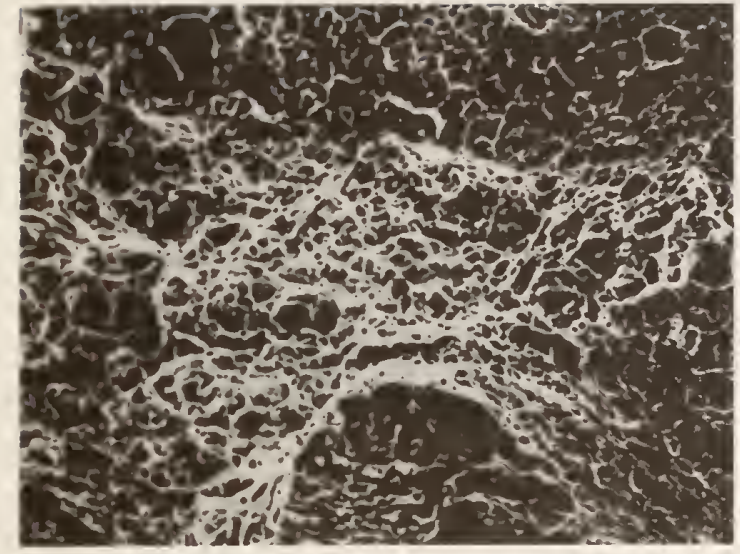

$50 \mu \mathrm{m}$
SA Weld Metal

(a)

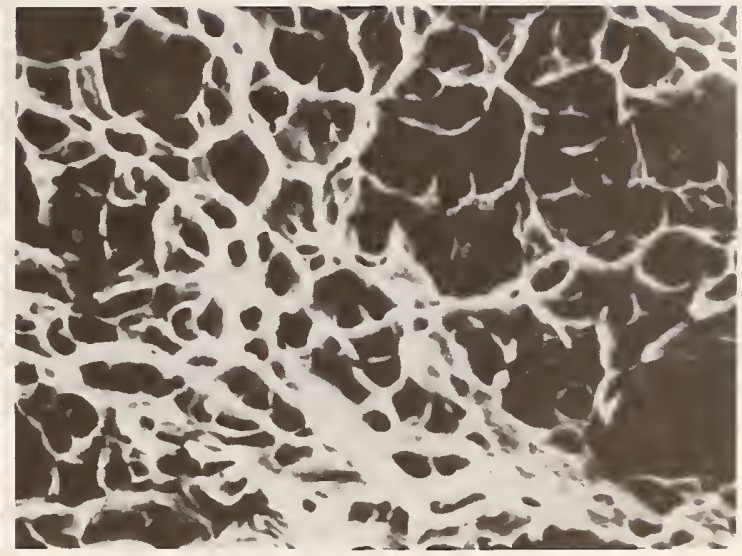

SA Weld Metal

(b)

Fig. 4 Typical fracture surface of weld metal fractured in a ductile manner.

resistance to crack initiation and ductile tearing. The variation in fracture toughness among weld metals produced by different welding processes has been attributed to the cleanliness of the weld metal.13 of the welding processes studied, the GTA and the SA processes are expected to produce the "cleanest" and the "dirtiest" welds, respectively.

All the fracture surfaces of weld metals, as revealed by scanning electron microscope, were typical of weld metal fractured in a ductile manner. Dimples were the predominant feature on the fracture surface, as shown in Figure 4. Small nonmetallic inclusions, about $2 \mu \mathrm{m}$ or smaller, were usually present at the centers of the dimples.

Effects of Crack Location in Weldment

In addition to weld metal, fracture toughness was also measured at the fusion line and in the HAZ for the SMA weldment. Table 2 and Figure 5 show that the fusion line and weld metal had similar fracture properties. However, the fracture toughness, $\mathrm{J}_{\text {Ic' }}$, of HAZ was degraded by $37 \%$.

Metallographic examination showed excessive grain boundary precipitation in $\mathrm{HAZ}$, which were identified as niobium carbide. The grain boundary precipitation caused the specimens to fracture in an intergranular fracture mode, as shown in Figure 6. Fractographic examination also showed defect-like inclusions in the HAZ, as shown in Figure 7 . 


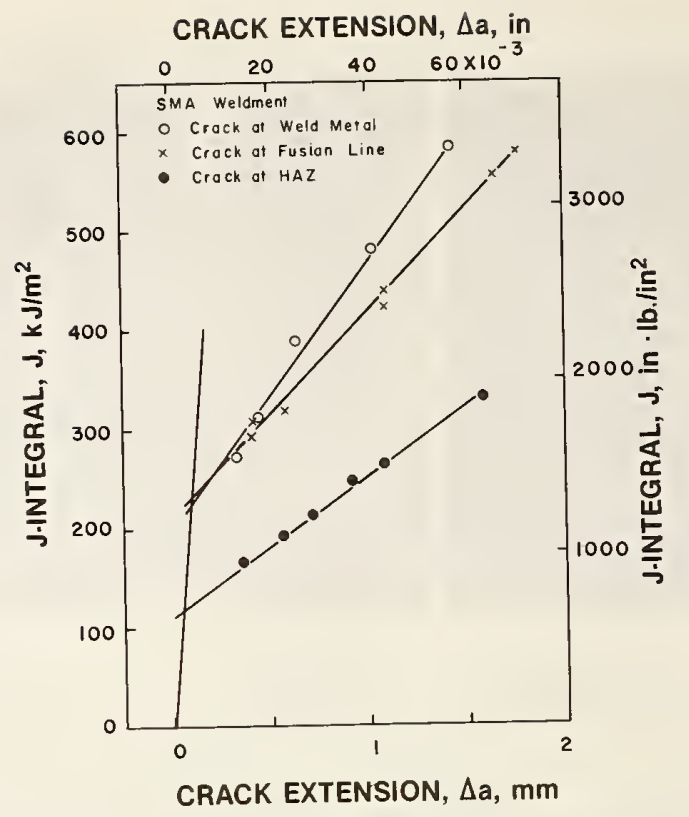

Fig. 5. J- $\Delta$ a curves of SMA weldments.

It should be noted that the fracture surfaces of both the SMA weld metal and SMA fusion line consisted of weld metal and base metal because of the weld joint design. The major portion of the fracture surface of weld metal specimens was weld metal. The reverse was true for fusion line specimens.

\section{CONCLUSIONS}

1. The J values of GTA, SMA, and SA welds are 258,221, and $119 \mathrm{kJgm}^{2}$, respectively. The higher fracture toughness of some welds tested is attributed to fewer nonmetallic inclusions.

2. For the SMA weldment, the $J$ value of the material along the fusion line is similar to that of the weld metal $\left(221 / \mathrm{kJ} / \mathrm{m}^{2}\right)$. However, the J value of $\mathrm{HAZ}$ is much lower, only $140 \mathrm{~kJ} / \mathrm{m}^{2}$. The degradation of fracture toughness of the HAZ is due to excessive carbide precipitations along the grain boundaries, resulting in an intergranular frácture.

\section{ACKNOWLEDGMENT}

The Department of Energy, Office of Magnetic Fusion Energy supported this study. P. Purtscher of NBS contributed the metallographic and fractographic examinations. 

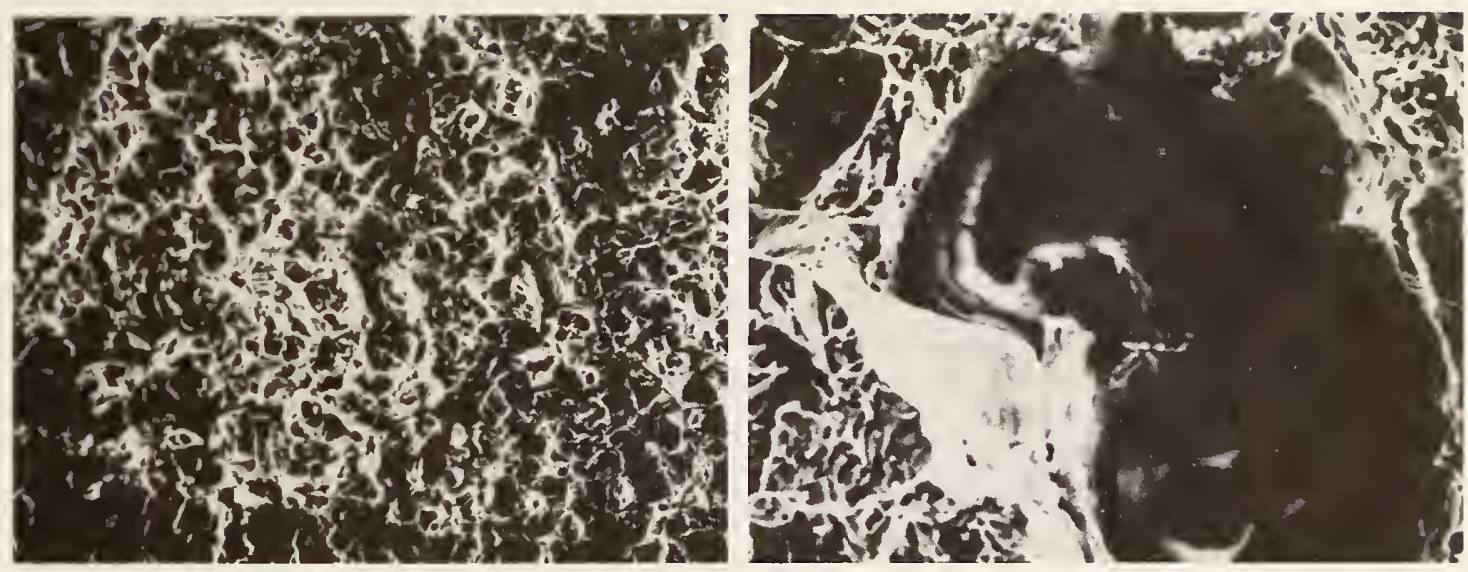

$250 \mu \mathrm{m}$

$\begin{array}{ll}40 \mu \mathrm{m} & \\ \text { Fig. } 7 & \begin{array}{l}\text { Fracture surface } \\ \text { of SMA HAZ. Defect- } \\ \text { like inclusions are } \\ \text { present in the HAZ. }\end{array}\end{array}$

REFERENCES

1. J. Charles, A. Berghezan and A. Lutts, High-manganese-aluminum steels for cryogenic applications: The Fe-30Mn-8Al-(0-1)C alloys, in: "Proceedings of the International Cryogenic Materials Conference," Butterworths, London (1983), pp. 360-363.

2. H. Yoshimura, M. Masumoto, and T. Inoue, Properties of lowcarbon $25 \mathrm{Mn}-5 \mathrm{Cr}-1 \mathrm{Ni}$ austenitic steel for cryogenic use, in "Advances in Cryogenic Engineering Materials," Vol. 28, Plenum Press, New York (1982), pp. 115-125.

3. H. Yoshimura, T. Shimizu, H. Yada, and K. Kitajima, Toughness of high manganese-chromium austenitic steels at liquid helium temperature, Trans. Iron Steel Inst. Jap. 20:187 (1980).

4. H. I. McHenry, J. W. Elmer, and T. Inoue, Fracture properties of a $25 \mathrm{Mn}$ austenitic steel and its welds at $4 \mathrm{~K}$, in: "Materials Studies for Magnetic Fusion Energy Applications at Low Temperatures-V," R. P. Reed and N. J. Simon, eds., NBSIR 82-1667, National Bureau of Standards, Boulder, Colorado (1982), p. 245.

5. H. Yoshimura, N. Yamada, H. Honma, and T. Ito, Microstructures, low temperature toughness and thermal expansion coefficients of high manganese-chromium austenitic steels, Trans. Iron Steel Inst. Jap. 16:98 (1976).

6. ASTM designation: E813-81, standard test for J fracture toughness, in: "Annual Book of ASTM ${ }^{c}$ 'Standards, 
Part 10," American Society for Testing and Materials, Philadelphia (1982), pp. 822-840.

7. C. W. Fowlkes and R. L. Tobler, Fracture testing and results for a Ti-6Al-4 alloy at liquid helium temperature, Eng. Fract. Mech. 8:487 (1976).

8. D. T. Read, The computer-aided J-integral test facility at NBS, in: "Materials Studies for Magnetic Fusion Energy Applications at Low Temperatures-III", R. P. Reed, ed., NBSIR 80-1627, National Bureau of Standards, Boulder, Colorado (1980), p. 205.

9. H. M. Ledbetter and M. W. Austin, Elastic constants of an $\mathrm{Fe}-5 \mathrm{Cr}-26 \mathrm{Mn}$ austenitic steel, 76-400 $\mathrm{K}$, in: "Materials Studies for Magnetic Fusion Energy Applications at Low Temperatures-VI, R. P. Reed and N. J. Simon, eds., NBSIR 83-1690, National Bureau of Standards, Boulder, Colorado (1983), p. 181 .

10. J. W. Elmer, H. I. McHenry, and T. A. Whipple, Strength and toughness of fully austenitic stainless steel filler metals at $4 \mathrm{~K}$, in: "Materials Studies for Magnetic Fusion Energy Applications at Low Temperatures-IV," R. P. Reed and N. J. Simon, eds., NBSIR 81-1645, National Bureau of Standards, Boulder, Colorado (1981), p. 289.

11. D. T. Read, H. I. McHenry, P. A. Steinmeyer, and R. D. Thomas, Jr., Metallurgical factors affecting the toughness of 316L SMA weldments at cryogenic temperatures, Weld. J. Res. Supp1. 59:104s (1980).

12. T. A. Whipple, H. I. McHenry and D. T. Read, Fracture behavior of ferrite-free stainless steel welds in liquid helium, Weld. J. Res. Supp1. 60:72s (1981).

13. T. A. Whipple and D. J. Kotecki, Weld process study for $316 \mathrm{~L}$ stainless steel weld metal for liquid helium service, in: "Materials Studies for Magnetic Fusion Energy Applications at Low Temperatures-IV," R. P. Reed and N. J. Simon. eds., NBSIR 81-1645, National Bureau of Standards, Boulder, Colorado 80303 (1981), p. 303. 


\title{
TENSILE PROPERTIES AND FRACTURE TOUGHNESS OF 320LR SMA WELD METAL AT $4 \mathrm{~K}^{*}$
}

\author{
Y. W. Cheng \\ Fracture and Deformation Division \\ National Bureau of Standards \\ Boulder, Colorado \\ T. A. Siewert \\ Alloy Rods, Inc. \\ Hanover, Pennsylvania
}

\section{ABSTRACT}

The tensile properties and fracture toughness of 320LR fully austenitic stainless steel weld metal, produced by the shielded-metal-arc process, were measured in liquid helium at $4 \mathrm{~K}$. The preliminary results showed that yield strength and ultimate tensile strength of the 320LR weld metal are 8 and 12 percent lower, respectively, than the lower bound of the published data for $316 \mathrm{~L}$ fully austenitic stainless steel weld metal, while values of fracture toughness are similar for the two weld metals.

Key Words: Austenitic stainless steels; cryogenic properties of materials; fracture toughness; J-integral; microfissures; tensile properties; weldments.

* Contribution of NBS; not subject to copyright. 



\section{INTRODUCTION}

It is well known that microfissures are usually present in fully austenitic stainless steel welds. To avoid microfissures, a small fraction of ferrite is desirable in austenitic stainless steel welds [1]. However, there are two properties of ferrite that are undesirable for applications in the construction of superconducting magnets. First, ferrite is brittle at low temperatures, which is one of the factors degrading the fracture toughness of austenitic stainless steel welds [2]. Second, ferrite is ferromagnetic, which enhances the forces in the magnetic field.

Therefore, superconducting magnet applications require ferrite-free austenitic stainless steel welds. This is usually accomplished by choosing chemical compositions for filler metals that will produce fully austenitic stainless steel welds, according to the Delong diagram [3].

To reduce or eliminate microfissures in the welds, levels of residual impurities, such as sulfur and phosphorus, are kept to a minimum. This is based on the theory that microfissures occur as a result of the segregation of residual impurities at the grain boundary during the solidification process [4].

The 320 electrode contains up to 32 to 36 weight percent nickel and will produce fully austenitic stainless steel welds. The most common application of this electrode is to weld alloys for use in highly corrosive environments. To reduce the microfissuring tendency, the LR (10w-residual) grade is introduced. Because the $320 \mathrm{LR}$ electrodes produce welds that meet the requirements for superconducting magnet applications in terms of being free of ferrite and microfissures, the objective of this study was to measure their tensile properties and fracture toughness at $4 \mathrm{~K}$, values that are not 
currently available. The results are compared with those of the more commonly used $316 \mathrm{~L}$ fully austenitic weld metal.

\section{MATERIALS}

The test weldment was a 25.4-mm-thick plate of $304 \mathrm{~L}$ stainless steel welded with a $320 L R$ electrode. The welding was done by the manual shieldedmetal-arc (SMA) process in the flat position. The welding parameters and joint design are given in Figure 1. The joint had a 12.7-mm root gap and a $45^{\circ}$ bevel. It was filled with one full layer, three split layers, five triple layers, and three quadruple layers, using $95 \mathrm{~A}$ and $21 \mathrm{~V}$ with reverse polarity. The chemical compositions of 320 electrodes, as specified in AWS A5.4-78, and 320 LR electrodes, as specified by the manufacturer, are summarized in Table 1.

\section{EXPERIMENTAL PROCEDURES}

Tensile properties were measured in the longitudinal weld direction (all weld metal) using a 6.35-mm-diameter, 50.8-mm-gage-length specimen (one specimen). The specimen was instrumented with electrical resistance strain gages in the gage section for strain measurements. The test was conducted in liquid helium at $4 \mathrm{~K}$ using a cryostat similar to that described by Reed [5]. The strain rate was $4.2 \times 10^{-4} / \mathrm{s}$ in the low elongation range for determination of $0.2 \%$ offset yield strength $\left(\sigma_{y}\right)$ and then was increased to $4.2 \times 10^{-3} / \mathrm{s}$ to expedite the test. The increase in strain rate is not expected to affect the test result because ultimate tensile strength (UTS) is insensitive to the strain rate within the test range. Young's modulus (E) was determined from the linear portion of the stress-strain curve of the tensile test. The location of the weld tensile specimen within the fusion zone is shown in Figure 1.

Fracture toughness of 25.4-mm-thick compact tension (CT) specimens (two specimens) were measured with the J-integral method [6]. The location and 
orientation of the specimens are shown in Figure 1. Tests were conducted in liquid helium at $4 \mathrm{~K}$ using a cryostat described by Read and Tobler [7]. The single-specimen unloading-compliance technique [8] was used to measure $\mathrm{J}-\Delta \mathrm{a}$ (crack extension) resistance curves. The $\mathrm{J}-\Delta \mathrm{a}$ curves were then used to determine $\mathrm{J}_{\mathrm{IC}}$. The plane strain fracture toughness estimate, $\mathrm{K}_{\mathrm{IC}}(\mathrm{J})$, was calculated from $J_{\text {Ic }}$ using the following relation [6]:

$$
K_{I C}(J)=\left(\frac{J_{I C} \cdot E}{1-v^{2}}\right)^{\frac{1}{2}}
$$

Poisson's ratio, $\nu$, was taken to be 0.3 , and Young's modulus, E, was determined in the present study.

\section{EXPERIMENTAL RESULTS AND DISCUSSION}

Tensile properties and fracture toughness results at $4 \mathrm{~K}$ are summarized in Table 2. For comparison, properties of the more commonly used fully austenitic $316 \mathrm{~L}$ weld metal [9] are also presented in Table 2 . The $316 \mathrm{~L}$ electrode contains 11 to 14 weight percent nickel, and is produced by the SMA process with welding conditions similar to those of the present study. Fracture toughness of the $320 L R$ weld metal is comparable to that of the fully austenitic $316 \mathrm{~L}$ weld metal. The results for elongation (EL) and reduction of area (RA) also fall within the scatter band of the $316 \mathrm{~L}$ weld metal data. Visual examination of fracture surfaces revealed no indications of welding flaws.

Young's modulus of the 320LR weld metal at $4 \mathrm{~K}$ is about $22 \%$ 10wer than that of 316 stainless steel plates owing to a higher nickel content (Invar effect) and texture in the weld $[10,11]$. The yield strength and ultimate tensile strength of the 320LR weld metal are 8 and 12 percent 1 ower, respectively, than the lower bound of the published data for $316 \mathrm{~L}$ weld metal. 
Note that there was only one tensile test in this study because of material unavailability. Based on analysis of the data in Reference 9, the data scatter estimates for well-controlled weldments (with respect to welding parameters) and testing conditions are \pm 15 percent for yield strength and \pm 10 percent for ultimate tensile strength of the mean value. For a better characterization and for confirmation of the observed lower strengths of the 320 LR weld metal, additional tensile tests are desirable.

The 320LR electrode costs more than the $316 \mathrm{~L}$ electrode, owing to a higher nickel content and lower levels of residual elements. At $4 \mathrm{~K}$, it has a comparable fracture toughness, and possibly lower yield and ultimate tensile strengths. Considering its higher cost and possibly lower strength, the 320LR weld metal appears less attractive for use in superconducting magnet designs than $316 \mathrm{~L}$.

SUMMARY

Tensile properties and fracture toughness of 320LR fully austenitic stainless steel weld metal, produced by the shielded-metal-arc process, were measured in liquid helium at $4 \mathrm{~K}$. The preliminary results show that yield strength and ultimate tensile strength of the 320LR weld metal are 8 and 12 percent lower, respectively, than the lower bound of the published data for $316 \mathrm{~L}$ fully austenitic stainless steel weld metal, and values of fracture toughness are similar for the two weld metals. Considering its higher cost and possibly lower strength, the 320LR weld metal appears less attractive for use in superconducting magnet designs than $316 \mathrm{~L}$. ACKNOWLEDGMENTS

This study was supported by the Department of Energy, Office of Magnetic Fusion Energy. R. P. Walsh of NBS conducted the tensile test. 
1. C. D. Lundin and D. F. Spond, "The Nature and Morphology of Fissures in Austenitic Stainless Steel Weld Metals, "Welding Journal, Welding Research Supplement, 55, 356s-367s (1976).

2. D. T. Read, H. I. McHenry, P. A. Steinmeyer, and R. D. Thomas, Jr., "Metallurgical Factors Affecting the Toughness of 316L SMA Weldments at Cryogenic Temperatures," in: Materials Studies for Magnetic Fusion Energy Applications at Low Temperatures-II, ed. R. P. Reed, NBSIR 79-1609, National Bureau of Standards, Boulder, Colorado (1979), pp. 313-351.

3. W. T. Delong, "Ferrite in Austenitic Stainless Steel Weld Metals," Welding Journal, Welding Research Supplement, 53, 273s-286s (1974).

4. J. A. Brooks and F. J. Lambert, Jr., "The Effects of Phosphorus, Sulfur and Ferrite Content on Welding Cracking of Type 309 Stainless Steel," Welding Journal, Welding Research Supplement, 57, 139s-143s (1978).

5. R. P. Reed, "A Cryostat for Tensile Tests in the Temperature Range 300 to $4 \mathrm{~K}$," in: Advances in Cryogenic Engineering, vol.7, Plenum Press, New York (1962), pp. 448-454.

6. "Standard Test for J , a Measure of Fracture Toughness," ASTM designation: E813-81, in: Annual Book of ASTM Standards, Part 10, American Society for Testing and Materials, Philadelphia, Pennsylvania (1982), pp. 822-840.

7. D.T. Read and R. L. Tobler, "Mechanical Property Measurements at Low Temperatures," in: Advances in Cryogenic Engineering, vol. 28, Plenum Press, New York (1982), pp. 17-28.

8. D. T. Read, "The Computer-Aided J-Integral Test Facility at NBS," in: Materials Studies for Magnetic Fusion Energy Applications at Low Temperatures-III, ed. R. P. Reed, NBSIR 80-1627, National Bureau of Standards, Boulder, Colorado (1980), pp. 205-216.

9. T. A. Whipple, H. I. McHenry, and D. T. Read, "Fracture Behavior of Ferrite-Free Stainless Steel Welds in Liquid Helium," in: Materials Studies for Magnetic Fusion Energy Applications at Low Temperatures-III, ed. R. P. Reed, NBSIR 80-1627, National Bureau of Standards, Boulder, Colorado (1980), pp. 167-194.

10. H. M. Ledbetter and R. P. Reed, "Elastic Properties of Metals and Alloys, I. Iron, Nickel, and Iron-Nickel Alloys," Journal of Physical and Chemical Reference Data, vol. 2, 531-618(1974).

11. H. M. Ledbetter, "Texture in Stainless-Steel Welds: An U1trasonic Study," in: Materials Studies for Magnetic Fusion Energy Applications at Low Temperatures-VI, eds., R. P. Reed and N. J. Simon, NBSIR 83-1690, National Bureau of Standards, Boulder, Colorado (1983), pp. 339-356. 


\section{LIST OF TABLES}

1. Chemical compositions of 320 and $320 \mathrm{LR}$ electrodes

2. Tensile properties and fracture toughness of 320LR weld metal at $4 \mathrm{~K}$

\section{LIST OF FIGURES}

1. Welding parameters and joint design of the test weldment; orientation and location of the specimens. 
Table 1. Chemical compositions of 320 and 320 LR electrodes

\begin{tabular}{|c|c|c|c|c|c|c|c|c|c|}
\hline Electrode & $C$ & $\mathrm{Cr}$ & $\mathrm{Ni}$ & Mo & $\mathrm{Cb}+\mathrm{Ta}$ & $\overline{M n}$ & $\mathrm{Si}$ & $P$ & 5 \\
\hline$E 320^{\star}$ & 0.07 & $19-21$ & $32-36$ & $2-3$ & $\begin{array}{l}8 \times C \min . \\
1.0 \text { max }\end{array}$ & $0.5-2.5$ & 0.60 & 0.04 & 0.03 \\
\hline$E 320 L R^{\star \star}$ & 0.035 & & & & & & 0.30 & 0.02 & 0.015 \\
\hline
\end{tabular}

Note: Single values are maximums.

* Specification of AWS A5.4-78.

** Specification of manufacturer.

Table 2. Tensile properties and fracture toughness of $320 \mathrm{LR}$ weld metal at $4 \mathrm{~K}$

\begin{tabular}{|c|c|c|c|c|c|c|}
\hline & $\begin{array}{c}\mathrm{K}_{\mathrm{Ic}}{ }^{\star}{ }^{\star} \\
\mathrm{MPa} \text { arm }\end{array}$ & $\begin{array}{l}\mathrm{E}, \\
\mathrm{GPa}\end{array}$ & $\begin{array}{l}{ }^{\sigma} y^{\prime} \\
\mathrm{MPa}\end{array}$ & $\begin{array}{l}\text { UTS, } \\
\mathrm{MPa}\end{array}$ & $\begin{array}{r}E L, \\
\%\end{array}$ & $\begin{array}{r}\text { RA, } \\
\% \\
\end{array}$ \\
\hline E320LR & ave $\begin{array}{r}163 \\
\frac{149}{156}\end{array}$ & 161.6 & 674 & 978 & 40 & 35.7 \\
\hline$E 316 L^{\star \star *}$ & $95-200$ & & $729-882$ & $1121-1300$ & $25-48$ & $23-44$ \\
\hline
\end{tabular}

* Estimated from J Ic

** Fully austenitic (0\% ferrite); from Reference 9. 

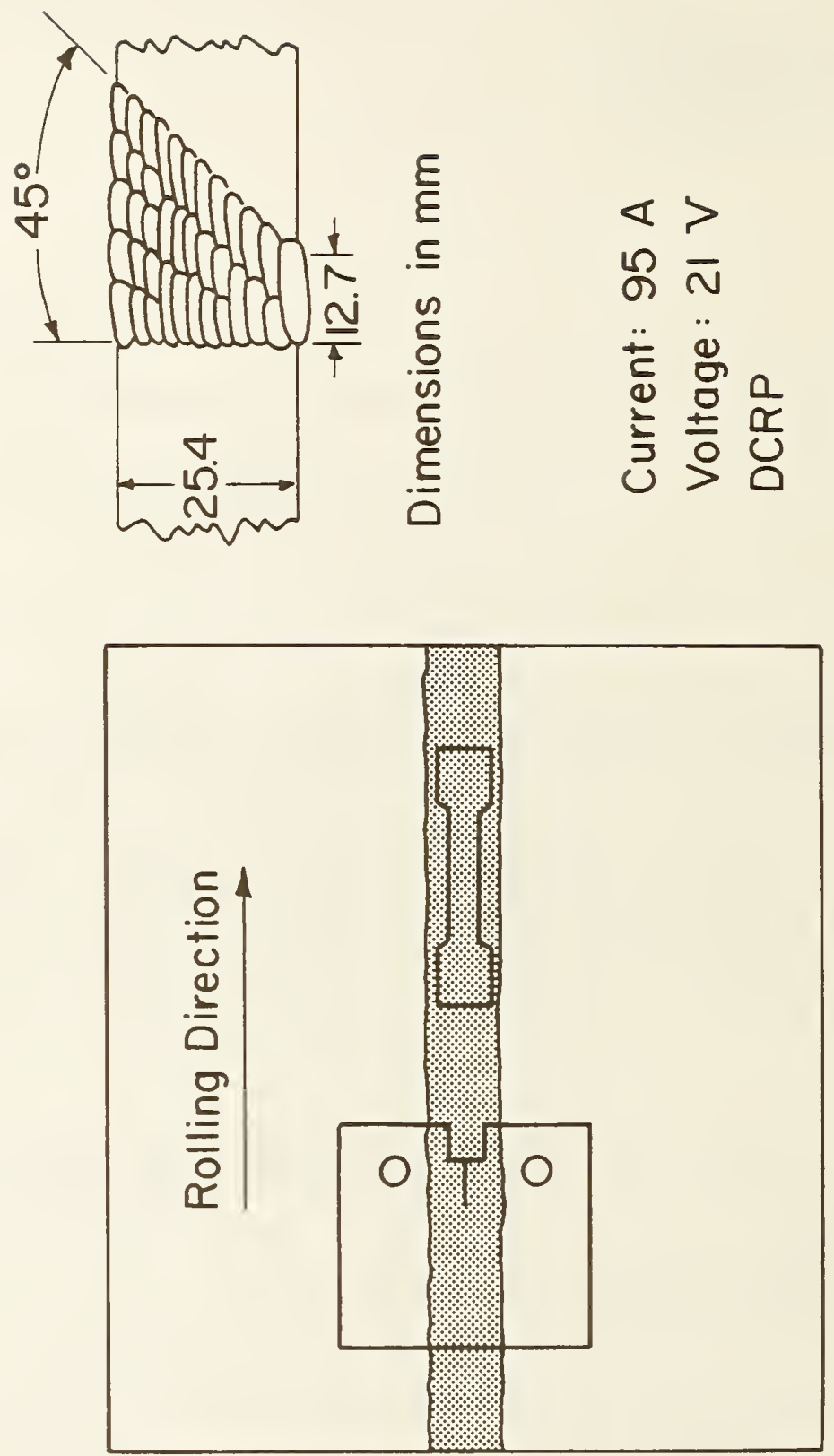

Fig. 1. Welding parameters and joint design of the test weldment; orientation and location of the specimens. 


\section{FATIGUE CRACK GROWTH OF DUPLEX STAINLESS STEEL CASTINGS AT $4 \mathrm{~K} *$ \\ P. T. Purtscher, Y. W. Cheng, P. N. Li** Fracture and Deformation Division National Bureau of Standards Boulder, Colorado}

\section{ABSTRACT}

Constant-load-amplitude stage II fatigue crack growth rates at $4 \mathrm{~K}$ were measured for duplex stainless steel castings. The results show that at a $\Delta K$ of $60 \mathrm{MPa} \cdot \mathrm{m}^{\frac{1}{2}}, \mathrm{da} / \mathrm{dN}=7.6 \times 10^{-4} \mathrm{~mm} /$ cycle for an alloy with $1 \%$ ferrite. For an alloy with $8 \%$ ferrite, da/dN is $35 \%$ greater, and for an alloy with $29 \%$ ferrite, $\mathrm{da} / \mathrm{dN}$ is $260 \%$ greater than for the $1 \%$ ferrite a $110 y$. However, the exponent in the Paris equation does not change appreciably (less than $18 \%$ ) as the ferrite content changes from 1 to $29 \%$.

Keywords: Austenitic stainless steel castings; cryogenic properties of materials; delta ferrite; fatigue crack growth rate; stainless steel

* Contribution of NBS; not subject to copyright.

**Guest worker; on leave from East China Institute of Chemical Technology, Shanghai, China. 



\section{INTRODUCTION}

Stainless steel castings can facilitate fabrication of structural components for low-temperature applications by eliminating the need for welding. The deformation and fracture behavior of stainless steel castings at $4 \mathrm{~K}$ has been reported previously. 1,2,3 However, fatigue design data for stainless steel castings at low temperature are needed to ensure reliable performance.

CF8M stainless steel castings are roughly equivalent in composition to wrought AISI 316. Conventionally processed AISI 316 is $100 \%$ austenite [facecentered cubic structure $(f c c)]$ at room temperature, but the cast structure normally contains some delta ferrite [body-centered cubic (bcc)] within the austenite matrix. The amount of bcc phase is determined by solidification and chemical composition variables. Delta ferrite in the microstructure of stainless steel castings reduces the toughness at $4 \mathrm{~K} .^{1,2,3}$ For CF8M castings, the $4-\mathrm{K}$ toughness was $352 \mathrm{MPa} \cdot \mathrm{m}^{\frac{1}{2}}$ with $1 \%$ ferrite, $148 \mathrm{MPa} \cdot \mathrm{m}^{\frac{1}{2}}$ for $8 \% \mathrm{ferrite}$, and approximately $110 \mathrm{MPa} \cdot \mathrm{m}^{\frac{1}{2}}$ for 17,23 , and $29 \%$ delta ferrite. Above $15 \%$ ferrite, the bcc phase was present as a nearly continuous phase in three dimensions and provided an easy path for crack propagation under monotonic loading.

The fatigue crack growth rate (FCGR) of stable fcc alloys is usually less at $4 \mathrm{~K}$ than at room temperature. For metastable fCC alloys, the FCGR may or may not increase as the test temperature drops from room temperature to $4 \mathrm{~K}$, depending on the specific composition. AISI 316 is metastable; it undergoes some strain-induced martensitic transformation at $4 \mathrm{~K}$, but the FCGR of AISI 316 does not change appreciably with temperature. 4

The FCGR of bcc alloys normally shows a higher stress dependence than the FCGR of fcc alloys as the test temperature is decreased from room temperature 
to $4 \mathrm{~K}$. The increased stress dependence can be correlated with the occurrence of brittle fracture modes (cleavage) on the surface rather than the fatigue striations typicaliy seen on the fatigue fracture surface of an fcc alloy. 4

There are no fatigue crack growth data for austenitic stainless steel castings at $4 \mathrm{~K}^{4}$ The purpose of this study is to determine the effect of delta ferrite on stage II FCGR of CF8M austenitic stainless steel castings at $4 K$.

\section{MATERIALS AND EXPERIMENTAL PROCEDURE}

Three different alloys were fatigue tested at $4 \mathrm{~K}$. The chemical composition, tensile properties at $4 \mathrm{~K}$, and the fracture toughness at $4 \mathrm{~K}$ of each alloy are shown in Table $I$. All three alloys fall within the compositional limits for the CF8M grade. These three alloys solidify as primary delta-ferrite alloys that intersect the eutectic triangle of the $\mathrm{Fe}-\mathrm{Cr}-\mathrm{Ni}$ phase diagram so that austenite envelops the ferritic dendrites before complete solidification. 5 The delta ferrite in the room-temperature microstructure is located at the spines of the dendrites.

A single compact tension specimen was tested for each of the alloys containing 1 and $8 \%$ ferrite. Duplicate specimens were tested for the $29 \%$ ferrite alloy. The test temperature was maintained at $4 \mathrm{~K}$ by submersing the specimens in liquid helium. The cryostat system that was used for the fatigue testing was described previous $7 y .^{6}$

The fatigue crack growth rate was determined by a computer-aided procedure $^{7}$ in accordance with ASTM E647-81 for constant-load-amplitude fatigue crack growth rates above $10^{-8} \mathrm{~m} /$ cycle. The crack growth was monitored by measuring the change in compliance of the specimen. The $R$ ratio (minimum load/maximum 1oad) used was 0.1 , and the loading frequency was $20 \mathrm{~Hz}$. 
The Paris equation ${ }^{8}$ was used to characterize the fatigue crack growth:

$$
d a / d N=A(\Delta K)^{m}
$$

where $d a / d N$ is the crack growth per cycle, $\Delta K$ is the stress intensity factor range $\left(K_{\max }-K_{\min }\right)$, and $A$ and $m$ are the parameters in the Paris equation.

The fatigue fracture surface of each alloy was examined with a scanning electron microscope.

\section{RESULTS}

Table II summarizes the FCGR results. On the basis of previous experience with the computer-aided FCGR procedure, the specimen to specimen variation in the results from duplicate specimens is estimated to be $\pm 20 \%$. For a better characterization and to confirm the results reported here, additional fatigue tests are desirable.

Figures 1 through 3 show the log-log plots of da/dN vs. $\Delta K$ for each of the three alloys. In figure 4 the three curves are superimposed on one plot with the reported 1 iterature value for AISI 316.5 For the castings, there was a general increase in FCGR with increasing delta ferrite, but the increase was relatively smal1. The FCGR of the AISI 316 that did not contain any delta ferrite was between the 1 and $8 \%$ ferrite alloys.

An interesting observation of the fatigue surfaces could be made with the unaided eye. The fracture surfaces of all specimens were relatively rough and appeared to follow the dendritic solidification structure (Figure 5); nomally the fatigue fracture surface of AISI 316 is normally smooth when observed with the unaided eye.

Scanning electron microscopy (SEM) was used to study the microscopic fracture features of each of the three alloys. For the alloy with 1\% delta 
ferrite, the surface was covered with poorly formed fatigue striations and a fracture morphology that was related to the dendritic solidification pattern. As $\Delta K$ increased, some secondary cracking was found on the fracture surface (Figures 6 and 7).

For the alloy with $8 \%$ delta ferrite, the fracture surface showed essentially the same topography, (Figure 6), but with some quasi-cleavage facets that represent fracture through the delta ferrite. Secondary cracking was observed on the fracture surface over the entire range of $\Delta K$ (Figure 8 ). Fracture morphology due to the dendritic solidification pattern was still present on that portion of the surface that corresponds to the austenite matrix.

When the delta ferrite content was increased to $29 \%$, the fatigue fracture surface showed more of the quasi-cleavage facets with secondary cracking (Figure 9). The fraction of the surface that was covered by the quasi-cleavage facets increased by an amount that correlates qualitatively with the increase in delta ferrite. The fracture morphology due to the dendritic solidification was still present, but to a lesser degree.

\section{DISCUSSION}

The degree of influence of second phase volume fraction on the FCGR of duplex microstructures is expected to depend on mechanical variables such as the relative flow strength of the two phases, applied $\Delta K$ and $K_{\max }$. In the case of CF8M castings with delta ferrite, the ferrite phase had higher strength, lower ductility, and lower fracture toughness at $4 \mathrm{~K}$ than the austenite phase.

The FCGR of these alloys was divided into regions of low and high $\Delta K$ behavior. At low $\Delta K$ values, the $d a / d N$ did not correlate with the delta 
ferrite content, as evidenced by the crossover in Figure 4 for the 8 and 29\% ferrite alloys. At high $\Delta K$ values, increasing ferrite content correlated well with the increase in $\mathrm{da} / \mathrm{dN}$.

SEM showed two distinct morphologies on the fracture surfaces of the three alloys: A morphology with poorly formed striations and dendritic features (referred to as striation morphology) and a quasi-cleavage morphology (referred to as cleavage morphology). For the sake of discussion, the measured crack growth rate can be thought of as the sum of the crack growth of each of the morphologies and can be expressed as:

$$
(d a / d N)_{\text {mea. }}=(d a / d N)_{\text {str. }}+(d a / d N)_{\text {cle. }}
$$

where $(d a / d N)_{\text {mea. }}=$ crack growth rate measured in test

$(\mathrm{da} / \mathrm{dN})_{\text {str. }}=$ crack growth rate (striation morphology)

$(\mathrm{da} / \mathrm{dN})_{\mathrm{cle}}=$ crack growth rate (cleavage morphology)

The striation morphology showed two microscopic features: the poorly formed striations and the dendritic features. Fracture exhibiting this striation morphology moved selectively through the austenite instead of following the plane of maximum stress, indicating that the crack was propagating through relatively weak points in the structure. However, the $(\mathrm{da} / \mathrm{dN})_{\mathrm{mea}}$. of the $1 \%$ alloy was lower than the reported value of $d a / d N$ for AISI 316 over the range of $\Delta K$ reported (Figure 4 ). Therefore, this striation morphology is not inherently weak, even though part of the fracture occurred through interdendritic regions of the austenite.

The delta ferrite in the microstructure fractures at $4 \mathrm{~K}$ with a quasicleavage morphology that is controlled by the applied stress in much 
the same way that stress controls cleavage fracture. The stress at the interface between ferrite and austenite must exceed a critical stress for quasi-cleavage fracture to occur. Once the critical stress is attained, the crack propagates through the ferrite by the quasi-cleavage mechanism. In fracture toughness testing, the crack will exhibit a cleavage morphology exclusively through the ferrite if the ferrite forms a nearly continuous path in three dimensions. ${ }^{1,2}$ However, in fatigue, the crack does not grow exclusively through the ferrite, even for the $29 \%$ ferrite alloy where the ferrite was nearly continuous in three dimensions.

The correlation between $(\mathrm{da} / \mathrm{dN})_{\text {mea. }}$ and delta ferrite at high values of $\Delta K$ and $K_{\max }$ can be explained by considering the fracture mechanisms. The high stress levels promote the cleavage fracture morphology at or ahead of the crack front during the fatigue test. Therefore, $(d a / d N)$ cle. exceeds (da/dN) str.' which explains why $(\mathrm{da} / \mathrm{dN})_{\text {mea. }}$ of the $8 \%$ ferrite alloy exceeds $(\mathrm{da} / \mathrm{dN})_{\text {mea. }}$ of the $1 \%$ ferrite alloy. Likewise, $(\mathrm{da} / \mathrm{dN})_{\text {mea }}$ of the $29 \%$ ferrite alloy exceeds $(\mathrm{da} / \mathrm{dN})_{\text {mea. }}$ of the $8 \%$ ferrite alloy.

Another factor to consider in examination of the results of the FCGR tests is the change in the stress dependence as a function of delta ferrite content (Table II). The results show that the $m$ value in the Paris equation does not increase uniformly along with the increase in ferrite content. When the magnitude of the $m$ values are compared with the $m$ values at $4 \mathrm{~K}$ reported tough austenitic stainless steels, ${ }^{4}$ there are no appreciable differences. 
The presence of delta ferrite in the microstructure of the CF8M castings has a significant effect on stage II FCGR at $4 \mathrm{~K}$. At a $\Delta \mathrm{K}$ of $60 \mathrm{MPa} \cdot \mathrm{m}^{\frac{1}{2}}$, da/dN $=7.6 \times 10^{-4} \mathrm{~mm} /$ cycle for the $1 \%$ ferrite alloy, $10.3 \times 10^{-4} \mathrm{~mm} /$ cycle for the $8 \%$ ferrite alloy, and $19.7 \times 10^{-4} \mathrm{~mm} /$ cycle for the $29 \%$ ferrite a $110 y$. The increase in $\mathrm{da} / \mathrm{dN}$ is correlated with the occurrence of a quasi-cleavage fracture morphology on the fatigue fracture surface of the ferrite-containing a $710 y s$. The increase in $d a / d N$ with increasing ferrite content is large, but the $m$ value in the Paris equation does not change appreciably (1ess than $18 \%$ ). ACKNOWLEDGMENT

This work was supported by the Department of Energy, Office of Fusion Energy.

\section{REFERENCES}

1. E. L. Brown, T. A. Whipple, and R. L. Tobler, "Fracture Toughness of CF8 Castings at Four Kelvin," Met. Trans. Vol. 14A, No. 8 (1983), pp. 1179-1188.

2. T. A. Whipple and E. L. Brown, "Deformation and Fracture of Stainless Steel Castings and Weldments at $4 \mathrm{~K}$," in Materials Studies for Magnetic Fusion Energy Applications at Low Temperatures - VI, NBSIR 81-1645, R. P. Reed and N. J. Simon, eds., National Bureau of Standards, Boulder, Colorado (1981), pp. 213-233.

3. T. A. Whipple and H. I. McHenry, "Mechanical Properties of Stainless Steel Castings at $4 \mathrm{~K}$," in Materials Studies for Magnetic Fusion Energy Applications at Low Temperatures - VI, NBSIR 81-1645, R. P. Reed and N. J. Simon, eds., National Bureau of Standards, Boulder, Colorado (1981), pp. 235-241.

4. R. L. Tobler and R. P. Reed, "Fatigue Crack Growth Resistance of Structural Alloys at Cryogenic Temperatures," in Advances in Cryogenic Engineering, Vo1. 24, K. D. Timmerhaus, R. P. Reed, and A. F. Clark, eds., Plenum Press, New York (1978), pp. 82-90.

5. E. L. Brown, T. A. Whipple, and G. Krauss, "Metallography of Duplex Steel Castings," in Materials Studies for Magnetic Fusion Energy Applications at Low Temperatures - VI, NBSIR 83-1645, R. P. Reed and N. J. Simon, eds., National Bureau of Standards, Boulder, Colorado (1983), pp. 243-271. 
6. C. W. Fowlkes and R.L. Tobler, "Fracture Testing and Results for a Ti-6Al-4V Alloy in Liquid Helium Temperature," Eng. Fract. Mech., Vol. 8 (1976), pp. 487-500.

7. Y.-W. Cheng, "A Computer-Interactive Fatigue Crack Growth Rate Test Procedure," in Materials Studies for Magnetic Fusion Energy Applications at Low Temperatures - VI, NBSIR 81-1645, R. P. Reed and N. J. Simon, eds., National Bureau of Standards, Boulder, Colorado (1981), pp. 41-51.

8. R. W. Hertzberg, Deformation and Fracture Mechanics of Engineering Materials, John Wiley and Sons, New York (1976), p. 468. 
Table I. Chemical Composition (wt.\%) and Mechanical Properties at $4 \mathrm{~K}$ of CF8M Castings

$\begin{array}{lll}\text { Heat \#47640 } & \text { Heat \# 48988 } & \text { Heat \#49021 } \\ 1 \% \text { ferrite } & 8 \% \text { ferrite } & 29 \% \text { ferrite }\end{array}$

\begin{tabular}{lrcc} 
Carbon & 0.06 & 0.06 & 0.05 \\
Manganese & 1.10 & 0.38 & 0.39 \\
Silicon & 0.59 & 1.16 & 1.11 \\
Chromium & 1.80 & 19.6 & 22.5 \\
Nickel & 13.2 & 10.6 & 9.8 \\
Molybdenum & 2.12 & 2.1 & 2.3 \\
Nitrogen & 0.05 & 0.05 & 0.05 \\
$\quad$ & & & 851 \\
$\sigma_{y}(\mathrm{MPa})$ & 581 & 1221 & 1164 \\
$\sigma_{\mathrm{u}}(\mathrm{MPa})$ & 1215 & 21 & 11 \\
$\% \mathrm{elongation}$ & 48 & 148 & 105 \\
$\mathrm{~K}_{\mathrm{IC}}(\mathrm{J})\left(\mathrm{MPa} \cdot \mathrm{m}^{\frac{1}{2}}\right)$ & 352 & & \\
\hline
\end{tabular}

Table II. Summary of Stage II Fatigue Crack Growth at $4 \mathrm{~K}$ of CF8M Casting from da/dN $=A(\Delta K)^{m}$

\begin{tabular}{cccc} 
Ferrite Content $(\%)$ & $A(\mathrm{~mm} / \mathrm{cycle})$ & $\mathrm{m}$ & $\Delta \mathrm{K}$ range $(\mathrm{MPa} \cdot$ \\
\hline 1 & $0.272 \times 10^{-9}$ & 3.63 & 23 to 83 \\
8 & $0.342 \times 10^{-8}$ & 3.08 & 23 to 68 \\
29 & $0.159 \times 10^{-9}$ & 3.99 & 20 to 60
\end{tabular}




\section{LIST OF FIGURES}

Figure 1. Plot of $d a / d N$ vs. $\triangle K$ for CF8M casting with $1 \%$ delta ferrite.

Figure 2. Plot of $d a / d N$ vs. $\Delta K$ for CF8M casting with $8 \%$ delta ferrite.

Figure 3. Plot of $d a / d N$ vs. $\Delta K$ for CF8M casting with $29 \%$ delta ferrite.

Figure 4. Summary of CF8M castings and AISI 316 fatigue data at $4 \mathrm{~K}$.

Figure 5. Fracture surface of CF8M casting with $1 \%$ ferrite at low magnification showing the relative roughness of the surface. The fracture surfaces of the castings with 8 and $29 \%$ ferrite were similar.

Figure 6. SEM photomicrograph of fatigue fracture surface of CF8M casting with $1 \%$ delta ferrite and low $\Delta K$ conditions.

Figure 7. SEM photomicrograph of fatigue fracture surface of CF8M casting with $1 \%$ delta ferrite and high $\Delta K$ conditions.

Figure 8. SEM photomicrograph of fatigue fracture surface of CF8M casting with $8 \%$ delta ferrite and low $\Delta K$ conditions.

Figure 9. SEM photomicrograph of fatigue fracture surface of CF8M casting with $29 \%$ delta ferrite and $10 w \Delta K$ conditions. 


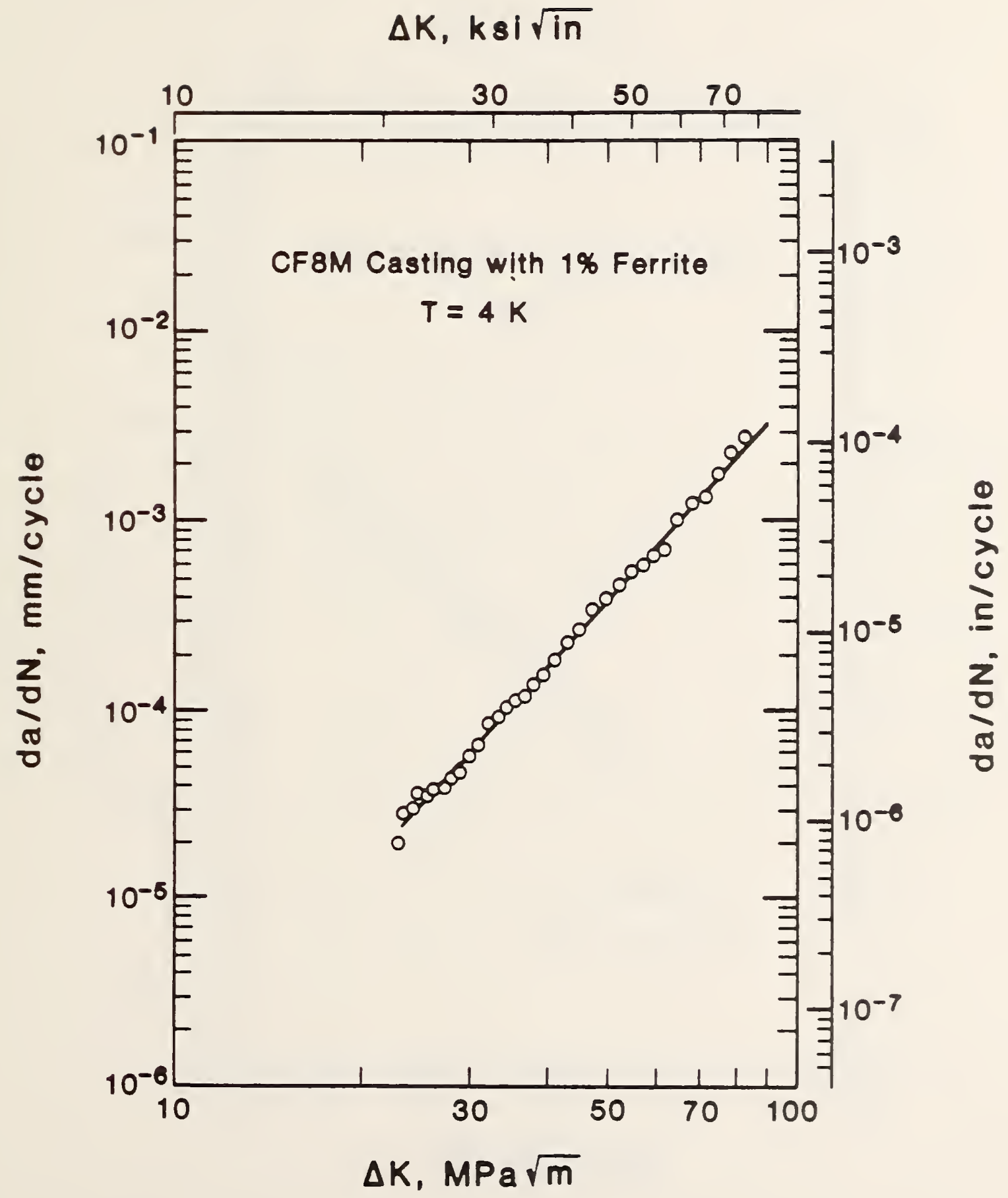

Figure 1. Plot of da/dN vs. $\triangle \mathrm{K}$ for CF8M casting with $1 \%$ delta ferrite. 


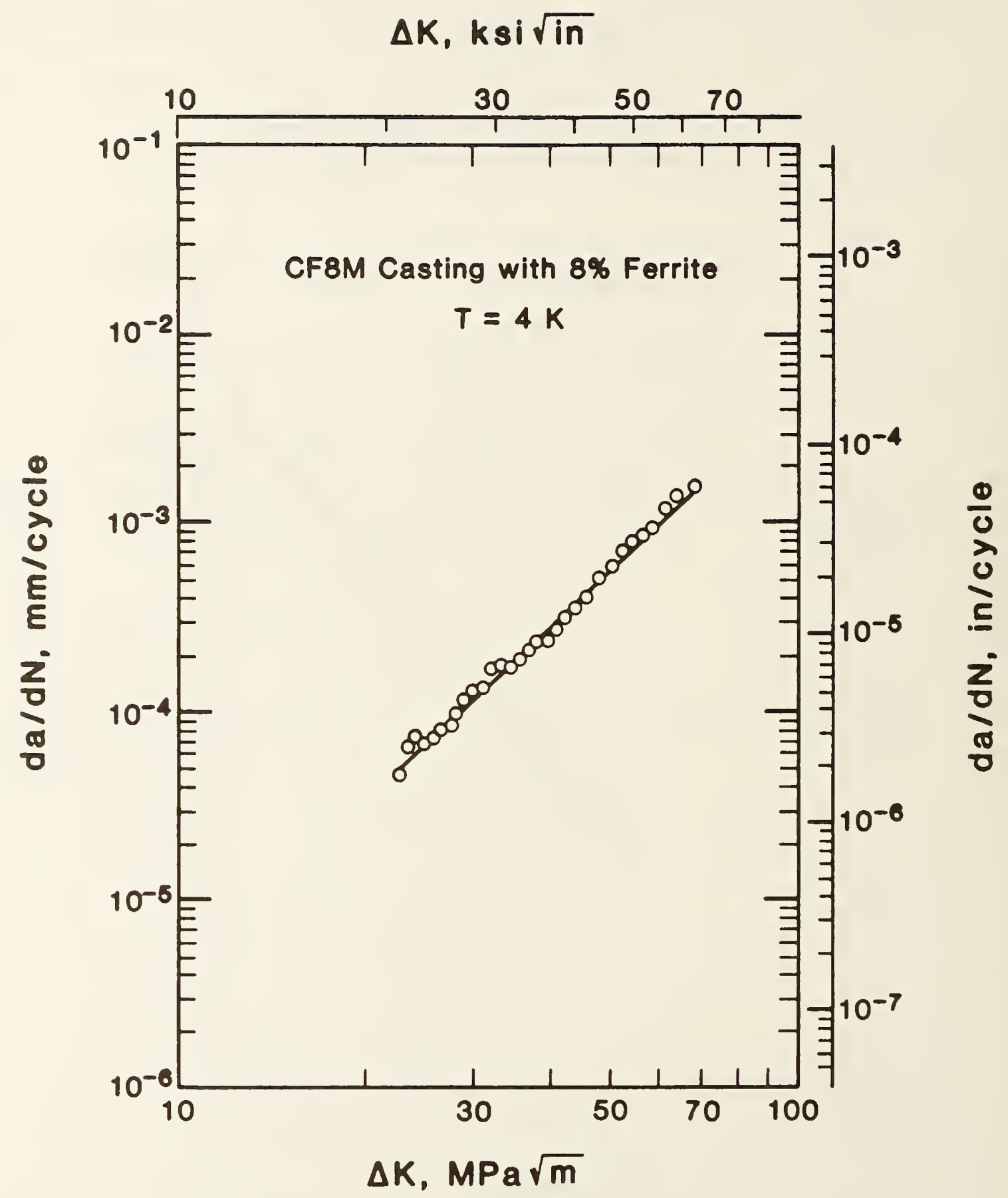

Figure 2. Plot of $\mathrm{da} / \mathrm{dN}$ vs. $\triangle \mathrm{K}$ for $\mathrm{CF} 8 \mathrm{M}$ casting with $8 \%$ delta ferrite. 


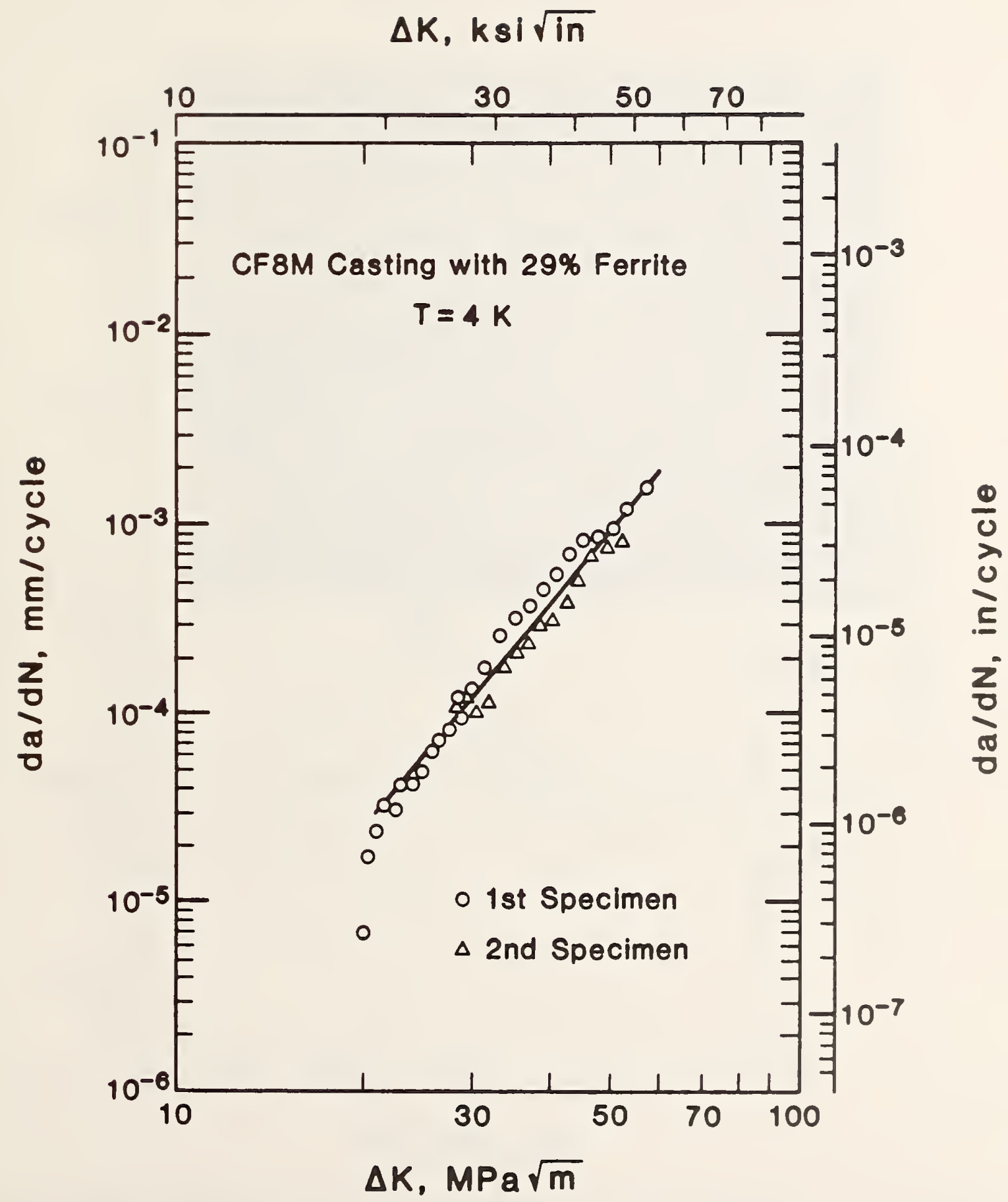

Figure 3. Plot of da/dN vs. $\triangle \mathrm{K}$ for CF8M casting with $29 \%$ delta ferrite. 
$\Delta K, k s i \sqrt{i n}$

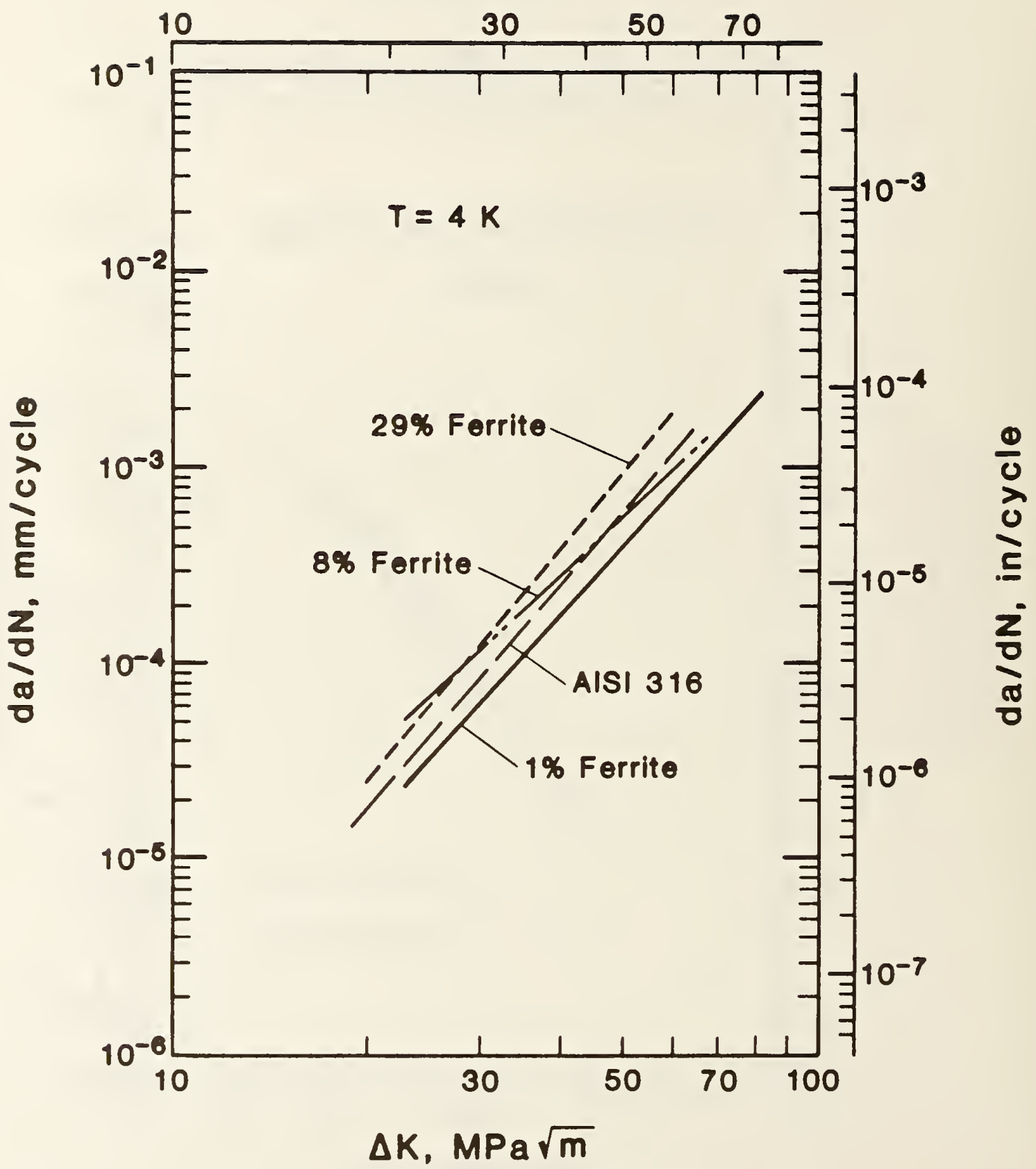

Figure 4. Summary plot of fatigue data at $4 \mathrm{~K}$ of $\mathrm{CF} 8 \mathrm{M}$ castings and AISI 316. 
$4 k$ fatigue fracture surface

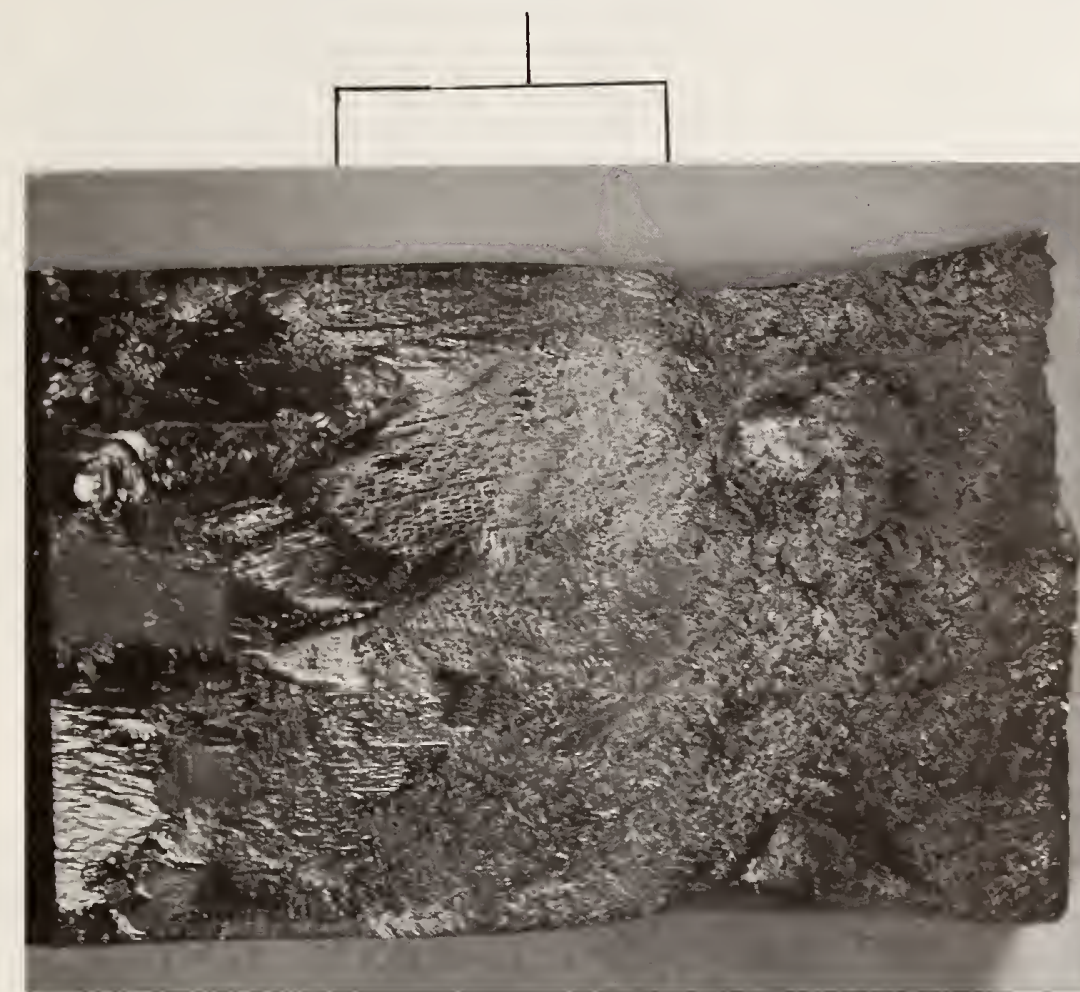

$1 \mathrm{~cm}$

Figure 5 Fracture surface of CF8M casting with $1 \%$ ferrite at low magnification showing the relative roughness of the surface. The fracture surfaces of the castings with 8 and $29:$ ferrite appeared to be similar. 


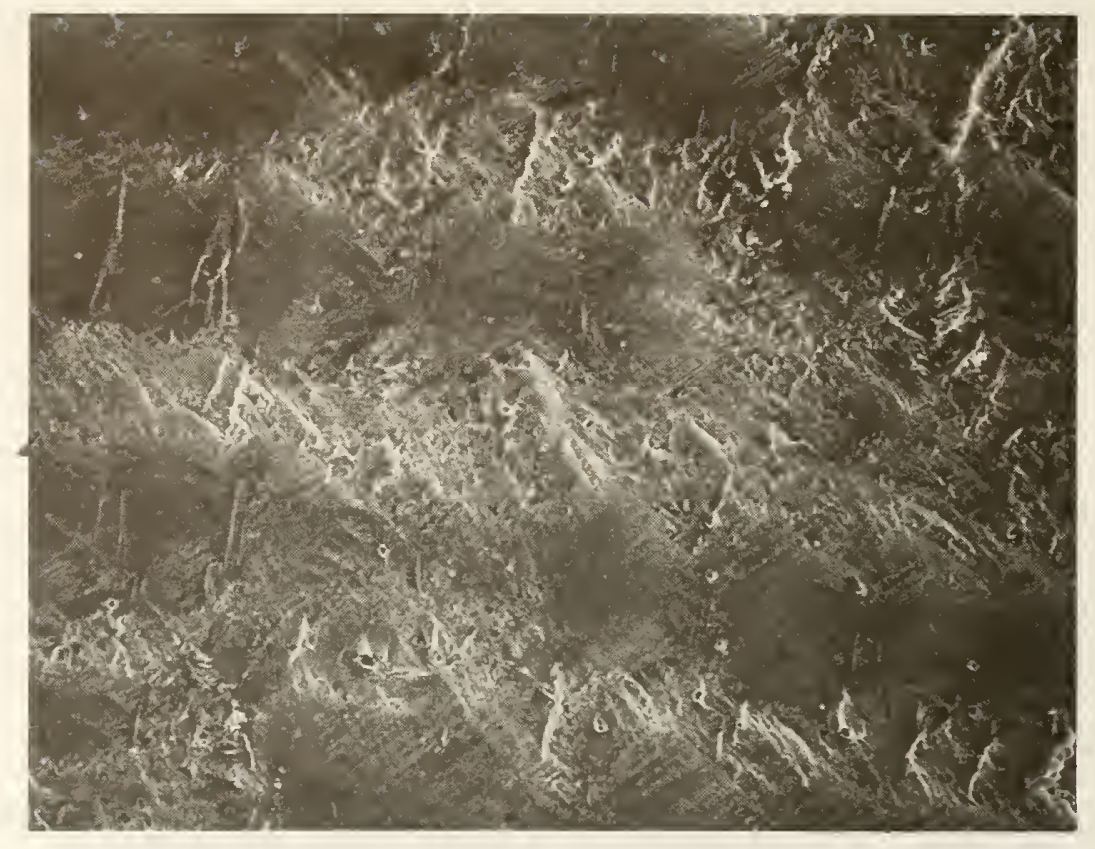

\section{$\longdiv { 1 0 0 \mathrm { rm } }$}

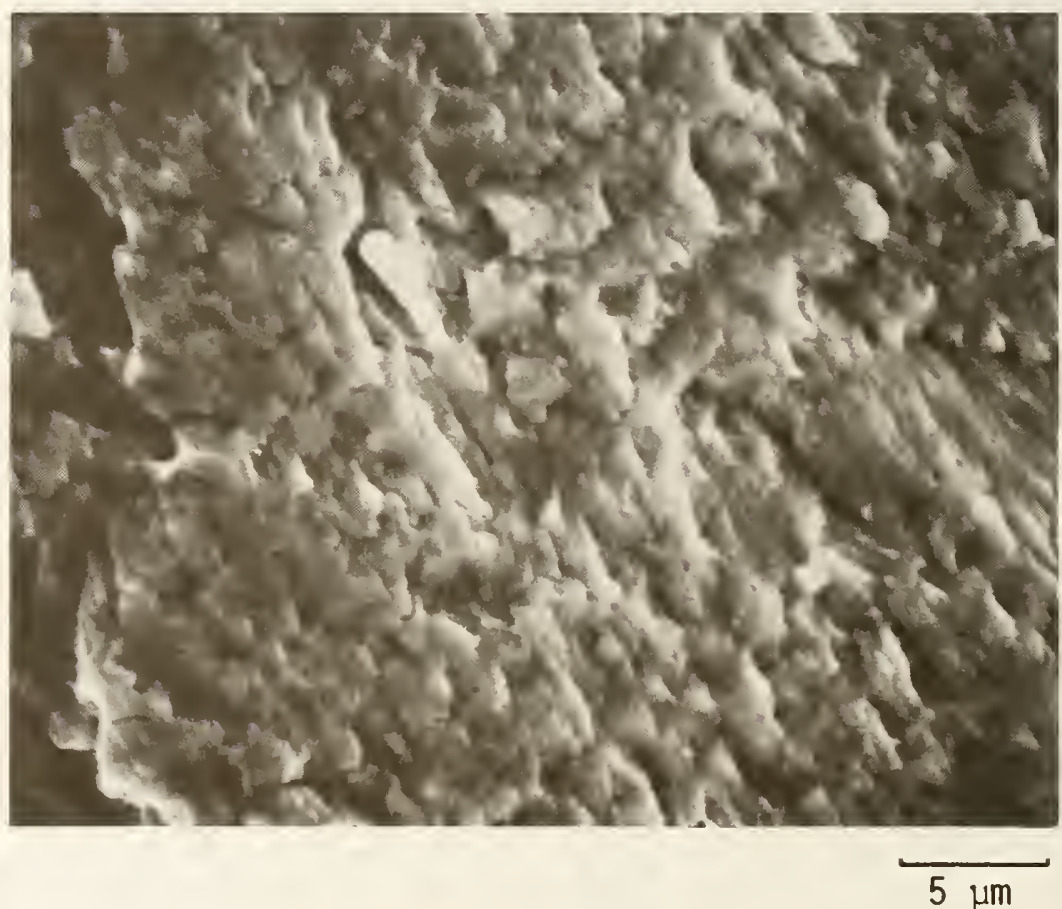

Figure 6 .

SEM photomicrograph of fatigue fracture surface of CF8M casting with $1 \%$ delta ferrite, low $\Delta \mathrm{K}$ conditions. 


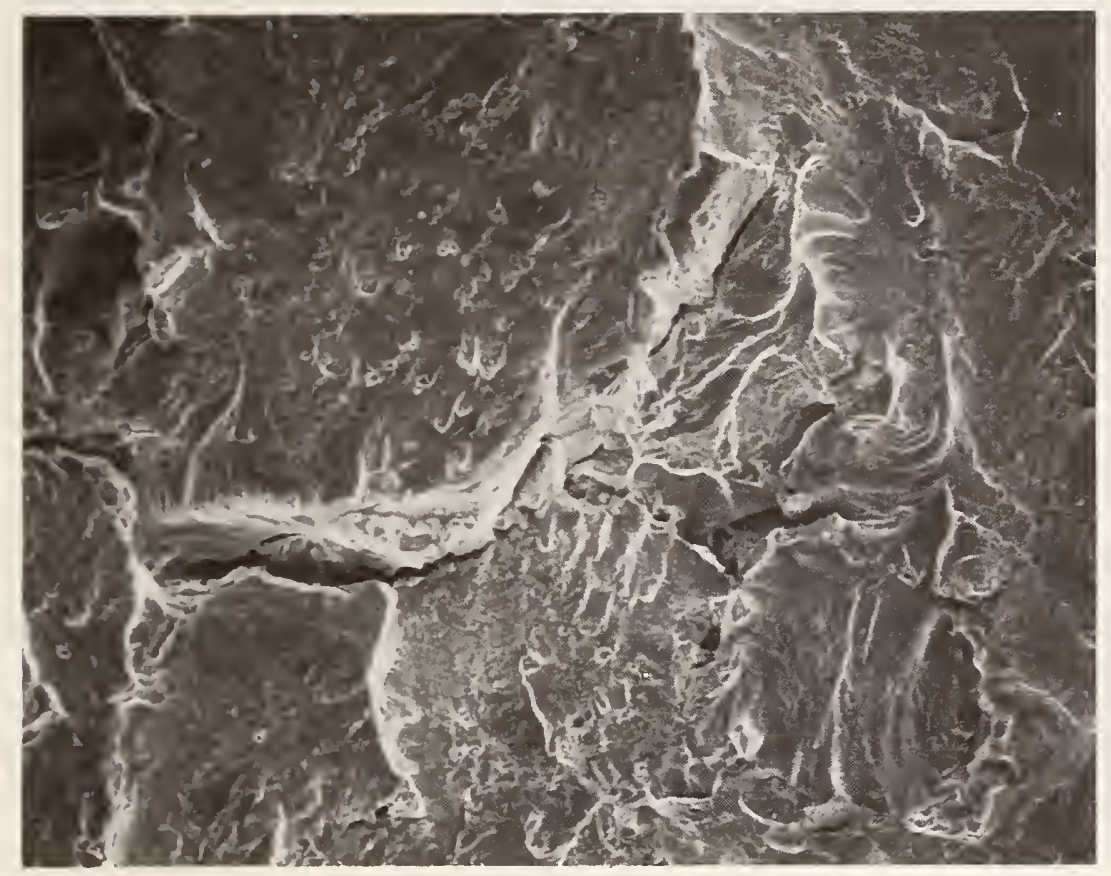

\section{$\longdiv { 1 0 0 \mu \mathrm { m } }$}

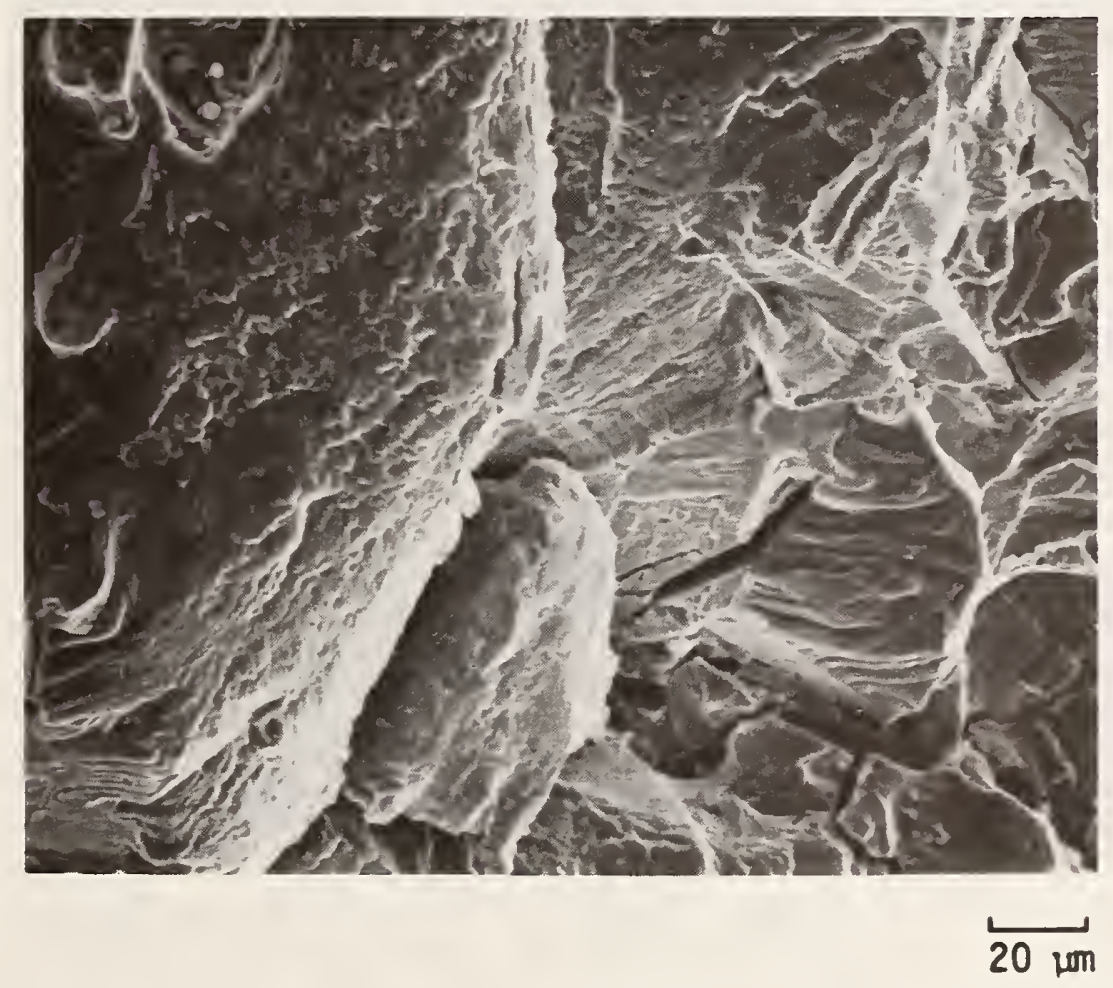

Figure 7.

SEM photomicrograph of fatigue fracture surface of CF8M casting with $1 \%$ delta ferrite, high $\Delta \mathrm{K}$ conditions. 


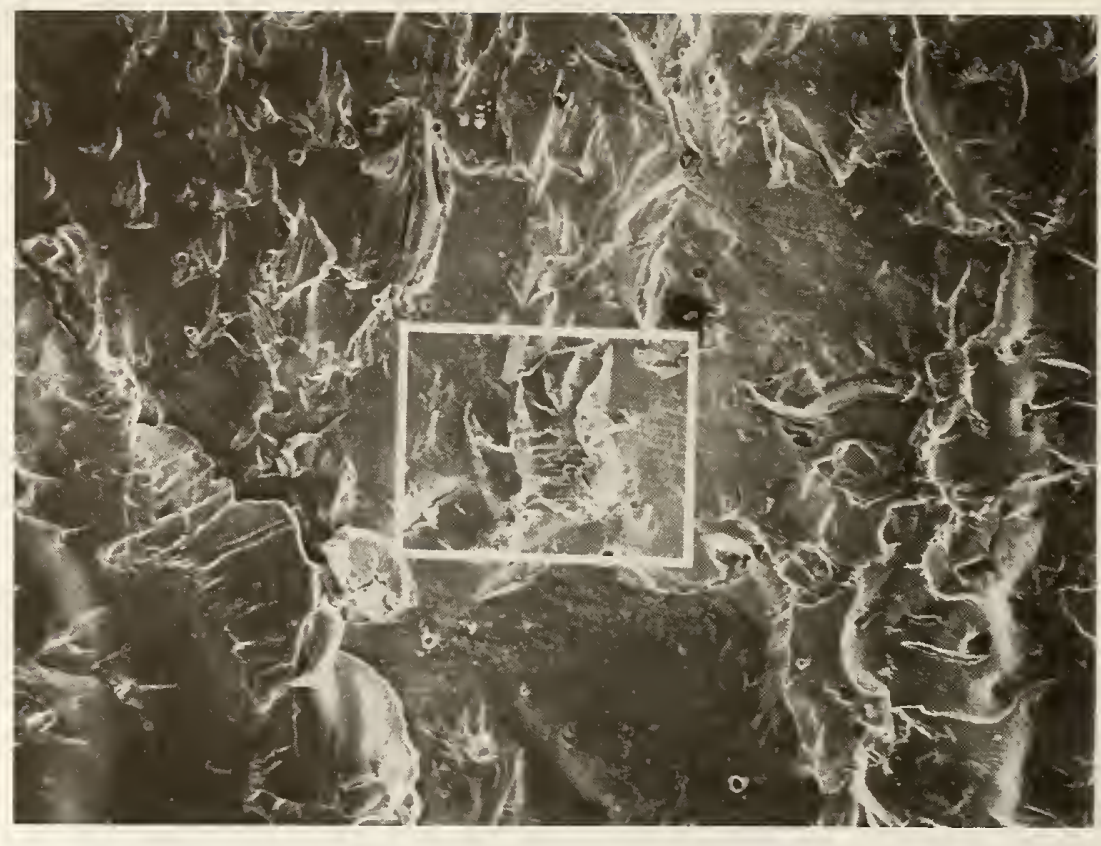

\section{$\stackrel{\longrightarrow}{100 \mathrm{~m}}$}

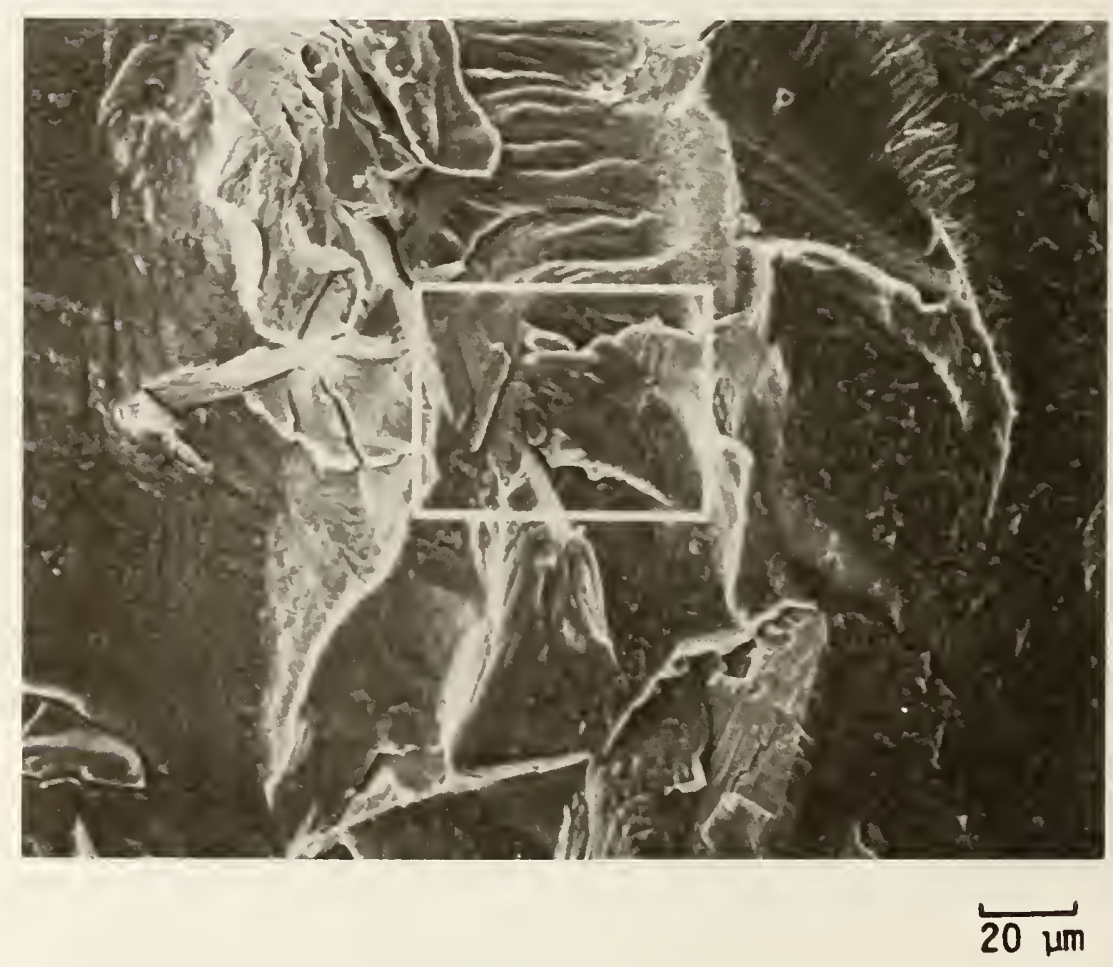

Figure 8 .

SEM photomicrograph of fatigue fracture surface of CF8M casting with $8 \%$ delta ferrite, low $\Delta \mathrm{K}$ conditions. 


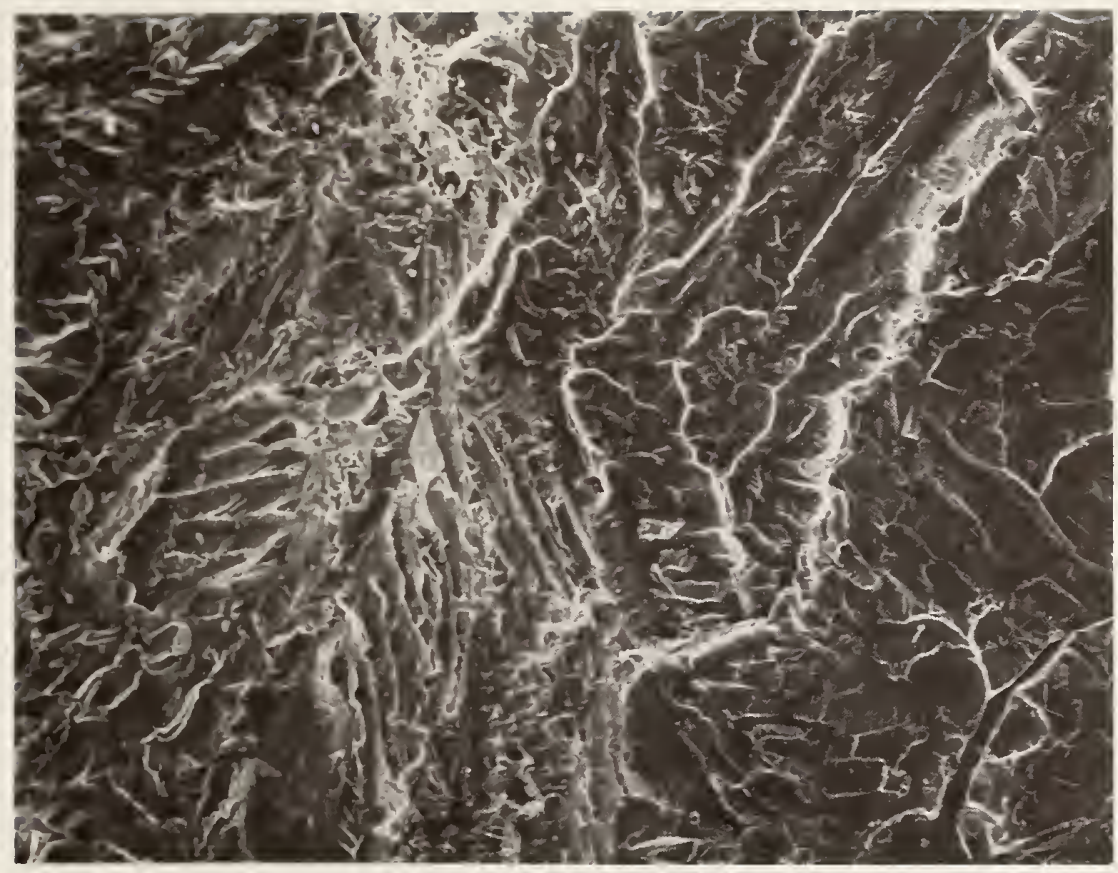

\section{$100 \mathrm{~m}$}

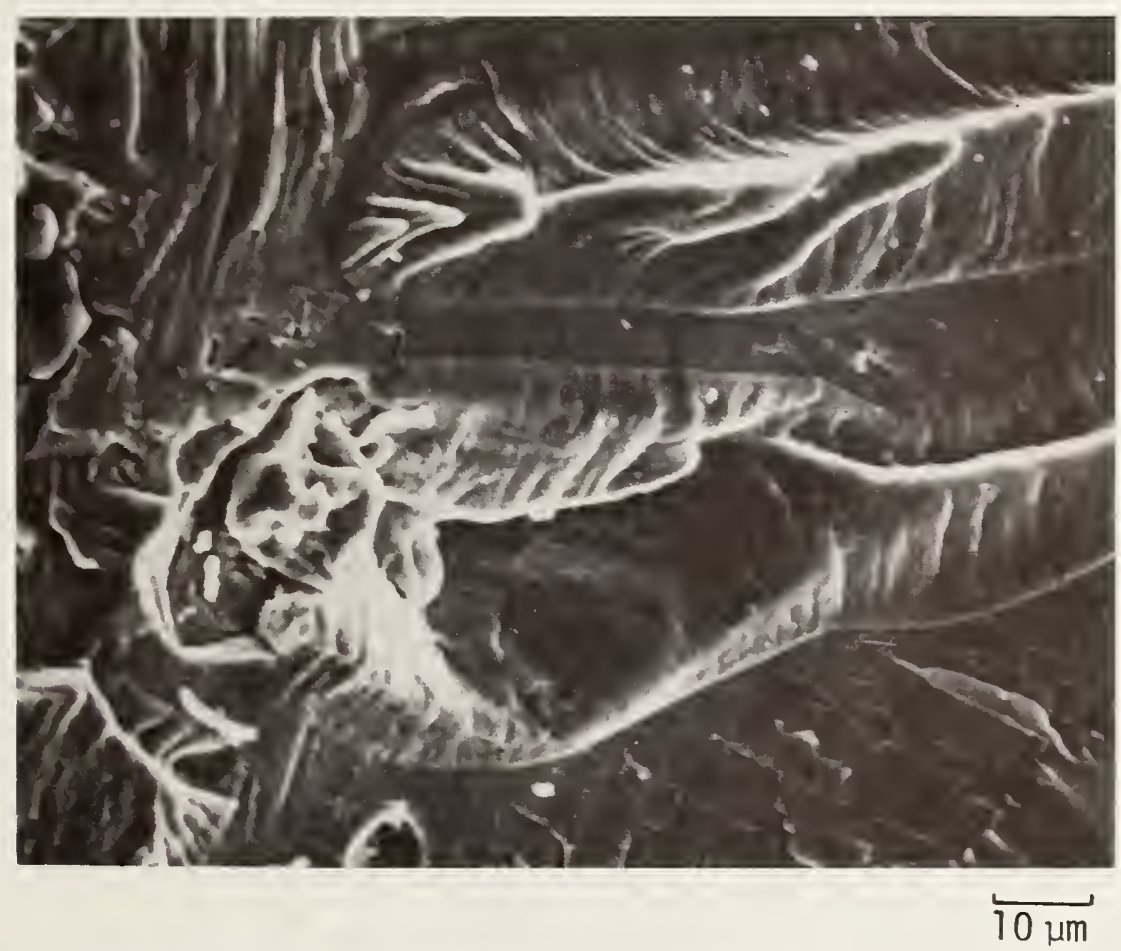

Figure 9.

SEM photomicrograph of fatigue fracture surface of CF8M casting with $29 \%$ delta ferrite low $\Delta \mathrm{K}$ conditions. 

NONMETALLICS 

LEADERS: M. B. Kasen, H. M. Ledbetter, NBS

STAFF: M. W. Austin, R. D. Kriz, NBS

CONTRACTS: S. K. Datta, University of Colorado

\section{OBJECTIVES :}

(1) To measure, model, and understand the properties of composites that enter essentially into the conception, design, construction, operation, and performance of magnetic-fusion-energy equipment.

(2) To cooperate with industry to establish and refine cryogenic-grade specifications for insulating laminates and coding systems for laminates.

RESEARCH PAST YEAR (1983):

(1) Kriz. Continuous-damage mechanics model of fracture in laminated composites.

(2) Kriz. Redistribution of localized stresses near damage in woven composites at low temperatures.

(3) Kasen. Continuation of a program on the standardization of cryogenic grades of insulating and structural laminates in cooperation with industry.

RESEARCH THIS YEAR (1984):

(1) Kriz. Damage accumulation in woven composites at low temperatures.

(2) Kriz. Development of fiber optics to study damage accumulation in woven composites at low temperatures.

(3) Kasen. Development of improved test methods for determining the effect of cryogenic temperatures on composite material performance. 

CONTINUOUS DAMAGE MECHANICS

MODEL OF FRACTURE IN LAMINATED COMPOSITES

\author{
M. P. Wnuk* and R. D. Kriz \\ Fracture and Deformation Division \\ National Bureau of Standards \\ Boulder, Colorado
}

\begin{abstract}
A modified version of the Kachanov damage accumulation law is employed to study the damage kinetics in laminated composite materials, such as epoxy-graphite laminates. The objective is to measure the characteristic events in the final stages of the failure process in composite materials following the "characteristic damage state" (CDS).

The process of localization and spread of damage ahead of the dominant matrix crack is viewed as a sequence of nucleation and propagation phases, both of which may be described by use of the internal damage parameter. This scalar quantity reflects the ratio of the current crack (or pore) density to its saturation, or critical level. It is shown that the "continuous damage mechanics" (CDM) approach is useful in modeling a damage field consisting mainly of the fiber breaks generated ahead of the matrix crack and clustered around the plane of a prospective fracture, thus forming the "damage band" embedded within the stress field of the dominant crack. Description of this type of damage applies to the failure process that follows formation of the CDS observed in a number of laminated materials.
\end{abstract}

*On leave from the University of Wisconsin-Milwaukee 



\section{Introduction}

Changes in the inner structure of multiphase materials leading to the failure of a structural component can be divided into two basic stages: The first one includes formation and growth of microscopic damages, such as vacancies, voids, micropores, and the like, randomly distributed throughout the body. This stage can be called a "latent" phase of the fracture process. It is terminated at the instant when the microdefects localize in a small volume of material leading to a formation of a dominant macroscopic crack. Propagation of this visible crack constifutes the second stage of the fracture process. When the length of such a crack or its rate reaches the critical value, the final rupture of a component takes place.

Although the damage occurring during any particular phase of life of a composite laminate may assume different forms (such as matrix cracking, interfacial debonding, delamination, formation of transverse cracks or so-called ply cracks, and fiber breakage), the nature and sequence of occurrence of these specific events justifies our general description of the damage accumulation process. One important feature of this process is the ability to localize the critical damage to a domain that represents only a small fraction of the material volume. When stress concentrators are not present, microdefects generated in the initial stage of fracture are randomly distributed. Although the initial formation of damage is random, the final rupture is localized in a well-defined region (e.g., a plane in the simple case of two-dimensional fracture). Furthermore, decohesion does not occur simultaneously within this region. Rather, it is a result of the coalescence of microcracks and, ultimately, is realized in the form of crack propagation initiated at a certain site. 
Reifsnider et al. [1] have pointed out that those laminates that develop relatively little visible damage during the latent phase of the fracture process (and, thus, show almost no loss of strength for the most of their life), display rapid and severe localized damage towards the end of their life resulting in "a residual strength curve that becomes almost a step function." A phenomenon of this type has been called a "sudden death" by Chou and Croman [2]. Reifsnider [3] suggested that one of the most common scenarios occurring just prior to the final stage of fracture in composite laminates is the formation of a regular and highly reproducible system of transverse cracks (called "ply cracks"). This system is so typical for the composite laminates that a new name has been coined, "characteristic damage state" (CDS) $[3,4]$ and used extensively in making predictions regarding residual strength and life of laminated composites. An interesting proof of the occurrence of the CDS has been provided by the experimental work of Kriz [5]. Figure la shows a photograph he obtained using an edge replica technique. The photograph clearly shows that a single transverse crack has penetrated the $90^{\circ}$ ply and then stopped at the interface between $90^{\circ}$ and $0^{\circ}$ laminae. Ahead of this ply crack, which includes both matrix and fiber fractures in the $90^{\circ}$ ply, one can see a number of fiber breaks appearing as dark spots in the picture. Before the dominant crack may penetrate* into the $0^{\circ}$ ply, which is the critical element in sustaining the load prior to final rupture, a sufficient number of fibers must break, not entirely at random, but in a preferential manner, clustering around the plane of the prospective final fracture. The aim of this work is to provide a quantitative description of such damage localization

*We note that the ply crack may or may not cross the interface between the two adjacent laminae, depending on the ratio of cohesive strength within the cracked lamina and the bonding strength (adhesion) occurring at the interface between the two laminae. Some insight into this problem may be gained by a careful study of an early work by Cook and Gordon [6]. 
and the growth process occurring within the stress field generated ahead of the dominant transverse matrix crack.

\section{Mathematical Modeling of Damage Accumulation}

Now we focus attention on the failure process, which begins with the appearance of the CDS and ends with the total loss of structural integrity of the composite laminate.

Although the primary component of the damage in this stage is fiber breakage, which is generated ahead of the dominant crack shown in Fig. 1a, other forms of damage, such as matrix cracking, void growth and coalescence, are also present. The theory, which allows one to model the process of damage accumulation and the associated extension of the dominant crack that interacts with the damage field, stems from the continuous damage mechanics (CDM). This model accounts for stress redistribution due to advancement of the crack and allows one to describe the effect of such stress redistribution on the rate of damage growth. The basic assumption underlying this mathematical modeling is a modified version of Kachanov's 1 aw $[7,8]$. In its original form, the Kachanov law relates the rate of damage growth, $\mathrm{d} \omega / \mathrm{dt}$, to the net-section stress, $\mathrm{s}$, that is,

$$
d \omega / d t=C s^{v}
$$

Here $C$ and $v$ are material constants, while the net-section stress, $s$ $\left(=P / A_{\text {eff }}\right)$, and the nominal stress, $\sigma\left(=P / A_{0}\right)$, are related as follows:

$$
s=\frac{p}{A_{e f f}}=\frac{p}{A_{0}(1-w)}=\frac{\sigma}{1-w}
$$

The scalar quantity, $w$, which has been identified as the internal damage parameter, represents the deterioration of the cross section that transmits the tensile load due to the formation and accumulation of microdefects. If 
the area actually transmitting the load is called the "effective area," A eff, then $\omega A_{0}$ represents the fraction of the initial area $A_{0}$ that no longer transmits any load. A plausible interpretation of the physical meaning of the parameter $\omega$ was given by Rousselier [9] and Mroz [10]. These authors considered $\omega$ to be a ratio of the defect density, say $d_{v}$, to the critical or "saturation" level of the defect density, say $d_{c}$. Thus, setting $w=d_{v} / d_{c}$, one would obtain $\omega=0$ for an undamaged state and $\omega=1$ for a fully damaged state. The formula $w=d_{v} / d_{c}$ suggests that experimental verification of the CDM predictions concerning composite laminates can be obtained; for example, the crack density may be estimated either by direct measurements of crack traces (an optical technique) or by indirect measurements by a wave-scattering method (see Hadley [11] and Datta et a1. [12]). In fact, any experimental procedure that allows for monitoring stiffness, elastic constants degradation, or both in a composite laminate subject to sustained or cyclic loading will shed light on the physical law governing the time dependence of the internal damage parameter. An example of such a law of damage accumulation is the Kachanov equation, which in its classic form may be obtained by combining equations (1) and (2) as follows:

$$
\frac{d \omega}{d t}=c\left(\frac{\sigma}{1-\omega}\right) v
$$

This equation defines the time-dependent quantity $w$ as a function of the uniform stress, $\sigma$. A modified version of the basic equation (3)* reads: *Yet a more general form of the modified Kachanov law is

$$
\frac{d \omega}{d t}= \begin{cases}0 & 0 \leq \sigma_{t h} . \\ c\left(\frac{\Sigma-\sigma_{t h}}{1-\omega}\right)^{v} & 0 \geq \sigma_{t h}\end{cases}
$$

where $\sigma_{\text {th }}$ denotes a certain stress threshold below which there is no visible damage generation. For stresses near the crack front, however, $\sigma_{\Sigma} \gg \sigma_{t h}$, and then equation (4a) reduces to equation (4). 


$$
\frac{d \omega}{d t}=c\left(\frac{\Sigma}{1-\omega}\right)^{v}
$$

in which the stress, $\sigma_{\Sigma}$, no longer is the uniform tensile stress but equals the actual stress occurring at the front of an initial stress concentrator, such as a sharp crack. Since $\sigma_{\Sigma}$ changes not only with the distance from the crack front (when the crack is stationary) but also undergoes a continued redistribution while the crack propagates, equation (4) may no longer be reduced to an ordinary differential equation. As we will show, the governing equation that results from the modified Kachanov's law, even for the simplest case of a constant external load, becomes a nonlinear integrodifferential equation. To state the problem somewhat differently, the difficulty of predicting the damage parameter, $\omega$, at any instant, $t$, and any location ahead of the crack front (point $P$ in Fig. 2) now becomes dependent on all the stress states that existed at this particular location before the crack front had reached the control point, $P$. Although equation (4) may be readily integrated

$$
\omega(r, t)=1-\left[1-c(v+1) \sigma_{0}^{t} \sigma_{\Sigma}^{v}[r(\tau), \tau] d \tau\right]^{\frac{1}{v+1}}
$$

this form is not of much help unless there are further details concerning the stress, $\sigma_{\Sigma}$, generated (a) ahead of the stationary crack for the latent phase of the fracture process, and (b) ahead of a moving crack for the second phase of the fracture process.

Assuming that the symbol $\sigma_{\Sigma}\left(P, P^{\prime}\right)=\sigma_{\Sigma}\left(a^{\prime}, r_{p p^{\prime}}\right)$ denotes the stress induced at the point $P$ while the crack tip is located at the point $P^{\prime}$, we shall distinguish the following stress fields:

1. $\sigma_{\Sigma}\left(a_{0}, r_{0}\right)=\sigma_{\Sigma}\left(a, a_{0}\right)$, stress field ahead of a stationary crack where $\left(r_{0}=\rho_{\star}+a-a_{0}\right)$ 
2. $\sigma_{\Sigma}\left(a, r^{\prime}\right)=\sigma_{\Sigma}\left(a, a^{\prime}\right)$, stress field ahead of a moving crack where $\left(r^{\prime}=\rho_{\star}+a-a^{\prime}\right)$

3. $\sigma_{\Sigma}\left(a_{0}, \rho_{*}\right)=\sigma_{\Sigma}\left(a_{0}, a_{0}\right)=\sigma_{\Sigma}\left(a_{0}\right)$, the stress at the tip of the initial $\operatorname{crack}\left(r=\rho_{\star}\right)$, and

4. $\sigma_{\Sigma}\left(a, \rho_{\star}\right)=\sigma_{\Sigma}(a, a)=\sigma_{\Sigma}(a)$, the stress at the tip of the "final" current crack tip $\left(r=\rho_{\star}\right)$.

The notation $\sigma_{\Sigma}(a, r)$ emphasizes that the stress, $\sigma_{\Sigma}$, depends on two variables: current crack length, $a$, and the distance measured from the crack front, $r$. On the other hand, the symbol $\sigma_{\Sigma}\left(a, a^{\prime}\right)$ indicates that after replacing $r$ by the quantity shown in the parentheses for each of the cases listed above, the stress, $\sigma_{\Sigma}$, becomes dependent on just one variable: crack length. For the propagation phase $(\dot{a} \neq 0)$, we consider a to be a time-like variable, and in fact, all the integrals with respect to time are replaced by integrals with respect to the crack length. Note that such a transformation is possible only when the crack propagates $(\dot{a} \neq 0)$, because then da and $d t$ can be used interchangeably, and therefore, $d t=d a / \dot{a}$.

If time is eliminated consistently whenever it appears in the problem (see the Appendix), equation (5) may be expressed in the following form:

$$
\frac{d a}{d t}=\frac{-C_{\Sigma}^{\nu}(a)}{c \int_{a_{0}^{\int}}^{a} \frac{\partial}{\partial a} \sigma_{\Sigma}^{\nu}\left(a, a^{\prime}\right) \frac{d a^{\prime}}{a^{\prime}}+\frac{d \Omega_{1}\left(a, a_{0}\right)}{d a}}
$$

Here the symbol $a^{\prime}$ denotes the rate of crack growth evaluated at the instant $t^{\prime}$, or, equivalently, for the crack length $a^{\prime}$. Note that $\dot{a}$ is a shorthand notation for $\dot{a}=\dot{a}\left(a^{\prime}\right)$. Both terms appearing in the denominator of equation involve not only stress, but also its gradient $\mathrm{do} \sigma_{\Sigma} / \mathrm{dr}$ (or $\mathrm{do} \sigma_{\Sigma} / \mathrm{da}$, since a is used as a yardstick to measure the current distance from the crack tip). The only quantity yet unexplained is $\Omega_{1}\left(a, a_{0}\right)$. The amount of damage generated at 
the point $P$ (see Figs. $1 b$ and 2) at the end of the latent phase of fracture $\left(t=t_{1}\right)$ is $\Omega_{1}$. During this phase, the crack remains stationary, and its length equals $a_{0}$. In general, the damage parameter, $\Omega$, is defined by the following equation:

$$
\Omega=\int_{0}^{\int^{\omega}}\left(1-\omega^{\prime}\right)^{v} \mathrm{~d} \omega^{\prime}=\frac{1-(1-\omega)^{v+1}}{v+1}
$$

The lower limit for $\Omega$ is zero (corresponding to the undamaged state, $\omega=0$ ), and the upper limit of $\Omega$ (corresponding to the "saturation" level of damage, $\omega=1)$ is the critical value $\Omega_{c}=(1+v)^{-1}$. The damage parameter, $\Omega$, is directly related to stress, $\sigma_{\Sigma}$, that is

$$
\Omega(r, t)=C \int_{0}^{t} \sigma_{\Sigma}^{\nu}[r(\tau), \tau] d \tau
$$

In fact, equation (8) may be used to formulate the fracture criterion based on the damage accumulation concept. The criterion may be verbalized as follows: for a collapse of a material element located at the distance $r$ from a dominant crack tip [which generates the stress field $\sigma_{\Sigma}(r, t)$ ], it is necessary that the time integral of the vth power of the stress, $\sigma_{\Sigma}$, attains the critical value, $\Omega_{c}$.

To evaluate the amount of damage generated at any instant during the latent phase of the fracture process $\left(0 \leq t \leq t_{1}\right)$, say $\Omega^{\prime}{ }_{1}$, we substitute $\sigma_{\Sigma}\left(a, a_{0}\right)$ for $\sigma_{\Sigma}$ in equation (8). If the stress $\sigma_{\Sigma}\left(a, a_{0}\right)$ is represented by the function $Y\left(r_{0}\right)$ with $r_{0}=\rho_{\star}+a-a_{0}$, we may write:

$$
\sigma_{\Sigma}\left(a, a_{0}\right)=\frac{K_{I}\left(a_{0}\right)}{\sqrt{2 \pi \rho_{\star}}} Y\left(r_{0}\right)
$$

in which $\mathrm{K}_{\mathrm{I}}\left(\mathrm{a}_{0}\right)$ is the stress-intensity factor [as defined in the LEFM (1inear elastic fracture mechanics)] associated with the initial crack length $a_{0}$. 
This form inserted into equation (8) gives:

$$
\begin{aligned}
\Omega_{1}^{\prime}\left(a_{,} a_{0}\right)=\Omega\left(\frac{t}{t_{1}}\right)\left[\frac{Y\left(r_{0}\right)}{Y\left(\rho_{\star}\right)}\right]_{r_{0}=\rho_{\star}}^{v} & +a-a_{0} \\
& t \leq t_{1}
\end{aligned}
$$

Interestingly, this expression is valid for an arbitrary loading history, $\sigma=\sigma(t)$, where $\sigma$ denotes the external load (see the Appendix for algebraic details). Equation (10) predicts the amount of damage that will be created ahead of the main crack during a time interval less than the incubation time, $t_{1}$, or the so-called first critical time. It is a simple matter to show that for an arbitrary loading history, $\sigma(t)$, the incubation time is determined by the relation:

$$
\sigma_{0}^{s} \sigma^{\nu}(t) d t=\frac{{ }^{\Omega} c}{c} \frac{\left(2 \pi \rho^{*}\right)^{\nu / 2}}{k_{I}^{\nu}\left(a_{0}\right) Y_{\star}^{\mu}}
$$

Here, $Y_{\star}=Y\left(\rho_{\star}\right)$, and $k_{I}\left(a_{0}\right)$ is the "reduced" stress-intensity factor, which does not include the loading parameter. Recalling the usual form [13]

$$
K_{I}\left(t, a_{0}\right)=\sigma(t) \sqrt{ } \pi a_{0} F\left(a_{0} / b\right)
$$

in which $\sigma(t)$ is the external load and $F\left(a_{0} / b\right)$ is the geometry-dependent factor, we may rewrite equation (12) as follows:

$$
k_{I}\left(t, a_{0}\right)=\sigma(t) k_{I}\left(a_{0}\right), k_{I}=\sqrt{\pi a_{0}} F\left(a_{0} / b\right)
$$

Plots of $\Omega_{1}^{\prime}$ vs. the reduced distance from the crack tip, $r_{0} / \rho_{\star}=\xi_{0}$, obtained at two values of the normalized time, $t / t_{1}$, are shown in Fig. $3 a$. These plots were constructed by assuming input data for $Y\left(r_{0}\right) / Y_{*}$, that is, the stress distribution ahead of the dominant ply-crack shown in Fig. 1a. An analytical 
form of the function $Y\left(r_{0}\right)$ was obtained by a Hermitian interpolation performed on the numerical solution by the finite-element method [5].

The distinct differences between the distributions of damage shown in Fig. 3b suggest that the exponent $v$ has a very strong effect on the nature of the damage accumulation process. For $v>1$ there is only a minimal amount of damage generated during the latent stage of fracture at a site some distance from the crack front. However, the opposite is true for $v<1$, e.g., $v=0.1$. When $v<1$, the damage built up at the control point $P$ during the time interval $\left(0, t_{1}\right)$ reaches nearly the critical level. Upon completion of the latent phase, relatively little life is left for the material element located at $P$. Therefore, the propagation phase rapidly leads to the final rupture or "sudden death" of the component.

To conclude this section, let us evaluate the "residual damage," $\Omega_{2}$, which is the amount of damage generated at a given point while the crack front is advancing toward that point. Evaluation of $\Omega_{2}$ involves numerical integration of the expression

$$
\Omega_{2}=\left(\frac{\Omega_{c}}{t_{1}}\right)_{a_{0}^{s}}^{a}\left[\frac{K_{I}\left(a^{\prime}\right)}{K_{I}\left(a_{0}\right)}\right]^{\nu}\left[\frac{Y\left(r^{\prime}\right)}{Y\left(\rho_{*}\right)}\right]^{\nu} \frac{d a^{\prime}}{\dot{a}\left(a^{\prime}\right)}, \quad r^{\prime}=\rho_{*}+a-a^{\prime}
$$

in which $\dot{a}\left(a^{\prime}\right)$ is found from the equation of a moving crack [equation (6)]. Examples of the damage distributions resulting from numerical evaluation of equation (14) are shown in Fig. 4. Again, to illustrate the distinct differences in possible scenarios of the damage accumulation process, these two values for the Kachanov exponent were used: $v=0.1$ and $v=2$. Since for $v<1$ most of the microstructural damage is generated during the latent stage of fracture, it becomes obvious why in this case the second phase of failure process, crack propagation, constitutes only a minor part of the total life of the component. 
The opposite is true for $v>1$. This effect is demonstrated by the three curves shown in Fig. $5 \mathrm{a}$, which represent the final outcome of the mathematical model, namely the integral curves resulting from a numerical solution of the integrodifferential equation (6). Note that both the crack length and time, as plotted in Fig. 5a, are nondimensional.

Fig. $5 b$ shows the three curves representing the three hypothetical failure processes obtained for $\nu=2$, the characteristic structural length $\rho_{\star} / b=0.02$, and the initial crack length $x_{0}=a_{0} / \rho_{\star}=10$ for the three different states of stress generated ahead of the dominant ply crack. The trend in the failure development process (shown in Fig. 5b) is the same as that inferred from the stress analysis of ply cracks in laminates [5] using the finite-element method (compare with Fig. 5c). Through-thickness variation of the tensile stress, $\sigma_{x}$, in the $0^{\circ}$ ply is shown in Fig. $5 c$ for three cases:

1. Mech - mechanical load only with no residual stress,

2. Dry - stresses in No. 1 altered by mismatch in thermal contractions between bonded layers when cooled from room temperature to $76 \mathrm{~K}$.

3. Wet - absorbed moisture swells individual layers and alters stresses in the dry case. Stress gradients shown in Fig. $5 \mathrm{c}$ are approximated by derivatives of a fourth-order polynomial:

$$
\sigma_{x}=\left[\left(-A-\left\{A^{2}-4 C\left[B(z / T)^{2}+D(z / T)^{4}-1\right]\right\}^{1 / 2}\right) /[2 C(z / T)]\right]^{1 / 2}
$$

where coefficients $A, B, C$, and $D$ are given' in Table 1 . At $76 \mathrm{~K}$ the stress gradient for the mechanical load is substantially altered by the dry residual stresses. When moisture is absorbed, swelling in the $90^{\circ}$ ply increases the stress near the crack tip, and consequently, the crack growth rate in Fig. 5b increases for the wet case. 
Table 1. Coefficients for Stress Gradients Shown in Fig. 5c
Case
A
B
C
D
Dry
$0.724 \times 10^{-5}$
0.607
$-0.172 \times 10^{-10}$
$0.12 \times 10^{-3}$

Wet

$$
0.115 \times 10^{-4}
$$

3.045

$-0.437 \times 10^{-10}$

$-0.212 \times 10^{-4}$

Mech $\quad 0.672 \times 10^{-5}$

3.411

$-0.299 \times 10^{-10}$

$-0.124 \times 10^{-3}$

\section{Discussion of Results and Conclusions}

Although the stacking sequence of the laminate used in Kriz's experiment [5] $\left[0,90^{\circ},+45^{\circ},-45^{\circ}\right]_{S}$, differs from the stacking sequence $\left[90^{\circ}, 0^{\circ}\right]_{S}$ for which our calculations have been performed, the basic conclusions of this work may be extended to other geometries and in particular, they remain valid for the laminates with the stacking sequences favoring formation of the transverse matrix cracks $[1,2]$ during the early stages of damage accumulation process. Figure 6 shows an edge view of a specimen that corresponds exactly to the geometrical configuration of a double-edge-notch tensile specimen chosen for the numerical examples presented in the preceding sections.

As we show in the Appendix, the geometry-dependent function

$$
\phi(a)=K_{I}(a) / K_{I}\left(a_{0}\right)
$$

that enters into the governing equation (6) controls the damage generation only during the second stage of failure process. This fact is reflected by 
the form of equations (10) and (14). The first of these equations contains no $\phi$ function at all, while the second one relates $\phi$ explicitly to the $\Omega_{2}$ damage, the damage generated during the propagation phase of the main crack, and to the geometry of the (cracked) structural component as defined by the ratio of the stress-intensity factors (see equation (16)). Therefore, for the case of $v \ll 1$, when the initiation phase plays a dominant role in the nucleation of damage, the effect of the $\phi$ function on the development of the failure process becomes negligible. In fact, by performing a series of "numerical experiments," one may prove that when $v \ll 1$, the integral appearing in the denominator of the governing equation of motion (6) has very little effect on the final outcome of the integration process. Thus, the equation for the rate of growth of the matrix crack interacting with a damage field generated in the adjacent ply assumes the form referred to as the "limit case"

$$
\begin{aligned}
& {[\dot{a}] \stackrel{\sim}{\sim}\left(1 / t_{1}\right) \phi^{\nu}(a) / F_{2}(a)} \\
& v \ll 1
\end{aligned}
$$

Here $t_{1}$ denotes the first critical time (end of the incubation phase), and the function $F_{2}$ can be obtained from the known stress distribution, $Y(r)$, namely

$$
F_{2}(x)=\left\{\left[\frac{Y\left(\xi_{0}\right)}{Y_{*}}\right]^{v-1}\left[\frac{d Y\left(\xi_{0}\right)}{Y_{*} d x}\right]\right\}_{\xi_{0}=1+x-x_{0}}
$$

where

$$
\left.Y_{*}=Y(1), \quad x=a / \rho_{\star}, \quad x_{0}=a_{0} / \rho_{\star}, \quad\right\} \xi_{0}=r_{0} / \rho_{\star}
$$

When these expressions are substituted into equation (14), the geometry-dependent function $\phi$ cancels out. Therefore, the damage generated during the second phase of failure may be represented simply as an integral of known functions, 
$y\left(x, x^{\prime}\right)=Y(\xi) / Y_{\star}$ and $y\left(x, x_{0}\right)=Y\left(\xi_{0}\right) / Y_{\star}$, in which $\xi=r / \rho_{\star}=1+x-x^{\prime}$, $\xi_{0}=r_{0} / \rho_{\star}=1+x-x_{0}$.

In the limit case, the final form for $\Omega_{2}$ reads

$$
\left[\Omega_{2}\right]_{\nu \ll 1} \stackrel{\sim}{\sim} \Omega_{c} \int_{x_{0}}^{x^{x}} y^{\nu}\left(x, x^{\prime}\right) y^{\nu-1}\left(x^{\prime}, x_{0}\right) \frac{d y\left(x^{\prime}, x_{0}\right)}{d x^{\prime}} d x^{\prime}
$$

Figure 7 shows an example of the $\Omega_{2}$ evaluated at $\nu=0.1$ from the exact equation (14) and from the approximate equation (19). The conclusion is that the approximate form [equation (19)] provides a valuable tool for an evaluation of the damage generated during the propagation phase whenever the Kachanov exponent, $v$, is small relative to one. Moreover, the numerical tests have shown that when $v \ll 1$, the value of $\Omega_{2}$ obtained for any pair of numbers, $x_{0}$ and $x$, becomes negligibly small as compared to the value of $\Omega_{1}$ evaluated from equation (10) at $t=t_{1}$, namely

$$
\Omega_{1}=\Omega_{C}\left[Y\left(r_{0}\right) / Y\left(\rho_{\star}\right)\right]^{\nu}
$$

This equation, along with the expression defining the incubation time, $t_{1}$,

$$
\left[0^{s^{t}} \sigma^{\nu}(t) d t\right] \nu \ll 1=\lim _{\nu \rightarrow 0}\left\{\frac{\Omega_{C}}{C} \frac{\left(2 \pi \rho_{\star}\right)^{\nu / 2}}{K_{I}^{\nu}\left(a_{0}\right) Y_{\star}^{\nu}}\right\}
$$

and with equation (17) provides the basis for quantifying the two phases of the failure process in laminated composites. The first and the second critical times can now be estimated using these relationships. When the "time zero" is identified with the establishment of the CDS, and when it may be shown that the Kachanov exponent, $\nu$, does indeed assume values close to zero, we obtain the following estimates $\left(\sigma \ll \sigma_{C}\right)$ : 


$$
\begin{aligned}
& t_{1} \simeq\left(\Omega_{c} / \sigma{ }_{C}^{\nu} C\right)\left(2 \rho_{\star} / a_{0}\right)^{\nu / 2} / F^{\nu}\left(a_{0} / b\right) Y_{\star}^{\nu} \\
& \Omega_{1}=\Omega_{C}\left[Y\left(r_{0}\right) / Y\left(\rho_{\star}\right)\right]^{\nu}, \quad r_{0}=\rho_{\star}+a-a_{0}
\end{aligned}
$$

(in which $\sigma_{c}$ denotes the ultimate tensile strength of the reinforcing fiber). Since $\Omega_{2} \ll \Omega_{1}$, we also have

$$
t_{2} \ll t_{1} \text { and } T \simeq t_{1}
$$

The symbol $T$ denotes the life of the composite laminate and is obtained as the sum of the critical times, $T=t_{1}+t_{2}$. For a general loading history and when the condition $\sigma \ll \sigma_{c}$ is not satisfied, the first critical time, $t_{1}$, has to be evaluated numerically as a root of equation (21). However, when the applied stress is maintained constant upon creation of the characteristic damage state, say $\sigma=\sigma_{0}=$ constant, and when the LEFM formulae for a pair of edge cracks penetrating a tensile specimen (see Fig. 6) are employed, an estimate for the first critical time results from equation (10). With a constant stress, $\sigma_{0}$, and $Y_{\star} \simeq 1$, we have

$$
t_{1}=\frac{\Omega_{c}}{\cos _{0}^{\nu}}\left(\frac{2 p^{*}}{a_{0}}\right)^{\nu / 2} F^{-\nu}\left(\frac{a_{0}}{b^{0}}\right)
$$

The symbol $\rho_{*}$ denotes the radius of a reinforcing fiber, a is the depth of ply crack, and $2 b$ denotes the width of a component (see Fig. 6). The material constants $C, \Omega_{C}$, and $\nu$, which appear in the damage accumulation law (equation 4), must be determined empirically. The function $F$ may be obtained from the LEFM catalog of the $K$ factors. Assuming occurrence of brittle fracture in an isotropic medium for the configuration under consideration (double-edge-notch, $D E N$ ), we would have the following closed form solution (see the $K$ factors in Ref. 13): 


$$
\begin{aligned}
& F\left(\frac{a_{0}}{b}\right)=\left(1-\frac{a_{0}}{b}\right)^{-1 / 2}\left[1.122-0.561\left(\frac{a_{0}}{b}\right)\right. \\
& \left.-0.205\left(\frac{a_{0}}{b}\right)^{2}+0.471\left(\frac{a_{0}}{b}\right)^{3}-0.190\left(\frac{a_{0}}{b}\right)^{4}\right]
\end{aligned}
$$

Again, it is noted that for the case of the exponent $v$ approaching zero, even large variations in the form of the F-function (and, thus in the $\phi$ function) will have only a minor influence on the predicted life span of a structural component subjected to tensile load, $\sigma_{0}$.

An alternative way of writing equation (24) is

$$
\left(\sigma_{0} / \sigma_{C}\right)^{v}=B\left(t_{R} / t_{1}\right)
$$

in which the constant, $B$, and the reference time, $t_{R}$, are defined as follows:

$$
\begin{aligned}
& B=\Omega_{C}\left(\frac{2 p^{*}}{a_{0}}\right)^{\nu / 2} / F^{\nu}\left(\frac{a_{0}}{b}\right) Y_{*}^{\nu} \\
& t_{R}=1 / C_{C}^{\nu}
\end{aligned}
$$

Interestingly, equation (26) predicts an experimentally confirmed linear relationship between the logarithm of the nondimensional applied stress, $\sigma_{0} / \sigma_{C}$, and the logarithm of the nondimensional time, $t_{1} / t_{R}$ (see Fig. 8 ). The slope of this line is the negative of the reciprocal of the damage exponent $v$. of course, for arbitrary loading histories, $\sigma(t)$, some deviations from the straight line shown in Fig. 8 are expected.

Degradation of elastic moduli and fracture toughness may be related to the "crack density" parameter, which in our model is represented by the internal damage parameter, $w=d_{v} / d_{c}$. Watt et al. [14] suggested various 
forms (linear and nonlinear) of the "mixture formulae," which allow for evaluation of the bulk and shear moduli in a multiphase aggregate, provided that the initial moduli of each component are known and that the pore density is given as a function of time [compare equation (5)]. The determination of the average fracture toughness of a multiphase material is a somewhat more difficult task. However, under certain simplifying assumptions, the average toughness of the epoxy-matrix graphite-fiber-reinforced composites may be predicted as a function of time for a given specimen geometry and loading history. We intend to address this topic in a subsequent paper, in which we will discuss an estimation procedure method involving a technique of Morozov and Fridman [15] (named "section method") and an approximation procedure suggested for multiphase materials by Rao [16]. The present work provides a quantitative basis for evaluation of residual strength of laminated composites. We hope that the model developed here will prove useful in predicting the deterioration of fracture toughness of composite materials due to a time-dependent damage accumulation process.

4. Summary

A modified version of the Kachanov damage accumulation law has been employed to study the damage kinetics in composite materials, such as epoxygraphite laminates embrittled by low temperature. The purpose of this study was to quantify the two basic phases of failure process in laminated composites: (1) localization of microdefects and (2) spread of a dominant crack after formation of the so-called characteristic damage state (CDS).

Considerations of interaction between the dominant crack and the field of secondary cracks, such as fiber breakage generated ahead of the macroscopic fracture front, lead to a certain nonlinear integrodifferential equation which defines the rate of the dominant crack growth. Numerical solution of this 
equation is possible if the stress and the stress gradient prevailing in the neighborhood of the macrocrack are known. Since these quantities are difficult to obtain analytically, the finite element method has been employed. In this way, stress distributions for an epoxy-graphite laminate, damaged by a dominant ply crack due to tensile load applied at a temperature of $76 \mathrm{~K}$ were obtained. These numerical results were then approximated by Hermitian polynomials, which were substituted into the governing equation. Subsequent numerical integration of this equation provided means for quantitative predictions regarding microand macrodamage accumulation and the fracture process in laminated composites.

of particular practical importance is the observation that relates time-to-failure to the applied stress level and material properties. For a constant load condition, a simple relationship has been given that suggests an inverse power law between the applied load and the time-to-failure. When a log-log scale is used for plotting, the resulting graph is a straight line (see Fig. 8). Since the slope of this line depends on the Kachanov parameters $C$ and $v$, which are inherent in the mathematical model, further research should focus on experimental determination of the load vs. time-to-failure relationship. Acknowledgments

This study was sponsored by the Fracture and Deformation Division of the National Bureau of Standards while Professor Wnuk was on leave from the University of Wisconsin-Milwaukee. A portion of the study at low temperatures was sponsored by the Department of Energy, Office of Fusion Energy.

\section{References}

1. K. L. Reifsnider, E. G. Henneke, W. W. Stinchcomb, and 3. C. Duke, Damage Mechanics and NDE of Composite Laminates, in Mechanics of Composite Materials: Recent Advances, eds., Z. Hashin and C. T. Herakovich (1982), pp. 399-420.

2. P. C. Chou and R. Croman, Residual Strength in Fatigue Based on the Strength-Life Equal Rank Assumption, J. Compos. Mater., Vol. 2 (1978), pp. 75-84. 
3. K. L. Reifsnider, Introduction, in Damage in Composite Materials, ASTM STP 775, American Society for Testing and Materials, Philadelphia (1982), pp. 552-563.

4. J. E. Masters and K. L. Reifsnider, An Investigation of Cumulative Damage Development in Quasi-Isotropic Graphite/Epoxy Laminates, in Damage in Composite Materials, ASTM STP 775, American Society for Testing and Materials, Philadelphia (1982), pp. 40-62.

5. R. D. Kriz, Influence of Ply Cracks on Fracture Strength of Graphite/Epoxy Laminates at $76 \mathrm{~K}$, in Effects of Defects in Composite Materials, ASTM STP 836, American Society for Testing and Materials, Philadelphia, in press.

6. J. Cook and J. E. Gordon, A Mechanism for the Control of Crack Propagation in a Brittle System, Proc. Roy. Soc. A, Vol. 282 (1964), p. 508-520.

7. L. M. Kachanov, Theory of Creep (in Russian), Nauka Publishers, Moscow (1966).

8. L. M. Kachanov, Some Problems of Creep Fracture Theory, in Advances in Creep Design, Applied Science Publishers, London (1971), pp. 21-29.

9. G. Rousselier, Finite Deformation Constitutive Relations and Ductile Fracture, in Proceedings of IUTAM Symposium on 3D Constitutive Relations and Ductile Fracture, ed. S. Nemat Nasser, Elsevier - North Holland, New York (1981), pp. 331-355.

10. Z. Mroz, Discussion on Session 7, in Proceedings of IUTAM Symposium on 3D Constitutive Relations and Ductile Fracture, ed. S. Nemat Nasser, ETsevier - North Holland, New York (1981), pp. 405-409.

11. K. Hadley, Dilatancy: "Further Studies in Crystalline Rock," Ph.D Thesis, M.I.T., Cambridge, Massachusetts (1975).

12. S. K. Datta, H. M. Ledbetter, and R. D. Kriz, Calculated Elastic Constants of Composites Containing Anisotropic Fibers, Int. J. Solids Struct., in press.

13. H. Tada, P. C. Paris, and G. R. Irwin, The Stress Analysis of Cracks Handbook, Del Research Corp., Hellertown, Pennsylvania (1973).

14. J. P. Watt, G. F. Davies, and R. J. O'Connell, The Elastic Properties of Composite Materials, Rev. Geophys. Space Phys., Vol. 14 (1976), pp. 541-563.

15. E. M. Morozov and Y. B. Fridman, Crack Analysis as a Method to Study Fracture Characteristics (in Russian), Zavod. Lab., No. 8 (1966), pp. 977-984. Reviewed by M. P. Wnuk in "Review of Some Russian Papers Pertinent to the Fracture of Solids," Technical Report GALCIT SM 67-9, California Institute of Technology, Pasadena (Sept. 1967). Also in V. Z. Parton and E. M. Morozov, Elastic Plastic Fracture Mechanics (translated from Russian), Mir Publishers, Moscow (1978), pp. 74-87. 


\section{APPENDIX}

\section{Distribution of damage ahead of the transverse matrix crack during the}

\section{two phases of failure process.}

During the latent phase of fracture process $(a=0)$, the nondimensional

damage parameter, $\Omega$, is evaluated as follows:

$$
\Omega=\left[\Omega_{1}^{\prime}(t)\right]_{0} \leq t \leq t_{1}=C \int_{0}^{t}\left[\sigma_{\Sigma}^{\nu}\left(P, P^{\prime}\right)\right]_{\dot{a}}=0 d t^{\prime}
$$

Since the crack length, $a_{0}=$ const, the stress, $\sigma_{\Sigma}$, does not depend on time and it may be factored out. If we identify $\sigma_{\Sigma}$ in equation (Al) with

$$
\sigma_{\Sigma}\left(a, a_{0}\right)=\frac{K_{I}\left(a_{0}\right)}{\sqrt{2 \pi \rho_{\star}}}\left[Y\left(r_{0}\right)\right]_{r_{0}}=\rho_{\star}+a-a_{0}
$$

and when the first critical time is introduced

$$
t_{1}=\left(\Omega_{c} / c\right) \sigma_{\Sigma}^{-v}\left(a_{0}\right)
$$

then equation $(A 1)$ reduces as follows

$$
\left[\Omega_{1}^{\prime}(t)\right]_{0} \leq t \leq t_{1}=\Omega_{c}\left\{\left[Y\left(r_{0}\right) / Y_{\star}\right]^{\nu}\left(t / t_{7}\right)\right\}_{r_{0}}=\rho_{*}+a-a_{0}
$$

This equation predicts $\Omega_{1}^{\prime}=0$ at time zero, and the maximum value

$$
\Omega_{1}=\Omega_{C}\left[Y\left(r_{0}\right) / Y_{\star}\right]_{r_{0}}^{\nu}=\rho_{*}+a-a_{0}
$$

at a time equal to the first characteristic time, $t_{1}$. Of course, at the point $p^{\prime}$ (see Fig. 2), that is when $r_{0}=e_{\star}\left(\right.$ or when $\left.a=a_{0}\right)$, we obtain 
the critical damage $\Omega_{\gamma}\left(P^{\prime}\right)=\Omega_{c}$, while at some distance away from the crack front, say at point $P$ shown in Fig. 2 , the amount of damage generated at the end of the incubation phase is predicted by equation (A5). The resulting distribution $\Omega_{1}=\Omega_{1}\left(r_{0}\right)$ is shown by the top curve in Fig. 3 a.

The first critical time $t_{1}$ is defined as the time at which the material element adjacent to the tip of an initial crack collapses. This occurs when the integral

$$
\int_{0}^{t_{1}} \sigma_{\Sigma}^{\nu}\left(a_{0}\right) d t^{\prime}
$$

attains the critical value, $\Omega_{c}$. Since the stress $\sigma_{\Sigma}\left(a_{0}\right)=K_{I}\left(a_{0}\right) Y_{\star} /$ $\sqrt{2 \pi \rho^{\star}}$ does not depend on time, the integral (A6) equals $\sigma_{\Sigma}^{\nu}\left(a_{0}\right) t_{1}$, and therefore

$$
t_{T}=\left(\Omega_{C} / C\right) \frac{\left(K_{I}\left(a_{0}\right) Y_{\star}\right)^{v}}{\left(2 \pi \rho_{\star}\right)^{v / 2}}
$$

Applying the fracture criterion (8) to the second phase of the failure process, we can evaluate the amount of damage generated within the time interval $t_{1} \leq t^{\prime} \leq t$. Here, $t$ coincides with the instant at which material element located at the point $P$ (see Fig. 2b) collapses. Now, the stress distribution $\sigma_{\Sigma}$ varies not only with the distance from the current crack tip but also it is time dependent, since at any fixed point in space, say $P$, the stress is elevated when the crack front propagates toward this point. The integral

$$
\Omega_{2}(t)=c \int_{t_{1}}^{t}\left[\sigma_{\Sigma}^{v}\left(P, P^{\prime}\right)\right] \underset{\dot{a} \neq 0}{ } d t^{\prime}
$$


may be replaced by an integral with respect to the current crack length

$$
\Omega_{2}(a)=c \int_{a_{0}}^{a} \sigma_{\Sigma}^{\nu}\left(a, a^{\prime}\right) \frac{d a^{\prime}}{\dot{a}\left(a^{\prime}\right)}
$$

When the nondimensional crack length $x=a / p_{\star}$ and the nondimensional time $\theta=t / t$, are introduced, the expression (A8) assumes the form

$$
\Omega_{2}(x)=\Omega_{C} \int_{x_{0}}^{x} \phi^{\nu}\left(x^{\prime}\right)\left[Y\left(x, x^{\prime}\right) / Y_{*}\right]^{\nu} \frac{d x^{\prime}}{x\left(x^{\prime}\right)}, \quad \dot{x}=d x / d \theta
$$

in which the geometry dependent function $\phi$ is defined as the ratio of the stress intensity factor for a current crack and that for the initial crack, i.e.

$$
\phi(x)=K_{I}(x) / K_{I}\left(x_{0}\right)
$$

The function $Y\left(x, x^{\prime}\right)$ is the familiar nondimensional stress ahead of a moving crack, $Y(\xi)$, in which the distance $\xi$ is expressed as $r / \rho_{\star}=$ $1+x x^{\prime}$. We note that the rate of crack propagation $\dot{x}^{\prime}$ appearing in the expression (A10) has to satisfy the governing equation (6), or (A20).

\section{Derivation of the governing equation (6).}

Two basic premises underlie the derivation process: (a) that the stress distribution ahead of a propagating crack is of the form

$$
\sigma_{\Sigma}\left(P, P^{\prime}\right)=\sigma_{\Sigma}\left(a, a^{\prime}\right)=\frac{K_{I}\left(a^{\prime}\right)}{\sqrt{2 \pi \rho_{\star}}}[Y(r)]_{r}=\rho_{\star}+a-a^{\prime}
$$

and (b) that a material element at any location along the prospective fracture path collapses when the following critical damage criterion is satisfied 


$$
c \int_{0}^{t} \sigma_{\Sigma}^{\nu}\left(P, P^{\prime}\right) d t^{\prime}=\Omega_{c}
$$

Decomposing the integral in equation (Al3) into two parts

$$
c \int_{0}^{t_{1}}\left[\sigma_{\Sigma}^{v}\right] \dot{a}=0 d t^{\prime}+c \int_{t_{1}}^{t}\left[\sigma_{\Sigma}^{v}\right] \dot{a} \neq 0
$$

and identifying the first part with the damage generated during the latent phase of failure process, $\Omega_{7}$, see equation (A5), we obtain

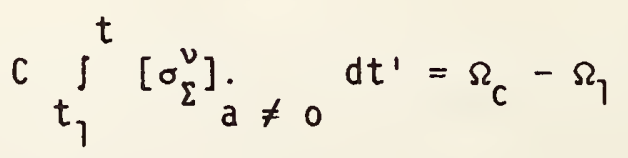

Next, we eliminate time by the time-like variable $a(t)$. Replacing dt' by $d a^{\prime} / a_{(a ')}$, we obtain

$$
c \int_{a_{0}}^{a} \sigma_{\Sigma}^{\nu}\left(a, a^{\prime}\right) \frac{d a^{\prime}}{a\left(a^{\prime}\right)}=\Omega_{c}-\Omega_{7}(a)
$$

When this equation is differentiated with respect to time, remembering that $d[] / d t=\dot{a} d[] / d a$, one arrives at

$$
\dot{a} c \int_{a_{0}}^{a} \sigma_{\Sigma}^{\nu}\left(a, a^{\prime}\right)\left[d \dot{a} / \dot{a}\left(a^{\prime}\right)\right]+C \sigma_{\Sigma}^{\nu}(a, a)=-\dot{a} d \Omega_{7} / d a
$$

Solving for the rate of crack growth gives

$$
\dot{a}=\frac{-c \sigma_{\Sigma}^{\nu}(a)}{c \int_{0}^{a} \frac{\partial}{\partial a} \sigma_{\Sigma}^{\nu}\left(a, a^{\prime}\right) \frac{d a^{\prime}}{\dot{a}\left(a^{\prime}\right)}+d \Omega_{7} / d a}
$$


which is identical with equation (6). We note that both terms appearing in the denominator of $(A 18)$ involve not only the stresses $\sigma_{\Sigma}\left(a, a^{\prime}\right)$ and $\sigma_{\varepsilon}\left(a, a_{0}\right)$ but also their gradients.

These gradients are always negative, and therefore the entire expression on the right-hand side of equation (A18) is positive.

Let us introduce the nondimensional variables

$$
\begin{aligned}
& x=a / p_{\star}, \quad \theta=t / t_{1} \\
& x^{\prime}=a^{\prime} / \rho_{\star}, \quad x_{0}=a_{0} / p_{\star}
\end{aligned}
$$

in which $\rho_{\star}$ denotes the characteristic structural length (such as fiber radius). while the critical time $t_{1}$ is defined by equation (A7). Substitution of (A19) into equation (A18) yields the nondimensional version of the governing equation, useful in further numerical studies, namely

$$
\frac{d x}{d \theta}=\frac{v^{-1} \phi^{\nu}(x)}{\int_{x_{0}}^{x} \phi^{\nu}\left(x^{\prime}\right) F_{1}\left(x, x^{\prime}\right)\left[d x^{\prime} / \dot{x}\left(x^{\prime}\right)\right]+F_{2}(x)}
$$

Here, the function $\phi(x)$ is geometry dependent, as indicated by equation (A11), while the other two auxiliary functions, $F_{1}$ and $F_{2}$, are defined as follows:

$$
\begin{aligned}
& F_{1}\left(x, x^{\prime}\right)=-\left\{\left(\frac{Y(\xi)}{Y_{\star}}\right)^{\nu-1} \frac{d Y(\xi)}{Y_{\star} d \xi}\right\}=1+x-x^{\prime} \\
& F_{2}(x) \equiv F_{1}\left(x, x_{0}\right)
\end{aligned}
$$

These forms were used in generating the curves shown in Figs. $5 a$ and $5 b$. 
3. Correction of the critical damage level, $\Omega$, due to a non zero initial damage associated with the existence of the characteristic damage state.

A final comment regarding modification of the expression for the critical value of the damage parameter $\left(\Omega_{c}\right)$ is in order. If the "time zero" coincides with creation of the characteristic damage state, then we would expect the initial value for the Kachanov parameter, $\omega$, to be greater than zero. Assuming that such initial damage exists and equals $\omega_{0}$, we may redefine the parameter $\Omega$ (see equation (7)) as follows:

$$
\Omega=\int_{\omega_{0}}^{\omega}\left(1-\omega^{\prime}\right) d \omega^{\prime}=\frac{\left(1-\omega_{0}\right)^{\nu+1}-(1-\omega)^{\nu+1}}{\nu+1}
$$

At $t=0, \omega=\omega_{0}$, and we again recover $\Omega=0$. However, for the other limit, when the internal damage parameter, w, attains its critical value, $\omega=1$, the capital omega assumes the level

$$
\Omega_{C}=\frac{\left(1-\omega_{0}\right)^{v+1}}{v+1}
$$

Since $\Omega_{c}$ enters into all pertinent expressions which describe damage accumulation and growth, acceptance of equation ( $A 23$ ) requires that an additional material property, namely the relative void density at the onset of the characteristic damage state $\left(\omega_{0}\right)$, be introduced into the model. Therefore, the number of independent material constants is increased by one; and, in order to match the experimental data with the mathematical model, one needs to determine all three constants, namely $\omega_{0}, v$, and $C$. 
1. (a) Characteristic damage state observed shortly prior to the final

failure of an epoxy-graphite $\left[0^{\circ}, 90^{\circ}, 45^{\circ},-45^{\circ}\right]$ laminate. The crack seen in the photograph penetrates the $90^{\circ}$ ply while the black dots ahead of it represent secondary fractures, such as fiber breaks contained within the adjacent $0^{\circ}$ ply. Both primary and secondary fractures were made visible by an edge replica technique (see Ref. 5).

(b) Mathematical model of the physical state depicted in Fig. 1a. The model stems from the continuous damage mechanics (CMD).

2. State of stress, $\sigma_{5}\left(P, P^{\prime}\right)$, generated at the point $P$ while the crack tip is located at the point $P^{\prime}$ depends on the distance $r_{p p^{\prime}}$. This distance is shown for (a) stationary crack, and (b) a propagaling crack. Symbol $\rho$ * denotes the characteristic microstructural length.

3. (a) Distribution of internal damage $\left(\Omega_{\rho}\right)$ constructed from stress distributions ahead of a dominant ply crack shown in Fig. la.

(b) Distribution of the internal damage $\left(\Omega_{1}\right)$ generated during the latent phase of fracture process $\left(t \leq t_{1}\right)$ when the dominant crack is stationary. A pronounced difference in the damage accumulation pattern is noted between the two situations corresponding to values for the exponent $v$ of 0.1 and 2 .

4. Distributions of the internal damage $\left(\Omega_{2}\right)$ generated during the second phase of fracture process associated with propagation of a dominant crack $\left(t \leq t \leq t_{2}\right)$. Two distinctly different situations are obtained from the exponent $v$ being less than one $(v=0.1)$ and greater than one $(v=2)$.

5. (a) Second phase of fracture process, that is the dominant crack propagation as calculated for $v=0.1, v=2$, and $v=4$ and a stress field, $\sigma_{\Sigma}$, generated by a ply crack traversing the remaining ligament that is $0^{\circ}$ ply (the crack is shown in Fig. 1). Nondimensional crack length, $x=a / \rho_{*}$, is shown as a function of nondimensional time, $\phi=t / t_{1}$.

(b) Length of the ply crack vs. time (both nondimensionalized, $v=2$ ) shown for the three different stress fields generated ahead of the ply crack contained in a laminated epoxy-graphite composite in the unrelaxed state (curve labeled "mech") and two relaxed states corresponding to the "wet" and "dry" condition of the laminate. The input data used to generate the three curves shown was taken from the finite-element studies of Kriz [5] (see Fig. 5c).

(c) Through-thickness variation of $\sigma$ in $0^{\circ}$ ply shown in Fig. la for three cases: 1. Mech - mechanical load only with no residual stresses at room temperature, 2. Dry - superposition of residual thermal stresses at $76 \mathrm{~K}$ in a dehydrated condition, 3 . Wet superposition of residual stresses caused by swelling when laminate is saturated with abosrbed moisture. 
6. Simplified version of a stacking sequence $\left[90^{\circ}, 0^{\circ}\right]$ for which the double-edge-notch configuration would apply. This Configuration was assumed for the purpose of numerical integration of the governing equation 6 (see the curves shown in Figs. $5 \mathrm{a}$ and $5 \mathrm{~b}$ ).

7. Comparison between the damage distributions, $\Omega_{2}$, pertaining to the second phase of fracture, as evaluated from the exact ${ }^{2}$ (curve 1) and approximate (curve 2) equations. When the exponent $v$ is much less than one ( $v=$ 0.1 ), both curves are almost identical.

8. Straight 1 ine shown represents the relation between the constant applied stress, $\sigma$, and the first critical time, $t$ [ [see equation 26]. Cohesive strength $8 \mathrm{f}$ the reinforcing fiber, $\sigma$, is ased to normalize stress, while the reference time, $t_{R}\left(=1 / \mathcal{C} \sigma_{C}\right)$, is efiployed to normalize time. 


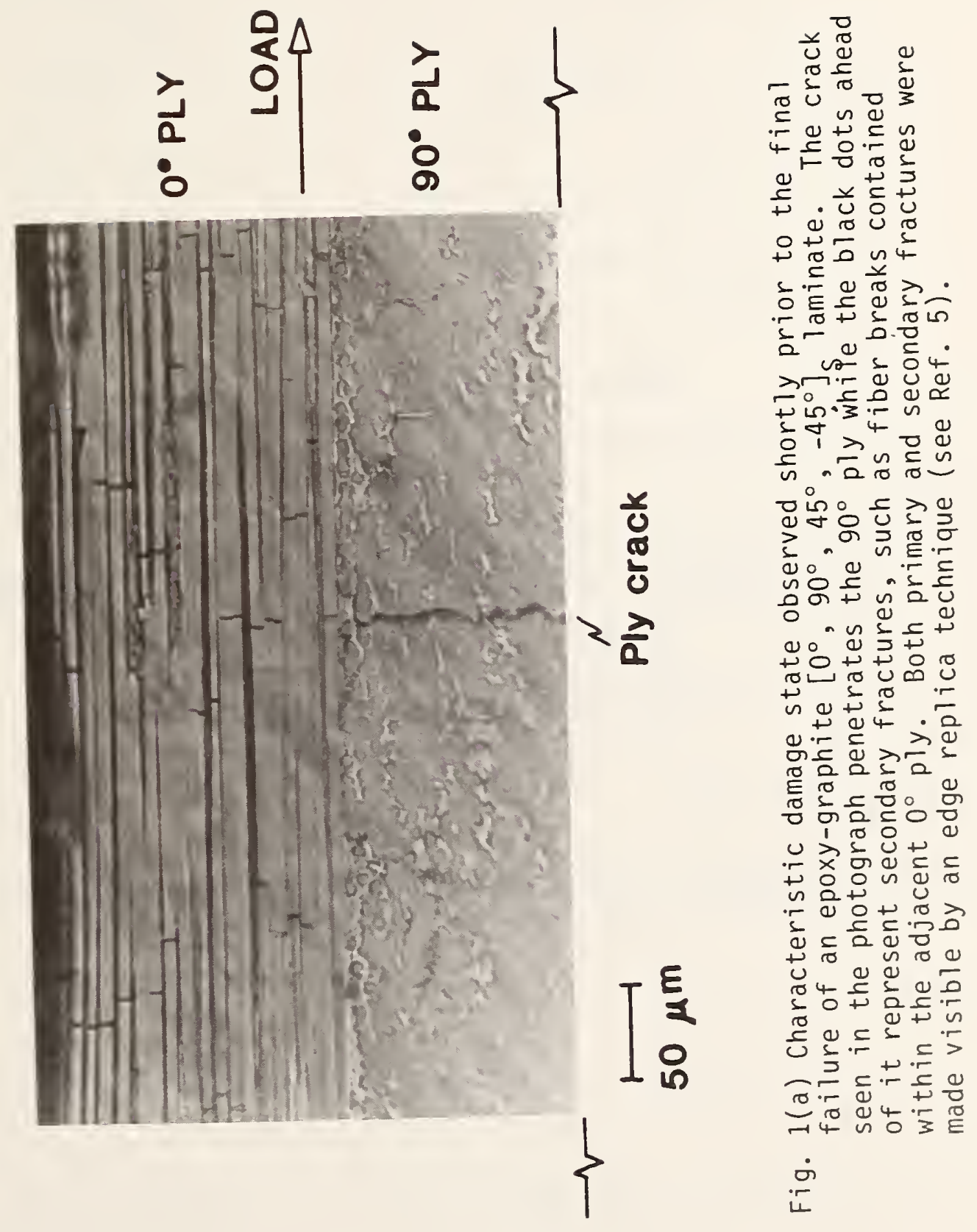




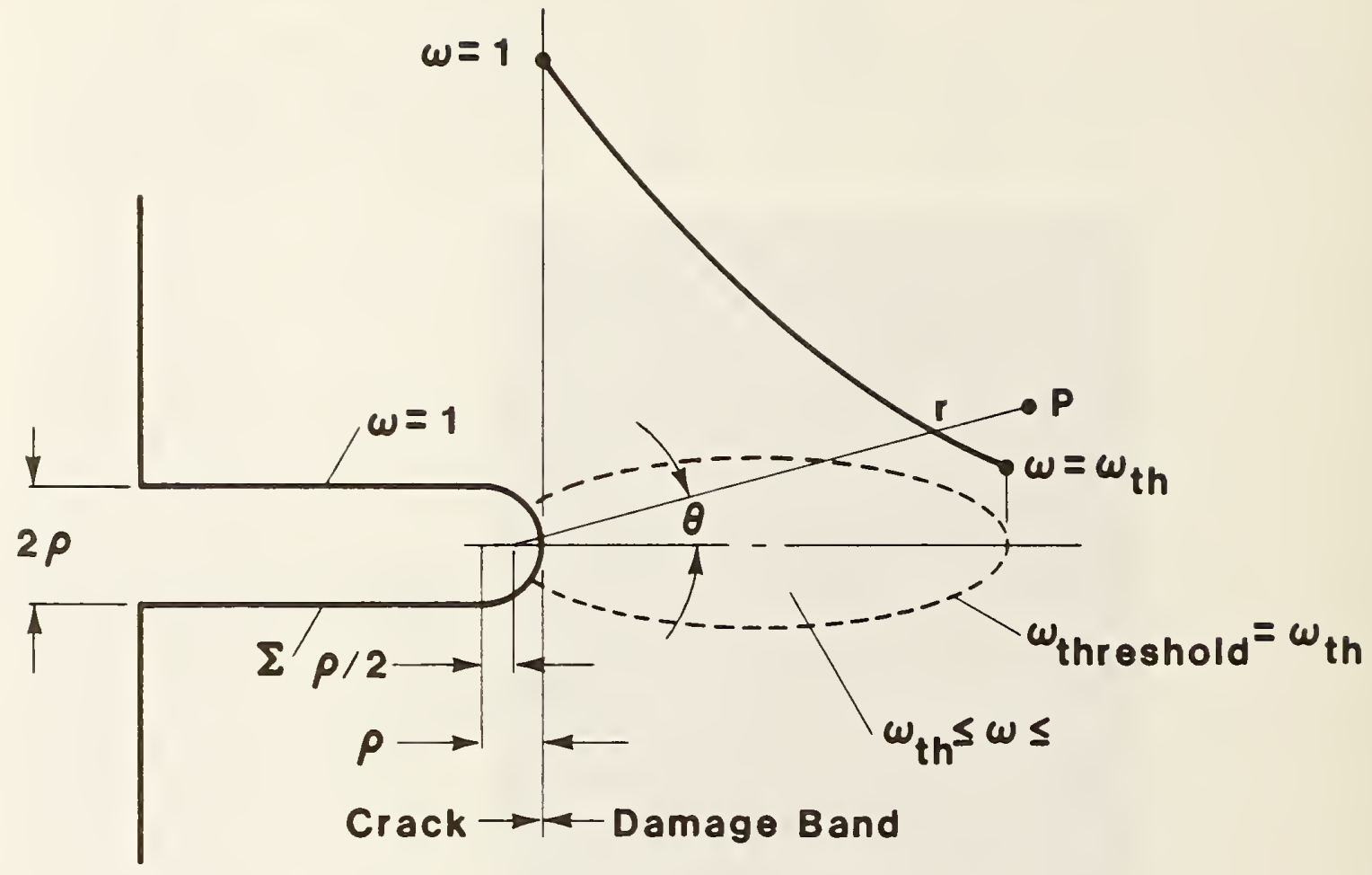

Fig. 1(b) Mathematical model of the physical state depicted in Fig. 1a. The model stems from the continuous damage mechanics (CMD). 


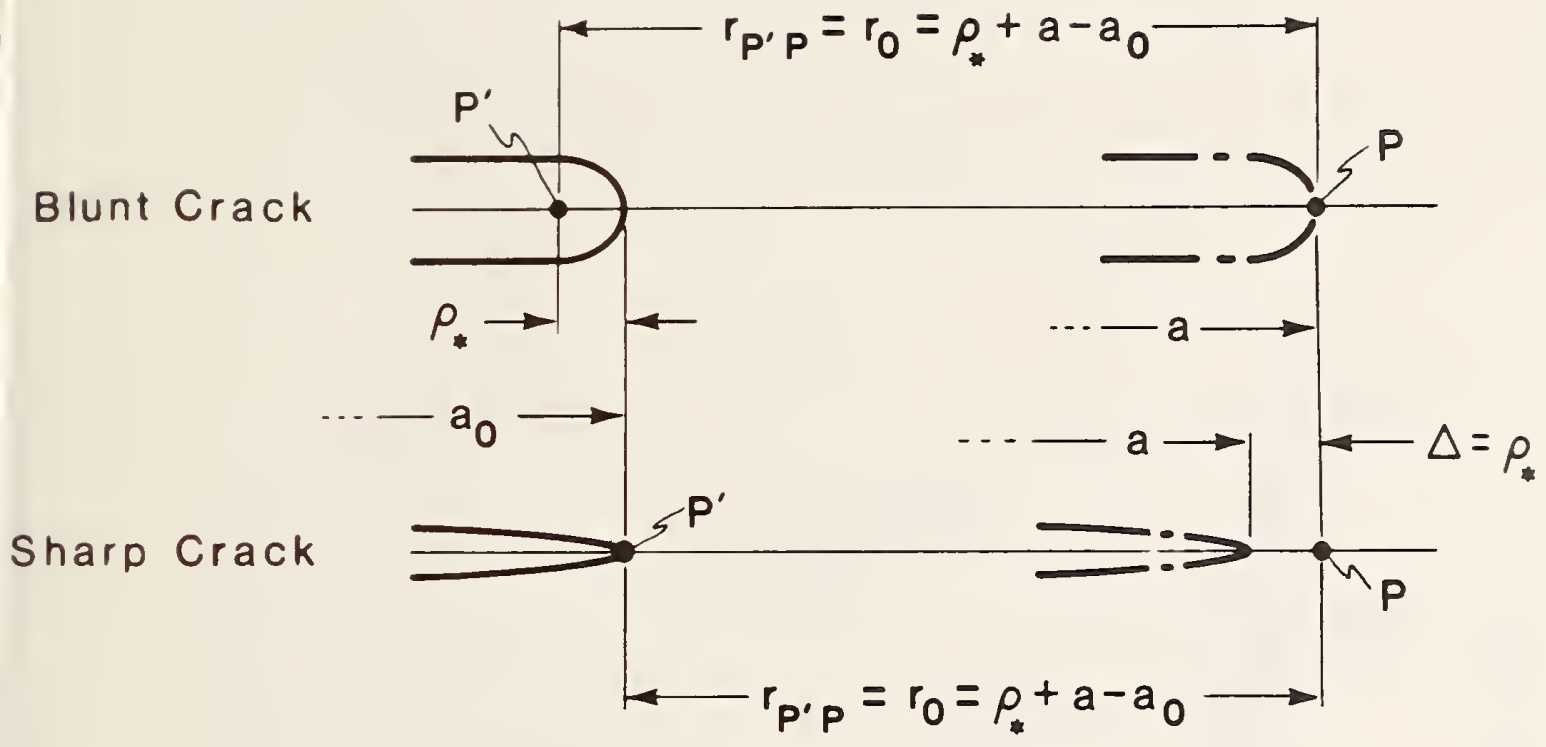

Fig. $2 b$

Blunt Crack

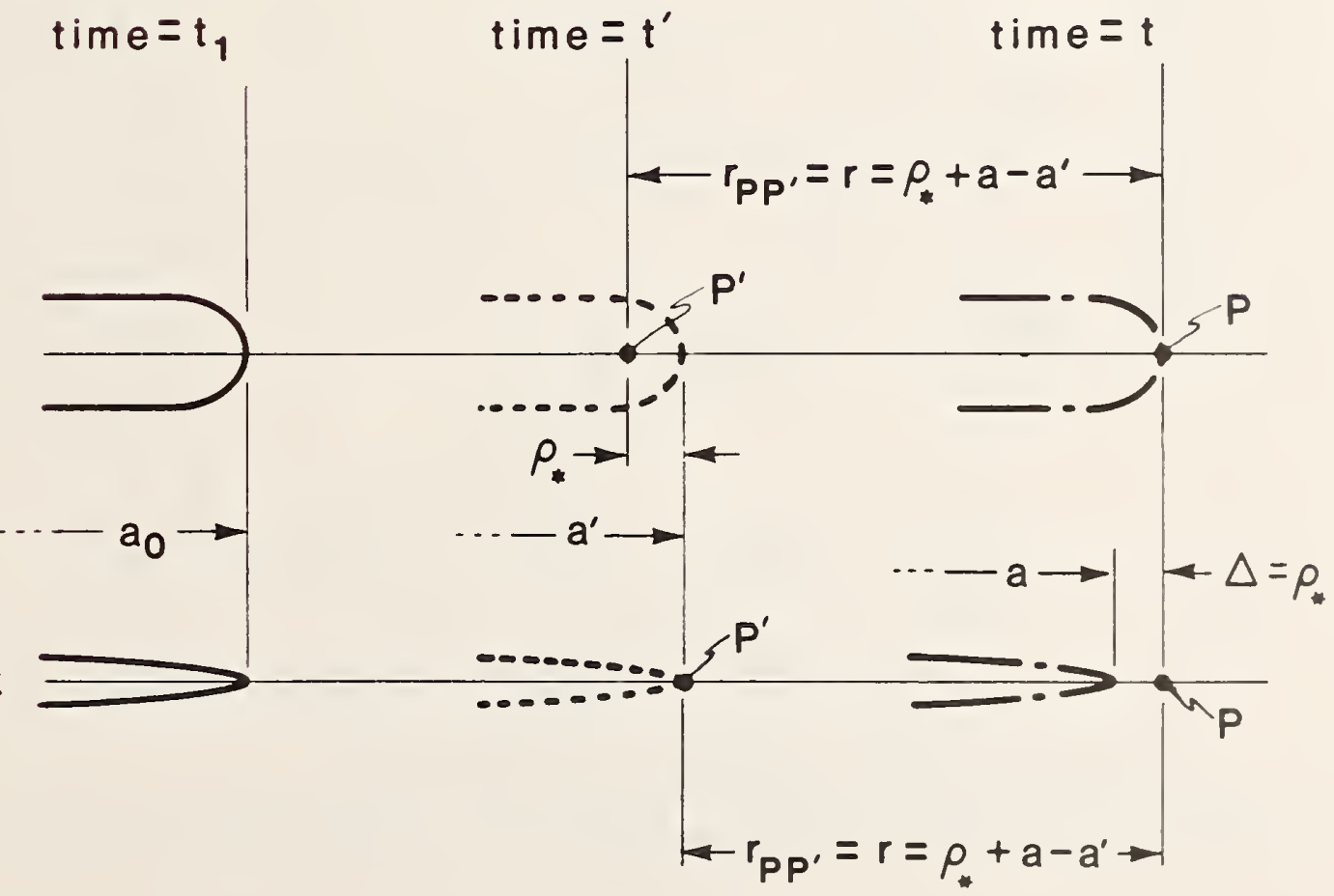

Fig. 2. State of stress, $\sigma_{\Sigma}\left(P, P^{\prime}\right)$, generated at the point $P$ while the crack tip is located at the point $p^{\prime}$ depends on the distance $r$. This distance is shown for (a) stationary crack, and (b) a prBpagating crack. Symbol $\rho^{*}$ denotes the characteristic microstructural length. 


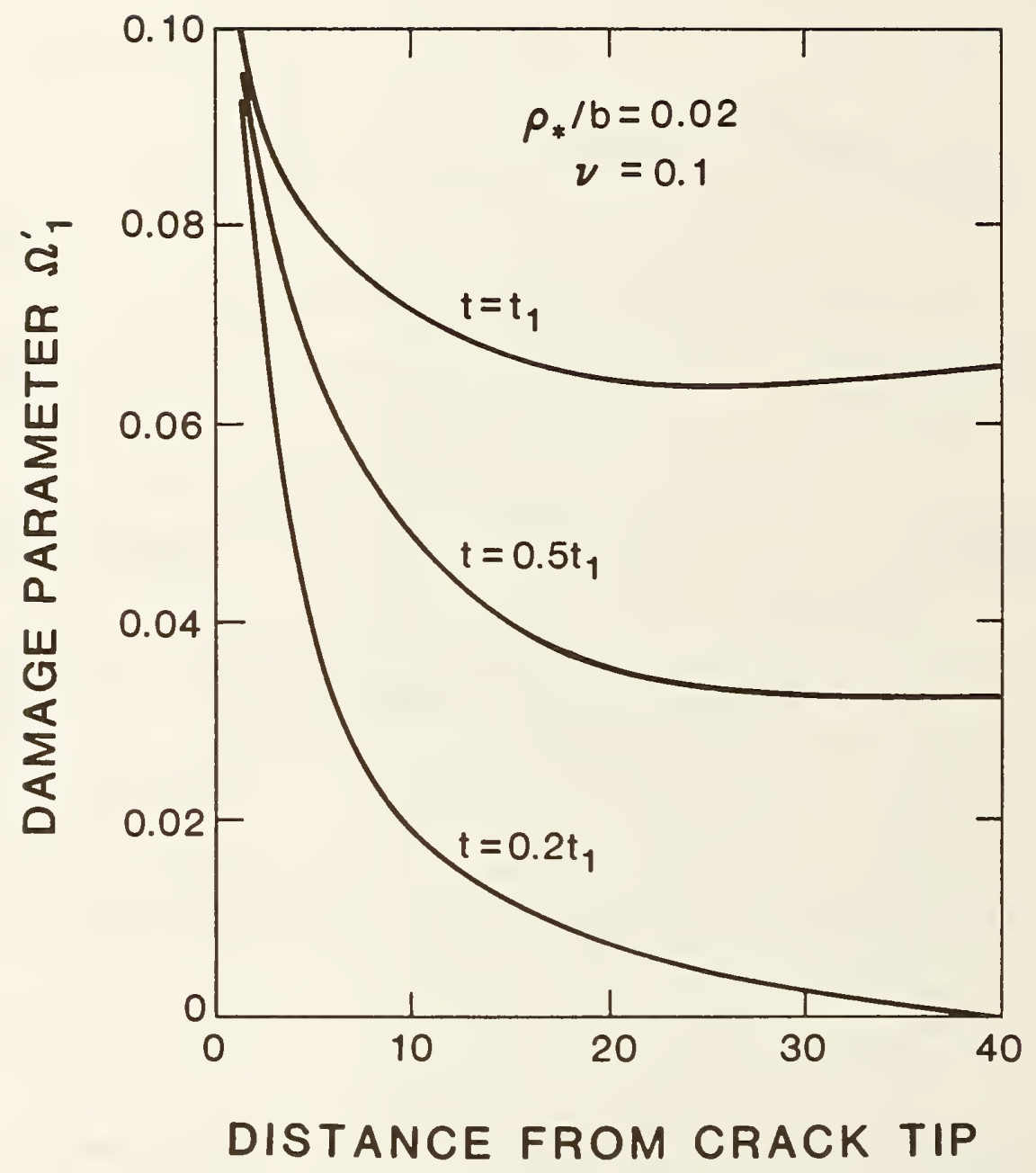

Fig. 3(a) Distribution of internal damage $\left(\Omega_{1}\right)$ constructed from stress distributions ahead of a dominant ply crack shown in Fig. la. 


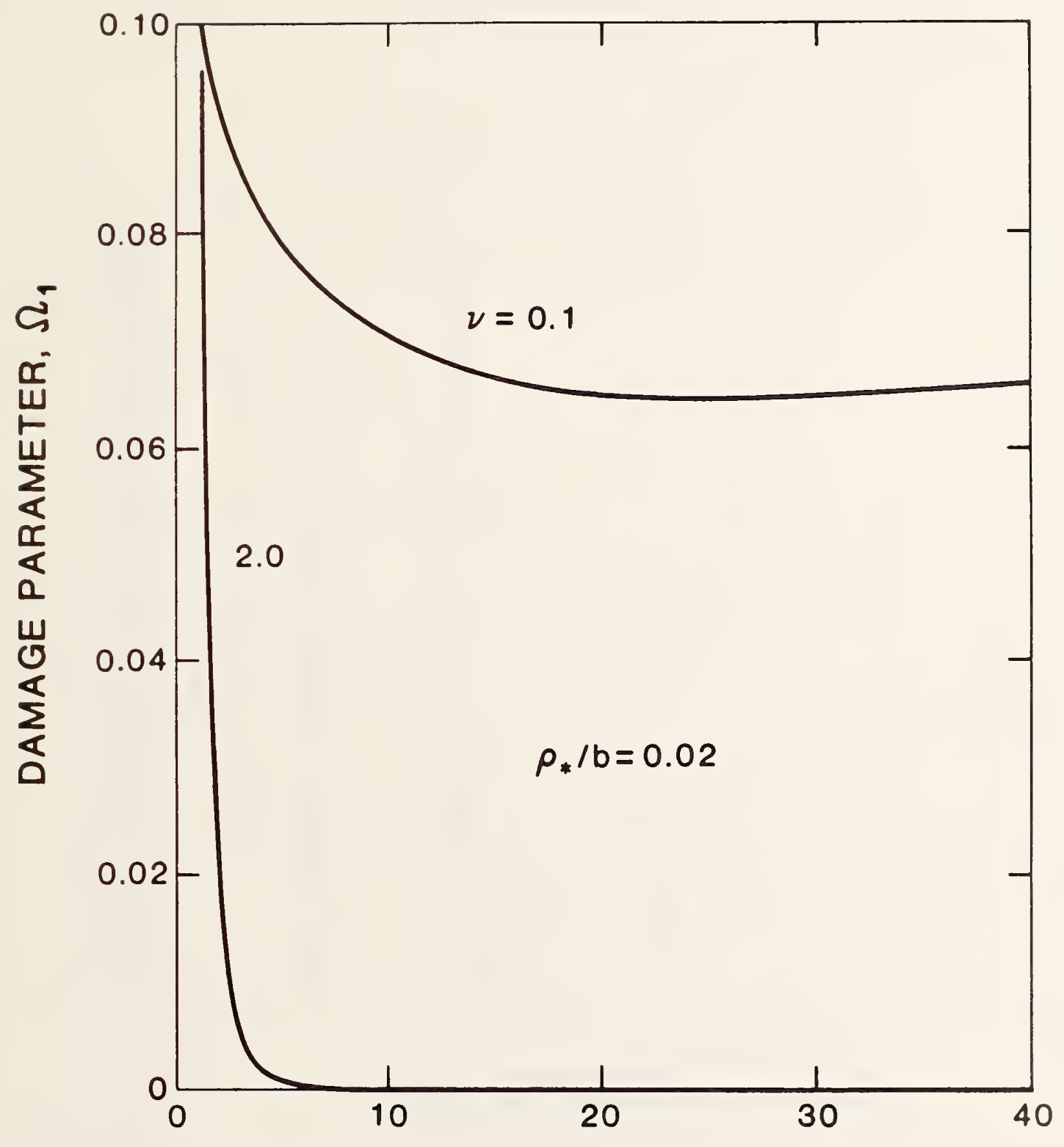

\section{DISTANCE FROM CRACK TIP}

Fig. 3(b) Distribution of the internal damage $\left(\Omega_{1}\right)$ generated during the latent phase of fracture process $(t \leq t)$ when the dominant crack is stationary. A pronounced difference in the damage accumulation pattern is noted between the two situations corresponding to values for the exponent $v$ of 0.1 and 2 . 


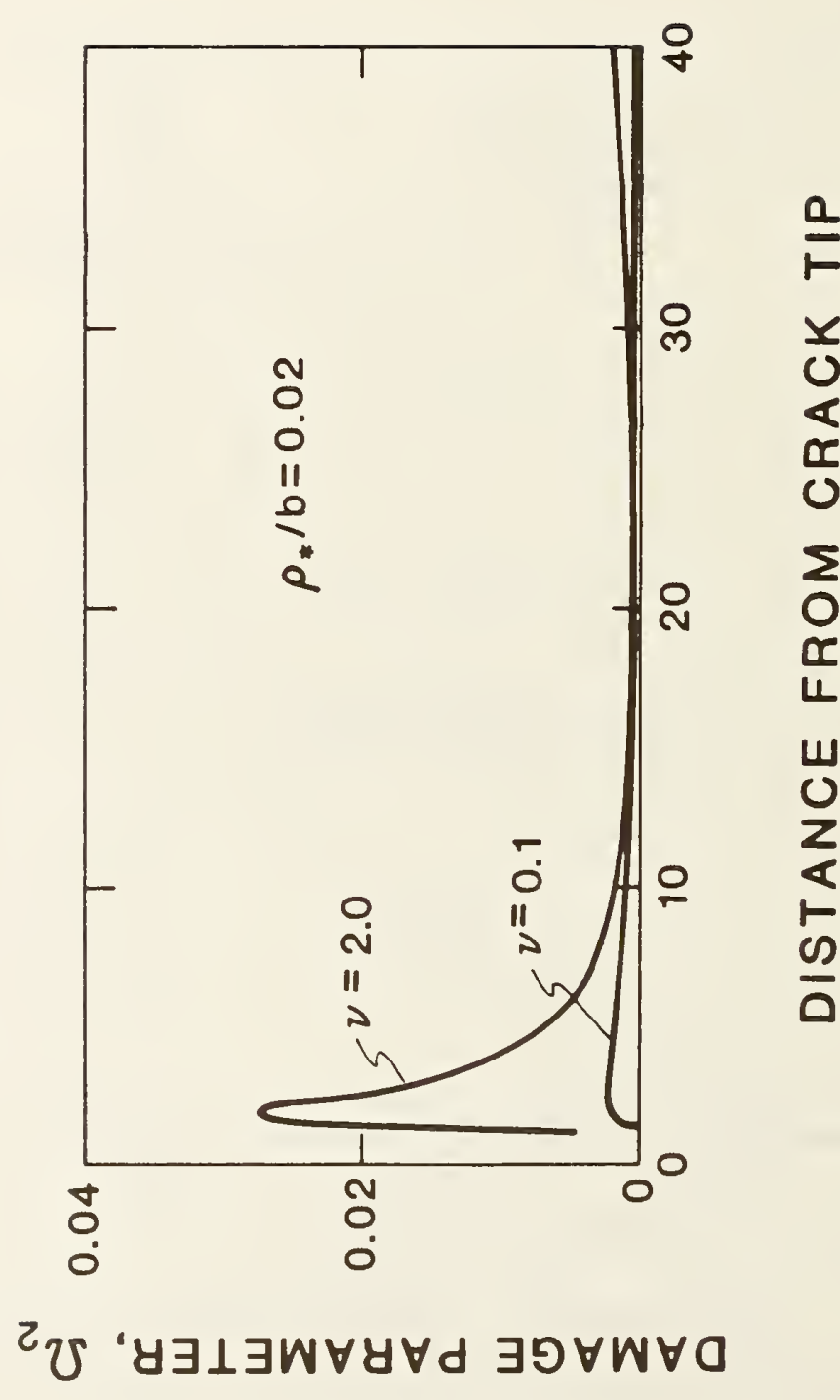

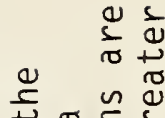
ॠ बुप ᄃ 응.․․ $0+0$ ه 苋造 a $ᄋ \frac{1}{4}$ Q 듬 등 Nis $>0$ c) Q 뮨 它 당 ฮ टे थู อ 둥 (1) $2+$

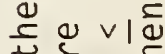
$+\frac{s}{3}+\frac{5}{\circ}$

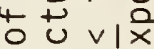
$\pi$

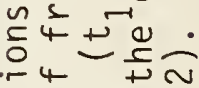
吉品 E

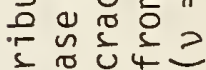

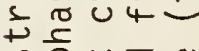
$\sim$ 几 ○ 으욛ㄷㅇ О윰듀 - 웡응용 i் 


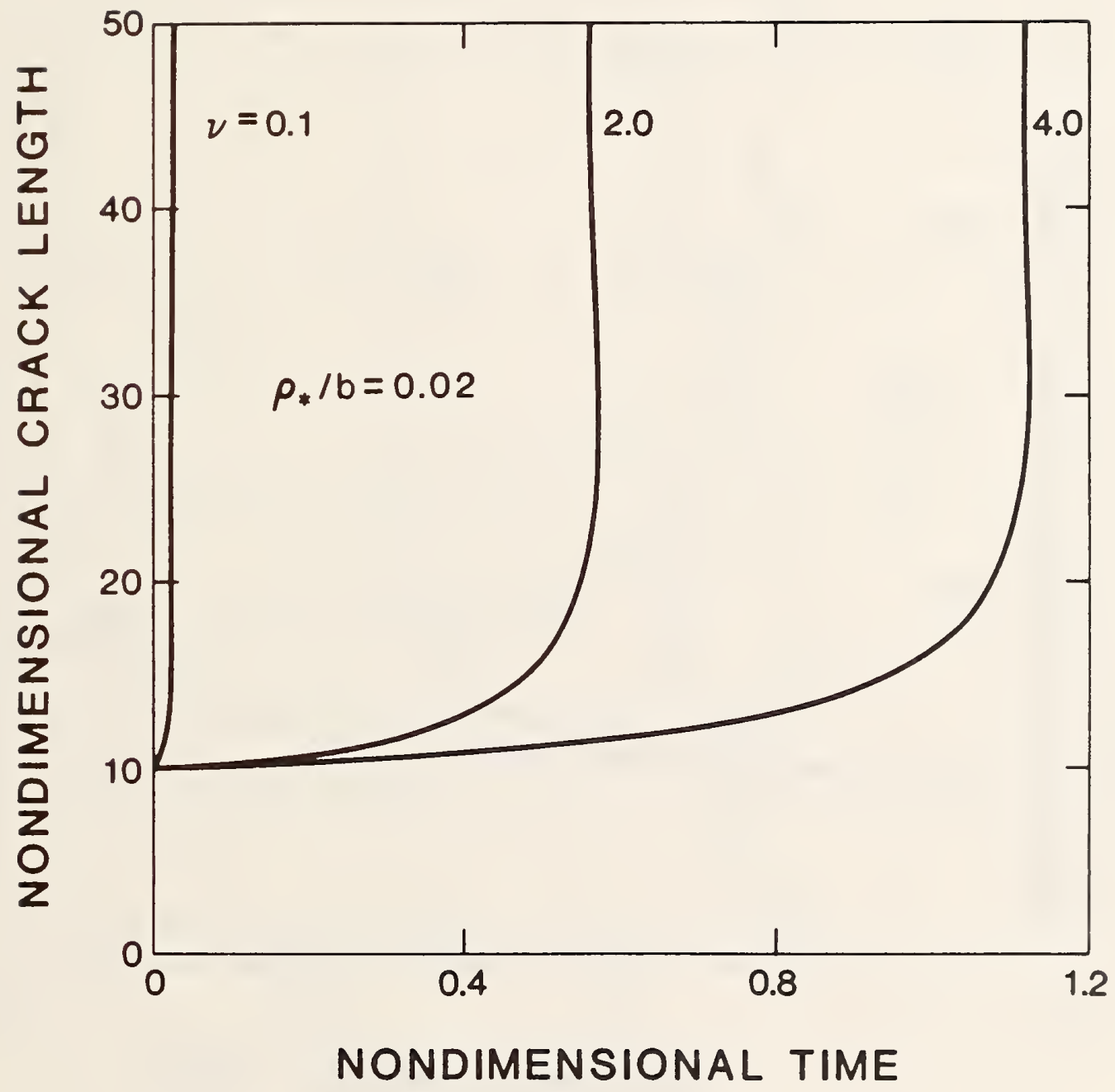

Fig. 5(a) Second phase of fracture process, that is the dominant crack propagation as calculated for $v=0.1, v=2$, and $v=4$ and a stress field, $\sigma_{\Sigma}$, generated by a ply crack traversing the remaining ligament ${ }^{5}$ that is $0^{\circ}$ ply (the crack is shown in Fig. 1 ).

Nondimensional crack length, $x=a / \rho_{\star}$, is shown as a function of nondimensional time, $\phi=t / t_{1}$. 


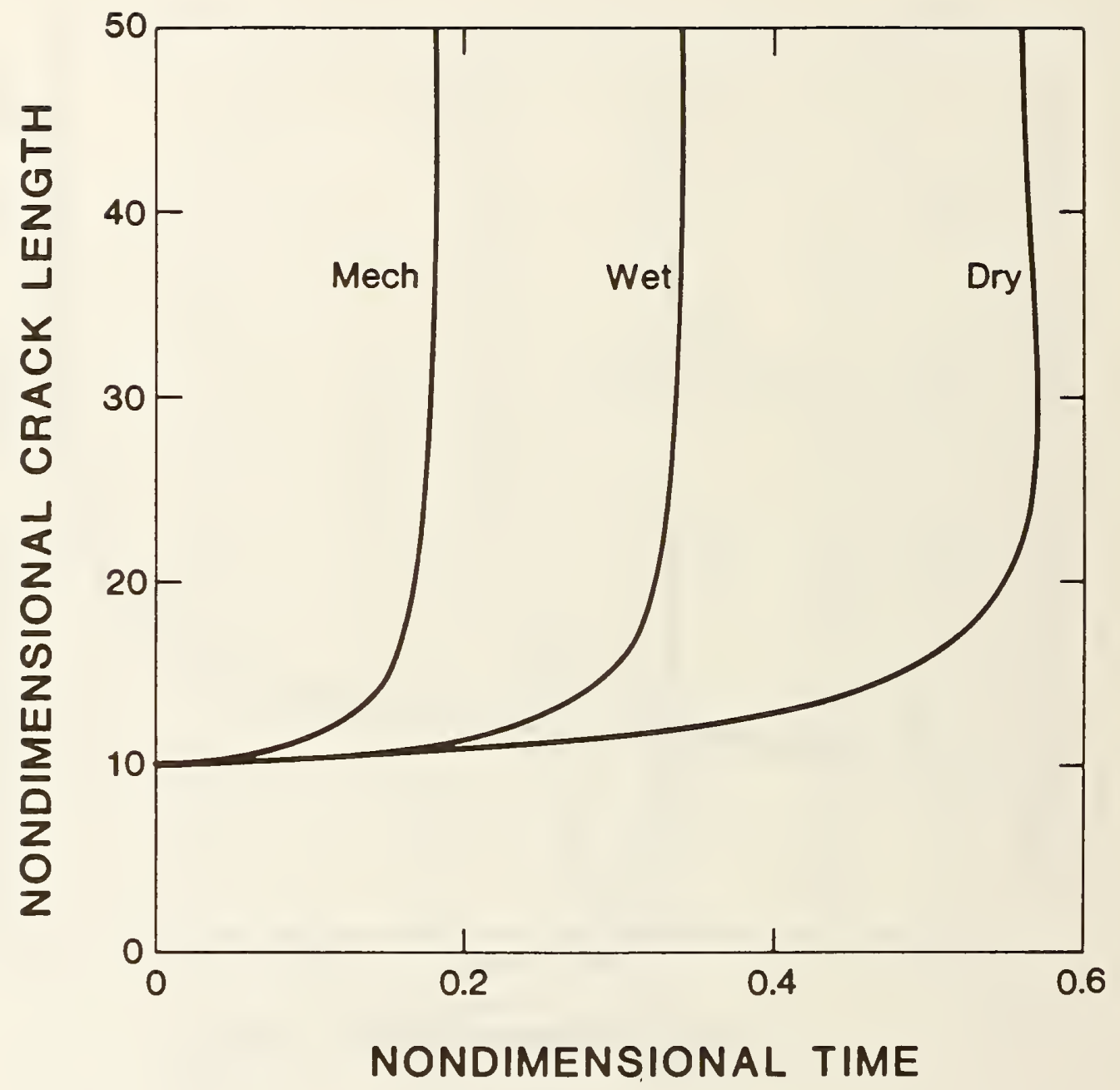

Fig. 5(b) Length of the ply crack vs. time (both nondimensionalized, $v=2$ ) shown for the three different stress fields generated ahead of the ply crack contained in a laminated epoxy-graphite composite in the unrelaxed state (curve labeled "mech") and two relaxed states corresponding to the "wet" and "dry" condition of the laminate. The input data used to generate the three curves shown was taken from the finite-element studies of Kriz [5] (see Fig. 5c). 

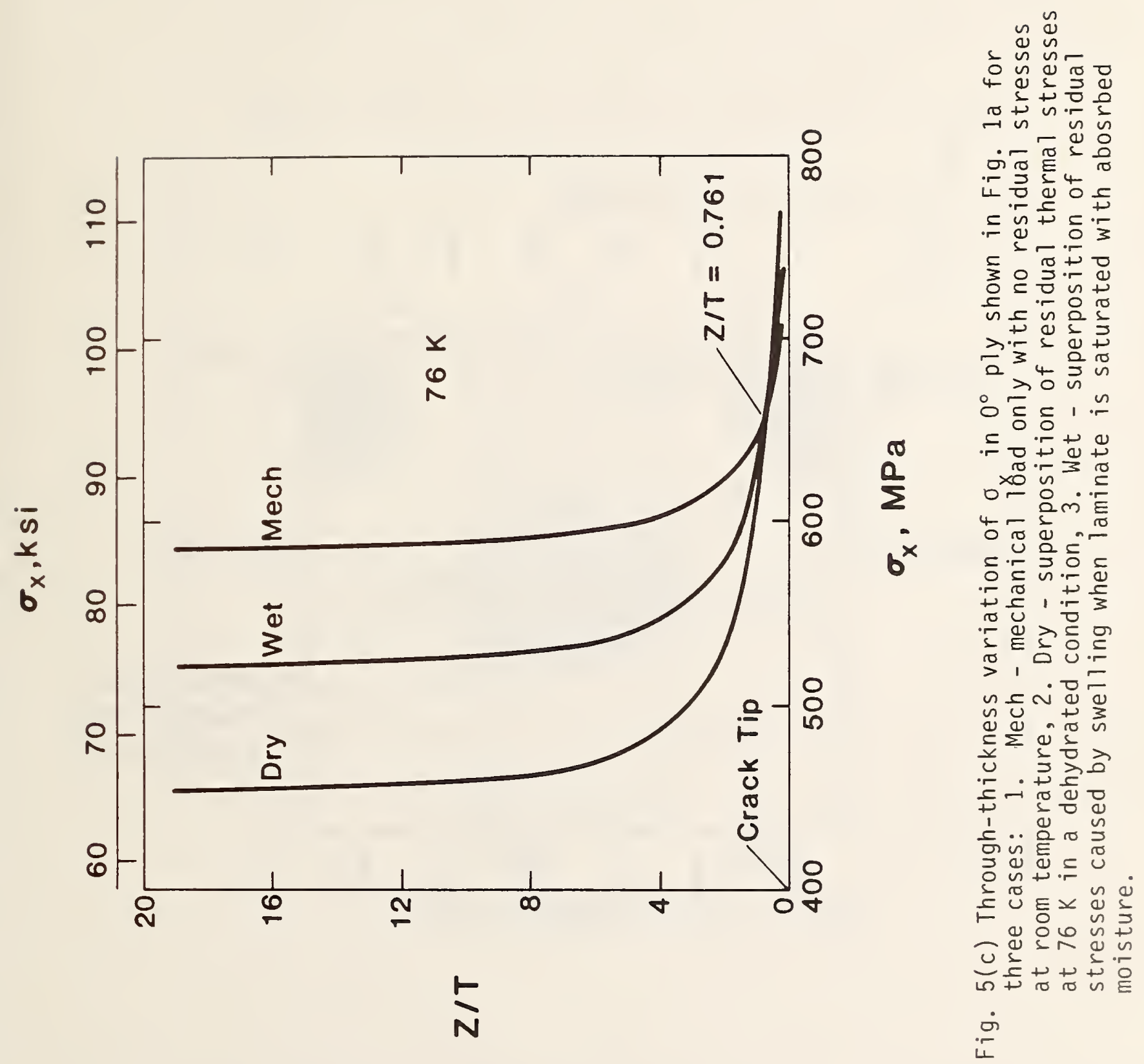


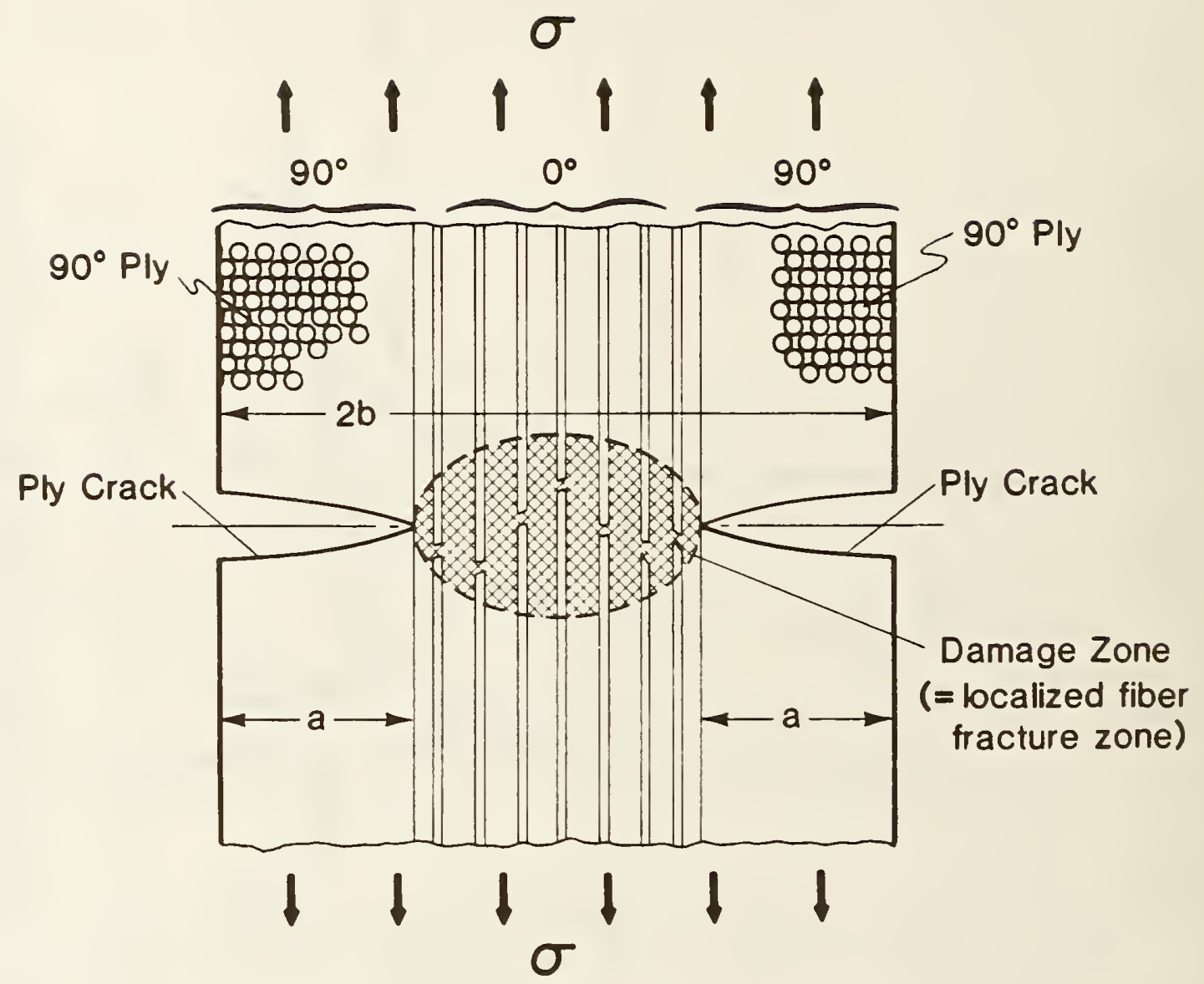

Fig. 6. Simplified version of a stacking sequence $\left[90^{\circ}, 0^{\circ}\right]_{S}$ for which the double-edge-notch configuration would apply. This configuration was assumed for the purpose of numerical integration of the governing equation 6 (see the curves shown in Figs. $5 \mathrm{a}$ and $5 \mathrm{~b}$ ). 


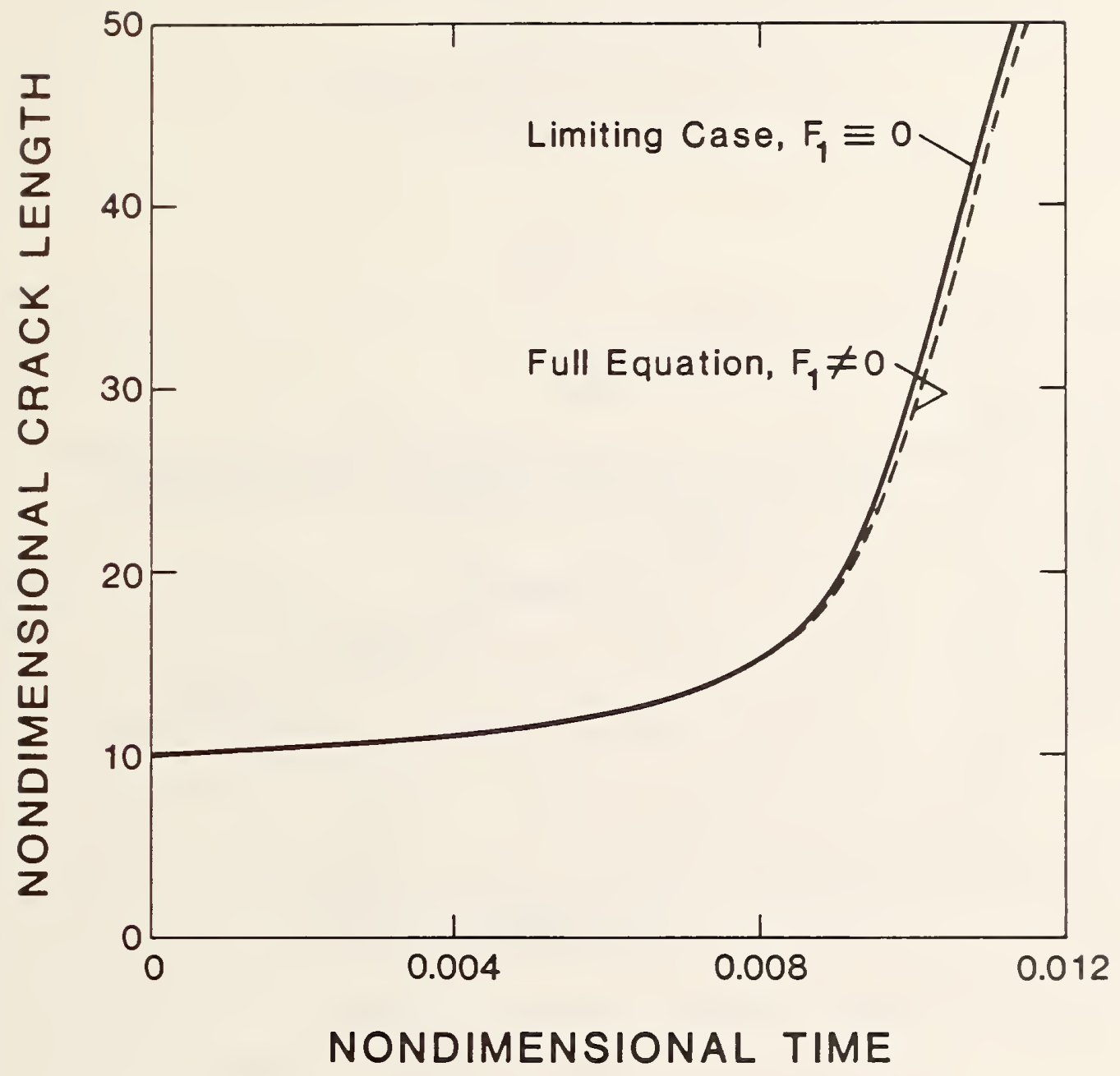

Fig. 7. Comparison between the damage distributions, $\Omega_{2}$, pertaining to the second phase of fracture, as evaluated from the exact (curve 1) and approximate (curve 2 ) equations. When the exponent $v$ is much less than one $(v=0.1)$, both curves are almost identical. 


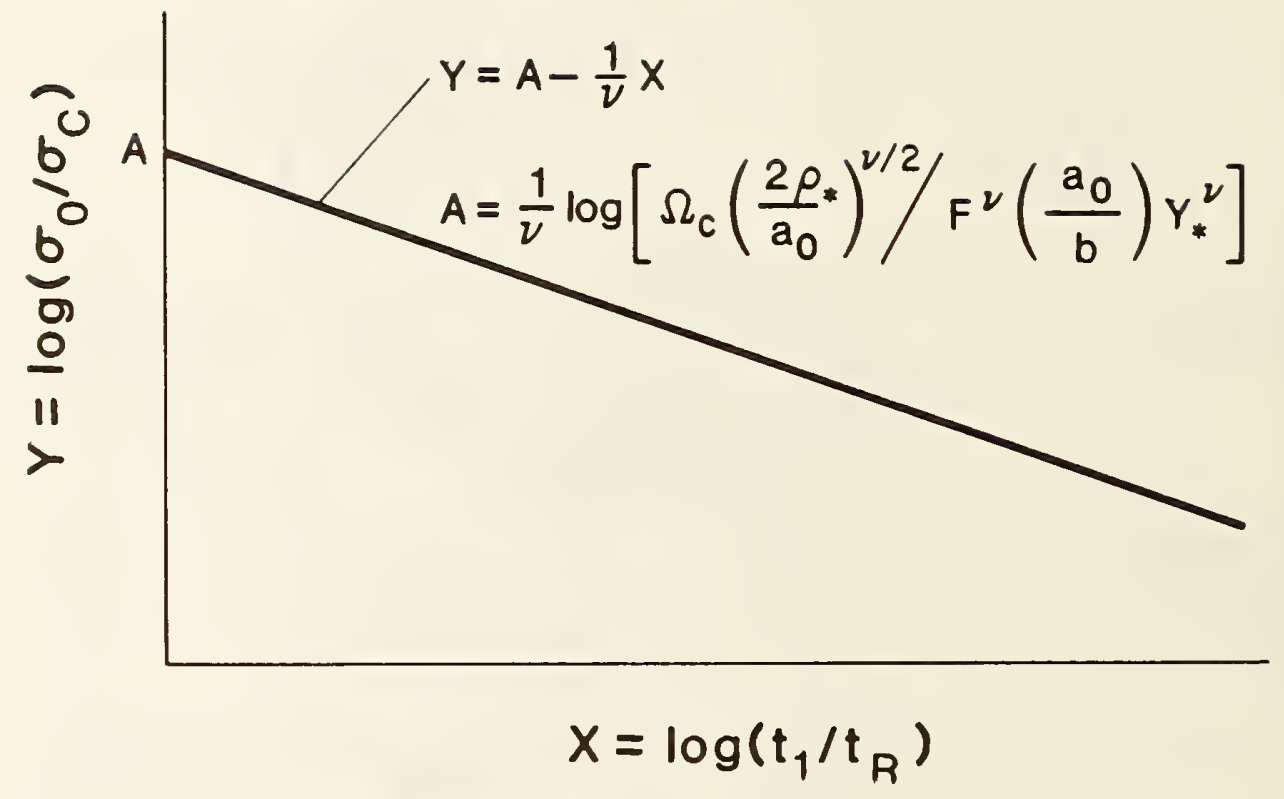

Fig. 8. Straight line shown represents the relation between the constant applied stress, $\sigma_{0}$, and the first critical time, $t_{1}$ [see equation 26]. Cohesive strength ${ }^{0}$ of the reinforcing fiber ${ }^{\sigma}$, is used to normalize stress, while the reference time, $t_{R}\left(=1 / C_{C}{ }_{C}\right), C_{i s}$ employed to normalize time. 
INFLUENCE OF DAMAGE ON MECHANICAL PROPERTIES

OF WOVEN COMPOSITES AT LOW TEMPERATURES

\author{
Ronald D. Kriz \\ Fracture and Deformation Division \\ National Bureau of Standards \\ Boulder, Colorado
}

\title{
- ABSTRACT
}

Large quantities of nonmetallic woven composites will be used in magnetic fusion energy (MFE) structures at low temperatures. We studied the influence of crack formation, residual thermal stresses, and weave curvature on the mechanical performance of G10-CR glass/epoxy laminates. Improved material performance was suggested by the load-deformation response of a unit cell of plain weave. A generalized plane-strain finite-element model was used to predict crack-tip singularities and redistribution of stresses within a thin slice of warp-fill fiber bundles. The model predicts that warp curvature and thermal stresses at low temperatures are beneficial in reducing crack-tip singularities of fill cracks. The opposite is true for stiffness, which is decreased both by curvature and fill cracks. Results of this model provide the MFE designer a tradeoff between stiffness and strength. 



\section{INTRODUCTION}

Large quantities of nonmetallic composites are forecast for use in future designs of magnetic-fusion-energy (MFE) power plants. ${ }^{1}$ In many applications, nonmetallic composites are used both as structural support and as thermal insulation. In superconducting magnets, nonmetallics are used primarily as electrical insulation. However, when cooled down to liquid-helium temperatures, large internal stresses can occur within MFE structures because of large differential thermal contractions between metals and nonmetals. When internal stresses are combined with mechanical loads, microcracks may initiate well below the ultimate strength of the composite. Large numbers of voids and microcracks could limit the mechanical usefulness of these materials.

In anticipation of MFE applications, standardization of G10-CR and GII-CR National Electrical Manufacturers' Association (NEMA) grade woven-fabric glass/epoxy laminates was established at the National Bureau of Standards. 2,3 Variability in mechanical, electrical, and thermal properties was minimized to provide the MFE designer with improved mechanical properties. Here we demonstrate the variability in mechanical performance caused by crack initiation in a unit cell of plain weave (Fig. 1). The thermal-mechanical response of the unit cell was studied in a damaged state to predict changes in the mechanical properties. Improvement in material performance was suggested by modeling redistribution of loads within a damaged unit cell. Changes in stiffnesses and load stresses were calculated by a finite-element model.

\section{ANALYSIS}

The unit cell of a woven structure is defined by Ishikawa ${ }^{4}$ as the smallest repeating structural unit. The plain-weave unit cell shown in Fig. 1 can be further characterized by four identical patterns in planes A, B, C, and D. The finite-element model assumes generalized plane strain exists in all four 
planes. Hence, the elastic response of the unit cell can be predicted by studying the three-dimensional load deformation response within a single plane parallel to the load direction, as shown in Fig. 2. Several load conditions of tension, shear, and compression are possible. Preliminary results given here focused on tensile loads, $N_{x}$, shown in Figs. $3 a$ and $3 b$. The displacements within the $x-z$ plane of Fig. 2 are linear functions of $x, y$, and $z$ coordinates and out-of-plane strain, $\varepsilon_{y}$ :

$$
\begin{aligned}
& u=a_{1}+a_{2} x+a_{3} z \\
& v=a_{4}+a_{5} x+a_{6} z+y \varepsilon_{y} \\
& w=a_{7}+a_{8} x+a_{9} z
\end{aligned}
$$

where the $a_{i}$ terms are evaluated in terms of nodal displacements. The inplane and out-of-plane strains, $\varepsilon_{x}$ and $\varepsilon_{y}$, are calculated from thin-laminateplate theory, ${ }^{5}$ assuming zero stresses through the thickness:

$$
\begin{aligned}
& \varepsilon_{x}=A_{y y} N_{x} /\left(A_{x x} A_{y y}-A_{x y}^{2}\right), \\
& \varepsilon_{y}=-A_{x y} N_{x} /\left(A_{x x} A_{y y}-A_{x y}^{2}\right)
\end{aligned}
$$

where $A_{x x}, A_{y y}$, and $A_{x y}$ are laminate midplane stiffnesses ${ }^{6}$ calculated from elastic properties listed in Table 1. A laminate load of $N_{X}=175 \mathrm{~N} / \mathrm{mm}$ yielded strains $\varepsilon_{x}=0.01095$ and $\varepsilon_{y}=0.001741$. A worst-case thermal load of $\Delta T=-318 \mathrm{~K}$ was chosen at $77 \mathrm{~K}$, assuming a strain-free state exists at $395 \mathrm{~K}$ (cure temperature). With these load conditions, we studied the influence of internal fill-fiber-bundle fracture (Fig. 3b) on the elastic-mechanical response and internal stresses of the unit cell.

\section{DISCUSSION}

\section{Stiffness}

For nonwoven laminated plates, stiffness can be predicted by thin. 
laminate-plate theory. 6 For woven laminated plates, Ishikawa and

Chou ${ }^{7}$ predicted stiffnesses for several different weaves by modifying existing thin-laminate-plate theory. Here we predicted the woven laminate stiffness by measuring the load-deformation response of a finite-element model of the unit ce11. The finite-element model used the elastic properties listed in Table 1, where epoxy and fiber elastic properties were calculated from experimental results ${ }^{7}$ and composite elastic properties were calculated using equations of Hashin. 8

Figure 4 shows the influence of warp-fiber orientation, $\theta$, on the elastic response of the unit cell with and without a fill-fiber-bundle crack. As expected, the elastic modulus increased with increasing alignment of warpfiber bundle along the load axis. Most interesting was the pronounced influence of fill-fiber-bundle cracks on modulus for large warp angles, $\theta$. Internal Stresses

Before mechanical loading, large internal stresses are caused by differential thermal contractions between warp and fill-fiber bundles at $77 \mathrm{~K}$. For nonwoven laminates, these internal stresses can influence the sequence of damage formation and reduce fracture strength. 10 In this study, the internal stresses were predicted for the unit cell with and without a fill-fiber-bundle crack. The stress-free condition was assumed at a cure temperature of $395 \mathrm{~K}$. Cooling to $77 \mathrm{~K}$ caused large changes in internal stresses.

Regions of expected large internal stresses are shown in Fig. 2 along lines $a-b, c-d$, and $e-d$. Variations in stress distributions along these 1 ines are compared in Figs. 5, 6, and 7. For all these figures, solid lines indicate stress caused by a moderate mechanical load of $175 \mathrm{~N} / \mathrm{mm}$ with different warp curvatures, ranging from $0^{\circ}$ to $45^{\circ}$ (see Figs. 3a and $3 b$ ). The superposition of residual thermal stresses at $77 \mathrm{~K}$ is shown by dashed 1 ines for 
minimum and maximum warp orientations of $0^{\circ}$ and $45^{\circ}$ respectively.

In Fig. 5, stresses normal to the warp-fill interface are compressive at $\theta=45^{\circ}$, far from the crack tip. Prior to crack formation these stresses were tensile. Hence, subsequent crack formation in this region was eliminated by the presence of a fill-fiber-bundle crack. In both the fill region and matrix region, stresses decreased with increasing warp orientation. The opposite was true prior to crack formation. If fill-warp interface debonding is a problem, fill-fiber-bundle cracks are beneficial when warp orientations are large at low temperatures.

Figure 6 illustrates that the largest stress existed near the crack tip in the warp-fiber bundle. Stresses far from the crack tip in the warp-fiber bundle were most affected by warp orientation, $\theta$, shown in Fig. 3b. Larger loads were carried by smaller warp angles. The addition of thermal residual stress decreased the far-field stresses. The same pattern was observed for stresses near the crack tip. Again, we observed beneficial effects from the interaction of thermal stresses and warp curvature.

Figure 7 shows that the debonding stresses in warp-fiber bundle above the fill-fiber-bundle crack were increased by curvature and thermal stresses. This pattern was not understood because large compressive stresses should exist in this region.

We have not established a failure criterion for woven laminated structures. Instead, we have focused on stress distributions near and far from the crack tip. In metals studies on stress, distributions near crack tips of dominant cracks provided the fundamental basis for a fracture criterion. 11,12 Unfortunately, cracks in composite laminates with or without curvature may not be dominant. Hence, a failure criterion based on a single dominant crack in composites is an idealization that is often forced into practice without 
experimental verification. Before a failure criterion is developed, experimental verification of a dominant crack is necessary. Until a failure criterion is established, we assume a decrease in stress near a crack tip corresponds to increased strength.

\section{CONCLUSIONS}

In general, warp-fiber curvature and thermal stresses at low temperatures are beneficial in reducing crack stresses near the tip of a fill-fiber-bundle crack. Formation of fill cracks decreases the stiffness more for large warp-fiber curvatures than for smal1 curvatures. Hence, a tradeoff between stiffness and strength is evident when choosing warp-fiber curvature. The designer interested in woven structural laminate performance at low temperatures can improve performance by proper selection of materials and by choosing curvature for improved stiffness or strength.

\section{ACKNOWLEDGMENT}

This study was sponsored by the U.S. Department of Energy, Office of Fusion Energy. 


\section{REFERENCES}

1. M. B. Kasen, Composite laminate applications in magnetic fusion energy superconducting magnet systems, Proceedings of the 1978 International Conference on Composite Materials, AIME, Toronto, Canada (1978).

2. M. B. Kasen, G. R. MacDonald, D. H. Beekman, Jr., and R. E. Schramm, Mechanical, electrical, and thermal characterization of G-10CR and G-11CR glass/epoxy laminates between room temperature and $4 \mathrm{~K}$, Advances in Cryogenic Engineering, Vol. 26, Plenum Press, New York, pp. 235-244 $(1980)$.

3. M. B. Kasen and R. E. Schramm, Current status of standardized nonmetallic cryogenic laminates, Advances in Cryogenic Engineering, Vol. 28, Plenum Press, New York, pp. 271-177 (1981).

4. T. Ishikawa, Anti-symmetric elastic.properties of composite plates of satin weave cloth, Fiber Sci. Technol. 15: 127-145 (1981).

5. R. Y. Kim and H. T. Hahn, Effect of curing stresses on first ply failure in composite laminates, J. Compos. Mater. 13: 2-16 (1979).

6. R. M. Jones, Mechanics of Composite Materials, McGraw-Hi11, New York, pp. $147-173(\overline{1975})$.

7. K. Dahlerup-Petersen and A. Perrot, "Properties of Organic Composite Materials at Cryogenic Temperatures," CERN ISR-BOM/79-39, Geneva, Switzerland (1979).

8. Z. Hashin, "Theory of Fiber Reinforced Materials," NASA-CR-1974, NASA Langley Research Center, Hampton, Virginia (1972).

9. T. Ishikawa and T. W. Chou, Stiffness and strength behavior of woven fabric composites, J. Mater. Sci. 17: 3211-3220 (1982).

10. R. D. Kriz, Influence of ply cracks on fracture strength of graphite/epoxy laminates at $76 \mathrm{~K}$, "Effects of Defects in Composite Materials," American Society for Testing and Materials, Philadelphia, Pennsylvania (1982), in press.

11. C. E. Inglis, Stresses in a plate due to the presence of cracks and sharp corners, Trans. Inst. Nav. Architects, 55: 219-241 (1913).

12. A. A. Griffith, The phenomena of rupture and flow in solids, Philos. Trans. R. Soc. Lond. A221: 163-197 (1921). 


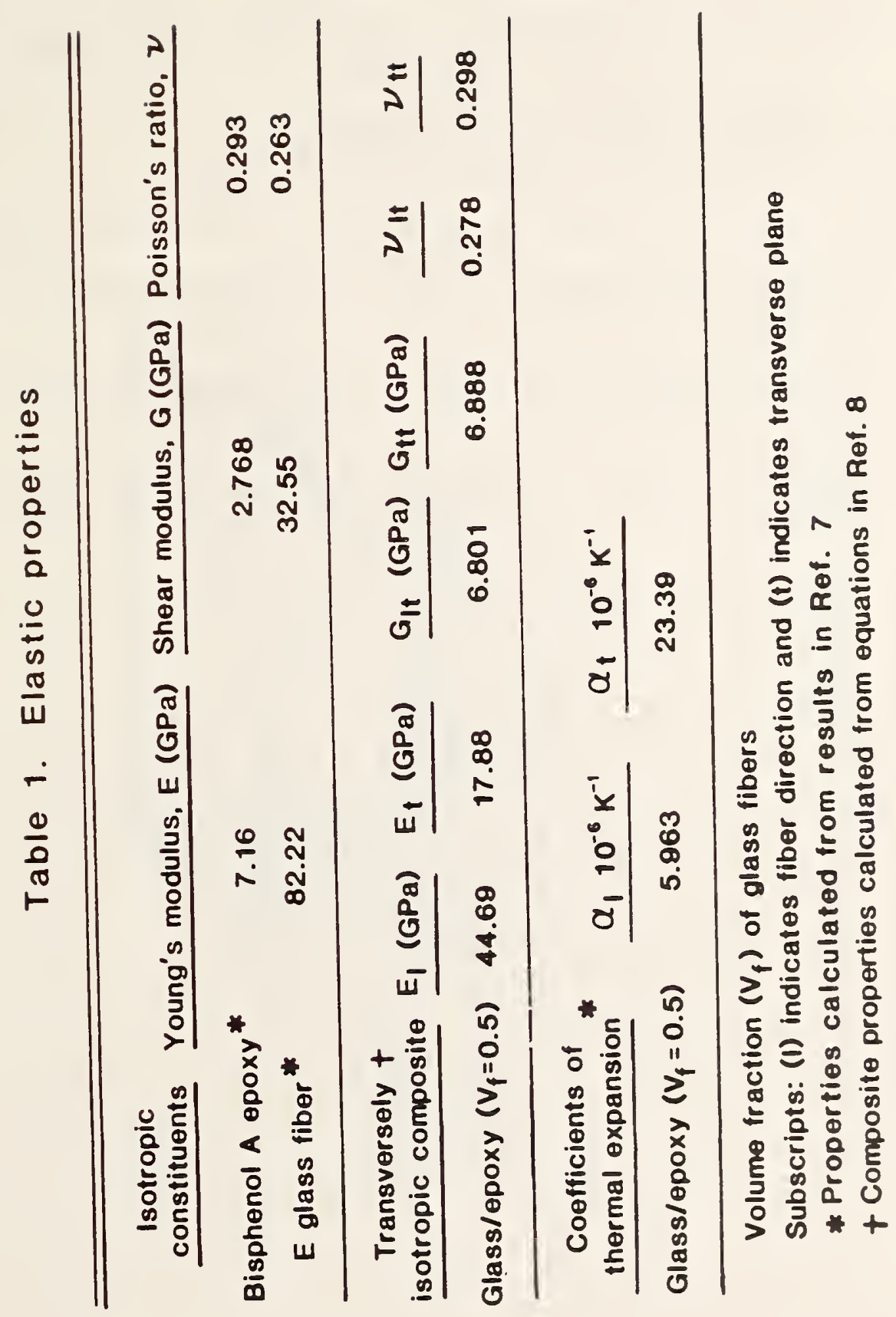




\section{LIST OF FIGURES}

Figure 1. Unit cell of woven-fabric composite.

Figure 2. Thin slice of unit cell. Theta denotes angle between warp-fiber orientation and the $x$ direction.

Figure 3a. [0/90]s laminate with $90^{\circ}$ ply crack.

3b. Two-layer. woven laminate with fill crack.

Figure 4. Influence of fill crack on woven unit cell Young's modulus.

Figure 5. Stress concentrations in warp fiber bundle above fill crack along 1 ine $a-b$ in Fig. 2 .

Figure 6. Stress concentrations in warp fiber bundle above fill crack along 1 ine $c-d$ in Fig. 2 .

Figure 7. Debond stresses in warp-fiber bundle above fill crack along line e-f in Fig. 2 . 


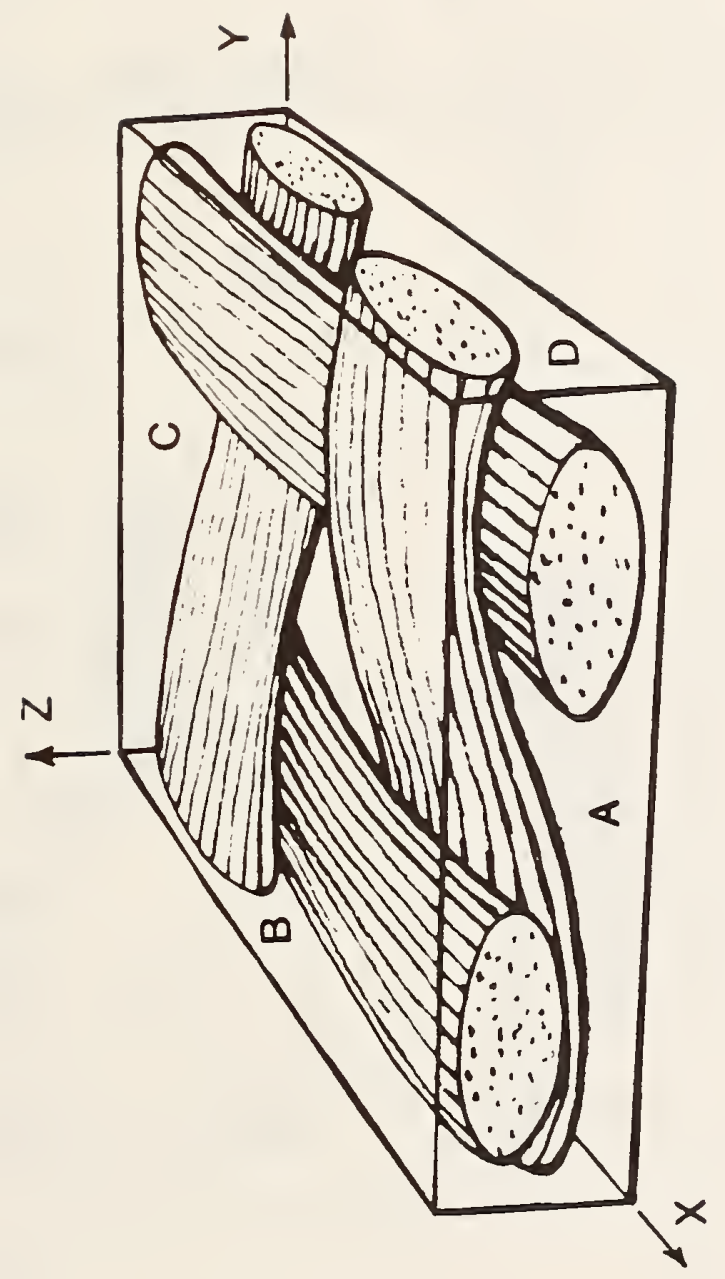

$\dot{0}$
+
$\tilde{0}$
0
हे
0

0
$\frac{1}{2}$
0
$\frac{0}{2}$
4
1
$\frac{1}{4}$
3
0
3

4

$\bar{g}$

点

㐫 


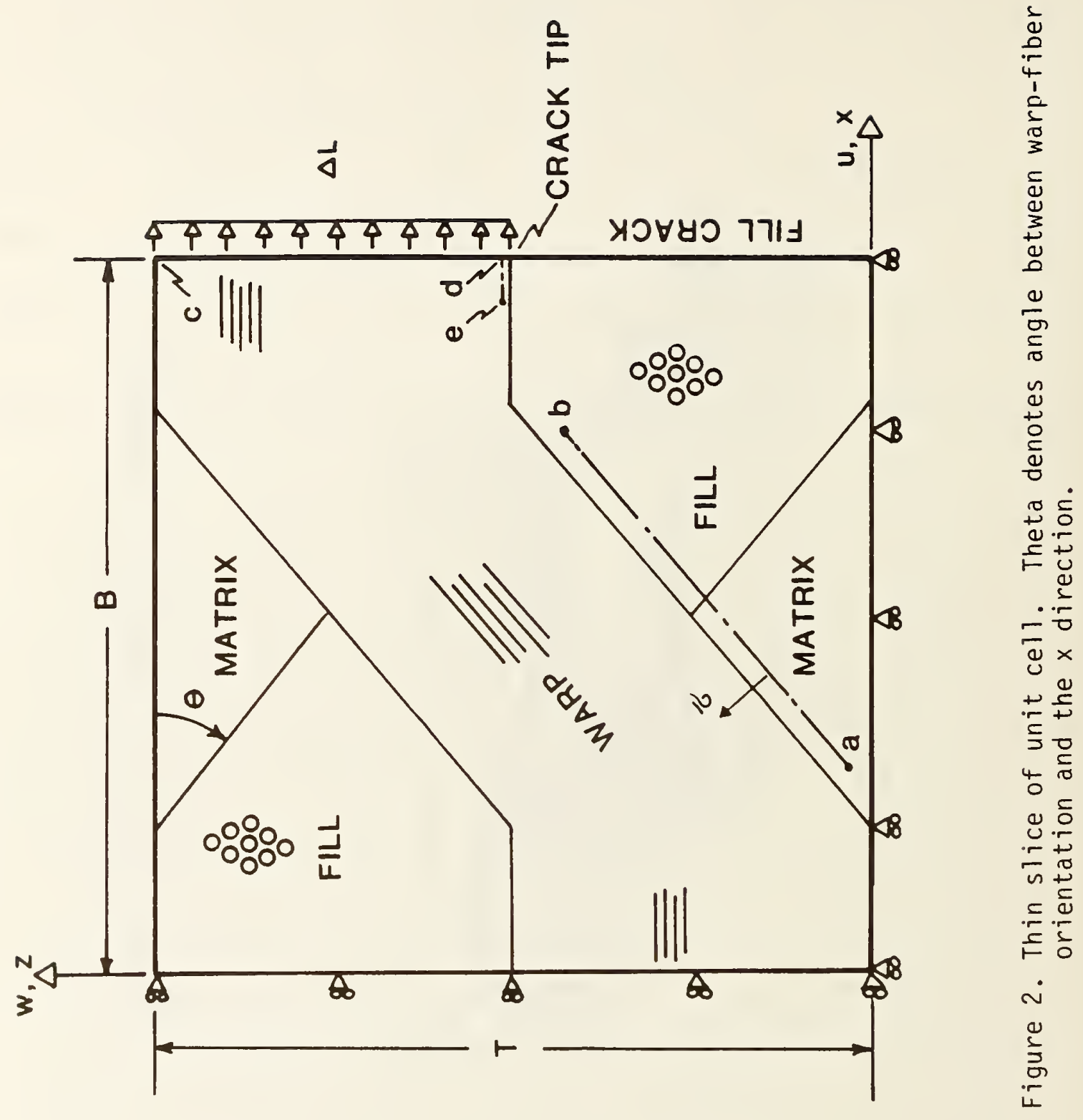



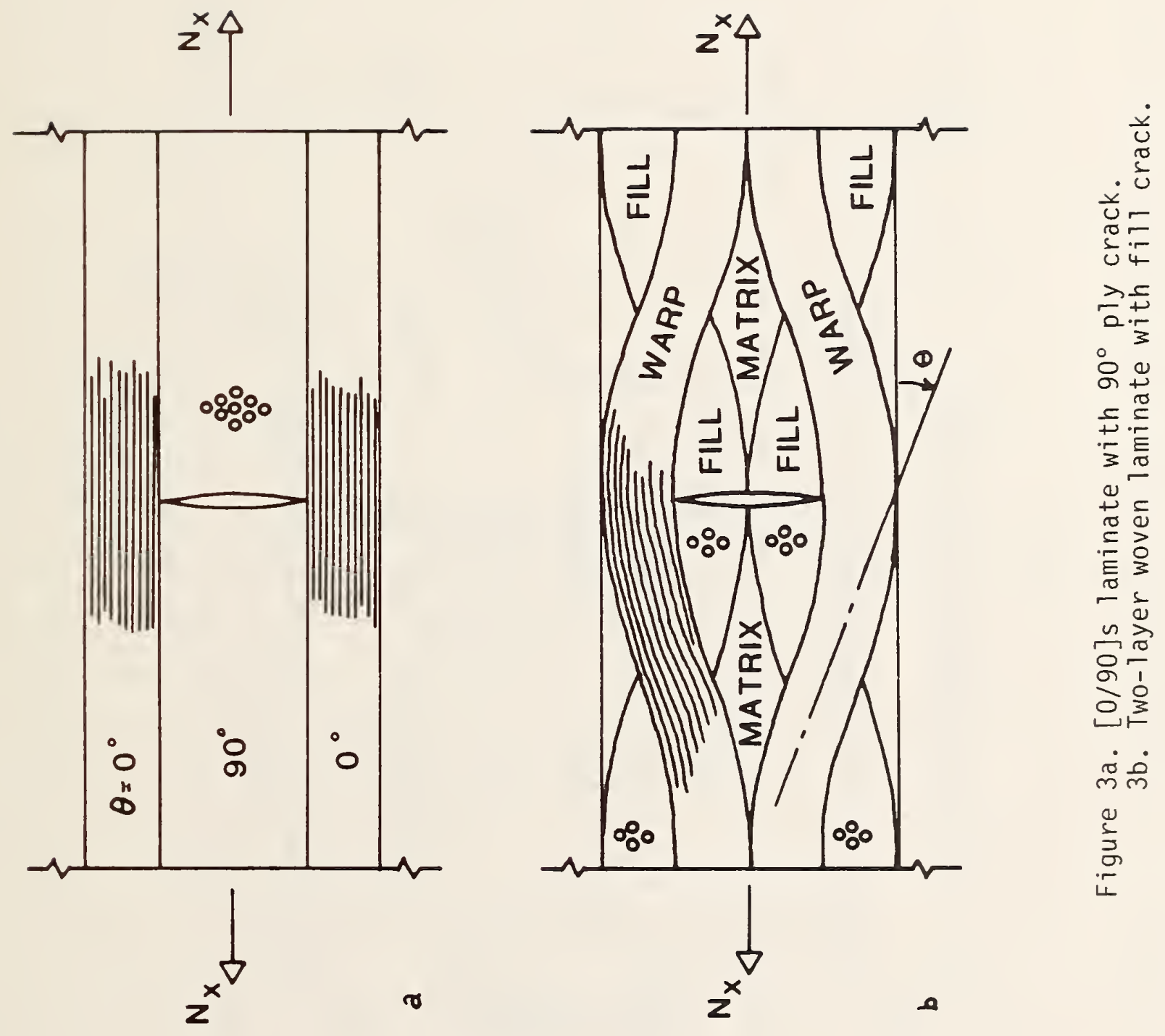


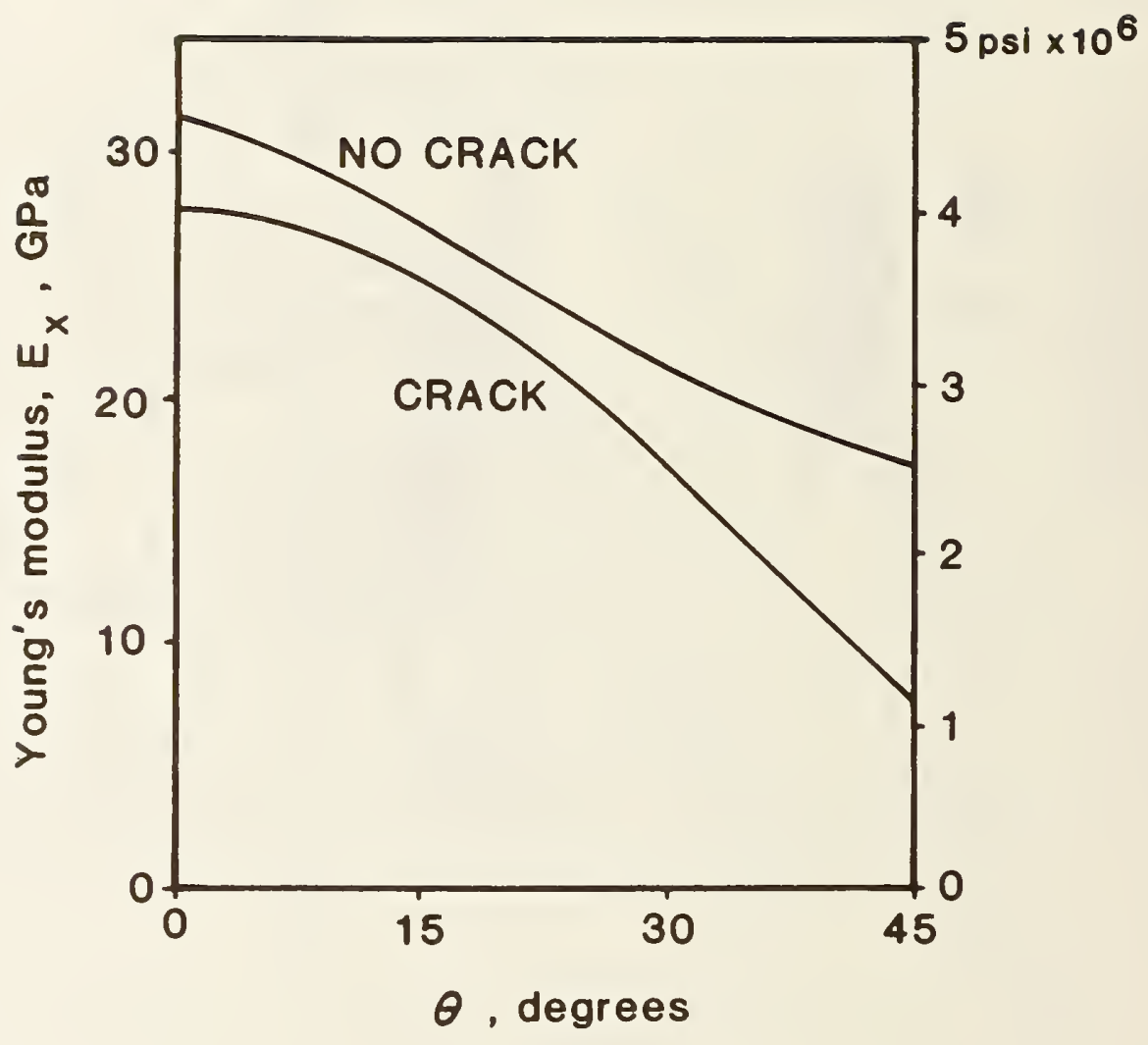

Figure 4. Influence of fill crack on woven unit cell Young's modulus. 


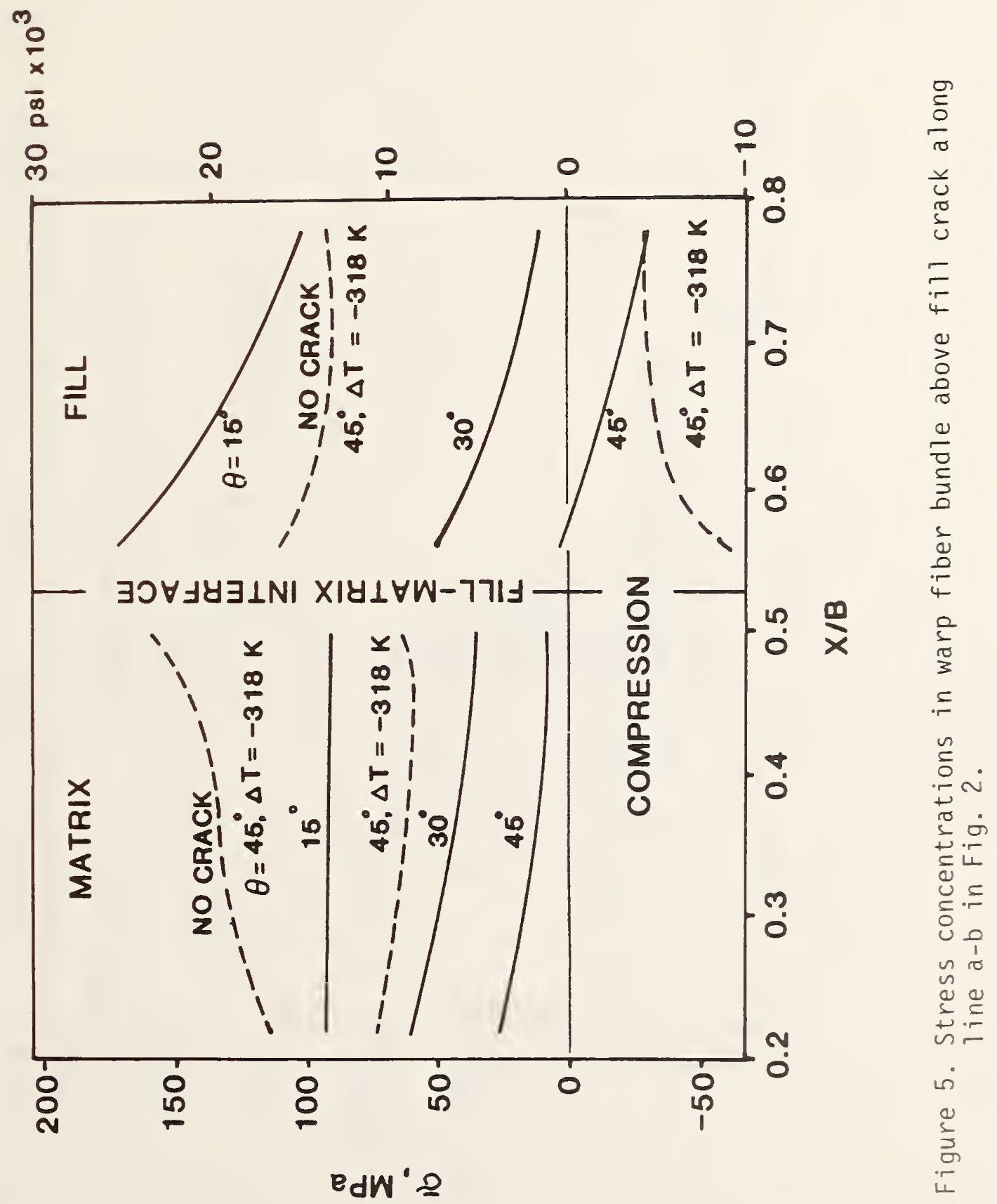




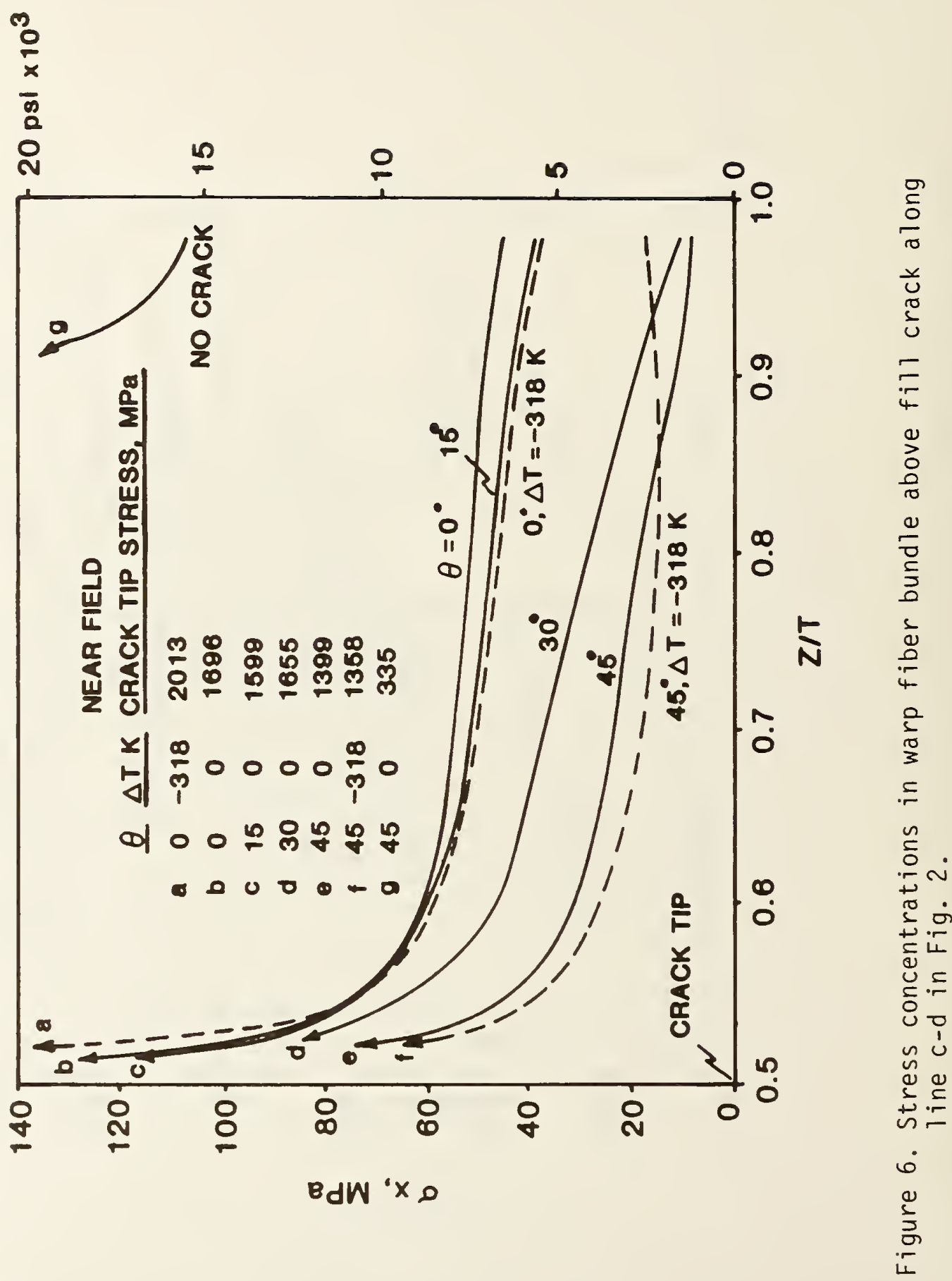




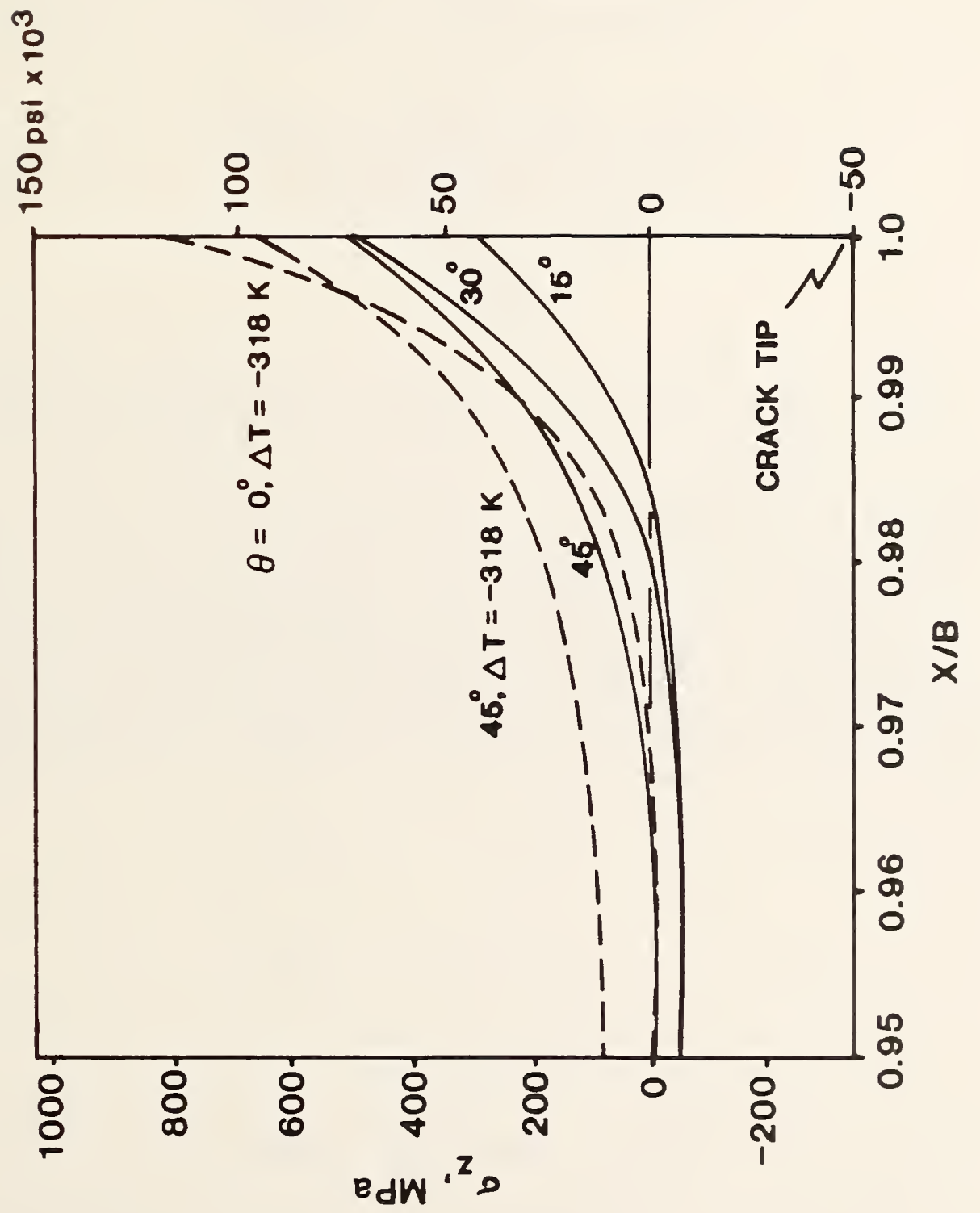





\section{NONMETALLIC MATERIAL STANDARDIZATION - \\ MATERIALS AND TEST METHODS ${ }^{*+}$ \\ M. B. Kasen \\ Fracture and Deformation Division \\ National Bureau of Standards \\ Boulder, Colorado}

\section{SUMMARY}

The industrial specification for production of the G-10CR grade of cryogenic high-pressure laminate has been revised and accepted by U.S. manufacturers. The objective was to make the specification as generic. as possible without adversely affecting performance and to add a material performance criteria to the specification. G-10CR and G-11CR products have been produced by five U.S. industrial laminating firms. No significant differences in cryogenic mechanical properties were found among G-10CR material produced by these manufacturers. This indicates that the specifications are fulfilling their intended purpose. An efficient system for producing research materials for systematic screening of the parameters influencing cryogenic radiation resistance was devised. Laboratories in Japan and England have agreed to actively cooperate with NBS in further development of this system.

*Work supported in part by the Office of Fusion Energy, U.S. Department of Energy.

+To be published in "Sixth Annual Progress Report on Special Pupropose Materials for Magnetically Confined Fusion Reactors," U.S. Department of Energy (1984). 

To provide, in cooperation with industry, controlled grades of stateof-the-art insulating laminates for superconducting magnet construction. To provide highly characterized test materials for studies to develop insulators of improved cryogenic radiation resistance. To stimulate international cooperation in nonmetallic insulator cryogenic radiation studies.

\section{PROGRESS AND STATUS}

Development of the CR grades of high-pressure industrial laminate reflected the need for commercial sources of controlled grades of laminates to be used in construction of developmental superconducting magnets. This was accomplished by NBS-industry development of component and processing specifications for NEMA G-10 and G-11 type materials having minimal performance variability at 4 K. This minimal variability was confirmed by laboratory testing. Radiation resistance was not optimized for these materials.

The requirements for test specimens to be used in screening of parameters affecting radiation resistance at $4 \mathrm{~K}$ were defined and consideration was given to the most efficient method of their production. A common approach has been agreed upon by NBS, the Rutherford Laboratory (UK) and Osaka University (Japan). Each laboratory will construct a similar apparatus and will compare results.

\section{DEVELOPMENT OF CR-GRADE INSULATING LAMINATES}

Specification revision. The CR-grade insulating laminates are high-quality, glass-fabric reinforced epoxy products representative of the best high-pressure industrial laminates currently produced in the United States. They are distinguished from conventional NEMA G-10 and G-11 products by being produced to component and manufacturing process specifications commonly agreed upon by the industry. This approach was required because the conventional NEMA grades are generic products providing specified electrical performance at room temperature. These criteria can be met by a variety of laminate components and production methods that introduce significant performance variability at cryogenic temperature.

The original specifications as established in 1978 required use of a specific manufacturer's epoxy resin and permitted only one type of finish to be used on the glass fabric. The laminating industry found this to be unnecessarily restrictive, as chemically and functionally equivalent epoxy resins and finishes were available from other manufacturers. The G-10CR specification was therefore modified at industry request to permit use of the functionally equivalent products.

The original specifications did not contain minimum performance criteria because such data were not available and manufacturers did not have the capability of testing at cryogenic temperatures. However, several users of the CR materials expressed a desire to have a performance criteria. This has been done by adding minimum requirements for mechanical, physical, and electrical properties at room temperature. All specification modifications have been reviewed and accepted by the manufacturers. 
Variability analysis. G-10CR laminates produced by five United States laminating firms were tested in tension, compression, and interlaminar shear at $295 \mathrm{~K}$ and $76 \mathrm{~K}$ to assess variability among manufacturers. Only the warp direction in the plane of the laminate was considered.

The results, obtained by procedures described el sewhere, 1 are summarized in Table 1. This Table reports averages, standard deviations, and coefficients of variation for the nine to eleven specimens tested in assessing each parameter. Lower tolerance limits on the properties are also reported, based on confidence limits of $99 \%$ and a confidence coefficient of 0.95 . Assuming that the distribution of test results is normal, and that the materials evaluated are representative of commercial products produced by each company, there is a $95 \%$ probability that $95 \%$ of the production will produce values higher than the lower tolerance limits. The assumption of a normal distribution of strength properties may be questioned--in particular, at cryogenic temperatures where the matrix becomes embrittled. However, there were insufficient data to justify assuming a different distribution, and the error introduced by the assumption is believed to be very small.

Table 1 Performance of G-10CR Cryogenic Grade Insulating Laminates

\begin{tabular}{|c|c|c|c|c|}
\hline Property & Average & $\begin{array}{l}\text { Standard } \\
\text { deviation }\end{array}$ & $\begin{array}{l}\text { Coefficient } \\
\text { of variation }\end{array}$ & $\begin{array}{l}\text { Lower } \\
\text { tolerance } \\
\text { limit } 1\end{array}$ \\
\hline
\end{tabular}

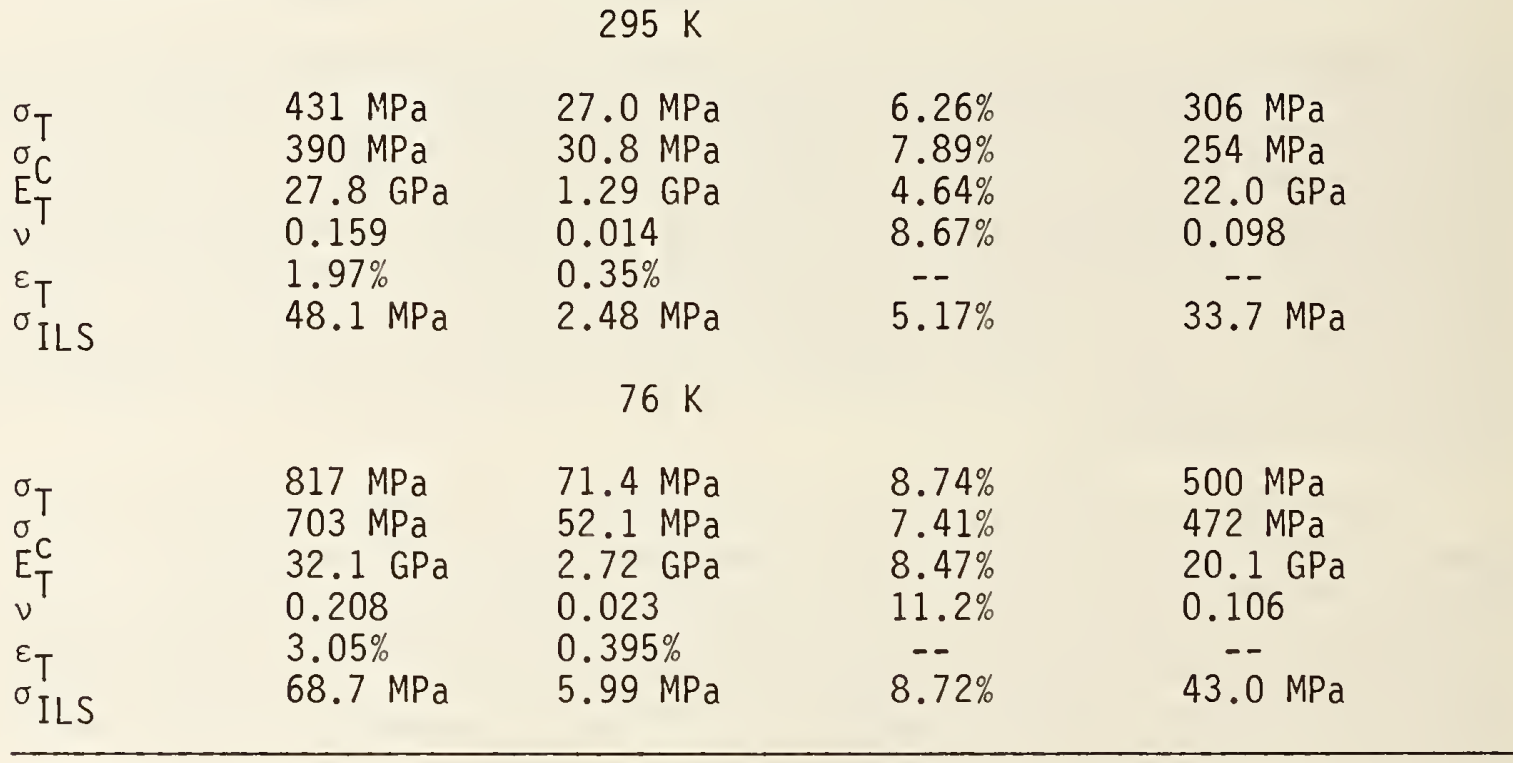

${ }^{1}$ Confidence 1 imits $99 \%$, confidence coefficient 0.95

Data on the coefficient of variation and on lower tolerance limits for tensile strain at failure are not reported because failure of the strain gauges at stresses below maximum required that this parameter be estimated from a strip recording. This significantly reduced the accuracy of the measurements, and precluded a determination of a meaningful variability. 
When applied to a single production lot of G-10CR, our test procedures produced coefficients of variation of about $4 \%$ for tensile strength, Young's modulus, and shear strength, and about $9 \%$ for compressive strength, Poisson's ratio, and failure strain. This suggests that the coefficients of variation in the present study primarily reflect uncertainties in the test procedure and intrinsic material variability. It is therefore concluded that differences in room or cryogenic mechanical performance of products produced to the G-10CR specification by different companies are probably not statistically significant. The specification therefore appears adequate to ensure the desired product uniformity.

The coefficient of variation is higher at $76 \mathrm{~K}$ than at $295 \mathrm{~K}$ for most properties. This is an expected consequence of matrix embrittlement, which severely 1 imits the operative relaxation processes, making the strength properties more sensitive to the presence of small flaws. Residual stresses combined with the possibility of microcracking also increase the variability in the elastic properties at cryogenic temperatures as compared to room temperature. Although not determined, it is probable that the coefficient of variation would be somewhat higher at $4 \mathrm{~K}$ than at $76 \mathrm{~K}$.

Recent data have suggested that the compression specimen used in this study may be sensitive to edge effects, and that the average and lower tolerance limits for this parameter may be lower than those of bulk material. It is probable that the interlaminar shear values are also conservative because available methods for testing this parameter can only approximate a pure shear condition.

Research Materials. The objective is to produce an efficient specimen for screening the parameters influencing performance of organic insulators under neutron and gamma irradiation at $4 \mathrm{~K}$. These data will then be used to design functional insulating laminates to meet the requirements of specific magnet designs.

The desired specimen characteristics are as follows:

-small size

-minimal edge effects

-neat or reinforced resin

-easily varied components

-highly characterizable
- simple and inexpensive

-adaptable to a variety of tests

-simple stress analysis

- compatible with test facilities

at different laboratories

These requirements reflect the space limitations in the test reactor and the large number of variables that must be investigated. Examples are type, cure state, and purity of the resin and type, density and finish of the fiber. The effect of residual stress must also be investigated.

Samples machined from fabric-reinforced laminates are deficient in almost all of the desired specimen characteristics. Furthermore, it is not possible to make a meaningful comparison of data among laboratories testing laminates of different construction. It is therefore concluded that the desired characteristics can only be met by the specimens containing uniaxial fiber reinforcement. 
Such specimens could be machined from uniaxial panels produced from preimpregnated tape. This approach would be adaptable to all resins and fibers of interest. However, the cost would be very high if a large number of variables are to be evaluated. Also, additional variability would be introduced from machined surfaces, imprecise fiber alignment and from residual molding stresses.

A more efficient approach appears to be offered by the production method illustrated in Fig. 1. A system based on this principle is presently under construction at NBS-Boulder. Here, resin-wetted fiber strand bundles are pulled into a tube mold by a drawing wire and are in-situ cured. After removal from the mold, the rods may be cut to the desired length and tested without further machining. Neat resin specimens may be produced by drawing resin up the tube and curing. A typical as produced rod would be $3.2 \mathrm{~mm}$ in diameter and $500 \mathrm{~mm}$ long. Several rods can be produced simultaneously. This technique is routinely used by industry to produce experimental glass-reinforced polyester specimens. Production of epoxy matrix specimens is not straightforward due to the lower shrinkage of epoxies on curing which increases problems in specimen removal from the mold. Nevertheless, as illustrated in Fig. 2 , use of a proper mold release agent can overcome this problem. The method is most easily used with resin systems that are liquid at room temperature. Hot melt resin systems present more difficulties; however, it is believed that most of the problems can be overcome by proper technique. Should this not be possible, the required specimens could always be produced by the more expensive flat plate laminating process.

The suggested specimen configuration is well adapted for testing in flexure and compression, and it can be directly used in dynamic resonance experiments to assess the state of internal damage. It is also very adaptable to use in test apparatus permitting the sequential cryogenic testing of a number of specimens without warmup of the test fixture. Its simplicity facilitates a quantitative correlation between internal stress state and damage, and the economy of production permits a large number of variables to be studied at a very low cost.

International Cooperation. Cooperative efforts to develop and refine a specimen production method based on the principle illustrated on Fig. 1 are underway between NBS, the Rutherford Appleton Laboratory, UK, (Dr. David Evans) and the Institute of Science and Industrial Research, Osaka University, Japan (Dr. Shigehiro Nishijima). Each facility will build its version of the proposed method. The first task will be to determine if the systems developed in each laboratory are capable of producing functionally the same test material. This will be done by each producing specimens using a commonly agreed upon resin system, fiber type, fiber content, and cure cycle. Resin and processing conditions will be provided by the Rutherford Laboratory. Fiber will be provided by the Owens-Corning Research Laboratory. Owens-Corning will also provide the analysis of each laboratory's production.

If this effort is successful, the next step will be to address commonality in test methodology and in approaches to analyzing test data. It is anticipated that this will eventually lead to more detailed cooperative programs involving materials selection and radiation conditions. 


\section{REFERENCES}

1. M. B. Kasen, G. R. MacDonald, D. H. Beekman, and R. E. Schramm, "Mechanical, Electrical, and Thermal Characterization of G-10CR and G-11CR Glass

Cloth/Epoxy Laminates Between Room Temperature and $4 \mathrm{~K}$, Adv. Cryo. Engr. $26: 235(1980)$. 


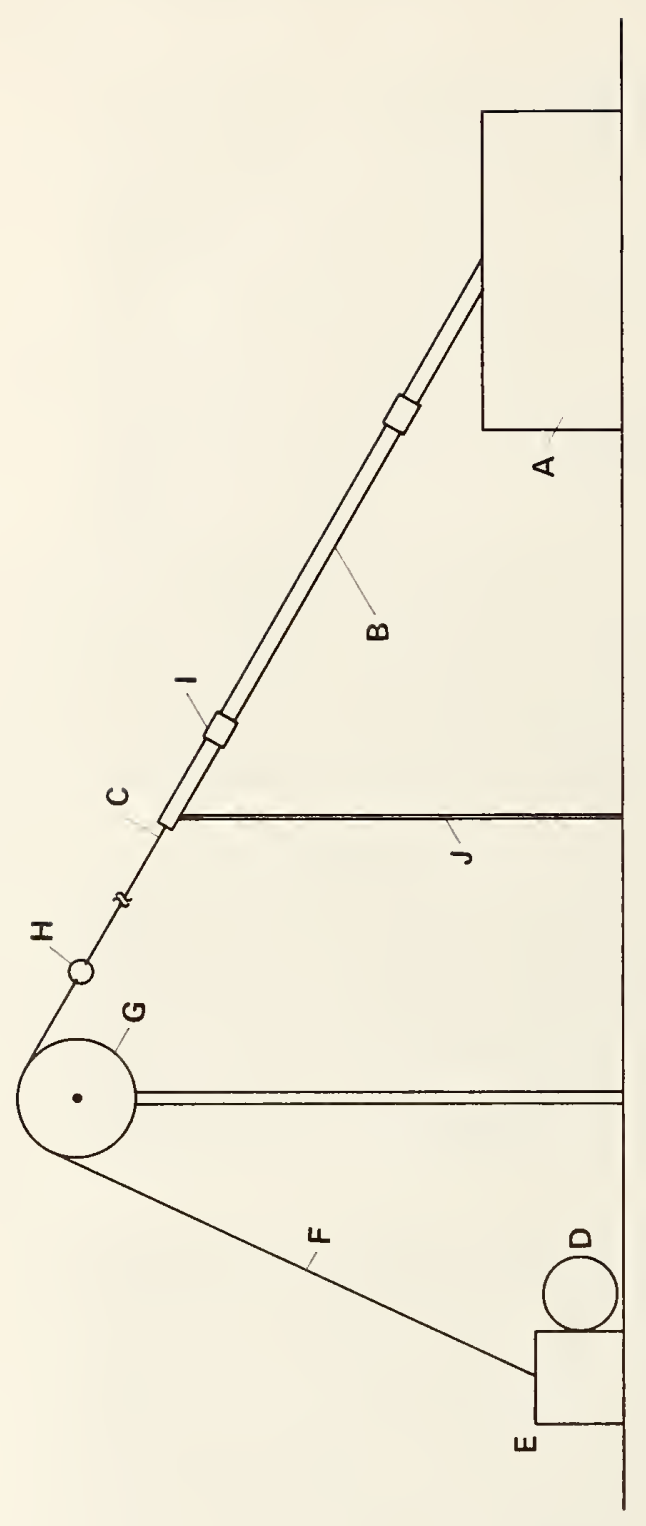

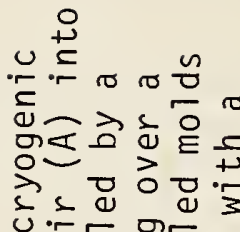
u.

< $>0.5 \div$. O $1<$ 的 4 - ये ข 50

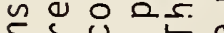
造的红 药

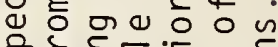

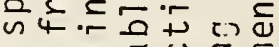
ه त ब 3 व 斤

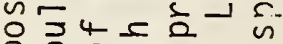
믕ํㅇㅁㅇ E

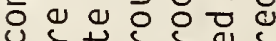
ठ 的的 $\therefore$ 응

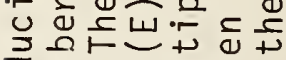
त्रा

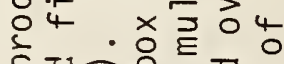
चல̃ 능 ○ $+\square$

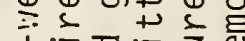

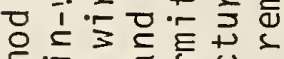

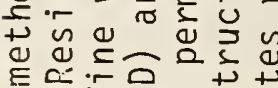
4 4 응 ¿ே.

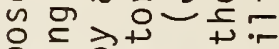
ک வ

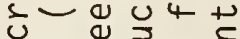

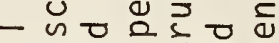

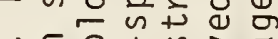

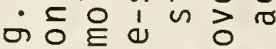
4 -

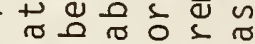
$\therefore \frac{\pi}{3} \cdot \pi$

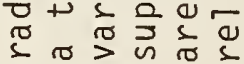



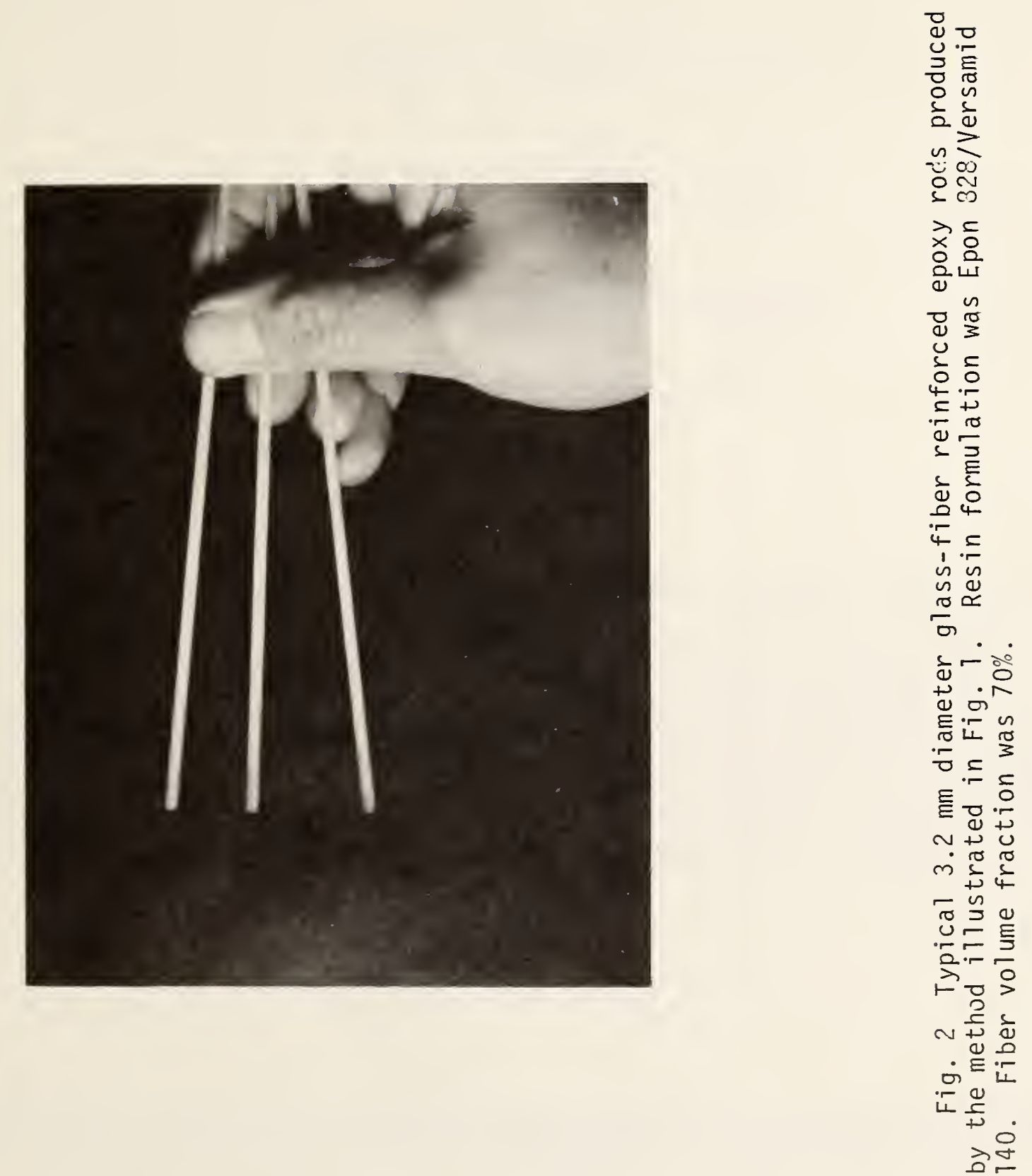

MECHANICAL PROPERTIES OF CONCRETE MORTAR AT LOW TEMPERATURES ${ }^{*}+$

\author{
J. M. Arvidson \\ Fracture and Deformation Division \\ National Measurement Laboratory \\ L. L. Sparks \\ Thermophysical Properties Division \\ National Engineering Laboratory \\ E. Steketee \\ Fracture and Deformation Division \\ National Measurement Laboratory \\ National Bureau of Standards \\ Boulder, Colorado
}

\title{
ABSTRACT
}

This report includes test results conducted at ambient (295 K), dry-ice and alcohol (195 K), liquid nitrogen (76 K), and liquid helium (4 K) temperatures. The compressive properties reported are Young's modulus, yield (at $0.2 \%$ offset) and maximum strengths, and elongation (elastic and plastic). Test specimens $(5.1 \mathrm{~cm}$ diameter $\times 10.2 \mathrm{~cm})$ were instrumented with a specially designed, diametrically opposed, cryogenic strain-gaged extensometer that minimizes possible errors due to specimen bending during the test.

Key Words: Compressive strength; concrete mortar; elongation; low temperature; maximum strength; mechanical properties; yield strength; Young's modulus.

\footnotetext{
* Supported by the Maritime Administration, U. S. Department of Commerce and Office of Fusion Energy, U. S. Department of Energy.

†Published as report number NBSIR 82-1658, National Bureau of Standards, Boulder, Colorado (1982).
} 



\section{Introduction}

Concretes are attractive materials for construction of large low-temperature installitions because of lower material cost and economies of fabrication compared to alternaLive construction methods. Furthermore, they exhibit favorable mechanical and thermal properties for use in low-temperature applications. Although these materials are presencly used to some extent in LNG and LPG construction, lack of confidence in their cryogenic behavior has restricted their use or has resulted in overly conservative and expensive designs. This reflects the lack of dependable cryogenic thermal and mechanical properties data and a poor understanding of the effect of field-fabrication variables on cryogenic performance.

Potential LNG- or LPG-oriented applications of concretes are diverse. Concrete is currently used for barge hulls and for ground-based storage facilities [1,2]. Proposals and designs for construction of large seagoing tankers and floating terminals, in which both the hull and the primary LNG containment systems are made of concrete, are also being considered. Possible applications of special concretes such as lightweight, cellular, fiber reinforced, and polymer will depend on their cryogenic properties which are not known at this time.

The research described below is part of a broader program to determine the thermal and mechanical properties of aggregate composites. The mechanical properties of two concrete mortars were determined at ambient (295 K), dry-ice and alcohol (195 K), 1 iquid nitrogen $(76 \mathrm{~K})$, and liquid helium $(4 \mathrm{~K})$ temperatures. The properties reported here are compressive Young's modulus, yield strength (at $0.2 \%$ offset), maximum, ultimate, flexural, and splitting strengths, $\mathrm{K}_{\mathrm{Ic}}$, and elastic and plastic elongations.

\section{Materials Characterization}

The physical properties of two concrete mortars (designated mix 1 and mix 2 ) were studied in this program. Mix 1 was made by a commercial-cement company and mix 2 was made at the National Bureau of Standards. Both mixes utilized portland type I cement and a resin air-entraining agent. The aggregate used in mix 1 is commonly known as Elgin sand and that used in mix 2 is commonly referred to as Clear Creek sand. The chemical makeup and sieve analysis of each type of aggregate are shown in tables 1 and 2 . Both mortars were mixed using the following ratios (by weight): water/cement $=0.5$, aggregate/cement $=3.4$. The air content of the hardened mortars was 11.0 and 17.7 vol.\%, respectively, and the evaporable moisture contents were 8.1 and $10.8 \mathrm{wt} . \%$ relative to the oven-dry weight. The mixing procedure described in ASTM C192 was utilized for both mixes.

Mix 1 was designed to produce a mortar with a compressive strength of approximately 17.2 $\mathrm{MPa}$ (2500 psi). To maintain this strength until testing, the 10-day-old specimens were placed in a freezer held at $0^{\circ} \mathrm{C}$. The hydration process, which causes concretes to increase in strength as they age, is slowed considerably at this temperature. Prior to the $0^{\circ} \mathrm{C}$ aging, the specimens were aged in covered glass molds for $24 \mathrm{~h}$ at $23^{\circ} \mathrm{C}$ and then removed from the molds and placed in saturated-1ime water at $23^{\circ} \mathrm{C}$ for 7 days. L'pon removal from the lime-water bath, they were wrapped in plastic and aluminum foil for shipment. 
Table 1. Primary components of aggregates by percentage of particle count remaining on standard sieves.

\begin{tabular}{|c|c|c|c|c|}
\hline Mix & Component & $\begin{array}{l}\text { No. } 8 \\
(2.36 \mathrm{~mm})\end{array}$ & $\begin{array}{c}\text { tandard Si } \\
\text { No. } 16 \\
(1.19 \mathrm{~mm})\end{array}$ & $\begin{array}{c}\text { No. } 30 \\
(0.60 \mathrm{~mm})\end{array}$ \\
\hline \multirow[t]{7}{*}{1} & Carbonate & 80.3 & 79.8 & 64.3 \\
\hline & Chert & 8.9 & 11.0 & --- \\
\hline & Granite & 3.6 & 2.4 & ---- \\
\hline & Basalts & 3.4 & 2.0 & 1.2 \\
\hline & Quartzite & 3.0 & 4.3 & --- \\
\hline & Quartz-Chalcedony & ---- & --- & 26.5 \\
\hline & Feldspar & ---- & ---- & 7.6 \\
\hline \multirow[t]{5}{*}{2} & Granite & 67.4 & 66.4 & 33.2 \\
\hline & Metamorphics & 7.2 & 3.7 & 1.5 \\
\hline & Basalts & 6.8 & 2.7 & 1.8 \\
\hline & Quartz & 12.4 & 17.2 & 44.9 \\
\hline & Feldspar & 5.7 & 7.2 & 15.9 \\
\hline
\end{tabular}

Table 2. Sieve analysis of the aggregates used in mix 1 and $\operatorname{mix} 2$.

\begin{tabular}{rrrr} 
Number Standard Sieve & \multicolumn{2}{c}{$\begin{array}{c}\text { Percent Passing } \\
\text { Sizix } 2 \\
\text { (Elgin) }\end{array}$} \\
\hline 4 & 4.75 & 100 & 99 \\
8 & 2.36 & 78 & 80 \\
16 & 1.18 & 63 & 59 \\
30 & 0.60 & 46 & 29 \\
50 & 0.30 & 10 & 7 \\
100 & 0.15 & 0 & 0 \\
\hline
\end{tabular}

Mix 2 was made in two batches separated by 8 months. Mix design and conditioning for both batches were identical. The mortar was formed in airtight plastic molds and aged in the mold for 2 days at $23^{\circ} \mathrm{C}$. After removal from the molds, the specimens were immersed in a saturated lime-water bath at $23^{\circ} \mathrm{C}$. They remained in the bath until tested. The age of the specimens at the time of testing was from 79 to 215 days.

\section{Specimens}

The solid core specimen geometry was chosen for the compression and splitting strength tests; specimens measured $5.1 \mathrm{~cm}$ in diameter and $9.9 \mathrm{~cm}$ long, as recommended by ASTM C469-65, C496-71, and C873-77T. The flexural strength test specimens were $10.1 \mathrm{~cm} \times 1.8 \mathrm{~cm} \times 4.6 \mathrm{~cm}$ per ASTM $\mathrm{C} 78-75$.

The ends of all specimens to be tested in compression were ground parallel and perpendicular to the longitudinal axis to within $\pm 6.3 \times 10^{-4} \mathrm{~cm}$. All mix 1 samples were completely saturated with lime-water solution and then kept at $0^{\circ} \mathrm{C}$ until the time for testing. All mix 2 specimens were stored in a lime-water solution and were removed just prior to testing.

\section{Test Procedure}

Tests were performed using a commercial $1.0 \mathrm{MN}\left(2.2 \times 10^{5} \mathrm{lbf}\right)$ servohydraulic static/fatigue test machine. The manufacturer's specifications indicate that the load 
weiphing system accuracy is $\pm 0.5 \%$ of indicated load or $\pm 0.25 \%$ of the load range in use, whichever is greater, on all load ranges. The crosshead speed used for all tests was $0.005 \mathrm{~cm} / \mathrm{min}$ and is accurate to $\pm 0.1 \%$ of set speed at all loads and speeds. Compression sperimens were instrumented with specially designed, diametrically opposed cryogenic strain-gage extensometers. This method for sensing strain worked at all temperatures, including total immersion in liquid nitrogen and liquid helium. Prior to each test, particular care was taken to insure coaxial alignment of all test components (e.g., actuator ram, specimen, dewar) to insure uniaxial loading.

Specimen failure modes indicated a well-aligned system with a minimum of bending, i.e., uniform, conically shaped fractures emanating from the specimen ends to the center.

Some testing was carried out to determine plane strain fracture toughness of mix 2 . Shurt-rod specimens with a single chevron in the configuration proposed by Barker and Baratta [3] were prepared. The diameter was $5.1 \mathrm{~cm}$ and the length was $10.2 \mathrm{~cm}$. Testing at all temperatures was carried out in a newly designed fixture that operates like a pinch-type clothespin to load the chevron-notched specimen in tension.

This fixture has a lever-arm ratio of $2: 1$ and can be fitted into most universaltesting machines. The plane strain fracture toughness, $K_{I C} S R$, was calculated using the following equation proposed by Baker and Baratta [3] and modified by Beech and Ingraffea [4]:

$$
K_{I C} S R=\frac{A P}{B^{3 / 2}}
$$

where $\mathrm{A}$ is a dimensionless calibration constant $22.5 \pm 15 \%$ (dependent on specimen geometry), $\mathrm{P}_{C}$ is the load at crack instability, and $B$ is the specimen diameter.

With one exception the specimens fractured across the chevron; one specimen fractured in the body of the specimen.

\section{Results}

The compressive Young's modulus for mix 1 increased in value from room temperature to $195 \mathrm{~K}$, and then at 76 and $4 \mathrm{~K}$ it decreased by approximately 30 percent (table 3 ). The compressive strength, however, increased as the test temperature decreased. Also, only at $195 \mathrm{~K}$ did mix 1 show a maximum compressive strength before reaching its ultimate.

The compressive modulus, proportional limit, and ultimate compressive strength for mix 2 all increased in value as the test temperature decreased (table 4). As shown in table 5, the splitting tensile strength increased from 295 to $195 \mathrm{~K}$ and then remained the same down to $76 \mathrm{~K}$. The modulus of rupture (flexural strength), however, shows a peak value at $195 \mathrm{~K}$.

The plane strain fracture toughness, $\mathrm{K}_{\mathrm{IC}} \mathrm{SR}$, for short-rod specimens of mix 2 are tabulated vs. temperature in table 6 . The room temperature results on moist mix 2 mortar are comparable to the fracture toughness reported for two kinds of rock [5]:

\begin{tabular}{|c|c|c|}
\hline \multirow{2}{*}{$\begin{array}{l}\text { TYPE OF } \\
\text { ROCK } \\
\end{array}$} & \multicolumn{2}{|c|}{$\mathrm{K}_{\mathrm{IC}} \mathrm{SR}$} \\
\hline & $\mathrm{MPa} \cdot \mathrm{m}^{1 / 2}$ & psi.in $1 / 2$ \\
\hline $\begin{array}{c}\text { Limestone } \\
\text { Granite }\end{array}$ & $\begin{array}{l}0.99 \\
2.48\end{array}$ & $\begin{array}{r}900 \\
2250\end{array}$ \\
\hline
\end{tabular}

The results in table 6 show that there was a substantial increase in $K_{\text {I }} S$ as temperature was lowered initially, but no additional increases as temperature was lowered further. Splitting strength showed the same trend with decreasing temperature. It is likely that the pronounced increase in toughness with decreasing temperature is related to changes in the internal structure of the moist specimens as the water entrained in the pores frecus 
and expands and then contracts with further cooling. Monfore and Lentz [6] discuss possible effects of freezing on concrete.

The plane strain fracture toughness of mix 2 mortar (table 6) is low compared to the fracture toughness of structured steels i.e., $54.9 \mathrm{MPa} \cdot \mathrm{m}^{1} 2$ (50 $\mathrm{ksi} \cdot \mathrm{in}^{1}{ }^{2}$ ). This comparison suggests that concrete is not a suitable structural material under tensile loading. Nevertheless, the low cost and widespread availability of concrete may favor its application in compressive-loading situations.

Table 3. Effect of temperature on compressive Young's modulus and compressive strength for moist concrete mortar (mix 1 ).

\begin{tabular}{|c|c|c|c|c|c|c|c|}
\hline \multirow{2}{*}{$\begin{array}{c}\text { Test } \\
\text { Temperature } \\
K\end{array}$} & \multicolumn{3}{|c|}{$\begin{array}{l}\text { Compressive } \\
\text { Young's Modulus }\end{array}$} & \multicolumn{4}{|c|}{ Compressive Strength } \\
\hline & & $\mathrm{GPa}$ & ksi & $\mathrm{MPa}$ & ksi & $\mathrm{MPa}$ & ksi \\
\hline 295 & $\bar{x}=$ & $\begin{array}{r}15.9 \\
8.6 \\
22.4 \\
15.6\end{array}$ & $\begin{array}{l}2300 \\
1250 \\
3250 \\
2270\end{array}$ & $\begin{array}{l}---- \\
---- \\
----\end{array}$ & $\begin{array}{l}---- \\
---- \\
----\end{array}$ & $\begin{array}{l}23.0 \\
21.8 \\
23.4 \\
22.7\end{array}$ & $\begin{array}{l}3.34 \\
3.16 \\
3.40 \\
3.30\end{array}$ \\
\hline 195 & $\bar{x}=$ & $\begin{array}{l}27.2 \\
---- \\
38.1 \\
----- \\
32.7\end{array}$ & $\begin{array}{l}3950 \\
---- \\
5530 \\
---- \\
4740\end{array}$ & $\begin{array}{l}---- \\
56.5 \\
49.1 \\
57.4 \\
54.3\end{array}$ & $\begin{array}{l}---- \\
8.20 \\
7.12 \\
8.32 \\
7.88\end{array}$ & $\begin{array}{l}---- \\
53.8 \\
47.6 \\
56.9 \\
52.8\end{array}$ & $\begin{array}{l}---- \\
7.81 \\
6.90 \\
8.25 \\
7.65\end{array}$ \\
\hline 76 & $\bar{x}=$ & $\begin{array}{l}14.3 \\
31.0 \\
17.7 \\
\frac{22.8}{21.5}\end{array}$ & $\begin{array}{l}2070 \\
4490 \\
2570 \\
3300 \\
3110\end{array}$ & $\begin{array}{l}---- \\
---- \\
---- \\
----\end{array}$ & $\begin{array}{l}---- \\
---- \\
---- \\
----\end{array}$ & $\begin{array}{r}71.1 \\
107.8 \\
90.9 \\
87.9 \\
89.4\end{array}$ & $\begin{array}{l}10.31 \\
15.64 \\
13.18 \\
12.75 \\
12.97\end{array}$ \\
\hline 4 & & 23.0 & 3340 & ---- & ---- & ---- & ---- \\
\hline
\end{tabular}

to Maximum: maximum stress the specimen reached during the test.

to Ultimate: stress at failure.

Table 4. Effect of temperature on compressive properties for moist concrete mortar (mix 2).

\begin{tabular}{|c|c|c|c|c|c|c|c|}
\hline \multirow{2}{*}{$\begin{array}{c}\text { Test } \\
\text { Temperature } \\
\mathrm{K}\end{array}$} & \multicolumn{3}{|c|}{$\begin{array}{l}\text { Compressive } \\
\text { Young's Modulus }\end{array}$} & \multicolumn{2}{|c|}{$\begin{array}{l}\text { Proportional } \\
\text { Limit }\end{array}$} & \multicolumn{2}{|c|}{$\begin{array}{c}\text { Ultimate Compressive } \\
\text { Strength }\end{array}$} \\
\hline & & $\mathrm{GPa}$ & ksi & $\mathrm{MPa}$ & ksi & $\mathrm{MPa}$ & ksi \\
\hline 295 & $\bar{x}=$ & $\begin{array}{l}15.25 \\
19.80 \\
17.26\end{array}$ & $\begin{array}{l}2210 \\
2800 \\
2510\end{array}$ & $\begin{array}{l}14.45 \\
15.65 \\
15.05\end{array}$ & $\begin{array}{l}2.10 \\
2.27 \\
2.19\end{array}$ & $\begin{array}{l}31.23 \\
\frac{28.40}{29.82}\end{array}$ & $\begin{array}{l}4.53 \\
4.12 \\
4.32\end{array}$ \\
\hline 195 & $\bar{x}=$ & $\begin{array}{l}30.65 \\
\frac{33.78}{32.22}\end{array}$ & $\begin{array}{l}4450 \\
4900 \\
4680\end{array}$ & $\begin{array}{l}33.04 \\
28.87 \\
30.96\end{array}$ & $\begin{array}{l}4.79 \\
4.19 \\
4.49\end{array}$ & $\begin{array}{l}89.19 \\
93.22 \\
91.21\end{array}$ & $\begin{array}{l}12.94 \\
13.52 \\
13.23\end{array}$ \\
\hline 76 & $\bar{x}=$ & $\begin{array}{l}38.59 \\
44.71 \\
41.65\end{array}$ & $\begin{array}{l}5600 \\
6480 \\
6040\end{array}$ & ---- & ---- & $\begin{array}{l}120 \cdot 9 \\
102 \cdot 5 \\
111 \cdot 7\end{array}$ & $\begin{array}{l}17.53 \\
14.87 \\
16.20\end{array}$ \\
\hline
\end{tabular}


Table 5. Effect of temperature on splitting and flexural strength of moist concrete mortar (mix 2).

\begin{tabular}{|c|c|c|c|c|}
\hline \multirow{2}{*}{$\begin{array}{c}\text { Tust } \\
\text { remperalure } \\
k\end{array}$} & \multicolumn{2}{|c|}{$\begin{array}{l}\text { Splitting Tensile } \\
\text { Strength* }\end{array}$} & \multicolumn{2}{|c|}{ Modulus of Rupture ${ }^{\dagger}$} \\
\hline & $M \mathrm{~Pa}$ & ksi & $\mathrm{MPa}$ & ksi \\
\hline 295 & $\bar{x}=\frac{2.32}{2.64}$ & $\begin{array}{l}0.34 \\
0.38 \\
0.36\end{array}$ & $\begin{array}{r}5.25 \\
5.25 \\
\bar{x}=\frac{5.72}{5.41}\end{array}$ & $\begin{array}{l}0.76 \\
0.76 \\
0.83 \\
0.78\end{array}$ \\
\hline 195 & 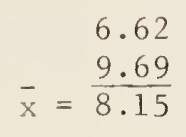 & $\begin{array}{l}0.96 \\
\frac{1.41}{1.19}\end{array}$ & $\begin{array}{r}13.44 \\
\bar{x}=\frac{13.88}{13.66}\end{array}$ & $\begin{array}{l}1.95 \\
2.01 \\
1.98\end{array}$ \\
\hline 76 & $\begin{array}{r}5.96 \\
\bar{x}=\frac{8.54}{7.25}\end{array}$ & $\begin{array}{l}0.86 \\
1.24 \\
1.05\end{array}$ & $\begin{array}{r}9.26 \\
\bar{x}=\frac{11.91}{10.59}\end{array}$ & $\begin{array}{l}1.34 \\
1.73 \\
1.54\end{array}$ \\
\hline
\end{tabular}

*ASTM C496-71 splitting tensile strength $=T=2 \mathrm{P} / \pi \ell \mathrm{d}$

where: $T=$ splitting tensile strength, MPa (or psi)

$\mathrm{P}=$ maximum applied load, $\mathrm{N}$ (or lbf)

1 = length, $\mathrm{mm}$ (or in)

$\mathrm{d}=$ diameter, $\mathrm{mm}$ (or in)

+ ASTM C78-75 modulus of rupture $=R=3 \mathrm{P} \ell / 2 \mathrm{bd}^{2}$

where: $R=$ modulus of rupture, $\mathrm{MPa}$ (or psi)

$\mathrm{P}=$ maximum applied load, $\mathrm{N}$ (or $1 \mathrm{bf}$ )

1 = span length, mm (or in)

$\mathrm{b}=$ average width of specimen, mm (or in)

$\mathrm{d}$ = average depth of specimen, $\mathrm{mm}$ (or in)

Table 6. Fracture toughness of short rod moist concrete mortar specimens (mix 2)**

\begin{tabular}{|c|c|c|c|c|}
\hline \multirow{2}{*}{ Temperature, $\mathrm{K}$} & \multicolumn{2}{|c|}{$\begin{array}{c}\mathrm{K}_{\mathrm{Ic}} \mathrm{SR} \\
\mathrm{MPa} \cdot \mathrm{m}^{1 / 2}\left(\mathrm{psi}^{\left.1 / \mathrm{in}^{1 / 2}\right)}\right.\end{array}$} & \multicolumn{2}{|c|}{$\begin{array}{l}\mathrm{P}_{c} \\
\mathrm{~kg}(1 \mathrm{~b})\end{array}$} \\
\hline & $\begin{array}{l}0.88 \\
0.95 \\
0.88\end{array}$ & $\begin{array}{l}(800) \\
(860) \\
(800)\end{array}$ & $\begin{array}{l}41.0 \\
41.8 \\
39.3\end{array}$ & $\begin{array}{l}(90.28) \\
(92.16) \\
(86.54)\end{array}$ \\
\hline 195 & $\begin{array}{l}2.26 \\
2.24 \\
2.04 \\
2.20\end{array}$ & $\begin{array}{l}(2060) \\
(2040) \\
(1860) \\
(2000) \dagger\end{array}$ & $\begin{array}{r}101.0 \\
99.9 \\
91.8 \\
97.9\end{array}$ & $\begin{array}{l}(222.56) \\
(220.30) \\
(202.32) \\
(215.80)\end{array}$ \\
\hline 76 & 1.91 & $(1740)$ & 85.1 & $(187.70)$ \\
\hline
\end{tabular}

*A11 test specimens were $5.08 \stackrel{+0.00}{-0.05} \mathrm{~cm}$ in diameter.

tSpecimen fractured in body away from chevron. 


\section{References}

[1] B. C. Gerwick, "Design and Construction of Prestressed Concrete Vessels," Paper Number OTC 1886, presented at the Fifth Annual offshore Technology Conference, Houston, Texas, (1973).

[2] B. C. Gerwick, "State of the Art Report - Durability of concrete Structures Under Water," presented at the International Association Colloquium-Liege, Belgium (June 5, 1975).

[3] L. Barker and Barrata: Comparison of fracture toughness measurements by the short rod and ASTM standard method of test for plane strain fracture toughness of metallic materials (E 399-78), J. Test. Eval. 8(3):97 (1980).

[4] J. F. Beech and A. R. Ingraffea, Three dimensional finite element calibration of the short-rod specimen, accepted for publication in the Int'1. J. Fract., in press.

[5] A. R. Ingraffea and H. Y. Ko, Determination of the fracture parameters for rock, paper to appear in: "Proceedings of the International Symposium on Absorbed Specific Energy," Budapest, Hungary (Sept. 1980), in press.

[6] G. E. Monfore and A. E. Lentz, Physical properties of concrete at very low temperatures, J. PCA Res. Dev. Lab. 4(2):33 (1962).

[7] Mindess, Sidney, "Application of Fracture Mechanics to Cement and Concrete," presented at the 81st Annual Meeting of the American Ceramic Society, Cincinnati, Ohio, Paper 1-S II - 79 (1979). 


\title{
TENSILE, COMPRESSIVE, AND SHEAR PROPERTIES OF A $64-\mathrm{kg} / \mathrm{m}^{3}$ POLYURETHANE FOAM AT LOW TEMPERATURES ${ }^{*}$
}

\author{
J. M. Arvidson \\ Fracture and Deformation Division \\ National Measurement Laboratory \\ L. L. Sparks and C. Guobang ${ }^{\ddagger}$ \\ Thermophysical Properties Division \\ National Engineering Laboratory \\ National Bureau of Standards \\ Boulder, Colorado
}

\section{ABSTRACT}

Polyurethane foam, having a density of $64 \mathrm{~kg} / \mathrm{m}^{3}$, was tested at 295, 111 , 76 and $4 \mathrm{~K}$. The material properties reported are Young's modulus, proportional limit, yield strength (at $0.2 \%$ offset), tensile, shear, and compressive strengths, and elongation (elastic and plastic). To perform these tests, a unique apparatus was developed. This apparatus permits tension, compression, and shear testing of materials at any temperature ranging from 295 to $1.8 \mathrm{~K}$. Strain is measured with a concentric, overlapping-cylinder capacitance extensometer that is highly sensitive and linear in output.

Key Words: Compressive strength; elongation; foam; insulation; low temperatures; mechanical properties, proportional limit; shear strength; tensile strength; yield strength; Young's modulus.

* Supported by the Gas Research Institute, Chicago and the Office of Fusion Energy, U. S. Department of Energy.

${ }^{\dagger}$ Published as report number NBSIR. 83-1684, National Bureau of Standards, Boulder, Colorado (1983). Also published in Advances in Cryogenic Engineering-Materials, vol. 30, Plenum Press, New York (1984), pp. 97-104. fGuest worker at NBS. Department of Thermal Science, Zhejiang University, Hangzhon, Zhejiang Province, People's Republic of China. 

1. INTRODUCTION

Polyurethane foams are used in many structural as well as insulating applications in which knowledge of material performance in extreme environments (e.g., at liquefied natural gas, liquid nitrogen, and liquid hel ium temperatures) is essential. Accurate data, predictive capability, and standardized methods and materials improve the selection and development of materials for these applications. The mechanical properties reported here are part of a broader effort to understand and predict the thermal and mechanical behavior of expanded plastics (foams) in cryogenic environments.

The tensile, compressive, and shear properties of polyurethane foam, having a density of $64 \mathrm{~kg} / \mathrm{m}^{3}$, were determined using a test fixture developed specifically for this program [1]. This fixture provides the capability of determining the above material properties at any temperature from ambient $(295 \mathrm{~K})$ to $1.8 \mathrm{~K}$. Tests can be done in a cold gaseous atmosphere or in liquids, such as helium $(4 \mathrm{~K})$, nitrogen $(76 \mathrm{~K})$, and dry ice and alcohol $(195 \mathrm{~K})$. The fixture has also been designed to test materials at the above temperatures while under static pressures ranging from subatmospheric to approximately $0.3 \mathrm{MPa}(43.7 \mathrm{psia})$.

A strain extensometer that was developed for use with soft viscoelastic materials utilizes concentric overlapping cylinders and the change in electrical capacitance to detect specimen strain [2]. This type of extensometer does not attach directly to the specimen, so the effect of instrumentation on the experimental results is negligible (verified to contribute $<2.5 \times 10^{-8} \mathrm{~m}$ for our specimen geometry). The extensometer works well in cryogenic environments, is accurate, and is linear for large strains $[3,4]$. The capacitance extensometer system designed for this work had a linearity range in excess of $2.5 \mathrm{~cm}$ when used with the current foam specimen geometry (2.9- cm diameter by 9.9- cm 1ength). 
Similar extensometers can be designed for specific sensitivities and extents of Tinearity [5]. As long as the capacitance extensometer is situated in a stable fluid (i.e., single phase and nonboiling) the resultant is a very high signal-to-noise ratio. These sensors function in gases as well as in liquids and the device is only sensitive to the dielectric constant of the test medium. The original calibration of the system, for example, can be performed at room temperature in air. To conduct a test in any other medium (e.g., liquid nitrogen) the original calibration need only be corrected for the change in dielectric constant [6].

\section{MATERIAL CHARACTERIZATION}

The material tested in this study is a nominal $64-\mathrm{kg} / \mathrm{m}^{3}$ polyurethane foam designated as GM35. This amorphous organic polymer is a thermosetting foam. Our supply of this material was obtained from the NBS Office of Standard Reference Materials (OSRM) in Gaithersburg, Maryland. The OSRM distributed this and other expanded plastics for the Products Research Committee $[7,8]$. These materials were commercially produced and designated as General Materials.

The bulk supply of GM35 was a $0.1-\mathrm{m} \times 0.6-\mathrm{m} \times 0.6-\mathrm{m}$ slab (figure $1 \mathrm{a}$ ). The orientation of the elongated cell axis for the material used in the physical properties tests was determined optically from statistical evaluation of photomicrographs. The ratios of cell height to cell width for the principal orthogonal planes of the physical test specimens were: $x / y=0.94 \pm$ $0.34, z / x=1.60 \pm 0.65, z / y=1.51 \pm 0.58$. The uncertainties given represent estimates of one standard deviation. The cell orientations relative to the orthogonal axes of the bulk slab are shown in figure $1 \mathrm{~b}$. 
The density of this resin-gas composite was found to be $62.22 \pm 0.28$ $\mathrm{kg} / \mathrm{m}^{3}, 62.52 \pm 0.11 \mathrm{~kg} / \mathrm{m}^{3}$, and $62.56 \pm 0.13 \mathrm{~kg} / \mathrm{m}^{3}$ after conditioning at $23^{\circ} \mathrm{C}$ and 24,50 , and 92 percent relative humidity respectively. The uncertainties given are estimates of one standard deviation.

\section{SPECIMENS}

Test specimens taken from the $x / y$ or $z / x$ plane in the bulk supply (see figure 1) are designated "longitudinal" when loaded parallel to the $z$ direction. Conversely, specimens taken from the $x / y$ plane and loaded parallel to either the $\mathrm{x}$ or $\mathrm{y}$ direction are designated "transverse".

The tensile specimens were rods $9.9-\mathrm{cm}$ long and $2.9-\mathrm{cm}$ in diameter. This specimen was used to determine Young's modulus, proportional limit, yield strength (at $0.2 \%$ offset), and elongation (extrapolated using ultimate tensile strength). For the determination of ultimate tensile strength, a reduced section specimen was used. Its gage length was $5.1 \mathrm{~cm}$ and its diameter was $1.9 \mathrm{~cm}$. All tensile specimens were epoxied to polycarbonate grips, which were threaded to accomodate the tensile pull-rod system. The reduced-section geometry forced fracture to occur within the gage length, thereby eliminating the effect of biaxial stresses at the grip ends.

The compression specimens were $2.54-\mathrm{cm}$ long and $2.9-\mathrm{cm}$ in diameter. These specimens did not require grips.

Shear specimens were $1.9 \mathrm{~cm} \times 2.54 \mathrm{~cm} \times 0.4 \mathrm{~cm}$. The specimens were epoxied to two flat plates and each plate was attached to the upper and lower tensile pull-rod system, respectively. An aluminum cylinder was slipped over the specimen and plates to help maintain alignment and minimize induced torque during testing. In addition, the cylinder has a built-in resistive heater that is controlled by a thermocouple to produce and maintain the desired test temperature. 
Most tests were conducted at $295 \mathrm{~K}$ (air), $111 \mathrm{~K}$ (gaseous helium), $76 \mathrm{~K}$ (liquid nitrogen), and $4 \mathrm{~K}$ (liquid helium). To minimize thermal shock to the specimen, the liquid helium or nitrogen was transferred at a very slow rate. The tensile and compressive properties included: Young's modulus, proportional limit, yield strength (at 0.2 percent offset), tensile and compressive strengths, and elongation (elastic and plastic).

Since an ASTM shear strength test method is not available for soft cellular materials such as these foams, several methods were carefully considered, and a version of the guillotine-type shear test was selected. Many specimen geometries (thicknesses and widths) were tested to find the best combination that most consistently failed in shear. At least three tests were conducted at each temperature; in some cases, more tests were run to determine material variability. Prior to testing, all specimens were "conditioned" in an environmental chamber for not less than four days at $23^{\circ} \mathrm{C}$ and 50 percent relative humidity. Each specimen was tested shortly after removal from the environmental chamber. A11 tests were conducted in a conventional compression/ tension test machine at a strain rate of $5 \times 10^{-3} \mathrm{~min}^{-1}$. (Varying the rate from $5 \times 10^{-4}$ to $5 \times 10^{-2} \mathrm{~min}^{-1}$ had no measurable effect on results.)

\section{RESULTS}

Results are presented in figures 2 through 15 and tables 1 through 6 . The bars on the figures indicate the data spread from replicate tests. Scatter is typicaliy higher for compression and shear than for tensile tests; this is because the compressive and shear tests are more sensitive to problems such as misalignment (tensile specimens self-align during the test). Unlike the $32-\mathrm{kg} / \mathrm{m}^{3}$ foam that was tested previously [1], the cell orientation of the $64-\mathrm{kg} / \mathrm{m}^{3}$ material agreed very well with the bun-line orientation 
(i.e., the vertical or "rise" direction is denoted as longitudinal). Tensile results shown in figures 2 through 6 are Young's modulus, ultimate strength, and strain-versus-temperature, as well as stress-versus-strain curves for all temperatures. In addition to the above properties, compressive results include yield strength (at $0.2 \%$ offset), proportional limit versus temperature, and a typical load-versus-displacement curve, as shown in figures 7 through 14. The shear results are given in figure 15.

Tensile, Young's modulus, proportional limit, yield strength, ultimate strength, and shear strength values all increase as temperature decreases from $295 \mathrm{~K}$ to $4 \mathrm{~K}$. The longitudinal orientation results have the highest values. As shown in figure 4, tensile strain decreases with temperature, and the material becomes brittle at temperatures below $111 \mathrm{~K}$. The compressive Young's modulus versus temperature, as shown in figure 7 , indicates a decrease in mean values from $111 \mathrm{~K}$ to $76 \mathrm{~K}$, for both longitudinal and transverse specimens. The same behavior was also noted for a $32-\mathrm{kg} / \mathrm{m}^{3}$ polyurethane foam material that was previously tested [1]. Using the Student's " $t$ " test for small sample size, the longitudinal and transverse compressive data were calculated for 76 and $111 \mathrm{~K}$. The results indicate a level of confidence of $>99.95 \%$ for the transverse and $88 \%$ for longitudinal tests that the mean compressive modulus at $76 \mathrm{~K}$ is lower than the mean compressive modulus at $111 \mathrm{~K}$ [9]. Figure 11 indicates a deformation capability during compression at low temperatures. However, since the polyurethane material is incapable of true plastic deformation at cryogenic temperatures, this apparent plastic strain is caused by individual cells that collapse during testing. Figures 12 and 13 show the stress-versus-strain behavior of longitudinal and transverse specimens at 295, 111,76 , and $4 \mathrm{~K}$. Figure 14 is an actual record of load-versus-displacement for a typical specimen. The load drops illustrate points 
at which individual or multiple cells fail under stress. Owing to material variability, the stress-strain graphs were plotted as smooth curves, which do not show the cell failure phenomena. Each stress-strain curve, at a given temperature and orientation, is the average of three or more specimens tested. 6. DISCUSSION

Polyurethane foam behavior is typical of polymers in general, with large mechanical property changes such as a complete loss of ductility and a doubling of $E_{T}$ (Young's modulus-tension) following a temperature reduction from $295 \mathrm{~K}$ to $4 \mathrm{~K}$. Certain longitudinal properties, like shear strength and $\mathrm{E}_{\mathrm{C}}$ (Young's modulus-compression), exhibit maximum values between the two extreme temperature limits; however this is probably not a true material behavior but an effect influenced by material variability and orientation irregularities.

The anomalous behavior of compressive Young's modulus as shown in figure 7 appears to be a real effect. As stated previously, the $32-\mathrm{kg} / \mathrm{m}^{3}$ polyurethane foam tested exhibited the same drop in modulus from 111 to $76 \mathrm{~K}$. In addition, a third density of polyurethane foam $\left(96-\mathrm{kg} / \mathrm{m}^{3}\right)$ has recently been tested and it shows the same trend.

Sectioning after testing revealed that cell orientation varied slightly from the orientation of the mold axes (see figure 1). It is generally thought that foam specimens from the center of a large billet have uniform cells oriented with respect to the vertical, but this is not true of foams formed on a continuous or bun-line production facility. The cell orientation reflects the movement of the foaming resin. However, as shown in this higher density foam, the problem of cell orientation with respect to vertical is not as severe as with less dense materials. Cells in the $x-z$ plane of the material reported here have only a 86 to $87^{\circ}$ inclination to the $x$-axis (figure 1 ). 
Specimens tested previously in liquid nitrogen [1] appeared to have slightly lower shear strength values than those tested at the same temperature in cold helium gas. This may be an indication of environmental sensitivity. Nitrogen at low temperatures is deleterious to a number of other polymeric materials. Thermoplastics have exhibited crazing or reduced fracture strengths, or both when tensile tested in cold liquid or gaseous nitrogen, but not in vacuum or helium environments [10]. Environmental effects must ultimately be taken into account in design applications.

The authors are indebted to Robert S. Bell and Ronald D. Kriz for their assistance in the preparation of this manuscript for publication.

\section{References}

[1] J. M. Arvidson and L. L. Sparks, "Low Temperature Mechanical Properties of a Polyurethane Foam", NBSIR 81-1654, National Bureau of Standards, Boulder, Colorado (November, 1981).

[2] R. P. Reed, J. M. Arvidson, and R. L. Durcholz, Tensile properties of polyurethane and polystyrene foams from 76 to $300 \mathrm{~K}$, in: "Advances in Cryogenic Engineering," Vol. 18, K. D. Timmerhaus, ed., Plenum Press, New York (1973), pp. 184-193.

[3] J. M. Roberts, R. B. Herring, and D. E. Hartman, The use of capacitance gauge sensors to make precision mechanical property measurements, in: "Materials Technology," American Society for Mechanical Engineers, New York (1968), pp. 87-96.

[4] "High-Temperature Capacitive Strain Measurement System," NASA Tech. Brief B75-10069, NASA (1975).

[5] P. C. F. Woldendale, Capacitive displacement transducers with high accuracy and resolution, J. Sci. Instrum. (J. Phys. E) 1:817 (1968).

[6] G. R. White, Measurement of thermal expansion at low temperatures, Cryogenics, 2:151 (1961).

[7] "Materials Bank Compendium of Fire Property Data," Products Research Committee, J. W. Lyons, chairman, National Bureau of Standards, Washington, D.C. (1980).

[8] W. G. Jurevic, "Structural Plastics Applications Handbook Supplement 1 Test Methods," Technical Report AFML-TR-67-332 (1969). 
[9] J. W. Dally, Statistical treatment of experimental data, Experimental Mechanics 19(11):421 (1979).

[10] A. Hiltner and E. Baer, Mechanical properties of polymers at cryogenic temperatures, Polymer 15:805 (1974). 
List of Figures

Figure $1(\mathrm{a})$. Bulk supply of bun- 7 ine-produced, $64-\mathrm{kg} / \mathrm{m}^{3}$ polyurethane foam.

(b). Cell orientation relative to the major coordinate axes of the bulk supply.

Figure 2. Tensile Young's modulus versus temperature.

Figure 3. Ultimate tensile strength versus temperature.

Figure 4. Tensile strain versus temperature.

Figure 5. Tensile stress versus strain (longitudinal orientation).

Figure 6. Tensile stress versus strain (transverse orientation).

Figure 7. Compressive Young's modulus versus temperature.

Figure 8. Compressive strength versus temperature.

Figure 9. Compressive proportional limit versus temperature.

Figure 10. Compressive yield strength versus temperature.

Figure 11. Compressive strain versus temperature.

Figure 12. Compressive stress versus strain (1ongitudinal orientation).

Figure 13. Compressive stress versus strain (transverse orientation).

Figure 14. Compressive load versus displacement (transverse orientation).

Figure 15. Shear strength versus temperature (longitudinal and transverse).

List of Tables

Table 1. Tensile test results for a $64-\mathrm{kg} / \mathrm{m}^{3}$ polyurethane foam.

Table 2. Compressive test results for a $64-\mathrm{kg} / \mathrm{m}^{3}$ polyurethane foam.

Table 3. Shear strength test results for a $64-\mathrm{kg} / \mathrm{m}^{3}$ polyurethane foam.

Table 4. Summary of tensile test results for a $64-\mathrm{kg} / \mathrm{m}^{3}$ polyurethane foam (average values).

Table 5. Summary of compressive test results for a $64-\mathrm{kg} / \mathrm{m}^{3}$ polyurethane foam (average values).

Table 6. Summary of shear strength test results for a $64-\mathrm{kg} / \mathrm{m}^{3}$ polyurethane foam (average values). 


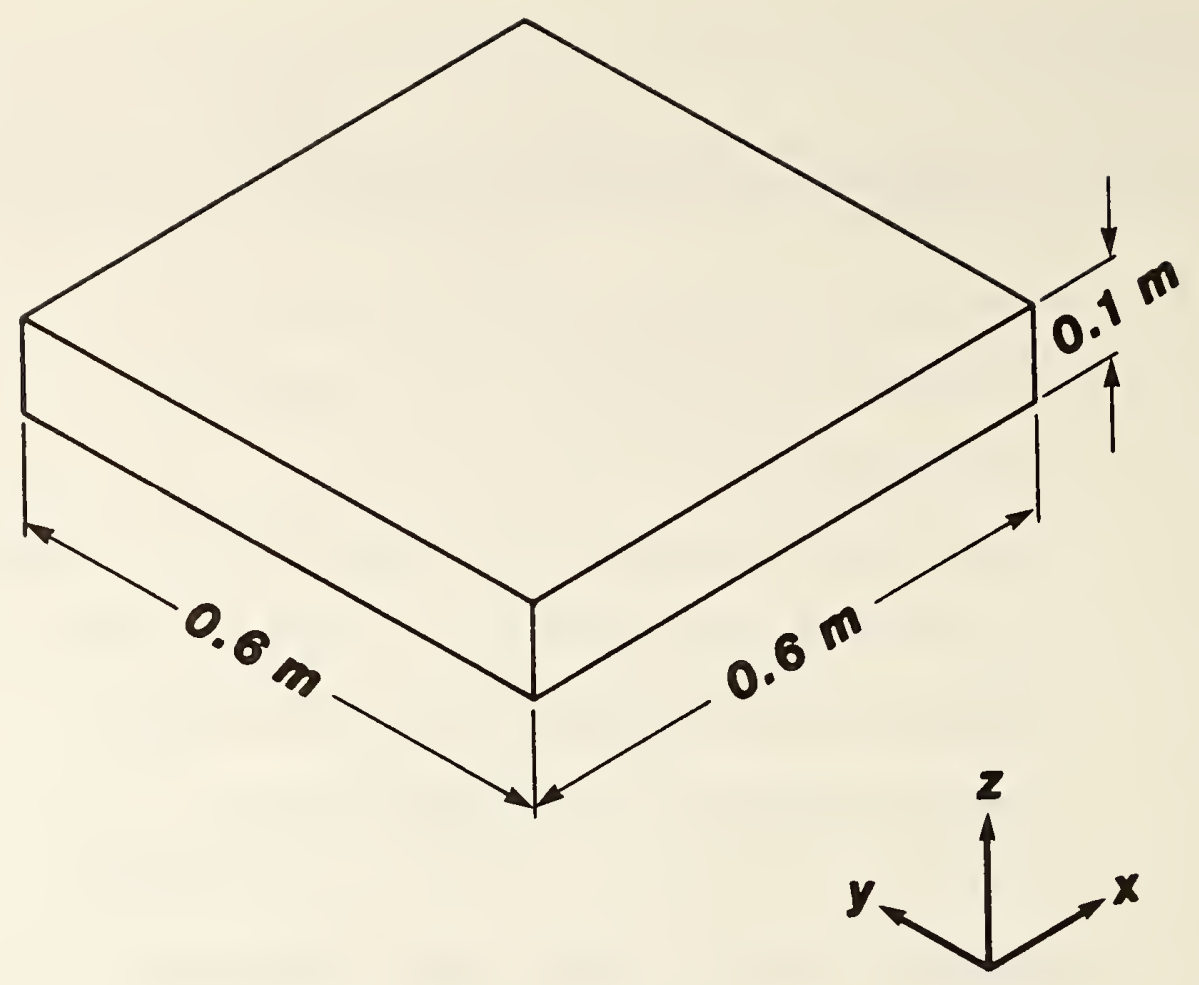

a)
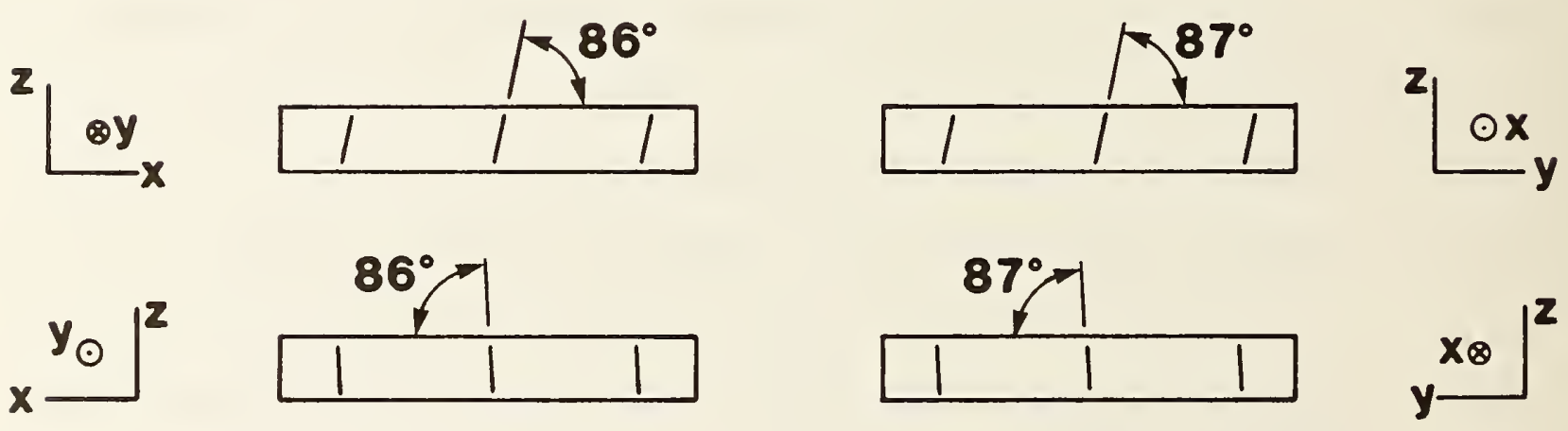

\section{$1 \mathrm{~m}$}

b)

Figure $7(a)$. Bulk supply of bun- 1 ine-produced, $64 \mathrm{~kg} / \mathrm{m}^{3}$ polyurethane foam.

(b). Cell orientation relative to the major coordinate axes of the bulk supply. 


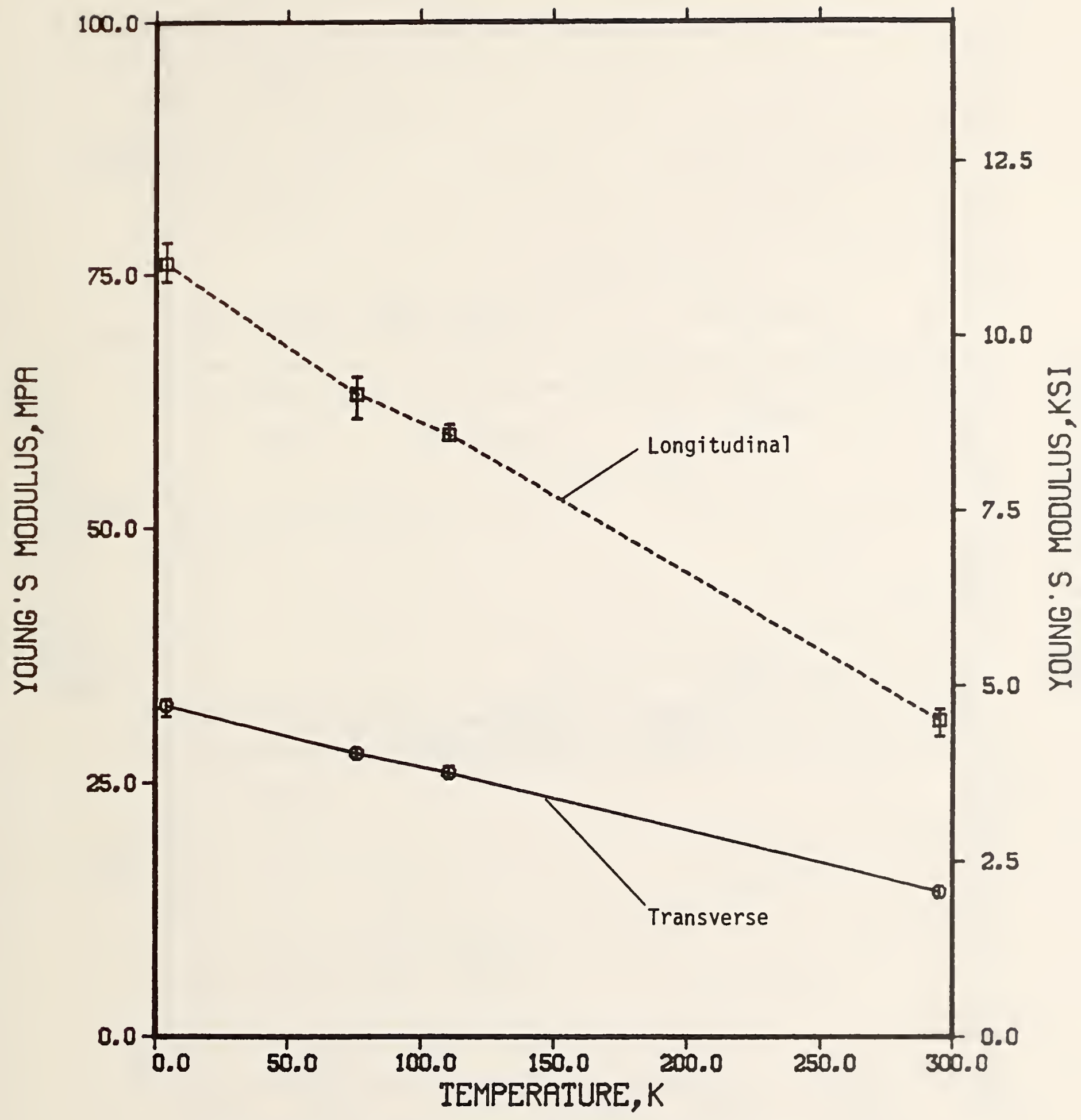

Figure 2. Tensile Young's modulus versus temperature. 


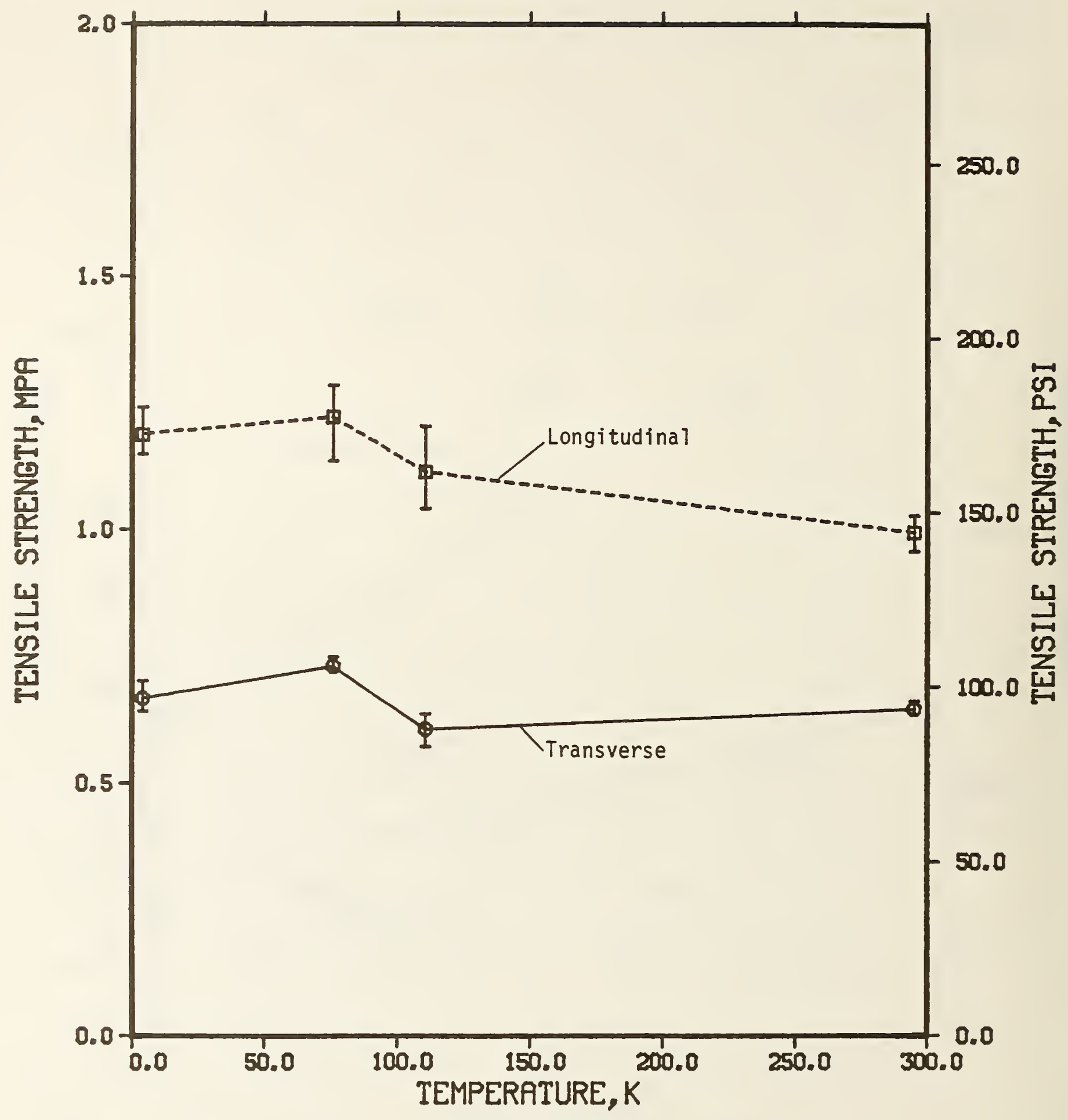

Figure 3. Ultimate tensile strength versus temperature. 


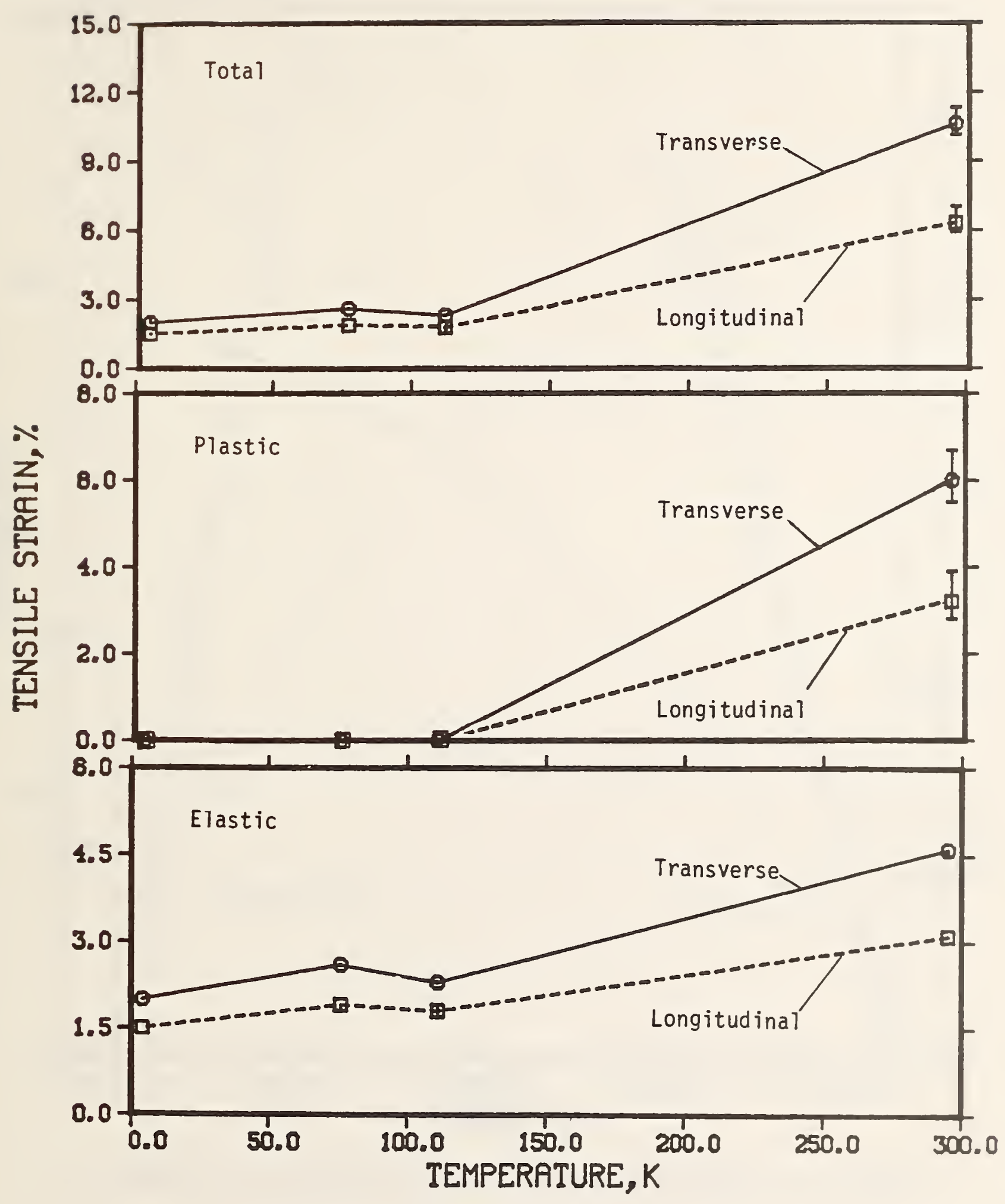

Figure 4. Tensile strain versus temperature. 


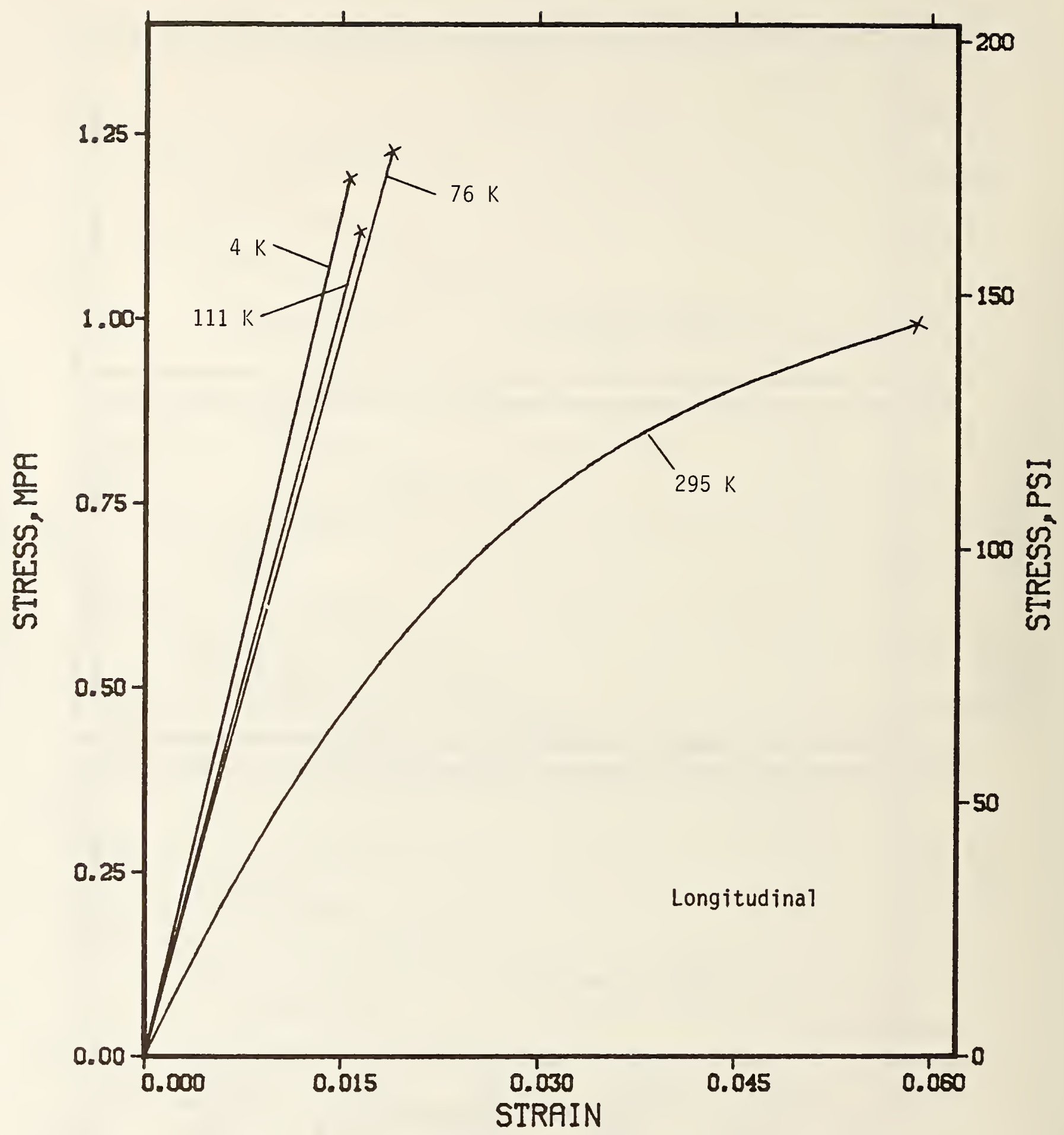

Figure 5. Tensile stress versus strain (longitudinal orientation). 


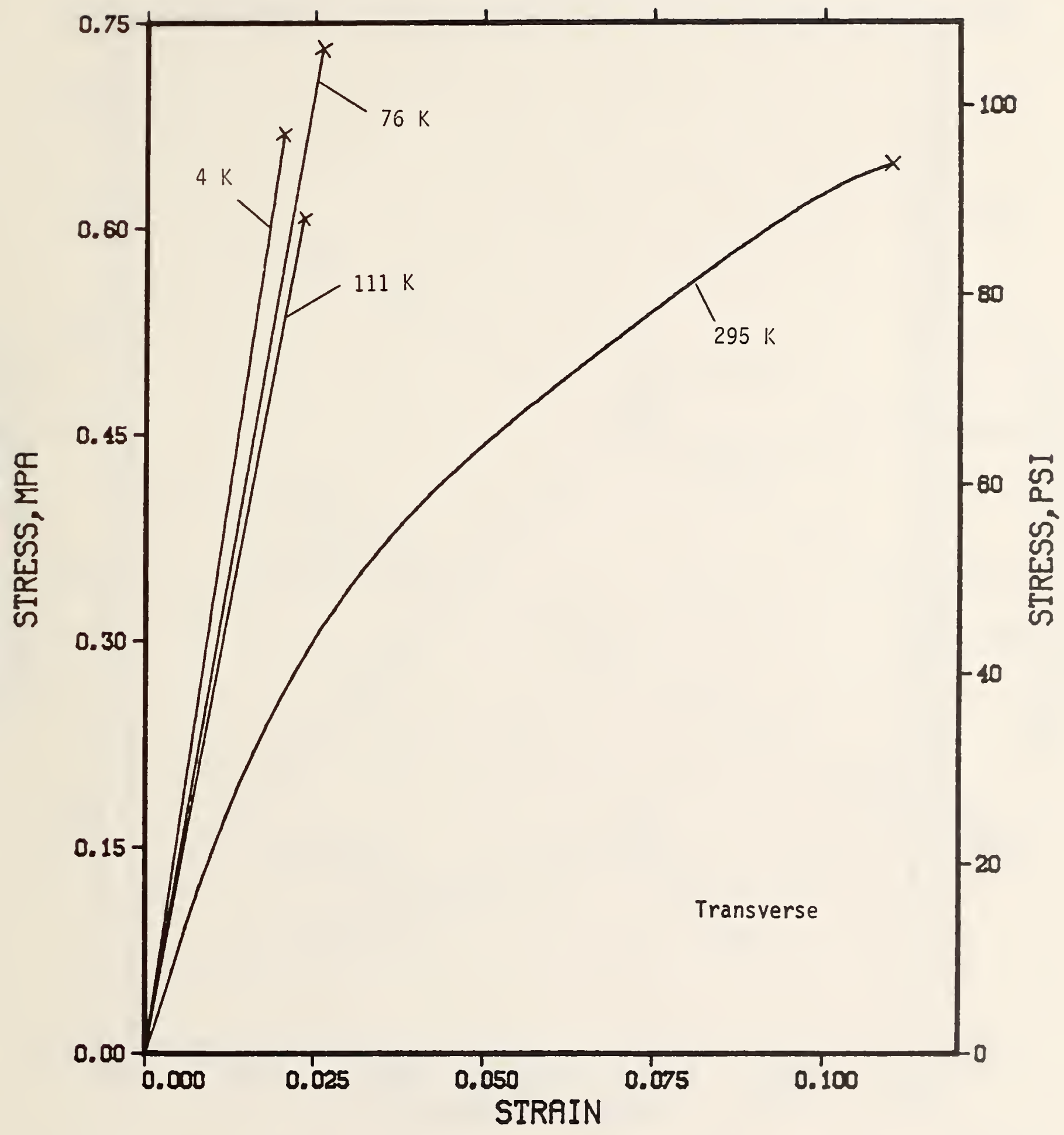

Figure 6. Tensile stress versus strain (transverse orientation). 


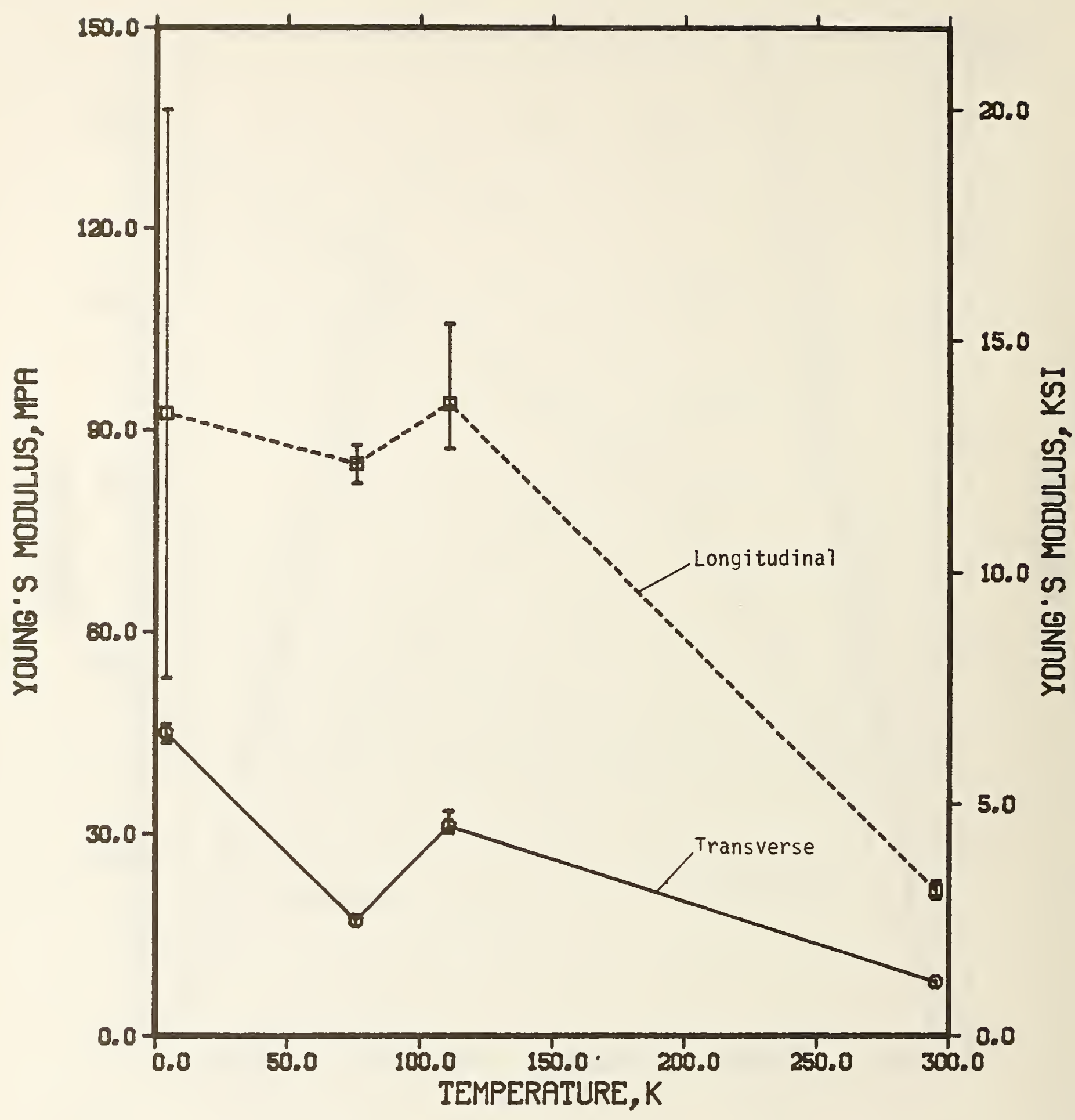

Figure 7. Compressive Young's modulus versus temperature. 


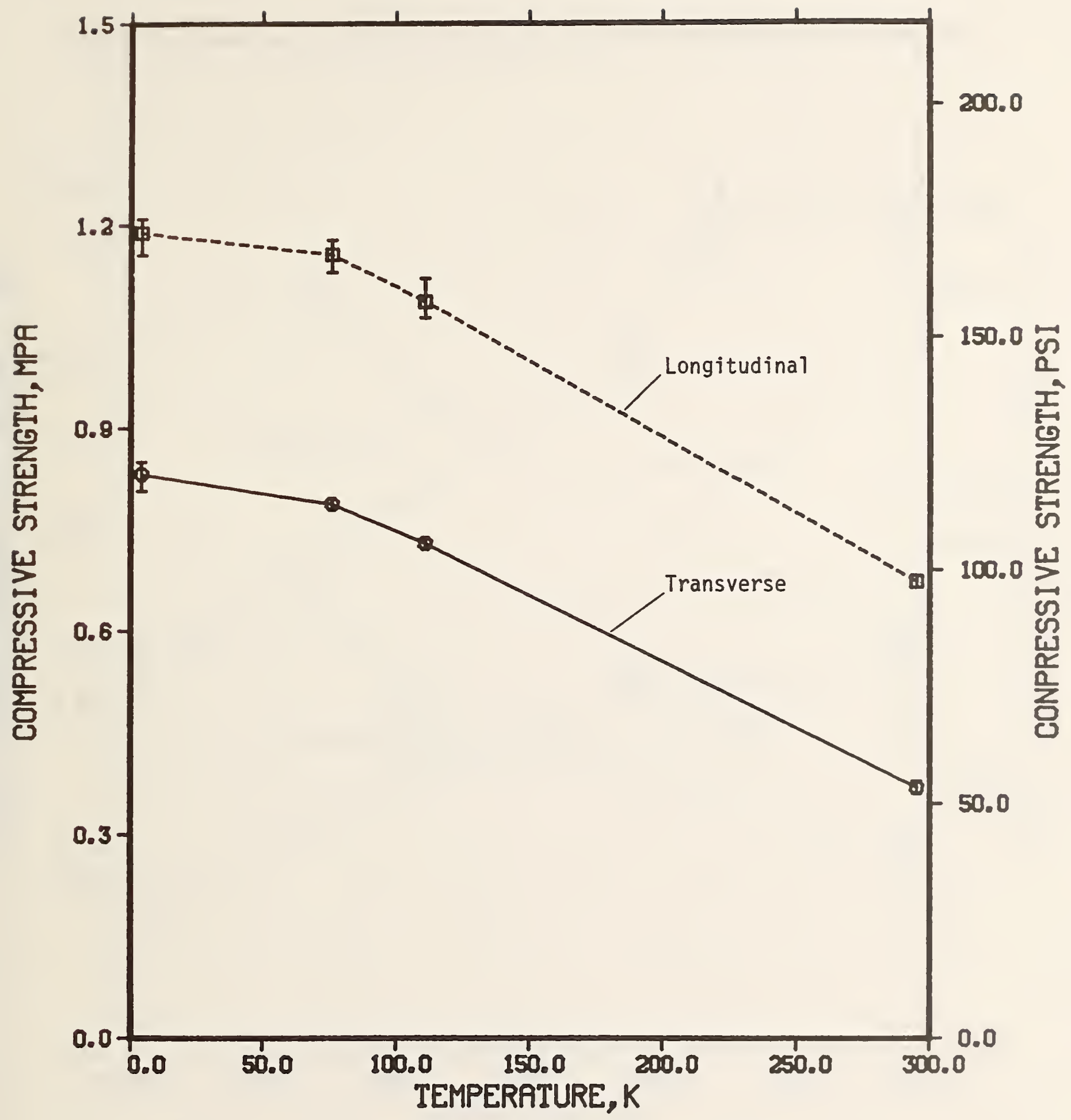

Figure 8. Compressive strength versus temperature. 


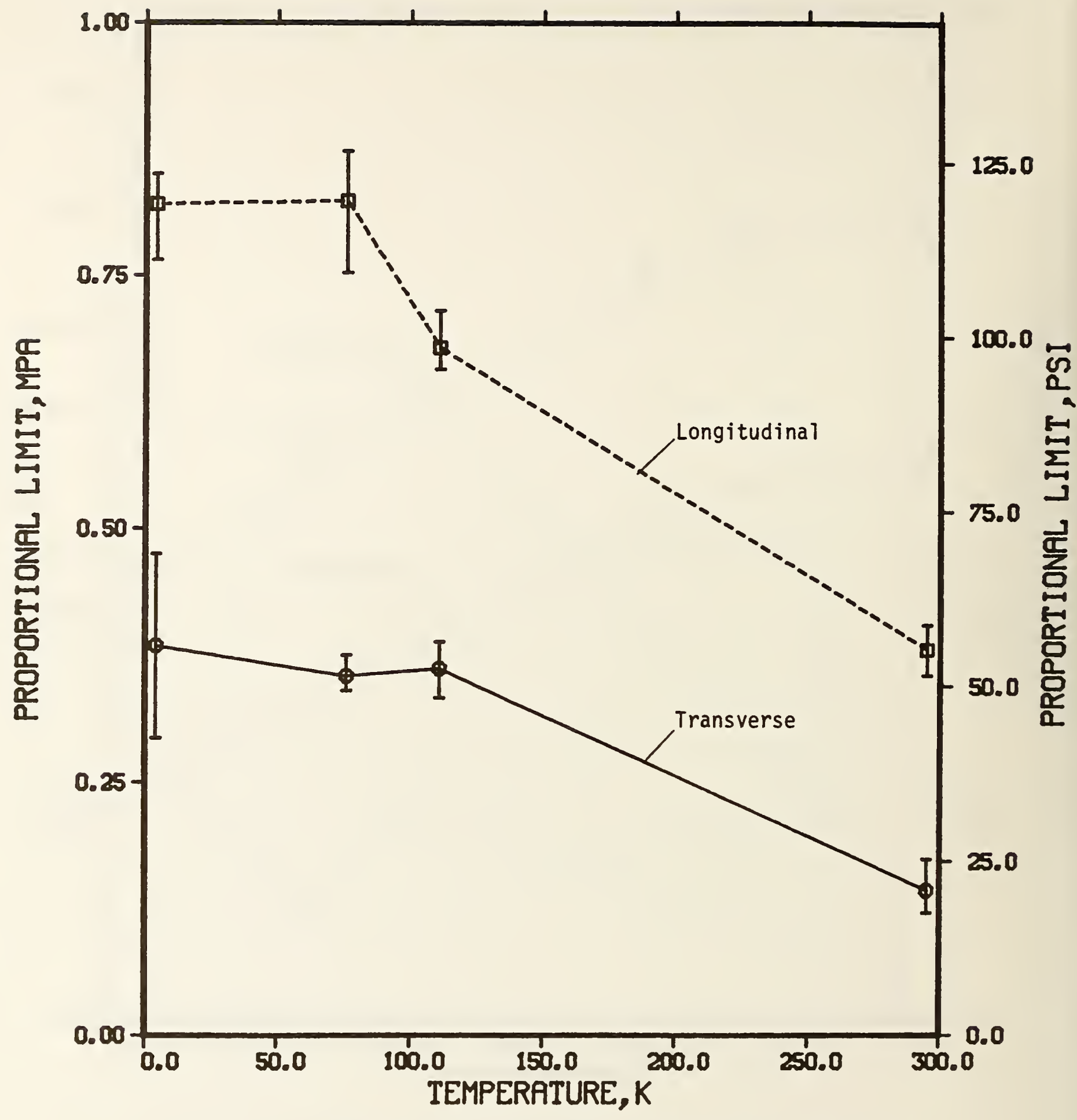

Figure 9. Compressive proportional limit versus temperature. 


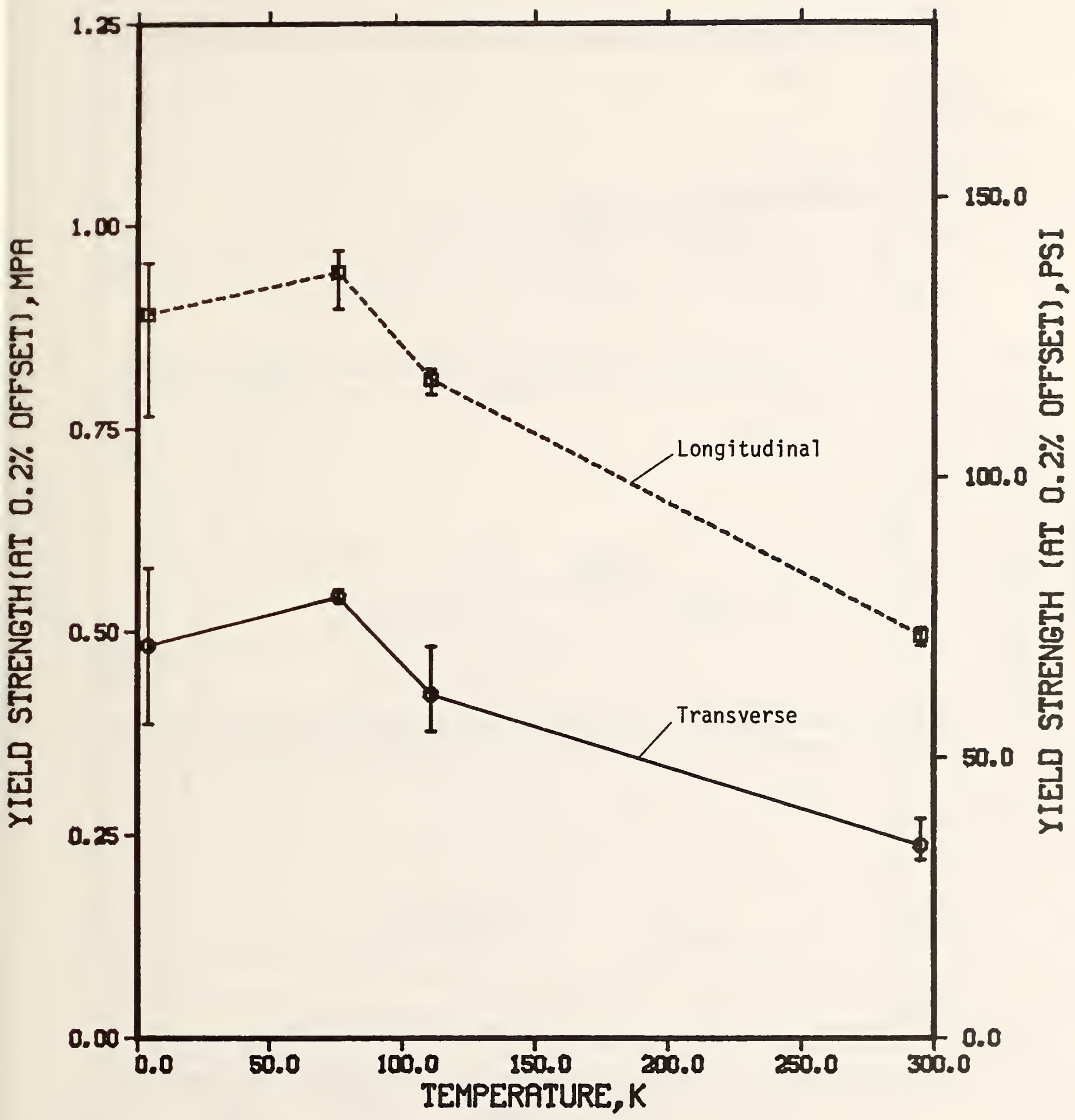

Figure 10. Compressive yield strength versus temperature. 


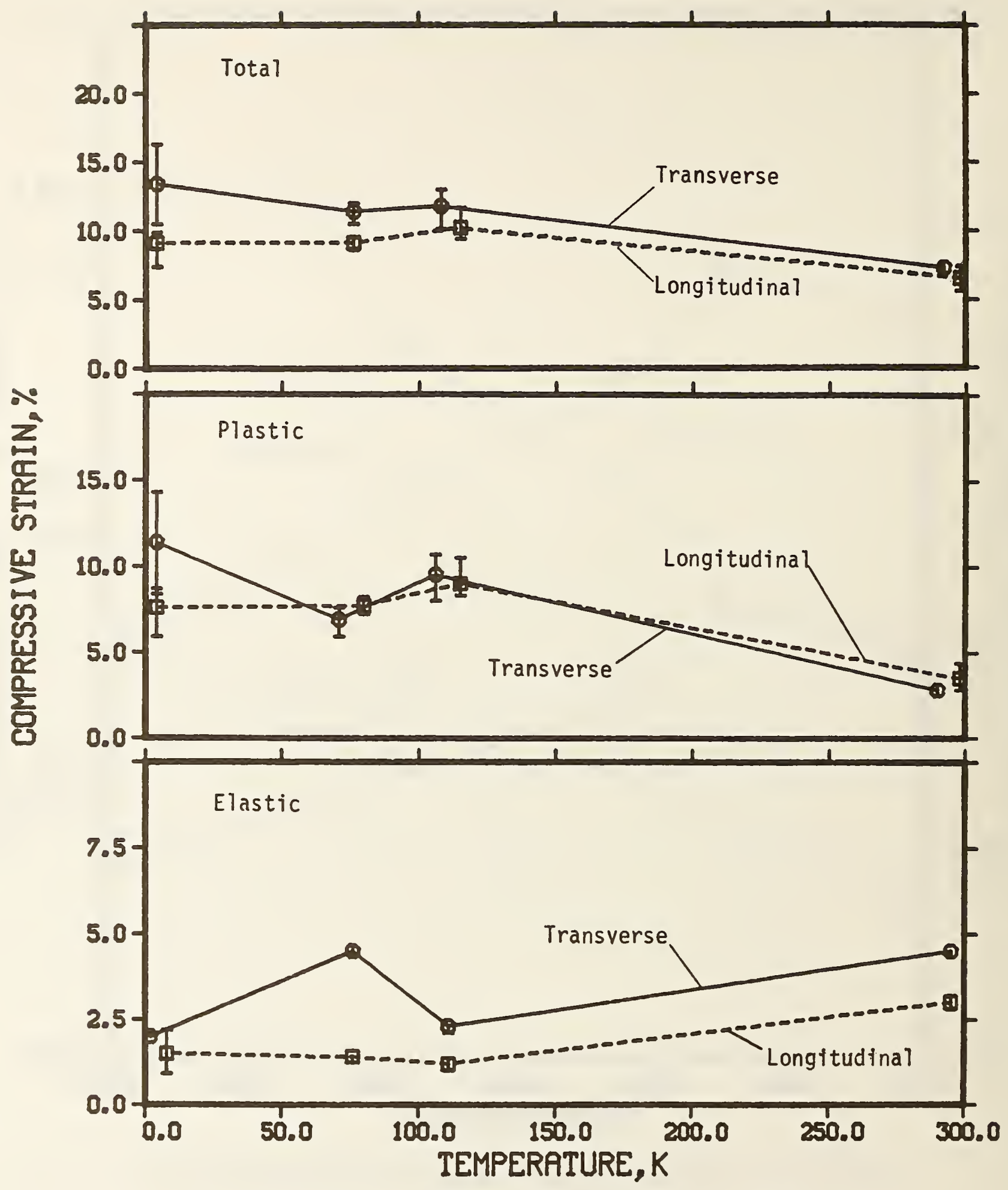

Figure 11. Compressive strain versus temperature. 


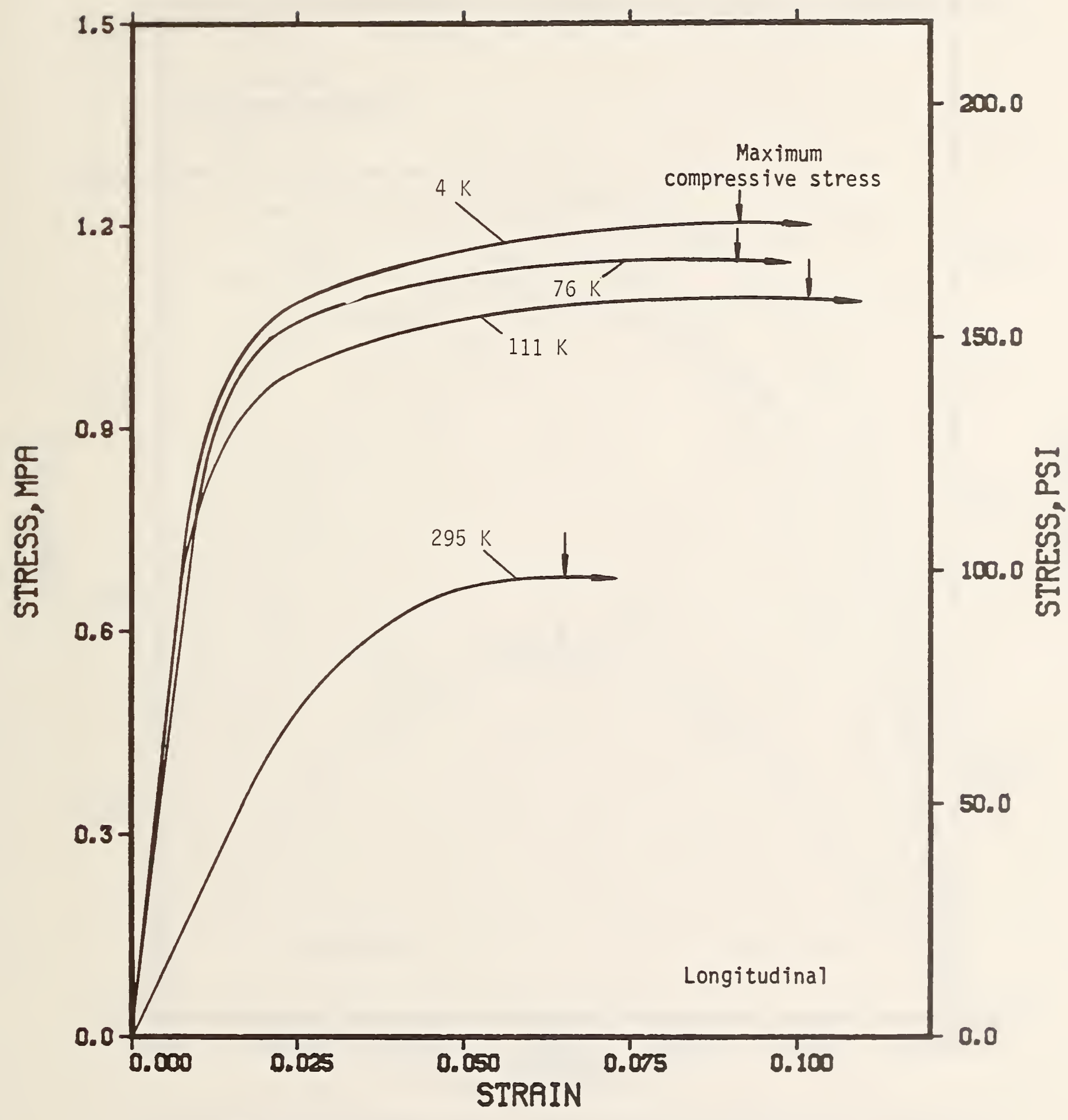

Figure 12. Compressive stress versus strain (1ongitudinal orientation). 


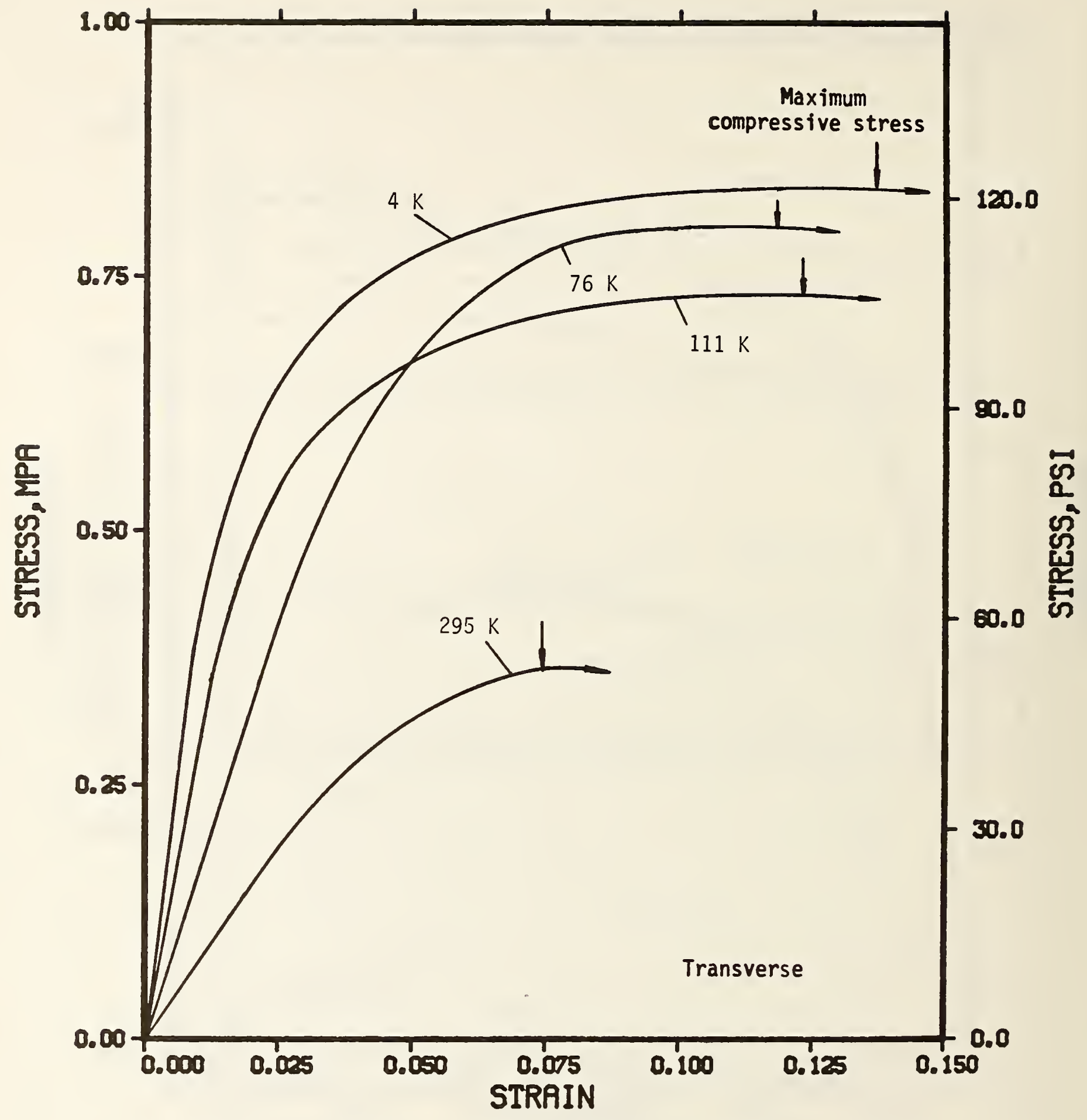

Figure 13. Compressive stress versus strain (transverse orientation). 


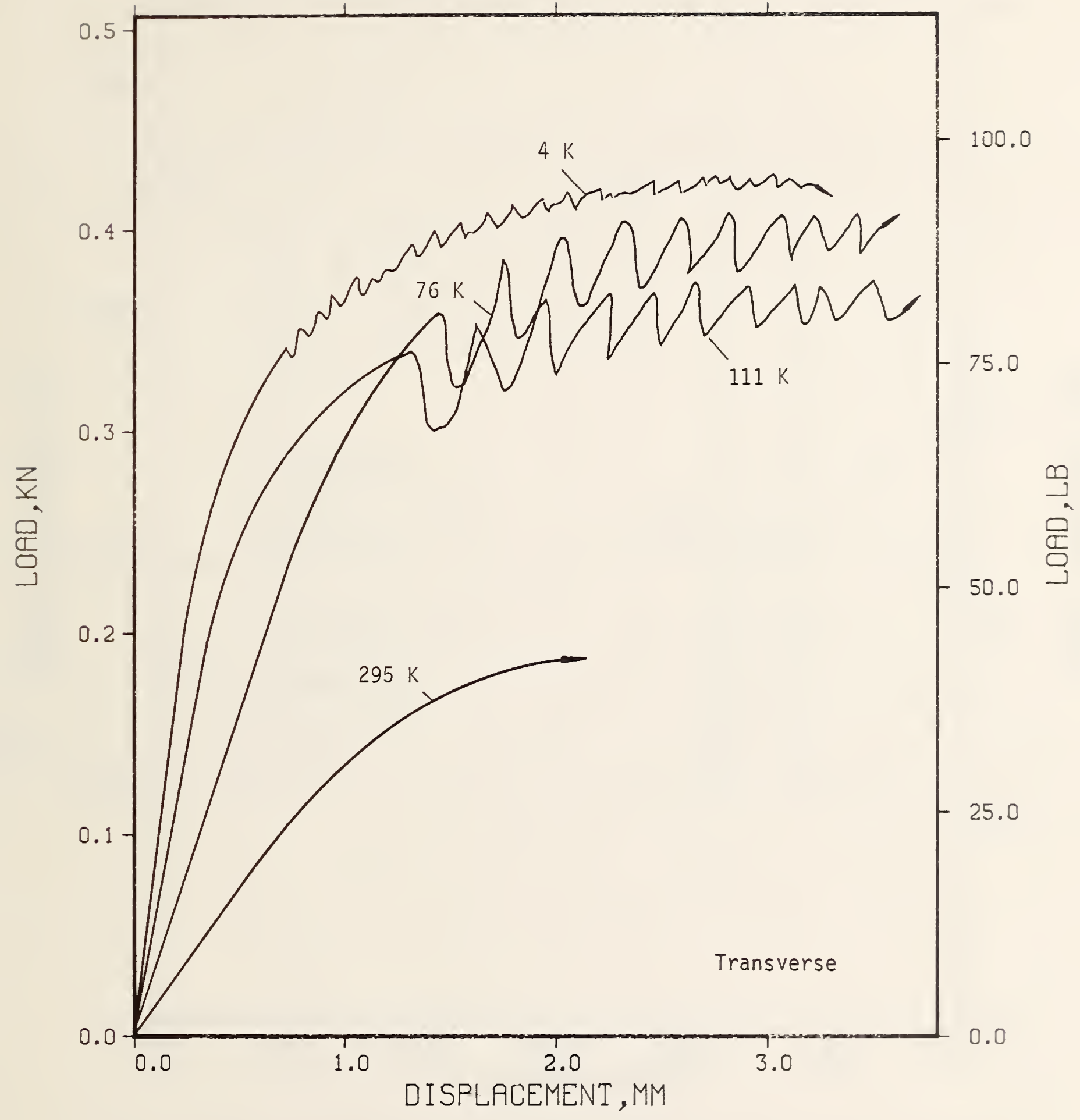

Figure 14. Compressive load versus displacement (transverse orientation). 


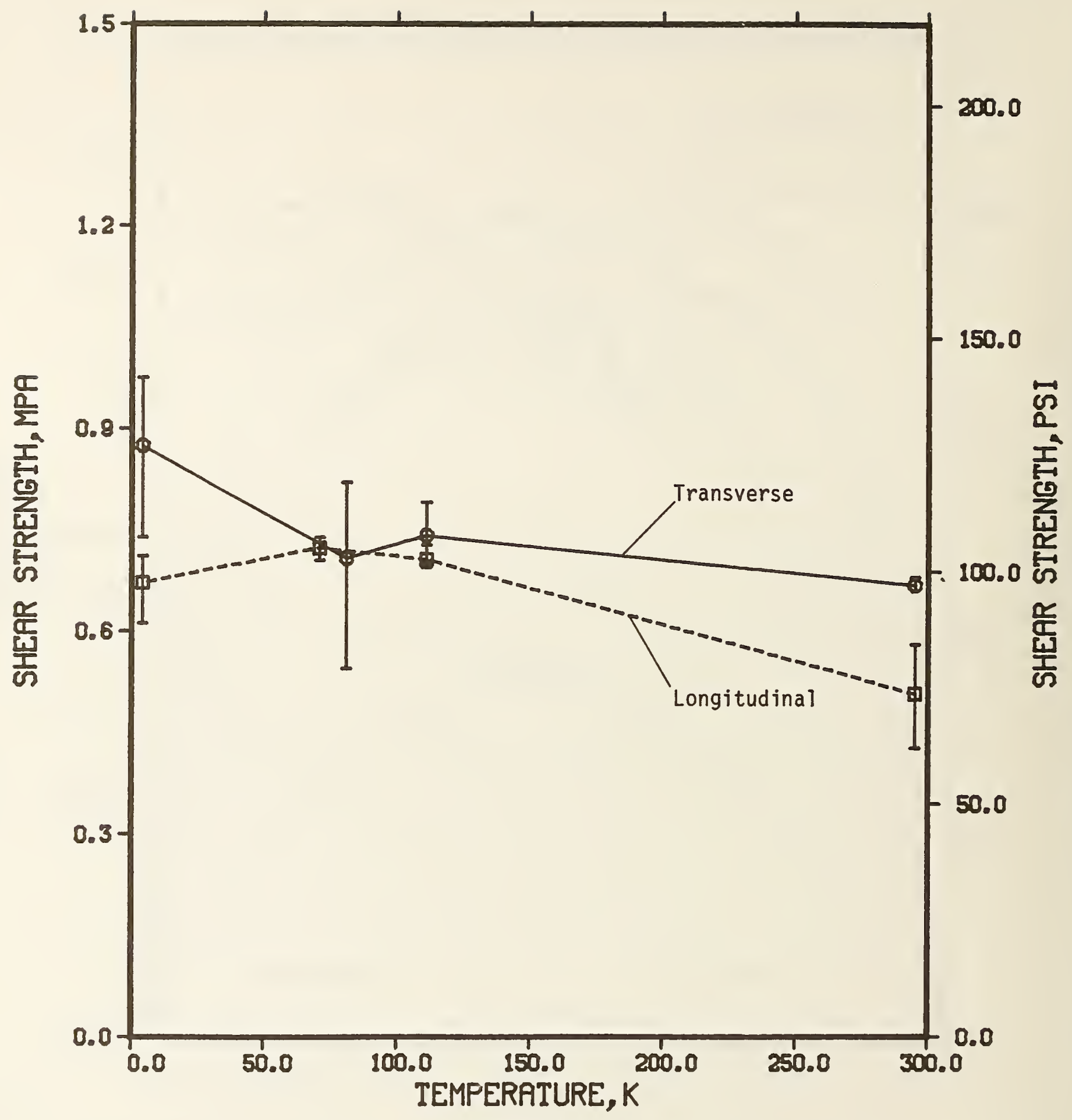

Figure 15. Shear strength versus temperature (longitudinal and transverse). 
Table 1. Tensile test results for a $64-\mathrm{kg} / \mathrm{m}^{3}$ polyurethane foam

\begin{tabular}{|c|c|c|c|c|c|c|c|c|c|c|c|c|c|}
\hline \multirow[t]{2}{*}{$\begin{array}{l}\text { Spec imen } \\
\text { number }\end{array}$} & \multirow{2}{*}{$\begin{array}{l}\text { Test } \\
\text { temp. . } \\
\mathbf{K}\end{array}$} & \multirow{2}{*}{$\begin{array}{c}\text { Specimen } \\
\text { orientza- } \\
\text { tion }\end{array}$} & \multirow{2}{*}{$\begin{array}{c}\text { Young's } \\
\mathrm{MPa}\end{array}$} & \multirow{2}{*}{$\begin{array}{c}\text { modulus, } \\
\text { psi }\end{array}$} & \multirow{2}{*}{\multicolumn{2}{|c|}{$\begin{array}{l}\text { Proportional limit. } \\
\mathrm{MPa} \quad \mathrm{psi}\end{array}$}} & \multicolumn{2}{|c|}{$\begin{array}{l}\text { Yield strength } \\
\text { (at } 0.2 \% \text { offset) }\end{array}$} & \multicolumn{2}{|c|}{$\begin{array}{l}\text { Ultimate tensile } \\
\text { strength }\end{array}$} & \multicolumn{3}{|c|}{ Tensile strain, $\%$} \\
\hline & & & & & & & $\mathrm{MPa}$ & psi & $\mathrm{MPa}$ & psi & Elastic & Plastic & Total \\
\hline $\begin{array}{l}2 L T, I L R T \\
4 L T, 3 L R T \\
6 L T, 5 L R T\end{array}$ & $\begin{array}{l}295 \\
295 \\
295\end{array}$ & $\begin{array}{l}L \\
L\end{array}$ & $\begin{array}{r}31.63 \\
32.13 \\
\bar{x}=\frac{29.51}{31.09}\end{array}$ & $\begin{array}{l}4587 \\
4660 \\
4280 \\
4509\end{array}$ & $\begin{array}{l}0.304 \\
0.315 \\
0.338 \\
0.319\end{array}$ & $\begin{array}{l}44.09 \\
45.68 \\
49.02 \\
46.26\end{array}$ & $\begin{array}{l}0.572 \\
0.602 \\
0.636 \\
0.603\end{array}$ & $\begin{array}{l}82.96 \\
87.31 \\
92.24 \\
87.50\end{array}$ & $\begin{array}{l}1.027 \\
0.957 \\
1.000 \\
0.995\end{array}$ & $\begin{array}{l}148.95 \\
138.79 \\
145.03 \\
144.26\end{array}$ & $\begin{array}{l}3.1 \\
3.1 \\
3.1 \\
3.1\end{array}$ & $\begin{array}{l}2.8 \\
2.8 \\
3.9 \\
3.2\end{array}$ & $\begin{array}{l}5.9 \\
5.9 \\
7.0 \\
6.3\end{array}$ \\
\hline $\begin{array}{r}2 T T, 1 T R T \\
\text { 4TT, 3TRT } \\
\text { 10TT,9TRT }\end{array}$ & $\begin{array}{l}295 \\
295 \\
295\end{array}$ & $\begin{array}{l}\mathrm{T} \\
\mathrm{T} \\
\mathrm{T}\end{array}$ & $\begin{array}{r}14.59 \\
14.00 \\
=\frac{14.08}{14.22}\end{array}$ & $\begin{array}{l}2116 \\
2030 \\
2042 \\
2063\end{array}$ & $\begin{array}{l}0.156 \\
0.145 \\
0.171 \\
0.157\end{array}$ & $\begin{array}{l}22.63 \\
21.03 \\
24.80 \\
22.82\end{array}$ & $\begin{array}{l}0.262 \\
0.252 \\
0.262 \\
0.260\end{array}$ & $\begin{array}{l}38.00 \\
36.55 \\
38.43 \\
37.66\end{array}$ & $\begin{array}{l}0.639 \\
0.662 \\
0.638 \\
0.646\end{array}$ & $\begin{array}{l}92.67 \\
96.01 \\
92.53 \\
93.74\end{array}$ & $\begin{array}{l}4.5 \\
4.6 \\
4.6 \\
4.6\end{array}$ & $\begin{array}{l}5.8 \\
6.7 \\
5.5 \\
6.0\end{array}$ & $\begin{array}{l}10.3 \\
11.3 \\
10.1 \\
10.6\end{array}$ \\
\hline $\begin{array}{l}\text { 22LT, 15LRT } \\
\text { 24LT, 17LRT } \\
\text { 34LT, 2ILRT }\end{array}$ & $\begin{array}{l}111 \\
111 \\
111\end{array}$ & $\begin{array}{l}L \\
L \\
L\end{array}$ & $\begin{array}{r}58.80 \\
58.75 \\
60.20 \\
\bar{x}=59.25\end{array}$ & $\begin{array}{l}8528 \\
8521 \\
8730 \\
8593\end{array}$ & $\begin{array}{l}- \\
- \\
-\end{array}$ & $\begin{array}{l}- \\
- \\
-\end{array}$ & $\begin{array}{l}- \\
- \\
-\end{array}$ & $\begin{array}{l}- \\
- \\
-\end{array}$ & $\begin{array}{l}1.204 \\
1.041 \\
1.101 \\
1.115\end{array}$ & $\begin{array}{l}174.61 \\
150.98 \\
159.68 \\
161.76\end{array}$ & $\begin{array}{l}1.9 \\
1.9 \\
1.7 \\
1.8\end{array}$ & $\begin{array}{l}0 \\
0 \\
0 \\
0\end{array}$ & $\begin{array}{l}1.9 \\
1.9 \\
1.7 \\
1.8\end{array}$ \\
\hline $\begin{array}{l}\text { 24TT, 19TRT } \\
\text { 26TT,23TRT } \\
\text { 42TT,25TRT }\end{array}$ & $\begin{array}{l}111 \\
111 \\
111\end{array}$ & $\begin{array}{l}\mathrm{T} \\
\mathrm{T} \\
\mathrm{T}\end{array}$ & $\begin{array}{r}25.58 \\
25.84 \\
26.63 \\
\bar{x}=\frac{26.02}{26}\end{array}$ & $\begin{array}{l}3710 \\
3748 \\
3862 \\
3774\end{array}$ & $\begin{array}{l}- \\
-\end{array}$ & $\begin{array}{l}- \\
- \\
-\end{array}$ & $\begin{array}{l}- \\
- \\
-\end{array}$ & $\begin{array}{l}- \\
-\end{array}$ & $\begin{array}{l}0.637 \\
0.611 \\
0.573 \\
0.607\end{array}$ & $\begin{array}{l}92.38 \\
88.61 \\
83.10 \\
88.03\end{array}$ & $\begin{array}{l}2.4 \\
2.3 \\
2.3 \\
2.3\end{array}$ & $\begin{array}{l}0 \\
0 \\
0 \\
0\end{array}$ & $\begin{array}{l}2.4 \\
2.3 \\
2.3 \\
2.3\end{array}$ \\
\hline $\begin{array}{l}\text { 8LT,9LRT } \\
\text { ILLT,1ILRT } \\
\text { I4LT, 13LRT }\end{array}$ & $\begin{array}{l}76 \\
76 \\
76\end{array}$ & $\begin{array}{l}L \\
L\end{array}$ & $\begin{array}{r}64.97 \\
60.80 \\
63.91 \\
63.23\end{array}$ & $\begin{array}{l}9423 \\
8818 \\
9269 \\
9170\end{array}$ & :- & $\begin{array}{l}- \\
-\end{array}$ & $\begin{array}{l}- \\
- \\
-\end{array}$ & : & $\begin{array}{l}1.136 \\
1.286 \\
1.247 \\
1.223\end{array}$ & $\begin{array}{l}164.75 \\
186.51 \\
180.85 \\
177.37\end{array}$ & $\begin{array}{l}1.9 \\
1.8 \\
1.9 \\
1.9\end{array}$ & $\begin{array}{l}0 \\
0 \\
0 \\
0\end{array}$ & $\begin{array}{l}1.9 \\
1.8 \\
1.9 \\
1.9\end{array}$ \\
\hline $\begin{array}{l}\text { 12TT, IITRT } \\
\text { 14TT, I ITRT } \\
\text { 16TT, 17TRT }\end{array}$ & $\begin{array}{l}76 \\
76 \\
76\end{array}$ & $\begin{array}{l}\text { T } \\
\text { T } \\
\text { T }\end{array}$ & $\begin{array}{r}27.82 \\
28.31 \\
27.68 \\
\bar{x}= \\
27.94\end{array}$ & $\begin{array}{l}4035 \\
4106 \\
4014 \\
4052\end{array}$ & : & $\begin{array}{l}- \\
-\end{array}$ & $\begin{array}{l}- \\
- \\
-\end{array}$ & : & $\begin{array}{l}0.750 \\
0.723 \\
0.721 \\
0.731\end{array}$ & $\begin{array}{l}108.77 \\
104.86 \\
104.57 \\
106.07\end{array}$ & $\begin{array}{l}2.6 \\
2.6 \\
2.6 \\
2.6\end{array}$ & $\begin{array}{l}0 \\
0 \\
0 \\
0\end{array}$ & $\begin{array}{l}2.6 \\
2.6 \\
2.6 \\
2.6\end{array}$ \\
\hline $\begin{array}{l}\text { 16LT, I ILRT } \\
\text { 18LT,23LRT } \\
\text { 32LT, 25LRT }\end{array}$ & $\begin{array}{l}4 \\
4 \\
4\end{array}$ & $\begin{array}{l}L \\
L \\
L\end{array}$ & $\begin{array}{r}78.14 \\
75.78 \\
74.26 \\
\bar{x}=76.06\end{array}$ & $\begin{array}{l}11333 \\
10990 \\
10770 \\
11031\end{array}$ & $\begin{array}{l}- \\
- \\
-\end{array}$ & : & - & : & $\begin{array}{l}1.172 \\
1.242 \\
1.149 \\
1.188\end{array}$ & $\begin{array}{l}169.97 \\
180.13 \\
166.64 \\
172.25\end{array}$ & $\begin{array}{l}1.5 \\
1.5 \\
1.6 \\
1.5\end{array}$ & $\begin{array}{l}0 \\
0 \\
0 \\
0\end{array}$ & $\begin{array}{l}1.5 \\
1.5 \\
1.6 \\
1.5\end{array}$ \\
\hline $\begin{array}{l}\text { 18TT, 15TRT } \\
\text { 20TT, 27TRT } \\
\text { 30TT, 3ITRT }\end{array}$ & $\begin{array}{l}4 \\
4 \\
4\end{array}$ & $\begin{array}{l}\mathrm{T} \\
\mathrm{T} \\
\mathrm{T}\end{array}$ & $\begin{array}{r}33.19 \\
32.99 \\
=31.54 \\
32.57\end{array}$ & $\begin{array}{l}4814 \\
4785 \\
4574 \\
4724\end{array}$ & $\begin{array}{l}- \\
- \\
-\end{array}$ & : & $\begin{array}{l}- \\
- \\
-\end{array}$ & : & $\begin{array}{l}0.702 \\
0.641 \\
0.662 \\
0.668\end{array}$ & $\begin{array}{r}101.81 \\
92.96 \\
96.01 \\
96.93\end{array}$ & $\begin{array}{l}2.0 \\
2.0 \\
2.1 \\
2.0\end{array}$ & $\begin{array}{l}0 \\
0 \\
0 \\
0\end{array}$ & $\begin{array}{l}2.0 \\
2.0 \\
2.1 \\
2.0\end{array}$ \\
\hline
\end{tabular}


Table 2. Compressive test results for a $64-\mathrm{kg} / \mathrm{m}^{3}$ polyurethane foam

\begin{tabular}{|c|c|c|c|c|c|c|c|c|c|c|c|c|c|}
\hline $\begin{array}{l}\text { Specimen } \\
\text { number }\end{array}$ & $\begin{array}{l}\text { Test } \\
\text { temp., } \\
k\end{array}$ & $\begin{array}{l}\text { Specimen } \\
\text { orienta- } \\
\text { tion }\end{array}$ & \multicolumn{2}{|c|}{ Young's modulus, } & \multicolumn{2}{|c|}{$\begin{array}{l}\text { Proportional limit, } \\
\qquad \mathrm{MPa}\end{array}$} & \multicolumn{2}{|c|}{$\begin{array}{l}\text { Yield strength } \\
\text { (at } 0.2 \% \text { offset), }\end{array}$} & \multicolumn{2}{|c|}{$\begin{array}{l}\text { Maximum compressive } \\
\text { strength, } \\
\mathrm{MPa}^{\mathrm{ps} \mathrm{i}}\end{array}$} & \multicolumn{3}{|c|}{$\begin{array}{l}\text { Compressive } \\
\text { strain, } \% \\
\text { Elastic Plastic Total }\end{array}$} \\
\hline $\begin{array}{l}26 L C \text { (A) } \\
26 L C \text { (B) } \\
28 L C(B)\end{array}$ & $\begin{array}{l}295 \\
295 \\
295\end{array}$ & $\begin{array}{l}L \\
L\end{array}$ & $\begin{array}{r}23.08 \\
20.37 \\
\bar{x}=\frac{21.63}{21.69}\end{array}$ & $\begin{array}{l}3347 \\
2954 \\
3137 \\
3146\end{array}$ & $\begin{array}{l}0.355 \\
0.405 \\
0.382 \\
0.381\end{array}$ & $\begin{array}{l}51.49 \\
58.74 \\
55.40 \\
55.21\end{array}$ & $\begin{array}{l}0.498 \\
0.482 \\
0.504 \\
0.495\end{array}$ & $\begin{array}{l}72.22 \\
69.90 \\
73.10 \\
71.74\end{array}$ & $\begin{array}{l}0.668 \\
0.668 \\
0.680 \\
0.672\end{array}$ & $\begin{array}{l}96.88 \\
96.88 \\
98.62 \\
97.46\end{array}$ & $\begin{array}{l}2.8 \\
3.2 \\
3.0 \\
3.0\end{array}$ & $\begin{array}{l}2.8 \\
3.4 \\
4.4 \\
3.5\end{array}$ & $\begin{array}{l}5.6 \\
6.6 \\
7.4 \\
6.5\end{array}$ \\
\hline $\begin{array}{l}32 \mathrm{TC}(\mathrm{A}) \\
32 \mathrm{TC}(\mathrm{B}) \\
38 \mathrm{TC}(\mathrm{A})\end{array}$ & $\begin{array}{l}295 \\
295 \\
295\end{array}$ & $\begin{array}{l}T \\
T \\
T\end{array}$ & $\begin{array}{r}7.86 \\
8.30 \\
\bar{x}=\frac{7.95}{8.04}\end{array}$ & $\begin{array}{l}1140 \\
1204 \\
1153 \\
1166\end{array}$ & $\begin{array}{l}0.121 \\
0.136 \\
0.174 \\
0.143\end{array}$ & $\begin{array}{l}17.55 \\
19.72 \\
25.24 \\
20.84\end{array}$ & $\begin{array}{l}0.222 \\
0.219 \\
0.270 \\
0.237\end{array}$ & $\begin{array}{l}32.20 \\
31.76 \\
39.16 \\
34.37\end{array}$ & $\begin{array}{r}0.360 \\
-\quad a \\
0.378 \\
0.369\end{array}$ & $\begin{array}{c}52.21 \\
- \\
54.82 \\
53.52\end{array}$ & $\begin{array}{c}4.4 \\
- \\
4.5 \\
4.5\end{array}$ & $\begin{array}{c}3.1 \\
- \\
\frac{2.6}{2.8}\end{array}$ & $\begin{array}{c}7.5 \\
- \\
\frac{7.1}{7.3}\end{array}$ \\
\hline $\begin{array}{l}28 L C \text { (A) } \\
28 L C(B) \\
30 L C(A)\end{array}$ & $\begin{array}{l}111 \\
111 \\
111\end{array}$ & $\begin{array}{l}L \\
L\end{array}$ & $\begin{array}{r}105.81 \\
87.19 \\
88.72 \\
\bar{x}=93.91\end{array}$ & $\begin{array}{l}15346 \\
12645 \\
12867 \\
13619\end{array}$ & $\begin{array}{l}0.715 \\
0.664 \\
0.657 \\
0.679\end{array}$ & $\begin{array}{r}103.70 \\
96.30 \\
95.28 \\
98.43\end{array}$ & $\begin{array}{l}0.817 \\
0.823 \\
0.792 \\
0.817\end{array}$ & $\begin{array}{l}118.49 \\
119.36 \\
114.86 \\
117.57\end{array}$ & $\begin{array}{l}1.078 \\
1.063 \\
1.121 \\
1.087\end{array}$ & $\begin{array}{r}156.34 \\
154.17 \\
162.58 \\
157.70\end{array}$ & $\begin{array}{l}1.0 \\
1.2 \\
1.3 \\
1.2\end{array}$ & $\begin{array}{r}8.4 \\
10.5 \\
8.3 \\
9.0\end{array}$ & $\begin{array}{r}9.4 \\
11.7 \\
9.6 \\
10.2\end{array}$ \\
\hline $\begin{array}{l}40 \mathrm{TC}(\mathrm{B}) \\
40 \mathrm{TC}(\mathrm{C}) \\
47 \mathrm{TC}(\mathrm{A})\end{array}$ & $\begin{array}{l}111 \\
111 \\
111\end{array}$ & $\begin{array}{l}T \\
T \\
T\end{array}$ & $\begin{array}{r}30.07 \\
30.07 \\
\bar{x}=\frac{33.46}{31.20}\end{array}$ & $\begin{array}{l}4361 \\
4361 \\
4853 \\
4525\end{array}$ & $\begin{array}{l}0.389 \\
0.362 \\
0.334 \\
0.362\end{array}$ & $\begin{array}{l}56.42 \\
52.50 \\
48.44 \\
52.45\end{array}$ & $\begin{array}{l}0.482 \\
0.409 \\
0.378 \\
0.423\end{array}$ & $\begin{array}{l}69.90 \\
59.32 \\
54.82 \\
61.35\end{array}$ & $\begin{array}{l}0.734 \\
0.722 \\
0.730 \\
0.729\end{array}$ & $\begin{array}{l}106.45 \\
104.71 \\
105.87 \\
105.68\end{array}$ & $\begin{array}{l}2.4 \\
2.3 \\
2.1 \\
2.3\end{array}$ & $\begin{array}{r}9.9 \\
10.7 \\
8.0 \\
9.5\end{array}$ & $\begin{array}{l}12.3 \\
13.0 \\
10.1 \\
11.8\end{array}$ \\
\hline $\begin{array}{l}31 L C \text { (A) } \\
31 L C \text { (B) } \\
31 L C \text { (C) }\end{array}$ & $\begin{array}{l}76 \\
76 \\
76\end{array}$ & $\begin{array}{l}\mathrm{L} \\
\mathrm{L} \\
\mathrm{L}\end{array}$ & $\begin{array}{r}85.13 \\
87.77 \\
\bar{x}=\frac{82.03}{84.98}\end{array}$ & $\begin{array}{l}12346 \\
12729 \\
11897 \\
12324\end{array}$ & $\begin{array}{l}0.846 \\
0.873 \\
0.753 \\
0.824\end{array}$ & $\begin{array}{l}122.70 \\
126.61 \\
109.21 \\
119.51\end{array}$ & $\begin{array}{l}0.970 \\
0.962 \\
0.897 \\
0.943\end{array}$ & $\begin{array}{l}140.68 \\
139.52 \\
130.09 \\
136.76\end{array}$ & $\begin{array}{l}1.179 \\
1.160 \\
1.131 \\
1.157\end{array}$ & $\begin{array}{l}170.99 \\
168.23 \\
164.03 \\
167.75\end{array}$ & $\begin{array}{l}1.4 \\
1.3 \\
1.4 \\
1.4\end{array}$ & $\begin{array}{l}7.7 \\
8.2 \\
7.2 \\
7.7\end{array}$ & $\begin{array}{r}9.1 \\
9.5 \\
8.6 \\
9.1\end{array}$ \\
\hline $\begin{array}{l}38 T C \text { (A) } \\
3 B T C \text { (B) } \\
\text { 49TC (A) }\end{array}$ & $\begin{array}{l}76 \\
76 \\
76\end{array}$ & $\begin{array}{l}T \\
T \\
T\end{array}$ & $\begin{array}{r}16.80 \\
17.72 \\
\bar{x}=\frac{16.85}{17.12}\end{array}$ & $\begin{array}{l}2436 \\
2570 \\
2444 \\
2483\end{array}$ & $\begin{array}{l}0.376 \\
0.341 \\
0.349 \\
0.355\end{array}$ & $\begin{array}{l}54.53 \\
49.46 \\
50.62 \\
51.54\end{array}$ & $\begin{array}{l}0.552 \\
0.537 \\
0.539 \\
0.543\end{array}$ & $\begin{array}{l}80.06 \\
77.88 \\
78.17 \\
78.70\end{array}$ & $\begin{array}{l}0.792 \\
0.792 \\
0.781 \\
0.788\end{array}$ & $\begin{array}{l}114.86 \\
114.86 \\
113.27 \\
114.33\end{array}$ & $\begin{array}{l}4.6 \\
4.4 \\
4.5 \\
4.5\end{array}$ & $\begin{array}{l}5.9 \\
7.6 \\
7.3 \\
6.9\end{array}$ & $\begin{array}{l}10.5 \\
12.0 \\
11.8 \\
11.4\end{array}$ \\
\hline $\begin{array}{l}33 L C(A) \\
33 L C(B) \\
33 L C(C) \\
35 L C(A)\end{array}$ & $\begin{array}{l}4 \\
4 \\
4 \\
4\end{array}$ & $\begin{array}{l}L \\
L \\
L \\
L\end{array}$ & $\begin{array}{r}79.55 \\
53.17 \\
99.43 \\
137.69 \\
\bar{x}=1.46\end{array}$ & $\begin{array}{r}11537 \\
7711 \\
14420 \\
19969 \\
13409\end{array}$ & $\begin{array}{c}0.765 \\
0.850 \\
0.846 \\
\frac{-}{0.820}\end{array}$ & $\begin{array}{c}110.95 \\
123.28 \\
122.70 \\
\frac{-.98}{118.98}\end{array}$ & $\begin{array}{l}0.897 \\
0.955 \\
0.947 \\
0.765 \\
0.891\end{array}$ & $\begin{array}{l}130.09 \\
138.50 \\
137.34 \\
110.95 \\
129.22\end{array}$ & $\begin{array}{l}1.156 \\
1.183 \\
1.210 \\
1.206 \\
1.189\end{array}$ & $\begin{array}{l}167.65 \\
171.57 \\
175.49 \\
174.91 \\
172.41\end{array}$ & $\begin{array}{l}1.5 \\
2.2 \\
1.2 \\
0.9 \\
1.5\end{array}$ & $\begin{array}{l}5.9 \\
7.4 \\
8.7 \\
8.5 \\
7.6\end{array}$ & $\begin{array}{l}7.4 \\
9.6 \\
9.9 \\
\frac{9.4}{9.1}\end{array}$ \\
\hline $\begin{array}{l}35 T C \text { (B) } \\
48 T C \text { (A) } \\
49 T C \text { (B) }\end{array}$ & $\begin{array}{l}4 \\
4 \\
4\end{array}$ & $\begin{array}{l}T \\
T \\
T\end{array}$ & $\begin{array}{r}43.48 \\
46.29 \\
45.17 \\
\bar{x}= \\
44.98\end{array}$ & $\begin{array}{l}6306 \\
6713 \\
6551 \\
6523\end{array}$ & $\begin{array}{l}0.294 \\
0.475 \\
-\quad \\
0.384\end{array}$ & $\begin{array}{c}42.64 \\
68.89 \\
\frac{-}{55.77}\end{array}$ & $\begin{array}{l}0.387 \\
0.579 \\
\frac{-}{0.483}\end{array}$ & $\begin{array}{l}56.13 \\
83.97 \\
\frac{-}{70.05}\end{array}$ & $\begin{array}{l}0.807 \\
0.850 \\
0.838 \\
0.832\end{array}$ & $\begin{array}{l}117.04 \\
123.28 \\
121.53 \\
120.62\end{array}$ & $\begin{array}{l}2.1 \\
2.0 \\
- \\
2.0\end{array}$ & $\begin{array}{c}8.4 \\
14.3 \\
- \\
11.4\end{array}$ & $\begin{array}{c}10.5 \\
16.3 \\
- \\
13.4\end{array}$ \\
\hline
\end{tabular}

\footnotetext{
a Stress continued to increase as strain increased - no maximum reached.
} 
Table 3. Shear strength test results for a $64-\mathrm{kg} / \mathrm{m}^{3}$ polyurethane foam

\begin{tabular}{|c|c|c|c|c|}
\hline \multirow{2}{*}{$\begin{array}{l}\text { Specimen } \\
\text { number }\end{array}$} & \multirow{2}{*}{$\begin{array}{c}\text { Test } \\
\text { temperature, } \\
K\end{array}$} & \multirow{2}{*}{$\begin{array}{l}\text { Specimen } \\
\text { orientation }\end{array}$} & \multicolumn{2}{|c|}{ Shear strength, } \\
\hline & & & $\mathrm{MPa}$ & psi \\
\hline $\begin{array}{l}\text { SL4 } \\
\text { SL6 } \\
\text { SL7 }\end{array}$ & $\begin{array}{l}295 \\
295 \\
295\end{array}$ & $\begin{array}{l}L \\
L\end{array}$ & $\begin{array}{l}0.428 \\
0.581 \\
0.514 \\
0.508\end{array}$ & $\begin{array}{l}61.99 \\
84.19 \\
74.53 \\
73.57\end{array}$ \\
\hline $\begin{array}{l}\text { ST6 } \\
\text { ST7 } \\
\text { ST8 }\end{array}$ & $\begin{array}{l}295 \\
295 \\
295\end{array}$ & $\begin{array}{l}T \\
T \\
T\end{array}$ & $\bar{x}=\begin{array}{l}0.681 \\
0.661 \\
0.663 \\
0.668\end{array}$ & $\begin{array}{l}98.68 \\
95.90 \\
96.19 \\
96.92\end{array}$ \\
\hline $\begin{array}{l}\text { SL } 11 \\
\text { SLI2 } \\
\text { SL13 }\end{array}$ & $\begin{array}{l}111 \\
111 \\
111\end{array}$ & $\begin{array}{l}L \\
L \\
L\end{array}$ & $\begin{array}{l}0.697 \\
0.728 \\
0.694 \\
0.706\end{array}$ & $\begin{array}{l}101.01 \\
105.54 \\
100.67 \\
102.41\end{array}$ \\
\hline $\begin{array}{l}\text { ST11 } \\
\text { ST12 } \\
\text { STI3 }\end{array}$ & $\begin{array}{l}111 \\
111 \\
111\end{array}$ & $\begin{array}{l}T \\
T \\
T\end{array}$ & $\bar{x}=\begin{array}{l}0.704 \\
0.729 \\
0.791 \\
0.741\end{array}$ & $\begin{array}{l}102.09 \\
105.65 \\
114.67 \\
107.47\end{array}$ \\
\hline $\begin{array}{l}\text { SL1 } \\
\text { SL2 } \\
\text { SL3 }\end{array}$ & $\begin{array}{l}76 \\
76 \\
76\end{array}$ & $\begin{array}{l}L \\
L \\
L\end{array}$ & $\begin{array}{r}0.727 \\
0.739 \\
0.705 \\
0.724\end{array}$ & $\begin{array}{l}105.38 \\
107.13 \\
102.23 \\
104.91\end{array}$ \\
\hline $\begin{array}{l}\text { ST4 } \\
\text { ST9 } \\
\text { ST10 }\end{array}$ & $\begin{array}{l}76 \\
76 \\
76\end{array}$ & $\begin{array}{l}T \\
T \\
T\end{array}$ & $\begin{array}{r}0.821 \\
0.546 \\
\bar{x}=\frac{0.759}{0.709}\end{array}$ & $\begin{array}{r}119.07 \\
79.19 \\
110.00 \\
102.75\end{array}$ \\
\hline $\begin{array}{l}\text { SL8 } \\
\text { SL9 } \\
\text { SL10 }\end{array}$ & $\begin{array}{l}4 \\
4 \\
4\end{array}$ & $\begin{array}{l}L \\
L \\
L\end{array}$ & $\bar{x}=\begin{array}{l}0.612 \\
0.691 \\
0.712 \\
0.672\end{array}$ & $\begin{array}{r}88.70 \\
100.18 \\
103.20 \\
97.36\end{array}$ \\
\hline $\begin{array}{l}\text { ST1 } \\
\text { ST3 } \\
\text { ST5 }\end{array}$ & $\begin{array}{l}4 \\
4 \\
4\end{array}$ & $\begin{array}{l}\mathrm{T} \\
\mathrm{T} \\
\mathrm{T}\end{array}$ & $\begin{array}{r}0.909 \\
0.739 \\
\bar{x}=\frac{0.975}{0.874}\end{array}$ & $\begin{array}{l}131.78 \\
107.08 \\
141.37 \\
126.74\end{array}$ \\
\hline
\end{tabular}


Table 4. Summary of tensile test results for a $64-\mathrm{kg} / \mathrm{m}^{3}$ polyurethane foam (average values)

\begin{tabular}{|c|c|c|c|c|c|}
\hline $\begin{array}{l}\text { Material } \\
\text { property }\end{array}$ & $\begin{array}{c}\text { Specimen } \\
\text { orientation }\end{array}$ & $295 \mathrm{~K}$ & $111 \mathrm{~K}$ & $76 \mathrm{~K}$ & $4 \mathrm{~K}$ \\
\hline $\begin{array}{l}\text { Young's } \\
\text { modulus, } \\
\text { MPa (psi) }\end{array}$ & $\begin{array}{l}\mathrm{L} \\
\mathrm{T}\end{array}$ & $\begin{array}{l}31.09(4,510) \\
14.22(2,060)\end{array}$ & $\begin{array}{l}59.25(8,590) \\
26.02(3,770)\end{array}$ & $\begin{array}{l}63.23(9,170) \\
27.94(4,050)\end{array}$ & 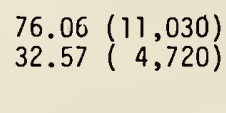 \\
\hline $\begin{array}{l}\text { Proportional } \\
\text { limit, } \\
\mathrm{MPa} \text { (psi) }\end{array}$ & $\stackrel{L}{T}$ & $\begin{array}{l}0.319(46.26) \\
0.157(22.82)\end{array}$ & - & - & - \\
\hline $\begin{array}{l}\text { Yield strength } \\
(0.2 \% \text { Offset), } \\
\mathrm{MPa} \text { (psi) }\end{array}$ & $\stackrel{L}{T}$ & $\begin{array}{l}0.603(87.50) \\
0.260(37.66)\end{array}$ & - & - & - \\
\hline $\begin{array}{l}\text { Ul timate ten- } \\
\text { sile strength, } \\
M P a(p s i)\end{array}$ & $\stackrel{L}{T}$ & $\begin{array}{l}0.995(144.26) \\
0.646(93.74)\end{array}$ & $\begin{array}{l}1.115(161.76) \\
0.607(88.03)\end{array}$ & $\begin{array}{l}1.223(177.37) \\
0.731(106.07)\end{array}$ & $\begin{array}{l}1.188(172.25) \\
0.668(96.93)\end{array}$ \\
\hline $\begin{array}{l}\text { Tensile strain, } \% \\
\text { Elastic } \\
\text { Plastic } \\
\text { Total }\end{array}$ & L & $\begin{array}{l}3.1 \\
3.2 \\
6.3\end{array}$ & $\begin{array}{r}1.8 \\
0 \\
1.8\end{array}$ & $\begin{array}{r}1.9 \\
0 \\
1.9\end{array}$ & $\begin{array}{r}1.5 \\
0 \\
1.5\end{array}$ \\
\hline $\begin{array}{l}\text { Elastic } \\
\text { Plastic } \\
\text { Total }\end{array}$ & $T$ & $\begin{array}{r}4.6 \\
6.0 \\
10.6\end{array}$ & $\begin{array}{r}2.3 \\
0 \\
2.3\end{array}$ & $\begin{array}{r}2.6 \\
0 \\
2.6\end{array}$ & $\begin{array}{r}2.0 \\
0 \\
2.0\end{array}$ \\
\hline
\end{tabular}

Table 5. Summary of compressive test results for a $64-\mathrm{kg} / \mathrm{m}^{3}$ polyurethane foam (average values)

\begin{tabular}{|c|c|c|c|c|c|}
\hline \multirow{2}{*}{$\begin{array}{l}\text { Material } \\
\text { property }\end{array}$} & \multirow{2}{*}{$\begin{array}{l}\text { Specimen } \\
\text { orientation }\end{array}$} & \multirow[b]{2}{*}{$295 \mathrm{~K}$} & \multicolumn{2}{|c|}{ Temperature } & \multirow[b]{2}{*}{$4 \mathrm{~K}$} \\
\hline & & & $111 \mathrm{~K}$ & $76 \mathrm{~K}$ & \\
\hline $\begin{array}{l}\text { Young's } \\
\text { modulus, } \\
\mathrm{MPa} \text { (psi) }\end{array}$ & $\stackrel{L}{T}$ & $\begin{array}{r}21.69(3,150) \\
8.04(1,170)\end{array}$ & $\begin{array}{l}93.91(13,620) \\
31.20(4,530)\end{array}$ & $\begin{array}{l}84.98\left(\begin{array}{r}12,320) \\
17.12\end{array}(2,480)\right.\end{array}$ & $\begin{array}{l}92.46(13,410) \\
44.98(6,520)\end{array}$ \\
\hline $\begin{array}{l}\text { Proportional } \\
\text { limit, } \\
\mathrm{MPa} \text { (psi) }\end{array}$ & $\stackrel{L}{T}$ & $\begin{array}{ll}0.381 & (55.21) \\
0.143(20.84)\end{array}$ & $\begin{array}{l}0.679(98.43) \\
0.362(52.45)\end{array}$ & $\begin{array}{l}0.824(119.51) \\
0.355(51.54)\end{array}$ & $\begin{array}{l}0.820(118.98) \\
0.384(55.77)\end{array}$ \\
\hline $\begin{array}{l}\text { Yield strength } \\
(0.2 \% \text { Offset), } \\
\operatorname{MPa~(psi)~}\end{array}$ & $\stackrel{L}{T}$ & $\begin{array}{l}0.495(71.74) \\
0.237(34.37)\end{array}$ & 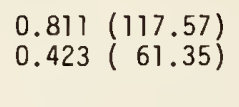 & $\begin{array}{l}0.943(136.76) \\
0.543(78.70)\end{array}$ & $\begin{array}{l}0.891(129.22) \\
0.483(70.05)\end{array}$ \\
\hline $\begin{array}{l}\text { Maximum compres- } \\
\text { sive strength, } \\
M P a(p s i)\end{array}$ & $\stackrel{L}{T}$ & $\begin{array}{l}0.672(97.46) \\
0.369(53.52)\end{array}$ & $\begin{array}{l}1.087(157.70) \\
0.729(105.68)\end{array}$ & $\begin{array}{l}1.157(167.75) \\
0.788(114.33)\end{array}$ & $\begin{array}{l}1.189(172.41) \\
0.832(120.62)\end{array}$ \\
\hline $\begin{array}{l}\text { Compressive stra } \\
\text { Elastic } \\
\text { Plastic } \\
\text { Total }\end{array}$ & , \% & $\begin{array}{l}3.0 \\
3.5 \\
6.5\end{array}$ & $\begin{array}{r}1.2 \\
9.0 \\
10.2\end{array}$ & $\begin{array}{l}1.4 \\
7.7 \\
9.1\end{array}$ & $\begin{array}{l}1.5 \\
7.6 \\
9.1\end{array}$ \\
\hline $\begin{array}{l}\text { Elastic } \\
\text { Plastic } \\
\text { Total }\end{array}$ & $T$ & $\begin{array}{l}4.5 \\
2.8 \\
7.3\end{array}$ & $\begin{array}{r}2.3 \\
9.5 \\
11.8\end{array}$ & $\begin{array}{r}4.5 \\
6.9 \\
11.4\end{array}$ & $\begin{array}{r}2.0 \\
11.4 \\
13.4\end{array}$ \\
\hline
\end{tabular}


Table 6 . Summary of shear strength test results for a $64-\mathrm{kg} / \mathrm{m}^{3}$ polyurethane foam (average values)

\begin{tabular}{|c|c|c|c|}
\hline \multirow{2}{*}{$\begin{array}{l}\text { Test } \\
\text { temperature, } \mathrm{K}\end{array}$} & \multirow[t]{2}{*}{ Specimen orientation } & \multicolumn{2}{|c|}{ Shear strength, } \\
\hline & & $\mathrm{MPa}$ & psi \\
\hline 295 & $\frac{L}{T}$ & $\begin{array}{l}0.508 \\
0.668\end{array}$ & $\begin{array}{l}73.57 \\
96.92\end{array}$ \\
\hline 111 & $\begin{array}{l}\mathrm{L} \\
\mathrm{T}\end{array}$ & $\begin{array}{l}0.706 \\
0.741\end{array}$ & $\begin{array}{l}102.41 \\
107.47\end{array}$ \\
\hline 76 & $\frac{\mathrm{L}}{\mathrm{T}}$ & $\begin{array}{l}0.724 \\
0.709\end{array}$ & $\begin{array}{l}104.91 \\
102.75\end{array}$ \\
\hline 4 & $\frac{L}{T}$ & $\begin{array}{l}0.672 \\
0.874\end{array}$ & $\begin{array}{r}97.36 \\
126.74\end{array}$ \\
\hline
\end{tabular}





\title{
TENSILE, COMPRESSIVE, AND SHEAR PROPERTIES OF A $96-\mathrm{kg} / \mathrm{m}^{3}$ \\ POLYURETHANE FOAM AT LOW TEMPERATURES ${ }^{\star}{ }^{\dagger}$
}

\author{
J. M. Arvidson and R. S. Bell \\ Fracture and Deformation Division \\ National Measurement Laboratory \\ L. L. Sparks and C. Guobang ${ }^{\ddagger}$ \\ Chemical Engineering Science Division \\ National Engineering Laboratory \\ National Bureau of Standards \\ Boulder, Colorado
}

\section{ABSTRACT}

Polyurethane foam, having a density of $96 \mathrm{~kg} / \mathrm{m}^{3}$, was tested at 295,111 , 76 and $4 \mathrm{k}$. The material properties reported are Young's modulus, proportional limit, yield strength (at $0.2 \%$ offset), tensile, shear, and compressive strengths, and elongation (elastic and plastic). The test apparatus permits tension, compression, and shear testing of materials at any temperature ranging from 295 to $1.8 \mathrm{~K}$. Strain is measured with a concentric, overlappingcylinder, capacitance extensometer that is highly sensitive and linear in output. The extent of 1 inearity was in excess of $2.5 \mathrm{~cm}$ for the cylinder geometry chosen, and the signal noise level was on $7 \mathrm{y} 10^{-6} \mathrm{~cm} / \mathrm{cm}$.

Key Words: Compressive strength; elongation; foam; insulation; low temperatures; mechanical properties; proportional 1 imit; shear strength; tensile strength; yield strength; Young's modulus.

\footnotetext{
* Supported by the Gas Research Institute, Chicago and the Office of Fusion Energy, U. S. Department of Energy.

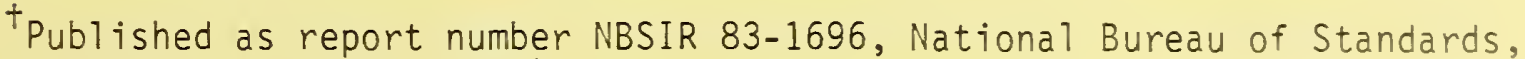
Boulder, Colorado (1983).

${ }^{\ddagger}$ Guest worker at NBS. Department of Thermal Science, Zhejiang University, Hangzhon, Zhejiang Province, People's Republic of China.
} 

In a continuing effort to increase the available knowledge of the mechanical properties of polyurethane foam (PU), a foam of density $96 \mathrm{~kg} / \mathrm{m}^{3}$ was subjected to the same test program as was previously conducted on less dense materials $[1,2]$. The data presented will complete a three year effort to characterize the mechanical properties of three dersities of PU foam at low temperatures. Previous reports on the mechanical properties of 32 and 64 $\mathrm{kg} / \mathrm{m}^{3}$ density foams may be obtained from the National Technical Information Service (NTIS), Springfield, VA 22.161 (request NBSIR 81-1654 and NBSIR 83-1684 respective1y).

The apparatus used $[1,2]$ has the capability of operating at various temperatures $(295 \mathrm{~K}$ to $4 \mathrm{~K}$ ), in gas or liquid environments and at pressures from subatmospheric to $0.3 \mathrm{MPa}$ absolute. Strain is measured by utilizing. concentric overlapping-cylinders and the change in electrical capacitance [3]. This method for strain extensometry is accurate to better than 0.1 percent, linear in excess of $2.5 \mathrm{~cm}$ elongation, functions well in low temperature environments, and provides a low-noise output signal $\left(\leq 10^{-6} \mathrm{~cm} / \mathrm{cm}\right)$ as 1 long as the device is situated in a stable single-phase fluid [4,5]. The calibration can be accomplished at room temperature, in air, and to conduct a test in any other medium (e.g., liquid nitrogen) the original calibration need only be corrected for the change in dielectric constant [6].

\section{MATERIAL CHARACTERIZATION}

The material tested in this study is a nominal $96 \mathrm{~kg} / \mathrm{m}^{3} \mathrm{PU}$ foam. This amorphous, organic polymer is a thermosetting foam. Our supply of this material was obtained from a commercial producer. 
The bulk supply was in the form of a $0.13 \times 1.22 \times 2.44 \mathrm{~m} \mathrm{slab}$; the coordinate axes relative to these dimensions are $z, y$, and $x$ respectively. The orientation of the cell axes was determined optically from statistical evaluation of microphotographs. The ratios of all height to cell width for the principal orthogonal planes of the physical test specimens were: $x / y=1.02 \pm 0.50, z / x=1.14 \pm 0.59, z / y=1.14 \pm 0.59$. The uncertainties given represent estimates of one standard deviation. The ratios indicate that the direction of foam rise is parallel to the $z$ axis, is essentially perpendicular to the $x y$ plane, and the cellular cross-section in the $x y$ plane is nearly circular.

The density of the resin-gas composite was found to be $99 \pm 3.4 \mathrm{~kg} / \mathrm{m}^{3}$ after conditioning at $23^{\circ} \mathrm{C}$ and 50 percent relative humidity. The uncertainty given is an estimate of one standard deviation.

\section{SPECIMENS}

Two tensile specimen geometries were used to determine all mechanical properties. A rod (epoxied to polycarbonate grip ends) of $9.9 \mathrm{~cm}$ in length and $2.9 \mathrm{~cm}$ in diameter was used to determine Young's modulus, proportional limit, yield strength, and elongation. A reduced-section specimen with a gage length of approximately $5.1 \mathrm{~cm}$, and $1.9 \mathrm{~cm}$ in diameter, was used to determine the ultimate tensile strength. Using this geometry forced a failure within the gage length, thus avoiding a premature failure elsewhere due to biaxial stresses at the epoxied polycarbonate grips.

The compression specimens were rods $2.54 \mathrm{~cm} 1 \mathrm{ong}$ and $2.54 \mathrm{~cm}$ in diameter. No grips were required for these specimens and therefore all compressive material properties were determined using this geometry. 
The shear specimens, $1.9 \times 2.54 \times 0.4 \mathrm{~cm}$, were epoxied to flat plates and each plate was attached to the tensile pull-rod system. An aluminum cylinder slipped over the specimen plates with a resistive heater and thermocouple, built into the cylinder, was used for temperature control during a test.

\section{TEST PROCEDURE}

Tests were conducted at $295 \mathrm{~K}$ (air), $111 \mathrm{~K}\left(\mathrm{GN}_{2}\right), 76 \mathrm{~K}\left(\mathrm{LN}_{2}\right)$, and 4 $K\left(\mathrm{LH}_{e}\right)$. A minimum of three samples were tested at each temperature, ari in some cases several more were tested to determine materjal variability. Minimization of thermal shock to the sample was accomplished by using very slow transfer rates of 1iquid helium or nitrogen; on the order of $0.2 \ell \mathrm{min}^{-1}$. A given temperature was held for a minimum of 15 minutes prior to testing, in order to ensure that the specimen was isothermal.

Each specimen was "conditioned" in an environmental chamber for at least four days at $23^{\circ} \mathrm{C}$ and 50 percent relative humidity. Tension, compression, and shear tests were conducted using a conventional tension/compression test machine at a strain rate of $5 \times 10^{-3} \mathrm{~min}^{-1}$. Preliminary tests were conducted, varying the strain rate from $5 \times 10^{-2}$ to $5 \times 10^{-4} \mathrm{~min}^{-1}$. The test results indicated there was no measurable effect on the mechanical property values.

Tensile and compressive properties reported include: Young's modulus, proportional limit, yield strength (at $0.2 \%$ offset), ultimate strength, and elongation (elastic and plastic).

\section{RESULTS}

Results are presented in figures 1 through 12 and tables 1 through 6. The bars on these figures indicate the data spread from replicate tests. The scatter is typically higher for compression and shear than for tensile tests 
because the compressive and shear tests are more sensitive to misalignment during testing (tensile specimens tend to self-align).

A1. properties were determined in both the longitudinal and transverse orientations. The temperature dependent tensile results for Young's modulus, strength, and strain are shown in figures 1 through 3 . Tensile stress versus strair at all test temperatures is shown in figure 4. Temperature dependent compressive results for Young's modulus, strength, proportional limit, yield strength, and strain are shown in figures 5 through 9 . Compressive stress versus strain at all test temperatures is shown in figure 10 . Figure 11 shows a typical load versus displacement plot that was taken during an actual test. The shear strength versus temperature is plotted in figure 12.

Tables 1 through 3 give the tensile, compressive, and shear results for individual specimens and tables 4 through 6 give the average values for all tests.

Owing to material variability, the stress versus strain graphs were plotted as smooth curves, which do not illustrate the individual cell fajlure phenomena. Fach stress versus strain curve at a given temperature and orientation is the average of three or more specimens tested.

\section{DISCUSSION OF RESULTS}

Compressive and tensile strength, proportional limit, yield strength, and Young's modulus increase with decreasing temperature. The longitudinally oriented specimens are always higher in strength than those obtained from the transverse orientation. 
As shown in figure 3, tensile strain decreases with temperature as the material becomes brittle at temperatures below $111 \mathrm{~K}$. Both tensile ard compressive stress versus strain plots (see figures 4 and 10) illustrate the behavior of longitudinal and transverse specimens tested at 295, 111, 76, and $4 \mathrm{~K}$.

Figure 11 is an actual record of load versus displacement for a typica] specimen. The load drops that occur at low temperature may be associated with individual or multiple cells collapsing $[7,8]$. Because the material is ]ess brittle at room temperature this phenomena is not seen.

The shear strergth, as shown in figure 12, increases from room temperature to $111 \mathrm{~K}$ and then levels off as the test temperature decreases to $4 \mathrm{~K}$. The large range of values of shear strength at a given temperature, as shown in figure 12, could result from misalignment during a test; and except for tests at $76 \mathrm{~K}$ the longitudinal and transverse curves are similar.

It is believed that thermal cycling produces cell degradation [9]. Variables such as thermal cycling, moisture content, aging, and others could be studied in the near future.

\section{ACKNOWLEDGMENT}

The authors are indebted to Edward A. Pierson for his assistance in the preparation of this manuscript for publication. 
[1] J. M. Arvidson and L. L. Sparks, Low Temperature Mechanical Properties of a Polyurethane Foam, NBSIR 81-1654, National Bureau of Standards, Poulder, Colorado 80303 (November, 1981).

[2] J. M. Arvidson, L. L. Sparks, and Chen Guobang, Tensile, Compressive, and Shear Properties of a $64 \mathrm{~kg} / \mathrm{m}^{3}$ Polyurethane Foam at Low Temperatures, NBSIR 83-1684, National Bureau of Standards, Boulder, Colorado 80303 (February, 1983).

[3] P. P. Reed, J. M. Arvidson, and R. L. Durcholz, Tensile Properties of Polyurethane and Polystyrene Foams From $76 \mathrm{~K}$ to $300 \mathrm{~K}$, in: "Advances in Cryogenic Engineering", Vol. 18, K.D. Timmerhaus, ed., Plenum Press, New York (1973), pp. 184-193.

[4] J. M. Roberts, R. E. Herring, and D. E. Hartman, The Use of Capacitance Gauge Sensors to Make Precision Mechanical Property Measurements, in: "Materials Technology", American Society for Mechanical Engineers, New York (1968), pp. 87-96.

[5] "High-Temperature Capacitive Strain Measurement System," NASA Tech. Brief B75-10069, NASA (1975).

[6] G. K. White, Measurement of Thermal Expansion at Low Temperatures, Cryogenics, 2 (1961), pp. 151-158.

[7] L. J. Gibson, M. F. Ashby, G. S. Schajer, and C. J. Robertson, The Mecharics of Two-Dimensional Cellular Materials, Proc. R. Soc. Lond. A382 (1982), pp. 25-42.

[8] I. J. Gibson and M. F. Ashby, The Mechanics of Three-Dimensional Cellular Materials, Proc. R. Soc. Lond. A382, pp. 43-59 (1982).

[9] E. L. Sharpe and R. G. Helenbrook, Durability of Foam Insulation for $\mathrm{LH}_{2}$ Fuel Tanks of Future Subsonic Transports, in Nonmetallic Materials and Composites at Low Temperatures, (Eds. A. F. Clark, R. P. Reed and G. Hartwig), Plenum Press, New York, 1979, pp. 207-230. 
Figure 1. Tensile Young's modulus versus temperature

Figure 2. Ultimate tensile strength versus temperature

Figure 3. Tensile strain versus temperature

Figure 4. Tensile stress versus strain (longitudinal anc transverse)

Figure 5. Compressive Young's modulus versus temperature

Figure 6. Compressive strength versus temperature

Figure 7. Compressive proportional limit versus temperature

Figure 8. Compressive yield strength versus temperature

Figure 9. Compressive strain versus temperature

Figure 10. Compressive stress versus strain (longitudinal and transverse)

Figure 11. Typical load versus displacement (arbitrary units)

Figure 12. Shear strength versus temperature (longitudinal and transverse)

\section{LIST OF TABLES}

Table 1. Tensile test results for a $96-\mathrm{kg} / \mathrm{m}^{3}$ polyurethane foam

Table 2. Compressive test results for a $96-\mathrm{kg} / \mathrm{m}^{3}$ polyurethane foam

Table 3. Shear strength test results for a $96-\mathrm{kg} / \mathrm{m}^{3}$ polyurethane foam

Table 4. Summary of tensile test results for a $96-\mathrm{kg} / \mathrm{m}^{3}$ polyurethane foam (average values)

Table 5. Summary of compressive test results for a $96-\mathrm{kg} / \mathrm{m}^{3}$ polyurethane foam (average values)

Table 6. Summary of shear strength test results for a $96-\mathrm{kg} / \mathrm{m}^{3}$ polyurethane foam (average values) 


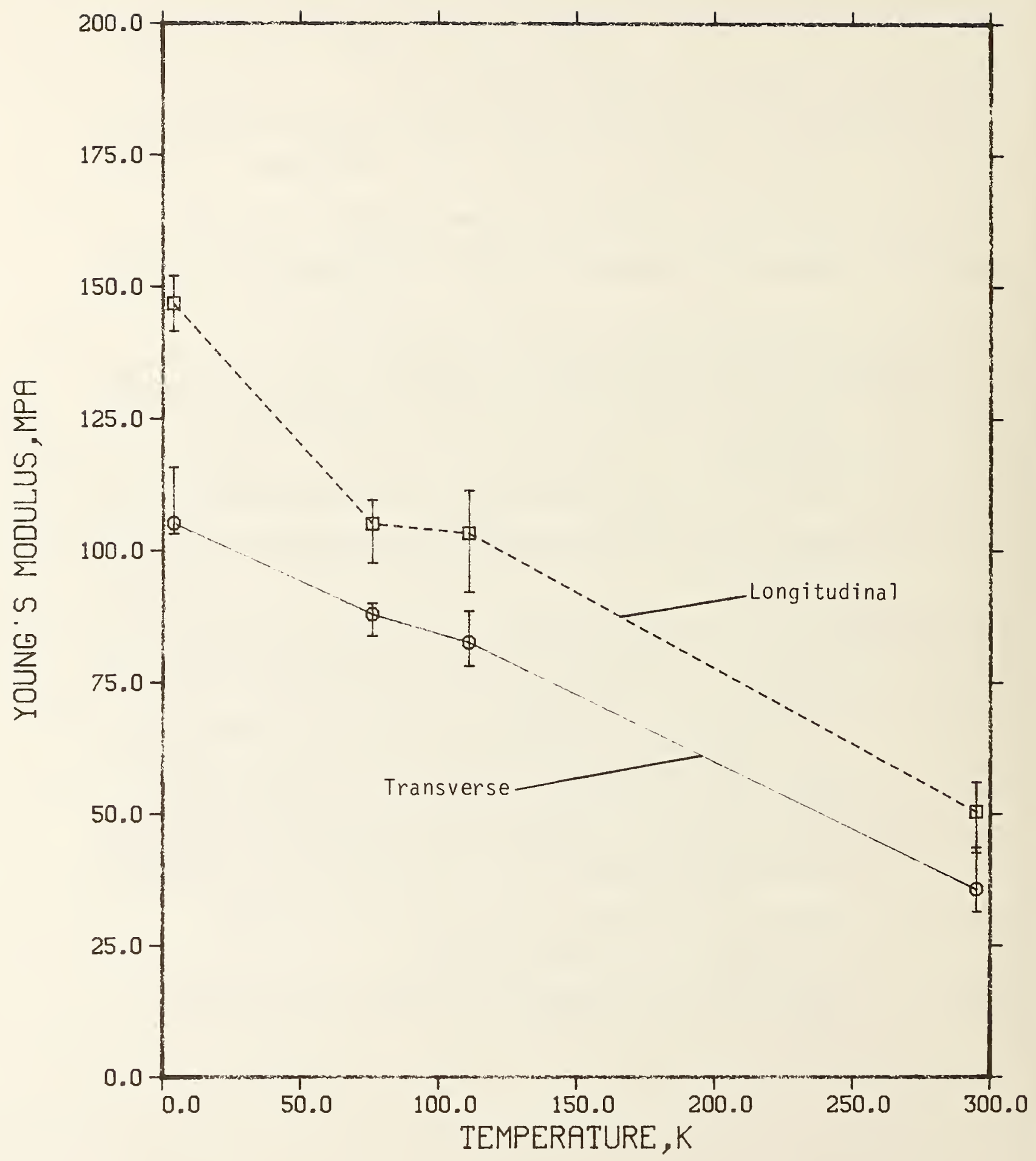

Figure 1. Tensile Young's modulus versus temperature. 


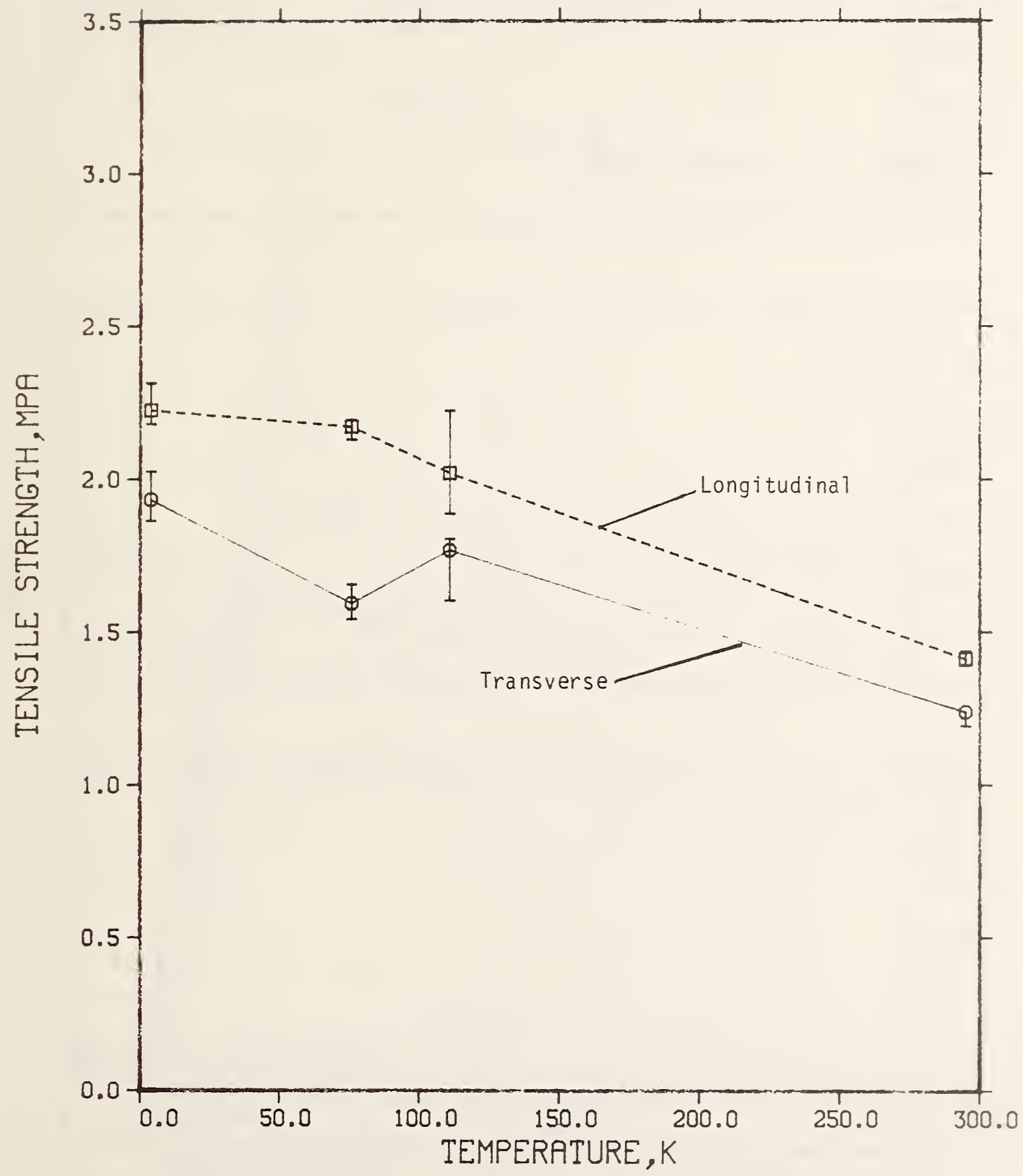

Figure 2. Ultimate tensile strength versus temperature. 

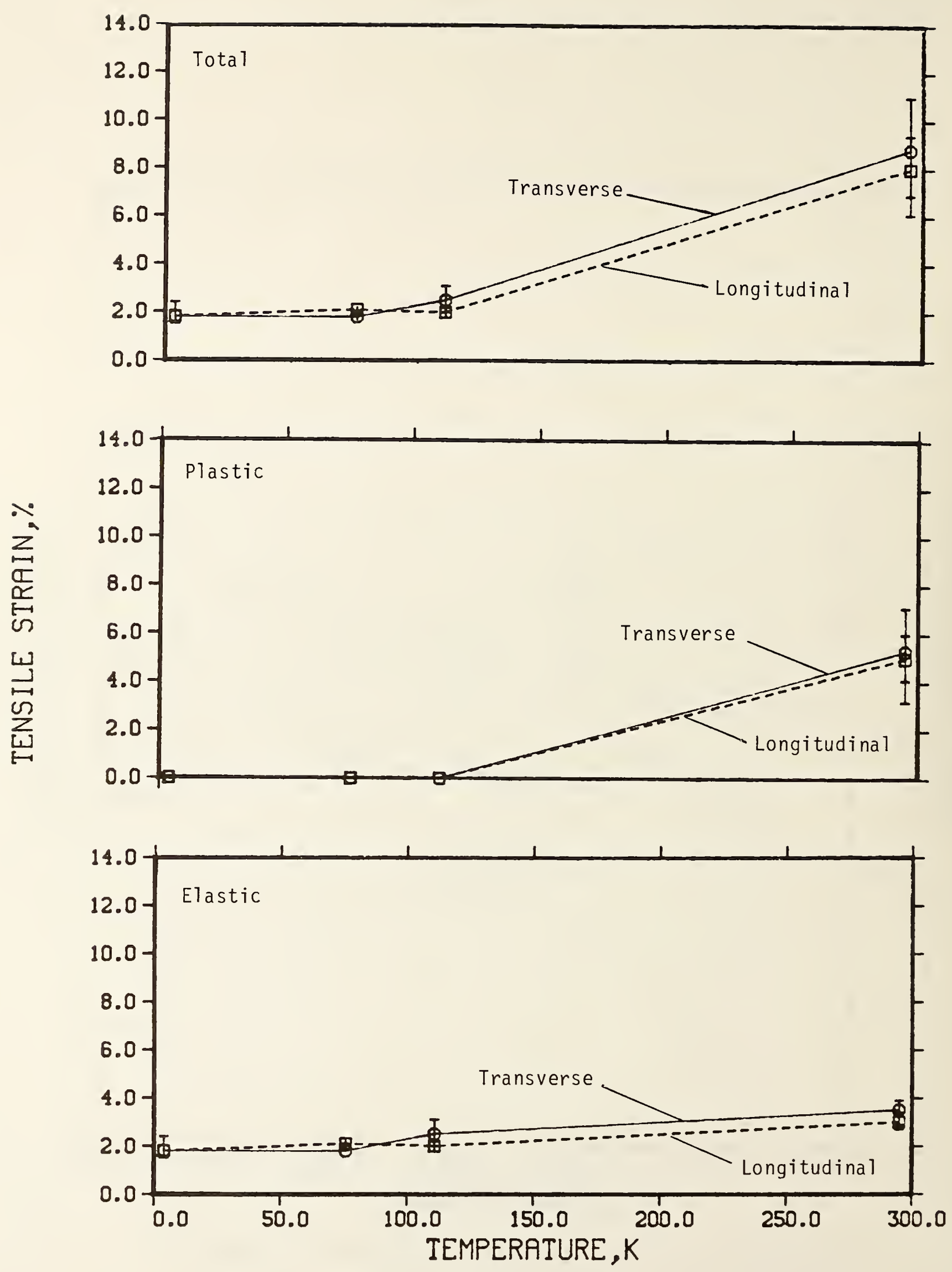

Figure 3. Tensile strain versus temperature. 408 


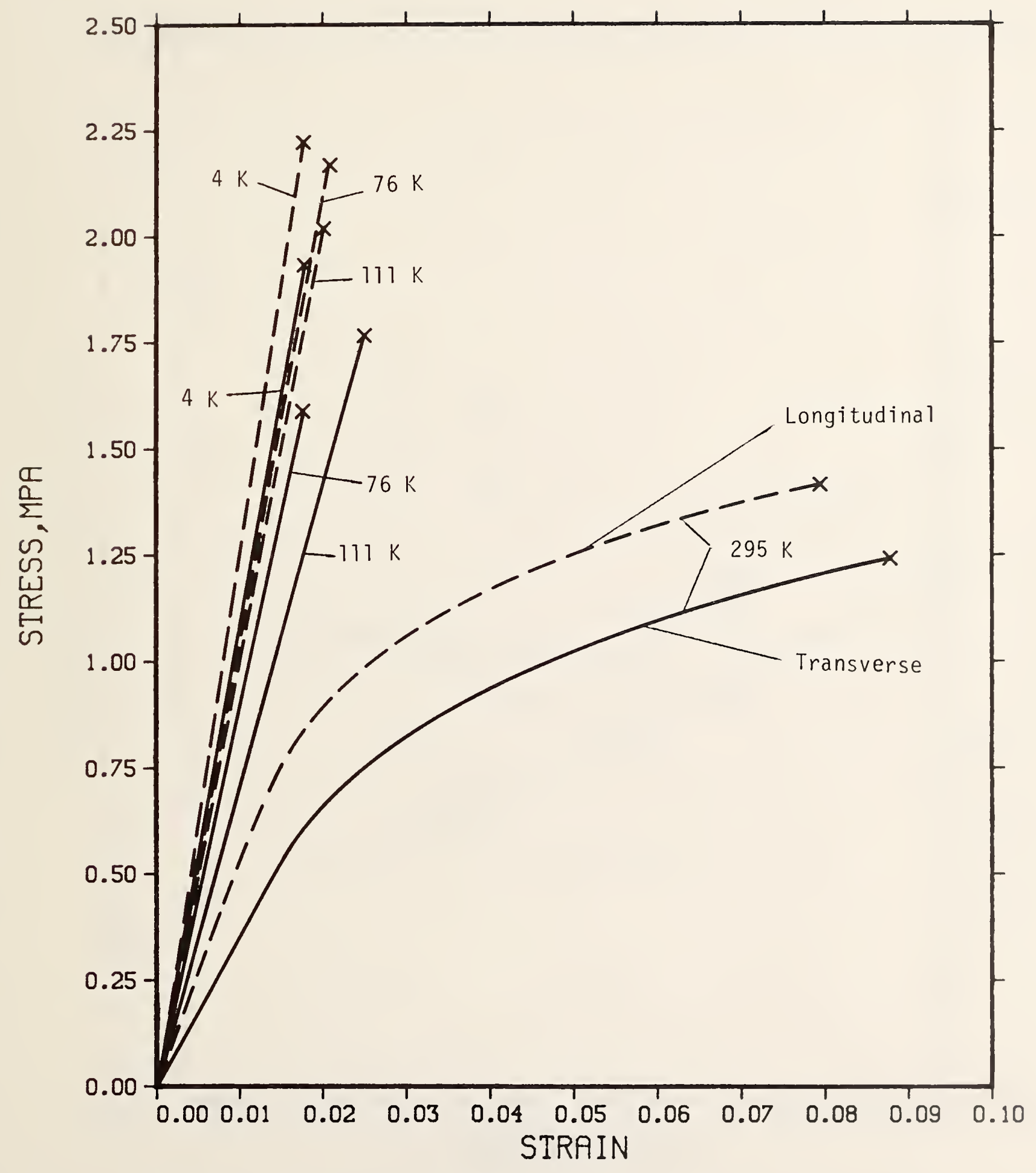

Figure 4. Tensile stress versus strain (1ongitudinal and transverse). 


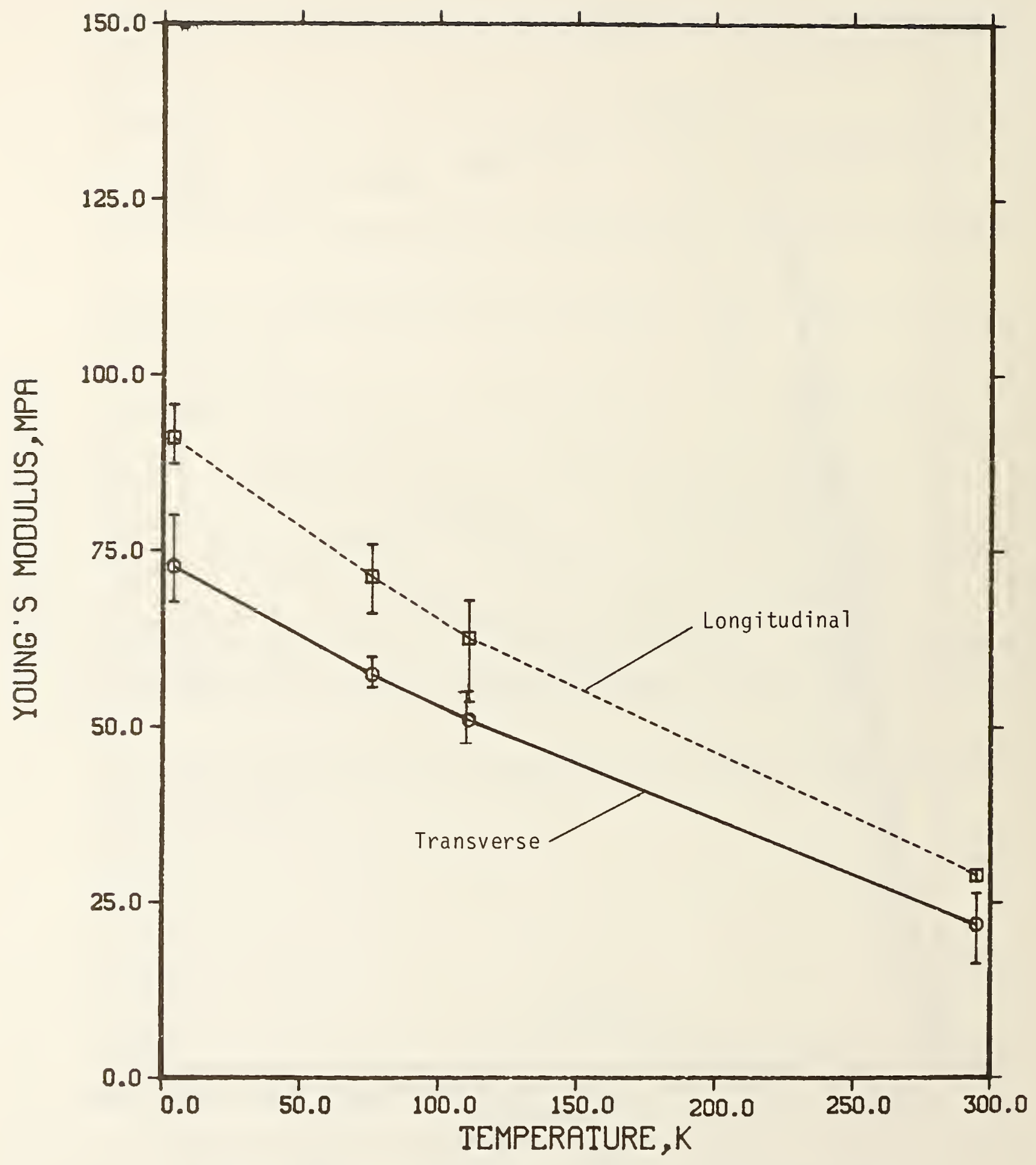

Figure 5. Compressive Young's modulus versus temperature. 


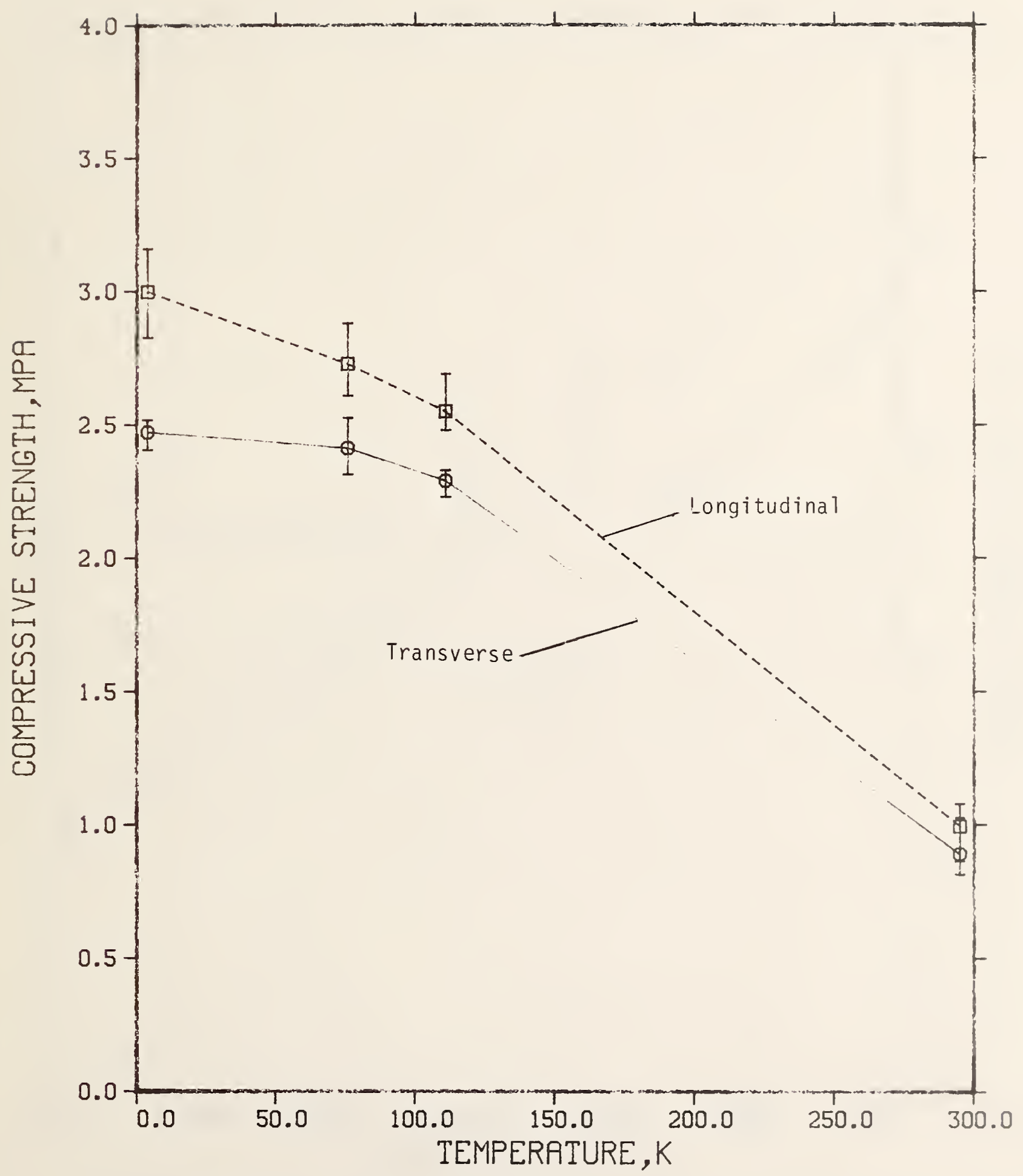

Figure 6. Compressive strength versus temperature. 


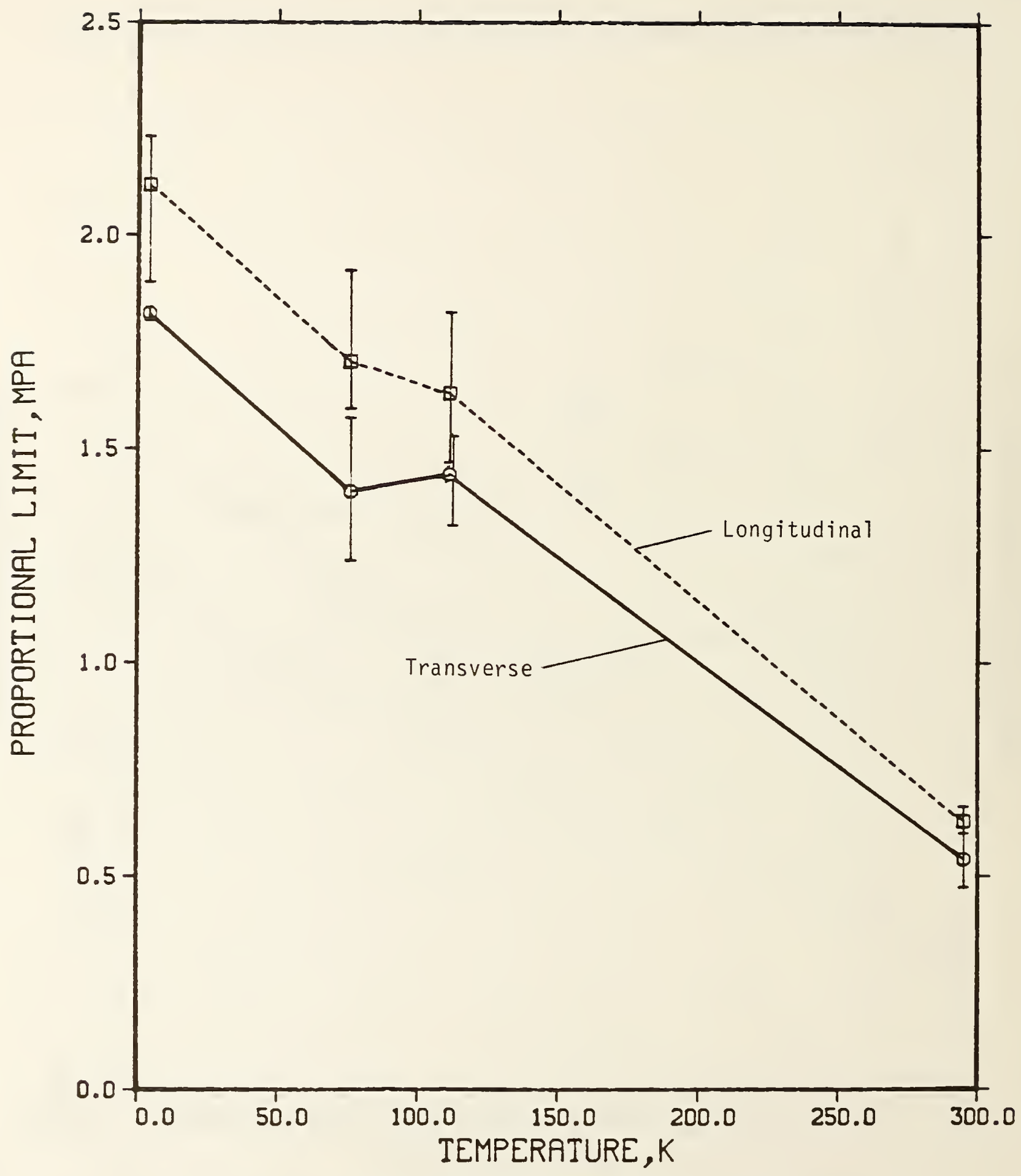

Figure 7. Compressive proportional limit versus temperature. 


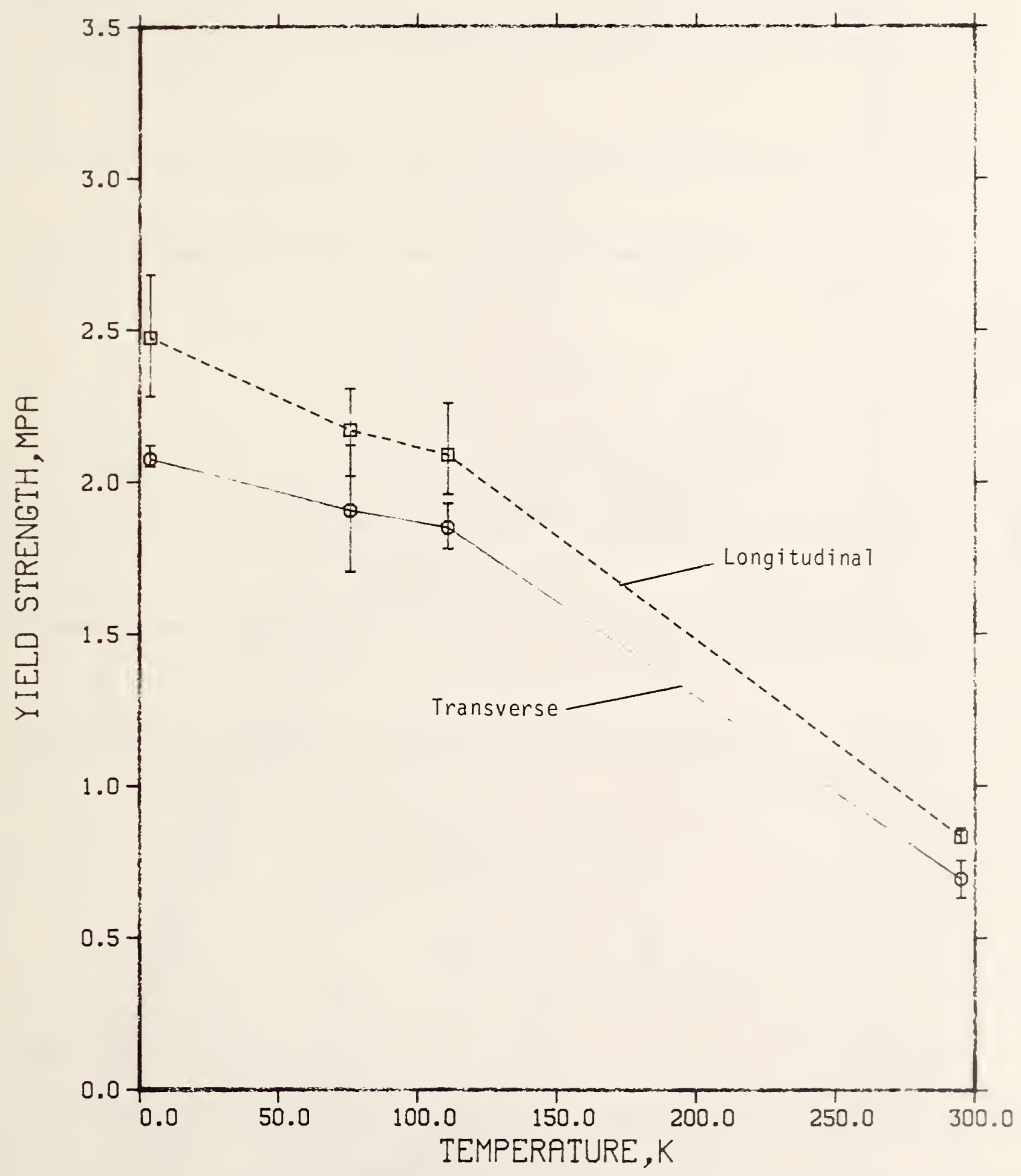

Figure 8. Compressive yield strength versus temperature. 

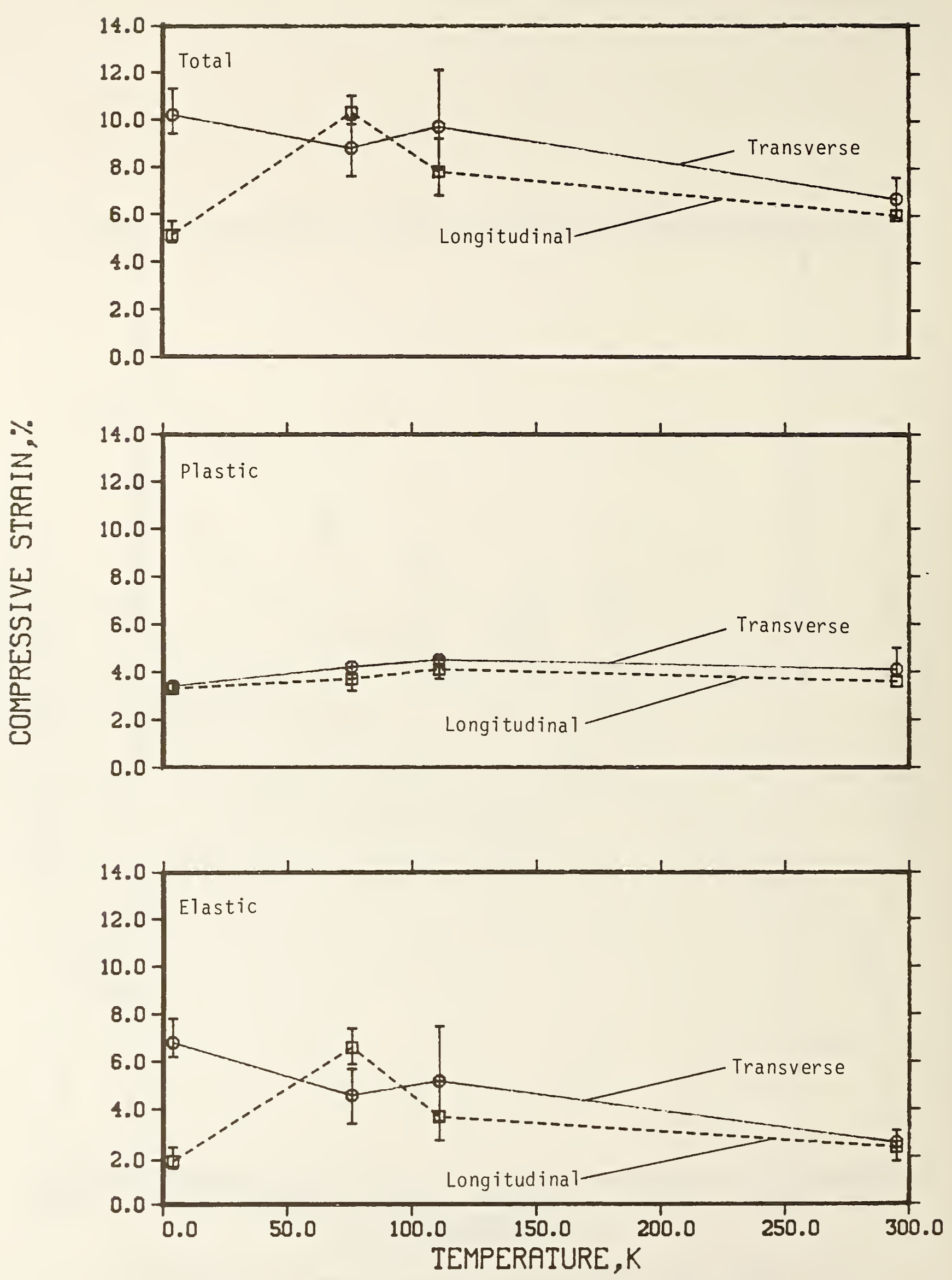

Figure 9. Compressive strain versus temperature. 


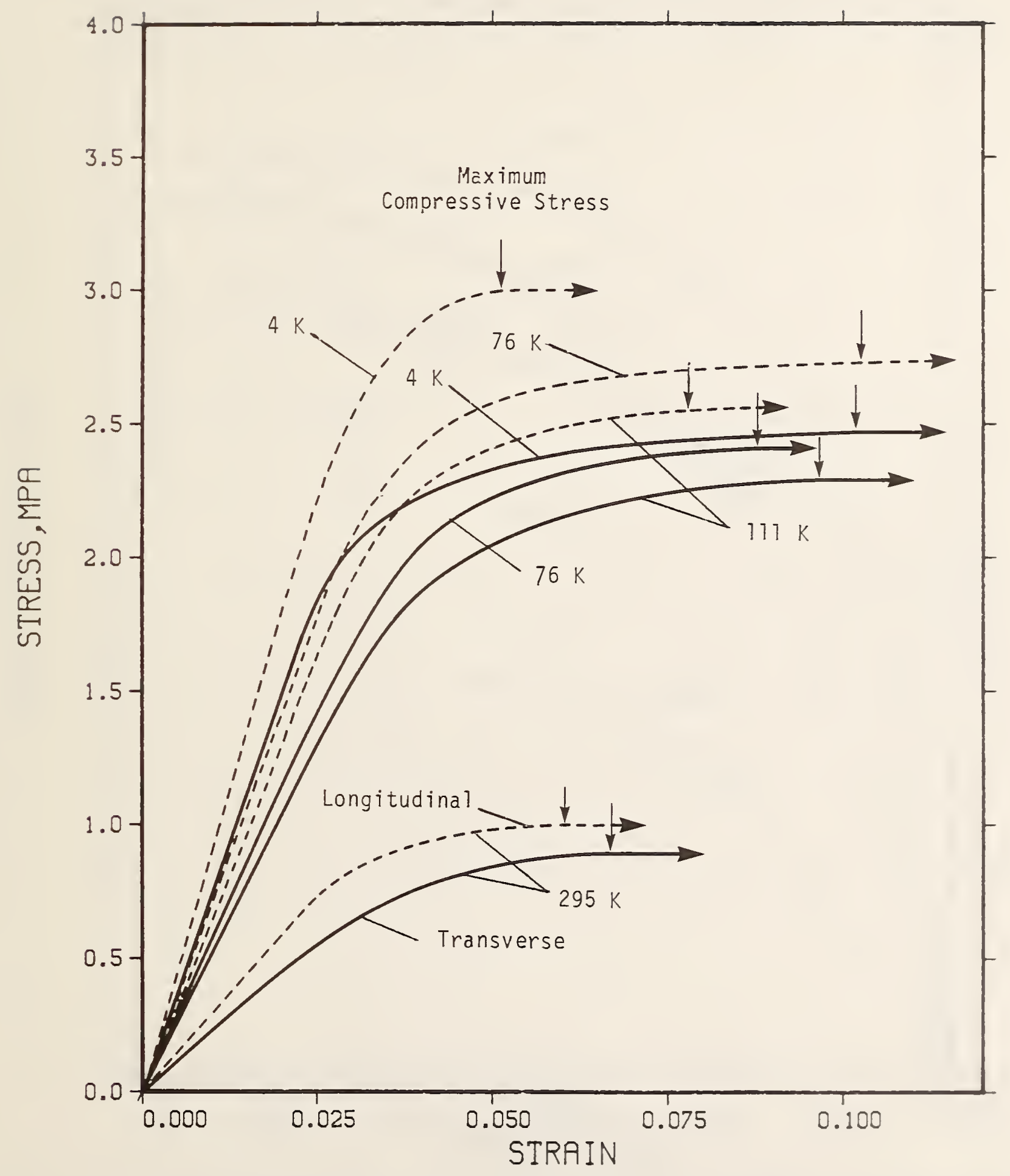

Figure 10. Compressive stress versus strain (langitudinal and transverse). 


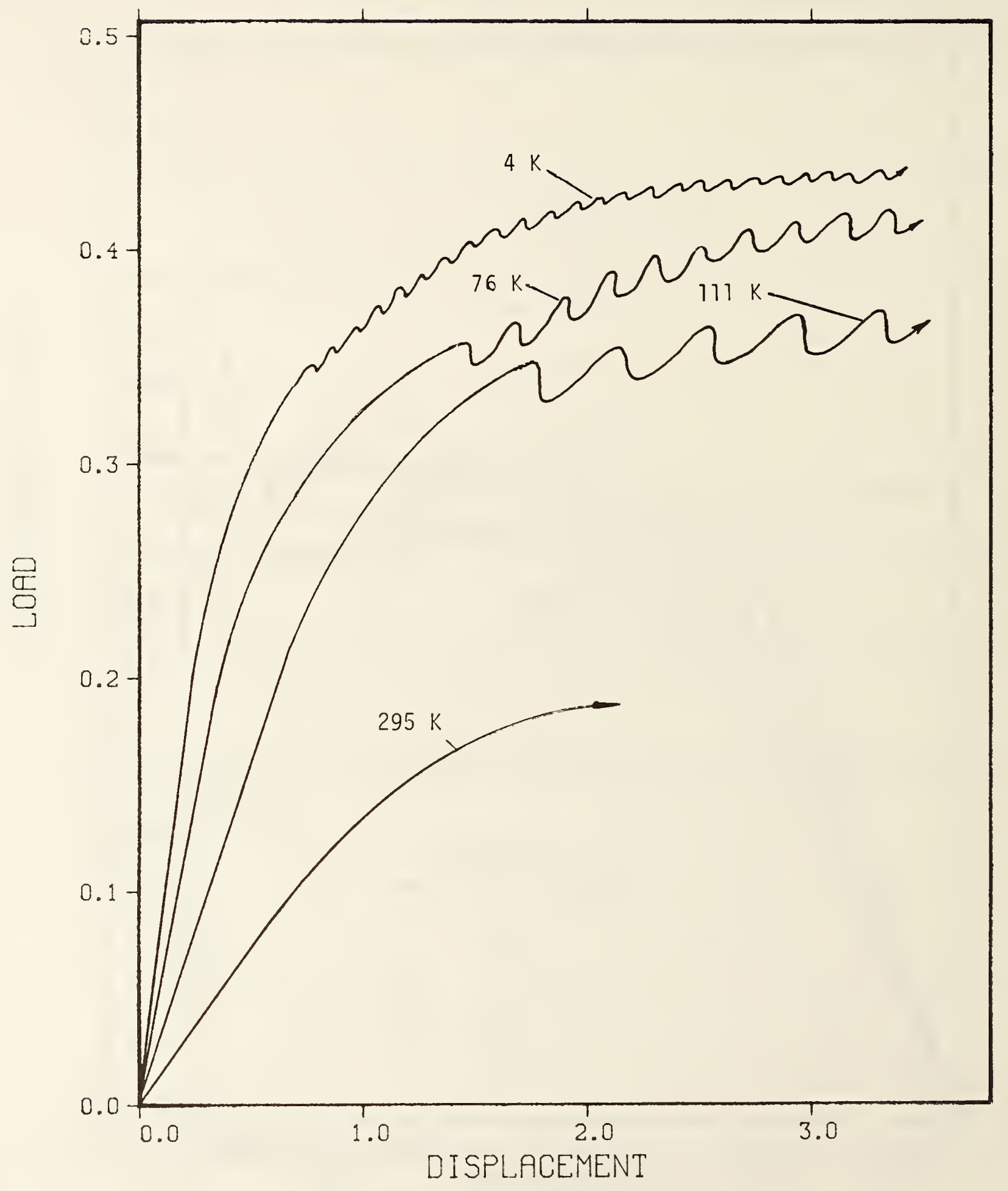

Figure 11. Typical load versus displacement (arbitrary units). 


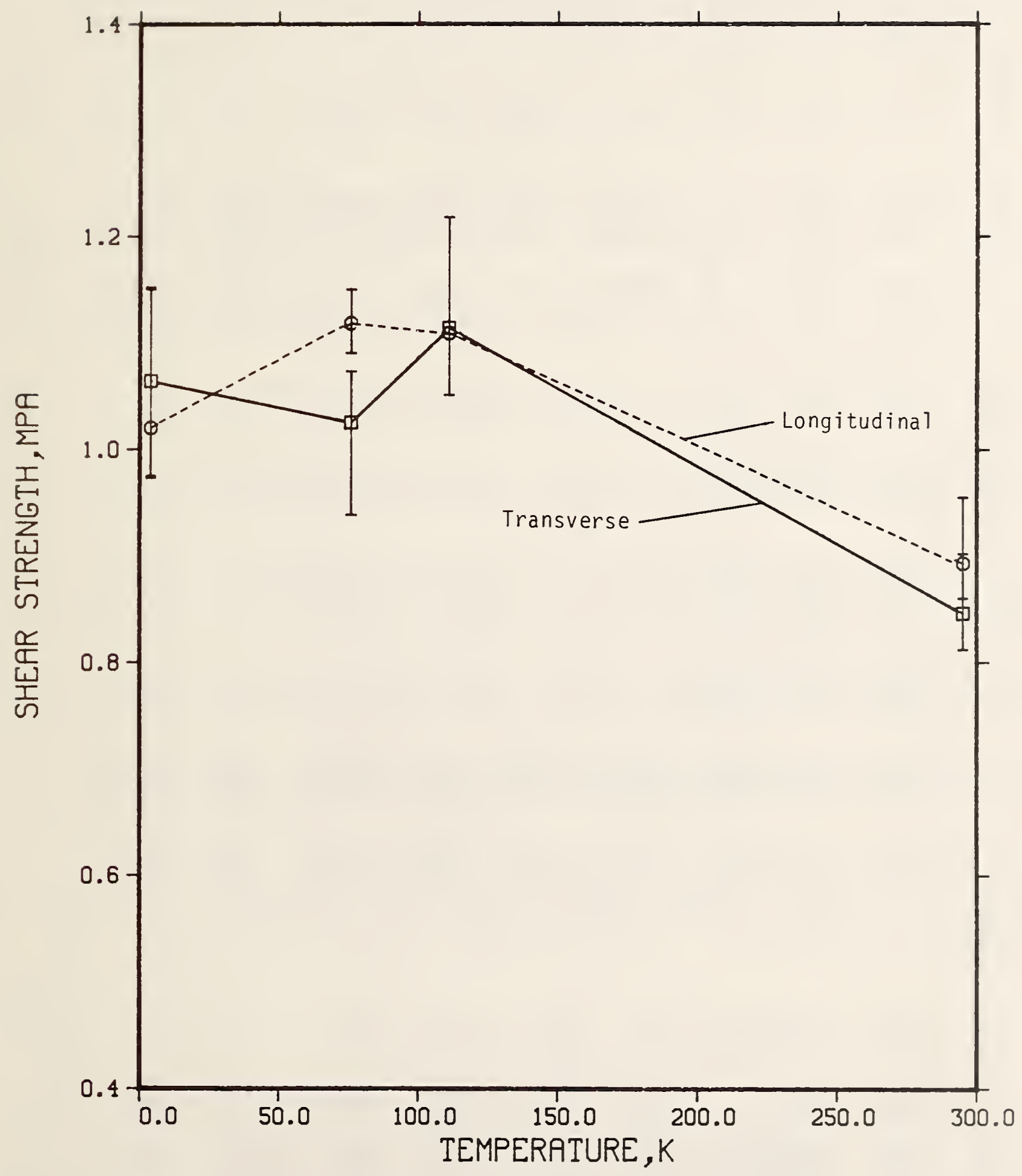

Figure 12. Shear strength versus temperature (1ongitudinal and transverse). 


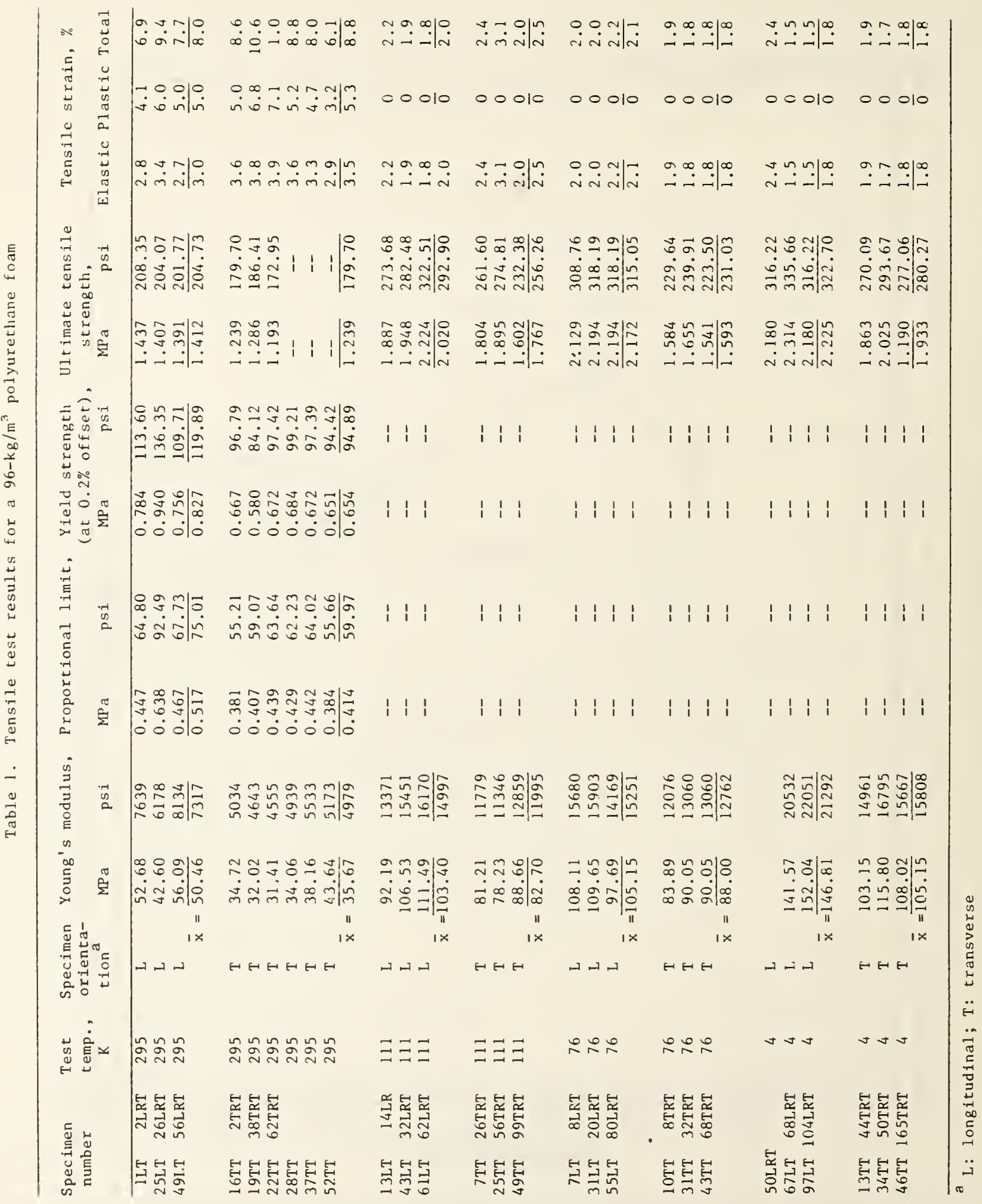




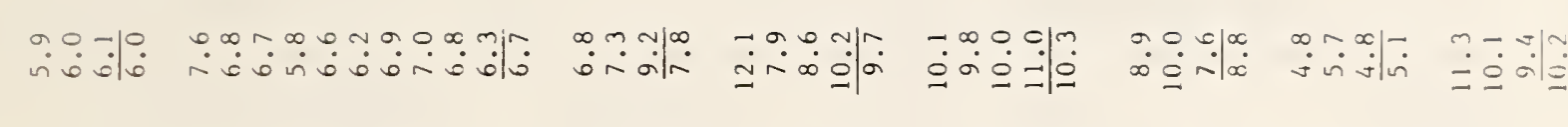

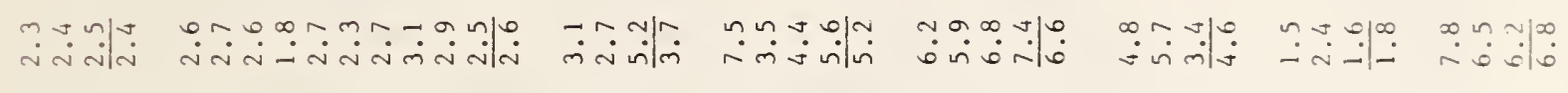

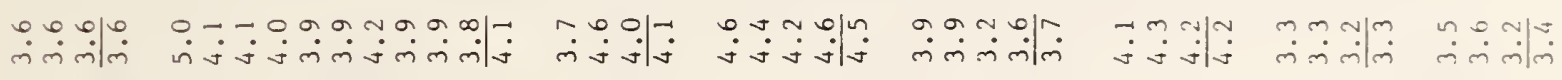

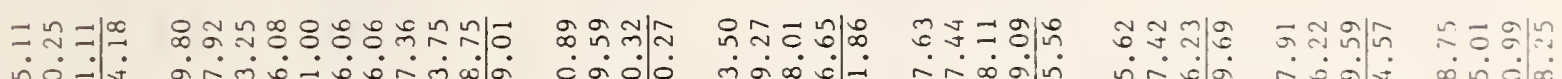

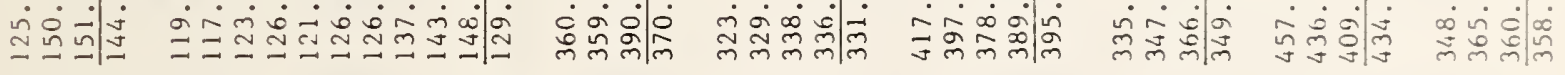

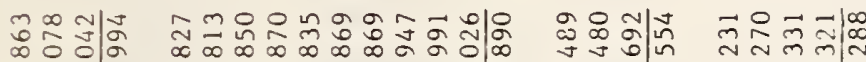

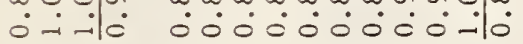

तiviti

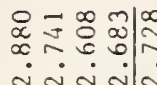

จำำ

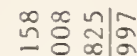

鱼云是原

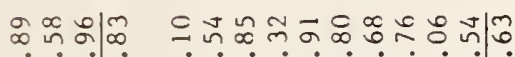

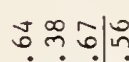

రం

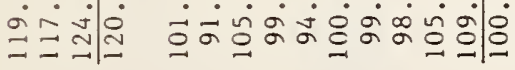

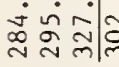

ปั่

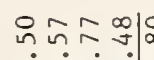

$\mid \begin{aligned} & \infty \\ & \dot{m} \\ & \dot{m}\end{aligned}$

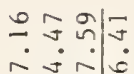

mंiniti

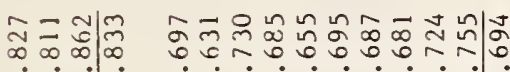

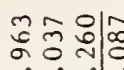

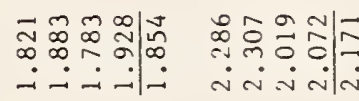

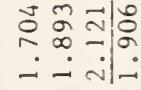

$\therefore \div$ 눙

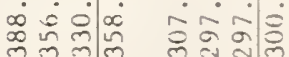

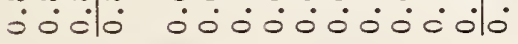

$\therefore \dot{\sim} \mathrm{N} \mid \dot{\mathrm{N}}$

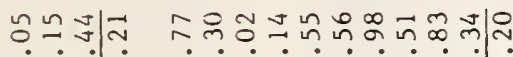

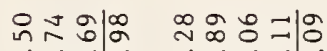

융ำำ

ज.

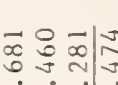

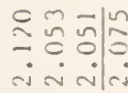

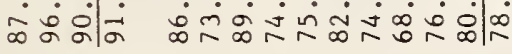

$\vec{\sim} \dot{\sim} \dot{\sim}$

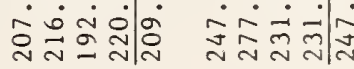

定家

กำ的路

정ㅇㅇㅇ워웡

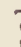

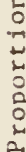

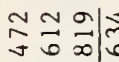

จิ จำำ

\section{ミンタัす}

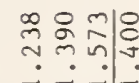

लें

造施 (1)

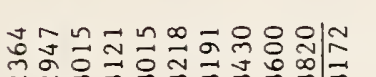

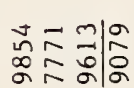

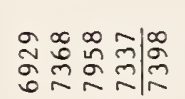

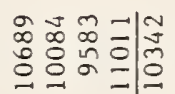

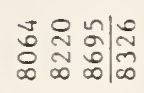

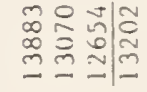

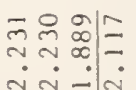

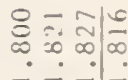

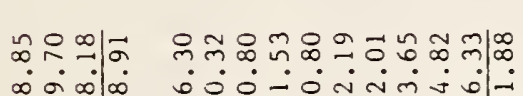

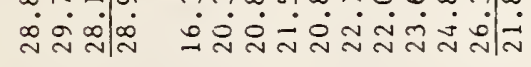

$+\infty \infty$

in

오. 임.

둉ำ

ำ 9020 in เึ่

ะำก

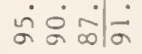

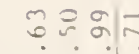
पूa

คน

HEFERERER

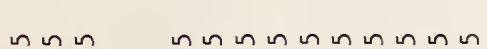

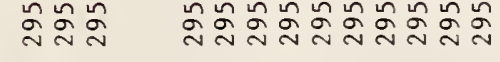

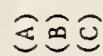

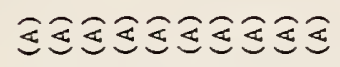

$\Xi \Xi \Xi$

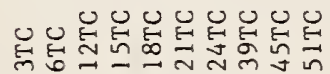

త્తฏ

बे

\section{$\Xi \Xi \Xi \Xi$}

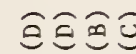

㫐㫐忎忎

\section{હૃછత}

过皆岕
ริอิ

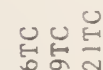

¿ฮิ 는 $\frac{0}{3}$ $x \underline{x}$ 는 
Table 3. Shear strength test results for a $96-\mathrm{kg} / \mathrm{m}^{3}$ polyurethane foam

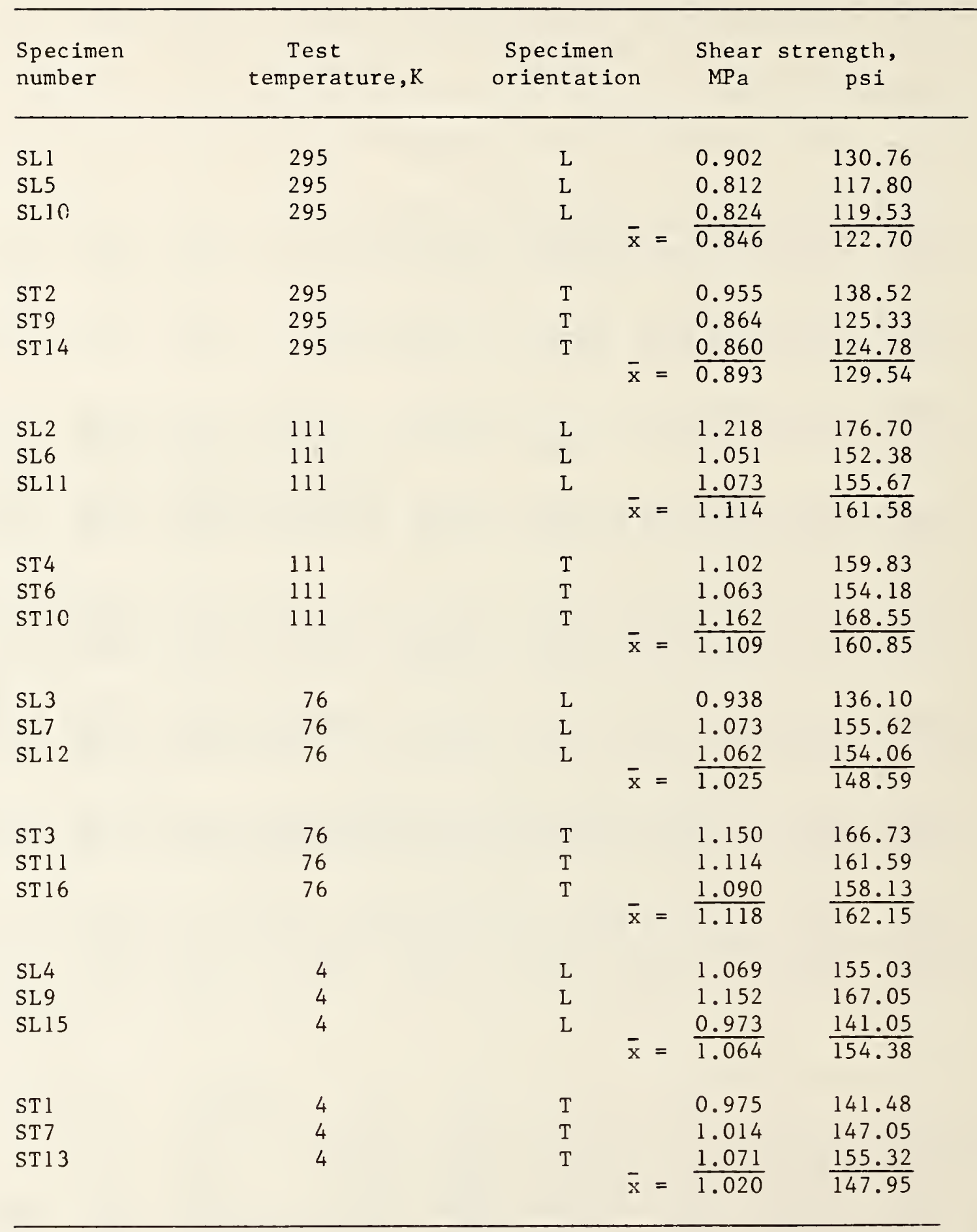




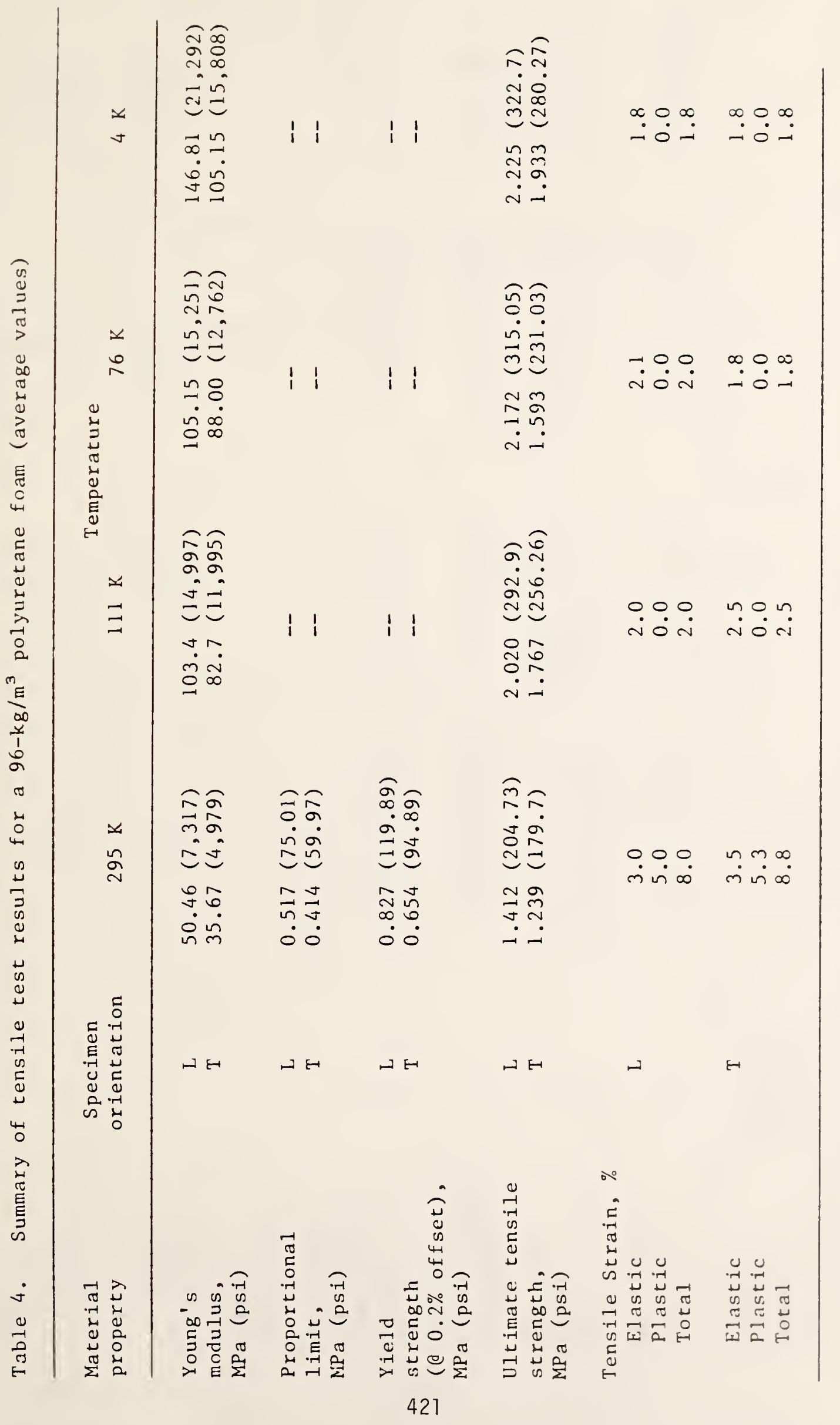




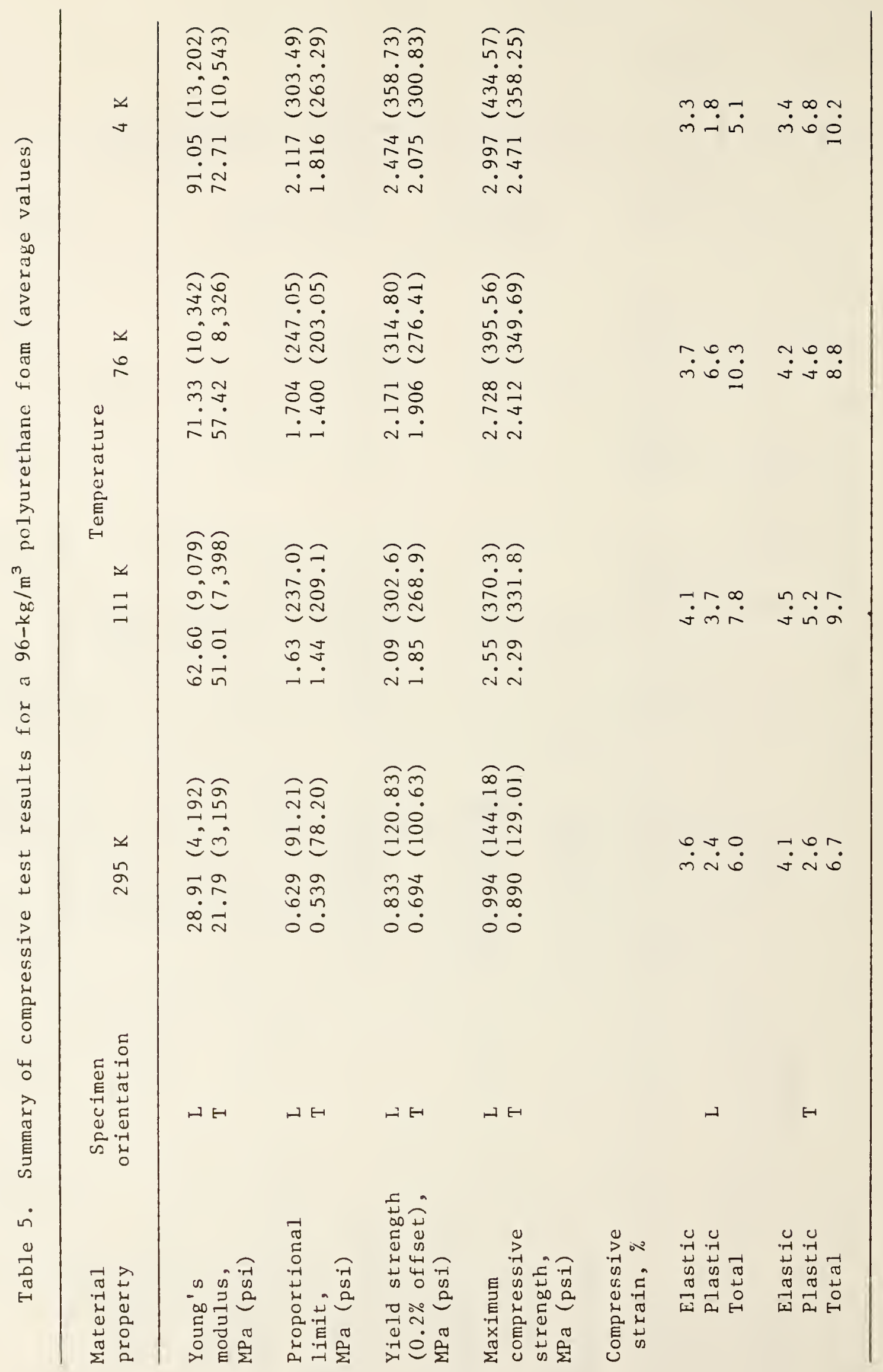


Table 6. Summary of shear strength test results for a $96-\mathrm{kg} / \mathrm{m}^{3}$ polyurethane foam (average values)

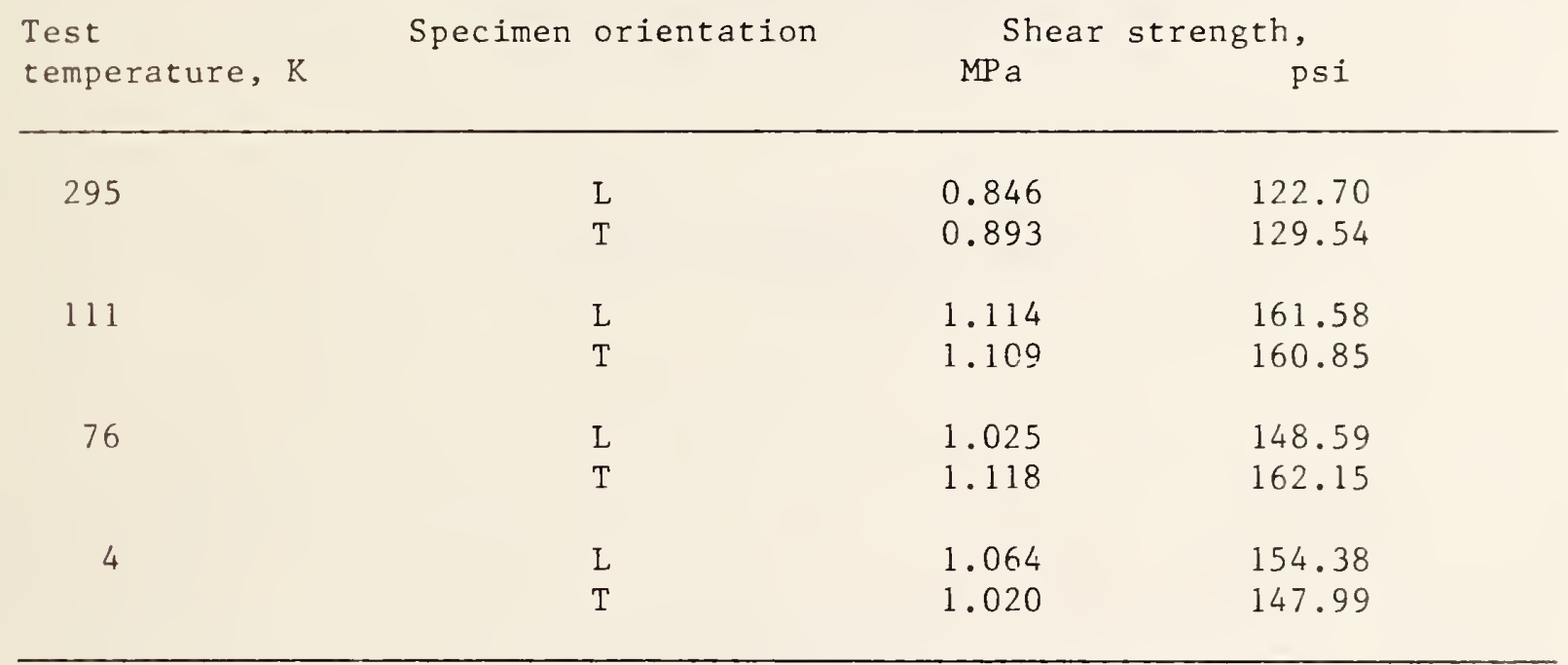





\title{
EXPERIMENTAL DATA TO SUPPORT EXTENSION OF \\ MECHANICAL PROPERTY DATA FOR TENSILE \\ TESTING OF COMPOSITE MATERIALS TO \\ LIQUID HELIUM TEMPERATURE ( $4 \mathrm{~K})$ *
}

\author{
Metals Properties Council \\ Low Temperature Task Group \\ Proposal
}

$11 / 25 / 83$

*This proposal was written and approved by the Low Temperature Task Group of the Metal Properties Council. NBS guidelines for the use of SI units were not followed. 

EXPERIMENTAL DATA TO SUPPORT EXTENSION OF

MECHANICAL PROPERTY DATA FOR TENSILE

TESTING OF COMPOSITE MATERIALS TO

LIQUID HELIUM TEMPERATURE ( $4 \mathrm{~K}$ )

Introduction

Organic-matrix, nonmetallic, filament-reinforced composite materials are critical components in many cryogenic structures. They serve as electrical and thermal insulators and for structural supports in superconducting magnets required for magnetic fusion energy (MFE) and magnetohydrodynamic (MHD) power generating systems. The high magnetic fields required for plasma confinement create large forces that are transmitted through the nonmetallic components to the primary metallic structure. In MFE applications, structural integrity must be maintained after exposure to large fluences of neutron and gamma irradiation at $4 \mathrm{~K}$. Nonmetallic composites also play a critical role as thermal standoff members supporting helium dewars in cryogenic spacecraft such as the IRAS satellite. In each of these technologies there is an imperative to improve performance by pushing the performance of composite materials to their practical operating limits consistent with structural integrity.

There are currently no standardized mechanical property test procedures for composite materials at liquid nitrogen $\left(77 \mathrm{~K},-320^{\circ} \mathrm{F}\right)$ temperatures or below or at liquid helium temperatures $\left(4 \mathrm{~K},-452^{\circ} \mathrm{F}\right)$. Mechanical testing under these conditions involve unique considerations as compared to room temperature. Thermal conductivity is considerably reduced and the specific heat tends toward zero. Consequently, when work is done on a specimen during testing, the resultant internal heating is not easily removed, leading to localized adiabatic heating. Special attention must therefore be paid to control over strain rates if the correct test temperature is to be maintained. Upon cooling, the organic matrix contracts more than does the reinforcing fiber and becomes embrittled. This reduces the failure strain of the matrix and can introduce significant damage in the early stages of tensile or compressive testing. This is observed as a "knee" in the stress strain curve. Embrittlement also increases the probability of premature failure from defects on the specimen edges. This alters the specimen "size effect" and requires a different specimen configuration if bulk properties are to be accurately predicted from cryogenic test data.

Testing at liquid helium temperatures is very expensive, both in cryogen cost and in the time required. Additionaliy, the increase in strength associated with low temperatures requires the use of larger test equipment, if room temperature specimen sizes are retained. Developing pull rods, grips, and cryostats for equipment applying loads in excess of 100,000 pounds is very costly and inefficient--to date, none exist in the world. Maximum capacity of existing cryogenic test systems are typically 20,000 to 50,000 pounds, dictating the use of smaller specimens than those which have been standardized for room temperature testing.

The proposed research is designed to produce the information required to extend existing room temperature composite tensile testing standards to cryogenic temperatures. 


\section{Internal Specimen Heating}

\section{A. Experimental: Strain Rate Effects in Various Media}

Specimen heating effects during straining at room temperature are relatively smal1, usually on the order of a few degrees at strain rates normally used. But as the test temperature decreases, the specific heat decreases, causing a greater temperature rise for the same amount of work. This is exacerbated by the intrinsically low thermal conductivity of nonmetallic composites and the further decrease of conductivity with cooling. The heating effect therefore becomes increasingly pronounced as temperature is lowered, reaching a maximum at $4 \mathrm{~K}$. The magnitude of this effect will vary for composites of differing types and orientations of layup. It may also vary with the media in which the tests are conducted. It is anticipated that increasing temperature will change the failure mode and reduce the rate and severity of damage accumulation, thus affecting the mechanical performance.

The objectives of this program are therefore as follows:

1. To determine the maximum strain rate at which cryogenic tensile tests can be performed on organic matrix composites without functionally altering the measured parameters.

2. To assure that data generated in different laboratories are of comparable validity.

It is proposed that this study be conducted with E-glass-fiber reinforced epoxy matrix laminates of uniaxial construction. This provides the highest elongation to failure and represents a worst case. It is also reflective of the most commonly used cryogenic laminates. Testing should be performed at $4.2 \mathrm{~K}\left(-452^{\circ} \mathrm{F}\right), 77 \mathrm{~K}\left(-320^{\circ} \mathrm{F}\right)$ and at $295^{\circ} \mathrm{K}\left(68^{\circ} \mathrm{F}\right)$. Test environments are liquid helium, liquid nitrogen, and air, respectively.

The experiments should be conducted at strain rates not exceeding those given in appropriate ASTM documents. Each specimen is to be instrumented to continuously record internal temperature during testing. Stress-strain curves should be recorded as a function of strain rate so as to relate changes in mechanical performance to heating. The limiting strain rate criteria should be a temperature rise not greater than that experienced during room temperature tests conducted in accordance with ASTM procedures.

\section{B. Model Development: Effects of strain rate and test media}

Cryogenic tests carried out in liquid media provide relatively good heat transfer characteristics between the test specimen and coolant. However, cryogenic tests conducted at temperatures other that of the boiling point of a cryogen require heat transfer through a cold gas. The relatively poor heat transfer of gasses will magnify the internal heating effects for a given test procedure. Furthermore, the heat transfer characteristics of gasses and the thermal conductivity and heat capacity of the specimens will change with temperature. 
An experimental program to assess the influence of all these variables would be prohibitively expensive. A more practical approach is to investigate development of analytic models that could predict the magnitude of internal heating in terms of the operative parameters. This task is made easier by the relatively simple specimen geometry and by relatively good knowledge of the significant physical properties of the relevant solids, 1iquids, and gasses.

Work on such models should be correlated with the experimental work of Test Program $1 A$, the results of which could serve as a criteria for model validity. However, additional valaidation tests must be conducted in gaseous helium and nitrogen. When verified, the appropriate model should then be used to establish a standard tensile testing procedure.

II. The Stress-Strain "Knee": Effects of strain rate and fiber orientation

A. Experimental: strain rate and temperature effects

Development of a "knee" in the stress-strain curve indicates the onset of internal damage. It is believed to reflect massive fracture of the matrix phase, and a shift of the load carrying capacity entirely to the fiber phase. It usually occurs at a stress significantly below the ultimate tensile strength of the laminate, and is associated with a decrease in modulus, an increase in damping capacity, and loss of dimensional stability. Its onset therefore establishes a maximum operating stress in many engineering applications. The "knee" is prominently observed when crossplied or woven-fabric glass-reinforced laminates are tested in a direction other than that of principle reinforcement. Figure 1 illustrates the phenomenon as observed in a G-IICR laminate tested in the $\pm 45^{\circ}$ direction to the warp and fill at room temperature. Here, the "knee" reflects debonding at the fiber-matrix interface. At this temperature, the effect is not often observed when testing in the fiber reinforcement direction because the strain capability of most epoxy resins is a reasonably close match to that of the fiber. But at cryogenic temperatures the strain capability of the matrix substantially decreases, while that of the glass increases. This causes early onset of damage whenever glass-reinforced laminates are stressed at cryogenic temperatures, regardless of the fiber orientation. However, because the stress-strain curve is steeper at the lower temperatures, the "knee" may not be as prominent as on Fig. 1 .

The objectives of this program are therefore as follows:

1. To develop cryogenic tensile test procedures that accurately document the onset of the stress-strain "knee", and therefore the onset of major internal material damage.

2. To determine the effect of strain rate and temperature on the position of the "knee".

3. To establish standard procedures for establishing the position of the "knee" in laminates of commercial cryogenic interest. 
It is proposed that this study be conducted on commercial, glass fabricreinforced, high-pressure epoxy laminates produced to the G-10CR and G-11CR specification. Testing should be performed at $4.2 \mathrm{~K}\left(-452^{\circ} \mathrm{F}\right.$ ) and at $77 \mathrm{~K}$ $\left(-320^{\circ} \mathrm{F}\right)$. Test environments are liquid helium and liquid nitrogen, respectively. Test orientations should be warp, fill, and $\pm 45^{\circ}$.

Experiments should be conducted at strain rates both above and below those specified in ASTM documents for room temperature tensile testing of composites. This is required to quantitatively establish the relationship between strain rate and the point of massive damage introduction. Instrumentation techniques must be developed to provide a high degree of accuracy in determining the "knee" position on recorded stress-strain curves produced at different strain rates.

\section{B. Model Development: Effects of strain rate and test media}

Position of the stress-strain "knee" will vary with parameters such as fiber orientation, fiber density, fiber type, and resin strength and toughness in addition to strain rate and temperature. It is impractical to experimentally assess the interaction of all these variables. Consequently, efforts must be made to devise analytical models that predict their synergistic effect.

The experimental studies of Test Program 2A will provide useful information on model validity. However, additional validation tests must be conducted on uniaxial laminates and laminates of crossply construction. When verified, the appropriate model should be used to establish a standard method of predicting the onset of significant internal damage in engineering structures.

\section{Intrinsic Specimen Size Effect}

\section{A. Experimental: Configurational dependency with temperature}

At any temperature there is a minimum number of replicated basic units of composite reinforcement that are required in a test specimen if the mechanical test results are to reflect bulk material properties. These may be a minimum number of uniaxial fibers or a minimum number of replications of the basic weave unit in a fabric-reinforced material in the cross section of the specimen. If fewer than required of such units are present, the determined mechanical property will usually be lower than that for the bulk material. This leads to excessive conservatism in design and prevents meaningful comparison of data between test laboratories. On the other hand, if many more than the required number of such units are present, the larger than required specimen size increases the cost of testing. At cryogenic temperatures the problems are magnified by an increase in internal stress, embrittling of the matrix, and by the increased cost of testing.

The objectives of this program are therefore as follows:

1. To determine the effect of cryogenic temperatures on the test specimen cross sectional dimensions required to produce consistent tensile strength data. 
2. To use these data to establish minimum specimen dimensions for such testing.

3. To establish standard criteria for specimen dimensions so as to ensure reproducibility among laboratories and to provide industry with the most meaningful design data.

It is proposed that this study be conducted with commercial, high-pressure, industrial laminates produced to the G-1OCR or G-l1CR specifications. Such materials are widely used in cryogenic construction, and present a worst case in size effect considerations. Tests should be performed at $4.2 \mathrm{~K}\left(-452^{\circ} \mathrm{F}\right)$, $77 \mathrm{~K}\left(-320^{\circ} \mathrm{F}\right)$ and $295 \mathrm{~K}\left(68^{\circ} \mathrm{F}\right)$. Evaluation should be made in the warp, fill, and $\pm 45^{\circ}$ direction of the laminate.

\section{B. Model Development}

The complexities cited as justification for undertaking modelling programs under under the work proposed in I and II may be repeated here to justify a similar program on size effect. Again, it is impractical to experimentally determine the minimum functional size for all of the possible composite types and orientations of technical interest. At room temperature the problem is more tractable, as large specimen can be used without substantial penalty. But the imperative to use of as small specimens as is practical for cryogenic testing justifies a finer tuning of the specifications. This is of particular importance where it is desired to test a number of specimens sequentially during one cool down of a cryostat.

The work proposed in Test Program IIIB will be of value in this modelling study. However, the scope should be increased to include discontinuous glassreinforced specimens as well as fabric-reinforced material. 


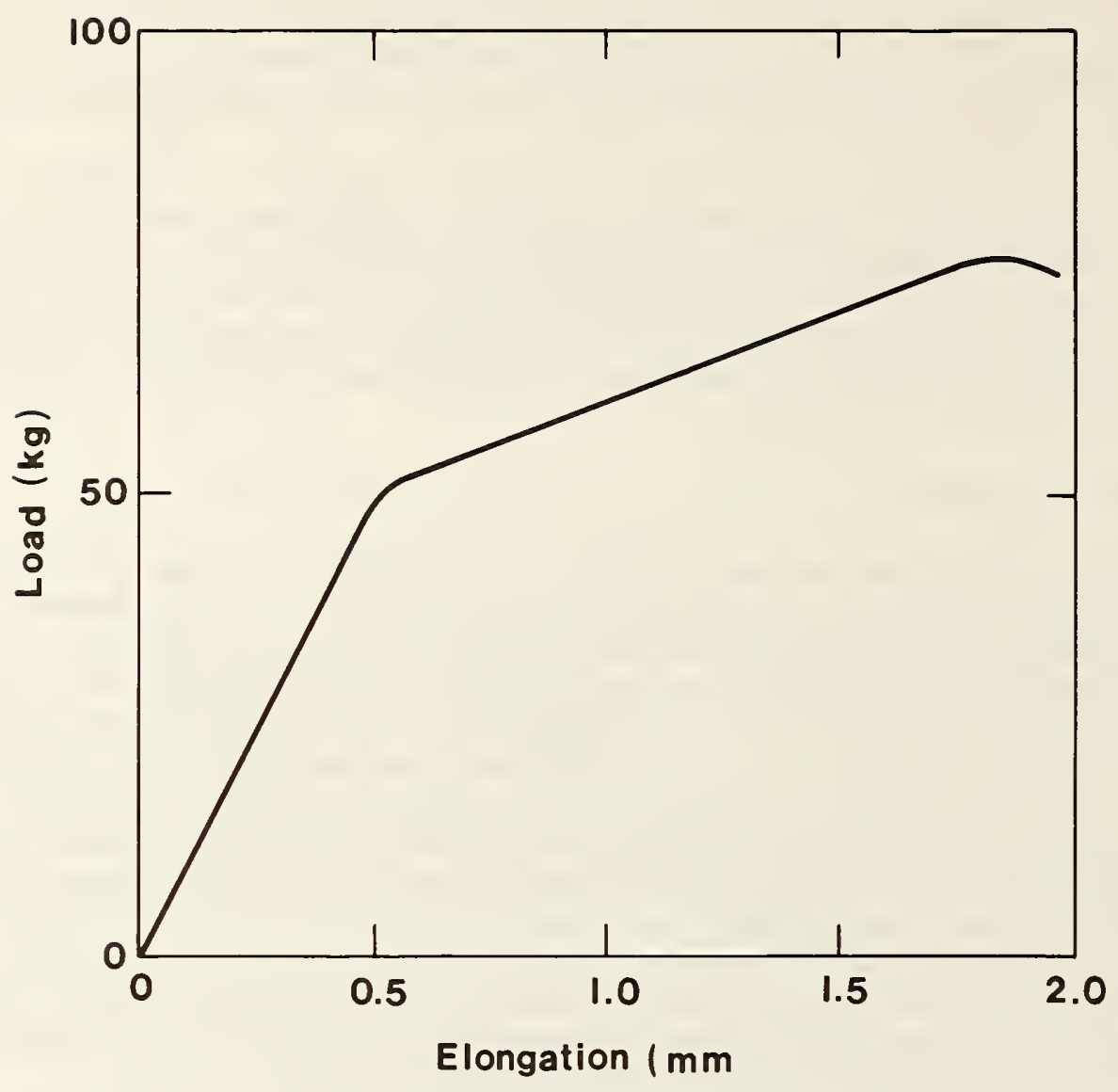

Fig. I Load-elongation curve for G-IICR tested in the \pm 450 direction to warp and fill at room temperature. (K. Fujioka, et al, "Construction of FRP Dewar by Adhesive Bonding Method for Large Pulsed Superconducting Magnet", presented at ICMC/CEC Conference, Colorado Springs, Co, August 1983. 
TECHNOLOGY TRANSFER 



\section{TECHNOLOGY TRANSFER PROGRAM}

LEADER: N. J. Simon, NBS

\section{OBJECTIVES :}

(1) To hold workshops to promote interaction between designers and material specialists. Major topics include design overviews of fusion energy projects with respect to low-temperature material needs and reviews and data on structural alloys, composites, and weldments.

(2) To produce and distribute an annual report as well as monthly highlight reports to OFE/DoE.

(3) To prepare handbook pages and supporting documentation on lowtemperature mechanical and physical properties of structural materials for superconducting magnets. The pages are to be distributed to workshop attendees and others in the low-temperature materials applications community. The pages will also be presented for inclusion in the "Materials Handbook for Fusion Energy Systems."

RESEARCH PAST YEAR (1983):

(1) "Materials Studies for Magnetic Fusion Energy Application's-VI," NBSIR 83-1690, 464 pages (May 1983), editors R. P. Reed and N. J. Simon, has been sent to the Technology Information Center, ORNL, and a number of copies have been requested by other interested persons.

(2) Handbook pages and supporting documentation covering mechanical and physical properties of $\mathrm{Fe}-21 \mathrm{Cr}-6 \mathrm{Ni}-9 \mathrm{Mn}$ have been distributed in preliminary draft form to interested persons. These pages have also been submitted to the "Materials Handbook for Fusion Energy Systems." Preliminary work on correlation of AISI 304N and 304LN tensile properties with nitrogen and carbon concentration has been completed in preparation for development of handbook pages on these 304 a 1 loys.

(3) Efforts were undertaken to encourage international cooperation in research to develop radiation-resistant laminates to meet requirements for the Engineering Test Reactor.

RESEARCH THIS YEAR (1984):

(1) Tentative plans are to hold the low-temperature materials workshop again in October 1984.

(2) "Materials Studies for Magnetic Fusion Energy Applications-VII," NBSIR 84-3000, 447 pages (1984), editors R. P. Reed and N. J. Simon, is the current edition of the annual report.

(3) The AISI 316 handbook pages and the Fe-21Cr-6Ni-9Mn handbook pages are currently in the review process for "Materials Handbook for Fusion Energy Systems," and the AISI 304N and 304LN handbook pages will enter the review process later this year.

(4) Preparation of AISI 304N and 304LN handbook pages will be completed this year. Preparation of handbook pages on AISI 316L, 304N, and 304LN weldments will be started. 
(5) Efforts promoting international cooperation in research to develop radiation-resistant laminates will continue. Interaction between the U.S. and Japan on structural materials research will be explored. 


$$
\begin{aligned}
& \text { NBS-DOE WORKSHOP: MATERIALS AT LOW TEMPERATURES } \\
& \text { October } 17-19,1983 \text {, Vai1, Colorado } \\
& \text { N. J. Simon } \\
& \text { Fracture and Deformation Division } \\
& \text { National Bureau of Standards } \\
& \text { Boulder, Colorado }
\end{aligned}
$$

\section{ABSTRACT}

A brief summary of the highlights and issues raised at this annual workshop is presented. The program and the list of registered participants follow this summary. 

A major purpose of the workshop is to bring together representatives from the community of users and suppliers of materials for low temperature magnet applications with those engaged in development and characterization of these materials. Participants this year came from industry, the national laboratories, the magnetic fusion energy programs, NBS, DoE, and universities. The proceedings of the workshop are not published, but extended abstracts of the presentations were provided to those who attended.

The structural and insulating materials used in the superconducting magnets of fusion energy systems were the subject of this workshop. Current methods of plasma confinement for tokamak and mirror fusion reactors necessitate the use of high-field superconducting magnets that operate at temperatures near $4 \mathrm{~K}$. The technical presentations stimulated much animated discussion. Some highlights and issues raised are:

1. Some concerns about the overall reliability of superconducting magnet systems (such as refrigeration, vacuum, leaks, etc.) are not being addressed in the Large Coil Project testing owing partly to the complexities of the additional instrumentation that would be required. It appears that this will remain an open issue for some time (but see Item 3 below).

2. The U.S. does not have mechanical property requirements for materials as JAERI does; however, such criteria may be an illusion at this stage when many important features of the design of fusion reactors have not been resolved. The Japanese are emphasizing high strength and toughness in their material requirements, much more than material cost and weldability. Discussion should be pursued between the U.S. and Japan to promote more uniform material research objectives. 
3. Although the constraints are different from those of fusion systems, Fermilab has been successful in constructing and operating a complex cryogenic system consisting of a large number of superconducting magnets installed in an accelerator $7 \mathrm{~km}$ in circumference.

4. Some high field magnet coils in currently planned prototype fusion systems will not be superconducting. Inserts of copper coils may be used in tandem mirror configurations. The tokamak prototype using D-T burn to reach ignition may or may not have superconducting toroidal field (TF) coils, although the poloidal coils are to be superconducting.

5. A sector module type of tokamak construction that is being considered would allow interior machine modules shaped somewhat like the segments of an orange to be inserted between the TF coils.

6. The present designs for tokamaks require fatigue crack growth rate data. These data may be more important to the designers than fracture toughness in setting stress levels. However, future fusion reactors might have steady-state operation. The importance of determining the R-ratio dependence of the Paris law crack-growth parameters was discussed: so far, low temperature data on this have been made available to designers only for Fe-21CR-6Ni-9Mn alloy in the handbook pages (see Item 12).

7. Procurement problems for MFTF-B were caused by the nonuniformity of $304 \mathrm{LN}$ yield strengths, especially for thick $(210-\mathrm{cm})$ plates in the ST orientation. The nonuniform yield strengths result from excessive grain sizes. A solution seems to be better understanding and control of processing with regard to temperatures for hot rolling so that defects are removed but grain size does not become excessive. Some characterization of this type of processing has been done in Japan. 
8. A discussion of future materials needs for mirror fusion reactors brought up the lack of property data on the thin reinforcing strips to be co-wound with the superconductor in high-field solenoids. There may be problems in matching thermal expansion coefficients. Inconel-group alloys are being considered for this purpose, but these alloys may have a low thermal expansion only over the narrow temperature range near ambient.

9. Tests on reinforcement of metastable stainless steel weldments have not shown notch brittle behavior at $4 \mathrm{~K}$, al though martensite is formed with the test system of $304 \mathrm{~L}$ base metal with AWS E316L electrodes.

10. Substantial temperature rises invalidate the low-temperature Charpy tests carried out in accord with ASTM E-23. Yield strengths are not sensitive to the strain rate used in testing, but the ultimate tensile strength and elongation are.

11. A $4 \mathrm{~K}$, gamma and neutron irradiation facility is needed to develop organic insulators that can withstand the radiation environment of superconducting magnets in fusion reactors. In late 1985, the National Low Temperature Neutron Irradiation Facility (NLTNIF) will provide the high radiation intensities needed as well as capabilities for subsequent 4-K testing without warmup. The Fusion Materials Irradiation Test facility to be built by Hanford Engineering Development Laboratory in Washington could have cryogenic capabilities also if suitable cryogenic equipment were installed, but the facility might not achieve a higher flux than NLTNIF. A problem with experimental design for NLTNIF is the internal heat generated in specimens, leading to an undesirable temperature rise. The international agreement on standardizing nonmetallic test methods reported at the workshop fortunately provides for uniaxial specimens that are of small diameter, so the problem will be minimized. 
12. Discussion on progress in codifying data on structural alloys for the Materials Handbook on Fusion Energy Systems brought out the importance of including weld data on $316 \mathrm{~L}$, since the base material has already been covered. The desirability of furnishing the supporting documentation pages to handbook users along with the handbook pages was discussed. Current policy is that the supporting documentation is on file at HEDL, available on request. Members of the DoE Analysis and Evaluating Task Group that were present will try to implement this. Workshop participants were satisfied with the format of and progress on the NBS contributions to the Materials Handbook. 


PROGRAM
NBS/DoE Workshop on Materials at Low Temperatures
October 17-19, 1983
Vai1, Colorado

Monday, October 17

Preconference Session (1:00-6:00 p.m.) Metal Properties Council

Low Temperature Codes and Standards Subcommittee Meeting

A. 0. Schaefer, Chairman

Tuesday, October 18

Session 1 (8:30-12:00 a.m.) Magnet Systems

R. P. Reed, Chairman

Introduction

Overview - Magnet Development

Westinghouse Electric Large Coil Project Materials

Construction of Superconducting Magnets for

Fermilab Accelerator

Overview of Recent Activities of FEDC

Future Cryogenic Structural Materials Needs for

Mirror Fusion Reactors

Failure of a Large Cryogenic MHD Magnet
R. P. Reed, NBS

D. S. Beard, DoE

A. Jarabak, Westinghouse

R. Lundy, FNAL

F. W. Wiffen, ORNL

R. Scanlan, LLL

H. Becker, MIT

Session 2 (2:00-5:00 p.m.) Austenitic Steels

E. N. C. Dalder, Chairman

Problems in the Use of Low-Temperature Materials Strength of Structural AlToys

Use of Crack Propagation Rate Test Data in

Establishing Design Allowable Stresses

Therma 7 Activated Glide through Distributions

of Point Obstacles

Progress in Fatigue Testing of Austenitic

Stainless Steels

Research on Iron-Manganese Cryogenic Steels
E. N. C. Dalder, LLL

R. P. Reed, NBS

R. J. Hooper, ORNL

J. W. Morris, Jr., University of California

R. L. Tobier, NBS

M. J. Strum, University of California 
Program, continued

Wednesday, October 19

Session 3 (8:30-11:30 a.m.) Properties and Welding for Low-Temperature Service

J. W. Morris, Jr., Chairman

Deformation and Fracture of Duplex Austenitic Stainless Steel Castings at $4 \mathrm{~K}$ : Microstructural Analysis and Mechanical Behavior Stress-Concentration Effect on Integrity of Stainless Steel Weldments

New Expressions for Prediction of Microstructures in High Alloy Austenitic Steels Effect of Strain Rate on Measured Mechanical Properties of Stainless Steel at $4 \mathrm{~K}$ The Effects of Martensitic Transformations on Low Temperature Mechanical Properties Materials Handbook for Fusion Energy Systems

T. A. Whipple, Rockwell International

E. L. Brown, Colo. School of Mines

Y. -W. Cheng, NBS

D. 01son, Colorado School of Mines

W. G. Dobson, Teledyne

B. Fultz, University of California

N. J. Simon, NBS

Session 4 (1:30-4:30 p.m.) Radiation-Resistant Organic Insulator Development M. B. Kasen, Chairman

Elastic Stiffnesses and Local Stresses in Woven-

Fabric Composites at $77 \mathrm{~K}$

Current and Future Possibilities for Cryogenic

Nonmetallic Radiation Research

MIT Development Program for Fusion Reactor

Magnet Insulators

Neutron Irradiation Studies of Polymers at LANL Cooperative Programs in Nonmetallic Radiation

R. Kriz, NBS

R. Col tman, ORNL

H. Becker, MIT

D. Fowler, Jr., LANL

Panel Discussion: Nonmetallic Research for MFE Magnets

M. B. Kasen, NBS 
NBS DOE WORKSHOP

ATTENDEES

John Arvidson, NBS

Don Beard, U. S. Department of Energy

Herb Becker, MIT

James Benzinger, Spaulding Fibre

Elliot Brown, Colorado School of Mines

Bernie Carpenter, Colorado School of Mines

Yi-Wen Cheng, NBS

Ralph Coltman, ORNL

Ed Dalder, LLL

Bill Dobson, Teledyne

John Fowler, Jr., LANL

Brent Fultz, University of California

Carl Goodzeit, Brookhaven

Richard Hooper, ORNL

Andrew Jarabak, Westinghouse

Maurice B. Kasen, NBS

Damian Kotecki, Teledyne McKay

Ronald D. Kriz, NBS

R. A. Lundy, FNAL

J. W. Morris, Jr., University of California

Lewis Myers, Carpenter Technology

Carl Osgood, Princeton University

Pat Purtscher, NBS

Richard Reed, NBS

Ron Scanlan, LLL

Joel Self, Colorado School of Mines

John Shepic, Martin Marietta

Nancy Simon, NBS

Mike Strum, University of California

Ralph Tobler, NBS

Robert Walsh, NBS

F. W. Wiffen, ORNL/FEDC

Jerry Wille, McDonnell Douglas

John Wollan, LANL

Tom Whipple, Rockwell International 


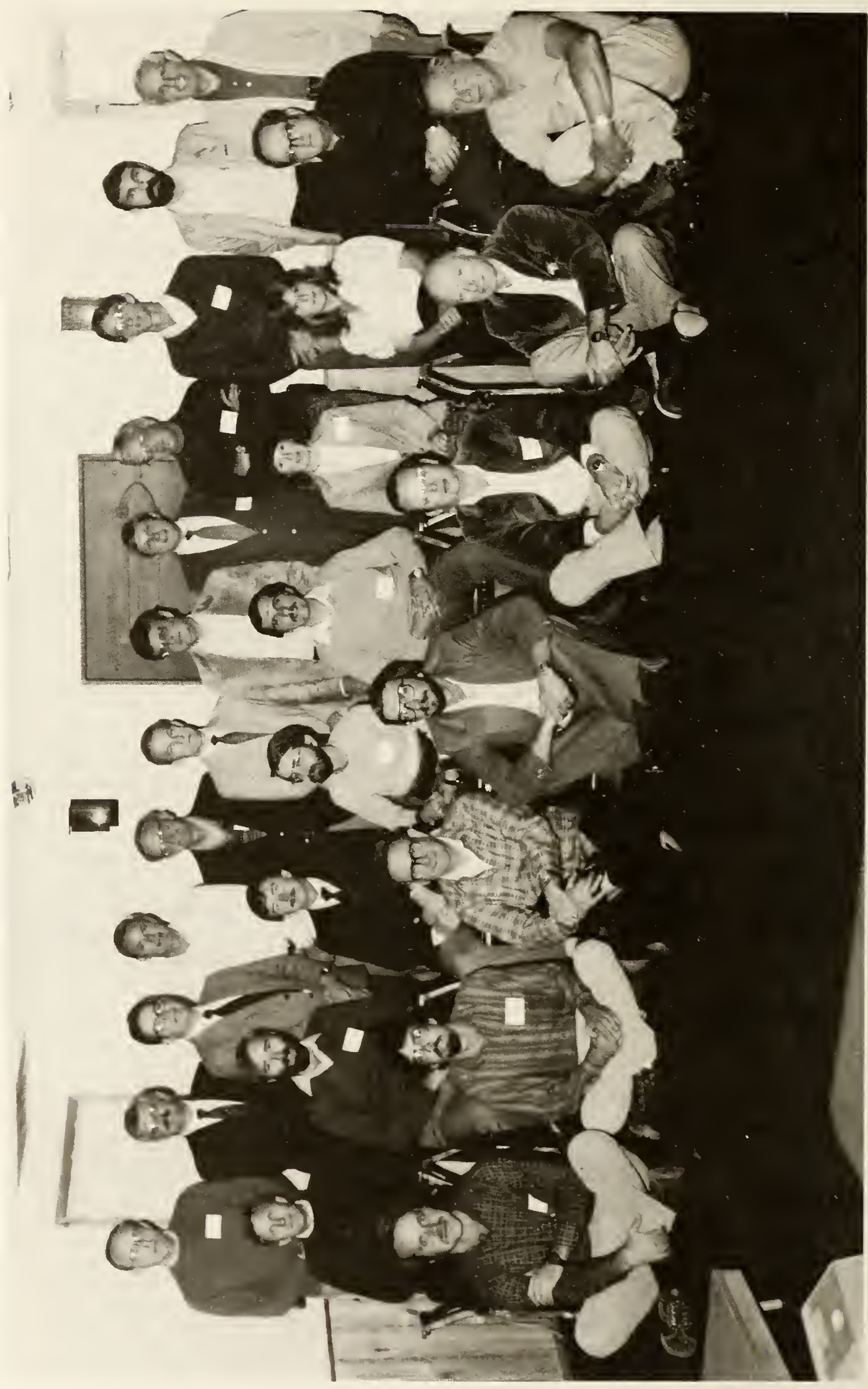

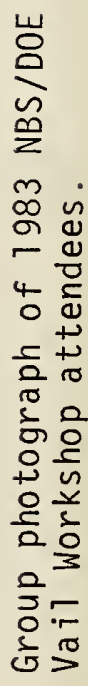




\section{ACKNOWLEDGMENT}

The editors wish to express their appreciation to JoAnne Wilken for her work in preparing the manuscript. She was assisted by Becky Stevenson and Dianna Wooton.

Marilyn Stieg removed many of the inconsistencies, grammatical errors, and awkward usages of language. The editors are responsible for those that remain. 
NBS-114A (REV. $2-8 C$ )

U.S. DEPT. OF COMM.
BIBLIOGRAPHIC DATA
SHEET (See instructions)

1. PUBLICATION OR REPORT NO.

NBSIR $84-3000$
2. Performing Organ. Report No.

3. Publication Date

MAY 1984

4. TITLE AND SUBTITLE

Materials Studies for Magnetic Fusion Energy Applications at Low Temperatures - VII

5. $\operatorname{AUTHOR}(\mathrm{S})$

R. P. Reed and N. J. Simon, Editors

6. PERFORMING ORGANIZATION (If joint or other than NBS, see instructions)

NATIONAL BUREAU OF STANDARDS

DEPARTMENT OF COMMERCE

WASHINGTON, D.C. 20234

9. SPONSORING ORGANIZATION NAME AND COMPLETE ADDRESS (Street, City, State, ZIP)

7. Contract/Grant No.

8. Type of Report \& Period Covered

Department of Energy

Office of Fusion Energy

Washington, D.C. 20545

10. SUPPLEMENTARY NOTES

Related Orevious Reports: NBSIR 83-1690, NBSIR 82-1667

NBSIR 81-1645, NBSIR 80-1627, NBSIR 79-1609

NBSIR 78-884

Document describes a computer program; SF-185. FIPS Software Summary, is attached.

11. ABSTRACT (A 200-word or less factual summary of most significant information. If document includes a significant bibliography or literature survey, mention it here)

This report contains results of a research program to produce material property data that will facilitate design and development of cryogenic structures for the superconducting magnets of magnetic fusion energy power plants and prototypes. The program was developed jointly by the staffs of the National Bureau of Standards and the Office of Fusion Energy of the Department of Energy; it is managed by NBS and sponsored by DoE. Research is conducted at NBS and at various other laboratories through subcontracts with NBS. Research results for 1983 are summarized in an initial "Highlights of Results" section and reported in detail in the 22 technical papers that form the main body of this report. The technical papers are presented under four headings reflecting the main program areas: structural alloys, weldments and castings, nonmetallics, and technology transfer. Objectives, approaches, and achievements are summarized in an introduction to each program area. Work leading toward development of strong, tough structural alloys for use in superconducting magnets continued this year, with low temperature studies assessing the quantitative dependence of the yield strength, density, and elastic constants of AISI 304 stainless steels upon carbon and nitrogen concentration. Tensile property measurements of developmental austenitic steels from the U.S., Japan, and the U.S.S.R. confirmed a logarithmic dependence of yield strength upon temperature between $4 \mathrm{~K}$ and room temperature. Evidence is presented to show that the flow strength and austenite stability of stainless steels are not significantly affected by $8-T$ fields at 4 K. New instrumentation developed for low-temperature testing included a computer-assisted apparatus that was used to measure threshold fatigue. Low-temperature welding research involved an investigation of the weld reinforcement effect on the weld joint strength and measurements of the $4-\mathrm{K}$ fracture toughness of $25 \mathrm{MN}-5 \mathrm{Cr}$ steel weldments and 320LR electrodes. In the area of nonmetallics, a standardized test specimen was devised for a screeting program to develop radiationi-resistant eomposites for magnet insulation, and niodels to predict dainage in woven glass/ epoxy laminates were tested experimentally at low temperatures. Mechanical properties of concrete mortar and polyurethane foam at $4 \mathrm{~K}$ are reported.

12. KEY WORDS (Six to twelve entries; alphabetical order: capitalize only proper names: and separate key words by semicolons) Austenitic steels; castings; composites; cryogenic properties; elastic properties; low temperatures; mechanical properties; nonmetallics; stainless steels; structural alloys, welds.

13. AVAILABILITY

X] Unlimited

For Official Distribution. Do Not Release to NTIS

Order From Superintendent of Documents, U.S. Government Printing Office, Washington, D.C. 20402.

14. NO. OF

PRINTED PAGES

419

X] Order From National Technical Information Service (NTIS), Springfield, VA. 22161

15. Price

$\$ 31.00$ 

